\title{
Transkriptionelle Regulation des pflanzlichen Detoxifikationsprogramms durch das GRAS-Protein SCL14
}

\author{
Dissertation \\ zur Erlangung des mathematisch-naturwissenschaftlichen Doktorgrades \\ „Doctor rerum naturalium“ \\ der Georg-August-Universität Göttingen
}

im Promotionsprogramm Biologie

der Georg-August University School of Science (GAUSS)

vorgelegt von

Alexander Meier

aus Hameln

Göttingen, 2014 


\section{Betreuungsausschuss}

Prof. Dr. Christiane Gatz

(Abteilung Molekularbiologie und Physiologie der Pflanze)

Prof. Dr. Volker Lipka

(Abteilung Zellbiologie der Pflanze)

Dr. Corinna Thurow

(Abteilung Molekularbiologie und Physiologie der Pflanze)

\section{Mitglieder der Prüfungskommission}

Referentin:

Prof. Dr. Christiane Gatz

(Abteilung Molekularbiologie und Physiologie der Pflanze)

Koreferent:

Prof. Dr. Volker Lipka

(Abteilung Zellbiologie der Pflanze)

Weitere Mitglieder der Prüfungskommission:

Prof. Dr. Ivo Feussner (Abteilung Biochemie der Pflanze)

Prof. Dr. Andrea Polle (Abteilung Forstbotanik und Baumphysiologie)

PD Dr. Thomas Teichmann (Abteilung Zellbiologie der Pflanze)

Jun. Prof. Dr. Cynthia Gleason (JP Molekulare Pflanzenwissenschaften)

Tag der mündlichen Prüfung: 20.10.2014 


\section{Erratum:}

Die Analysen des mutierten SCL14 Proteins, in denen die Cysteine in den Positionen C400 und C691 zu Serinen mutiert wurden (Kapitel 4.2.1 bis Kapitel 4.2.3), sind nicht relevant, da nach Abgabe der Arbeit festgestellt wurde, dass das Protein einen zusätzlichen Austausch in einer konservierten Aminosäure (S762F) der GRASDomäne enthält. Der beschriebene Funktionsverlust in der C5,9S Doppelmutante könnte daher auf die ungewollte Mutation zurückzuführen sein. 



\section{Inhaltsverzeichnis}

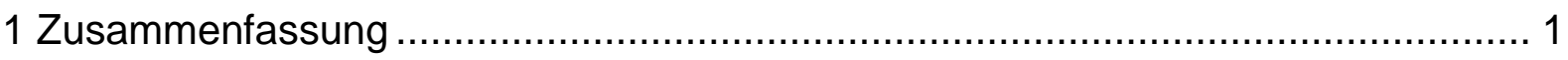

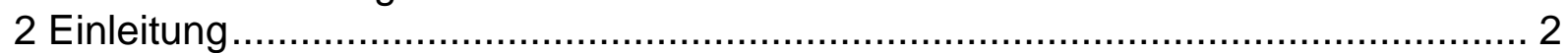

2.1 Das pflanzliche Detoxifikationsprogramm .............................................. 2

2.2 SCL14 gehört zur Familie der GRAS-Transkriptions-faktoren ....................... 5

2.3 Redox-basierte Proteinmodifikationen und Signal-transduktion ........................ 9

2.4 Reaktive Elektrophile Spezies.............................................................. 14

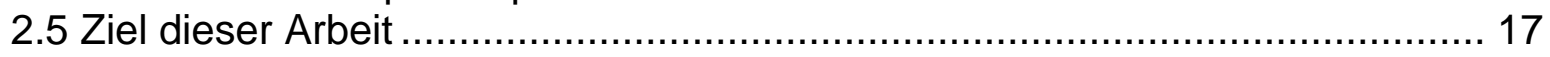

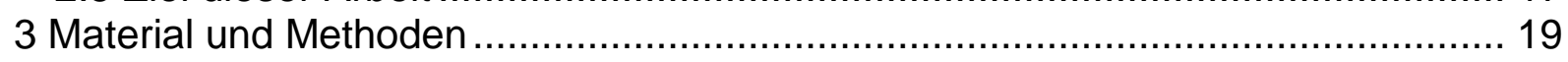

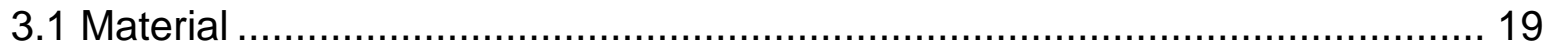

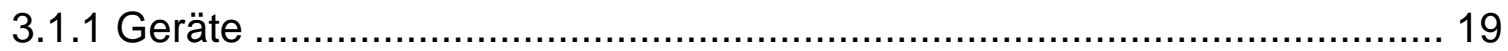

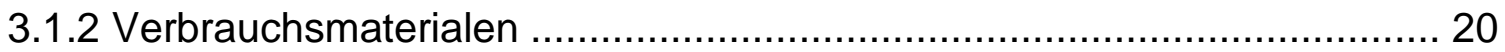

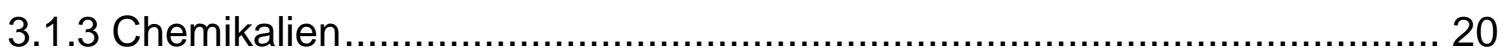

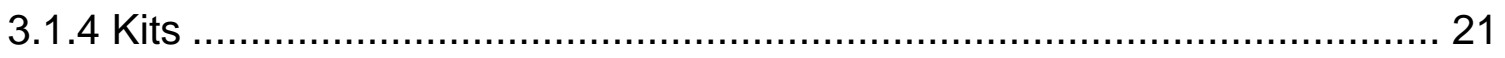

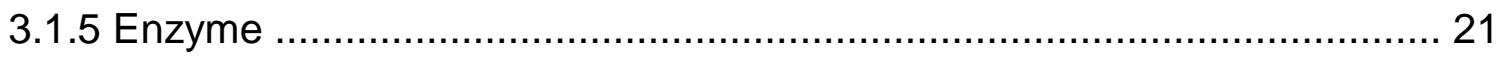

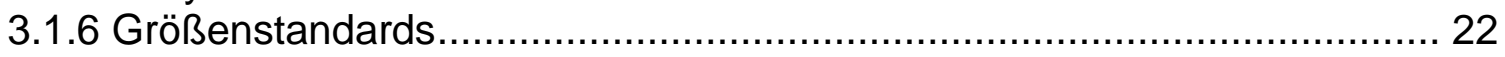

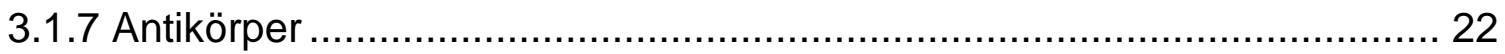

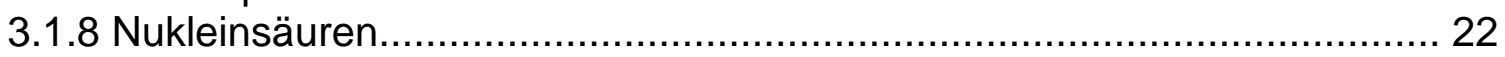

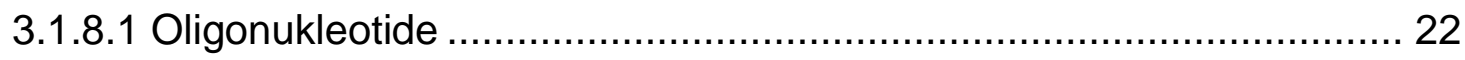

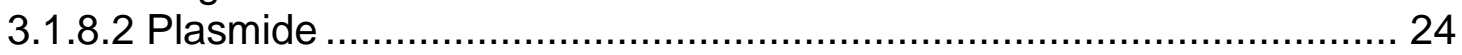

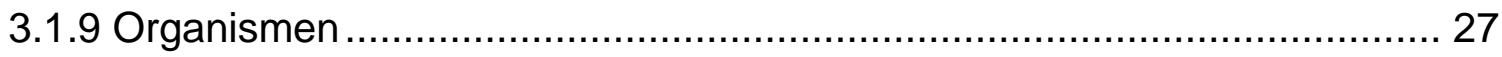

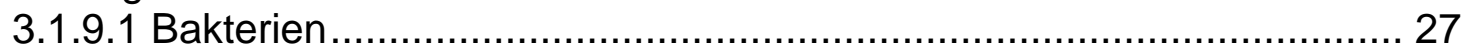

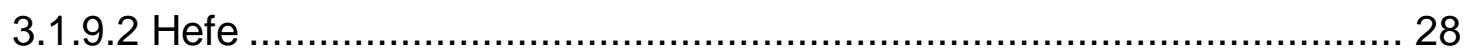

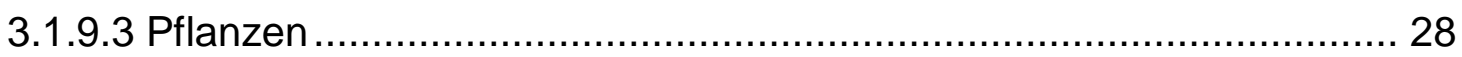

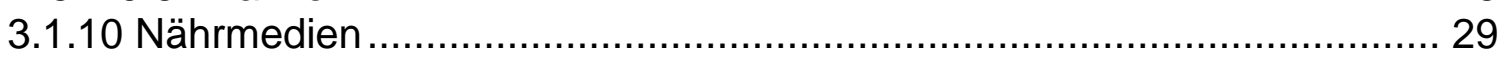

3.1.11 Standardpuffer …….................................................................. 29

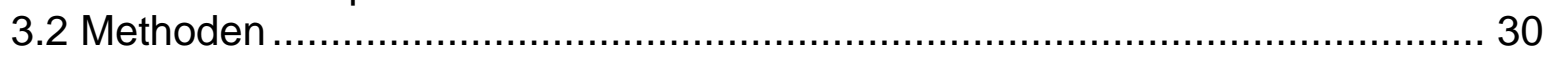

3.2.1 Molekularbiologische Standardmethoden ........................................... 30

3.2.1.1 Plasmidisolation aus E. coli....................................................... 30

3.2.1.2 DNA-Isolation aus $A$. thumefaciens ............................................. 30

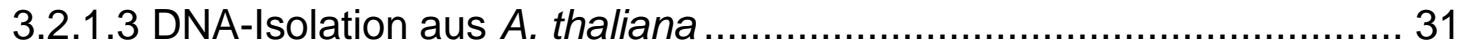

3.2.1.4 Polymerase Kettenreaktion ......................................................... 31

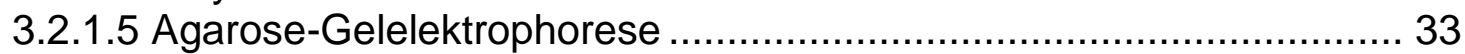

3.2.1.6 Konzentrationsbestimmung von Nukleinsäuren .............................. 33

3.2.1.7 Restriktionsspaltung von DNA ……........................................... 33

3.2.1.8 Ligation von DNA-Molekülen...................................................... 34

3.2.1.9 Dephosphorylierung von DNA.................................................. 34

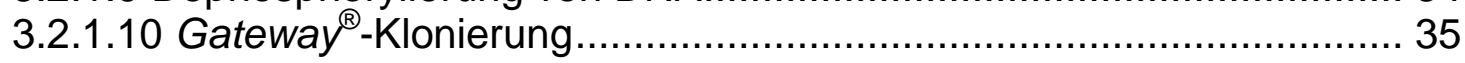

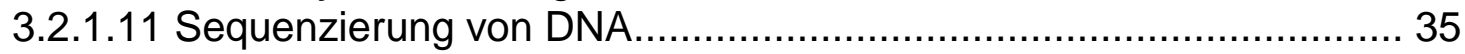

3.2.1.12 Transformation von E. coli .................................................... 35

3.2.1.13 Transformation von $A$. thumefaciens ........................................... 35

3.2.1.14 Stabile Transformation von $A$. thaliana ....................................... 36

3.2.2 Biochemische Standardmethoden .................................................... 36

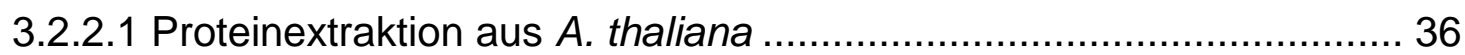

3.2.2.2 Proteinextraktion aus S. cerevisiae ................................................ 36

3.2.2.3 Konzentrationsbestimmung von Proteinlösungen ............................. 37

3.2.2.4 SDS - Polyacrylamidgelelektrophorese ........................................ 37

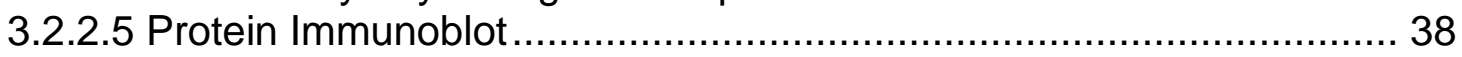

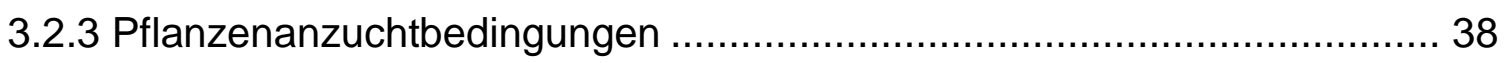


3.2.3.1 Pflanzenanzucht auf Erde ......................................................... 38

3.2.3.2 Sterile Pflanzenanzucht in einem hydroponischen System ................ 39

3.2.3.3 Sterile Pflanzenanzucht auf mit Nährmedium beschichteten

Objektträgern und Schrägagarplatten ................................................... 39

3.2.4 Oberflächensterilisation von Samen ................................................... 39

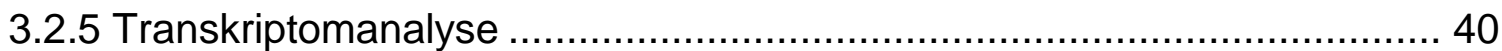

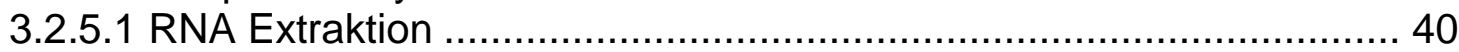

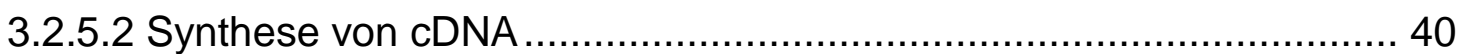

3.2.5.3 Quantitative Echtzeit PCR (qRT - PCR) .................................... 41

3.2.5.4 Microarrayanalyse .............................................................. 42

3.2.6 Behandlung von A.thaliana mit Chemikalien ........................................ 43

3.2.6.1 Chemikalienbehandlung im hydroponischen System....................... 43

3.2.6.2 Chemikalienbehandlung auf mit Nährmedium beschichteten

Objektträgern ................................................................................ 43

3.2.6.3 Behandlung von auf Erde angezogenen Pflanzen mit TIBA ............. 45

3.2.7 Transiente Luciferase Reporterassays in Protoplasten ........................... 45

3.2.7.1 Protoplastierung von A.thaliana Blattgewebe ................................. 45

3.2.7.2 Transiente Transformation von A.thaliana Protoplasten ................... 46

3.2.7.3 Luciferase Reporterassay ......................................................... 46

3.2.7.4 Für die Protoplastierung und Transformation genutzte Puffer............ 47

3.2.8 Hefe - Zwei - Hybrid - System ..................................................... 48

3.2.8.1 Transformation von Hefezellen .................................................. 49

3.2.8.2 Bestimmung der B-Galaktosidaseaktivität in Hefeextrakten (oNPG-

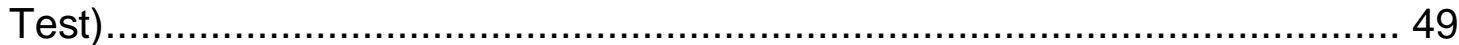

3.2.9 Markierung von cysteinhaltigen Proteinen mit mPEG-Mal-5000 .............. 50

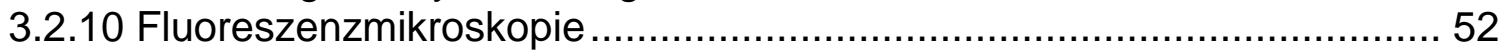

3.2.11 Bestimmung von Wurzellängen ..................................................... 52

4 Ergebnisse ............................................................................................. 53

4.1 Chemischer Stress induziert die Akkumulation von SCL14 in Zellkernen

von $A$. thaliana Wurzelzellen ....................................................................... 53

4.1.1 Die Inhibition des Kernexports führt zur Akkumulation von SCL14 im

Zellkern von Arabidopsis Wurzelzellen..................................................... 53

4.1.2 SCL14 akkumuliert im Zellkern nach der Behandlung von Arabidopsis

Wurzeln mit Salicylsäure, 2,3,5-Triiodo-benzoesäure und

12-oxo-Phytodiensäure

4.1.3 Die Stickstoffmonooxiddonatoren Natriumnitroprussid und

S-Nitrosoglutathion induzieren nicht die Akkumulation von SCL14 im Zellkern. 60

4.1.4 NaCl und $\mathrm{CdCl}_{2}$ induzieren nicht die Akkumulation

von SCL14 im Zellkern

4.1.5 Die Akkumulation von SCL14 im Zellkern ist 30 Minuten nach Beginn des

Stimulus abgeschlossen....

4.1.6 Die Akkumulation von SCL14 im Zellkern ist unabhängig von den TGA-

Transkriptionsfaktoren der Klasse II .....

4.2 Cysteine spielen eine Rolle für die Aktivität von SCL14 .............................. 67

4.2.1 Die Cysteine C400 und C691 sind notwendig für die

transkriptionsaktivierende Funktion von SCL14 .

4.2.2 Die Cysteine 400 (C5) und 691 (C9) sind essentiell für die Interaktion von SCL14 mit TGA2 und XPO1a

4.2.3 Die Cysteine C400 und C691 sind innerhalb der nächsten Verwandten

von SCL14 konserviert 
4.2.4 Die Cysteine in der GRAS-Domäne von SCL14 sind notwendig für die

Akkumulation des Proteins im Zellkern.

4.3 Analyse und Identifikation von SCL14 Zielgenen in Wur-zeln von Arabidopsis thaliana nach chemischem Stress

4.3.1 Die Aktivierung des SCL14 Zielgenes GSTU7 erfolgt in Wurzeln von Arabidopsis durch SA und TIBA .

4.3.2 Microarray-Analyse der Expression von SCL14 Zielgenen in Wurzeln nach Behandlung mit SA ................................................................... 78

4.3.3 Einfluss der Deletion von SCL14 und SCL33 auf die Genexpression ...... 85 4.3.4 SA und TIBA induzieren die Expression von SCL14 Zielgenen in

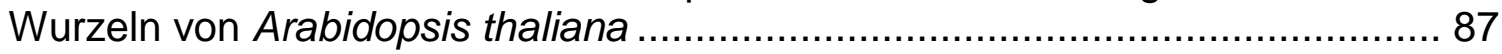

4.3.5 Jasmonsäure induziert die Expression von GSTU7 .......................... 88 4.3.6 Die Expression von GSTU7, UGT73B3, AT3G04130 und AT5G61800 ist abhängig von den TGA-Transkriptionsfaktoren der Klasse II...................... 89 4.3.7 Das GFP-SCL14 Fusionsprotein komplementiert den Phänotyp der

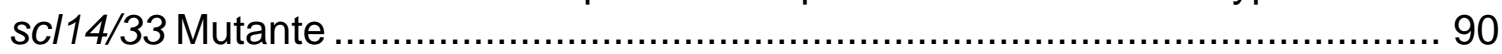

4.3.8 SCL14 akkumuliert auch im hydroponischen System nach SA

Behandlung im Zellkern 92

4.4 SCL14 scheint nach der Behandlung von Arabidopsis Wurzeln mit SA oxidiert zu werden 93

4.5 Suche nach Interaktionspartnern von SCL14 mit dem Hefe-Zwei-HybridSystem

4.5.1 AtNAC017 interagiert mit der GRAS-Domäne von SCL14 ..................... 95

4.5.2 Charakterisierung einer NAC017T-DNA Insertionslinie ........................ 100

4.5.3 Expression von SCL14 Zielgenen in der nac017 Mutante..................... 102

5 Diskussion 104

5.1 Unterschiedliche Substanzen führen zu einer Akkumulation von SCL14 im

Zellkern ..... 105

5.2 Die Cysteine C400 und C691 sind essentiell für die Funktionalität von

SCL14

5.3 SA induziert Gene der Stressantwort in Wurzeln von Arabidopsis thaliana .. 117

5.4 SCL14 interagiert mit dem Transkriptionsfaktor NAC017 ............................ 119

6 Anhang 122

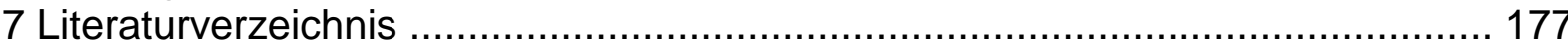

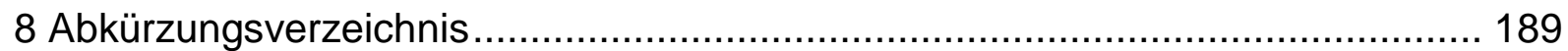

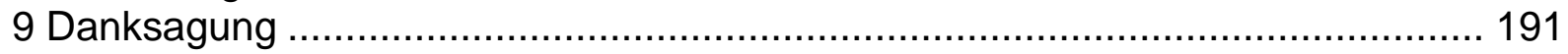

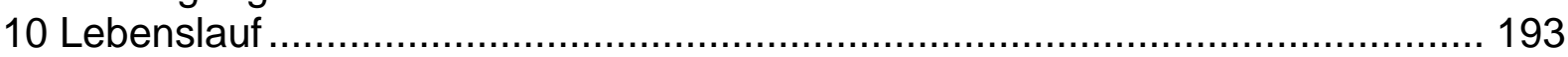




\section{Zusammenfassung}

In Pflanzen wird durch den Kontakt mit toxischen Substanzen eine Gruppe von Genen aktiviert, die in die Detoxifikation dieser Substanzen involviert sind. Ein Teil dieser Gene wird durch den Transkriptionskoaktivator Scarecrow-like 14 (SCL14) aus der Familie der GRAS-Transkriptionsfaktoren reguliert. SCL14 interagiert mit den redundanten bZIP Transkriptionsfaktoren TGA2, TGA5 und TGA6. Der SCL14/TGA Komplex bindet an as-1-ähnliche Elemente in den Promotoren der Zielgene von SCL14.

In dieser Arbeit konnte mittels konfokaler Fluoreszenzmikroskopie gezeigt werden, dass sich die intrazelluläre Lokalisation von SCL14 in Wurzelzellen von Arabidopsis thaliana nach der Einwirkung des Phytohormons Salicylsäure (SA), des Xenobiotikums 2,3,5-Triiodobenzoesäure (TIBA) und des Oxilipins 12-oxoPhytodiensäure (OPDA) ändert. In der unbehandelten Wurzelzelle ist das Protein gleichmäßig zwischen Cytosol und Kern verteilt, nach der Behandlung der Wurzel mit den genannten Substanzen kommt es zu einer Akkumulation von SCL14 im Zellkern. Da es sich bei SA, TIBA und OPDA um elektrophile Substanzen handelt, könnte der auslösende Stimulus für die Akkumulation von SCL14 im Zellkern oxidativer Stress sein. Da die Mutation von zwei Cysteinen zu Serinen in der GRAS-Domäne von SCL14 zu einem vollständigen Aktivitätsverlust des Proteins führt, könnten die kritischen Cysteine Ziele von Redoxmodifikationen sein.

Transkriptomanalysen von unbehandelten und SA-behandelten Wurzeln von Wildtypund sc/14/33 Pflanzen zeigten, dass SCL14 bei manchen Genen spezifisch die SAInduktion, nicht aber die Basalexpression beeinflusst. Hier scheint die Kernakkumulation eine wichtige Rolle zu spielen. Bei einer zweiten Gruppe wirkt SCL14 als ein konstitutiver Verstärker sowohl der basalen als auch der SAinduzierten Expression.

In einem Hefe-Zwei-Hybrid Experiment wurde der Transkriptionsfaktor NAC017 als neuer Interaktionspartner von SCL14 identifiziert. Allerdings war die Expression der Zielgene von SCL14 in der nac017 knockout Mutante nach der Behandlung mit SA ähnlich zum Wildtyp. Die Interaktion von SCL14 mit NAC017 spielt daher entweder keine Rolle für die Expression der untersuchten Gene, oder ein weiterer NAC Transkriptionsfaktor kann die Aufgaben von NAC017 in der Mutante übernehmen. 


\section{Einleitung}

Als sessile Organismen haben Pflanzen nicht die Möglichkeit, ungünstigen Umweltbedingungen auszuweichen. Aus diesem Grund haben sie eine breite Palette von Strategien entwickelt, um schädliche Einflüsse, sowohl biotischen als auch abiotischen Ursprungs, zu überdauern. Physikalische Barrieren wie Trichome und die Kutikula gegen abiotische Stressfaktoren, wie starke Sonneneinstrahlung und Trockenheit, sowie Dornen, die Zellwand und wiederum Trichome gegen biotische Stressfaktoren wie Fraßfeinde und Pathogene bilden einen ersten Verteidigungsmechanismus. Hinzu kommen in geringer Menge produzierte Chemikalien als zusätzlicher Schutz gegen Pathogene und Herbivoren.

Zusätzlich verfügt die Pflanze über induzierbare Mechanismen, sowohl zur Abwehr von Pathogenen als auch zur Entgiftung toxischer Substanzen.

\subsection{Das pflanzliche Detoxifikationsprogramm}

Pflanzen werden während ihres Lebenszyklus mit zahlreichen toxischen Substanzen konfrontiert. Hierbei kann es sich um von Pathogenen synthetisierte Toxine handeln, aber auch um von anderen Pflanzen im Wettbewerb um Lebensraum und Ressourcen abgesonderte Substanzen, die sogenannten Allelochemikalien. Hinzu kommen Toxine menschlichen Ursprungs in Form von Herbiziden oder Umweltgiften (Coleman et al. 1997). Die Detoxifikation dieser Xenobiotika kann in drei durch Enzyme katalysierte Stufen unterteilt werden: eine Aktivierungsstufe, eine Konjugationsstufe und eine Kompartimentierungsstufe (Sandermann 1992). In der Aktivierungsstufe erfolgt das Einfügen oder Freilegen einer reaktiven Gruppe. Ein Großteil dieser Aktivierungsreaktionen wird durch die Aktivität von Cytochrom P450 Monooxygenasen vermittelt (Ekman et al. 2003; Bolwell et al. 1994). Aufgrund des Einfügens von reaktiven Gruppen sind die Produkte dieser Reaktionen oft ebenso toxisch wie die Ausgangssubstanzen oder sogar toxischer (Baerson et al. 2005). In der Konjugationsstufe erfolgt die kovalente Modifikation der aktivierten Substanzen mit einem hydrophilen Molekül, wie Glutathion durch Glutathion S-Transferasen (Armstrong 1991; Dixon et al. 1998) oder Glukose, durch Glykosyltransferasen (Coleman et al. 1997). Diese Modifikation führt zur Inaktivierung der Toxine und erhöht ihre Hydrophilie, wodurch sie nicht mehr durch Membranen diffundieren 
können. Dies ist eine Voraussetzung für die dritte Stufe der Detoxifikation. In dieser Stufe erfolgt der aktive Transport der Konjugate in die Vakuole oder den apoplastischen Raum durch ATP-Bindekassetten-Transporter (ABC-Transporter) (Martinoia et al. 2001; Li et al. 2002). In der Vakuole erfolgt teilweise ein Abbau der eingelagerten Substanzen (Grzam et al. 2007) während im apoplastischen Raum eine Integration in die Zellwand erfolgen kann (Sandermann et al. 1984).

Die an den Detoxifikationsmechanismen beteiligten Gene werden durch die Einwirkung von Xenobiotika auf die Pflanze induziert. Zumindest ein Teil dieser Gene, die in die Detoxifikation von Xenobiotika involviert sind, werden in Abhängigkeit von bZIP-Transkriptionsfaktoren aus der Familie der TGATranskriptionsfaktoren exprimiert. So wurden durch Phytoprostane in Arabidopsis Detoxifikationsgene aktiviert und die Expression von $60 \%$ dieser Gene war in der tga256 Mutante, in der die drei TGA-Faktoren der Klasse II deletiert sind, reduziert (Mueller et al. 2008). Weiterhin konnte in den Promotoren von Genen, die durch die Allelochemikalie Benzoxazolin-2(3H)-on (BOA) induziert wurden, eine Anreicherung von TGA-Bindemotiven festgestellt werden (Baerson et al. 2005). Die TGA-Faktoren binden an das as-1 Element (Katagiri et al. 1992), welches zuerst als funktionelles cis Element des 35S-Promotors des Blumenkohlmosaikvirus identifiziert wurde (Benfey et al. 1989). Es besteht aus zwei imperfekten Wiederholungen der Sequenz TGACGTCA, deren palindromische Zentren 12 Basenpaare voneinander entfernt liegen (Qin et al. 1994; Krawczyk et al. 2002). Die Aktivierung des as-1 Elements erfolgt unter anderem durch Salicylsäure (SA), Auxin, das Auxin Analogon und Herbizid 2,4-Dichlorphenoxyessigsäure (2,4-D) und oxidativen Stress (Liu \& Lam 1994; Zhang \& Singh 1994; Uquillas et al. 2004; Garretón et al. 2002). Die Aktivierung des as-1 Elementes durch TGA-Faktoren erfolgt unter Zusammenwirkung mit weiteren Transkriptionskofaktoren. So ist für die SA-abhängige Aktivierung des Gens Pathogenesis Related 1 (PR1) die Anwesenheit des Proteins NONEXPRESSOR OF PR1 (NPR1) und dessen Interaktion mit TGA-Faktoren nötig (Després et al. 2003; Zhou et al. 2000; Fan \& Dong 2002). Die Aktivierung des as-1 Elementes durch oxidativen Stress ist unabhängig von NPR1, nicht jedoch von TGAFaktoren (Uquillas et al. 2004). Fode et al. konnten zeigen, dass der TGA-Faktor TGA2 mit dem GRAS-Protein SCARECROW-LIKE 14 (SCL14) interagiert und dass diese Interaktion für die Aktivierung einer Gruppe von Genen notwendig ist, die potentiell an pflanzlichen Entgiftungsmechanismen beteiligt sind (Fode et al. 2008). 
Die Aktivierung der Gene, unter anderem eine Glutathion S-Transferase (GSTU7) und eine Cytochrom P450 Monooxigenase (CYP81D11), erfolgte SCL14-abhängig durch das Xenobiotikum 2,3,5-Triiodobenzoesäure (TIBA) und 2,4-D. Des Weiteren konnte durch Fode et al. gezeigt werden, dass scl14 knockout Mutanten auf Nährmedium, welches TIBA enthielt, ein reduziertes Keimlingswachstum im Vergleich zum Wildtyp zeigten, während eine Überexpressionslinie von SCL14 weniger empfindlich gegenüber der Chemikalie war. SCL14 scheint also an der Regulation von Teilen des pflanzlichen Detoxifikationsprogrammes beteiligt zu sein.

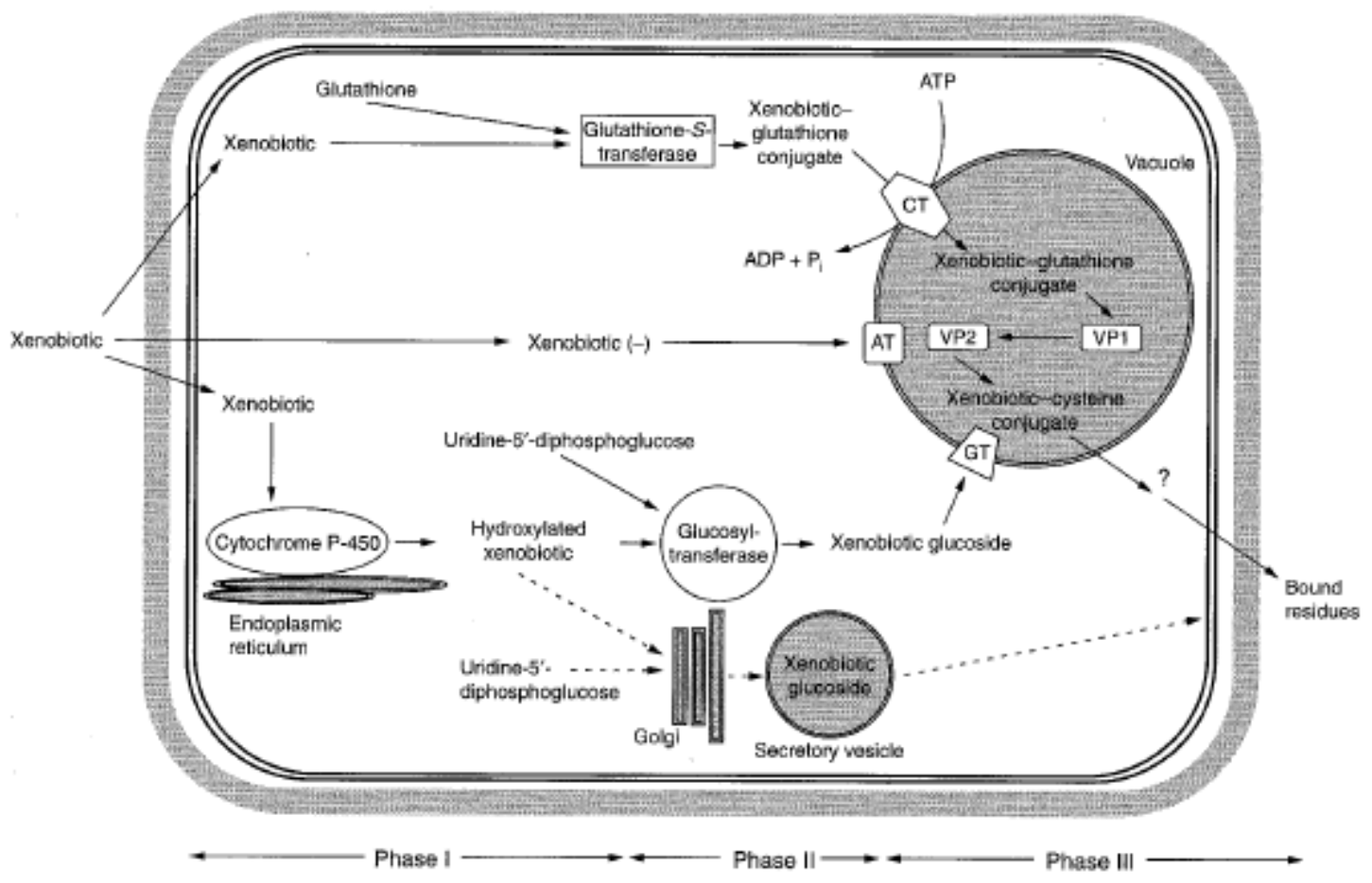

\section{Abbildung 2.1: Die Detoxifikation xenobiotischer Substanzen in Pflanzen}

Die enzymkatalysierten Reaktionen im Verlauf der Detoxifikation xenobiotischer Substanzen sind in unterschiedlichen Organellen und zellulären Kompartimenten lokalisiert. Die gestrichelten Pfeile stellen einen möglichen Weg für die Glycosylierung von Xenobiotika im Golgiapparat, gefolgt von der Ablagerung der Metabolite im apoplastischen Raum durch Exocytose, dar.

Abkürzungen: CT: Glutathionkonjugat Transporter; AT: ATP-abhängiger Transporter für xenobiotische Anionen; GT: ATP-abhängiger Glucosidkonjugat Transporter; VP: vakuoläre Peptidase. (Coleman et al. 1997)

Die Wahrnehmung der xenobiotischen Substanzen kann auf unterschiedliche Weise erfolgen. Da es sich bei Xenobiotika um reaktive Moleküle handelt, können diese direkt Sensormoleküle kovalent modifizieren. Anstatt einer kovalenten Modifikation kann die Erkennung der Xenobiotika durch die Sensormoleküle auch im Sinne der Erkennung eines Rezeptors erfolgen, wie es bei Säugetieren beispielsweise durch die Arylhydrocarbonrezeptoren geschieht (Ramel et al. 2012). Die Wahrnehmung der 
Xenobiotika kann jedoch auch über die Detektion sekundärer Stoffe, die aufgrund der schädigenden Wirkung in der Zelle entstehen, geschehen. Bei diesen sekundären Substanzen handelt es sich zumeist ebenfalls um Reaktive Sauerstoffspezies (ROS) oder reaktive elektrophile Spezies (RES) wie beispielsweise Wasserstoffperoxid $\left(\mathrm{H}_{2} \mathrm{O}_{2}\right)$, Singulettsauerstoff $\left({ }^{1} \mathrm{O}_{2}\right)$ oder Lipidperoxide.

\subsection{SCL14 gehört zur Familie der GRAS-Transkriptions-}

\section{faktoren}

Die Familie der GRAS-Transkriptionsfaktoren wurde zum ersten Mal von Pysh et al 1999 beschrieben (Pysh et al. 1999) und nach den drei zuerst entdeckten Mitgliedern GIBBERELLIN-INSENSITVE (GAI), REPRESSOR OF Ga1-3 (ㅁG스) und SCARECROW ( $\underline{S} C R$ ) benannt (Peng et al. 1997; Silverstone et al. 1998; Di Laurenzio et al. 1996). Neben Arabidopsis thaliana wurden auch in weiteren Pflanzenspezies GRAS-Proteine gefunden. Unter anderem in Reis, Mais, Gerste, Erbse und Moosen (Pysh et al. 1999; Bolle 2004; Tian et al. 2004; Sassa et al. 2001; Nishiyama et al. 2003). Die GRAS-Proteine sind durch einen konservierten CTerminus, die GRAS-Domäne, charakterisiert, während der N-Terminus sehr variabel ist. Lediglich innerhalb von Unterfamilien ist auch der N-Terminus konserviert (Sun et al. 2012). Die GRAS-Domäne umfasst mehrere konservierte Motive (Abb. 2.2). Das VHIID Motiv, welches in allen Mitgliedern der GRAS-Familie vorhanden und von zwei Leucin reichen Sequenzen umgeben ist, sowie die PFYRE-, RVER- und SAWMotive. Die Benennung dieser Motive erfolgte nach den darin konservierten Aminosäuren (Bolle 2004). Einige GRAS-Proteine weisen in ihrer GRAS-Domäne außerdem ein LXXLL-Motiv auf (Bolle 2004). Dieses Motiv vermittelt in Säugertieren die Bindung von Steroidrezeptor Koaktivator Komplexen an ihre Kernrezeptoren (Heery et al. 1997). In Arabidopsis thaliana ist dieses Motiv essentiell für die Interaktion von Glutaredoxinen des CC-Typs mit TGA-Transkriptionsfaktoren (Li et al. 2011). 


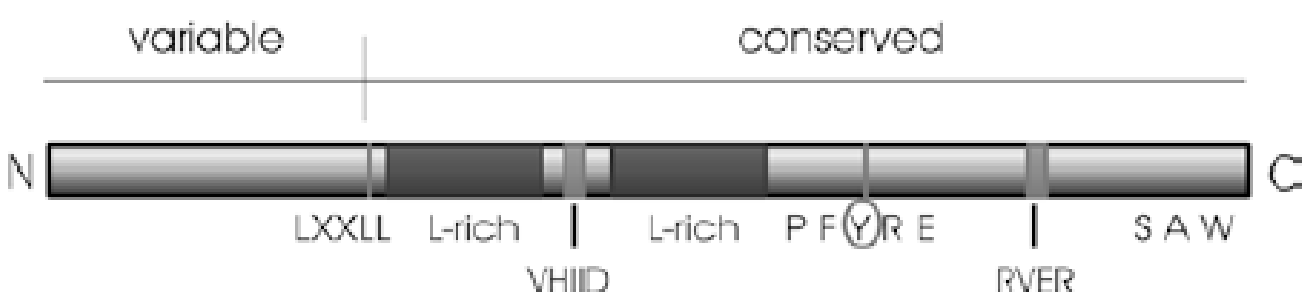

Abbildung 2.2: Schematische Darstellung der Domänenstruktur der GRAS-Proteine. (Bolle 2004)

Aufgrund der Homologie der Domänenstruktur wurden die GRAS-Proteine mit der Proteinfamilie Signal Transducers and Activators of Transcription (STAT) in Verbindung gebracht. Die STAT-Proteine sind eine Familie von Signalübertragungsproteinen in der Gruppe der Metazoa, die den Effekt von extrazellulären Signalmolekülen auf die Genexpression vermitteln. Ausgelöst durch die Bindung eines Signalmoleküls an einen extrazellulären Rezeptor werden die STAT-Proteine an einem Tyrosinrest phosphoryliert, was zur Dimerisierung und zum Transport in den Zellkern und somit zur Aktivierung der Genexpression führt (Richards et al. 2000). Neuere Erkenntnisse weisen jedoch darauf hin, dass die Pflanzlichen GRAS-Proteine eher mit bakteriellen GRAS-Proteinen als mit der STATProteinfamilie verwandt sind, bei denen es sich um Methyltransferasen handelt. Zwar haben die meisten der pflanzlichen GRAS-Proteine die für die Methyltransferaseaktivität notwendigen Aminosäuren verloren, jedoch nicht diejenigen, die für die Substratbindung notwendig sind. Daher wird eine Funktion der GRAS-Proteine bei der Bindung von kleinen Molekülen, speziell von Gibberellinen oder deren biologisch inaktiven Methylestern, postuliert (Zhang et al. 2012).

GRAS-Proteine sind an zahlreichen Prozessen, wie der Organisation von Meristemen und der Wurzelarchitektur, der Regulation des Sprosswachstums, der hormonellen Signalübertragung und der Stressantwort beteiligt. Beispielsweise verursacht das Fehlen des GRAS-Proteins SCARECROW (SCR) eine Verschmelzung des Wurzelcortex und der Endodermis (Di Laurenzio et al. 1996). Außerdem ist SCR ebenfalls notwendig für die normale Entwicklung von oberirdischen Pflanzenteilen. Unter anderem fehlt scr Mutanten die Stärkescheide, die für die Perzeption des Schwerkraftreizes notwendig ist (Fukaki et al. 1998; Wysocka-Diller et al. 2000). SCR wird ebenfalls im Ruhenden Zentrum von Apikalmeristemen exprimiert und ist dort für die Erhaltung des Stammzellstatus notwendig (Sabatini et al. 2003). Ein weiteres GRAS-Protein, welches für die normale Entwicklung der Architektur von Wurzel und Spross erforderlich ist, ist SHORTROOT 
(SHR). SHR ist ein positiver Regulator von SCR und wirkt mit diesem zusammen bei der Differenzierung der Gewebe (Helariutta et al. 2000; Nakajima et al. 2001).

Das GRAS-Protein LATERAL SUPPRESSOR (LS) aus Tomate ist wichtig für die Initialisierung von Lateralmeristemen im Spross. Mutanten, denen dieses Protein fehlt, weisen einen Defekt in der Bildung von Seitensprossen, eine geringere Blütenzahl pro Blütenstand, eine reduzierte Fruchtbarkeit sowie veränderte Hormonspiegel auf und bilden keine Kronblätter. Für das Homolog in Arabidopsis, SCL18, konnte ebenfalls eine Beteiligung an der Seitensprossbildung nachgewiesen werden und das Homolog in Reis OsMOC1, ist wichtig für die Bildung von Ausläufern (Schumacher et al. 1999; Greb et al. 2003; Li et al. 2003). Das Arabidopsis GRASProtein PAT1 ist in den Phytochrom A Signalweg involviert, da die pat1-1 Mutante veränderte Reaktionen auf dunkelrotes Licht zeigt. So ist die Expression der durch dunkelrotes Licht induzierten Chalcon Synthase ( $\mathrm{CHS}$ ) und des Chlorophyll a/bBindeproteins reduziert und das Hypokotylwachstum in dunkelrotem Licht ist verstärkt, was dem Phänotyp der phyA Mutante entspricht, der der Rezeptor für dunkelrotes Licht fehlt (Bolle et al. 2000). Die DELLA-Unterfamilie der GRASProteine stellt mit Gibberellin-insensitive (GAI), Repressor of ga1-3 (RGA) und RGAlike (RGL) 1-3 wichtige Regulatoren des Gibberellin Signalweges. Die DELLA Proteine wirken als Repressoren der durch Gibberellin aktivierten Gene. Diese Repression wird durch Gibberellin aufgehoben und es konnte für einige der DELLAProteine gezeigt werden, dass sie nach Gibberellineinwirkung abgebaut werden (Peng et al. 1997; Silverstone et al. 1998; Lee et al. 2002; Wen \& Chang 2002; Dill et al. 2001; Silverstone et al. 2001). An der Antwort auf toxischen Stress ist das GRASProtein SCARECROW-like 14 (SCL14) beteiligt. SCL14 Zielgene, zu denen Cytochrom P450 Monooxygenasen und Glutathion S-Transferasen gehören und die Teil des pflanzlichen Detoxifikationsprogrammes sind, werden durch Salicylsäure, aber auch durch das Xenobiotikum TIBA und das Herbizid 2,4-D induziert (Fode et al. 2008). SCL14 gehört innerhalb der GRAS-Familie zur SCL9 Unterfamilie, zu der auch SCL9, SCL11, SCL30, SCL31 und SCL33 gehören. Die nächsten verwandten von SCL14 sind SCL31 und SCL33 (Abb. 2.3) 


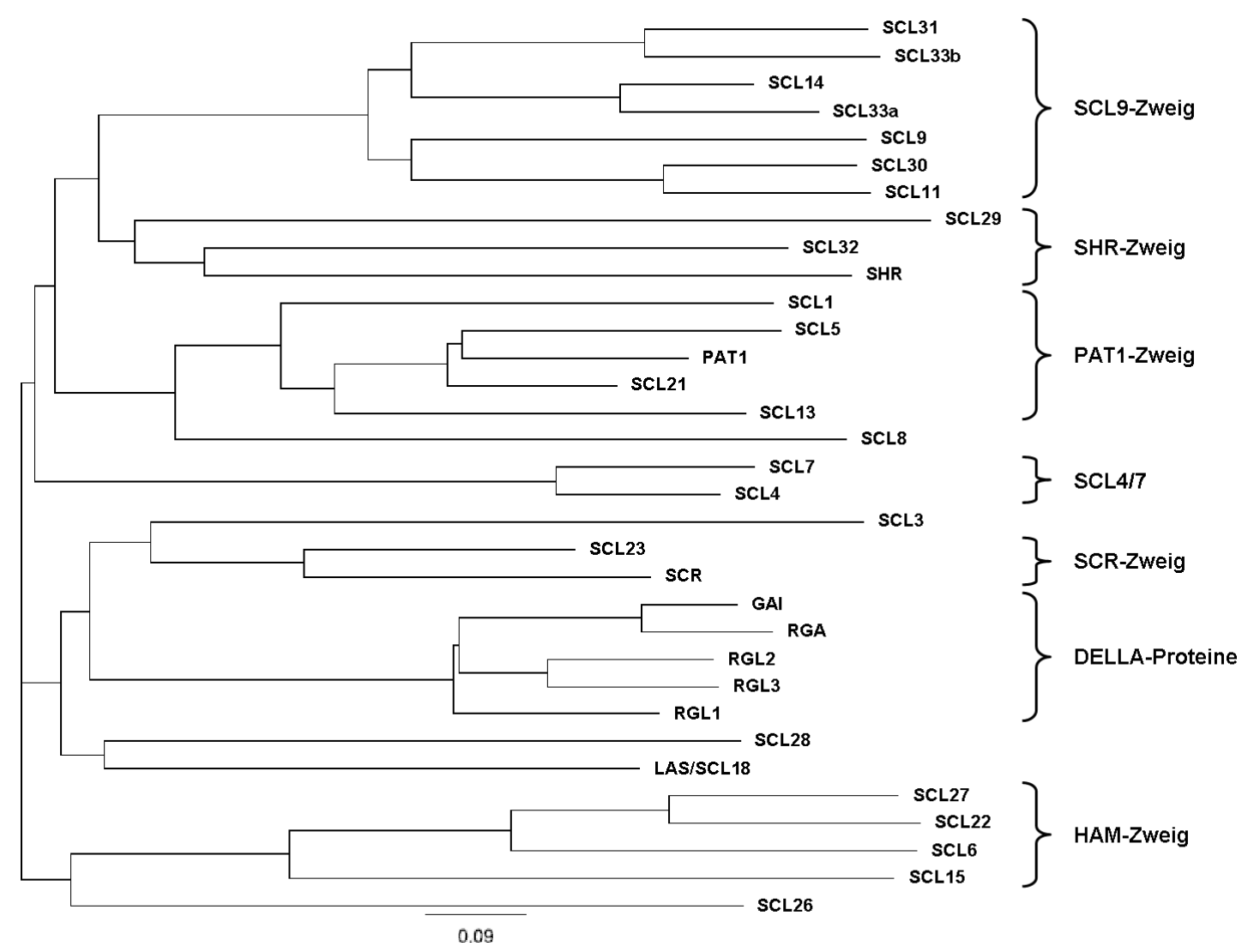

\section{Abbildung 2.3: Stammbaum der GRAS-Genfamilie}

Die GRAS-Genfamilie kann in sieben Unterfamilien eingeteilt werden und enthält einige Mitglieder, die in keine der Unterfamilien eingeordnet werden können. SCL14 gehört der SCL9-Unterfamilie an. Der Stammbaum wurde mit dem Programm Geneius erstellt (Cost Matrix: Blosum 62; Gap open penalty: 12; Gap extension penalty: 3; Global Alignment; Genetic Distance Model: Jukes-Cantor; Tree build method: Neighbour-Joining), die Benennung der Unterfamilien erfolgte nach Bolle 2004 (Bolle 2004).

Trotz ihrer Funktion als Regulatoren der Transkription konnte für die meisten GRASProteine keine direkte Bindung an DNA nachgewiesen werden (Bolle 2004), für das GRAS-Protein SCL27 wurde diese DNA-Bindung aber inzwischen gezeigt. SCL27 ist an der Regulation der Chlorophyllsynthese im Licht beteiligt und inhibiert diese durch die Bindung an cis-Elemente im Protmotor der Protochlorophylid Oxidoreductase $C$ (PORC) mit der Sequenz $\mathrm{G}(\mathrm{A} / \mathrm{G})(\mathrm{A} / \mathrm{T}) \mathrm{AA}(\mathrm{A} / \mathrm{T}) \mathrm{GT}$, was zur Repression des Gens führt. Die Inhibition wird aufgehoben durch die Interaktion von SCL27 mit DELLAProteinen, wodurch die DNA-Bindefähigkeit von SCL27 reduziert wird (Ma et al. 2014). SCL14 bindet ebenfalls nicht direkt an die Promotoren seiner Zielgene, sondern wird durch die Interaktion mit TGA2 dorthin rekrutiert. Fode et al. konnten durch Chromatin Immunopräzipitationsexperimente zeigen, dass sich der Komplex aus TGA2 und SCL14 sowohl im uninduzierten Zustand als auch im induzierten Zustand an den Promotoren seiner Zielgene befindet. Die Promotorbindung stellt daher nicht den Mechanismus zur Aktivierung dieser Gene dar. In transient mit einem SCL14-GFP-Fusionsprotein transformierten Tabakprotoplasten ist das GFP-Signal 
sowohl im Zellkern als auch im Cytoplasma zu beobachten. Nach der Behandlung der Protoplasten mit dem Kernexportinhibitor Leptomycin B findet sich SCL14 nur noch im Zellkern (Fode et al. 2008), was auf einen ständigen Austausch des Proteins zwischen Zellkern und Cytoplasma schließen lässt. Möglicherweise findet der Schritt zur Aktivierung von SCL14 im Cytoplasma statt und das aktive Protein wird dann in den Zellkern transportiert.

\subsection{Redox-basierte Proteinmodifikationen und Signal- transduktion}

Durch eine Vielzahl von Stoffwechselreaktionen werden reaktive Sauerstoffspezies (ROS) und reaktive Stickstoffspezies (RNS) produziert. Dies geschieht einerseits als unerwünschte Beiprodukte, beispielsweise während der Photosynthese und der Zellatmung, andererseits werden ROS und RNS wie Wasserstoffperoxid $\left(\mathrm{H}_{2} \mathrm{O}_{2}\right)$ und Stickstoffmonooxid (NO) als Signalmoleküle nach Pathogenbefall durch Mitglieder der Respiratory burst oxidase homolog-Familie (Rboh) bzw. Stickstoffmonooxid Synthasen (NOS) und Nitratreduktasen (NR) produziert (Torres \& Dangl 2005; Modolo et al. 2005). Weiterhin lösen Xenobiotika die Entstehung von ROS in der Zelle aus (Ramel et al. 2012)

Die Kontrolle der ROS und RNS und die Weiterleitung des Signals zu Redox Sensor Proteinen erfolgt hauptsächlich durch die drei Redox Paare $N A D(P)^{+} / N A D(P) H$, Glutathion/Glutathiondisulfid (GSH/GSSG) und Ascorbat/Dehydroascorbat (ASC/DHASC) (Noctor 2006). Durch das ansteigende Redox-Potential dieser RedoxPaare, kommt es zu einem Elektronenfluss von $\mathrm{NAD}(\mathrm{P}) \mathrm{H}$ über Glutathion zu Ascorbat. Die Dehydroascorbat Reduktase reduziert Dehydroascorbat zu Ascorbat unter Verwendung von Glutathion als Reduktionsäquivalent. Die Regeneration des Glutathions erfolgt durch Thioredoxine und Glutathionreduktasen. Im Verlauf dieser Regeneration wird $\mathrm{NAD}(\mathrm{P}) \mathrm{H}$ zu $\mathrm{NAD}(\mathrm{P})^{+}$oxidiert (Noctor 2006). Eine durch ROS/RNS hervorgerufene Veränderung im Verhältnis der Redox-Partner wird durch Redox-Sensorproteine erkannt und führt so zu einer Änderung der Genexpression (Abb. 2.4) (Spoel \& Loake 2011). Beispiele für solche Sensormoleküle, deren Aktivität durch Redoxmodifikationen von Cysteinen reguliert wird, sind NPR1, das 


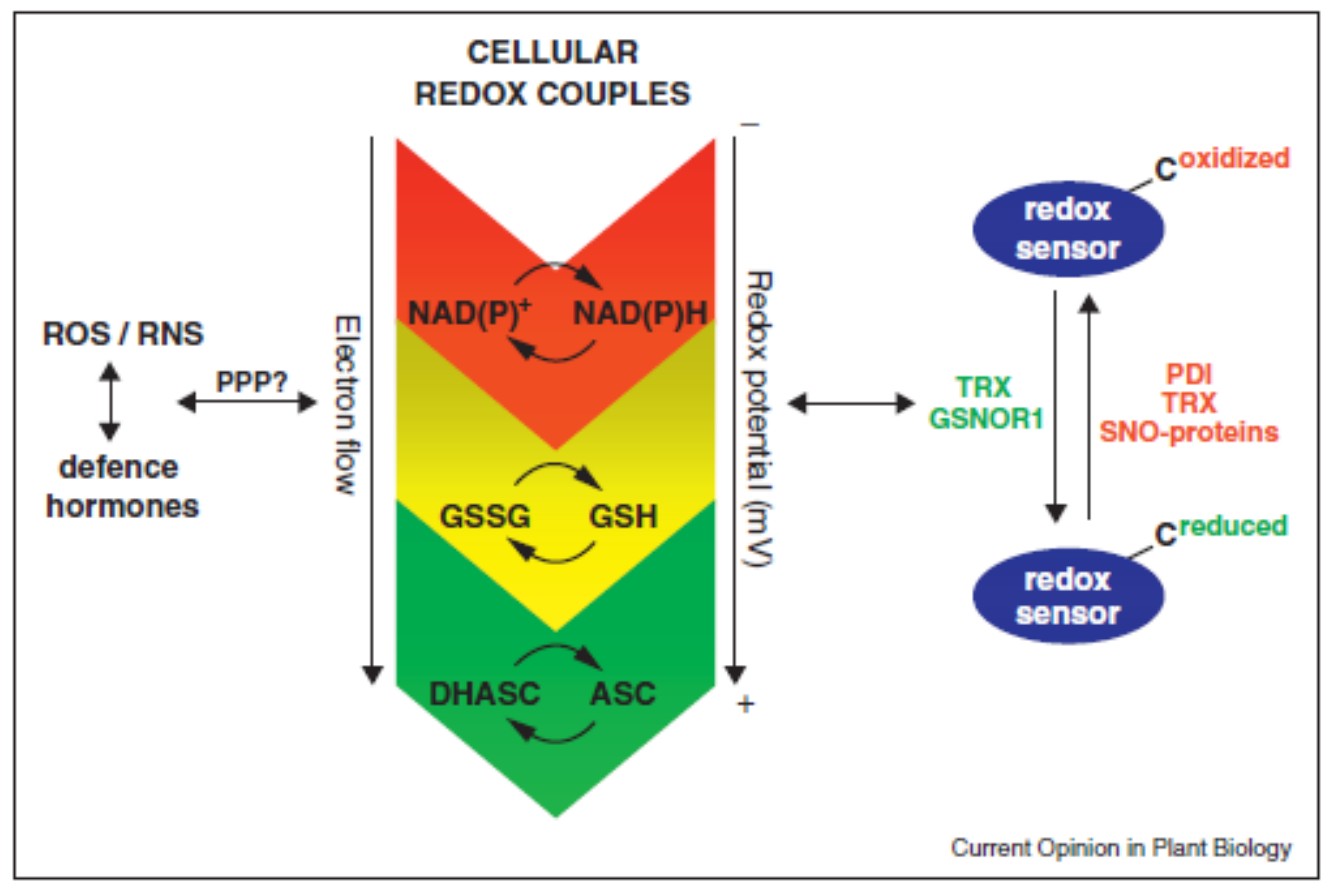

\begin{abstract}
Abbildung 2.4: Modell der Signalvermittlung von Abwehrhormonen zu Redox-Sensor Proteinen über Redox-Paare kleiner Moleküle.

Ausgelöst durch Pathogeninfektion induzieren Abwehrhormone die Produktion von ROS und RNS und umgekehrt. Diese Änderungen in der Konzentration von Hormonen und reaktiven Molekülen werden durch die zellulären Redox-Paare NAD(P)H/NAD(P) ${ }^{+}, G S H / G S S G$ und ASC/DHASC detektiert. Das Bindeglied zwischen den Hormonen und reaktiven Molekülen auf der einen und den Redox-Paaren auf der anderen Seite, ist vermutlich der Pentosephosphatweg (PPP). Das ansteigende RedoxPotential der Redox-Paare sorgt für einen Elektronenfluss von NAD(P)H über Glutathion zu Ascorbat. Änderungen im Verhältnis der Partner der einzelnen Redox-Paare zueinander werden durch reaktive Cysteine in Redox-Sensor Proteinen erkannt, welche reversibel zwischen dem reduzierten und dem oxidierten Status umschalten können. Die Reduktion von Redox-Sensor Proteinen wird durch Thioredoxine (TRX) und die S-Nitrosoglutathionreduktase 1 (GSNOR1) vermittelt, die Oxidation erfolgt durch die Proteindisulfid Isomerase (PDI), TRX und SNO-Donorproteine (Spoel \& Loake 2011).
\end{abstract}

Die Wichtigkeit vor allem des Glutathions für die Aufrechterhaltung des RedoxGleichgewichtes in der Zelle zeigt sich unter anderem dadurch, dass mehrere Mutanten, die in der Synthese oder der Reduktion von Glutathion beeinträchtigt sind, eine erhöhte Empfindlichkeit gegenüber oxidativem Stress zeigen. In der Arabidopsis Mutante glutathione reductase 1 (gr1) ist das Verhältnis von GSH zu GSSG in Richtung des GSSG verschoben. Diese Pflanzen weisen eine reduzierte Pufferkapazität gegenüber ROS im Vergleich zum Wildtyp auf (Marty et al. 2009). Eine weitere Mutante, mit der die Bedeutung von Glutathion speziell auch für die Resistenz gegenüber Pathogenen und Fraßinsekten gezeigt werden konnte, ist pad2. Diese Mutante exprimiert eine inaktive Form der $y$-Glutamylcysteinsynthetase 1 (GSH1). Dieses Enzym ist an der Synthese von Glutathion beteiligt indem es die 
Bildung von y-Glutamylcystein aus Glutaminsäure und Cystein katalysiert. Die pad2 Mutante akkumuliert nur etwa ein fünftel des Glutathions im Vergleich zum Wildtyp und ist empfindlicher gegenüber der Infektion mit den Pathogenen Pseudomonas syringae und Phytophtora brassicae sowie gegenüber dem Befall mit dem Fraßinsekt Spodoptera littoralis (Parisy et al. 2007; Schlaeppi et al. 2008; Ball et al. 2004). Auch die direkte Behandlung von Arabidopsis Pflanzen mit den Hormonen Salicylsäure und Jasmonsäure beeinflussen sowohl die Gesamtmenge von Glutathion in der Pflanze als auch das Verhältnis von reduziertem Glutathion gegenüber Glutathiondisulfid (Mou et al. 2003; Koornneef et al. 2008; Vanacker et al. 2000; Mateo et al. 2006). Wie genau diese Hormone den Glutathionhaushalt beeinflussen, ist noch nicht genau bekannt, jedoch gibt es Hinweise darauf, dass der SA-Effekt über den Pentosephosphatweg vermittelt wird (Xiong et al. 2009).

Die Wahrnehmung von Änderungen im Redox-Milieu der Zelle durch Redox-Sensor Proteine erfolgt durch die Modifikation von in diesen Proteinen enthaltenen Cysteinen (Spoel \& Loake 2011). Es wird jedoch nicht jedes Cystein modifiziert, da die chemische Umgebung der Cysteine eine Rolle für die Reaktivität der Thiolgruppe spielt (Weerapana et al. 2010). Bisher wurden die Nitrosylierung, die Bildung von Sulfensäure und Disulfidbrücken, die Glutathionylierung, die Bildung von Sulfinsäure und die Bildung von Sulfonsäure als mögliche Redox-basierte Modifikationen von Cysteinen beobachtet (Abb. 2.5) (Spadaro et al. 2010).

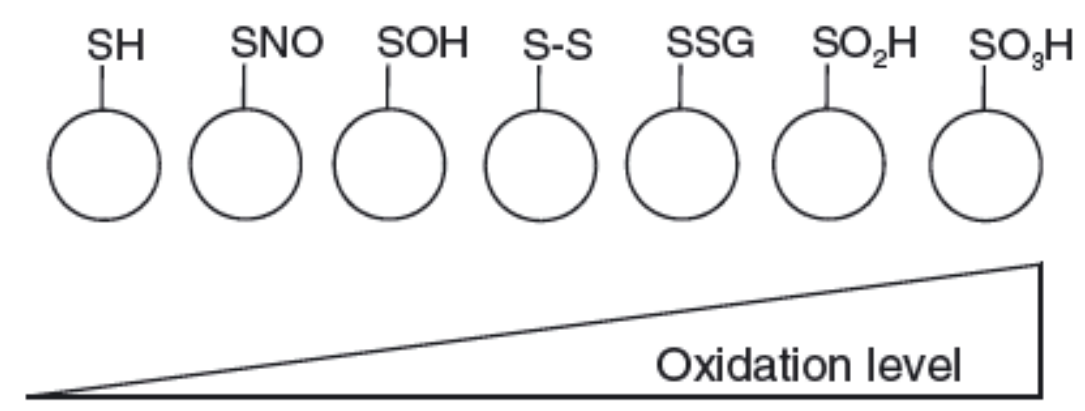

Abbildung 2.5: Überblick über Redox-basierte Cysteinmodifikationen

Der Oxidationsgrad steigt von links nach rechts an. Cystein Thiol (SH), S-Nitrosothiol (SNO), Sulfensäure $(\mathrm{SOH})$, Disulfid $(\mathrm{S}-\mathrm{S})$, S-Glutathionylierung (SSG), Sulfinsäure $\left(\mathrm{SO}_{2} \mathrm{H}\right)$, Sulfonsäure $\left(\mathrm{SO}_{3} \mathrm{H}\right)$ (Spadaro et al. 2010)

Als Nitrosylierung wird die Modifikation eines Thiols durch Stickstoffmonooxid bezeichnet. Beispiele für Proteine, die durch Nitrosylierung reguliert werden, sind NONEXPRESSOR OF PR1 (NPR1), ein Schlüsselregulator der Pathogenabwehr, 
und das SALICYLIC ACID BINDING PROTEIN 3 (SABP3), welches ebenfalls an der Pathogenabwehr beteiligt ist. Bei beiden Proteinen führt die Nitrosylierung zu einer Deaktivierung (Tada et al. 2008; Y.-Q. Wang et al. 2009).

Bisher konnte noch kein Enzym identifiziert werden, welches spezifisch die Nitrosylierung von Proteinen katalysiert. Vielmehr wird die Nitrosylierung durch die Verfügbarkeit von NO oder Übergangsmetallen, einer hydrophoben oder elektrostatischen Umgebung des Cysteins oder der Änderung von Protein-Protein Wechselwirkungen kontrolliert (Bosworth et al. 2009; Kim et al. 2005; Hess et al. 2001; Stamler et al. 1997). Die Transnitrosylierung, d.h. die Übertragung von NO von einem Thiol auf ein anderes spielt ebenfalls eine Rolle. So konnte die Übertragung von NO von nitrosyliertem Hämoglobin auf das interagierende Protein Band-3 beobachtet werden (Pawloski et al. 2001). Ein wichtiger NO-Donator ist nitrosyliertes Glutathion, S-Nitrosoglutathion (GSNO), welches ebenfalls Proteine transnitrosylieren kann (Spadaro et al. 2010). So weist die Arabidopsis thaliana gsnor1-3 Mutante, der mit der S-Nitrosoglutathion Reduktase (GSNOR) das Enzym für den Abbau von GSNO fehlt, einen, im Vergleich zum Wildtyp, erhöhten GSNO Gehalt auf, was zu verstärkter Nitrosylierung der Proteine in diesen Pflanzen führt (Feechan et al. 2005). Die Denitrosylierung der Proteine erfolgt in der Regel durch Enzyme der Thioredoxinfamilie (Tada et al. 2008).

Sulfensäure entsteht durch die Hydroxylierung einer Thiolgruppe und es konnte gezeigt werden, dass die Behandlung von Säugerzellen mit Wasserstoffperoxid zur Hydroxylierung eines Cysteins im aktiven Zentrum von Protein-Tyrosinphosphatasen und somit zur Inaktivierung dieser Enzyme führt. Da es sich hierbei um eine reversible Modifikation des Cysteins handelt, könnte dies einen Mechanismus zur Regulation dieser Enzyme darstellen (Denu \& Tanner 1998; Meng et al. 2002). Für eine Protein-Tyrosinphosphatase aus Arabidopsis, AtPTP1, konnte ebenfalls gezeigt werden, dass diese durch die Hydroxylierung des Cysteins im aktiven Zentrum inaktiviert wird (Gupta \& Luan 2003).

Die Bildung von Disulfidbrücken kann sowohl zwischen zwei Cysteinen innerhalb eines Proteins geschehen, als auch zwischen den Cysteinen unterschiedlicher Proteine. Diese Disulfidbrücken können dann zum Einen statisch sein und ihre Funktion in der Beibehaltung der korrekten Proteinkonformation haben, zum Anderen können sie aber auch reversibel und für die Regulation des Proteins wichtig sein. So liegt beispielsweise NPR1 im uninduzierten Zustand als Oligomer im Cytoplasma der 
Zelle vor, welches durch Disulfidbrücken zusammengehalten wird. In Folge einer Pathogeninfektion werden diese Disulfidbrücken reduziert, was zu einer Freigabe der Monomere führt, welche daraufhin in den Zellkern gelangen können (Mou et al. 2003). Ein weiteres Protein, dessen Aktivität durch die Formation von Disulfidbrücken reguliert wird, ist der Sensor für oxidativen Stress aus Saccharomyces cerevisiae, YAP1p. Dieser Transkriptionsfaktor verfügt über ein Kernlokalisationssignal und ein Kernexportsignal, was zu einem konstanten Austausch des Proteins zwischen Zellkern und Cytoplasma führt. Nach dem einsetzen von oxidativem Stress werden vier Cysteine in YAP1p oxidiert und es bilden sich zwei intramolekulare Disulfidbrücken, wodurch sich die Konformation des Proteins ändert und das Kernexportsignal maskiert wird. Dadurch kommt es zur Akkumulation von YAP1p im Zellkern (Kuge et al. 1997; Menezes et al. 2004).

Die S-Glutathionylierung spielt eine wichtige Rolle in Detoxifikationsprozessen. So wird GSH bei der Detoxifikation von ROS zu GSSG oxidiert und bei der Detoxifikation von Xenobiotika durch Glutathion S-Transferasen auf diese Substanzen übertragen. Die Glutathionverbindungen werden dann in die Vakuole oder den apoplastischen Raum transportiert und das GSSG kann durch die GSSG-Reduktase wieder zu GSH reduziert werden (Lillig et al. 2003). Die Glutathionylierung von Proteinen spielt unter anderem eine Rolle in der Regulation der Kohlenstofffixierung während der Photosynthese. Die Enzyme der Kohlenstofffixierung werden im Dunkeln durch die Bildung von Disulfidbrücken inhibiert. Die Reduktion dieser Disulfidbrücken und somit die Aktivierung dieser Enzyme erfolgt im Licht durch das Thioredoxin TRXf (Meyer et al. 2008). Durch die Glutathionylierung eines Cysteins wird die Regeneration dieser Thioredoxine durch die Ferredoxin-TRX Reduktase verhindert, was zur Deaktivierung der Thioredoxine und daraus folgend auch der Enzyme der Kohlenstofffixierung führt (Casagrande et al. 2002; Michelet et al. 2005). Weiterhin kann die Glutathionylierung von Proteinen zum Schutz der Proteine unter oxidativen Bedingungen dienen, da die Glutathionylierung von Thiolgruppen diese vor der weiteren Oxidation schützt, wodurch Sulfin- und Sulfonsäuren entstehen würden.

Sulfin- und Sulfonsäuren entstehen unter starkem oxidativen Stress, beispielsweise durch die weitere Oxidation von Sulfensäuren, und galten bis vor kurzem als irreversible Modifikationen. Zumindest können sie nicht durch das Thioredoxinsystem reduziert werden (Spadaro et al. 2010). Jedoch konnten Biteau et al. in Hefe ein Sulphiredoxin genanntes Enzym nachweisen, dass auch Sulfinsäuren unter ATP- 
Verbrauch reduziert (Biteau et al. 2003). Inzwischen konnte auch in Arabidopsis ein Enzym mit Sulfinsäurereduktaseaktivität nachgewiesen werden (Rey et al. 2007). Allerdings stellt sich die Frage, ob es sich bei der Sulfinierung von Cysteinen um eine regulatorische Modifikation handelt, da sie nur unter extremen Bedingungen auftritt und schwer zu reduzieren ist.

Teilweise werden Proteine durch unterschiedliche Cysteinmodifikationen reguliert, wovon jede das Protein auf unterschiedliche Weise beeinflusst (Spadaro et al. 2010). So wird der Transkriptionsfaktor OxyR aus Escherichia coli durch die Einwirkung von Wasserstoffperoxid, GSSG, GSNO oder S-Nitrosocystein oxidiert, was in einer Sulfensäure, einem gemischten Disulfid oder einer Nitrosylierung resultiert. Jede dieser Modifikationen erfolgt an dem gleichen Cystein und beeinflusst die Konformation von OxyR und dessen DNA-Bindeeigenschaften auf unterschiedliche Weise (Kim et al. 2002).

\subsection{Reaktive Elektrophile Spezies}

Bei Reaktiven Elektrophilen Spezies (RES) handelt es sich um Substanzen, die eine reaktive elektrophile Gruppe, wie zum Beispiel eine $\alpha, \beta$-ungesättigte Carbonylgruppe, enthalten (Farmer \& Davoine 2007). RES werden in der Zelle teilweise durch enzymatische Reaktionen produziert, wie beispielsweise OPDA und das flüchtige Aldehyd 2-(E)-Hexenal (Mueller et al. 2008; Matsui 2006), teilweise entstehen sie durch die nichtenzymatische Oxidation von Lipiden (Ishii et al. 2006; Winger et al. 2005; Weber et al. 2004; Mueller 2004). Allerdings handelt es sich bei RES nicht ausschließlich um im Stoffwechsel der Zelle entstandene Substanzen. So stellen viele Herbizide ebenfalls Reaktive Elektrophile Spezies dar. Paraquat und 2,4Dichlorphenoxyessigsäure können zum Beispiel zu den RES gerechnet werden (Abb. 2.6). Für Paraquat ist bekannt, dass es Elektronen vom Photosystem I übernehmen kann. Das dadurch entstehende Paraquat Radikal kann $\mathrm{O}_{2}$ zu Superoxid $\left(\mathrm{O}_{2}^{-}\right)$ reduzieren, welches durch Superoxiddismutasen $\mathrm{zu}$ Wasserstoffperoxid $\left(\mathrm{H}_{2} \mathrm{O}_{2}\right)$ umgewandelt wird. Aus dem Wasserstoffperoxid kann dann in einer Fenton-Reaktion oder durch die Reaktion mit einem weiteren Paraquatradikal das hochreaktive Hydroxylradikal $\left(\mathrm{HO}^{\circ}\right)$ gebildet werden, das Membranlipide und andere Biomoleküle durch Oxidation schädigen kann (Babbs et al. 1989). Die Oxidation der Membranlipide führt dann zur Bildung weiterer RES. Eine weitere Quelle für RES 
sind Kontaminanten aus Rückständen der industriellen Produktion. So handelt es sich bei dem Sprengstoff Trinitrotoluol (TNT) (Abb. 2.6) um ein starkes Phytotoxin, welches seine Reaktivität durch die Nitrogruppen am Benzolring erhält. Die Nitrogruppen entziehen dem Ring Elektronen und verleihen im dadurch einen elektrophilen Charakter (Beynon et al. 2009). Ein ähnlicher Elektronen ziehender Effekt geht von den Halogensubstituenten bei 2,4-D und TIBA, bzw. dem Sauerstoff bei SA aus (Abb. 2.6).

RES sind jedoch nicht in jedem Fall schädlich für die Zelle. In geringen Konzentrationen können sie einen positiven Effekt ausüben, indem sie die Expression von Genen induzieren, die an der Abwehr von Pathogenen oder an der Detoxifikation von Xenobiotika beteiligt sind. So konnte für OPDA und das Phytoprostan $A_{1}\left(\mathrm{PPA}_{1}\right)$ nachgewiesen werden, dass sie in Arabidopsis Gene aktivieren, die allen drei Stufen des pflanzlichen Detoxifikationsprogrammes zugeordnet werden, wie Cytochrom P450 Monooxygenasen (CYPs), GSTs, und ATP-Bindekassetten Transporter (ABC-Transporter). Für die Induktion eines großen Teils dieser Gene durch OPDA und $\mathrm{PPA}_{1}$ war die Anwesenheit von TGATranskriptionsfaktoren der Klasse II erforderlich (Mueller et al. 2008). Fettsäureketodiene und Fettsäureketotriene, die eine $\alpha, \beta$-ungesättigte Carbonylgruppe enthalten und daher auch als RES klassifiziert werden können, sind in Arabidopsis der Lage, die Glutathion S-Transferase GST1 zu aktivieren, die ebenfalls durch die Infektion mit dem Pathogen Pseudomonas syringae pv. Tomato induziert wird (Vollenweider et al. 2000) und Syringolin A, ein RES das von Pseudomonas syringae produziert und sekretiert wird, löst in Pflanzen an der Infektionsstelle Zelltod aus und vermittelt so eine Resistenz gegenüber biotrophen Pathogenen (Michel et al. 2006).

RES können sich prinzipiell auf zwei Arten auf den Stoffwechsel der Zelle auswirken. Zum Einen durch einen eher indirekten Effekt, indem sie das Redox-Gleichgewicht beeinflussen. Dies geschieht, da bei der Reduktion der reaktiven Doppelbindung in $\alpha, \beta$-ungesättigten Carbonylgruppen Reduktionsäquivalente in Form von NADPH und Flavinmononukleotiden (FMN) verbraucht werden (Farmer \& Davoine 2007). Ebenso können RES, da sie mit nukleophilen Gruppen reagieren können, durch die Oxidation der Sulfhydrylgruppe des Glutations den Glutathionpool beeinflussen. Zum Anderen können RES einen direkteren Effekt ausüben, da sie Biomoleküle wie Proteine direkt modifizieren können. Ein Beispiel hierfür ist der Transkriptionsfaktor NUCLEAR 
FACTOR-ERYTHROID 2-RELATED FACTOR 2 (NRF2) aus Säugetieren. Dieser interagiert mit dem Protein KELCH-LIKE ECH-ASSOCIATED PROTEIN 1 (KEAP1), was dazu führt, dass NRF2 im Cytoplasma zurück gehalten, ubiquitiniert und durch das Proteasom abgebaut wird. Durch die Modifikation von Sulfhydrylgruppen in KEAP1 wird die Interaktion von KEAP1 mit NRF2 unterbunden, woraufhin NFR2 in den Zellkern gelangen und die Genexpression induzieren kann (Satoh et al. 2006; Dinkova-Kostova et al. 2005). Ein Beispiel für ein Protein aus Pflanzen, das direkt durch RES modifiziert werden kann, ist die ALTERNATIVE OXIDASE (AOX), die durch 4-Hydroxy-2-nonenal modifiziert und dadurch inaktiviert wird (Winger et al. 2005).<smiles>O=C(O)c1ccccc1O</smiles>

SA<smiles>O=C(O)c1cc(I)cc(I)c1I</smiles>

TIBA

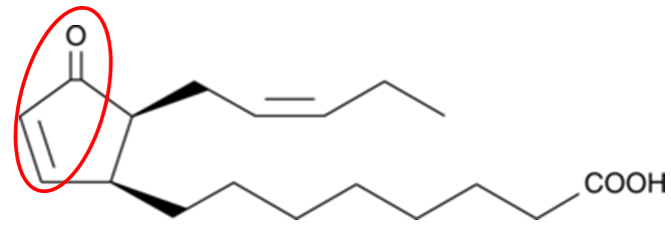

OPDA<smiles>Cc1c([N+](=O)[O-])cc([N+](=O)[O-])cc1[N+](=O)[O-]</smiles>

TNT<smiles>O=C(O)COc1ccc(Cl)cc1Cl</smiles>

2,4-D

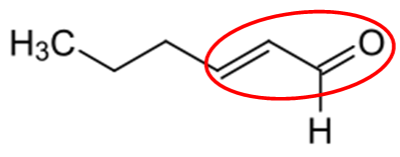

2(E)-hexenal<smiles>C[n+]1ccc(-c2cc[n+](C)cc2)cc1</smiles><smiles>O=CC1CCCCC1</smiles>

Paraquat

\section{Abbildung 2.6: Strukturformeln unterschiedlicher Reaktiver Elektrophiler Spezies}

Der elektrophile Charakter der RES Salicylsäure (SA), 2,3,5-Triiodobenzoesäure (TIBA), Trinitrotoluol (TNT) und 2,4-Dichlorphenoxyessigsäure (2,4-D) wird durch die Elektronen ziehenden Substituenten am Benzolring vermittelt, bei Paraquat befinden sich die elektrophilen Zentren an den beiden Stickstoffatomen innerhalb der Ringe. Bei 12-Oxophytodiesäure (OPDA), 2(E)-Hexenal und Akrolein stellt die $\alpha, \beta$-ungesättigte Carbonylgruppe (rote Markierung) das elektrophile Zentrum dar. 


\subsection{Ziel dieser Arbeit}

Die Fragestellung dieser Arbeit beruht auf den Ergebnissen von Tanja Siemsen und Benjamin Fode. In ihren Arbeiten konnten sie SCL14 als Interaktionspartner des bZIP-Transkriptionsfaktors TGA2 identifizieren und haben bei der weiteren Charakterisierung des Proteins durch Microarray Analysen festgestellt, dass SCL14 an der transkriptionellen Kontrolle von Genen beteiligt ist, die Teil des pflanzlichen Detoxifikationsprogrammes sind. Für die Aktivierung dieser Gene ist die Interaktion von SCL14 mit TGA2 nötig, da SCL14 nicht direkt an die Promotoren seiner Zielgene bindet. Diese Bindung wird durch TGA2 vermittelt. Passend zu diesen Ergebnissen konnten sie zeigen, dass sc/14 Mutanten auf SA, Isonikotinsäure (INA) und TIBA schlechter wachsen als Wildtyppflanzen, während Überexpressionslinien von SCL14 sogar ein besseres Wachstumsverhalten zeigen als der Wildtyp (Fode et al. 2008). Weiterhin konnte Neena Ratnakaran in ihrer Doktorarbeit zeigen, dass die beiden NAC-Traskriptionsfaktoren ATAF1 und NAC032 SCL14-abhängig durch TIBA induziert werden und auf diesen Stimulus hin ihrerseits Detoxifikationsgene aktivieren (Ratnakaran 2014). Somit konnte in diesen Arbeiten sowohl eine direkte wie auch eine indirekte Regulation von Detoxifikationsgenen durch SCL14 nachgewiesen werden. Bisher konnte der Mechanismus, welcher zur Aktivierung von SCL14 führt, jedoch noch nicht aufgeklärt werden. Durch Chromatin Immunopräzipitationsexperimente konnte gezeigt werden, dass der Komplex aus SCL14 und TGA2 im uninduzierten wie auch im induzierten Zustand an die DNA bindet (Fode et al. 2008). Die Bindung allein führt also nicht zur Aktivierung dieser Zielpromotoren. Eine mögliche Rolle könnte ein ständiger Austausch von SCL14 zwischen dem Zellkern und dem Cytoplasma, der in Tabakprotoplasten beobachtet werden konnte, spielen. In unbehandelten Protoplasten ist die Fluoreszenz eines SCL14-GFP Fusionsproteins in der gesamten Zelle zu beobachten, nach der Behandlung mit dem Kernexportinhibitor Leptomycin B befindet sich SCL14 nur noch im Zellkern (Fode et al. 2008). Ob dieser Austausch auch in Arabidopsis Pflanzen vorkommt und wenn ja, unter welchen Bedingungen, soll an transgenen Pflanzen untersucht werden, die ein GFP-SCL14 Fusionsprotein unter der Kontrolle des CaMV 35S-Promotors exprimieren. Diese Pflanzen werden mit Xenobiotika wie TIBA aber auch mit Hormonen wie Salicylsäure und Jasmonsäure behandelt und die Lokalisation des Fusionsproteins durch Fluoreszenzmikroskopie überprüft. Da sich die Fluoreszenz des GFP-SCL14 Fusionsproteins, aufgrund der sehr schwachen 
Fluoreszenz in Blättern, in Wurzeln besser beobachten lässt, sollen diese Experimente an Wurzeln durchgeführt werden. Zusätzlich wird die Expression von SCL14 Zielgenen in Wurzeln von Wildtyppflanzen und sc/14/33 Mutanten nach der Behandlung mit diesen Substanzen in einem hydroponischen System untersucht, um einen eventuellen Effekt auf die Lokalisation von SCL14 mit der Genexpression korrelieren zu können. Dieses hydroponische System soll auch für ein Mikroarray Experiment genutzt werden, um in Wurzeln nach neuen Zielgenen von SCL14 zu suchen.

Die posttranslationale Regulation einiger an der Stressantwort beteiligter Transkriptionsfaktoren erfolgt über die Redox-Modifikation von in diesen Proteinen vorhandenen Cysteinen. So wird der Schlüsselregulator der pflanzlichen Pathogenabwehr, NPR1, welcher ebenfalls ein Interaktionspartner von TGA2 ist, durch Cysteinnitrosylierung und die Ausbildung von Disulfidbrücken reguliert (Tada et al. 2008) und auch der Transkriptionsfaktor YAP1p aus Hefe, welcher einen Sensor für oxidativen Stress darstellt, wird durch die Ausbildung von Disulfidbrücken aktiviert (Wood et al. 2003). Um die Bedeutung von Cysteinmodifikationen für die Aktivierung von SCL14 zu überprüfen, werden die neun in SCL14 enthaltenen Cysteine mutiert und die Fähigkeit dieser Mutanten, den Promotor des bereits bekannten SCL14 Zielgens GSTU7 zu aktivieren, in einem transienten Protoplastensystem getestet. Die Mutanten, die in diesem System einen Unterschied zum Wildtypprotein zeigen, sollen ebenfalls als GFP-Fusion in transgenen Pflanzen stabil exprimiert und ihre intrazelluläre Lokalisation unter chemischen Stressbedingungen beobachtet werden. Da für die Aktivierung des SCL14/TGA2-Komplexes möglicherweise die Anwesenheit eines weiteren Proteins notwendig ist, soll in einem Hefe-Zwei-Hybrid Experiment nach weiteren Interaktionspartnern von SCL14 gesucht werden. Da SCL14 in Hefe jedoch alleine bereits in der Lage ist, die Transkription der Reportergene zu induzieren, wird nur die GRAS-Domäne als Köder angeboten, die diese Autoaktivierungsfunktion nicht aufweist. 


\section{Material und Methoden}

\subsection{Material}

\subsubsection{Geräte}

\begin{tabular}{|c|c|c|}
\hline Gerät & Modell & Hersteller \\
\hline 3D Schüttler & Vibrax VXR basic & IKA \\
\hline Agarose Gelsystem & & Universität Göttingen \\
\hline Analysewaage & Extend & Sartorius \\
\hline Autoklav & VX-95 & Systec \\
\hline Autoklav & VX-150 & Systec \\
\hline CCD Kamera & ChemoCam & Intas \\
\hline Elektrophoresestromgeber & PowerPac HC & BioRad \\
\hline Elektrophoresestromgeber & EV243 & Consort \\
\hline Elektrophoresestromgeber & EV231 & Consort \\
\hline Feinwaage & 572 & Kern \\
\hline $\begin{array}{l}\text { Geldokumentationssystem } \\
\text { (Agarosegele) }\end{array}$ & Transillumiator & Biostep \\
\hline Geldokumentationssystem (PA-Gele) & Gel Imager & Intas \\
\hline Heizblock & MHR 11 & HLC Biotech \\
\hline Heizblock & TH 26 & HLC Biotech \\
\hline Inkubator & & memmert \\
\hline Konfokales Lasermikroskop & DM6000CS & Leica \\
\hline Kühlzentrifuge & Heraeus Fresco 17 & ThermoScientific \\
\hline Kühlzentrifuge & Rotina 38R & Hettich \\
\hline Kühlzentrifuge & RC6+ & Sorvall \\
\hline Luminometer & CentroXS3 LB 960 & \begin{tabular}{|l|} 
Berthold \\
Technologies
\end{tabular} \\
\hline Magnetrührer & RH basic 2 & IKA \\
\hline Mikrotiterplattenleser & SynergyHT & BioTek \\
\hline PA-Gelsystem & $\begin{array}{l}\text { Mini Protean Tetra } \\
\text { Cell }\end{array}$ & BioRad \\
\hline PCR-Gerät & MyCycler & BioRad \\
\hline Pflanzenwuchskammer & & JohnssonControls \\
\hline Pflanzenwuchsschrank & AR-66L/3 & CLF Plant Climatics \\
\hline pH-Meter & $\mathrm{pH} 211$ & Hanna Instruments \\
\hline Photometer & Libera S11 & biochrom \\
\hline qRT-PCR-Gerät & iCycler & BioRad \\
\hline RNA-/DNA-Messgerät & NanoDrop2000 & ThermoScientific \\
\hline Schüttelinkubator & Certomat BS-1 & Sartorius \\
\hline Schwenker & $\begin{array}{l}\text { minigyro-rocker } \\
\text { SSM3 }\end{array}$ & Stuart \\
\hline Sterilbank & Heraguard & ThermoScientific \\
\hline Sterilbank S1 & SAFE2020 & ThermoScientific \\
\hline
\end{tabular}


Tischzentrifuge

Trockensterilisator

Vakuumpumpe

Wasserbad

Wasserentsalzer

Western Blot Halbtrockenkammer

\begin{tabular}{|l|l} 
Heraeus Pico 117 & ThermoScientific \\
\hline MD 1C & memmert \\
\hline 1092 & vacuubrand \\
\hline arium pro DI & GFL \\
\hline & Sartorius \\
\hline & Universität Göttingen
\end{tabular}

\subsubsection{Verbrauchsmaterialen}

\begin{tabular}{c|l}
\hline \multicolumn{1}{|c|}{ Produkt } & \multicolumn{1}{|c}{ Hersteller } \\
\hline Blotpapier 3 mm & Whatman \\
\hline Deckgläser & Roth \\
\hline Einweg Plastikmaterial & $\begin{array}{l}\text { Biozym, Eppendorf, Greiner, Roth, } \\
\text { Sarstedt }\end{array}$ \\
\hline Elektroporationsküvetten & BioRad \\
\hline Leukopor & BSNmedical \\
\hline Mikrotiterplatten & Greiner bio-one \\
\hline Objektträger & Roth \\
\hline Parafilm M & Pechiney Plastic Packaging \\
\hline PVDF-Membran & Millipore
\end{tabular}

\subsubsection{Chemikalien}

\begin{tabular}{l|l}
\hline \multicolumn{1}{c|}{ Chemikalie } & \multicolumn{1}{c}{ Hersteller } \\
\hline $30 \%$ Acrylamid:N,N'-Methylenbisacrylamid $(37,5: 1)$ & Roth \\
\hline Ammoniumpersulfat & Biometra \\
\hline Ampicillin & AGS \\
\hline Bakterienagar & Roth \\
\hline bovines Serumalbumin & Serva \\
\hline Bromphenolblau & Roth \\
\hline Cadmiumchlorid & Roth \\
\hline EDTA & Applichem \\
\hline Ethidiumbromid & Roth \\
\hline Fluorescein & BioRad \\
\hline Gelrite & Duchefa \\
\hline Gentamycin & Duchefa \\
\hline GSNO & Sigma-Aldrich \\
\hline Harnstoff & Roth \\
\hline Kanamycin & Sigma-Aldrich \\
\hline Leptomycin B & Santa Cruz Biotechnologies \\
\hline MES & Roth \\
\hline Methyljasmonat & Sigma-Aldrich \\
\hline mPEG & Sigma-Aldrich \\
\hline Murashige und Skoog Medium & Duchefa \\
\hline
\end{tabular}




\begin{tabular}{l|l}
$\mathrm{NaCl}$ & Roth \\
\hline Natriumhypochloridlösung & Roth \\
\hline Natriumnitroprussid & Roth \\
\hline Natriumsalicylat & Merck \\
\hline N-Ethylmaleimide & Sigma-Aldrich \\
\hline Orange G & Sigma-Aldrich \\
\hline Phenol & Sigma-Aldrich \\
\hline Polyethylenglykol & Roth \\
\hline Propidiumiodid & Roth \\
\hline Rifampicin & Duchefa \\
\hline Saccharose & Roth \\
\hline SD-Medium & Gibco BRL \\
\hline Select Agar & Life Technologies \\
\hline Select Hefeextrakt & Gibco BRL \\
\hline Spectinomycin & Duchefa \\
\hline B-Mercaptoethanol & Roth \\
\hline SYBR Green I & Cambrex \\
\hline TEMED & Roth \\
\hline TIBA & Sigma-Aldrich \\
\hline Trichloressigsäure & Sigma-Aldrich \\
\hline Tris & Roth \\
\hline Trypton & Oxoid \\
\hline Tween20 & Roth
\end{tabular}

\subsubsection{Kits}

\begin{tabular}{l|l}
\hline \multicolumn{1}{c|}{ Kit } & \multicolumn{1}{c|}{ Hersteller } \\
\hline BioTaq DNA Polymerase Kit & Bioline \\
\hline Dual-luciferase reporter assay system & Promega \\
\hline lonic Detergent Compatibility Reagent & ThermoScientific \\
\hline iProof High-Fidelity PCR Kit & BioRad \\
\hline LuminataForte Western HRP & Millipore \\
\hline Substrate & Macherey-Nagel \\
\hline NucleoBond PC500 & Macherey-Nagel \\
\hline NucleoSpin Gel and PCR Clean-up & Macherey-Nagel \\
\hline NucleoSpin Plasmid & ThermoScientific \\
\hline Pierce 660 nm Protein Assay Kit & ThermoScientific
\end{tabular}

\subsubsection{Enzyme}

\begin{tabular}{|l|l|}
\hline \multicolumn{1}{|c|}{ Enzym } & \multicolumn{1}{c|}{ Hersteller } \\
\hline Biotaq DNA Polymerase & Bioline \\
\hline Cellulase Onozuka R-10 & Serva \\
\hline
\end{tabular}




\begin{tabular}{|l|l|} 
Clonase Mix (BP,LR) & Invitrogen \\
\hline DNasel & ThermoScientific \\
\hline iProof high fidelity DNA polymerase & BioRad \\
\hline Macerozyme R-10 & Serva \\
\hline Restriktionsenzyme & $\begin{array}{l}\text { MBI Fermentas, New England } \\
\text { Biolabs }\end{array}$ \\
\hline Reverse Transkriptase & MBI Fermentas \\
\hline RNAse A & Qiagen \\
\hline T4 DNA-Ligase & MBI Fermentas \\
\hline
\end{tabular}

\subsubsection{Größenstandards}

\begin{tabular}{l|l|}
\hline Größenstandard & Hersteller \\
\hline GeneRuler DNA Ladder Mix & MBI Fermentas \\
\hline Prestained Protein Ladder Plus & MBI Fermentas
\end{tabular}

\subsubsection{Antikörper}

\begin{tabular}{l|l|l}
\hline \multicolumn{1}{c|}{ Antikörper } & \multicolumn{1}{c|}{ Eigenschaften } & \multicolumn{1}{c|}{ Quelle } \\
\hline $\begin{array}{l}\text { aSCL14 (Serum) } \\
\text { SA2495 }\end{array}$ & $\begin{array}{l}\text { polyklonal, aus } \\
\text { Kaninchen }\end{array}$ & $\begin{array}{l}\text { Dissertation Tanja Siemsen } \\
2005\end{array}$ \\
\hline aHA-Tag & $\begin{array}{l}\text { polyklonal, aus } \\
\text { Kaninchen }\end{array}$ & abcam \\
\hline aMYC-Tag & aus Maus & Cell Signaling Technology \\
\hline aKaninchen & aus Esel & Amersham \\
\hline aMaus & aus Schaf & Amersham
\end{tabular}

\subsubsection{Nukleinsäuren}

\subsubsection{Oligonukleotide}

\begin{tabular}{c|l}
\hline Oligonukleotid & \multicolumn{1}{c|}{ Sequenz } \\
\hline SCL14 300 bp-fwd & 5'-CTGATGACGCTGATTTCTCTG-3' \\
\hline SCL14 600 bp-fwd & 5'-CTTCTAGGTCCAACAGTGTC-3' \\
\hline SCL14 900 bp-fwd & 5'-TAGCTATGCTCCTCCTCC-3' \\
\hline SCL14 1200 bp-fwd & 5'-CTCTTTTGGTGTTATGTGC-3' \\
\hline SCL14 1388-rev & 5'-TGGTAAGCCTTCAACATGTCTGCTG-3' \\
\hline SCL14 1500 bp-fwd & 5'-AAACGCCAACACGATCCAC-3' \\
\hline SCL14 1960 bp-fwd & 5'-TCATTACTCGGCTGTGTTTG-3' \\
\hline SCL14-attB-for & 5'-GGGGACAAGTTGTACAAAAAAGCAGGCTCA \\
& ATGGGTTCTTATCCGGATGGATTCC-3' \\
\hline SCL14-attB-Stop-rev & 5'-GGGGACCACTTTGTACAAGAAAGCTGGGTCCT \\
& ATGAAGACGAAGGAACCCATAGAG-3' \\
\hline
\end{tabular}




\begin{tabular}{|c|c|}
\hline SCL14C104S-fwd & $\begin{array}{l}\text { 5'-GATATGGAAGAGAAGCCTTCTATGTTTCATGACG } \\
\text { CTTTGGCTC-3' }\end{array}$ \\
\hline SCL14C104S-rev & $\begin{array}{l}\text { 5'-CAAAGCGTCATGAAACATAGAAGGCTTCTCTTCCA } \\
\text { TATCCTCTTC-3' }\end{array}$ \\
\hline SCL14C151S-fwd & $\begin{array}{l}\text { 5'-GCCCTGACGGTTCTTCTTCAGGTGGTG } \\
\text { CTTTTAGTG-3' }\end{array}$ \\
\hline SCL14C151S-rev & 5'-GCACCACCTGAAGAAGAACCGTCAGGGCTATCAC-3' \\
\hline SCL14C342S-fwd & $\begin{array}{l}\text { 5'-GAAATGTTTGATAAGATCTTGGTATCTGGCCCTGGG } \\
\text { AAACCTGTATG-3' }\end{array}$ \\
\hline SCL14C342S-rev & $\begin{array}{l}\text { 5'-GTTTCCCAGGGCCAGATACCAAGATCTTATCAAACA } \\
\text { TTTCAGAAAGC-3' }\end{array}$ \\
\hline SCL14C349S-fwd & $\begin{array}{l}\text { 5'-CCCTGGGAAACCTGTATCCATTCTTAACCAG } \\
\text { AACTTTCC-3' }\end{array}$ \\
\hline SCL14C349S-rev & $\begin{array}{l}\text { 5'-GTTCTGGTTAAGAATGGATACAGGTTTCCCA } \\
\text { GGGCCAC-3' }\end{array}$ \\
\hline SCL14C400S-fwd & $\begin{array}{l}\text { 5'-GCTGATTTGAGGACTCTTTTGGTGTTATCTGCAC } \\
\text { AAGCTGTATC-3' } \\
\end{array}$ \\
\hline SCL14C400S-rev & $\begin{array}{l}\text { 5'-GATACAGCTTGTGCAGATAACACCAAAAGAGTCCT } \\
\text { CAAATCAGC-3' }\end{array}$ \\
\hline SCL14C477S-fwd & $\begin{array}{l}\text { 5'-CTTACCAGACATACATGTCGGTCTCCCC } \\
\text { TTTCAAGAAAGC-3' } \\
\end{array}$ \\
\hline SCL14C477S-rev & $\begin{array}{l}\text { 5'-GCTTCCTTGAAAGGGGAGACCGACATGTATGT } \\
\text { CTGGTAAG-3' }\end{array}$ \\
\hline SCL14C561S-fwd & $\begin{array}{l}\text { 5'-GGTCATCGCTTGGCTCGATACTC } \\
\text { TCAGCGACACAATG-3' }\end{array}$ \\
\hline SCL14C561S-rev & $\begin{array}{l}\text { 5'-CATTGTGTCGCTGAGAGTATCGA } \\
\text { GCCAAGCGATGACC-3' }\end{array}$ \\
\hline SCL14C662S-fwd & $\begin{array}{l}\text { 5'-CTCGGCTGTGTTTGATATGTCTGACTCGAA } \\
\text { GCTAGC-3' }\end{array}$ \\
\hline SCL14C662S-rev & $\begin{array}{l}\text { 5'-GCTAGCTTCGAGTCAGACATATCAAACACA } \\
\text { GCCGAG-3' }\end{array}$ \\
\hline SCL14C691S-fwd & $\begin{array}{l}\text { 5'-GAGATTGTGAATGTTGTGGCTTCTGAAGGAACAGA } \\
\text { GAGAGTGG-3' }\end{array}$ \\
\hline SCL14C691S-rev & $\begin{array}{l}\text { 5'-CCACTCTCTCTGTTCCTTCAGAAGCCACAACA } \\
\text { TTCACAATCTC-3' }\end{array}$ \\
\hline SCL14GRAS-fwd & $\begin{array}{l}\text { 5'-GGGGGGCATATGGCTGATTTGAGGACTCTT } \\
\text { TTGGTG-3' }\end{array}$ \\
\hline SCL14GRAS-rev & $\begin{array}{l}\text { 5'-GGGGGGCCATGGTGAAGACGAAGGAACCC } \\
\text { ATAGAG-3' }\end{array}$ \\
\hline SCL14GRAS-attB-fwd & $\begin{array}{l}\text { 5'-GGGGACAAGTTTGTACAAAAAAGCAGGCTCTG } \\
\text { CTGATTTGAGGACTCTTTTGGTG-3' }\end{array}$ \\
\hline SCL14EcoNde-for & $\begin{array}{l}\text { 5'-GATATCGCATCGGCTCATATGATGGGTTCTTATCCG } \\
\text { GATGGATTCC-3' }\end{array}$ \\
\hline SCL14Sac-attB-rev & $\begin{array}{l}\text { 5'-GGGGACCACTTTGTACAAGAAAGCTGGGTCCTACC } \\
\text { GCGGAGCCGATGCGAGCTCTGAAGACGAAGGAAC } \\
\text { CCATAGAGATG-3' }\end{array}$ \\
\hline GFP-attB-for & $\begin{array}{l}\text { 5'-GGGGACAAGTTTGTACAAAAAAGCAGGCTCAATG } \\
\text { GTGAGCAAGGGCGAGGA-3' }\end{array}$ \\
\hline GFPEcoNde-rev & $\begin{array}{l}\text { 5'-CATATGAGCCGATGCGATATCCTTGTACAGCTC } \\
\text { GTCCATGCC-3' }\end{array}$ \\
\hline
\end{tabular}




\begin{tabular}{c|l} 
NAC017-attB-for & $\begin{array}{c}\text { 5'-GGGGACAAGTTTGTACAAAAAAGCAGGCTCTAT } \\
\text { GGCGGATTCTTCACCGATTC-3' }\end{array}$ \\
\hline Nac017-attB-rev & $\begin{array}{c}\text { 5'-GGGGACCACTTTGTCAAGAAGCTGGGTCTAG } \\
\text { TCTTTCAAGAGAAGACTTCTACC-3' }\end{array}$ \\
\hline SeqL1 & 5'-TCGCGTTAACGCTAGCATGGATCTC-3' \\
\hline SeqL2 & 5'-GTAACATCAGAGATTTTGAGACAC-3' \\
\hline SeqpAct2-for & 5'-CACGATGCACAGTTGAAGTGAAC-3' \\
\hline SeqpAct2-rev & 5'-GCTTACCCATACGATGTTCCAG-3' \\
\hline gsnor1-3 LP & 5'-TATAATGGTTCGACGCATATTTTTC-3' \\
\hline gsnor1-3 RP & 5'-CAAGGAAAGAGACCTTCAGGATC-3' \\
\hline 08409mod & 5'-CCATATTGACCATCATACTCATTGC-3' \\
\hline 03144 & 5'-GTGGATTGATGTGATATCTCC-3' \\
\hline SALK_025104 LP & 5'-CAAGGAGCCAGTTCTCATCAG-3' \\
\hline SALK_025104 RP & 5'-CGAAATTTACCAGGCAATTCC-3' \\
\hline SALK_117000 LP & 5'-AGGGTTTCGATTTCATCCAAC-3' \\
\hline SALK_117000 RP & 5'-AAAGACATGGAAACGTCATGG-3' \\
\hline GSTU7 & Quantitect \\
\hline UGT73B3 & Quantitect \\
\hline AT3G04130 & Quantitect \\
\hline AT5G61800 & Quantitect \\
\hline NAC017 & Quantitect
\end{tabular}

\subsubsection{Plasmide}

\begin{tabular}{|c|c|c|}
\hline Plasmid & Beschreibung & Referenz \\
\hline pDONR201-SCL14 & $\begin{array}{l}\text { SCL14 wurde mittels PCR mit } \\
\text { genspezifischen Oligonukleo- } \\
\text { tiden mit GW-Sequenzen aus } \\
\text { CDNA amplifiziert und per BP- } \\
\text { Reaktion in pDONR201 } \\
\text { kloniert }\end{array}$ & diese Arbeit \\
\hline pDONR201-SCL14C1S & $\begin{array}{l}\text { Cystein } 104 \text { wurde mittels } \\
\text { PCR durch spezifische Oligo- } \\
\text { nukleotide durch ein Serin } \\
\text { ersetzt, ein Vollängenfrag- } \\
\text { ment durch überlappende } \\
\text { PCR synthetisiert und per BP- } \\
\text { Reaktion in pDONR201 } \\
\text { kloniert }\end{array}$ & diese Arbeit \\
\hline pDONR201-SCL14C2S & $\begin{array}{l}\text { Cystein } 151 \text { wurde mittels } \\
\text { PCR durch spezifische Oligo- } \\
\text { nukleotide durch ein Serin } \\
\text { ersetzt, ein Volllängenfrag- } \\
\text { ment durch überlappende } \\
\text { PCR synthetisiert und per BP- } \\
\text { Reaktion in pDONR201 } \\
\text { kloniert }\end{array}$ & diese Arbeit \\
\hline
\end{tabular}




\begin{tabular}{|c|c|c|}
\hline pDONR201-SCL14C3S & $\begin{array}{l}\text { Cystein } 342 \text { wurde mittels } \\
\text { PCR durch spezifische Oligo- } \\
\text { nukleotide durch ein Serin } \\
\text { ersetzt, ein Volllängenfrag- } \\
\text { ment durch überlappende } \\
\text { PCR synthetisiert und per BP- } \\
\text { Reaktion in pDONR201 } \\
\text { kloniert }\end{array}$ & diese Arbeit \\
\hline pDONR201-SCL14C4S & $\begin{array}{l}\text { Cystein } 349 \text { wurde mittels } \\
\text { PCR durch spezifische Oligo- } \\
\text { nukleotide durch ein Serin } \\
\text { ersetzt, ein Vollängenfrag- } \\
\text { ment durch überlappende } \\
\text { PCR synthetisiert und per BP- } \\
\text { Reaktion in pDONR201 } \\
\text { kloniert }\end{array}$ & diese Arbeit \\
\hline pDONR201-SCL14C5S & $\begin{array}{l}\text { Cystein } 400 \text { wurde mittels } \\
\text { PCR durch spezifische Oligo- } \\
\text { nukleotide durch ein Serin } \\
\text { ersetzt, ein Volllängenfrag- } \\
\text { ment durch überlappende } \\
\text { PCR synthetisiert und per BP- } \\
\text { Reaktion in pDONR201 } \\
\text { kloniert }\end{array}$ & diese Arbeit \\
\hline pDONR201-SCL14C6S & $\begin{array}{l}\text { Cystein } 477 \text { wurde mittels } \\
\text { PCR durch spezifische Oligo- } \\
\text { nukleotide durch ein Serin } \\
\text { ersetzt, ein Volllängenfrag- } \\
\text { ment durch überlappende } \\
\text { PCR synthetisiert und per BP- } \\
\text { Reaktion in pDONR201 } \\
\text { kloniert }\end{array}$ & diese Arbeit \\
\hline pDONR201-SCL14C7S & $\begin{array}{l}\text { Cystein } 561 \text { wurde mittels } \\
\text { PCR durch spezifische Oligo- } \\
\text { nukleotide durch ein Serin } \\
\text { ersetzt, ein Vollängenfrag- } \\
\text { ment durch überlappende } \\
\text { PCR synthetisiert und per BP- } \\
\text { Reaktion in pDONR201 } \\
\text { kloniert }\end{array}$ & diese Arbeit \\
\hline pDONR201-SCL14C8S & $\begin{array}{l}\text { Cystein } 662 \text { wurde mittels } \\
\text { PCR durch spezifische Oligo- } \\
\text { nukleotide durch ein Serin } \\
\text { ersetzt, ein Volllängenfrag- } \\
\text { ment durch überlappende } \\
\text { PCR synthetisiert und per BP- } \\
\text { Reaktion in pDONR201 } \\
\text { kloniert }\end{array}$ & diese Arbeit \\
\hline
\end{tabular}




\begin{tabular}{|c|c|c|}
\hline pDONR201-SCL14C9S & $\begin{array}{l}\text { Cystein } 691 \text { wurde mittels } \\
\text { PCR durch spezifische Oligo- } \\
\text { nukleotide durch ein Serin } \\
\text { ersetzt, ein Volllängenfrag- } \\
\text { ment durch überlappende } \\
\text { PCR synthetisiert und per BP- } \\
\text { Reaktion in pDONR201 } \\
\text { kloniert }\end{array}$ & diese Arbeit \\
\hline pDONR201-SCL14C5,9S & $\begin{array}{l}\text { Die Cysteine } 400 \text { und } 691 \\
\text { wurden mittels PCR durch } \\
\text { spezifische Oligonukleotide } \\
\text { durch ein Serin ersetzt, ein } \\
\text { Volllängenfragment durch } \\
\text { überlappende PCR syntheti- } \\
\text { siert und per BP-Reaktion in } \\
\text { pDONR201 kloniert }\end{array}$ & diese Arbeit \\
\hline pDONR201-SCL14C5-9S & $\begin{array}{l}\text { Die Cysteine } 400-691 \\
\text { wurden mittels PCR durch } \\
\text { spezifische Oligonukleotide } \\
\text { durch ein Serin ersetzt, ein } \\
\text { Volllängenfragment durch } \\
\text { überlappende PCR syntheti- } \\
\text { siert und per BP-Reaktion in } \\
\text { pDONR201 kloniert }\end{array}$ & diese Arbeit \\
\hline pDONR201-SCL14C1-9S & 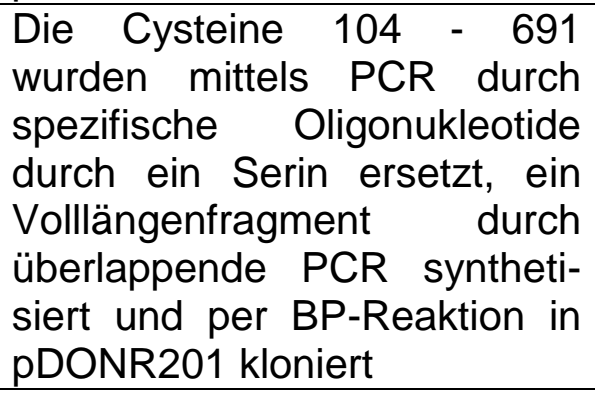 & diese Arbeit \\
\hline pB2GW7HA-SCL14 & $\begin{array}{l}\text { LR-Reaktion von pDONR201- } \\
\text { SCL14 und pB2GW7HA }\end{array}$ & diese Arbeit \\
\hline pB2GW7HA-SCL14C1S & $\begin{array}{l}\text { LR-Reaktion von pDONR201- } \\
\text { SCL14C1S und pB2GW7HA }\end{array}$ & diese Arbeit \\
\hline pB2GW7HA-SCL14C2S & $\begin{array}{l}\text { LR-Reaktion von pDONR201- } \\
\text { SCL14C2S und pB2GW7HA }\end{array}$ & diese Arbeit \\
\hline pB2GW7HA-SCL14C3S & $\begin{array}{l}\text { LR-Reaktion von pDONR201- } \\
\text { SCL14C3S und pB2GW7HA }\end{array}$ & diese Arbeit \\
\hline pB2GW7HA-SCL14C4S & $\begin{array}{l}\text { LR-Reaktion von pDONR201- } \\
\text { SCL14C4S und pB2GW7HA }\end{array}$ & diese Arbeit \\
\hline pB2GW7HA-SCL14C5S & $\begin{array}{l}\text { LR-Reaktion von pDONR201- } \\
\text { SCL14C5S und pB2GW7HA }\end{array}$ & diese Arbeit \\
\hline pB2GW7HA-SCL14C6S & $\begin{array}{l}\text { LR-Reaktion von pDONR201- } \\
\text { SCL14C6S und pB2GW7HA }\end{array}$ & diese Arbeit \\
\hline pB2GW7HA-SCL14C7S & $\begin{array}{l}\text { LR-Reaktion von pDONR201- } \\
\text { SCL14C7S und pB2GW7HA }\end{array}$ & diese Arbeit \\
\hline pB2GW7HA-SCL14C8S & $\begin{array}{l}\text { LR-Reaktion von pDONR201- } \\
\text { SCL14C8S und pB2GW7HA }\end{array}$ & diese Arbeit \\
\hline
\end{tabular}




\begin{tabular}{|c|c|c|}
\hline pB2GW7HA-SCL14C9S & $\begin{array}{l}\text { LR-Reaktion von pDONR201- } \\
\text { SCL14C9S und pB2GW7HA }\end{array}$ & diese Arbeit \\
\hline pUBQ10-Renilla & & M. Zander \\
\hline GSTU7-Prom-Firefly & & C. Thurow \\
\hline pGBKT7-SCL14GRAS & $\begin{array}{l}\text { Die GRAS-Domäne von } \\
\text { SCL14 wurde mit spezifischen } \\
\text { Primer mittels PCR amplifiziert } \\
\text { und klassisch in pGBKT7 } \\
\text { kloniert }\end{array}$ & P. Demeshko \\
\hline pGBKT7-RGAGRAS & $\begin{array}{l}\text { Die GRAS-Domäne von RGA } \\
\text { wurde mit spezifischen } \\
\text { Primern mittels PCR } \\
\text { amplifiziert und klassisch in } \\
\text { pGBKT7 kloniert }\end{array}$ & J. Truskina \\
\hline pDONR201-NAC017 & $\begin{array}{l}\text { NAC017 wurde mittels PCR } \\
\text { mit genspezifischen Oligo- } \\
\text { nukleotiden mit GW-Sequen- } \\
\text { zen aus cDNA amplifiziert und } \\
\text { per BP-Reaktion in } \\
\text { pDONR201 kloniert }\end{array}$ & p. Demeshko \\
\hline pDESTGAD-NAC017 & $\begin{array}{l}\text { LR-Reaktion von pDONR201- } \\
\text { NAC017 mit pDESTGAD }\end{array}$ & diese Arbeit \\
\hline pDESTGAD-NAC002 & & N. Ratnakaran \\
\hline pDESTGAD-NAC032 & & N. Ratnakaran \\
\hline pDESTGAD-TGA2 & & J. Oberdiek \\
\hline pDESTGAD-XPOI & & J.Oberdiek \\
\hline pDESTGAD-SCL14 & $\begin{array}{l}\text { LR-Reaktion von pDONR201- } \\
\text { SCL14mit pDESTGAD }\end{array}$ & diese Arbeit \\
\hline pDESTGAD-SCL14C5,9S & $\begin{array}{l}\text { LR-Reaktion von pDONR201- } \\
\text { SCL14C5,9S mit pDESTGAD }\end{array}$ & diese Arbeit \\
\hline pDESTGAD-SCL14C5-9S & $\begin{array}{l}\text { LR-Reaktion von pDONR201- } \\
\text { SCL14C5-9S mit pDESTGAD }\end{array}$ & diese Arbeit \\
\hline
\end{tabular}

\subsubsection{Organismen}

\subsubsection{Bakterien}

\begin{tabular}{|l|l|l|}
\hline \multicolumn{1}{|c|}{ Bakterium } & \multicolumn{1}{|c|}{ Eigenschaften } & Referenz \\
\hline $\begin{array}{l}\text { Agrobacterium } \\
\text { thumefaciens GV3101 }\end{array}$ & $\begin{array}{l}\text { PMP90RK } \\
\text { rifr, gmr }\end{array}$ & \\
\hline Escherichia coli DH5a & F-, gyrA 96 (Nalr), recA1, & (Hanahan 1983) \\
& endA1, thi-1, hsdR17 (rk- & \\
& mk+), glnV44, deoR, D & \\
& (lacZYA-argF) U169 &
\end{tabular}


[p80dD(lacZ)M15]

3.1.9.2 Hefe

\begin{tabular}{|c|l|c|}
\hline Hefestamm & \multicolumn{1}{|c|}{ Eigenschaften } & \multicolumn{1}{|c|}{ Referenz } \\
\hline PJ69-4A & MATa, trp1-901, & (James et al. 1996) \\
& leu2-3,112, ura3-52, & \\
& his3-200, gal4 4 , gal80, & \\
& GAL2-ADE2, & \\
& LYS2 ::GAL1-HIS3, & \\
& met2::GAL7-lacZ &
\end{tabular}

3.1.9.3 Pflanzen

\begin{tabular}{|c|c|c|}
\hline Genotyp & Beschreibung & Referenz \\
\hline$\overline{\mathrm{Col}-0}$ & Wildtyp & $\begin{array}{ll}\text { NACS } & \text { Bestandsnummer } \\
\text { N1920 } & \end{array}$ \\
\hline$s c / 14 / 33$ & $\begin{array}{lr}\text { Kreuzung der } & \text { knockout } \\
\text { Mutanten } & \text { scl14 } \\
\text { (SALK_126931) } & \text { und sc/33 }\end{array}$ & diese Arbeit \\
\hline gsnor1-3 & $\begin{array}{lr}\text { knockout } & \text { Mutante mit } \\
\text { reduzierter } & \text { GSNOR } \\
\text { Aktivität } & \\
\end{array}$ & (Feechan et al. 2005) \\
\hline gsnor1-3/sc/14 & $\begin{array}{lcr}\text { Kreuzung } & \text { der } & \text { knockout } \\
\text { Mutanten } & \text { scl14 } & \text { und } \\
\text { gsnor1-3 } & & \\
\end{array}$ & diese Arbeit \\
\hline $\operatorname{tga} 256$ & $\begin{array}{l}\text { knockout Mutante der drei } \\
\text { Klasse II TGA-Transkrip- } \\
\text { tionsfatoren TGA2, TGA5 } \\
\text { und TGA6 }\end{array}$ & (Zhang et al. 2003) \\
\hline nac017 & $\begin{array}{l}\text { knockout Mutante des } \\
\text { Transkriptionsfaktors } \\
\text { NAC017 (SALK_117000) }\end{array}$ & diese Arbeit \\
\hline $\begin{array}{ll}\text { sc/14/33 } & \text { 35S:HA-GFP- } \\
\text { SCL14 } & \end{array}$ & $\begin{array}{l}\text { Expressionslinie, die }{ }^{\text {HA- }} \\
\text { GFP-SCL14 unter der } \\
\text { Kontrolle des CaMV } 35 \mathrm{~S} \\
\text { Promotors exprimiert }\end{array}$ & diese Arbeit \\
\hline $\begin{array}{l}\text { sc/14/33 35S:HA-GFP- } \\
\text { SCL14C5,9S }\end{array}$ & $\begin{array}{l}\text { Expressionslinie, die HA- } \\
\text { GFP-SCL14C5,9S unter } \\
\text { der Kontrolle des CaMV } \\
\text { 35S Promotors exprimiert }\end{array}$ & diese Arbeit \\
\hline $\begin{array}{l}\text { sCl14/33 35S:HA-GFP- } \\
\text { SCL14C5-9S }\end{array}$ & $\begin{array}{l}\text { Expressionslinie, die HA- } \\
\text { GFP-SCL14C5-9S unter } \\
\text { der Kontrolle des CaMV } \\
\text { 35S Promotors exprimiert }\end{array}$ & diese Arbeit \\
\hline
\end{tabular}




\subsubsection{Nährmedien}

\begin{tabular}{l|l|}
\hline \multicolumn{1}{|c|}{ Nährmedium } & \multicolumn{1}{|c|}{ Zusammensetzung } \\
\hline dYT & $20 \mathrm{~g} / \mathrm{L}$ Trypton, $10 \mathrm{~g} / \mathrm{L}$ Hefeextrakt, 10 \\
$\mathrm{~g} / \mathrm{L} \mathrm{NaCl}$
\end{tabular}

\subsubsection{Standardpuffer}

\begin{tabular}{|c|c|}
\hline Puffer & Zusammensetzung \\
\hline $\operatorname{TAE}(20 x)$ & $\begin{array}{l}0.8 \mathrm{M} \text { Tris, } 2.3 \%(\mathrm{v} / \mathrm{v}) \text { Essigsäure, } 20 \\
\text { mM EDTA }\end{array}$ \\
\hline TBS (10x) & $24.2 \mathrm{~g}$ Tris, $80 \mathrm{~g} \mathrm{NaCl}, \mathrm{pH} 7.6$ \\
\hline TBST (1x) & $1 \times$ TBS $+0.1 \%$ Tween 20 \\
\hline SDS-PAGE Laufpuffer & 25 mM Tris, $200 \mathrm{mM}$ Glycin, 0,1 \% SDS \\
\hline Western Blot Transferpuffer & $\begin{array}{l}25 \mathrm{mM} \text { Tris, } 188 \mathrm{mM} \text { glycine, } 20 \% \\
\text { Methanol }\end{array}$ \\
\hline
\end{tabular}




\subsection{Methoden}

\subsubsection{Molekularbiologische Standardmethoden}

\subsubsection{Plasmidisolation aus E. coli}

\section{Alkalische Lyse}

Geringe DNA Mengen zu analytischen Zwecken wurden aus E. coli mittels der Alkalischen Lyse isoliert. Hierfür wurden die Bakterien aus 1,5 mL Übernachtkultur durch Zentrifugation für $1 \mathrm{~min}$ bei 13000 rpm geerntet. Der Überstand wurde verworfen und das Bakterienpellet in $100 \mu \mathrm{L}$ Puffer I resuspendiert. Durch Zugabe von $250 \mu \mathrm{L}$ Puffer II und 1 min Inkubation bei RT erfolgte die Lyse der Bakterien. Nach Neutralisation der Lösung durch Zugabe von $150 \mu \mathrm{L}$ Puffer III wurden die Zelltrümmer durch Zentrifugation für $10 \mathrm{~min}$ bei $13000 \mathrm{rpm}$ abgetrennt. Der Überstand wurde mit Chloroform versetzt. Nach Zentrifugation für $10 \mathrm{~min}$ bei 13000 rpm wurde die wässrige Phase mit $1 \mathrm{~mL}$ Ethanol versetzt und die DNA durch Zentrifugation für 15 min bei $4^{\circ} \mathrm{C}$ gefällt. Das DNA-Pellet wurde mit $70 \%$ Ethanol gewaschen, für $10 \mathrm{~min}$ bei $37^{\circ} \mathrm{C}$ getrocknet und in $20 \mu \mathrm{L}$ vollentsalztem Wasser aufgenommen.

\section{Isolation geringer Mengen hochreiner DNA}

Für Sequenzierungen wurde zur DNA-Isolation das Plasmid Mini Kit ${ }^{\circledR}$ von Macherey und Nagel verwendet. Die DNA-Isolation erfolgte aus $5 \mathrm{~mL}$ Übernachtkulturen nach Angaben des Herstellers.

\section{Isolation großer Mengen hochreiner DNA}

Zur Transformation von Hefen oder Protoplasten wurden das Plasmid Midi Kit ${ }^{\circledR}$ oder das Plasmid Maxi Kit ${ }^{\circledR}$ von Macherey und Nagel verwendet. Die DNA-Isolation erfolgte aus 200 mL bzw. 400 mL Übernachtkulturen nach Angaben des Herstellers.

\subsubsection{DNA-Isolation aus A. thumefaciens}

Die Isolation von Plasmid - DNA aus $A$. thumefaciens erfolgte aus $5 \mathrm{~mL}$ einer zwei Tage alten Agrobakterienkultur. Die Bakterien wurden durch Zentrifugieren für 1 min 
bei 13000 rpm geerntet, der Überstand verworfen und das Bakterienpellet in $300 \mu \mathrm{L}$ Puffer I (50 mM Tris-HCl pH8,0, 10 mM EDTA, $100 \mu \mathrm{g} / \mathrm{mL}$ RNase A) resuspendiert. Die Lyse der Zellen erfolgte durch Zugabe von $300 \mu \mathrm{L}$ Puffer II $(200$ mM NaOH, 1\% SDS (w/v)) und Inkubation für 5 min bei Raumtemperatur. Anschließend folgte die Neutralisation der Lösung durch Zugabe von $300 \mu \mathrm{L}$ Puffer III (294 g/L Kaliumacetat, $5 \%$ Ameisensäure) und eine Inkubation für 5 min auf Eis. Die Zelltrümmer wurden durch Zentrifugieren für $10 \mathrm{~min}$ bei 13000 rpm und Raumtemperatur abgetrennt. $600 \mu \mathrm{L}$ des Überstandes wurden mit $500 \mu \mathrm{L}$ Phenol - Chloroform - I - Mix (PCI Mix) versetzt, gemischt und für 1 min bei 13000 rpm und Raumtemperatur zentrifugiert. Die wässrige Phase wurde erneut mit $500 \mu \mathrm{L} \mathrm{PCl}$ - Mix versetzt, gemischt und für 1 min bei 13000 rpm und Raumtemperatur zentrifugiert. Zur Fällung der DNA wurde die wässrige Phase mit 0,7 Volumen Isopropanol versetzt, gemischt und für $15 \mathrm{~min}$ bei $13000 \mathrm{rpm}$ und Raumtemperatur zentrifugiert. Anschließend wurde der Überstand abgenommen und das entstandene Pellet mit $1 \mathrm{~mL} 70 \%$ Ethanol gewaschen und $10 \mathrm{~min}$ bei $13000 \mathrm{rpm}$ und Raumtemperatur zentrifugiert. Der Überstand wurde verworfen, das Pellet für 10 min bei Raumtemperatur getrocknet und anschließend in $12 \mu \mathrm{L}$ Wasser gelöst.

\subsubsection{DNA-Isolation aus A. thaliana}

Für die DNA-Isolation aus Arabidopsis thaliana wurden Blattproben in Stickstoff gemörsert und das Pulver mit $400 \mu \mathrm{L}$ Extraktionspuffer $(200 \mathrm{mM}$ Tris- $\mathrm{HCl} \mathrm{pH} 7,5$; $250 \mathrm{mM} \mathrm{NaCl} ; 25 \mathrm{mM}$ EDTA; 0,5\% SDS) versetzt, gemischt und für 5 min bei $13000 \mathrm{rpm}$ und $4^{\circ} \mathrm{C}$ zentrifugiert. $300 \mu \mathrm{L}$ des Überstandes wurden mit $300 \mu \mathrm{L}$ Isopropanol versetzt, gemischt und für $5 \mathrm{~min}$ bei $13000 \mathrm{rpm}$ und RT zentrifugiert. Das entstandene DNA-Pellet wurde mit $200 \mu \mathrm{L} 70 \%$ Ethanol gewaschen und für 5 min bei $13000 \mathrm{rpm}$ und RT zentrifugiert. Die DNA wurde $10 \mathrm{~min}$ bei $37^{\circ} \mathrm{C}$ getrocknet und in $100 \mu \mathrm{L} \mathrm{H}{ }_{2} \mathrm{O} 10$ min bei $65^{\circ} \mathrm{C}$ gelöst.

\subsubsection{Polymerase Kettenreaktion}

Die Polymerase Kettenreaktion ist eine Methode zur Amplifikation definierter DNASequenzen. Hierbei macht man sich die Fähigkeit von DNA-Polymerasen zu nutze, eine DNA-Matrize in vitro zu replizieren. Da die DNA-Polymerase als Startpunkt für die Amplifikation ein dem 5'-Ende des zu vervielfältigenden Bereiches komplemen- 
täres Oligonukleotid benötigt, lässt sich über die Gestaltung der Oligonukleotide der Zielbereich festlegen. Da die Oligonukleotide in das Amplifikat mit eingebaut werden, können so auch beispielsweise Schnittstellen für Restriktionsenzyme oder Mutationen in die DNA-Sequenz eingefügt werden.

Die Polymerase Kettenreaktion unterteilt sich in mehrere Schritte. Während der primären Denaturierung werden die DNA-Stränge aufgeschmolzen, sodass in der Anlagerungsphase die Startoligonukleotide an die komplementären Bereiche der Zielsequenz binden können. Während der zyklischen Elongation erfolgt die Amplifikation der DNA. Durch die zyklische Denaturierung werden die neu entstandenen DNA-Stränge aufgeschmolzen, sodass sich erneut Oligonukleotide anlagern können. Die Schritte zwei bis fünf werden zyklisch wiederholt. Hierdurch kommt es zu einer exponentiellen Amplifikation der DNA. Die finale Elongation dient dazu, unvollständig amplifizierte DNA-Fragmente zu vervollständigen. Tabelle 3.1 zeigt ein Beispielrezept einer PCR-Reaktion, Tabelle 3.2 ein beispielhaftes Ablaufschema.

Tabelle 3.1: Beispielrezept eines $50 \mu \mathrm{L}$ PCR Ansatzes

Konzentration

Endkonzentration

\begin{tabular}{ccc}
\hline DNA-Matrize & $1 \mu \mathrm{g} / \mu \mathrm{L}$ & $0,02 \mu \mathrm{g} / \mu \mathrm{L}$ \\
\hline Oligonukleotid 1 & $10 \mu \mathrm{M}$ & $0,5 \mu \mathrm{M}$ \\
\hline Oligonukleotid 2 & $10 \mu \mathrm{M}$ & $0,5 \mu \mathrm{M}$ \\
\hline Polymerase & $1 \mathrm{U} / \mu \mathrm{L}$ & $0,02 \mathrm{U} / \mu \mathrm{L}$ \\
\hline Puffer & $5 \mathrm{X}$ & $1 \mathrm{X}$ \\
\hline dNTPs & $10 \mathrm{mM}$ & $200 \mu \mathrm{M}$ \\
\hline ddH $_{2} \mathrm{O}$ & ad $50 \mu \mathrm{L}$ & ad $50 \mu \mathrm{L}$ \\
\hline Endvolumen & $50 \mu \mathrm{L}$ & $50 \mu \mathrm{L}$
\end{tabular}

Tabelle 3.2: Beispielhaftes Ablaufschema einer PCR Reaktion

\begin{tabular}{cccc} 
& Dauer & Temperatur & Wiederholungen \\
\hline primäre Denaturierung & $30 \mathrm{sek}$ & $95^{\circ} \mathrm{C}$ & $1 \times$ \\
\hline zyklische Denaturierung & $5-10 \mathrm{sek}$ & $95^{\circ} \mathrm{C}$ & \multirow{2}{*}{$35 \mathrm{x}$} \\
\cline { 1 - 3 } Anlagerungsphase & $10-30 \mathrm{sek}$ & $58-63^{\circ} \mathrm{C}$ & \\
\hline zyklische Elongation & $2 \mathrm{~min}$ & $72^{\circ} \mathrm{C}$ & $1 \mathrm{x}$
\end{tabular}




\subsubsection{Agarose-Gelelektrophorese}

Bei der Agarose-Gelelektrophorese handelt es sich um eine Methode zur Auftrennung von DNA-Fragmenten zwischen ca. 0,5 kb und 25 kb Größe. Der Trenneffekt beruht auf der Tatsache, dass die Agarose ein molekulares Sieb bildet, durch dessen Maschen große DNA-Fragmente in einem elektrischen Feld langsamer wandern als kleine.

Zum anfertigen der Gele wurde die Agarose in der Konzentration von $1 \%$ in TAEPuffer aufgekocht. Die aufzutrennenden Proben wurden vor dem Beladen des Gels mit 5x Probenpuffer gemischt. Als Größenstandard diente der "GeneRuler $1 \mathrm{~kb}$ Ladder" (Fermentas), welcher einen Bereich von 0,25 kb bis $10 \mathrm{~kb}$ abdeckt. Die Elektrophorese erfolgte bei $120 \mathrm{~V}$ für 45 Minuten. Um die DNA unter UV-Licht sichtbar zu machen, wurden die Gele nach dem Lauf für 15 Minuten in einem Ethidiumbromidbad mit $0,5 \mu \mathrm{g} / \mathrm{mL}$ Ethidiumbromid inkubiert. Die Isolation der DNAFragmente aus dem Agarosegel erfolgte mit dem Kit Nucleo Spin Gel and PCR Clean-up ${ }^{\circledast}$ der Firma Macherey und Nagel nach Angaben des Herstellers.

\subsubsection{Konzentrationsbestimmung von Nukleinsäuren}

Die Konzentration von Nukleinsäurelösungen erfolgte durch Absorptionsmessung mit dem NanoDrop $2000^{\circledR}$ der Firma Thermo Scientific bei einer Wellenlänge von 260 nM. Die Reinheit der Nukleinsäuren wurde über das Verhältnis der Absorptionen bei $260 \mathrm{~nm}$ und $280 \mathrm{~nm}$ bestimmt. Ein optimales $\mathrm{OD}_{260} / \mathrm{OD}_{280}$ Verhältnis für DNA ist 1,8 und für RNA 1,9-2,0.

\subsubsection{Restriktionsspaltung von DNA}

Mit Hilfe von Restriktionsendonukleasen des Typs II lassen sich DNA-Doppelstränge sequenzspezifisch schneiden. Die Enzyme binden im DNA-Strang eine Erkennungssequenz, welche in der Regel aus sechs bis acht Basenpaaren besteht und im Doppelstrang ein Palindrom bildet. Durch den Schnitt entstehen entweder glatte Enden oder ein 3'- bzw. ein 5'-Überhang.

Zur Ermittlung der für die Spaltung einer gegebenen DNA-Menge erforderliche Enzymmenge wurde folgende Formel verwendet: 
$\frac{b p[\lambda-D N A] \times \text { Schnittstellen }[D N A] \times \mu g[D N A]}{\text { Schnittstellen }[\lambda-D N A] \times b p[D N A] \times \operatorname{Zeit}(\text { Stunden })}$

Für eine Restriktionsspaltung wurden $1-2 \mu \mathrm{g}$ DNA mit der ermittelten Menge Enzym und $2 \mu \mathrm{L}$ des entsprechenden 10x Puffers in einem Reaktionsgefäß gemischt und mit $\mathrm{ddH}_{2} \mathrm{O}$ auf $20 \mu \mathrm{L}$ aufgefüllt. Der Restriktionsansatz wurde für zwei Stunden nach Angaben des Herstellers bei $37^{\circ} \mathrm{C}$ bzw. $65^{\circ} \mathrm{C}$ inkubiert. Der Erfolg der Reaktion wurde mittels Agarose-Gelelektrophorese überprüft und die entstandenen DNAFragmente gegebenenfalls aus dem Agarosegel extrahiert.

\subsubsection{Ligation von DNA-Molekülen}

Die Ligation von durch Restriktionsspaltung erzeugten DNA-Fragmenten erfolgte durch die T4 DNA-Ligase. Hierbei wurden 100 ng geschnittenes Plasmidrückgrat verwendet. Das in das Plasmid einzufügende DNA-Fragment wurde im dreifachen molaren Überschuss eingesetzt. Die notwendige Menge an DNA-Fragment wurde mit folgender Formel berechnet:

$$
\frac{n g_{\text {Plasmid }} \times k b_{\text {Fragment }}}{k b_{\text {Plasmid }}} \times 3
$$

Die DNA wurde mit $2 \mu \mathrm{L}$ 10x Reaktionspuffer und 5 Units T4 DNA-Ligase in einem Reaktionsgefäß gemischt und mit $\mathrm{ddH}_{2} \mathrm{O}$ auf $20 \mu \mathrm{L}$ aufgefüllt. Der Reaktionsansatz wurde für 1 Stunde bei Raumtemperatur inkubiert und anschließend wurden $10 \mu \mathrm{L}$ des Ansatzes zur Transformation von chemisch kompetenten $E$. coli Zellen verwendet.

\subsubsection{Dephosphorylierung von DNA}

Um die Wahrscheinlichkeit einer Selbstligation eines Plasmids während einer Ligationsreaktion zu verringern, wurde das mit Restriktionsenzymen geschnittene Plasmid mit der calf intestine alkaline phosphatase (CIAP) dephosphoryliert. Die Dephosphorylierung erfolgte durch Zugabe von 5 Units CIAP zum Restriktionsansatz nach Beendigung der Restriktionsreaktion und Inkubation für 1 Stunde bei $37^{\circ} \mathrm{C}$. 


\subsubsection{Gateway ${ }^{\circledR}-$ Klonierung}

Die gateway ${ }^{\circledR}$ Technologie der Firma Invitrogen zur Klonierung basiert auf der sequenzspezifischen Rekombination des Bakteriophagen Lambda und stell eine einfache und schnelle Methode zur Klonierung eines DNA-Fragmentes in unterschiedliche Vektoren dar (Landy 1989; Hartley et al. 2000). Alle Klonierungen erfolgten wie in der Gebrauchsanweisung Gateway ${ }^{\circledR}$ Technology with Clonase ${ }^{\mathrm{TM}}$ ॥ (25-0749) in der Version vom 22. Mai 2009 angegeben.

\subsubsection{Sequenzierung von DNA}

Die Sequenzierung von DNA erfolgte durch die Firma SeqLab. Für eine Sequenzierungsreaktion wurden 1,2 $\mu$ g Plasmid mit $30 \mathrm{pmol}$ Oligonukleotid in $15 \mu \mathrm{L}$ $\mathrm{H}_{2} \mathrm{O}$ gemischt.

\subsubsection{Transformation von E. coli}

Die Transformation von E. coli erfolgte mittels der Hitzeschockmethode nach Hanahan (Hanahan 1983). $200 \mu \mathrm{L}$ kompetente Bakterien wurden für 30 min zum Auftauen auf Eis gestellt. Anschließend wurde DNA zugegeben (in der Regel $10 \mu \mathrm{L}$ eines Ligationsansatzes oder $0,5 \mu \mathrm{L}$ einer Plasmidpräparation) und die Bakterien weitere 30 min auf Eis inkubiert. Es folgte der Hitzeschock bei $42{ }^{\circ} \mathrm{C}$ für 45 Sekunden und eine weitere Inkubation auf Eis für $3 \mathrm{~min}$. Anschließend wurden die Bakterien mit $800 \mu \mathrm{L}$ dYT-Medium versetzt und für $45 \mathrm{~min}$ bei $37^{\circ} \mathrm{C}$ auf einem Schüttler inkubiert, bevor sie auf LB-Agarplatten mit zugesetztem Antibiotikum ausplattiert wurden. Die Inkubation der Platten erfolgte über Nacht bei $37^{\circ} \mathrm{C}$.

\subsubsection{Transformation von $A$. thumefaciens}

Die Transformation von Agrobacterium thumefaciens GV3101 erfolgte mittels der Elektroschockmethode. $50 \mu \mathrm{L}$ kompetente Bakterien wurden zum Auftauen für 30 min auf Eis inkubiert. Anschließend wurden $0,5 \mu \mathrm{L}$ einer DNA-Präparation zugegeben und für $5 \mathrm{~ms}$ ein Elektroschock (2,5 kV, $25 \mu \mathrm{F}, 400 \Omega$ ) appliziert, die Bakterien in $950 \mu \mathrm{L}$ YEB-Medium aufgenommen und für zwei Stunden bei $29^{\circ} \mathrm{C}$ auf einem Schüttler inkubiert. Danach wurden die Bakterien auf YEB-Agarplatten mit 
zugesetztem Antibiotikum ausplattiert und die Agarplatten für zwei bis drei Tage bei $29^{\circ} \mathrm{C}$ inkubiert.

\subsubsection{Stabile Transformation von $A$. thaliana}

Die stabile Transformation von Arabidopsis thaliana erfolgte durch Agrobacteriumvermittelten Gentransfer nach Clough (Clough 2005). Es wurde eine $20 \mathrm{~mL}$ Kultur von mit dem zu übertragenden Plasmid transformierten Agrobakterien in YEBMedium angesetzt und für zwei Tage bei $29^{\circ} \mathrm{C}$ unter Schütteln inkubiert. $5 \mathrm{~mL}$ dieser Kultur wurden zur DNA-Extraktion verwendet (Abschnitt 3.2.1.5) um mittels Restriktionsverdau die Anwesenheit des zu übertragenden Plasmids zu überprüfen. Mit den verbliebenen $15 \mathrm{~mL}$ wurde eine $400 \mathrm{~mL}$ Kultur angeimpft und bei $29^{\circ} \mathrm{C}$ über Nacht unter Schütteln inkubiert. Die Bakterien wurden durch Zentrifugation für 30 min bei 5000 rpm und RT geerntet und das Pellet in 5\% Saccharoselösung mit 0,02\% Silvet L-77 gelöst und die Lösung auf eine $O_{600}$ von 0,8 eingestellt. Blühende Arabidopsis Pflanzen wurden in die Bakterienlösung getaucht und über Nacht mit einer Haube abgedeckt. Die Selektion auf positive Transformanden erfolgte in der nächsten Generation durch Besprühen mit dem Herbizid BASTA ${ }^{\circledR}$ gegen welches der Übertragene Vektor ein Resistenzgen trägt.

\subsubsection{Biochemische Standardmethoden}

\subsubsection{Proteinextraktion aus A. thaliana}

Zur Proteinextraktion aus Arabidopsis thaliana wurden Wurzel- oder Blattproben gemörsert, mit $100 \mu \mathrm{L}$ Laemmli Puffer (Laemmli 1970) gemischt und 5 min bei $95^{\circ} \mathrm{C}$ unter Schütteln erhitzt. Es folgte eine Zentrifugation für $10 \mathrm{~min}$ bei $13000 \mathrm{rpm}$ und $4{ }^{\circ} \mathrm{C}$. Nach der Zentrifugation wurde der Überstand in ein neues Reaktionsgefäß überführt und die Zelltrümmer verworfen.

\subsubsection{Proteinextraktion aus S. cerevisiae}

Für die Proteinextraktion aus Saccharomyces cerevisiae wurden die Hefezellen einer $20 \mathrm{~mL}$ Übernachtkultur mit einer $\mathrm{OD}_{600}$ von 0,8-1,3 durch Zentrifugation für 5 min bei $1000 \mathrm{rpm}$ und $4{ }^{\circ} \mathrm{C}$ geerntet. Das Zellpellet wurde in flüssigem Stickstoff eingefroren 
und bei $37^{\circ} \mathrm{C}$ aufgetaut. Dieser Schritt wurde wiederholt. Anschließend wurden die Hefezellen mit $75 \mu \mathrm{L}$ Proteinextraktionspuffer (8 M Harnstoff; $5 \%$ SDS; 40 mM Tris- $\mathrm{HCl}$ pH 6,8; 0,4 mg/mL Bromphenolblau; $10 \mu \mathrm{L} / \mathrm{mL}$ B-Mercaptoethanol; 0,1 mM EDTA) pro 7,5 OD-Einheiten resuspendiert, mit $80 \mu \mathrm{L}$ Glasperlen (Durchmesser $425-600 \mu \mathrm{m}$ ) versetzt und $10 \mathrm{~min}$ bei $70^{\circ} \mathrm{C}$ inkubiert. Anschließend wurde das Reaktionsgefäß für eine Minute bei RT auf einem Schüttler bei hoher Geschwindigkeit inkubiert. Nach einer Zentrifugation für 5 min bei 13000 rpm und RT wurde der Überstand in ein neues Reaktionsgefäß überführt. Das verbleibende Pellet wurde in dem gleichen Volumen Proteinextraktionspuffer resuspendiert wie zuvor und 5 min bei $95^{\circ} \mathrm{C}$ inkubiert. Nach einer Zentrifugation für 5 min bei $13000 \mathrm{rpm}$ und RT wurden beide Überstände vereinigt und das Pellet verworfen.

\subsubsection{Konzentrationsbestimmung von Proteinlösungen}

Die Konzentrationsbestimmung von Proteinextrakten erfolgte mit dem Pierce $660 \mathrm{~nm}$ Protein assay ${ }^{\circledR}$ der Firma ThermoScientific. $5 \mu \mathrm{L}$ des zu messenden Proteinextraktes wurden mit $150 \mu \mathrm{L}$ Messreagenz gemischt und die Absorption bei $660 \mathrm{~nm}$ bestimmt. Da die für die Proteinextraktion verwendeten Puffer SDS enthielten, mussten dem

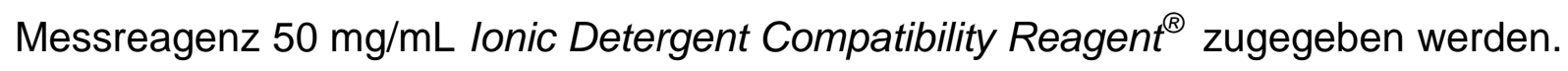
Um die Proteinkonzentration berechnen zu können, wurde eine Referenzreihe mit $1 \mu \mathrm{g}, 3 \mu \mathrm{g}, 6 \mu \mathrm{g}$ und $9 \mu \mathrm{g}$ BSA gemessen.

\subsubsection{SDS - Polyacrylamidgelelektrophorese}

Die Auftrennung von Proteinen nach ihrer Größe erfolgte mittels SDS-Polyacrylamidgelelektrophorese (SDS-PAGE) in einem diskontinuierlichen Puffersystem nach Laemmli (Laemmli 1970), bestehend aus einem Sammelgel (4\% Acrylamid/Bisacrylamid (37,5:1); $125 \mathrm{mM}$ Tris- $\mathrm{HCl}$ ph 6,8; 0,1\% SDS; 0,1\% Ammoniumpersulfat (APS); $0,1 \%$ TEMED) und einem Trenngel (10\% Acrylamid/Bisacrylamid (37,5:1); $375 \mathrm{mM}$ Tris- $\mathrm{HCl} \mathrm{pH} 8,8 ; 0,1 \%$ SDS; 0,1\% APS; 0,1\% TEMED). Die Elektrophorese erfolgte in 1x SDS-Laufpuffer (25 mM Tris; 200 mM Glycin; 0,1\% SDS) bei 200 V für 45 min. 


\subsubsection{Protein Immunoblot}

Die spezifische Detektion von Proteinen nach der Auftrennung durch SDS-PAGE erfolgte mittels Western Blot. Hierbei wurden die Proteine in einer Halbtrockenzelle auf eine PVDF-Membran transferiert. Das Trenngel wurde für 10 Minuten in 1x Transferpuffer (20\% Methanol; $25 \mathrm{mM}$ Tris; $192 \mathrm{mM}$ Glycin; 0,1\% SDS) äqulibriert und die Membran für eine Minute in Methanol aktiviert. Anschließend wurde der Blot in der Halbtrockenzelle aus drei Lagen in Transferpuffer getränktem Whatman Papier, der Membran, dem Gel und drei weiteren Lagen in Transferpuffer getränktem Whatman Papier aufgebaut. Der Proteintransfer erfolgte für zwei Stunden bei RT und einer Stromstärke von $1 \mathrm{~mA}$ pro $\mathrm{cm}^{2}$ Membran. Nach dem Transfer folgte das Blocken der Membran in TBST mit $2 \%(\mathrm{w} / \mathrm{v})$ Milchpulver für zwei Stunden bei RT oder über Nacht bei $4^{\circ} \mathrm{C}$ unter konstantem Schwenken. Die Inkubation der Membran mit dem Primärantikörper erfolgte in TBST mit $2 \%(\mathrm{w} / \mathrm{v})$ Milchpulver für zwei Stunden bei RT oder über Nacht bei $4{ }^{\circ} \mathrm{C}$ unter konstantem Schwenken. Anschließend wurde die Membran 3x 5 Minuten mit TBST gewaschen. Die Inkubation der Membran mit dem Sekundärantikörper erfolgte in TBST mit $2 \%(\mathrm{w} / \mathrm{v})$ Milchpulver für zwei Stunden bei RT unter konstantem Schwenken. Nach dem Waschen der Membran in TBST für 3x 5 Minuten erfolgte die Inkubation mit einer Substratlösung für die an den Sekundärantikörper gekoppelte Meerrettichperoxidase für fünf Minuten und die Detektion der Peroxidaseaktivität mit einer CCD-Kamera.

\subsubsection{Pflanzenanzuchtbedingungen}

\subsubsection{Pflanzenanzucht auf Erde}

Zur Pflanzenanzucht auf Erde wurden oberflächensterilisierte Samen auf Anzuchterde (Archut, Fruhstorfer Erde, T25, Str1 fein) ausgelegt, über Nacht bei $4{ }^{\circ} \mathrm{C}$ stratifiziert und unter Langtagbedingungen (16 Stunden Licht/8 Stunden Dunkelheit; $22{ }^{\circ} \mathrm{C}, 60 \%$ Luftfeuchtigkeit am Tag; $18^{\circ} \mathrm{C}, 60 \%$ Lufteuchtigkeit bei Nacht; $120 \mu \mathrm{mol}$ Photonen $/ \mathrm{m}^{2} / \mathrm{sek}$ ) oder Kurztagbedingungen (8 Stunden Licht/16 Stunden Dunkelheit; $22{ }^{\circ} \mathrm{C}, \quad 60 \%$ Luftfeuchtigkeit bei Tag und Nacht; $90 \mu \mathrm{mol}$ Photonen $/ \mathrm{m}^{2} / \mathrm{sek}$ ) kultiviert. 


\subsubsection{Sterile Pflanzenanzucht in einem hydroponischen System}

Zur Pflanzenanzucht im hydroponischen System wurden oberflächensterilisierte Samen unter sterilen Bedingungen in Kulturgläsern (Abb. 3.1) mit MSS-Medium ausgelegt, die Gläser mit Parafilm $\mathrm{M}^{\circledR}$ versiegelt und für 10 Tage unter Langtagbedingungen (16 Stunden Licht/8 Stunden Dunkelheit; $22^{\circ} \mathrm{C}, 60 \%$ Luftfeuchtigkeit bei Tag und Nacht; $90 \mu \mathrm{mol}$ Photonen $/ \mathrm{m}^{2} / \mathrm{sek}$ ) kultiviert.
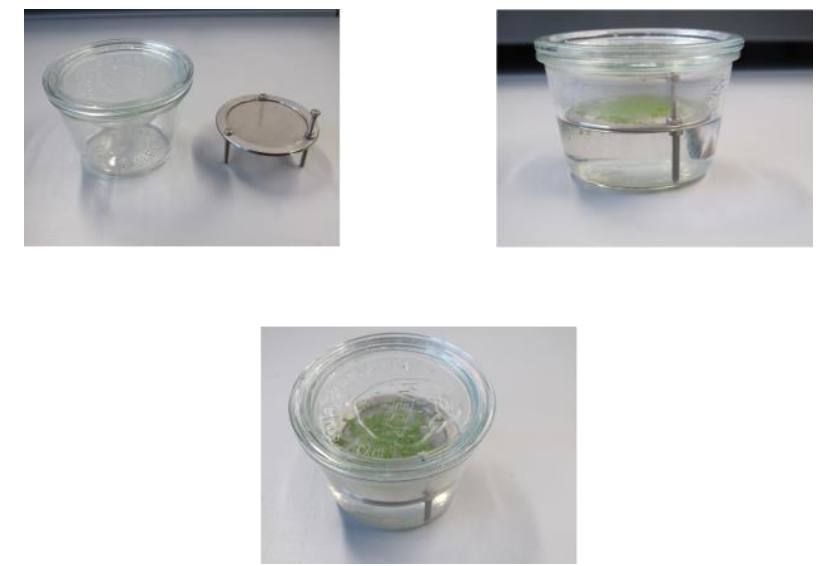

Abbildung 3.1: Anzuchtgläser zur Kultivierung von Arabidopsis thaliana im hydroponischen System.

\subsubsection{Sterile Pflanzenanzucht auf mit Nährmedium beschichteten Objektträgern und Schrägagarplatten}

Zur Pflanzenanzucht auf festem Nährmedium (MSS mit 0,7\% Gelrite) wurden oberflächensterilisierte Samen unter sterilen Bedingungen auf mit Nährmedium beschichteten Objektträgern oder auf Schrägplatten ausgelegt, über Nacht bei $4{ }^{\circ} \mathrm{C}$ stratifiziert und unter Langtagbedingungen (14 Stunden Licht/10 Stunden Dunkelheit; $23^{\circ} \mathrm{C}$ bei Tag und Nacht, keine Regulation der Luftfeuchtigkeit; $90 \mu \mathrm{mol}$ Photonen $/ \mathrm{m}^{2} / \mathrm{sek}$ ) kultiviert.

\subsubsection{Oberflächensterilisation von Samen}

Die Oberflächensterilisation von Samen erfolgte in einem Exsikkator unter leichtem Vakuum in einer Chlorgasatmosphäre. Für die Erzeugung dieser Chlorgasatmosphäre wurde dem Exsikkator ein Gemisch aus $100 \mathrm{~mL}$ Natriumhypochlorid und $5 \mathrm{~mL}$ Salzsäure beigefügt. Für die Aussaat auf Erde betrug 
die Dauer der Sterilisation zwei Stunden, für die Aussaat in hydroponischen Kulturen oder auf festem Nährmedium vier Stunden.

\subsubsection{Transkriptomanalyse}

\subsubsection{RNA Extraktion}

Die Extraktion von RNA aus Blatt- und Wurzelgewebe erfolgte mit der TRIZOLMethode nach Chomczynski (Chomczynski 1993). Das Pflanzenmaterial wurde in Stickstoff gemörsert und $50 \mu \mathrm{L}-250 \mu \mathrm{L}$ des Pulvers mit 1,3 mL Extraktionspuffer (380 mL/L Phenol, gesättigt mit 0,1 M Citratpuffer pH 4,3; 0,8 M Guanidinthiocyanat; 0,4 M Ammoniumthiocyanat; 33,4 mL/L 3 M Na-Acetatlösung pH 5,2; $5 \%$ Glycerin) versetzt und 10 Minuten bei RT unter Schütteln inkubiert. Anschließend wurden $260 \mu \mathrm{L}$ Phenol zugegeben, worauf eine weitere Inkubation für 10 Minuten bei RT unter Schütteln erfolgte. Die Trennung der wässrigen Phase mit den Nukleinsäuren und der organischen Phase mit Proteinen und Zelltrümmern erfolgte durch Zentrifugation für 30 Minuten bei $13000 \mathrm{rpm}$ und $4^{\circ} \mathrm{C} .800 \mu \mathrm{L}$ der wässrigen Phase wurden in ein neues Reaktionsgefäß überführt und mit $300 \mu \mathrm{L}$ Isopropanol und $300 \mu \mathrm{L}$ Hochsalzpuffer (1,2 M Natriumchlorid; 0,8 M tri-Na-Citrat) versetzt. Die Fällung der Nukleinsäuren erfolgte durch Zentrifugation für 15 Minuten bei 13000 rpm und $4{ }^{\circ} \mathrm{C}$. Die Nukleinsäurepellets wurden mit $70 \%$ Ethanol gewaschen und für 10 Minuten bei $13000 \mathrm{rpm}$ und RT zentrifugiert. Der Waschschritt wurde einmal wiederholt. Nach dem Trocknen der Pellets für 10 Minuten bei RT wurden die Nukleinsäuren in $15 \mu \mathrm{L}-50 \mu \mathrm{L}$ autoklaviertem $\mathrm{ddH}_{2} \mathrm{O}$ durch Inkubation für 10 Minuten bei $65^{\circ} \mathrm{C}$ und zweimaligem Einfrieren und Auftauen in flüssigem Stickstoff gelöst.

\subsubsection{Synthese von cDNA}

Für die Synthese von cDNA wurde $1 \mu \mathrm{g}$ RNA eingesetzt. Diese wurde zuerst für 30 Minuten bei $37^{\circ} \mathrm{C}$ mit DNAsel behandelt, um Kontaminationen der cDNA mit genomischer DNA zu verhindern. Die Inaktivierung der DNAse erfolge durch Zugabe von 25 mM EDTA und Inkubation für 10 Minuten bei $65^{\circ} \mathrm{C}$. Als Startoligonukleotide für die Synthese der cDNA wurden Zufallsnonamere und oligo-dT Oligonukleotide verwendet. Die Anlagerung an die RNA erfolgte für 10 Minuten bei $70^{\circ} \mathrm{C}$. Die 
Elongation fand für 70 Minuten bei $42{ }^{\circ} \mathrm{C}$ durch die Reverse Transkriptase $\mathrm{H}$ (Fermentas) statt, gefolgt von einem Schritt zur Inaktivierung der Reversen Transkriptase für 10 Minuten bei $70^{\circ} \mathrm{C}$. Tabelle 3.3 zeigt den schematischen Ablauf der cDNA Synthese und die Konzentrationen der verwendeten Komponenten.

Tabelle 3.3: Schematische Darstellung der cDNA-Synthese und der verwendeten Komponenten

\begin{tabular}{|c|c|c|c|}
\hline 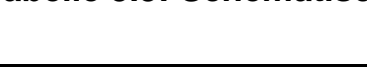 & Dauer/Temperatur & Komponenten & Endvolumer \\
\hline DNA-Verdau & $30 \mathrm{~min} / 37^{\circ} \mathrm{C}$ & $\begin{array}{l}\text { 1x DNAse Puffer } \\
0,1 \mathrm{U} / \mu \mathrm{L} \text { DNAse }\end{array}$ & $10 \mu \mathrm{L}$ \\
\hline DNAse Inaktivierung & $10 \mathrm{~min} / 65^{\circ} \mathrm{C}$ & $2,5 \mathrm{mM}$ EDTA & $10,5 \mu \mathrm{L}$ \\
\hline $\begin{array}{l}\text { Anlagerung der } \\
\text { Oligonukleotide }\end{array}$ & $10 \mathrm{~min} / 70^{\circ} \mathrm{C}$ & $\begin{array}{c}20 \text { pmol oligo-dT } 200 \text { pmol } \\
\text { Randomnonamer }\end{array}$ & $12,2 \mu \mathrm{L}$ \\
\hline Elongation & $70 \mathrm{~min} / 42^{\circ} \mathrm{C}$ & $\begin{array}{c}\text { 1x Puffer Reverse Transkriptase } \\
\text { dNTPs (jeweils } 1 \mathrm{mM} \text { ) } \\
3 \mathrm{U} / \mu \mathrm{L} \text { Reverse Transkriptase }\end{array}$ & $20 \mu \mathrm{L}$ \\
\hline $\begin{array}{l}\text { Inaktivierung der } \\
\text { Reversen } \\
\text { Transkriptase }\end{array}$ & $10 \mathrm{~min} / 70^{\circ} \mathrm{C}$ & & $20 \mu \mathrm{L}$ \\
\hline
\end{tabular}

\subsubsection{Quantitative Echtzeit PCR (qRT - PCR)}

Für die Quantifizierung der cDNA mittels quantitativer Echtzeit PCR (qRT-PCR) wurde die Fluoreszenz des Farbstoffes SyberGreen ${ }^{\circledR}$ gemessen. Dieser Farbstoff fluoresziert nur, wenn er an DNA bindet, so dass die Fluoreszenz in einem PCRAnsatz mit der vorhandenen DNA-Menge zunimmt. Die qRT-PCR wurde im iCycler ${ }^{\circledR}$ der Firma BioRad durchgeführt, Ubiquitin5 diente als Referenzgen. Die relative Genexpression wurde mit der $2^{-\left[C_{T}(Z i e l g e n)-C_{T}(\text { Re erenzzgen })\right]}$-Methode (Schmittgen \& Livak 2008) berechnet. Tabelle 3.4 zeigt die Konzentrationen der verwendeten Komponenten, Tabelle 3.5 das verwendete PCR-Programm. 
Tabelle 3.4: Beispielrezept für eine qRT-PCR Reaktion

\begin{tabular}{|c|c|c|}
\hline & Konzentration & Endkonzentration \\
\hline Reaktionspuffer & $10 x$ & $1 x$ \\
\hline $\mathrm{MgCl} 2$ & $50 \mathrm{mM}$ & $2 \mathrm{mM}$ \\
\hline dNTPs & $10 \mathrm{mM}$ & $100 \mu \mathrm{M}$ \\
\hline Oligonukleotid 1 & $4 \mu \mathrm{M}$ & $0,4 \mu \mathrm{M}$ \\
\hline Oligonukleotid 2 & $4 \mu \mathrm{M}$ & $0,4 \mu \mathrm{M}$ \\
\hline $\begin{array}{l}\text { SybrGreen Mol Probes } \\
1: 1000\end{array}$ & $10 x$ & $0,1 x$ \\
\hline Fluorescein $1 \mu \mathrm{M} / 1: 1000$ & $1 \mu \mathrm{M}$ & $10 \mathrm{nM}$ \\
\hline DNA-Polymerase & $5 \mathrm{U} / \mu \mathrm{L}$ & $0,25 \mathrm{U}$ \\
\hline cDNA 1:10 & $1 \mathrm{x}$ & $0,04 x$ \\
\hline $\mathrm{H}_{2} \mathrm{O}$ & & ad $25 \mu \mathrm{L}$ \\
\hline
\end{tabular}

Tabelle 3.5: Ablauf einer qRT-PCR Reaktion

\begin{tabular}{c|c|c|c} 
& Dauer & Temperatur & \\
\hline primäre Denaturierung & $2 \mathrm{~min}$ & $95^{\circ} \mathrm{C}$ & $1 \mathrm{x}$ \\
\hline Denaturierung & $20 \mathrm{sek}$ & $95^{\circ} \mathrm{C}$ & \multirow{2}{*}{$39 \mathrm{x}$} \\
\hline Anlagerungsphase & $20 \mathrm{sek}$ & $55^{\circ} \mathrm{C}$ & \\
\hline Elongation & $40 \mathrm{sek}$ & $72^{\circ} \mathrm{C}$ & \multirow{2}{*}{$1 \mathrm{x}$} \\
\cline { 1 - 3 } finale Elongation & $4 \mathrm{~min}$ & $72^{\circ} \mathrm{C}$ & \\
\cline { 2 - 3 } & $1 \mathrm{~min}$ & $95^{\circ} \mathrm{C}$ & \\
\cline { 2 - 3 } & $1 \mathrm{~min}$ & $55^{\circ} \mathrm{C}$ & $81 \times 0,5^{\circ} \mathrm{C}$-Schritte
\end{tabular}

\subsubsection{Microarrayanalyse}

Die Transkriptome aus Wurzeln der Genotypen Col-0 und sc/14/33 nach der Behandlung mit $1 \mathrm{mM}$ Salicylsäure für eine Stunde wurden mittels Microarrayanalyse miteinander verglichen. Die Pflanzen wurden in hydroponischen Kulturen für 10 Tage unter Langtagbedingungen angezogen. Die Extraktion der RNA erfolgte wie in Abschnitt 3.2.5.1 beschrieben. Für jede Probe wurde Material aus fünf Anzuchtgläsern vereinigt. Die Qualitätskontrolle der RNA und die Durchführung der Microarrayanalyse erfolgten durch das Transkriptomanalyselabor der Universität Göttingen. Es wurde der GeneChip ${ }^{\circledR}$ Gene 1.0 ST der Firma Affymetrix verwendet. 


\subsubsection{Behandlung von A.thaliana mit Chemikalien}

\subsubsection{Chemikalienbehandlung im hydroponischen System}

Für die Behandlung von Wurzeln mit Chemikalien in hydroponischen Kulturen wurden die betreffenden Substanzen direkt dem Nährmedium (MSS) zugesetzt. Hierfür wurde das Metallsieb, auf dem die Pflanzen wuchsen kurz aus dem Anzuchtglas genommen, die Chemikalie mit dem Nährmedium vermischt, das Sieb wieder Eingesetzt und der Deckel wieder aufgesetzt, ohne das Glas jedoch erneut mit Parafilm $\mathrm{M}^{\circledR}$ zu versiegeln. Die Behandlung der Pflanzen mit den Chemikalien erfolgte für eine bis vier Stunden unter Lichtbedingungen.

\section{Salicylsäure}

Für die Behandlung mit Salicylsäure wurde Natriumsalicylat mit einer Konzentration von $1 \mathrm{M}$ in Wasser gelöst und 1:1000 im Nährmedium verdünnt. Als Kontrollbehandlung diente Wasser.

\section{2,3,5 - Triiodobenzoesäure (TIBA)}

2,3,5-Triiodobenzoesäure wurde mit einer Konzentration von $50 \mathrm{mM}$ in DMSO gelöst und 1:500 im Nährmedium verdünnt. Als Kontrolle diente 0,2 \% DMSO.

\section{Methyljasmonat}

Methyljasmonat wurde mit Ethanol auf eine Konzentration von 0,5 $\mathrm{M}$ eingestellt und 1:10000 im Nährmedium verdünnt. Als Kontrolle diente 0,01 \% Ethanol.

\subsubsection{Chemikalienbehandlung auf mit Nährmedium beschichteten Objektträgern}

Für die Chemikalienbehandlung wurden die Wurzeln von 10 Tage alten, auf mediumbeschichteten (MSS) Objektträgern gewachsenen, Pflanzen für 30 - 60 Minuten mit der entsprechenden Chemikalienlösung überschichtet. 


\section{Salicylsäure}

Für die Behandlung mit Salicylsäure wurde Natriumsalicylat mit einer Konzentration von 1M in Wasser gelöst und 1:1000 mit Nährmedium (MSS) verdünnt. Als Kontrollbehandlung diente Nährmedium (MSS) ohne Zusätze.

\section{2,3,5 - Triiodobenzoesäure (TIBA)}

2,3,5-Triiodobenzoesäure wurde mit einer Konzentration von $50 \mathrm{mM}$ in DMSO gelöst und 1:500 im Nährmedium (MSS) verdünnt. Als Kontrolle diente Nährmedium (MSS) mit $0,2 \%$ DMSO.

\section{Methyljasmonat}

Methyljasmonat wurde mit Ethanol auf eine Konzentration von 0,5 M eingestellt und 1:10000 mit Nährmedium (MSS) verdünnt. Als Kontrolle diente Nährmedium (MSS) mit $0,01 \%$ Ethanol.

\section{2 - oxo - Phytodiensäure (OPDA)}

OPDA wurde mit Nährmedium (MSS) auf eine Konzentration von $75 \mu \mathrm{M}$ eingestellt. Als Kontrolle diente Nährmedium (MSS) mit $2 \%$ Ethanol.

\section{Leptomycin B (LMB)}

Leptomycin B wurde mit Nährmedium (MSS) auf eine Konzentration von $2 \mu \mathrm{M}$ eingestellt. Als Kontrolle diente Nährmedium (MSS) mit 0,2 \% Ethanol.

\section{Natriumchlorid ( $\mathrm{NaCl})$}

Natriumchlorid wurde mit einer Konzentration von $5 \mathrm{M}$ in Wasser gelöst und mit Nährmedium (MSS) auf eine Konzentration von $100 \mathrm{mM}$ eingestellt. Als Kontrolle diente Nährmedium (MSS) ohne Zusätze. 


\section{Cadmiumchlorid $\left(\mathrm{CdCl}_{2}\right)$}

Cadmiumchlorid wurde mir einer Konzentration von $100 \mathrm{mM}$ in Wasser gelöst und mit Nährmedium (MSS) auf eine Konzentration von $250 \mu \mathrm{M}$ eingestellt. Als Kontrolle diente Nährmedium (MSS) ohne Zusätze.

\subsubsection{Behandlung von auf Erde angezogenen Pflanzen mit TIBA}

Vier Wochen alte, unter Kurztagbedingungen angezogene, Pflanzen wurden mit einer Lösung von $100 \mu \mathrm{M}$ TIBA in Wasser besprüht, bis alle sichtbaren Pflanzenteile gleichmäßig benetzt waren, und mit einer durchsichtigen Haube abgedeckt. Die Ernte des Pflanzenmaterials erfolgte acht Stunden nach der Behandlung. Als Kontrolle diente 0,2 \% DMSO in Wasser.

\subsubsection{Transiente Luciferase Reporterassays in Protoplasten}

Für die Untersuchung der Aktivität eines Promotors eignen sich transiente Luciferase Reporterassays in Protoplasten. Hierfür werden die Protoplasten mit einer Glühkäferluciferase unter der Kontrolle des zu untersuchenden Promotors (Reporterkonstrukt) und einem Effektorprotein unter der Kontrolle des 35S-Promotors transformiert. Eine durch das Effektorprotein hervorgerufene Aktivierung oder Reprimierung des Promotors kann über die gesteigerte oder verminderte Aktivität der Glühkäferluciferase gemessen werden. Zur Normalisierung dient eine Renillaluciferase unter der Kontrolle des Ubiquitin10-Promotors (Referenzkonstrukt).

\subsubsection{Protoplastierung von A.thaliana Blattgewebe}

Die Gewinnung von Protoplasten aus Blättern von 4-6 Wochen im Langtag angezogenen Pflanzen erfolgte nach der Methode von Sheen (Sheen 2001). Die Unterseite der Blätter wurde in ca. 2 mm Abständen mit einer Rasierklinge eingeritzt und die Blätter mit der Unterseite nach unten in eine Petrischale mit $10 \mathrm{~mL}$ Enzymlösung gelegt, ohne zu überlappen. Die Protoplasten aus einer komplett ausgefüllten Petrischale reichen für 48 Transformationsansätze. Nach dem Verdau der Zellwände durch die Enzyme der Enzymlösung über Nacht unter Anzuchtbedingungen wurden die Protoplasten durch Filtration durch ein Metallsieb (75 $\mu \mathrm{M}$ Maschengröße) von den Blattresten getrennt. Anschließend wurden die 
Protoplasten für zwei Minuten bei 780 rpm und RT mit geringster Beschleunigunsund Bremsstufe zentrifugiert. Die Enzymlösung wurde vorsichtig abgenommen und die Protoplasten mit $10 \mathrm{~mL}$ W5-Puffer gewaschen und zwei Minuten bei $780 \mathrm{rpm}$ und RT mit geringster Beschleunigungs- und Bremsstufe zentrifugiert. Der Waschschritt wurde einmal wiederholt und die Protoplasten anschließend für 4-6 Stunden in $10 \mathrm{~mL}$ W5-Puffer auf Eis inkubiert.

\subsubsection{Transiente Transformation von A.thaliana Protoplasten}

Für die transiente Transformation der Protoplasten wurde der W5-Puffer von den abgesetzten Protoplasten vorsichtig abgenommen und die Protoplasten in $12 \mathrm{~mL}$ MMG-Puffer resuspendiert. Pro Transformationsansatz wurden zu $200 \mu \mathrm{L}$ Protoplastenlösung $20 \mu \mathrm{L}$ DNA-Lösung gegeben (1 $\mu \mathrm{g}$ Reporterkonstrukt, $1 \mu \mathrm{g}$ Referenzkonstrukt, $7.5 \mu \mathrm{g}$ Effektorkonstrukt in $20 \mu \mathrm{L} \mathrm{H}_{2} \mathrm{O}$ ) und durch invertieren vermischt. Nach Zugabe von $220 \mu \mathrm{L}$ PEG-Lösung und abermaligem Mischen folgte eine Inkubation für 30 Minuten bei Raumtemperatur. Nach Ablauf der Inkubationszeit wurden $800 \mu \mathrm{L}$ W5-Puffer durch Invertieren mit den Transformationsansätzen vermischt. Anschließend wurden die Transformationsansätze für zwei Minuten bei 780 rpm und RT mit geringster Beschleunigungs- und Bremsstufe zentrifugiert, der Überstand abgenommen und die Protoplasten in $250 \mu \mathrm{L}$ WI-Puffer resuspendiert. Es folgte eine Inkubation über Nacht unter Anzuchtbedingungen.

\subsubsection{Luciferase Reporterassay}

Die Messung der Luciferaseaktivität in den transformierten Protoplasten erfolgte unter Verwendung des Dual-luciferase reporter assay ${ }^{\circledR}$ Systems der Firma Promega mit dem Centro XS ${ }^{3}$ LB $960^{\circledR}$ Mikrotiterplattenleser der Firma Berthold Technologies. Die transformierten Protoplasten wurden durch Zentrifugation für eine Minute bei 780 rpm und RT mit geringster Beschleunigungs- und Bremsstufe sedimentiert. Nach dem Abnehmen des Überstandes mit einer Insulinspritze wurden die Protoplasten in flüssigem Stickstoff eingefroren und durch Zugabe von $20 \mu \mathrm{L} 1 \mathrm{x}$ passive lysis buffer lysiert. Von den Lysaten wurden jeweils $3 \mu \mathrm{L}$ in eine Vertiefung einer $384 \mathrm{er}$ Mikrotiterplatte gegeben und gemessen. Der Mikrotiterplattenleser wurde vor der Messung mit der erforderlichen Menge an Substratlösung für die verwendeten 
Luciferasen beladen (LARII-Substrat für die Glühkäferluciferase und Stop+Glo 1:50 für die Renillaluciferase). Tabelle 3.6 zeigt das Ablaufschema einer Messung.

Tabelle 3.6: Ablauf der Messung der Luciferaseaktivitäten in einem Transformationsansatz 30 sek warten

\begin{tabular}{c}
\hline Zugabe von $15 \mu \mathrm{L}$ LARII Substrat \\
\hline 5 sek warten \\
\hline sek Messung der Aktivität der \\
Glühkäferluciferase \\
\hline Zugeben vom $15 \mu \mathrm{L}$ Stop+Glo \\
Substrat \\
\hline 5 sek Warten \\
\hline sek Messung der Aktivität der
\end{tabular}

Renillaluciferase

\subsubsection{Für die Protoplastierung und Transformation genutzte Puffer}

W5-Puffer:

$154 \mathrm{mM} \mathrm{NaCl}$

$125 \mathrm{mM} \mathrm{CaCl}_{2}$

$5 \mathrm{mM} \mathrm{KCl}$

2 mM MES

ad $50 \mathrm{~mL} \mathrm{H} \mathrm{H}_{2} \mathrm{O}$

WI-Puffer:

0,5 M Mannitol

$0,02 \mathrm{M} \mathrm{KCl}$

0,004 M MES

ad $50 \mathrm{~mL} \mathrm{H}_{2} \mathrm{O}$

\section{MMg-Puffer:}

0,4 M Mannitol

$0,015 \mathrm{M} \mathrm{MgCl}_{2}$

0,004 M MES

ad $50 \mathrm{~mL} \mathrm{H} \mathrm{H}_{2} \mathrm{O}$ 


\title{
Enzymlösung:
}

\author{
$0,625 \mathrm{~g}$ Cellulase \\ $0,150 \mathrm{~g}$ Macerozym \\ 0,4 M Mannitol \\ $0,02 \mathrm{M} \mathrm{KCl}$ \\ $0,02 \mathrm{M}$ MES \\ $0,01 \mathrm{M} \mathrm{CaCl}_{2}$ \\ ad $50 \mathrm{~mL} \mathrm{H}_{2} \mathrm{O}$
}

PEG-Lösung (40 \%)

20 g PEG 4000

$14,16 \mathrm{~mL} \mathrm{H}_{2} \mathrm{O}$

13,3 mL Mannitol (0,75 M Stock)

$5 \mathrm{~mL} \mathrm{CaCl} 2$ (1 M Stock)

ad $50 \mathrm{~mL} \mathrm{H}_{2} \mathrm{O}$

\subsubsection{Hefe - Zwei - Hybrid - System}

Das Hefe-Zwei-Hybrid-System ist ein System zur Untersuchung von Protein-Protein Interaktionen (Fields \& Song 1989). Hierbei wird einer der Interaktionspartner mit der DNA-Bindedomäne des GAL4 Transkriptionsfaktors der Hefe Saccharomyces cerevisiae fusioniert (Köderprotein), der andere Interaktionspartner mit der Aktivierungsdomäne desselben Transkriptionsfaktors (Beuteprotein). Das Köderprotein kann aufgrund der angefügten DNA-Bindedomäne an den GAL-Promotor binden. Kommt es zu einer Interaktion mit dem Beuteprotein, werden die beiden Domänen der GAL4 Transkriptionsfaktors vereinigt und es kommt zur Aktivierung der Transkription. Befindet sich unter der Kontrolle des GAL-Promoters in der Hefe ein Reportergen, kann über die Aktivierung dieses Reportergens die Interaktion von Köder- und Beuteprotein nachgewiesen werden. Durch die Verwendung einer cDNABank für die Erstellung des Beutekonstrukts, kann auch nach völlig neuen Interaktionspartnern für ein gegebenes Köderprotein gesucht werden. 


\subsubsection{Transformation von Hefezellen}

Die Transformation der Hefezellen erfolgte nach der Methode von Gietz und Woods (Gietz \& Woods 2002). Zur Erzeugung von Kompetenten Hefezellen des Stammes PJ69-4a wurde eine $20 \mathrm{~mL}$ Hefekultur in YPAD-Medium angesetzt über Nacht bei $30{ }^{\circ} \mathrm{C}$ unter Schütteln inkubiert. Am nächsten Tag wurde diese Kultur verwendet, um eine $50 \mathrm{~mL}$ - Kultur mit einer $\mathrm{OD}_{600}$ von 0,5 in YPAD-Medium anzusetzen. Diese Kultur wurde bei $30^{\circ} \mathrm{C}$ unter Schütteln inkubiert, bis sie eine $O_{600}$ von 2 aufwies. Die Hefezellen wurden durch Zentrifugation für 5 Minuten bei $4000 \mathrm{rpm}$ und RT geerntet und in $25 \mathrm{~mL}$ sterilem $\mathrm{ddH}_{2} \mathrm{O}$ gewaschen. Nach erneuter Zentrifugation wurden die Hefezellen in $1 \mathrm{~mL}$ sterilem $\mathrm{ddH}_{2} \mathrm{O}$ aufgenommen und in ein $2 \mathrm{~mL}$ Reaktionsgefäß überführt und für 30 Sekunden bei 13000 rpm und RT zentrifugiert. Der Überstand wurde verworfen und die Hefezellen in einem Gesamtvolumen von $1 \mathrm{~mL}$ resuspendiert. Die Hefesuspension wurde in $10100 \mu \mathrm{L}$ Aliquots aufgeteilt, die Ansätze für 30 Sekunden bei $13000 \mathrm{rpm}$ und RT zentrifugiert und der Überstand verworfen. Anschließend wurden die Hefezellen in $355 \mu \mathrm{L}$ Transformationsmix (Tab. 3.7) resuspendiert und in neue Reaktionsgefäße überführt, in die jeweils $0,5 \mu \mathrm{g}$ des Köderplasmids und des Beuteplasmids in einem Gesamtvolumen von $5 \mu \mathrm{L}$ vorgelegt wurden. Nach einer Inkubation für 30 Minuten bei $30^{\circ} \mathrm{C}$ erfolgte ein Hitzeschock für 40 Minuten bei $42^{\circ} \mathrm{C}$. Nach dem Hitzeschock wurden die Transformationsansätze für 1 Minute bei 13000 rpm und RT zentrifugiert, der Überstand verworfen, die Zellen in $1 \mathrm{~mL}$ sterilem $\mathrm{dd}_{2} \mathrm{O}$ resuspendiert und auf Selektions- und Interaktionsmedium ausplattiert.

Tabelle 3.7: Zusammensetzung des Transformationsmixes für einen Transformationsansatz.

\begin{tabular}{c|c} 
PEG 3500 50\% (w/v) & $240 \mu \mathrm{L}$ \\
\hline Lithiumacetat $1 \mathrm{M}$ & $36 \mu \mathrm{L}$ \\
\hline $\begin{array}{c}\text { erhitzte einzelstrang } \\
\text { träger DNA }\end{array}$ & $50 \mu \mathrm{L}$ \\
\hline $\mathrm{H} 2 \mathrm{O}$ & $29 \mu \mathrm{L}$ \\
\hline Gesamtvolumen & $355 \mu \mathrm{L}$
\end{tabular}

\subsubsection{Bestimmung der B-Galaktosidaseaktivität in Hefeextrakten (oNPG-Test)}

Der oNPG-Test ist eine Methode zur Quantifizierung von Proteininteraktionen im Hefe-Zwei-Hybrid-System. Dabei wird das bakterielle lacZ-Gen, welches für eine BGalactosidase kodiert, als Reportergen verwendet. Dieses Enzym spaltet 
normalerweise das Disaccharid Laktose, nimmt aber auch o-Nitrophenyl-B-Dgalactopyranosid (oNPG) als Substrat an. oNPG ist ein farbloser Stoff, bei der Spaltung wird jedoch das gelbe o-Nitrophenol freigesetzt, welches bei einer Wellenlänge von $420 \mathrm{~nm}$ photometrisch quantifiziert werden kann. Mittels der Formel $\frac{1000 * O D_{420}}{V * T * O D_{600} * F} \quad(\mathrm{~V}=$ Volumen der Hefekultur, $\mathrm{T}=$ Reaktionszeit, $\mathrm{F}=$ Verdünnungsfaktor) kann die Aktivität der ß-Galaktosidase bestimmt werden.

Für einen oNPG-Test wurde eine $3 \mathrm{~mL}$ Hefekultur in Selektionsmedium angeimpft und über Nacht bei $30^{\circ} \mathrm{C}$ unter Schütteln inkubiert. Aus 1,5 mL dieser Kultur wurden die Hefezellen durch Zentrifugation für 1 Minute bei 13000 rpm und RT geerntet. Der Überstand wurde verworfen und die Hefezellen mit $1 \mathrm{~mL}$ Z-Puffer $\left(60 \mathrm{mM} \mathrm{Na} 2 \mathrm{HPO}_{4}\right.$; $40 \mathrm{mM} \mathrm{NaH} \mathrm{PO}_{4} ; 10 \mathrm{mM} \mathrm{KCl} ; 1 \mathrm{mM} \mathrm{MgSO} 4$; pH7,0) gewaschen. Nach erneuter Zentrifugation für 1 Minute bei 13000 rpm und RT wurden die Hefezellen in $300 \mu \mathrm{L}$ ZPuffer resuspendiert. Hiervon wurden $100 \mu \mathrm{L}$ in ein neues Reaktionsgefäß überführt und zweimal in flüssigem Stickstoff eingefroren und bei $37^{\circ} \mathrm{C}$ aufgetaut. Anschließend wurden $700 \mu \mathrm{L}$ Z-Puffer mit 2,7 $\mu \mathrm{L}$ B-Mercaptoethanol pro $\mu \mathrm{L}$ zugegeben. Nach Zugabe von $160 \mu \mathrm{L}$ oNPG-Lösung (Z-Puffer mit 4 mg/mL oNPG) folgte eine Inkubation für 30-60 Minuten bei $37^{\circ} \mathrm{C}$ unter Schütteln. Nach eintreten einer Gelbfärbung wurde die Reaktion durch Zugabe von $400 \mu \mathrm{L} \mathrm{Na} \mathrm{CO}_{3}$ gestoppt und der Reaktionsansatz für 10 Minuten bei 1300 rpm und RT zentrifugiert. Vom Überstand wurden $200 \mu \mathrm{L}$ für die Messung der $\mathrm{OD}_{420}$ eingesetzt. Als Negativkontrolle diente ein Reaktionsansatz mit $100 \mu \mathrm{L}$ Z-Puffer statt Hefelösung. Für die Normalisierung der ß-Galaktosidaseaktivität wurde die $\mathrm{OD}_{600}$ der anfangs abgenommen $200 \mu \mathrm{L}$ bestimmt.

\subsubsection{Markierung von cysteinhaltigen Proteinen mit mPEG-Mal-5000}

Um den Redox-Status von Proteinen in Pflanzenzellen zu untersuchen wurden reduzierte Cysteine der Proteine mit Methoxypolyethylenglycol Maleimide-5000 (mPEG-Mal-5000) markiert. Durch das anfügen eines solchen Moleküls wird dem Molekulargewicht des Proteins eine Masse von $5 \mathrm{kDa}$ hinzugefügt, was sich als Änderung der Laufhöhe in einem SDS-Polyacrylamidgel gegenüber einem unmarkierten Protein äußert. Die Markierung der Cysteine mit mPEG-Mal-5000 erfolgte nach der Methode von Muthuramalingam et al. (Muthuramalingam et al. 
2010). Die verwendeten Pflanzen wurden für 10 Tage unter Langtagbedingungen im hydroponischen System angezogen und die Wurzeln für eine Stunde mit $1 \mathrm{mM} \mathrm{SA}$ behandelt. Sowohl von den SA-behandelten Pflanzen als von den Kontrollpflanzen wurden jeweils zwei Proben bearbeitet. Das geerntete Wurzelmaterial wurde in flüssigem Stickstoff gemörsert. Ca. $50 \mu \mathrm{L}$ Pflanzenpulver wurden in $200 \mu \mathrm{L} 20 \%$ Trichloressigsäure (TCA) aufgenommen, gemischt und 30 Minuten bei $-18^{\circ} \mathrm{C}$ inkubiert. Nach einer Zentrifugation für 15 Minuten bei $13000 \mathrm{rpm}$ und $4{ }^{\circ} \mathrm{C}$ wurde das entstandene Pellet mit $500 \mu \mathrm{L} 10 \%$ TCA gewaschen und für 2 Minuten bei 13000 und $4{ }^{\circ} \mathrm{C}$ zentrifugiert. Es folgten ein Waschschritt mit $250 \mu \mathrm{L} 5 \%$ TCA und Zentrifugation für 2 Minuten bei $13000 \mathrm{rpm}$ und $4{ }^{\circ} \mathrm{C}$. Das Pellet wurde in $180 \mu \mathrm{L}$ Reaktionspuffer (6 M Harnstoff; $200 \mathrm{mM}$ Bis-Tris pH 6,5; 0,5\% (w/v) SDS; $10 \mathrm{mM}$ EDTA) mit $100 \mathrm{mM} \mathrm{N}$-Ethylmaleimide (NEM) aufgenommen und für 60 Minuten bei $25^{\circ} \mathrm{C}$ im Dunkeln inkubiert. Das NEM diente als Schutzgruppe für bereits reduzierte Cysteine. Die Reaktion mit dem NEM wurde durch Zugabe von $180 \mu \mathrm{L} 20 \%$ TCA gestoppt. Es folgten eine Inkubation für 30 Minuten bei $-18^{\circ} \mathrm{C}$ und eine Zentrifugation für 15 Minuten bei $13000 \mathrm{rpm}$ und RT sowie eine Wiederholung der Waschschritte mit 10\% und 5\% TCA. Von den SA-behandelten Proben und den Kontrollproben wurde jeweils eine durch Inkubation in $180 \mu \mathrm{L}$ Reaktionspuffer mit $100 \mathrm{mM}$ Dithiothreitol (DTT) für 60 Minuten bei $25^{\circ} \mathrm{C}$ im Dunkeln reduziert, zu der jeweils anderen Probe wurde kein DTT hinzugegeben. Die Reduktionsreaktion wurde durch Zugabe von $180 \mu \mathrm{L} 20 \%$ TCA gestoppt. Es folgte eine Inkubation für 30 Minuten bei $-18{ }^{\circ} \mathrm{C}$ und eine Zentrifugation für 15 Minuten bei $13000 \mathrm{rpm}$ und $4^{\circ} \mathrm{C}$ sowie die Wiederholung der Waschschritte mit 10\% und 5\% TCA. Die Markierung der Proben mit mPEG-Mal-5000 erfolgte durch Zugabe von $180 \mu \mathrm{L}$ Reaktionspuffer mit $5 \mathrm{mM}$ mPEG-Mal-5000 und Inkubation für 60 Minuten bei $25^{\circ} \mathrm{C}$ im Dunkeln. Die Reaktion wurde gestoppt durch Zugabe von $2 \mu \mathrm{L} 1 \mathrm{M}$ DTT. Abschließend wurden die Proben mit $180 \mu \mathrm{L} 2 \times \mathrm{SDS}$-Probenpuffer versetzt und für 5 Minuten bei $95^{\circ} \mathrm{C}$ erhitzt. Die Markierten Proteine wurden über SDS-Polyacrylamidgelelektrophorese aufgetrennt und mittels Western Blot visualisiert. 


\subsubsection{Fluoreszenzmikroskopie}

Die mikroskopische Analyse der intrazellulären Lokalisation der GFP-SCL Fusionsproteine erfolgte mit dem konfokalen Lasermikroskop SP5 der Firma Leica. Die zu analysierenden Pflanzen wurden für 10 Tage unter Langtagbedingungen auf mit Nährmedium (MSS) beschichteten Objektträgern angezogen. Dadurch sollte gewährleistet werden, dass derselbe Bereich derselben Wurzel nach der Kontrollbehandlung und der Chemikalienbehandlung betrachtet werden konnte. Die Pflanzen wurden für die Kontrolle für 30 Minuten mit flüssigem Nährmedium ohne Zusätze bzw. mit dem entsprechenden Lösungsmittel versetzt überschichtet und Anschließend mikroskopiert. Nach Aufnahme der Fluoreszenzbilder erfolgte die Chemikalienbehandlung für 30 Minuten und die erneute Aufnahme des bereits nach der Kontrollbehandlung aufgenommenen Wurzelbereiches. Die Anregung des GFP erfolgte durch das Licht eines Argon Lasers mit einer Wellenlänge von $488 \mathrm{~nm}$. Das vom GFP emittierte Licht wurde mit dem Detektor PMT1 im Wellenlängenbereich von $500 \mathrm{~nm}$ bis $540 \mathrm{~nm}$ detektiert.

\subsubsection{Bestimmung von Wurzellängen}

Zur Bestimmung der Inhibition des Wurzelwachstums durch Salicylsäure wurden Pflanzen der Genotypen Col-0, sc/14/33 und sc/14/33 35S:HA-GFP-SCL14 für sechs Tage auf Schrägplatten mit Nährmedium (MSS) unter Langtagbedingungen angezogen. Die Pflanzen wurden auf neue Schrägplatten mit Nährmedium bzw. auf Schrägplatten mit Nährmedium, versetzt mit $100 \mu \mathrm{M}$ SA, umgesetzt und die Wurzellänge wurde gemessen. Nach weiteren sechs Tagen bei Langtagbedingungen wurde die Wurzellänge erneut gemessen und der Wurzelzuwachs auf SA, relativ zur Kontrolle, berechnet. 


\section{Ergebnisse}

\subsection{Chemischer Stress induziert die Akkumulation von SCL14 in Zellkernen von A. thaliana Wurzelzellen}

Das GRAS-Protein SCL14 ist ein Transkriptionskoaktivator, der an der Regulation von Genen beteiligt ist, die Teil der pflanzlichen Entgiftungsmaschinerie sind, wie zum Beispiel Glutathion S-Transferasen und Cytochrom P450 Monooxygenasen (Fode et al. 2008). Der Mechanismus, der zur Aktivierung des SCL14 Proteins führt, ist bisher allerdings nicht bekannt. Fode et al. konnten mittels Chromatinimmunopräzipitation nachweisen, dass der Proteinkomplex aus SCL14 und TGA2 sowohl im uninduzierten als auch im induzierten Zustand an die Promotoren seiner Zielgene bindet (Fode et al. 2008). In Tabakprotoplasten ist SCL14 sowohl im Zellkern als auch im Cytoplasma lokalisiert. Nach der Behandlung der Protoplasten mit dem Kernexportinhibitor Leptomycin B (LMB) ist SCL14 ausschließlich im Zellkern zu finden (Fode et al. 2008), was auf einen konstanten Austausch von SCL14 zwischen dem Zellkern und dem Cytoplasma schließen lässt. Um zu untersuchen, ob die Akkumulation des Proteins im Zellkern auch in Arabidopsis Pflanzen stattfindet, welche Stimuli die Akkumulation auslösen und ob diese eine Bedeutung bei seiner Regulation spielt, wurden transgene Pflanzen hergestellt, die ein HA-GFP-SCL14 Fusionskonstrukt unter der Kontrolle des 35S-Promotors des Blumenkohlmosaikvirus exprimieren (Abb. 4.1).

\subsubsection{Die Inhibition des Kernexports führt zur Akkumulation von SCL14 im Zellkern von Arabidopsis Wurzelzellen}

Da die Fluoreszenz des HA-GFP-SCL14 Konstruktes in oberirdischen Pflanzenteilen nur sehr schwach und nur in einzelnen Zellen zu detektieren war, wurde der Einfluss von chemischen Substanzen auf die Lokalisierung und die Aktivität von SCL14 in Wurzeln untersucht. Über die Wurzeln erfolgt die Aufnahme zahlreicher Toxine, wie Schwermetalle, Allelochemikalien und anthropogener Umweltgifte (Schützendübel \& Polle 2002; Beynon et al. 2009). Um zu überprüfen, ob auch in Wurzeln ein konstanter Austausch von SCL14 zwischen dem Zellkern und dem Cytoplasma stattfindet, wurden die Wurzeln mit $2 \mu \mathrm{M}$ LMB behandelt. 
$\begin{array}{lll}\text { 35S-Promotor } & \text { GA } & \text { GFP } 14\end{array}$

Abbildung 4.1: Schema des HA-GFP-SCL14 Fusionsproteins, welches für die Lokalisationsstudien in Wurzeln von Arabidopsis thaliana verwendet wurde.

Das GFP Signal in den HA-GFP-SCL14 exprimierenden Pflanzen ist in den Wurzeln nach der Kontrollbehandlung sowohl im Cytoplasma zu erkennen, als auch im Zellkern (Abb. 4.2). Nach der Behandlung der Wurzeln mit $2 \mu \mathrm{M} \mathrm{LMB}$ kann immer noch ein GFP Signal im Cytoplasma der Zellen beobachtet werden, allerdings hat die Fluoreszenz im Zellkern gegenüber der Kontrollbehandlung zugenommen. Hier liegt ein Unterschied zu den Tabakprotoplasten vor, da sich in diesen die Fluoreszenz nach der LMB-Behandlung auf den Zellkern beschränkt. In Wurzeln von Pflanzen, die freies GFP exprimieren, findet keine Änderung in der Verteilung der Fluoreszenzintensität nach Behandlung der Wurzeln mit LMB im Vergleich zur Kontrollbehandlung statt (Abb. 4.2). 


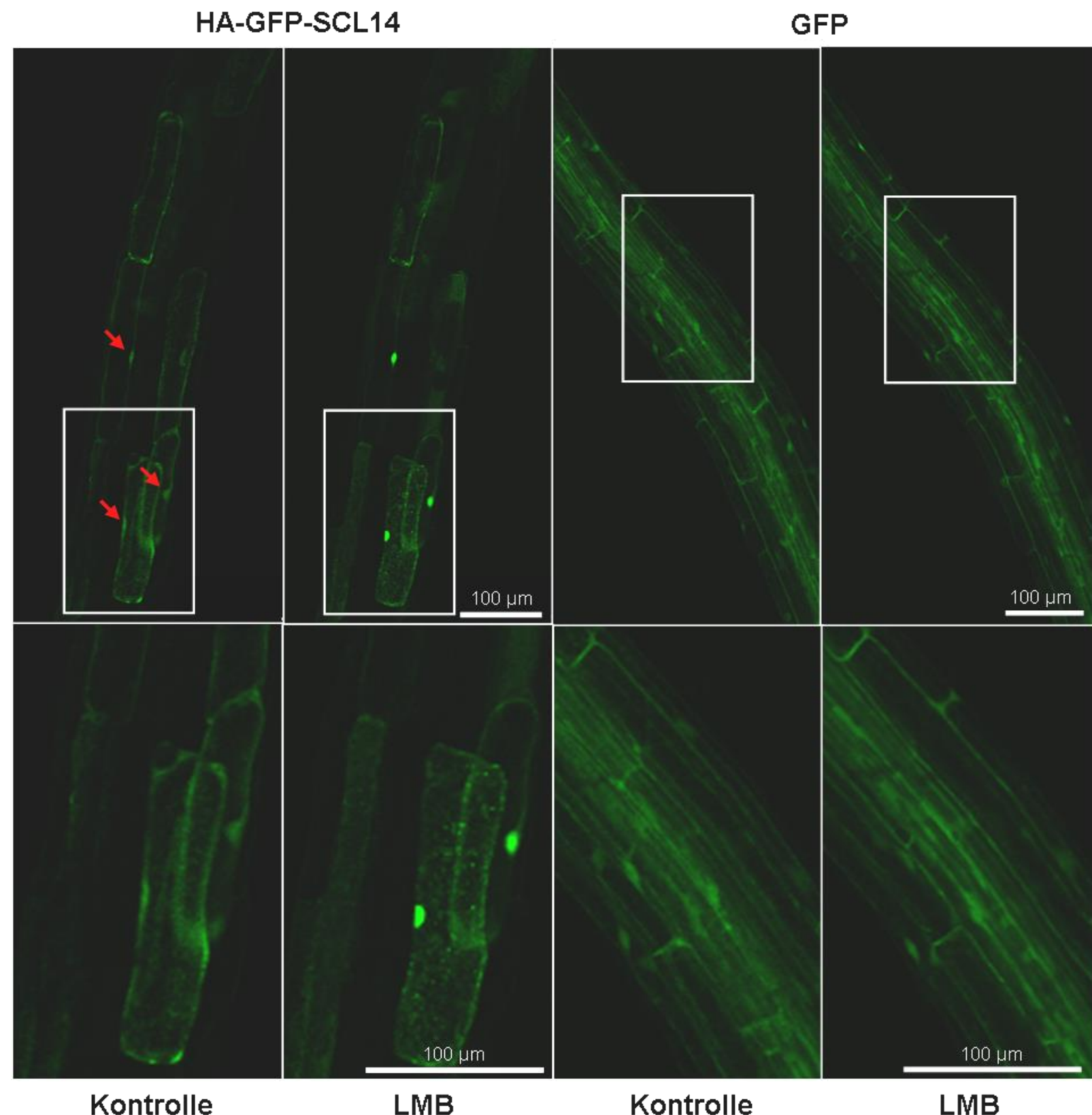

Abbildung 4.2: HA-GFP-SCL14 akkumuliert in Zellkernen von Arabidopsis thaliana Wurzelzellen nach Behandlung mit Leptomycin $B$ (LMB)

10 Tage alte Pflanzen der Genotypen sc/14/33 35S:HA-GFP-SCL14 und Col-0 35S:GFP wurden mit $2 \mu \mathrm{M}$ LMB behandelt. Als Kontrolle diente 0,2 \% Ethanol. Die Anzucht der Pflanzen erfolgte steril auf mediumbeschichteten Objektträgern unter Langtagbedingungen. Die Kontrollbehandlung und die Chemikalienbehandlung wurden nacheinander an derselben Wurzel vorgenommen. Die Aufnahme der Fluoreszenzbilder erfolgte jeweils $30 \mathrm{~min}$ nach Beginn der Behandlung. Gezeigt ist ein repräsentatives Bild von zwei unabhängigen Replikaten. Die markierten Ausschnitte sind im unteren Bildteil vergrößert dargestellt. 


\subsubsection{SCL14 akkumuliert im Zellkern nach der Behandlung von Arabidopsis Wurzeln mit Salicylsäure, 2,3,5-Triiodo- benzoesäure und 12-oxo-Phytodiensäure}

Das Pflanzenhormon Salicylsäure (SA) und das Xenobiotikum 2,3,5Triiodobenzoesäure (TIBA) aktivieren in Blättern die Transkription von SCL14 Zielgenen wie GSTU7 und CYP81D11 in Abhängigkeit von SCL14 (Fode et al. 2008). Um zu testen, ob diese Substanzen auch die Akkumulation von SCL14 im Zellkern induzieren, wurden Wurzeln von transgenen Pflanzen, die ein HA-GFPSCL14 Fusionsprotein exprimieren, mit 1 mM SA bzw. $100 \mu \mathrm{M}$ TIBA behandelt. Sowohl nach der Behandlung der Pflanzen mit SA, als auch nach der Behandlung der Pflanzen mit TIBA ist eine Akkumulation von SCL14 im Zellkern zu beobachten (Abb. 4.3). Nach SA Behandlung nimmt die Fluoreszenz im Zellkern etwa auf das 8fache zu, nach der Behandlung der Wurzeln mit TIBA etwa auf das 6-fache (Abb. 4.5). Sowohl SA als auch TIBA beeinflussen also den Austausch von SCL14 zwischen dem Zellkern und dem Cytoplasma in ähnlicher Weise wie LMB. 


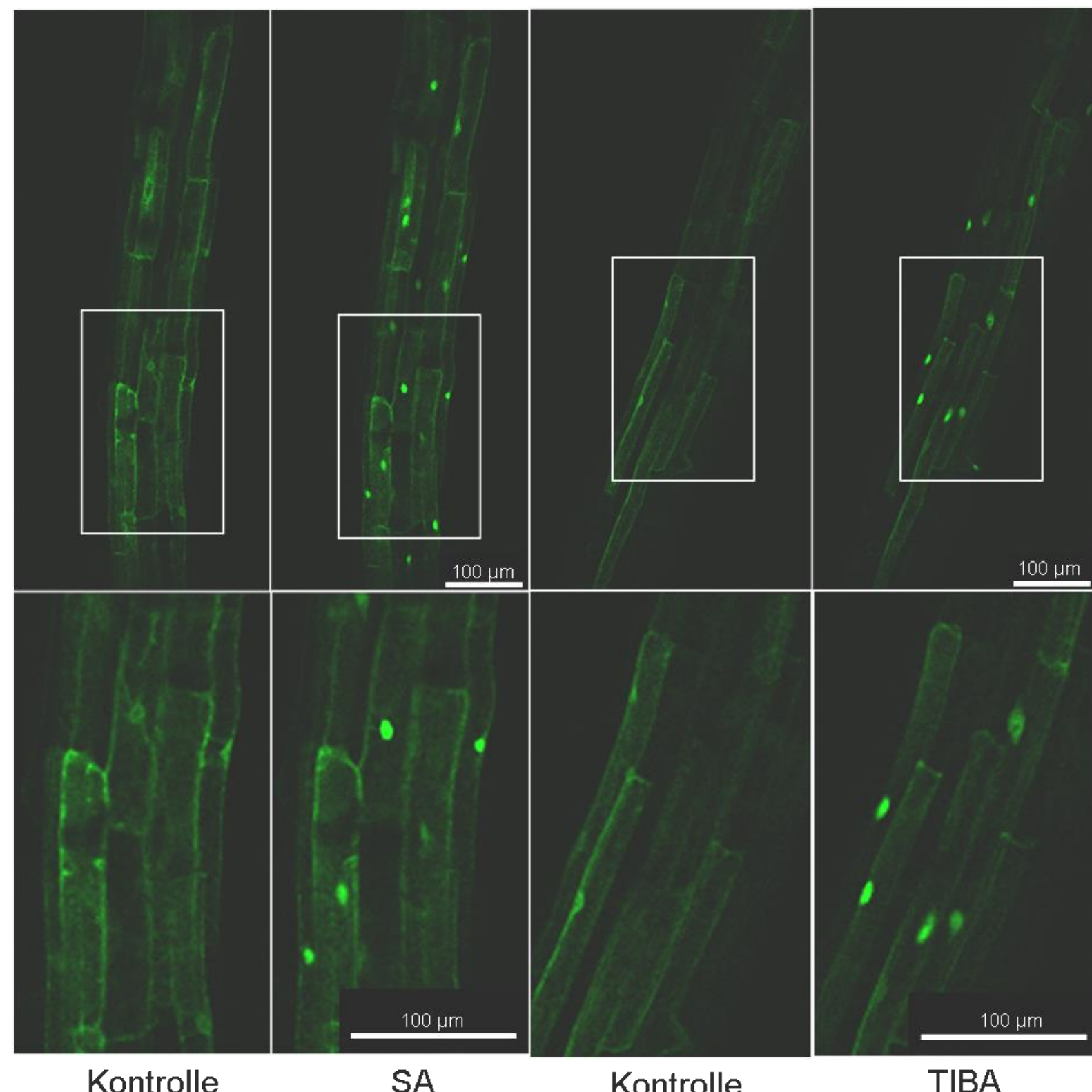

Abbildung 4.3: HA-GFP-SCL14 akkumuliert in Zellkernen von Arabidopsis thaliana Wurzelzellen nach Behandlung mit Salicylsäure (SA) und 2,3,5-Triiodobenzoesäure

10 Tage alte Pflanzen des Genotyps sc/14/33 35S:HA-GFP-SCL14 wurden mit 1 mM SA bzw. $100 \mu \mathrm{M}$ TIBA behandelt. Als Kontrolle diente Wasser bzw. 0,2 \% DMSO. Die Anzucht der Pflanzen erfolgte steril auf mediumbeschichteten Objektträgern unter Langtagbedingungen. Die Kontrollbehandlung und die Chemikalienbehandlung wurden nacheinander an derselben Wurzel vorgenommen. Die Aufnahme der Fluoreszenzbilder erfolgte jeweils $30 \mathrm{~min}$ nach Beginn der Behandlung. Gezeigt ist ein repräsentatives Bild von zwei unabhängigen Replikaten. Die markierten Ausschnitte sind im unteren Bildteil vergrößert dargestellt.

Eine weitere Substanz, die die Akkumulation von SCL14 im Zellkern induziert, ist das Oxilipin 12-oxo-Phytodiensäure (OPDA), eine Vorstufe des Pflanzenhormons Jasmonsäure (JA) (Abb. 4.4). JA hat diese Wirkung jedoch nicht (Abb. 4.4), woraus sich schließen lässt, dass die Wirkung durch OPDA selbst hervorgerufen wird und nicht indirekt nach der Überführung in JA, bzw. das biologisch aktive Konjugat der 
Jasmonsäure mit der Aminosäure Isoleucin (JA-lle), durch den Stoffwechsel der Pflanze.

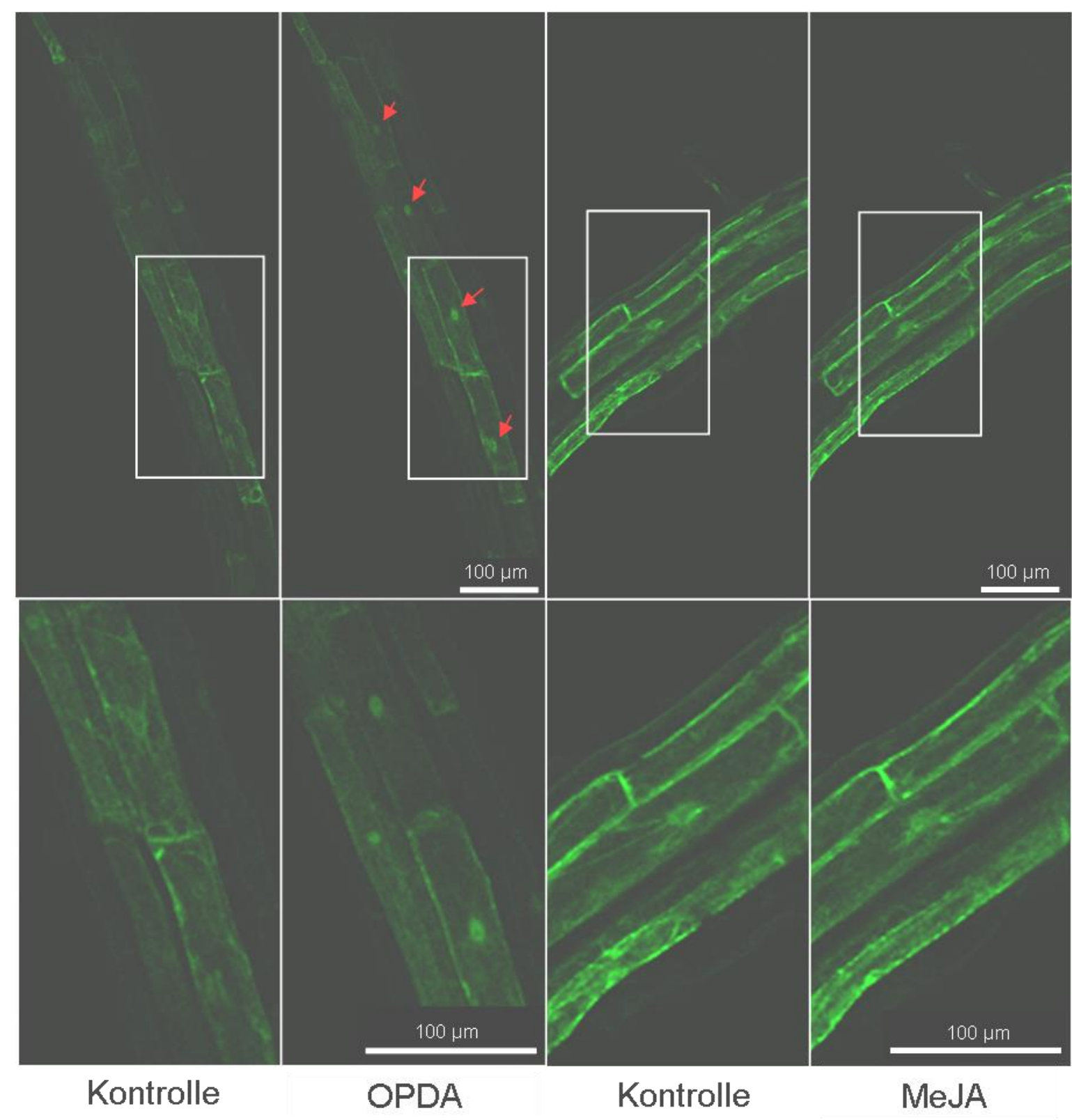

Abbildung 4.4: HA-GFP-SCL14 akkumuliert in Zellkernen von Arabidopsis thaliana Wurzeln nach Behandlung mit 12-oxo-Phytodiensäure (OPDA), jedoch nicht nach Behandlung mit Methyljasmonat (MeJA)

10 Tage alte Pflanzen des Genotyps sc/14/33 35S:HA-GFP-SCL14 wurden mit $75 \mu$ M OPDA bzw. 50 $\mu \mathrm{M}$ MeJA behandelt. Als Kontrolle diente 0,01\% Ethanol. Die Anzucht der Pflanzen erfolgte steril auf mediumbeschichteten Objektträgern unter Langtagbedingungen. Die Kontrollbehandlung und die Chemikalienbehandlung erfolgten nacheinander an derselben Wurzel. Die Aufnahme der Fluoreszenzbilder erfolgte jeweils 30 Minuten nach Beginn der Behandlung. Gezeigt ist ein repräsentatives Bild von drei unabhängigen Replikaten. Die markierten Ausschnitte sind im unteren Bildteil vergrößert dargestellt. 
Der Effekt von OPDA ist jedoch schwächer als der von SA und TIBA, da nach der OPDA Behandlung der Wurzeln die Fluoreszenz in den Zellkernen nur auf etwa das 2-fache zunimmt (Abb. 4.5).

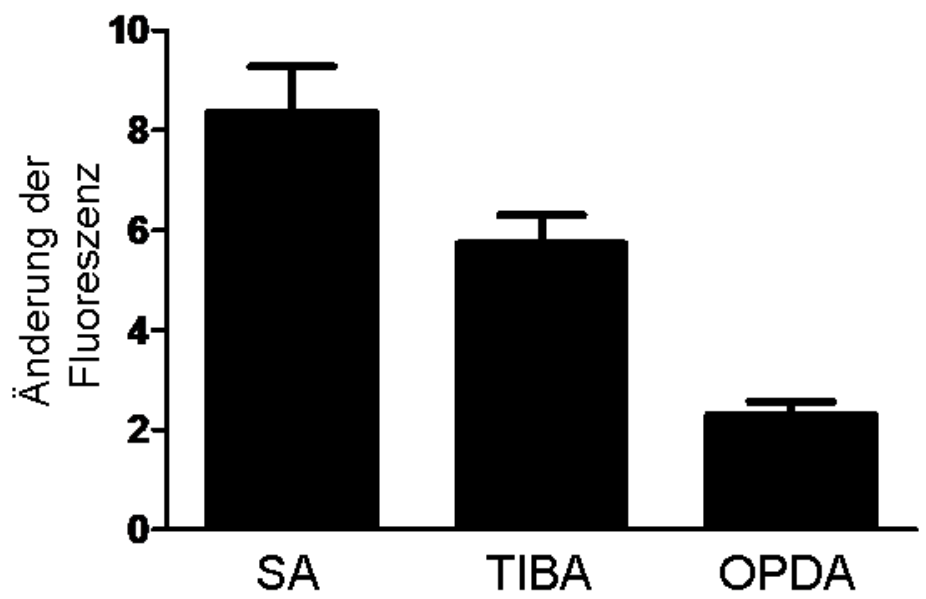

Abbildung 4.5: Änderung der Intensität der Fluoreszenz in den Zellkernen SA-, TIBA- und OPDA- behandelter Wurzeln im Vergleich zur Kontrollbehandlung

Die Quantifizierung der Fluoreszenz erfolgte mit dem Programm Leica Application Suite Advanced Fluorescence Lite ${ }^{\circledR}$ der Firma Leica Microsystems CMS GmbH. Gezeigt ist der Mittelwert der Fluoreszenzänderung in 20-30 Kernen (SA und TIBA) bzw. 10 Kernen (OPDA) ( \pm SEM) aus zwei unabhängig behandelten Wurzeln. 


\subsubsection{Die Stickstoffmonooxiddonatoren Natriumnitroprussid und S-Nitrosoglutathion induzieren nicht die Akkumulation von SCL14 im Zellkern}

In der gsnor1-3 Mutante ist die Expression des SCL14 Zielgens GSTU7, zumindest in Blättern, hyperinduziert (Anhang Abb. 6.1). Dieser Mutante fehlt das Enzym $S$-Nitrosoglutathion Reduktase, sodass in diesen Pflanzen eine höhere Konzentration des NO-Donators S-Nitrosoglutathion (GSNO) im Vergleich zum Wildtyp vorliegt, was zu einer verstärkten Nitrosylierung der Proteine führt (Feechan et al. 2005). Bei der Nitrosylierung von Proteinen handelt es sich um die Oxydation der Sulfhydrylgruppe der Aminosäure Cystein durch Stickstoffmonooxid. Diese Modifikation spielt in Pflanzen beispielsweise eine Rolle bei der Regulation des Schlüsselregulators der systemischen erworbenen Resistenz (Systemic Acquired Resistance, SAR) NONEXPRESSOR OF PR1 (NPR1) (Tada et al. 2008). Da es in der gsnor1-3 Mutante unter bestimmten Bedingungen zu einer verstärkten Expression von SCL14 Zielgenen im Vergleich zum Wildtyp kommt, könnte die Nitrosylierung auch bei der Aktivierung von SCL14 eine Rolle spielen. Daher wurden Arabidopsis Wurzeln mit den NO-Donatoren GSNO und Natriumnitroprussid (SNP) behandelt.

Weder nach der Behandlung mit GSNO noch mit SNP erfolgt eine Akkumulation von SCL14 in den Zellkernen (Abb. 4.6). Sofern SCL14 durch die NO-Donatoren nitrosyliert wird, ist dies daher nicht der Stimulus, welcher die Akkumulation im Zellkern auslöst. 


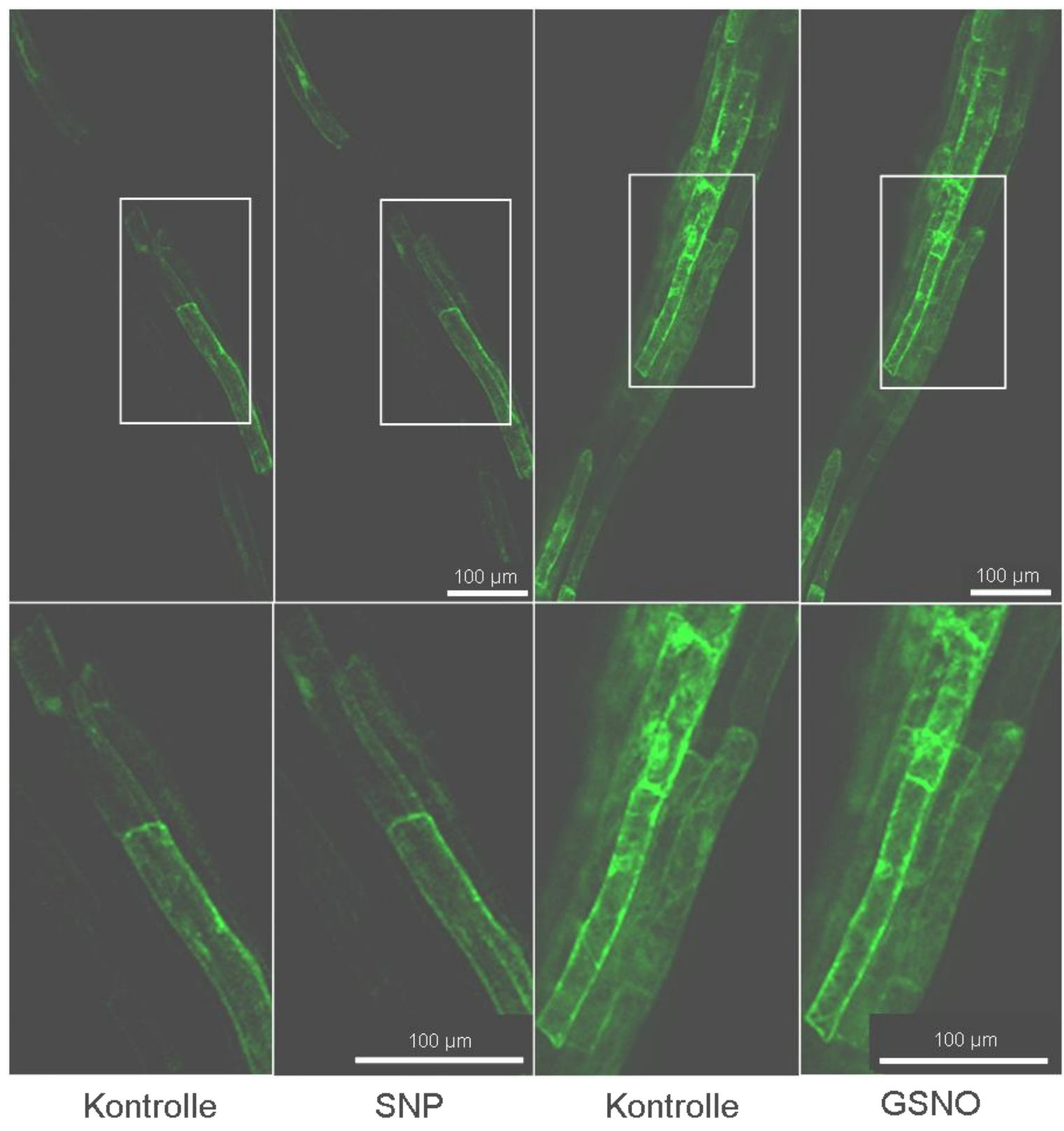

Abbildung 4.6: HA-GFP-SCL14 akkumuliert nicht in Zellkernen von Arabidopsis thaliana Wurzeln nach der Behandlung mit den Stickstoffmonooxid Donatoren Natriumnitroprussid (SNP) und S-Nitrosoglutathion (GSNO)

10 Tage alte Pflanzen des Genotyps sc/14/33 35S:HA-GFP-SCL14 wurden mit $200 \mu \mathrm{M}$ SNP bzw. $100 \mu \mathrm{M}$ GSNO behandelt. Als Kontrolle diente Wasser. Die Anzucht der Pflanzen erfolgte steril auf mediumbeschichteten Objektträgern unter Langtagbedingungen. Die Kontrollbehandlung und die Chemikalienbehandlung erfolgten nacheinander an derselben Wurzel. Die Aufnahme der Fluoreszenzbilder erfolgte jeweils 30 min nach Beginn der Behandlung. Gezeigt ist ein repräsentatives Experiment von zwei unabhängigen Replikaten. Die markierten Ausschnitte sind im unteren Bildteil vergrößert dargestellt. 


\subsection{4 $\mathrm{NaCl}$ und $\mathrm{CdCl}_{2}$ induzieren nicht die Akkumulation von SCL14 im Zellkern}

Natriumchlorid und das Schwermetall Cadmium lösen in pflanzlichem Gewebe die Produktion von reaktiven Sauerstoffspezies (Reactive Oxygen Species, ROS) wie Wasserstoffperoxid $\left(\mathrm{H}_{2} \mathrm{O}_{2}\right)$ und Superoxid $\left(\mathrm{O}_{2}{ }^{-}\right)$aus (Borsani et al. 2001; Remans et al. 2010). Um zu Untersuchen, ob die durch $\mathrm{NaCl}$ und $\mathrm{CdCl}_{2}$ ausgelöste Produktion von ROS und der damit verbundene oxidative Stress zur Akkumulation von SCL14 im Zellkern führt, wurden Arabidopsis Wurzeln mit $100 \mathrm{mM} \mathrm{NaCl}$ bzw. $250 \mu \mathrm{M} \mathrm{CdCl}_{2}$ behandelt.

Da unter diesen Bedingungen keine Änderung der Fluoreszenz in den Zellen zu erkennen ist (Abb. 4.7), kann gefolgert werden, dass es sowohl nach der Behandlung der Wurzeln mit $\mathrm{NaCl}$ als auch nach der Behandlung mit $\mathrm{CdCl}_{2}$ nicht zu einer Akkumulation von SCL14 im Zellkern kommt. 


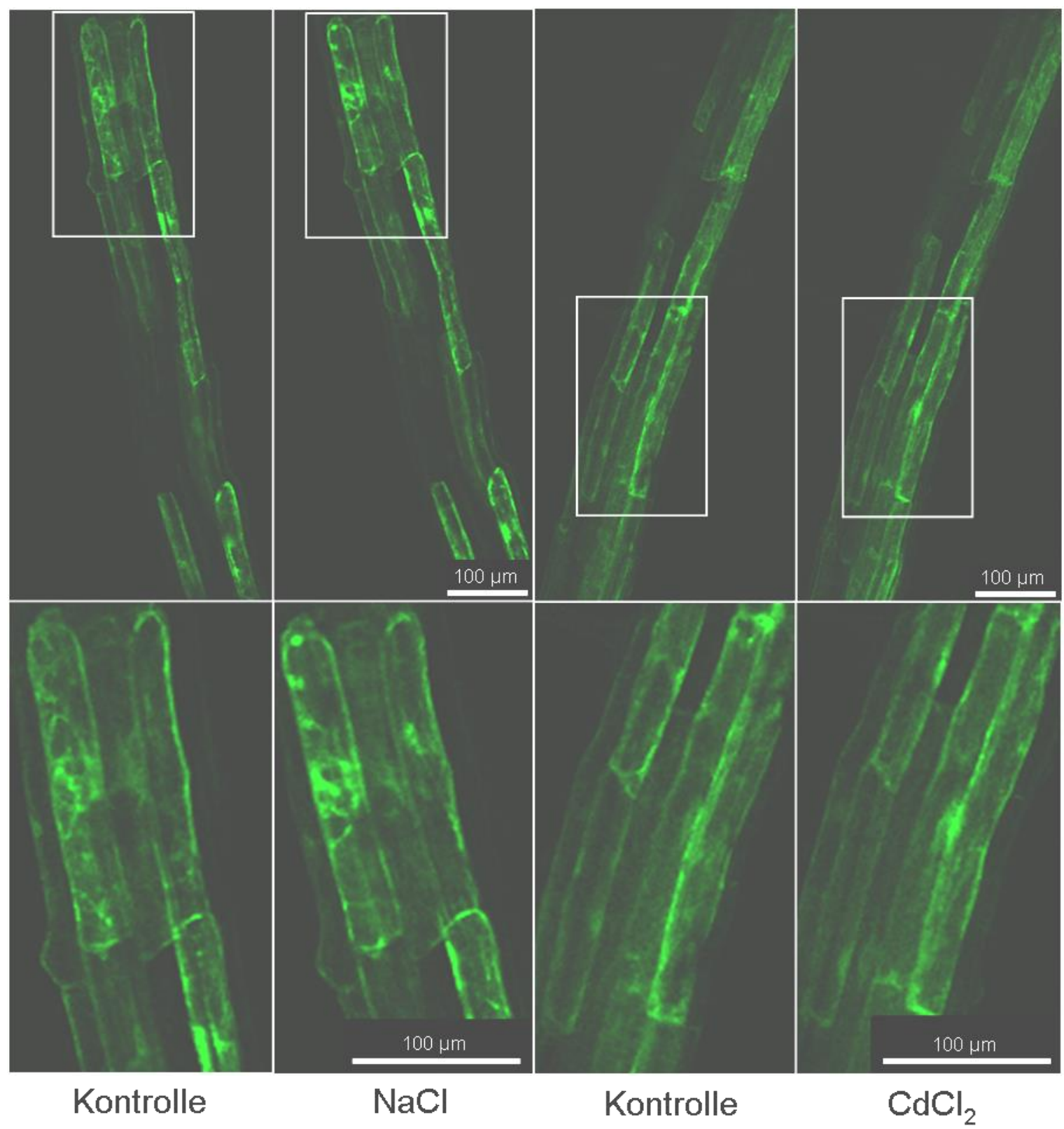

Abbildung 4.7: HA-GFP-SCL14 akkumuliert nicht in Zellkernen von Arabidopsis thaliana Wurzeln nach der Behandlung mit Natriumchlorid $(\mathrm{NaCl})$ und Cadmiumchlorid $\left(\mathrm{CdCl}_{2}\right)$.

10 Tage alte Pflanzen des Genotyps sc/14/33 35S:HA-GFP-SCL14 wurden mit $100 \mathrm{mM} \mathrm{NaCl}$ bzw. $250 \mu \mathrm{M} \mathrm{CdCl} 2$ Behandelt. Als Kontrolle diente Wasser. Die Anzucht der Pflanzen erfolgte steril auf mediumbeschichteten Objektträgern unter Langtagbedingungen. Die Kontrollbehandlung und die Chemikalienbehandlung erfolgten nacheinander an derselben Wurzel. Die Aufnahme der Fluoreszenzbilder erfolgte jeweils 30 min nach Beginn der Behandlung. Gezeigt ist ein repräsentatives Bild von zwei Replikaten. Die markierten Ausschnitte sind im unteren Bildteil vergrößert dargestellt. 


\subsubsection{Die Akkumulation von SCL14 im Zellkern ist 30 Minuten nach Beginn des Stimulus abgeschlossen}

Um die Kinetik der Akkumulation von SCL14 im Zellkern zu beobachten, wurde eine Wurzel mit $100 \mu \mathrm{M}$ TIBA behandelt. Über den Verlauf von 60 Minuten wurden im Abstand von fünf Minuten Bilder des gleichen Bereiches der Wurzel aufgenommen. Die erste Aufnahme erfolgte fünf Minuten nach Beginn der Behandlung. Die Fluoreszenz in den Zellkernen nimmt über die betrachtete Zeitdauer stetig zu (Abb. 4.8). Fünf Minuten nach Beginn des TIBA Stimulus ist noch keine Akkumulation der Fluoreszenz zu erkennen, jedoch ist bereits nach 10 Minuten eine Akkumulation sichtbar (A). Nach 20 bis 25 Minuten zeigt sich auch in weiteren Zellen ein deutlicher Anstieg der Fluoreszenz im Zellkern $(B+C)$, welcher sich bis 30 Minuten nach Beginn des Stimulus fortsetzt. Darüber hinaus ist keine weitere Zunahme der Fluoreszenz im Zellkern zu beobachten (Abb. 4.9). Die Akkumulation von SCL14 im Zellkern ist also nach etwa 30 Minuten abgeschlossen.

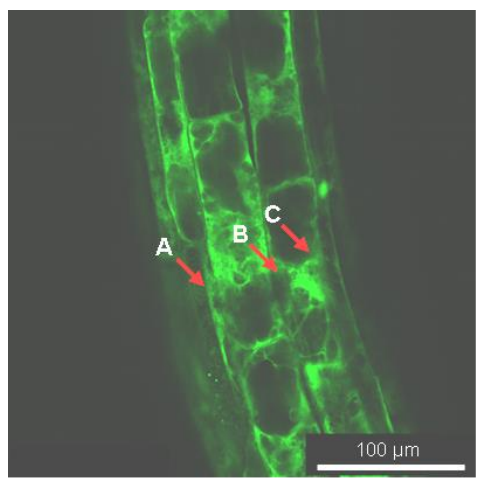

$5 \mathrm{~min}$

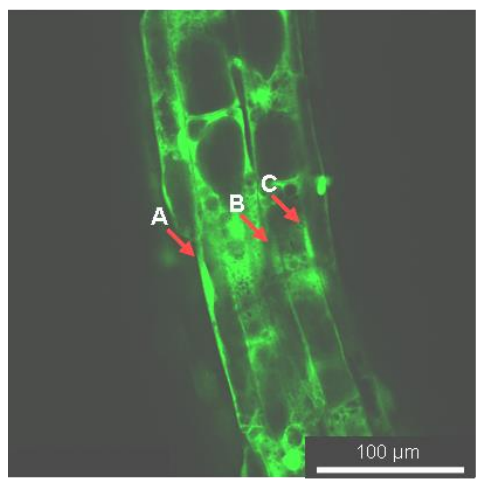

$20 \mathrm{~min}$

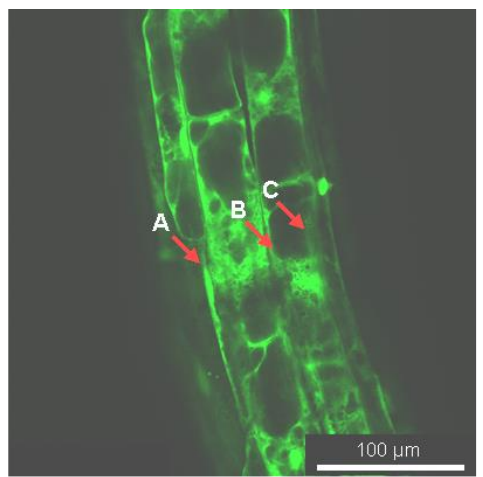

$10 \mathrm{~min}$

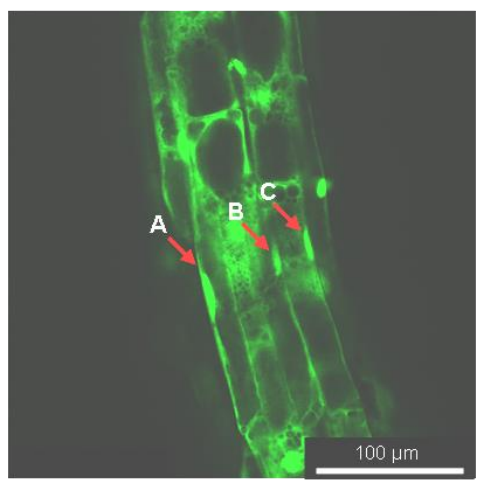

$25 \mathrm{~min}$

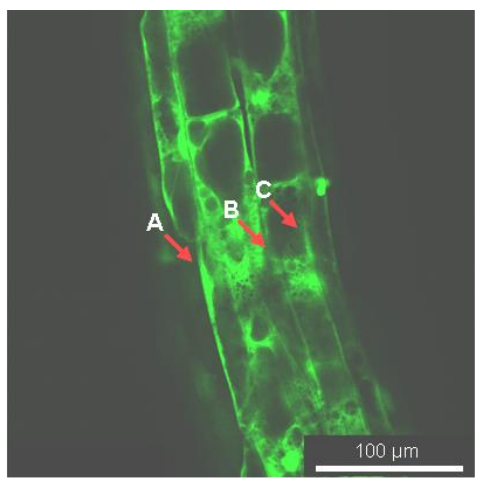

$15 \mathrm{~min}$

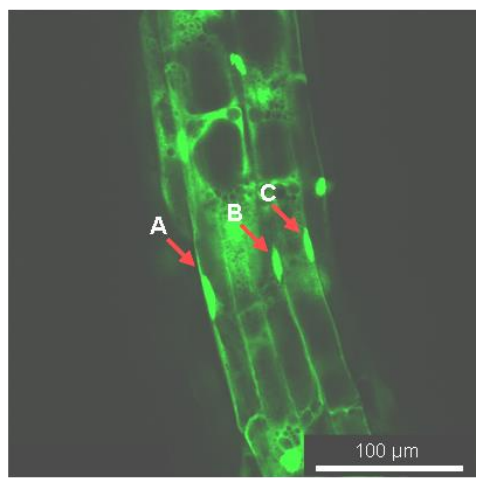

$30 \mathrm{~min}$

Abbildung 4.8: Die Akkumulation von HA-GFP-SCL14 im Zellkern nach TIBA Behandlung ist nach 30 Minuten abgeschlossen.

10 Tage alte Pflanzen des Genotyps sc/14/33 35S:HA-GFP-SCL14 wurden mit $100 \mu \mathrm{M}$ TIBA behandelt. Die Anzucht der Pflanzen erfolgte steril in Flüssigmedium in einer 12-Napf-Mikrotiterplatte. Die Aufnahme der Fluoreszenzbilder erfolgte an derselben Wurzel in Abständen von fünf Minuten über einen Zeitraum von 60 Minuten nach Beginn der TIBA Behandlung. Gezeigt ist ein repräsentatives Experiment von zwei unabhängigen Replikaten. 


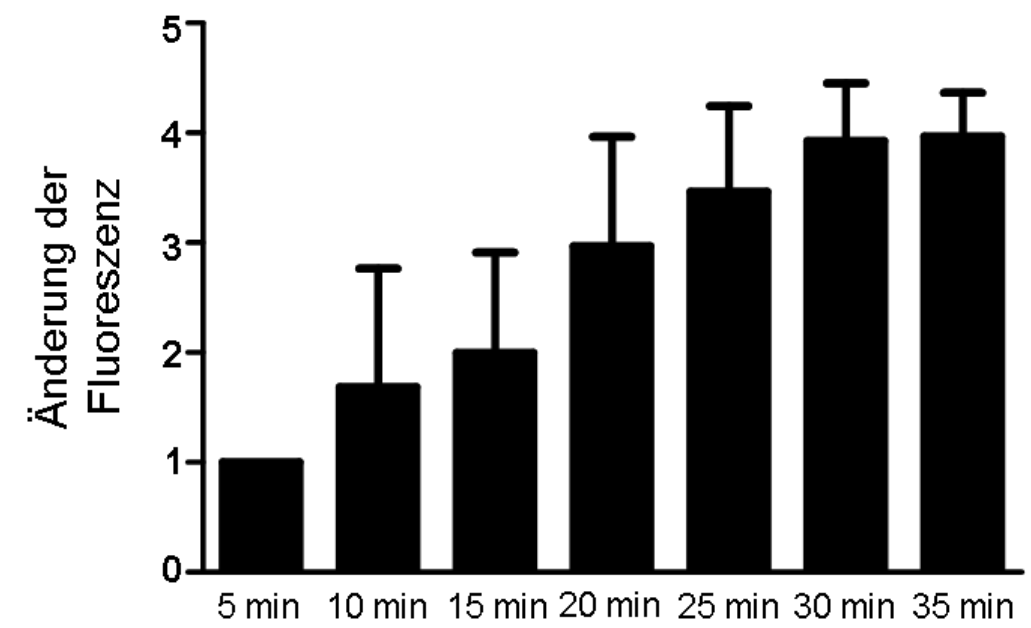

Abbildung 4.9: Zeitlicher Verlauf der Änderung der Fluoreszenz in Zellkernen von Arabidospsis Wurzeln.

Die Quantifizierung der Fluoreszenz erfolgte mit dem Programm ImageJ. Gezeigt ist die Änderung der Fluoreszenz in den in Abb. 1.8 markierten Zellkernen über den Verlauf von 35 Minuten nach TIBABehandlung (Mittelwert \pm SEM). Die Fluoreszenz in den Zellkernen fünf Minuten nach TIBABehandlung wurde als 1 definiert.

\subsubsection{Die Akkumulation von SCL14 im Zellkern ist unabhängig von den TGA-Transkriptionsfaktoren der Klasse II}

SCL14 interagiert mit dem bZIP Transkriptionsfaktor TGA2 und bildet mit diesem einen Aktivierungskomplex an den as-1-ähnlichen Elementen in den Promotoren der SCL14 Zielgene (Fode et al. 2008). Um zu überprüfen, ob diese Interaktion für die Akkumulation von SCL14 im Zellkern notwendig ist, wurde die tga256 Mutante mit dem HA-GFP-SCL14 Konstrukt transformiert. In dieser Mutante sind neben TGA2 auch die Gene der beiden anderen Klasse II TGA Transkriptionsfaktoren, TGA5 und TGA6, deletiert.

Die transgenen Pflanzen wurden mit SA und TIBA behandelt, um die Kernakkumulation des HA-GFP-SCL14 Fusionsproteins zu induzieren. Sowohl nach der Behandlung der Pflanzen mit SA als auch nach der Behandlung mit TIBA akkumuliert HA-GFP-SCL14 in den Zellkernen der Wurzeln (Abb.4.10). Die TGAFaktoren der Klasse II sind daher für die Akkumulation von SCL14 im Zellkern nicht erforderlich. 


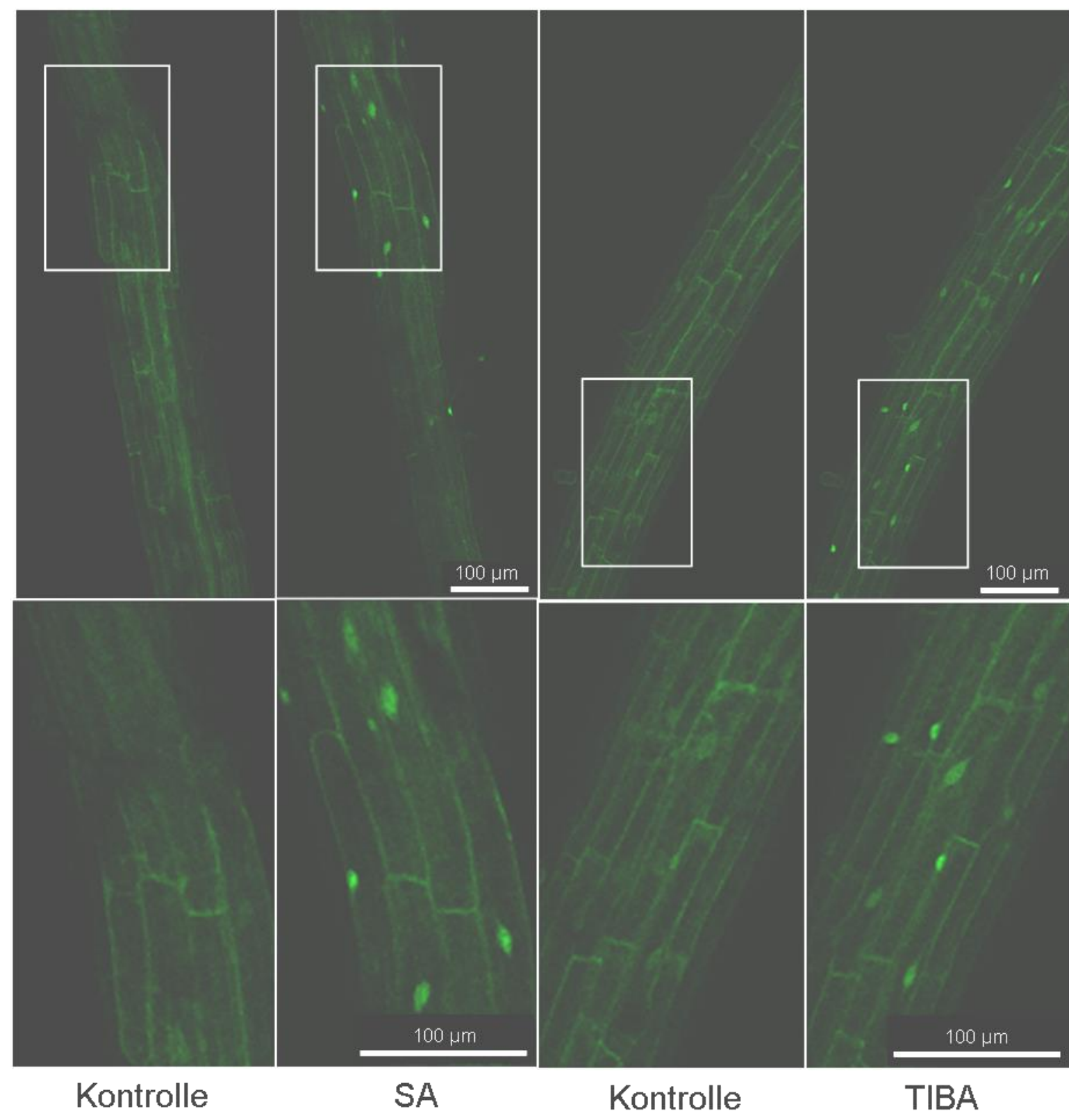

Abbildung 4.10: HA-GFP-SCL14 akkumuliert auch in Abwesenheit der Transkriptionsfaktoren TGA2, TGA5 und TGA6 nach der Behandlung mit SA und TIBA in Zellkernen von Arabidopsis thaliana Wurzeln.

10 Tage alte Pflanzen des Genotyps tga256 35S:HA-GFP-SCL wurden mit 1 mM SA bzw. $100 \mu \mathrm{M}$ TIBA behandelt. Als Kontrolle diente Wasser bzw. 0,2 \% DMSO. Die Anzucht der Pflanzen erfolgte steril auf mediumbeschichteten Objektträgern unter Langtagbedingungen. Die Kontrollbehandlung und die Chemikalienbehandlung erfolgten nacheinander an derselben Wurzel. Die Aufnahme der Fluoreszenzbilder erfolgte jeweils 30 min nach Beginn der Behandlung. Gezeigt ist ein repräsentatives Experiment von zwei unabhängigen Replikaten. 


\subsection{Cysteine spielen eine Rolle für die Aktivität von SCL14}

Eine Möglichkeit der Modifikation von Proteinen durch oxidativen Stress ist die Oxidation der Sulfhydrylgruppe der Aminosäure Cystein (siehe Abschnitt 2.1.4). Eine Oxidation eines oder mehrerer der in SCL14 vorhandenen Cysteine könnte einen Mechanismus darstellen, der für die beobachtete Akkumulation von SCL14 im Zellkern von Wurzelzellen verantwortlich ist. Ein Protein, welches auf diese Weise reguliert wird und welches an der Antwort auf oxidativen Stress beteiligt ist, ist ein bZIP Transkriptionsfaktor der Hefe, YEAST ACTIVATOR PROTEIN 1 (YAP1p). Unter oxidativen Bedingungen bildet YAP1p zwei intramolekulare Disulfidbrücken aus, die zu einer Konformationsänderung des Proteins führen, wodurch der Kernexport von YAP1p verhindert wird (Wood et al. 2003). Eine ähnliche Regulation von SCL14 ist denkbar.

\subsubsection{Die Cysteine C400 und C691 sind notwendig für die}

\section{transkriptionsaktivierende Funktion von SCL14}

Um zu untersuchen, ob Cysteine bei der Regulation von SCL14 von Bedeutung sind, wurden mutierte Varianten des Proteins hergestellt, in denen neun Cysteine (Abb. 4.11) jeweils gegen die Aminosäure Serin ausgetauscht wurden. Serin ist dem Cystein strukturell sehr ähnlich, wodurch die Sekundärstruktur des Proteins möglichst wenig beeinflusst werden soll, enthält in der Seitenkette statt eines Schwefelatoms jedoch ein Sauerstoffatom, welches nicht in gleicher Weise Reaktionen eingeht wie das Schwefelatom des Cysteins. Durch diese Mutationen soll ein Protein dargestellt werden, welches der Konformation eines reduzierten Proteins entspricht.

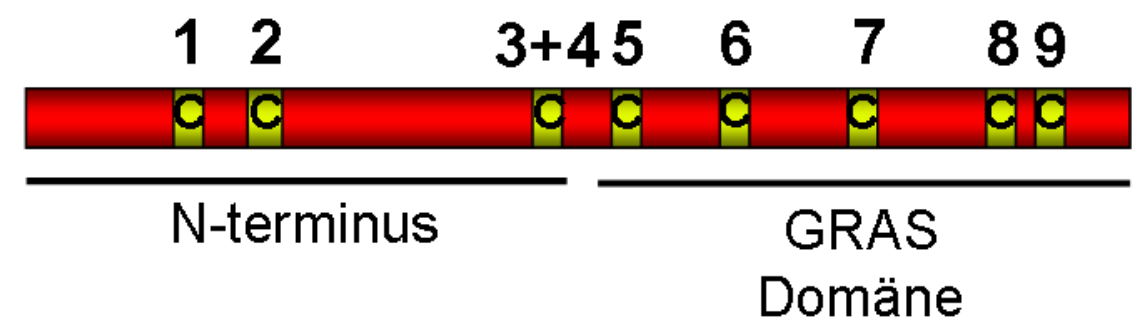

Abbildung 4.11: Schema des SCL14 Proteins mit der Anordnung der neun enthaltenen Cysteine.

1: C104; 2: C151; 3: C342; 4: C349; 5: C400; 6: C477; 7: C561; 8: C662; 9: C691

Die mutierten Proteine wurden als HA-Fusion transient in einem Protoplastensystem unter der Kontrolle des 35S-Promotors exprimiert und ihre Fähigkeit, den Promotor 
des Gens GSTU7 zu aktivieren, getestet. GSTU7 wurde von Fode et al. als Zielgen von SCL14 identifiziert (Fode et al. 2008). Der Promotor des Gens enthält ein as-1ähnliches Element, welches als Bindestelle für den SCL14/TGA-Komplex dienen kann.

Das SCL14 Wildtypprotein (SCL14) aktiviert in diesem System den GSTU7Promotor ohne weiteren Stimulus (Abb. 4.12). Die mutierten Proteine (C1S - C9S) zeigen in diesem System keine signifikante Abweichung in der Aktivierung des GSTU7-Promotors.

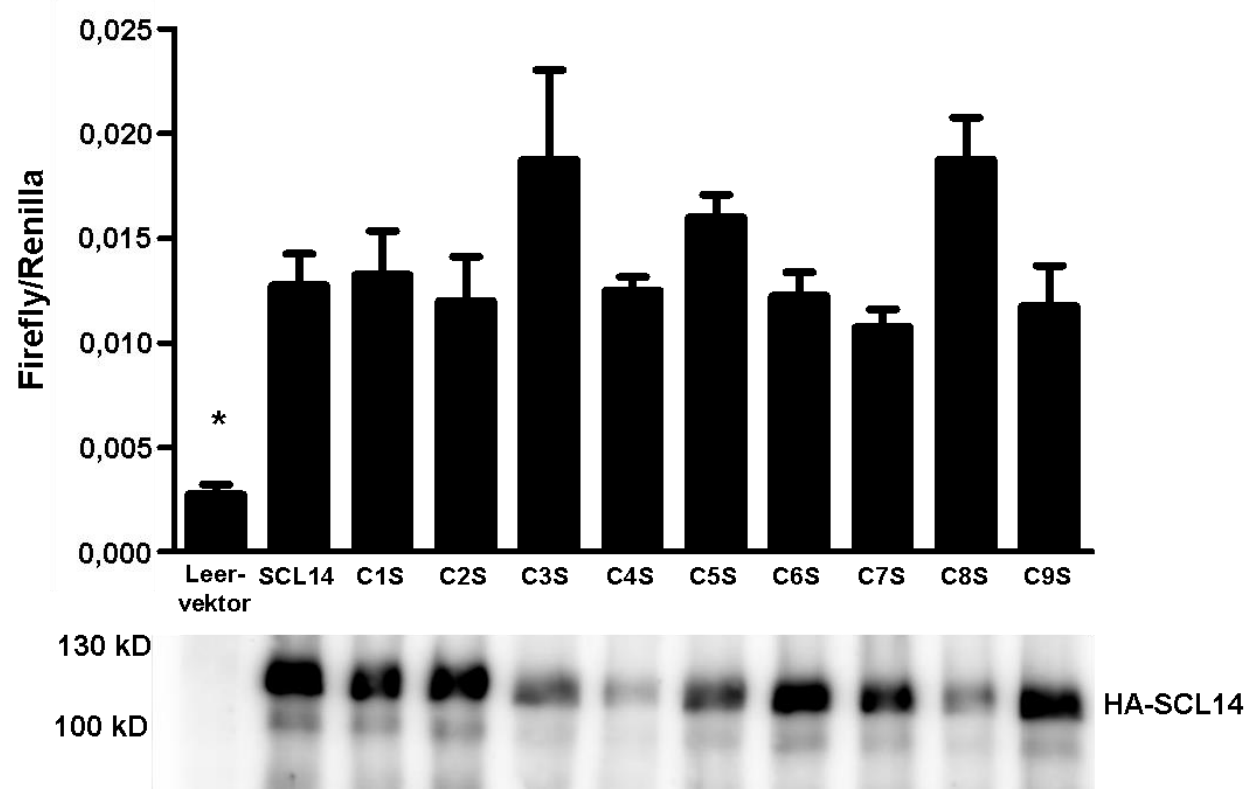

Abbildung 4.12: Der Austausch von einzelnen Cysteinen gegen Serine hat keinen Effekt auf die Fähigkeit von SCL14, den GSTU7 Promotor in Protoplasten zu aktivieren.

Protoplasten aus Blattgewebe von 4 Wochen alten Arabidopsis thaliana Pflanzen des Genotyps sc/14/33 wurden mit einer Firefly Luciferase unter der Kontrolle des GSTU7-Promotors und dem SCL14 Wildtypprotein bzw. den SCL14 Mutanten unter der Kontrolle des 35S-Promotors transformiert. Zur Normalisierung der Luciferasesignale diente eine Renillaluciferase unter der Kontrolle des UBQ10Promotors. Gezeigt ist der Mittelwert von 4 Replikaten ( \pm SEM) eines repräsentativen Experimentes. Sterne markieren einen signifikanten Unterschied in der Promotoraktivierung im Vergleich zur Promotoraktivierung durch SCL14 $\left({ }^{*}: p \leq 0,05,{ }^{* *}: p \leq 0,01,{ }^{* *}: p \leq 0,001\right.$; One-way ANOVA). Die Detektion des SCL14 Proteins im Western Blot erfolgte mit einem gegen SCL14 gerichteten Antikörper.

$\mathrm{Da}$ der Austausch von einzelnen Cysteinen gegen Serin keinen Effekt auf die Aktivität des SCL14 Proteins hat, wurden Mehrfachmutanten hergestellt und ebenfalls transient im Protoplastensystem exprimiert. Es wurden drei unterschiedliche Mutanten getestet. Bei einer wurden die vier im $\mathrm{N}-$ Terminus befindlichen Cysteine gegen Serine ausgetauscht (C1-4S), in den weiteren Mutanten wurden die fünf in der GRAS-Domäne befindlichen Cysteine (C5-9S), bzw. alle neun Cysteine (C1-9S) gegen Serine ausgetauscht. Der Austausch der vier N-terminalen 
Cysteine hat keinen Effekt auf die Aktivität von SCL14. Diese Mutante kann den GSTU7-Promotor in Protoplasten in gleichem Maße aktivieren wie das Wildtypprotein (Abb. 4.13). Im Gegensatz dazu führt die Mutation der fünf Cysteine der GRAS-Domäne zu einem vollständigen Verlust der Transkriptionsaktivatorfunktion von SCL14. Durch die Mutation aller neun Cysteine wird keine weitere Reduktion der Transkriptionsaktivatorfunktion von SCL14 hervorgerufen. Die für die Aktivität von SCL14 wichtigen Cysteine befinden sich daher innerhalb der GRASDomäne.

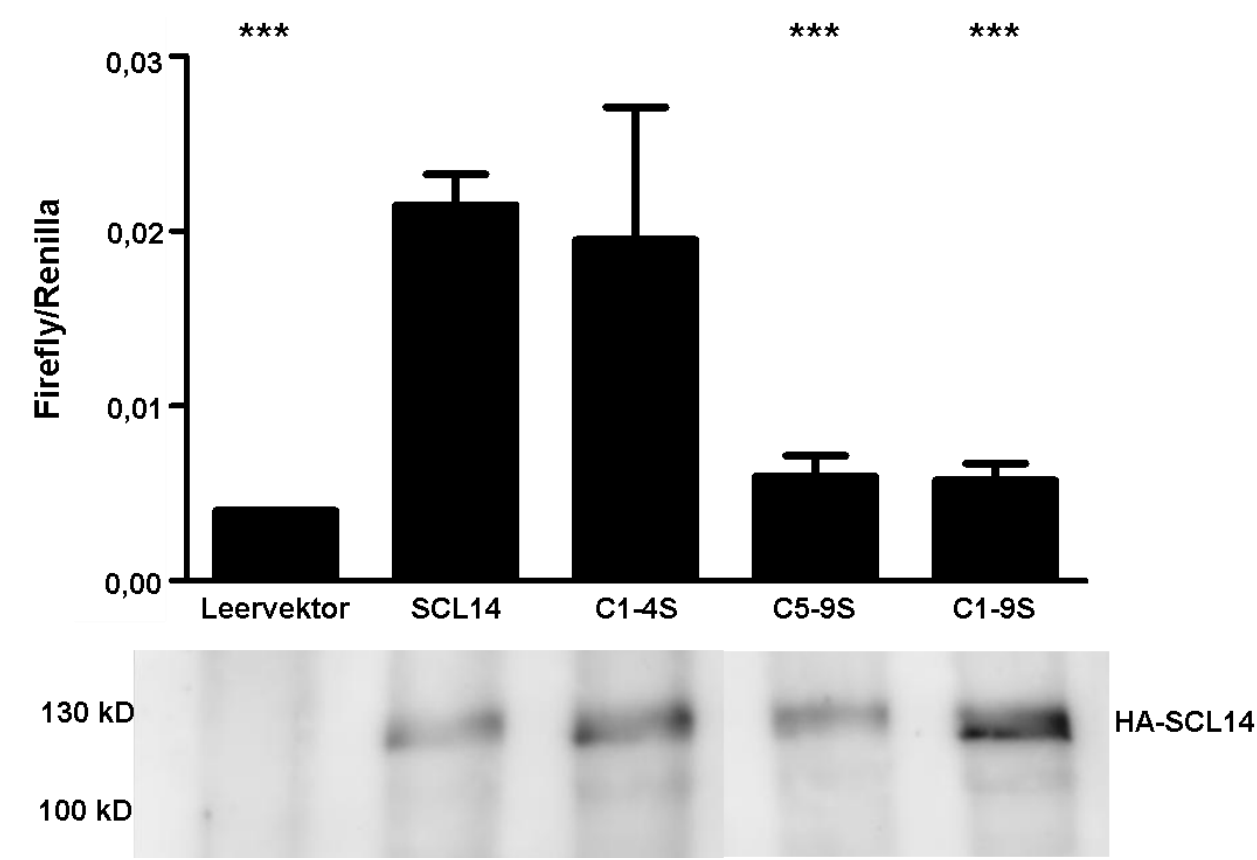

Abbildung 4.13: Die Mutation der Cysteine in der GRAS-Domäne von SCL14 beeinträchtigt die Fähigkeit des Proteins, den GSTU7-Promotor in Protoplasten zu aktivieren.

Protoplasten aus Blattgewebe von 4 Wochen alten Arabidopsis thaliana Pflanzen des Genotyps sc/14/33 wurden mit einer Firefly Luciferase unter der Kontrolle des GSTU7-Promotors und dem SCL14 Wildtypprotein bzw. der SCL14C1-4S-, der SCL14C5-9S- oder der SCL14C1-9S Mutante unter der Kontrolle des 35S-Promotors transformiert. Zur Normalisierung der Luciferasesignale diente eine Renilla Luciferase unter der Kontrolle des UBQ10-Promotors. Gezeigt ist der Mittelwert von 4 Replikaten ( \pm SEM) eines repräsentativen Experimentes. Sterne markieren einen signifikanten Unterschied in der Promotoraktivierung im Vergleich zur Promotoraktivierung durch SCL14 $\left(^{* * *}\right.$ : $\mathrm{p} \leq 0,001$; One-way ANOVA). Die Detektion des SCL14 Proteins im Western Blot erfolgte mit einem gegen SCL14 gerichteten Antikörper.

Um die für die Aktivität von SCL14 kritischen Cysteine weiter eingrenzen zu können, wurden Doppelmutanten hergestellt, bei denen jeweils zwei der Cysteine in der GRAS-Domäne gegen Serine ausgetauscht wurden. In einem ersten Test war eine leichte Verringerung der Promotoraktivierung bei den meisten Mutanten im Vergleich zum SCL14 Wildtypprotein zu beobachten. Jedoch zeigte lediglich die Mutante, bei der Cystein 5 und Cystein 9 gegen Serine ausgetauscht wurden $(C 5,9 S)$ einen vollständigen Verlust der Transkriptionsaktivatorfunktion (Abb. 4.14 A). In einem 
weiteren Experiment, in dem auch die beiden Mutanten C6,8S und C6,9S getestet wurden, ist die Aktivierung des GSTU7-Promotors durch SCL14 weniger stark ausgeprägt. Die beiden neuen Mutanten sind im Gegensatz zur C5,9S Mutante sogar stärker aktiv als das Wildtypprotein (Abb. 4.14 B). Daraus kann gefolgert werden, dass die gleichzeitige Mutation der Cysteine 6 und 8 bzw. der Cysteine 6 und 9 nicht zu einer Verringerung der Fähigkeit von SCL14 den GSTU7-Promotor zu aktivieren, führt.

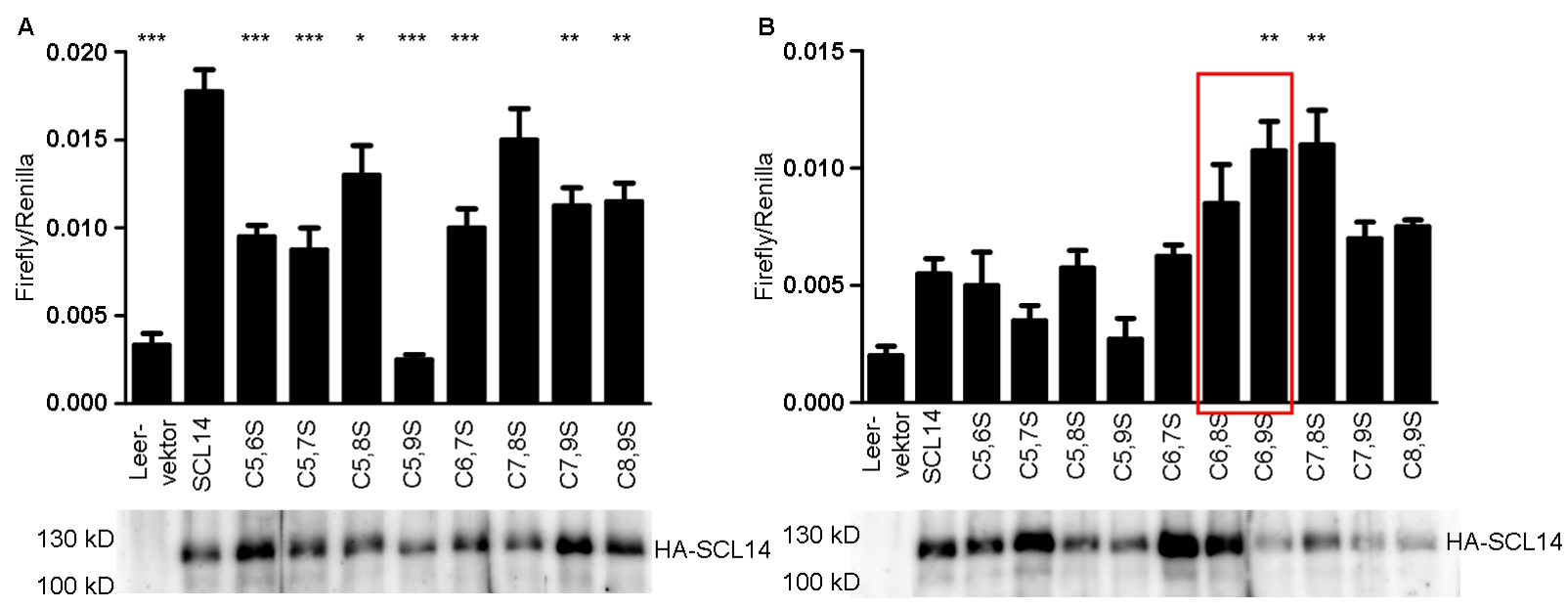

Abbildung 4.14: Die Doppelmutanten der Cysteine in der GRAS-Domäne von SCL14 verhalten sich, bis auf die C5,9S Mutante, in mehreren Experimenten nicht unterschiedlich in Bezug auf die Aktivierung des GSTU7-Promotors.

Protoplasten aus Blattgewebe von 4 Wochen alten Arabidopsis thaliana Pflanzen des Genotyps sc/14/33 wurden mit einer Firefly Luciferase unter der Kontrolle des GSTU7-Promotors und dem SCL14 Wildtypprotein bzw. der Doppelmutanten der Cysteine in der GRAS-Domäne (C6,7S und C6,8S nur in B (rote Markierung)) unter der Kontrolle des 35S-Promotors transformiert. Zur Normalisierung der Luciferasesignale diente eine Renilla Luciferase unter der Kontrolle des UBQ10Promotors. Gezeigt ist der Mittelwert von 4 Replikaten ( \pm SEM). Sterne markieren einen signifikanten Unterschied in der Promotoraktivierung im Vergleich zur Promotoraktivierung durch SCL14 $\left(^{*}: p \leq 0,05\right.$, ${ }^{* *}: p \leq 0,01,{ }^{* * *}: p \leq 0,001$; One-way ANOVA). Die Detektion des SCL14 Proteins im Western Blot erfolgte mit einem gegen SCL14 gerichteten Antikörper.

Der Funktionsverlust der C5,9S Mutante wurde in einem unabhängigen Experiment reproduziert (Abb. 4.15). 


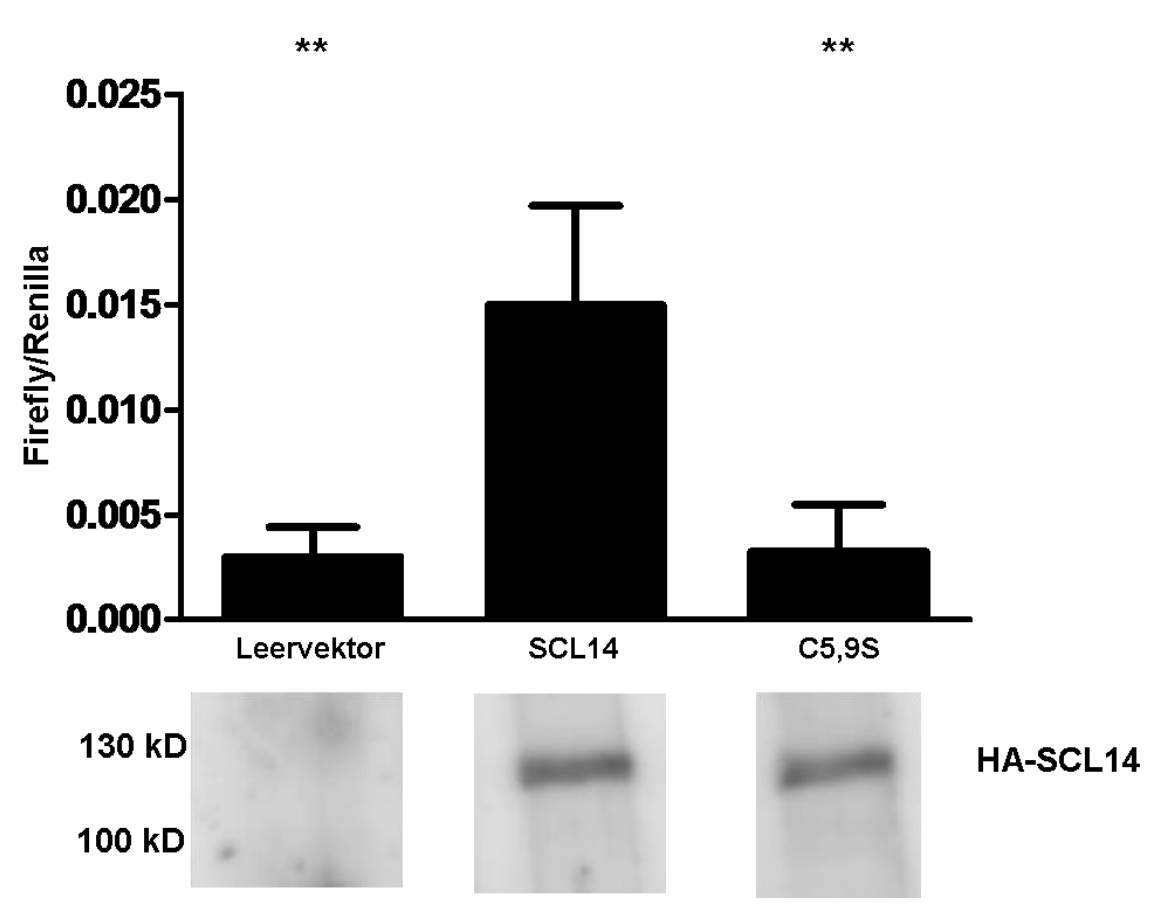

Abbildung 4.15: Die Cysteine C400 (C5) und C691 (C9) sind essentiell für die Fähigkeit von SCL14, den GSTU7-Promotor zu aktivieren.

Protoplasten aus Blattgewebe von 4 Wochen alten Arabidopsis thaliana Pflanzen des Genotyps sc/14/33 wurden mit einer Firefly Luciferase unter der Kontrolle des GSTU7-Promotors und dem SCL14 Wildtypprotein bzw. der SCL14C5,9S Mutante unter der Kontrolle des 35S-Promotors transformiert. Zur Normalisierung der Luciferasesignale diente eine Renilla Luciferase unter der Kontrolle des UBQ10-Promotors. Gezeigt ist der Mittelwert von 4 Replikaten ( \pm SEM) eines repräsentativen Experimentes. Sterne markieren einen signifikanten Unterschied in der Promotoraktivierung im Vergleich zur Promotoraktivierung durch SCL14 $\left(^{* *}\right.$ : $p \leq 0,01$; One-way ANOVA). Die Detektion des SCL14 Proteins im Western Blot erfolgte mit einem gegen SCL14 gerichteten Antikörper.

Aus diesen Ergebnissen folgt, dass die beiden Cysteine an Position 400 (C5) und an Position 691 (C9) wichtig für die die Transkription stimulierende Aktivität von SCL14 sind. Da beide Cysteine mutiert werden müssen, um einen Effekt auf die Aktivität von SCL14 zu erreichen, ist es unwahrscheinlich, dass eine Disulfidbrücke zwischen diesen beiden Aminosäuren ausgebildet wird. Auch die Ausbildung von zwei redundanten Disulfidbrücken ist unwahrscheinlich, da dann eine weitere Doppelmutante den gleichen Aktivitätsverlust hätte zeigen müssen, wie die C5,9SMutante. Wahrscheinlicher ist, dass eine andere oxidative Modifikation, wie zum Beispiel eine Sulphenierung oder eine Glutathionylierung, an einer der beiden Aminosäuren vorhanden sein muss. 


\subsubsection{Die Cysteine 400 (C5) und 691 (C9) sind essentiell für die Interaktion von SCL14 mit TGA2 und XPO1a}

Im Hefe-Zwei-Hybrid-System wurde die Interaktion der beiden SCL14 Mutanten SCL14C5,9S und SCL14C5-9S mit TGA2 und dem Kernexportrezeptor XPO1a getestet. Hiefür wurde der Hefestamm PJ69-4A mit Fusionsproteinen aus der GAL4 DNA-Bindedomäne mit TGA2 (BD-TGA2) beziehungsweise XPO1a (BD-XPO1a) und Fusionsproteinen aus der GAL4 Aktivierungsdomäne mit SCL14 (GAD-SCL14) beziehungsweise den beiden mutierten Proteinen (GAD-SCL14C5,9S; GADSCL14C5-9S) transformiert. Die Stärke der Interaktionen wurde in einem oNPG-Test gemessen (Abb. 4.16 A) und die Expression von SCL14, SCL14C5,9S und SCL14C5-9S mittels Westernblotanalyse überprüft (Abb. 4.16 B). Das SCL14 Wildtypprotein interagiert in diesem Experiment sowohl mit TGA2 als auch mit XPO1a. Den mutierten Proteinen ist jedoch die Fähigkeit zur Interaktion, sowohl mit TGA2 als auch mit XPO1a, verloren gegangen. Die Interaktion von SCL14 mit TGA2 und XPO1a findet jedoch nicht an der GRAS-Domäne, sondern ausschließlich am NTerminus von SCL14 statt (Fode et al. 2008)(J. Oberdiek; unveröffentlichte Daten). Daher scheint die Mutation der beiden Cysteine C400 und C691 eine starke Auswirkung auf die Konformation des Proteins zu haben, da hierdurch domänenübergreifend die Funktion des Proteins beeinflusst wird. 


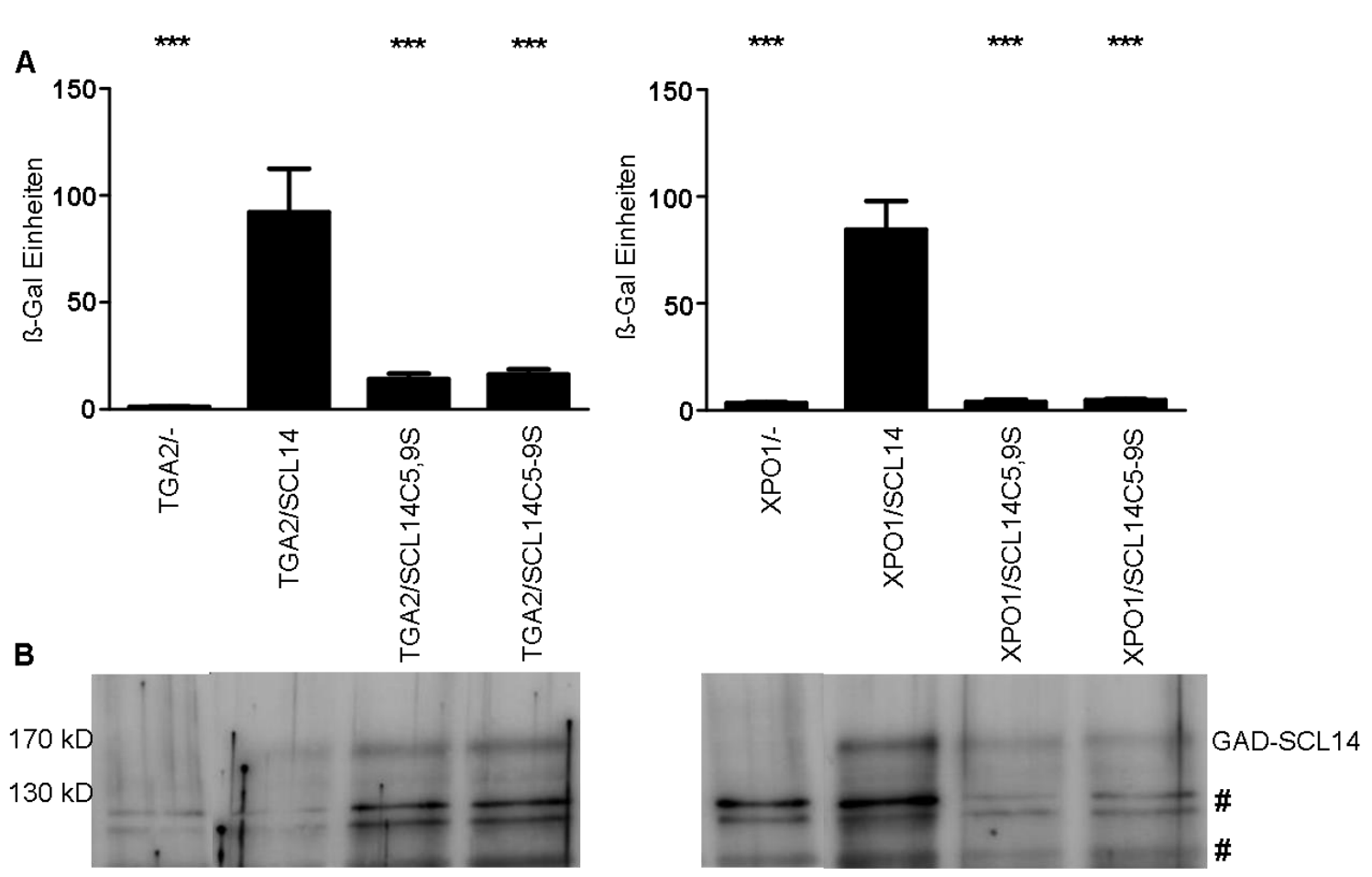

Abbildung 4.16: oNPG-Test zur Quantifizierung der Interaktion von SCL14, SCL14C5,9S und SCL14C5-9S mit TGA2 und XPO1a im Hefe-Zwei-Hybrid-System.

Die Transformation der Hefe erfolgte mit SCL14, SCL14C5,9S und SCL14C5-9S im Plasmid pDESTGAD sowie TGA2 bzw. XPO1a im Plasmid pDESTGBKT7. Gezeigt sind die Mittelwerte aus vier unabhängigen Hefeklonen ( \pm SEM). Sterne markieren einen signifikanten Unterschied in der B-Galaktosidaseaktivität im Vergleich zur B-Galaktosidaseaktivität in Hefen, transformiert mit SCL14 $\left(^{* * *}: p \leq 0,001\right.$; One-way ANOVA). Der Nachweis der SCL14 Varianten im Western Blot erfolgte mit einem gegen SCL14 gerichteten Antikörper. Die Rauten markieren unspezifische Banden, die sowohl in Proteinextrakten aus Transformierten als auch aus untransformierten Hefen auftreten.

\subsubsection{Die Cysteine C400 und C691 sind innerhalb der nächsten}

\section{Verwandten von SCL14 konserviert}

SCL14 wird phylogenetisch mit seinen nächsten Verwandten innerhalb der Familie der GRAS-Transkriptionsfaktoren SCL9, SCL11, SCL30, SCL31, SCL33a und SCL33b zum SCL9 Zweig zusammengefasst (Abb. 2.3). Bei einem Sequenzvergleich der Aminosäuresequenzen dieser Proteine wird deutlich, dass die beiden Cysteine, die sich im SCL14 Protein an den Positionen 400 und 691 befinden, in allen sieben Proteinen konserviert sind. Zusätzlich befinden sich beide Cysteine in einer konservierten Region (Abb. 4.17). In Sequenz 1 befinden sich an den Positionen +1 und +2 ein Alanin und ein Glutamin, in Sequenz 2 an Position +1 ein Glutamat. Zusätzlich befindet sich in Sequenz 1 an Position -3, relativ zum Cystein, ein konserviertes Leucin, in Sequenz 2 an Position +5 ein konserviertes Arginin. 
Möglicherweise sind neben den beiden Cysteinen auch die anderen konservierten Aminosäuren in diesen beiden Regionen für die Aktivität der Proteine notwendig.

\section{Sequenz 1}

$\begin{array}{llll}\text { SCL 9: } & 347 & \text { LLIHCAQAVA } & 356 \\ \text { SCL11: } & 227 & \text { LLTQCAQAVA } & 236 \\ \text { SCL14: } & 396 & \text { LLVLCAQAVS } & 405 \\ \text { SCL 30: } & 212 & \text { LLMQCAQAVA } & 221 \\ \text { SCL 31: } & 318 & \text { LLTLCAQSVS } & 327 \\ \text { SCL 33a: } & 321 & \text { MLVSCAQAVS } & 330 \\ \text { SCL 33b: } & 252 & \text { LLTHCAQAIS } & 261\end{array}$

\section{Sequenz 2}

$\begin{array}{llll}\text { SCL 9: } & 635 & \text { NVIACEGWER } & 644 \\ \text { SCL11: } & 520 & \text { SVISCEGAER } & 529 \\ \text { SCL1 4: } & 687 & \text { NNVACEGTER } & 696 \\ \text { SCL 30: } & 501 & \text { SVIACEGSER } & 510 \\ \text { SCL 31: } & 614 & \text { NVIACEGVDR } & 623 \\ \text { SCL 33a: } & 613 & \text { NVVACEGTER } & 622 \\ \text { SCL 33b: } & 549 & \text { NVIACEEADR } & 558\end{array}$

Abbildung 4.17: Aminosäureumgebung der beiden in allen Mitgliedern des SCL9 Zweiges konservierten Cysteine. Konservierte Aminosäuren sind in rot dargestellt.

\subsubsection{Die Cysteine in der GRAS-Domäne von SCL14 sind notwendig für die Akkumulation des Proteins im Zellkern}

Da die Cysteine in der GRAS-Domäne wichtig für die Aktivität von SCL14 sind, wurde überprüft, ob sich der Austausch dieser Aminosäuren auch auf die Akkumulation des Proteins im Zellkern nach chemischem Stress auswirkt. Hierfür wurden sc/14/33 Pflanzen mit einem HA-GFP-SCL14C5-9S Fusionsprotein unter der Kontrolle des 35S-Promotors transformiert. Die transgenen Pflanzen wurden mit LMB, SA und TIBA behandelt und mittels konfokaler Lasermikroskopie untersucht.

Die intrazelluläre Lokalisation von HA-GFP-SCL14C5-9S unterscheidet sich bereits im uninduzierten Zustand von der des Wildtypproteins. Während das Wildtypprotein teilweise bereits in den unbehandelten Wurzeln innerhalb der Zellkerne zu sehen ist (siehe Abbildungen in den Abschnitten 4.1.1 - 4.1.6), kann diese Beobachtung für die Mutante nicht gemacht werden. Weiterhin erfolgt keine Akkumulation von HAGFP-SCL14C5-9S nach der Behandlung der Pflanzen mit $2 \mu \mathrm{M}$ LMB, 1 mM SA oder $100 \mu \mathrm{M}$ TIBA (Abb. 4.18). Die Akkumulation des mutierten Proteins kann also weder durch die Inhibition des Kernexports durch LMB, noch durch die Wirkung von SA oder TIBA induziert werden. Dies lässt, zusammen mit der Beobachtung, dass keine basalen Mengen von HA-GFP-SCL14C5-9S im Zellkern vorhanden zu sein scheinen, den Schluss zu, dass sich die Mutation der Cysteine in der GRAS-Domäne bereits 
auf den Kernimport auswirkt. Offensichtlich ist das die reduzierte Form repräsentierende SCL14 in allen getesteten Funktionen inaktiv.

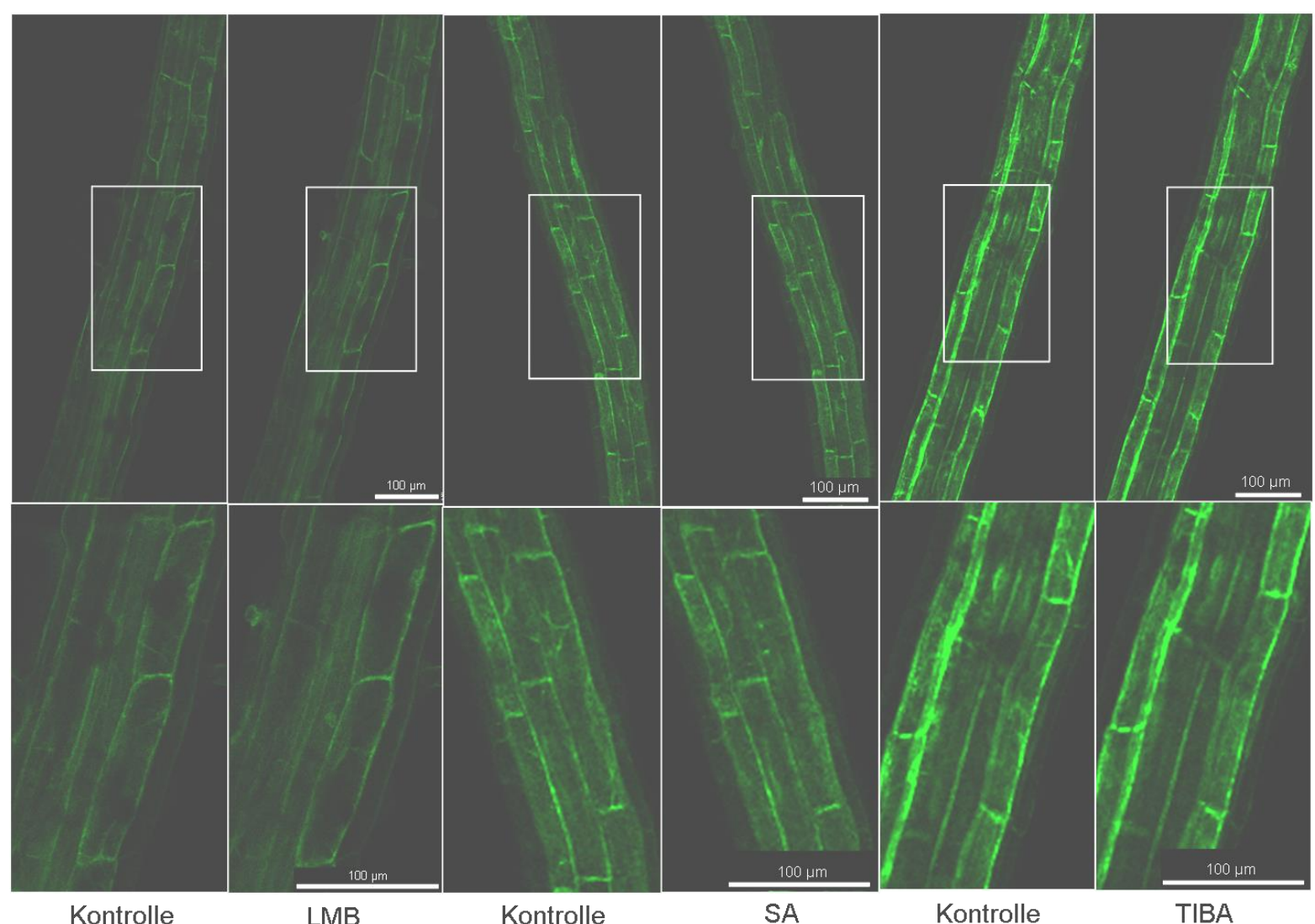

Abbildung 4.18: HA-GFP-SCL14C5-9S akkumuliert nach chemischem Stimulus nicht im Zellkern von Arabidopsis thaliana Wurzelzellen.

10 Tage alte Pflanzen des Genotyps sc/14/33 35S:HA-GFP-SCLC5-9S wurden mit $2 \mu \mathrm{M}$ LMB, $1 \mathrm{mM}$ SA bzw. $100 \mu \mathrm{M}$ TIBA behandelt. Als Kontrolle diente 0,2\% EtOH, Wasser bzw. 0,2\% DMSO. Die Anzucht der Pflanzen erfolgte steril auf mediumbeschichteten Objektträgern unter Langtagbedingungen. Die Kontrollbehandlung und die Chemikalienbehandlung erfolgten nacheinander an derselben Wurzel. Die Aufnahme der Fluoreszenzbilder erfolgte jeweils 30 min nach Beginn der Behandlung. Gezeigt ist ein repräsentatives Experiment von zwei unabhängigen Replikaten. Die markierten Ausschnitte sind im unteren Bildteil vergrößert dargestellt. 


\subsection{Analyse und Identifikation von SCL14 Zielgenen in Wur- zeln von Arabidopsis thaliana nach chemischem Stress}

Im Verlauf dieser Arbeit konnte gezeigt werden, dass nach der Behandlung von Arabidopsis Pflanzen mit SA und TIBA eine Akkumulation von SCL14 im Zellkern von Wurzeln stattfindet, während dies nach der Behandlung mit MeJA nicht der Fall ist (Abschnitt 4.1). Um die biologische Relevanz dieser Akkumulation zu untersuchen, wurde die Wirkung von SA, TIBA und MeJA auf die Expression von SCL14 Zielgenen mittels quantitativer RealTime PCR (qRT-PCR) untersucht. Außerdem wurde eine Microarray Analyse mit SA-behandelten Wildtyp- und scl14/33-Pflanzen durchgeführt, um neue Zielgene von SCL14 zu finden.

\subsubsection{Die Aktivierung des SCL14 Zielgenes GSTU7 erfolgt in Wurzeln von Arabidopsis durch SA und TIBA}

Bei den bisher untersuchen Zielgenen von SCL14 handelt es sich um Gene, die im Prozess der Detoxifikation giftiger Substanzen eine Rolle spielen, wie Cytochrom P450 Monooxygenasen, Glutathion S-Transferasen (GSTs) oder UDPGlycosyltransferasen (UGTs). Diese Gene, wie beispielsweise die Glutathion $S$ Transferase GSTU7, werden durch die Einwirkung von Xenobiotika wie TIBA in Blättern SCL14-abhängig aktiviert (Fode et al. 2008). In dieser Arbeit konnte gezeigt werden, dass die SCL14-abhängige Aktivierung von GSTU7 auch in Wurzeln durch TIBA sowie durch SA und JA erfolgt (Abb. 4.19). Allerdings scheint SCL14 in Wurzeln bei der Aktivierung dieser Gene nicht der hauptsächliche Regulator zu sein, sondern nur verstärkende Funktion zu haben, da auch in der sc/14/33 Doppelmutante eine Aktivierung von GSTU7 nach der Behandlung der Pflanzen mit SA oder TIBA zu beobachten ist. Zwar ist die absolute Expression der Gene, sowohl im uninduzierten als auch im induzierten Zustand, geringer als im Wildtyp, die relative Stärke der Induktion ist jedoch in beiden Genotypen gleich. 
A

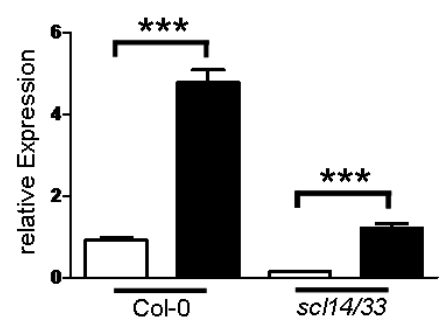

C

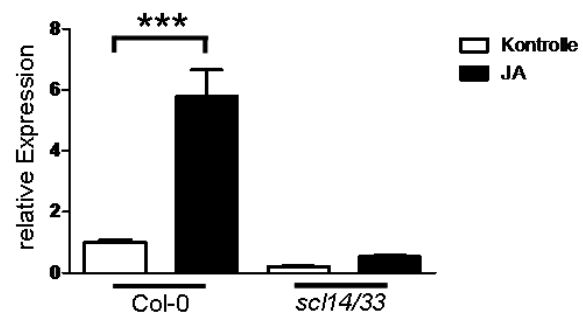

B GSTU7

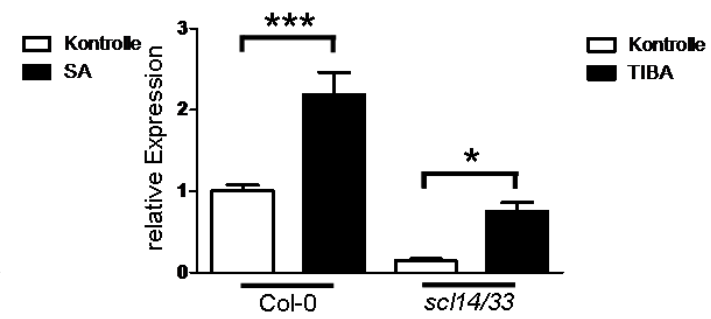

Abbildung 4.19: Expression des SCL14 Zielgens GSTU7 nach SA-, TIBA- und JA-Behandlung Die Behandlung mit $1 \mathrm{mM} \mathrm{SA}, 100 \mu \mathrm{M}$ TIBA bzw. $50 \mu \mathrm{M}$ JA erfolgte für vier Stunden an 10 Tage alten, in hydroponischen Kulturen unter Langtagbedingungen angezogenen Pflanzen. Die relativen Transkriptmengen von GSTU7 wurden mittels qRT-PCR bestimmt. Die Extraktion der RNA erfolgte aus Wurzelmaterial. Zur Normalisierung der Expression diente UBQ5. Die mittlere relative Expression der Wildtyp Kontrolle wurde gleich 1 gesetzt. Gezeigt sind die Mittelwerte von $13-15$ Hydroponikkulturen ( \pm SEM) aus drei unabhängigen Experimenten. $\left({ }^{* * *}: p \leq 0,001\right.$; One-way ANOVA)

Um Gene zu finden, deren induzierbare Expression SCL14-abhängig ist, das heißt Gene, deren basale Expression in der Mutante, im Vergleich zum Wildtyp, nicht reduziert ist und die in der Mutante nicht induziert werden, wurde eine Microarray Analyse durchgeführt. Für diese Analyse wurden Pflanzen der Genotypen Col-0 und sc/14/33 für 10 Tage in hydroponischen Kulturen unter Langtagbedingungen angezogen und für eine Stunde mit $1 \mathrm{mM}$ SA behandelt. Dieses Experiment wurde dreimal unabhängig wiederholt. Aus dem geernteten Wurzelmaterial wurde RNA für die Analyse extrahiert. Die Durchführung der Microarray Analyse erfolgte durch das Transkriptomanalyselabor der Universität Göttingen. Es wurde der GeneChip ${ }^{\circledR}$ Gene 1.0 ST der Firma Affymetrix verwendet. 


\subsubsection{Microarray-Analyse der Expression von SCL14 Zielgenen in Wurzeln nach Behandlung mit SA}

Die Expressionsmuster der Gene, die durch SA in einem der beiden Genotypen Col-0 oder sc/14/33 mindestens zweifach $(p \leq 0,05)$ induziert oder reprimiert wurden, erfolgte mit dem Programm MarVis (Kaever et al. 2009). Das Computer Programm MarVis gruppiert Gene mit ähnlichem Expressionsmuster in Prototypen ein und kodiert farblich die relative Expression der Gene unter den unterschiedlichen Bedingungen. Die funktionelle Einordnung erfolgte anhand von Genontologien mit agriGO (Du et al. 2010). Durch SA wurde die Expression von 516 Genen in mindestens einem der beiden Genotypen positiv oder negativ beeinflusst (Anhang Tab. 6.6). Diese Gene ließen sich nach der Analyse mit MarVis anhand ihres Expressionsmusters in sieben Gruppen einteilen (A-G; Abb. 4.20).

Die erste Gruppe (A) enthält 64 Gene, deren Expression in Col-0 durch SA induziert wurde, in der sc/14/33 Mutante jedoch nicht. Hier finden sich viele Gene, die der zweiten Stufe des pflanzlichen Detoxifikationssystems zugeordnet werden können, wie GSTs und UGTs. Ebenso wurden das Glutaredoxin ROXY19, welches mit TGAFaktoren interagiert, als auch mehrere NAC-Transkriptionsfaktoren in diese Gruppe eingeordnet. Darunter die beiden NAC-Faktoren ATAF1 und NAC032, welche bereits von Fode et al. als Zielgene von SCL14 identifiziert werden konnten (Fode et al. 2008) und die von Neena Ratnakaran in ihrer Doktorarbeit als an der Regulation des Detoxifikationsprogrammes beteiligte Transkriptionsfaktoren identifiziert werden konnten (Ratnakaran 2014). Zwei weitere Gene des pflanzlichen Detoxifikationsprogrammes, die in diese Gruppe eingeordnet wurden, sind die Oxophytodiensäure Reduktasen 1 und 2 (OPR1 und OPR2). Für diese beiden Enzyme konnte eine Funktion bei der Entgiftung des Xenobiotikums 2,4,6Trinitrotoluol (TNT) nachgewiesen werden (Beynon et al. 2009).

In der zweiten Gruppe (B) finden sich Gene, die sowohl im Wildtyp als auch in der Mutante durch SA gleichermaßen induziert werden, deren Expression daher nicht abhängig von SCL14 oder SCL33 ist. In dieser Gruppe fand sich keine signifikante Anreicherung von Genen, die einer bestimmten Genontologie zugeordnet werden konnten.

In die dritten Gruppe (C) wurden neun Gene eingeordnet, die im Wildtyp durch SA induziert wurden und in der Mutante sowohl im unbehandelten Zustand als auch nach der SA-Behandlung so stark exprimiert wurden wie im Wildtyp nach SA- 
Behandlung. In dieser Gruppe finden sich mit einem HSP20-ähnlichen Gen (AT5G51440), COX19 und HSP70 Gene, die an der Antwort auf toxischen bzw. oxidativen Stress und Hitzestress beteiligt sind (Chen et al. 2003; Attallah et al. 2007; Sung et al. 2001).

Die vierte Gruppe (D) enthält 50 Gene, die in der sc/14/33 Mutante im Vergleich zum Wildtyp nach SA Behandlung hyperinduziert waren. Hierunter finden sich unter anderem acht Gene aus der Familie der WRKY-Transkriptionsfaktoren und Gene, die in die Pathogenabwehr involviert sind, wie NIM INTERACTING 1 (NIMIN1) (Weigel et al. 2005) und LEGUME LECTINE-LIKE PROTEIN1 (LLP1) (Breitenbach et al. 2014). Die fünfte Gruppe (E) enthält acht, ausschließlich chloroplastidäre, Gene, von denen es sich bei sechs um tRNAs handelt. Diese Gene werden im Wildtyp durch SA reprimiert, in der Mutante jedoch nicht.

Die sechste Gruppe (F) enthält zwei Gene, die im Wildtyp durch SA reprimiert und in der Mutante durch SA induziert wurden. Hierbei handelt es sich um ein Gen unbekannter Funktion (AT2G16200) und um COP1 INTERACTING PROTEINRELATED.

Die siebte Gruppe $(G)$ enthält 265 Gene, deren Expression in beiden Genotypen durch SA unterdrückt wurde und von denen etwa 10\% an der Entwicklung und der Morphogenese der Wurzel beteiligt sind.
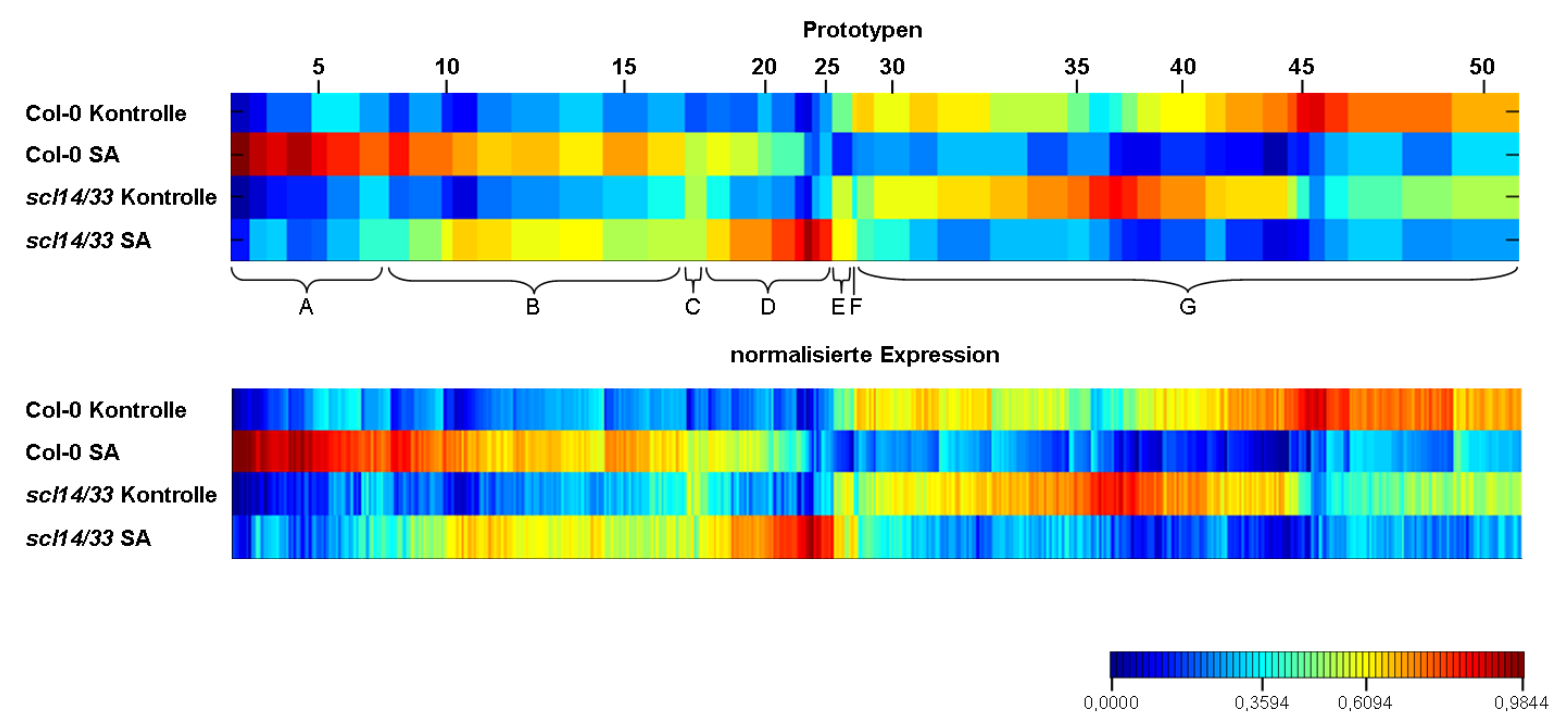

Abbildung 4.20: MarVis Analyse der von SA beeinflussten Gene in den Arabidopsis thaliana Genotypen Col-0 und sc/14/33.

Der obere Teil der Abbildung zeigt die Einteilung der Gene in 50 Prototypen, entsprechend ihres normalisierten Expressionsmusters. Die Breite jedes Prototyps ist proportional zu der darin enthaltenen Anzahl an Genen. Der untere Teil der Abbildung zeigt die normalisierte Expression der einzelnen Transkripte. Eine rote Färbung zeigt eine starke Expression an, eine blaue Färbung eine schwache Expression. 
Die Gene, deren Expression in Col-0 oder in der sc/14/33 Mutante durch SA mindestens zweifach induziert wurde $(p \leq 0,05)$, wurden einer weiteren Analyse unterzogen. In Col-0 waren 202 Gene nach SA Behandlung mindestens zweifach induziert $(\mathrm{p}<0,05)$, in der sc/14/33 Mutante waren dies 107 Gene (Anhang Tab. 6.4 und 6.5). 71 Gene waren in beiden Genotypen induziert. Somit sind in dieser Microarray Analyse 131 Gene SCL14- und SCL33-abhängig durch SA induziert (Abb. 4.21).

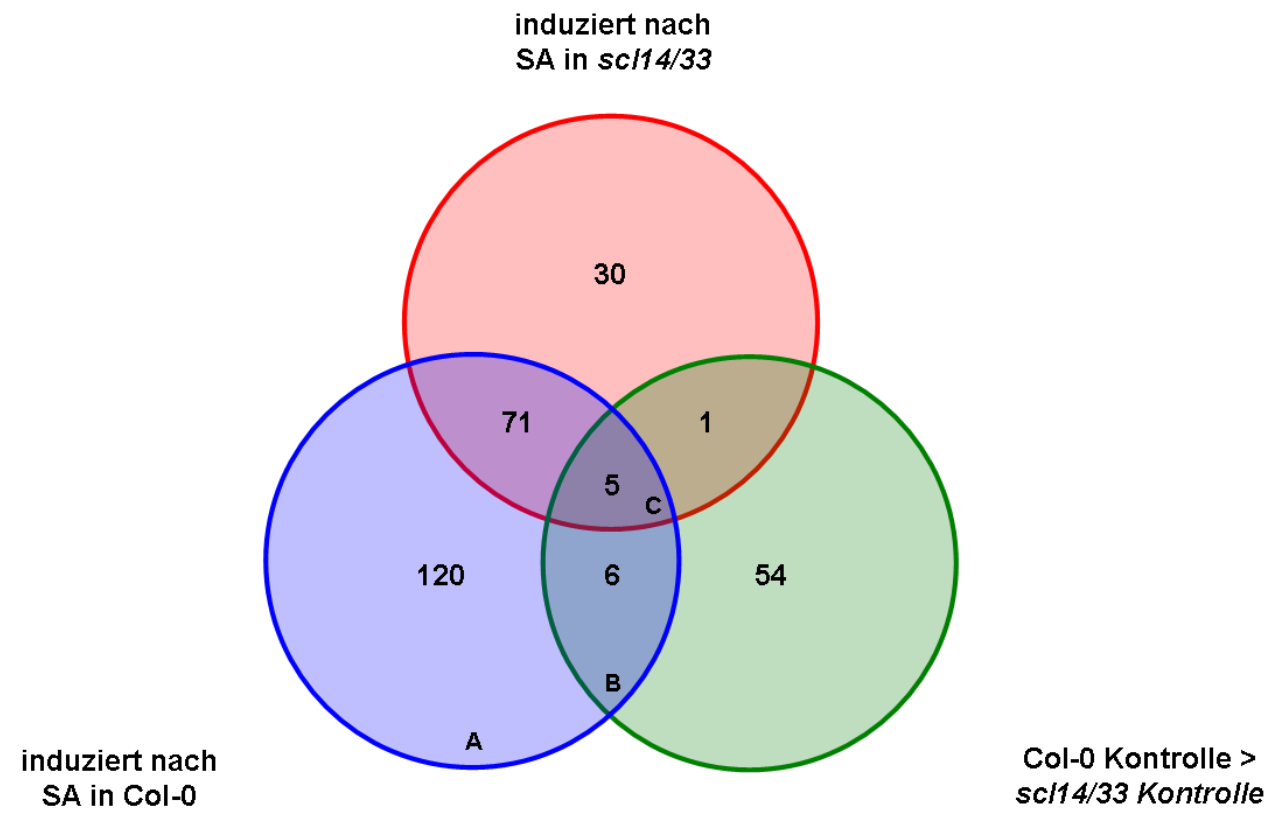

Abbildung 4.21: Venn Diagramm der in Col-0 und in der sc/13/44 Mutante nach SA Behandlung induzierten Gene.

Dargestellt sind die nach SA Behandlung im Wildtyp (induziert nach SA in Col-0) und in der sc/14/33 Mutante (induziert nach SA in sc/14/33) induzierten Gene, sowie die Gene, deren basale Expression im Wildtyp höher ist als in der Mutante (Col-0 Kontrolle > sc/14/33 Kontrolle). In Feld A befinden sich die in Gruppe 1 eingeordneten Gene und in den Feldern B und C die in Gruppe 2 eingeordneten.

Die SA-induzierten Gene können, sowohl in Col-0 als auch in der sc/14/33 Mutante, in zwei Gruppen unterteilt werden. Eine Gruppe wird von 120 Genen (Anhang Tab. 6.1) gebildet, deren Expression sich in Col-0 und in der Mutante im uninduzierten Zustand nicht unterscheidet (Gruppe 1). Die zweite Gruppe umfasst 11 Gene (Anhang Tab. 6.2), deren basale Expression in der sc/14/33 Mutante gegenüber dem Wildtyp reduziert ist (Gruppe 2). In dieser Gruppe finden sich Glutathion STransferasen, UDP-Glycosyltransferasen und Transkriptionsfaktoren aus der NACGenfamilie. Die Gruppe enthält sowohl Gene, die nur in Col-0 induziert sind, als auch Gene, die in Col-0 und der sc/14/33 Mutante induziert sind. Generell können die Gene der Gruppe 1 als strikt SCL-abhängig bezeichnet werden, da in der sc/14/33 
Mutante keine Induktion der Gene nach SA-Behandlung zu beobachten ist. Für die Gene der Gruppe 2 hingegen fungiert SCL14 lediglich als Verstärker der Expression, da eine SA-Induktion auch in der sc/14/33 Mutante stattfindet und lediglich die absolute Höhe der Expression verringert ist. Bei 54 weiteren Genen war die Expression in der Mutante im uninduzierten Zustand im Vergleich zum Wildtyp ebenfalls reduziert, jedoch fand bei diesen Genen in keinem der beiden Genotypen eine Induktion durch SA statt (Anhang Tab. 6.3).

Die Expression von je zwei repräsentativen Genen aus den Gruppen 1 und 2 nach SA-Behandlung ist in Abb. 4.22 dargestellt. Diese Gene wurden auch für weitere Genexpressionsanalysen mittels quantitativer Realtime PCR verwendet.

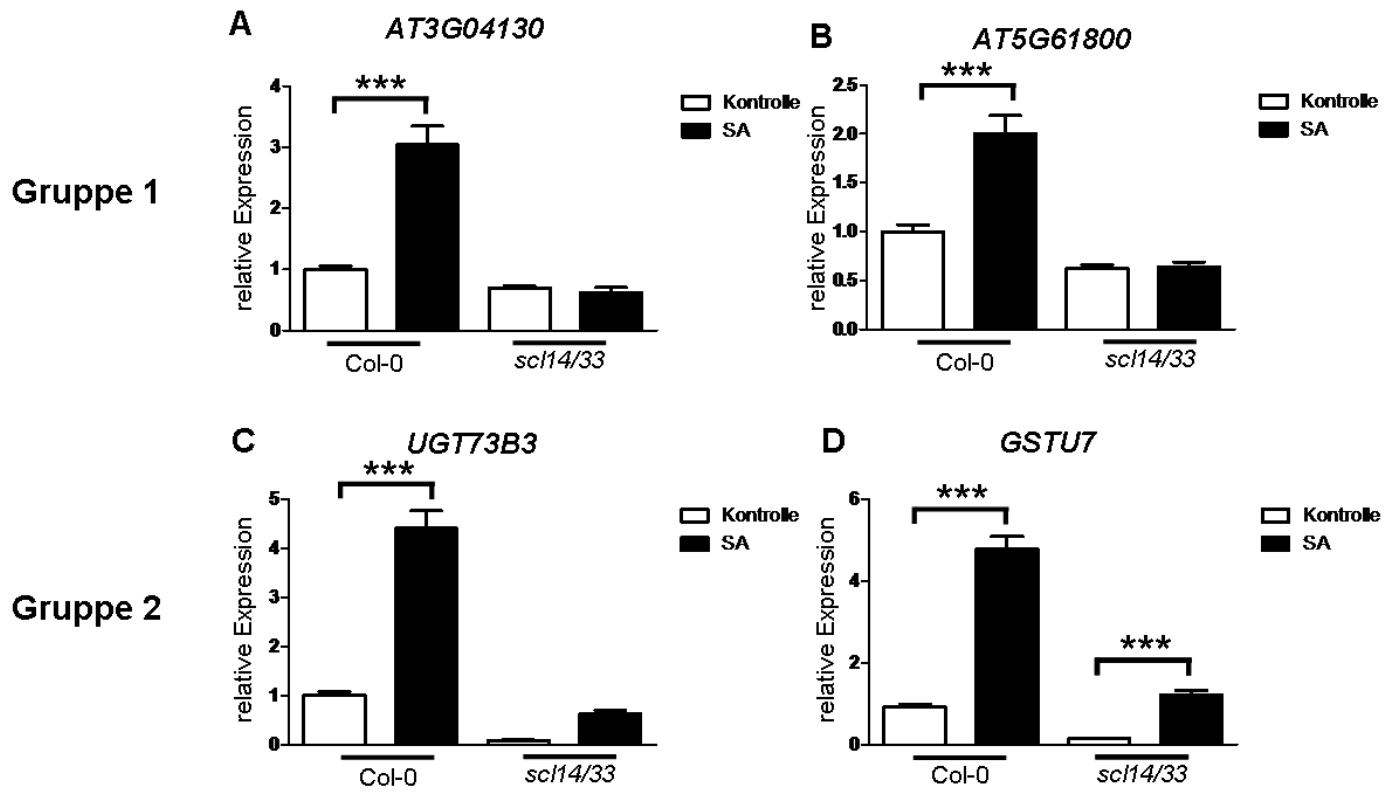

\begin{abstract}
Abbildung 4.22: Expression der SCL14 Zielgene AT3G04130, AT5G61800 UGT73B3 und GSTU7 in Wurzeln nach SA Behandlung.

Die Gene der Gruppe 1 können als strikt SCL14-abhängig bezeichnet werden, da ihre basale Expression in der sc/14/33 Mutante im Vergleich zum Wildtyp nicht reduziert ist und keine Induktion der Genexpression in der Mutante erfolgt (A+B). Für die Gene der Gruppe 2 stellt SCL14 lediglich einen Verstärker der Expression dar, da die Expression dieser Gene auch in der Mutante induziert wird und lediglich die absolute Höhe der Expression verringert ist $(C+D)$.

Die Behandlung mit $1 \mathrm{mM}$ SA erfolgte für vier Stunden an 10 Tage alten, in hydroponischen Kulturen unter Langtagbedingungen angezogenen Pflanzen. Die relativen Transkriptmengen von AT4G04130, AT5G61800, UGT73B3 und GSTU7 wurden mittels qRT-PCR bestimmt. Zur Normalisierung der Expression diente UBQ5. Die mittlere relative Expression der Wildtyp Kontrolle wurde gleich 1 gesetzt. Gezeigt sind die Mittelwerte von 13 - 15 Hydroponikkulturen ( \pm SEM) aus drei unabhängigen Experimenten. $\left({ }^{* * *}\right.$ : $p \leq 0,001$; One-way ANOVA)
\end{abstract}

Aus Gruppe 1 sind dies das am stärksten durch SA induzierte Gen in dieser Gruppe, das PENTATRICOPEPTIDE REPEAT Protein AT3G04130, und AT5G61800, welches auch zu den PENTATRICOPEPTIDE REPEAT Proteinen gehört. Aus Gruppe 2 die beiden, in dieser Gruppe, am stärksten durch SA induzierten Gene, die 
Glutathion S-Transferase GSTU7 sowie die UDP-Glykosyltransferase UGT73B3. Über die genaue Funktion der beiden PENTATRICOPEPTIDE REPEAT Proteine ist noch nichts bekannt, GSTU7 und UGT73B3 sind an Detoxifikationsmechanismen beteiligt (Mueller et al. 2008; Simon et al. 2014).

Um Hinweise auf funktionelle Unterschiede der Gene in beiden Gruppen zu erhalten, wurde eine Genontologie-Analyse durchgeführt. Hierfür wurde die agriGO Datenbank verwendet ( $\mathrm{Du}$ et al. 2010). Das Programm vergleicht den Anteil von Genen der untersuchten Gruppe, die einer bestimmten Genontologie zugeordnet werden mit dem Anteil der Gene der Referenzgruppe, die der gleichen Genontologie zugeordnet werden und überprüft, ob hier signifikante Unterschiede vorliegen. Die Genontologien, in denen in Gruppe 1 und in Gruppe 2 eine signifikante Anreicherung im Vergleich zur Referenz (Arabidopsis genemodel (TAIR9)) zu beobachten war, sind in Tabelle 4.1 aufgeführt.

Tabelle 4.1: Signifikant angereicherte Genontologien in SA-induzierten Genen der Gruppen 1 und 2

\begin{tabular}{|c|c|c|c|}
\hline Gruppe & Genontologie & $\begin{array}{c}\text { Anteil assoziierter } \\
\text { Gene }\end{array}$ & FDR \\
\hline \multirow{4}{*}{$\begin{array}{c}\text { Gruppe } \\
1\end{array}$} & Antwort auf Temperaturstimulus & $7,7 \% / 1,3 \%$ & 0,0015 \\
\cline { 2 - 4 } & Hitzeantwort & $6 \% / 0,43 \%$ & 0,00017 \\
\cline { 2 - 4 } & Antwort auf anorganische & $6,8 \% / 0,74 \%$ & 0,00035 \\
\cline { 2 - 4 } & Substanzen & $4,3 \% / 0,14 \%$ & 0,00017 \\
\hline \multirow{3}{*}{$\begin{array}{c}\text { Gruppe } \\
2\end{array}$} & Antwort auf Wasserstoffperoxid & $45,5 \% / 10,7 \%$ & 0,022 \\
\cline { 2 - 4 } & Sekundärstoffwechselprozess & $45,5 \% / 1,3 \%$ & $\begin{array}{c}0,000001 \\
9\end{array}$ \\
\cline { 2 - 4 } & Transferaseaktivität & $63,6 \% / 8,8 \%$ & 0,000029 \\
\hline
\end{tabular}

Gezeigt sind Genontologien, bei denen in Gruppe 1 oder Gruppe 2 eine Anreicherung von Genen vorliegt. In Spalte 3 ist der Anteil der den Genontologien assoziierter Gene in der untersuchten Gruppe und in der Referenz in der Form untersuchte Gruppe/Referenz angegeben. Bei den Genen der Gruppe 1 handelt es sich um solche, deren Expression strikt SCL-abhängig ist, bei den Genen der Gruppe 2 handelt es sich um solche, für die SCL14 nur einen Verstärker der Expression darstellt. Die Prozentzahlen geben an, welcher Anteil der Gene der untersuchten Gruppe bzw. der Referenz in die entsprechende Genontologie eingeordnet wurde. FDR: False Discovery Rate

Da SCL14 für die Gene der Gruppe 2 nur einen Expressionsverstärker darstellt, wurde eine Analyse der Promotoren der Gruppe 1 und der Gruppe 2 durchgeführt, um über die mögliche Anreicherung von unterschiedlichen Promotorelementen in den beiden Gruppen Rückschlüsse auf mögliche Transkriptionsfaktoren ziehen zu können, welche Schlüsselregulatoren dieser Gene darstellen. Für diese Analyse 
wurde das Programm Motif Mapper cis-element analysis tool verwendet (Berendzen et al. 2012). Das Programm vergleicht die Anzahl spezifischer Bindestellen in den Promotoren der untersuchten Gene mit der durchschnittlichen Anzahl dieser Bindestellen in den Promotoren von der gleichen Anzahl von Genen, die 1000 mal zufällig aus dem gesamten Genom ausgewählt werden. In den Promotoren der Gruppe 1 sind neben as-1-ähnlichen Elementen, die als Bindestelle für den SCL14/TGA2-Komplex dienen, Bindestellen für ETHYLEN RESPONSE FACTORs (ERFs) und Transkriptionsfaktoren aus der NAC-Genfamilie angereichert. Eine Anreicherung von as-1-ähnlichen Elementen und NAC-Bindestellen ist in den Promotoren der Gruppe 2 ebenfalls zu beobachten. Zusätzlich sind hier G-Boxen, die Bindestellen für den Transkriptionsfaktor MYC2 und Transkriptionsfaktoren aus der bZIP-Familie, sowie W-Boxen, Bindestellen für Transkriptionsfaktoren aus der $W R K Y$-Genfamilie überrepräsentiert. Da die letzteren beiden nicht in den Promotoren der Gruppe 1 angereichert sind, könnten WRKY-Transkriptionsfaktoren oder MYC2 bzw. G-Box-bindende bZIP-Transkriptionsfaktoren die Schlüsselregulatoren dieser Gene darstellen. Tabelle 4.2 zeigt repräsentative Beispiele für die angereicherten Sequenzen. Ähnliche Sequenzen, die ebenfalls angereichert waren, aber als Bindemotiv für den gleichen Transkriptionsfaktor dienen können, wurden in der Tabelle nicht berücksichtigt.

Tabelle 4.2: Signifikant angereicherte Promotorelemente in SA-induzierten Genen der Gruppen 1 und 2

\begin{tabular}{|c|c|c|c|c|}
\hline Gruppe & Motiv & Anreicherung & Transkriptionsfaktor & $\mathrm{p}$ \\
\hline \multirow{4}{*}{ Gruppe 1 } & GCCGCC/CGGCGG & 1,72 -fach (22/13) & ERF1 & 0,0113 \\
\cline { 2 - 5 } & AGCAGC/GCTGCT & 1,51 -fach (47/31) & ERF2 & 0,0064 \\
\cline { 2 - 5 } & TGACGT/ACGTCA & 1,61 -fach (56/35) & TGA & 0,0006 \\
\cline { 2 - 5 } & TCCGTG/CACGGA & 1,48 -fach (25/17) & NAC & 0,0233 \\
\hline \multirow{3}{*}{ Gruppe 2 } & CACGTG & 4,53 -fach (9/2) & MYC/bZIP & 0 \\
\cline { 2 - 5 } & TGACGT/ACGTCA & 5,48 -fach (16/3) & TGA & 0 \\
\cline { 2 - 5 } & TTVCGT/ACGBAA & 1,61 -fach (16/10) & NAC & 0,0367 \\
\cline { 2 - 5 } & TTGACY/RGTCAA & 1,5 -fach (20/13) & WRKY & 0,0375 \\
\hline
\end{tabular}

Angereicherte Bindestellen für Transkriptionsfaktoren in den Promotoren der Gene aus den Gruppen 1 und 2. Angegeben ist der Anreicherungsfaktor und die gefundene und die erwartete Anzahl der entsprechenden Elemente (gefunden/erwartet). B: nicht Adenin; R: Adenin oder Guanin; Y: Cytosin oder Thymin

In den Promotoren (-3000 BP-Region) der beiden Gene GSTU7 und UGT73B3 findet sich keine G-Box, MYC2 bzw. andere G-Box bindende Faktoren stellen also nicht 
den Schlüsselregulator dieser beiden Gene dar. Beide Promotoren enthalten allerdings Bindestellen für WRKY-Transkriptionsfaktoren. Diese könnten für diese beiden Gene daher die Schlüsselregulatoren darstellen. In beiden Promotoren sind auch Bindestellen für NAC-Transkriptionsfaktoren und Bindestellen für TGATranskriptionsfaktoren enthalten. Letztere finden sich bei UGT73B3 innerhalb eines as-1-ähnlichen Elementes, bei GSTU7 kommen, zusätzlich zu den in einem as-1ähnlichen Elementen vorhandenen, zwei einzelne TGA-Bindemotive vor. Die Promotoren der beiden Gene AT3G04130 und AT5G61800 enthalten jeweils ein Bindemotiv für ERF2 und für NAC-Transkriptionsfaktoren, jedoch keine Bindemotive für TGA-Transkriptionsfaktoren. Die Regulation dieser beiden Gene durch den SCL14/TGA-Komplex muss also indirekt geschehen, möglicherweise über NACTranskriptionsfaktoren. Die identifizierten Promotorelemente sind in Tabelle 4.3 gezeigt.

Tabelle 4.3: Identifizierte Bindestellen für Transkriptionsfaktoren in den Promotoren von GSTU7, UGT73B3, AT4G04130 und AT5G61800

\begin{tabular}{|c|c|c|c|}
\hline Promotor & Motiv & Anzahl & Transkriptionsfaktor \\
\hline \multirow{7}{*}{ GSTU7 } & -164 TTGACC -155 & \multirow{3}{*}{$3 / 2,22$} & \multirow{3}{*}{ WRKY } \\
\hline & -545 TTGACT -540 & & \\
\hline & -574 TTGACT -569 & & \\
\hline & -813 TGCGTG -808 & $1 / 1$ & NAC \\
\hline & -64 GTTCGTCActggTGACGTCA -45 & \multirow{3}{*}{$3 / 1,7$} & \multirow{3}{*}{ TGA } \\
\hline & -909 TGACGTCT -902 & & \\
\hline & -2698 TGACGTAA -2691 & & \\
\hline \multirow{6}{*}{ UGT73B3 } & -1028 TTGACC -1023 & \multirow{3}{*}{$3 / 2,22$} & \multirow{3}{*}{ WRKY } \\
\hline & -1351 TTGACT -1346 & & \\
\hline & -2780 TTGACC -2775 & & \\
\hline & -54 TTCCGT -49 & \multirow{2}{*}{$2 / 1,2$} & \multirow{2}{*}{ NAC } \\
\hline & -302 TTCCGT -297 & & \\
\hline & -114 TGACGTATgtcaCGACGTCA -95 & $1 / 1,77$ & TGA \\
\hline \multirow{2}{*}{ AT3G04130 } & -1312 AGCAGC -1307 & $1 / 1,34$ & ERF2 \\
\hline & -1239 TCCGTG -1234 & $1 / 1,09$ & NAC \\
\hline \multirow{2}{*}{ AT5G61800 } & -2546 ACGACG -2541 & $1 / 1,34$ & ERF2 \\
\hline & -205 TTCCGT -200 & $1 / 1,13$ & NAC \\
\hline
\end{tabular}

Gezeigt sind die identifizierten Bindemotive für Transkriptionsfaktoren, die, gemäß der Promotoranalyse mit Motif Mapper, in der entsprechenden Gruppe im Vergleich zur Referenz angereichert waren. Die Anzahl der Elemente in den Promotoren der einzelnen Gene ist im Vergleich zur durchschnittlichen Anzahl der Elemente in den Promotoren der entsprechenden Gruppe angegeben (Anzahl der Elemente im Promotor/durchschnittliche Anzahl der Elemente). Die Bindemotive für TGA-Faktoren sind, sofern zutreffend, mit den as-1-ähnlichen Elementen angegeben. Die angereicherten TGA-Bindemotive innerhalb der as-1-ähnlichen Elemente sind in Fettschrift dargestellt. 


\subsubsection{Einfluss der Deletion von SCL14 und SCL33 auf die}

\section{Genexpression}

In einer zweiten MarVis Analyse sollte der Effekt der Deletion von SCL14 und SCL33 auf die Genexpression untersucht werden. Hierfür wurden die Expressionsmuster der 620 Gene (Anhang Tab. 6.7), deren Expression sich in Col-0 und der sc/14/33 Mutante im uninduzierten Zustand oder nach SA-Behandlung um mindestens den Faktor zwei $(p \leq 0,05)$ unterschied mit MarVis visualisiert. Anhand ihrer Expressionsmuster konnten diese Gene in acht Gruppen eingeteilt werden ( $A^{\prime}-H^{\prime}$; Abb. 4.23).

Die erste Gruppe (A') enthält 60 Gene und entspricht größtenteils der Gruppe A der SA-beeinflussten Gene.

In die zweite Gruppe (B') wurden 70 Gene eingeordnet, die im Wildtyp bereits im unbehandelten Zustand exprimiert wurden und deren Expression nicht durch SA beeinflusst wurde und die in der Mutante unter beiden Bedingungen nicht exprimiert wurden. Hier sind Gene überrepräsentiert die an der Antwort auf biotischen und abiotischen Stress, wie Toxine und Pathogenbefall beteiligt sind.

Die dritte Gruppe (C') enthielt 16 Gene, deren Expression im Wildtyp durch SA reprimiert wurden und die in der Mutante weder im uninduzierten Zustand noch nach SA exprimiert wurden. In dieser Gruppe war keine Anreicherung von Genen zu beobachten, die einer bestimmten Genontologie zuzuordnen waren.

In die vierte Gruppe (D') wurden zehn Gene eingeordnet, die in beiden Genotypen durch SA reprimiert wurden, deren Expression jedoch in der Mutante nach SABehandlung stärker war als im Wildtyp nach SA-Behandlung. In dieser Gruppe war keine Anreicherung von Genen zu beobachten, die einer bestimmten Genontologie zugeordnet werden konnten.

In die Gruppe E', die sich in die Gruppen E'1 und E'2 aufteilt, wurden 42 Gene eingeordnet, die im Wildtyp nicht exprimiert wurden und in der Mutante durch SA reprimiert wurden. In dieser Gruppe war keine signifikante Anreicherung von Genen zu beobachten, die einer bestimmten Genontologie zugeordnet werden konnten.

In der Gruppe G', in die 58 Gene eingruppiert wurden die im Wildtyp nicht und in der Mutante unabhängig von SA exprimiert waren, ist eine Anreicherung von Genen der Glucosinolat- und der Cysteinbiosynthese zu beobachten. 
Die größte Gruppe in dieser Analyse ist die achte Gruppe ( $\left.\mathrm{H}^{\prime}\right)$. Die $359 \mathrm{Gene}$, die in diese Gruppe eingeordnet wurden, waren im Wildtyp weder im unbehandelten Zustand noch nach SA-Behandlung exprimiert, in der Mutante war jedoch bei den meisten Genen bereits im unbehandelten Zustand eine Expression zu beobachten, die durch die SA Behandlung verstärkt wurde. SCL14 scheint also als Repressor dieser Gene zu fungieren. Ein großer Teil der in diese Gruppe eingeordneten Gene sind im Stroma und in den Thylakoidmembranen von Chloroplasten zu finden und an der Photosynthese beteiligt, es konnte jedoch auch eine Anreicherung von Genen beobachtet werden, die an der Etablierung der SAR beteiligt sind. Diese Gene wurden in der ersten MarVis Analyse größtenteils nicht als SA-induzierte Gene erfasst, da der Induktionsfaktor in der Mutante für die meisten dieser Gene kleiner als zwei ist und die Einordnung in diese Analyse erfolgte aufgrund der Tatsache, dass sich die Expression in der Mutante von der Expression im Wildtyp entweder im uninduzierten Zustand oder nach SA-Behandlung um mindestens den Faktor zwei unterscheidet.
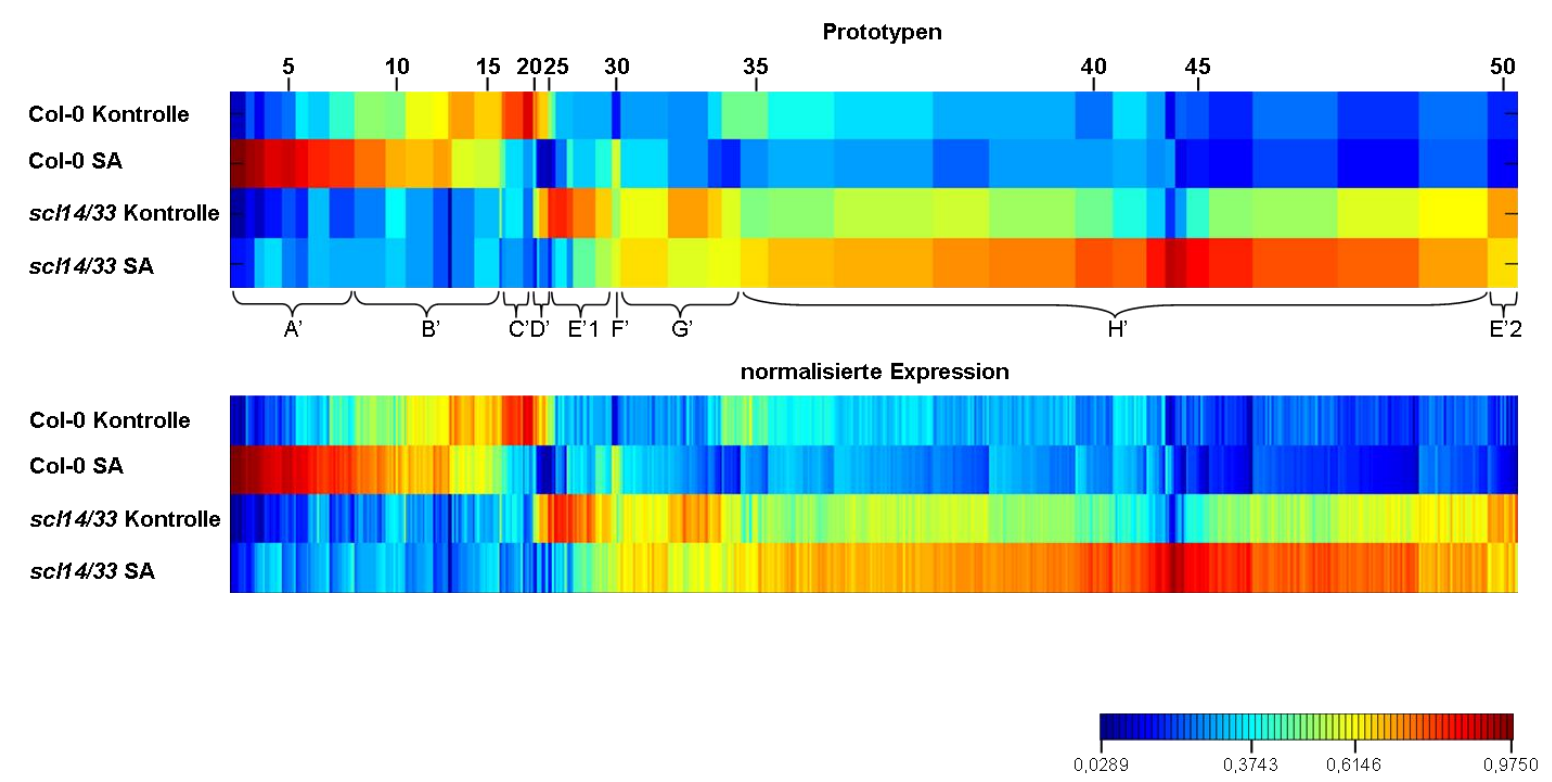

Abbildung 4.23: MarVis Analyse der in Col-0 und sc/14/33 unterschiedlich exprimierten Gene. Der obere Teil der Abbildung zeigt die Einteilung der Gene in 50 Prototypen, entsprechend ihres normalisierten Expressionsmusters. Die Breite jedes Prototyps ist proportional zu der darin enthaltenen Anzahl an Genen. Der untere Teil der Abbildung zeigt die normalisierte Expression der einzelnen Transkripte. Eine rote Färbung zeigt eine starke Expression an, eine blaue Färbung eine schwache Expression. 


\subsubsection{SA und TIBA induzieren die Expression von SCL14 Zielgenen in Wurzeln von Arabidopsis thaliana}

Für die Validierung der Ergebnisse des Microarray Experiments wurde die Expression der Gene GSTU7, UGT73B3 (Gene der Gruppe 2) und AT3G04130 sowie AT5G61800 (Gene der Gruppe 1) nach der Behandlung mit SA und TIBA in unabhängigen Experimenten analysiert. Die Expression von GSTU7 ist im uninduzierten Zustand in der sc/14/33 Mutante im Vergleich zum Wildtyp etwa um den Faktor sieben reduziert. Für UGT73B3 beträgt der Unterschied etwa den Faktor 10. Die relative Induktion ist bei beiden Genen in der sc/14/33 Mutante jedoch stärker als im Wildtyp. Nach SA Behandlung beträgt der Induktionsfaktor für GSTU7 in der Mutante 8,4 gegenüber 4,7 im Wildtyp (Abb. $4.19 \mathrm{~A}$ ) und nach TIBA Behandlung 5,3 gegenüber 2,1 (Abb. 4.19 B). Für UGT73B3 betragen die Induktionsfaktoren 7,5 gegenüber 4,4 nach SA Behandlung (Abb. $4.22 \mathrm{C}$ ) und 8 gegenüber 1,7 nach TIBA Behandlung (4.24 B). Sowohl AT3G04130 als auch AT5G61800 zeigen nach der Behandlung mit SA (Abb. 4.22 A und B) und TIBA (Abb. 4.24 C und D) im Wildtyp eine Erhöhung der Expression, welche in der sc/14/33 Mutante nicht zu beobachten ist. Außerdem zeigen die beiden Gene, im Gegensatz zu GSTU7 und UGT73B3, nur eine sehr geringe Verringerung der basalen Expression im Vergleich zum Wildtyp. Somit konnten die Ergebnisse der Microarray Analyse bezüglich der Expression von GSTU7, UGT43B3, AT3G04130 und AT5G61800 nach SA-Behandlung und die Einordnung der Gene in die Gruppen 1 und 2 bestätigt werden. Außerdem konnte gezeigt werden, dass TIBA einen ähnlichen Effekt auf die Expression dieser vier Gene hat wie SA. 
A

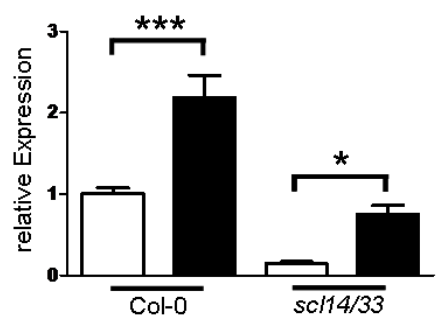

C

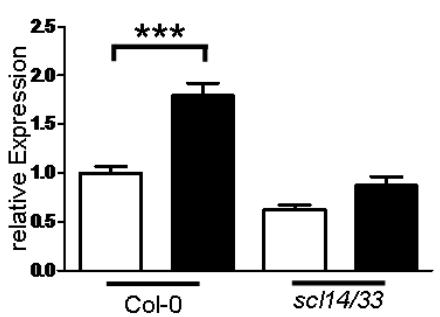

B

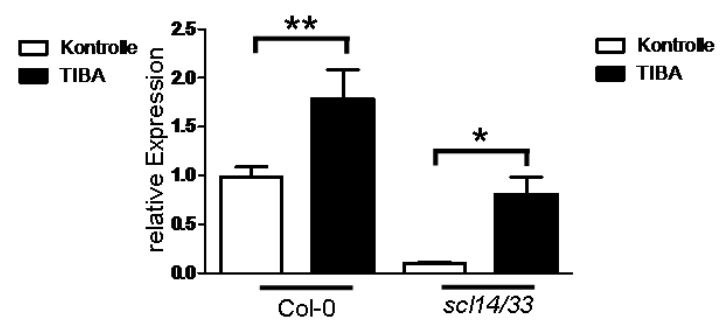

D

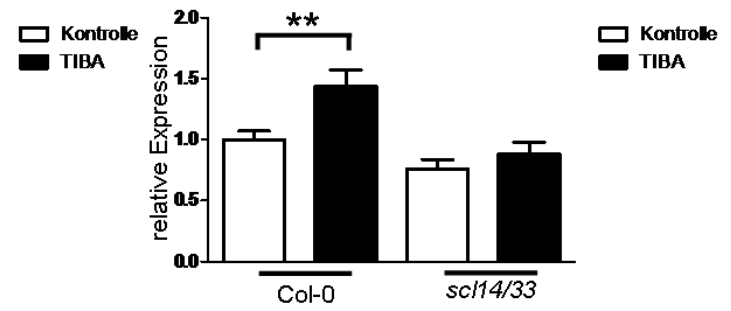

Abbildung 4.24: Expression der SCL14 Zielgene GSTU7, UGT73B3, AT3G04130 und AT5G61800 nach TIBA Behandlung.

Die Behandlung mit $100 \mu \mathrm{M}$ TIBA erfolgte für vier Stunden an 10 Tage alten, in hydroponischen Kulturen unter Langtagbedingungen angezogenen Pflanzen. Die Extraktion der RNA erfolgte aus Wurzelmaterial. Die relativen Transkriptmengen von GSTU7, UGT73B3, AT3G04130 und AT5G61800 wurden mittels qRT-PCR bestimmt. Zur Normalisierung der Expression diente UBQ5. Die mittlere relative Expression der Wildtyp Kontrolle wurde gleich 1 gesetzt. Gezeigt sind die Mittelwerte von 13 15 Hydroponikkulturen ( \pm SEM) aus drei unabhängigen Experimenten. $\left({ }^{*}: p \leq 0,05,{ }^{* *}: p \leq 0,01,{ }^{* * *}: p \leq\right.$ 0,001; One-way ANOVA)

\subsubsection{Jasmonsäure induziert die Expression von GSTU7}

Die Behandlung mit Methyljasmonat führt nicht zur Akkumulation von SCL14 im Zellkern (Abschnitt 4.1.2). Diese Beobachtung legt den Schluss nahe, dass unter diesen Bedingungen auch keine Induktion der SCL14 Zielgene stattfindet. Für UGT73B3, AT3G04130 und AT5G61800 trifft diese Annahme zu. Eine Ausnahme bildet jedoch GSTU7, da dieses Gen nach der Behandlung mit Methyljasmonat induziert wird (Abb. 4.25). Im Wildtyp beträgt der Induktionsfaktor 5,7 und in der sc/14/33 Mutante 2,5. GSTU7 wird also durch Methyljasmonat ebenso induziert wie durch SA und TIBA. Allerdings ist die Induktion durch MeJA im Wildtyp stärker als in der Mutante, während es nach SA und TIBA umgekehrt ist. Für die Aktivierung von GSTU7 scheint die induzierbare Akkumulation von SCL14 im Zellkern also nicht erforderlich zu sein, da das Gen auch unter Bedingungen SCL14-abhängig induziert werden kann, unter denen diese nicht zu beobachten ist. 
A

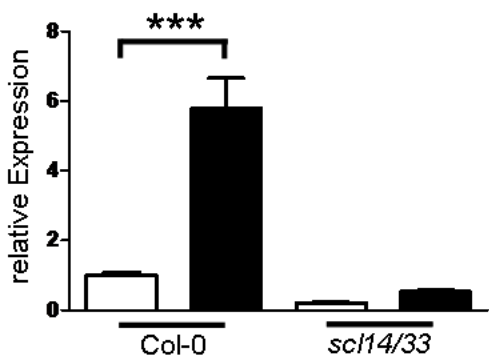

C

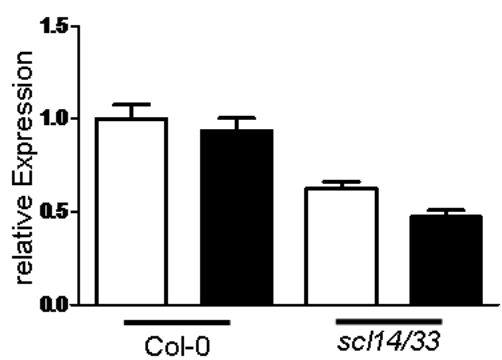

B

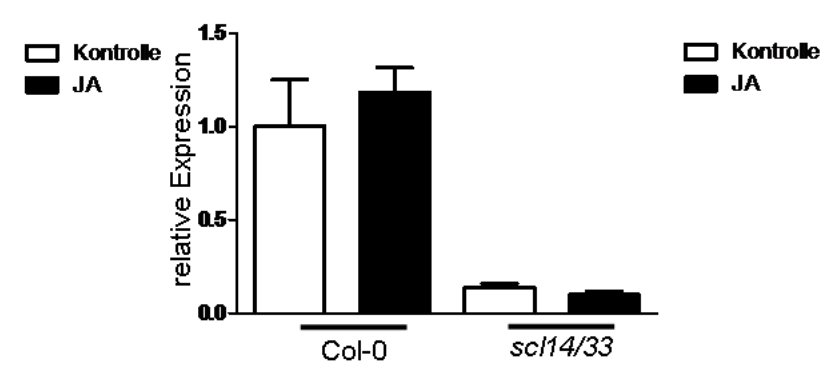

D

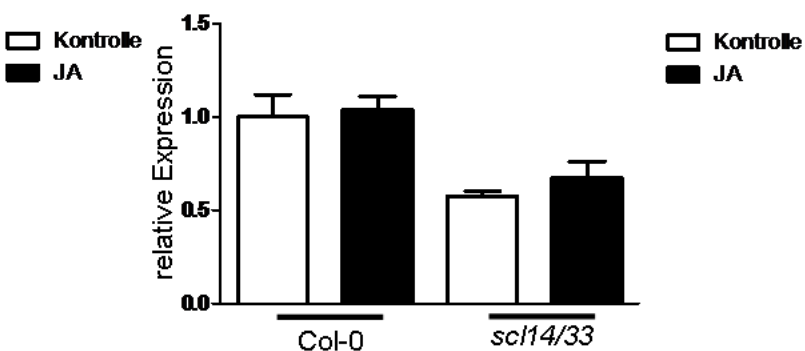

Abbildung 4.25: Expression der SCL14 Zielgene GSTU7, UGT73B3, AT3G04130 und AT5G61800 nach MeJA Behandlung.

Die Behandlung mit $50 \mu \mathrm{M}$ SA erfolgte für vier Stunden an 10 Tage alten, in hydroponischen Kulturen unter Langtagbedingungen angezogenen Pflanzen. Die Extraktion der RNA erfolgte aus Wurzelmaterial. Die relativen Transkriptmengen von GSTU7, UGT73B3, AT3G04130 und AT5G61800 wurden mittels qRT-PCR bestimmt. Zur Normalisierung der Expression diente UBQ5. Die mittlere relative Expression der Wildtyp Kontrolle wurde gleich 1 gesetzt. Gezeigt sind die Mittelwerte von 8 10 Hydroponikkulturen $\left( \pm\right.$ SEM) aus zwei unabhängigen Experimenten. ${ }^{* * *}$ : $p \leq 0,001$; One-way ANOVA)

\subsubsection{Die Expression von GSTU7, UGT73B3, AT3G04130 und AT5G61800 ist abhängig von den TGA-Transkriptionsfaktoren der Klasse II}

SCL14 interagiert mit den TGA-Transkriptionsfaktoren der Klasse II, TGA2, TGA5 und TGA6, wobei die Interaktion mit TGA5 im Hefe-Zwei-Hybrid-System sehr schwach ausgeprägt ist (Siemsen 2005). Das Vorhandensein dieser TGA-Faktoren ist in Blättern essentiell für die SA-induzierte Expression der SCL14 Zielgene (Fode et al. 2008). Um zu überprüfen, ob die Expression der SCL14 Zielgene auch in Wurzeln abhängig von den TGA-Transkriptionsfaktoren der Klasse II ist, oder ob hier möglicherweise ein anderes Protein die Bindung von SCL14 an die DNA vermittelt, wurde die tga256 Mutante im hydroponischen System angezogen und die Wurzeln mit SA behandelt. Die SA-induzierte Induktion von GSTU7 in Col-0 ist in der Mutante nicht zu beobachten (Abb. 4.26). Das gleiche ist für die anderen getesteten Gene, UGT73B3, AT3G04130 und AT5G61800 zu beobachten. Daher ist sind die TGA- 
Transkriptionsfaktoren der Klasse II sowohl für die Expression der Gruppe von Genen erforderlich, für die SCL14 einen Verstärker der Expression darstellt, als auch für die Expression der Gene, bei denen SCL14 der hauptsächliche Regulator ist.
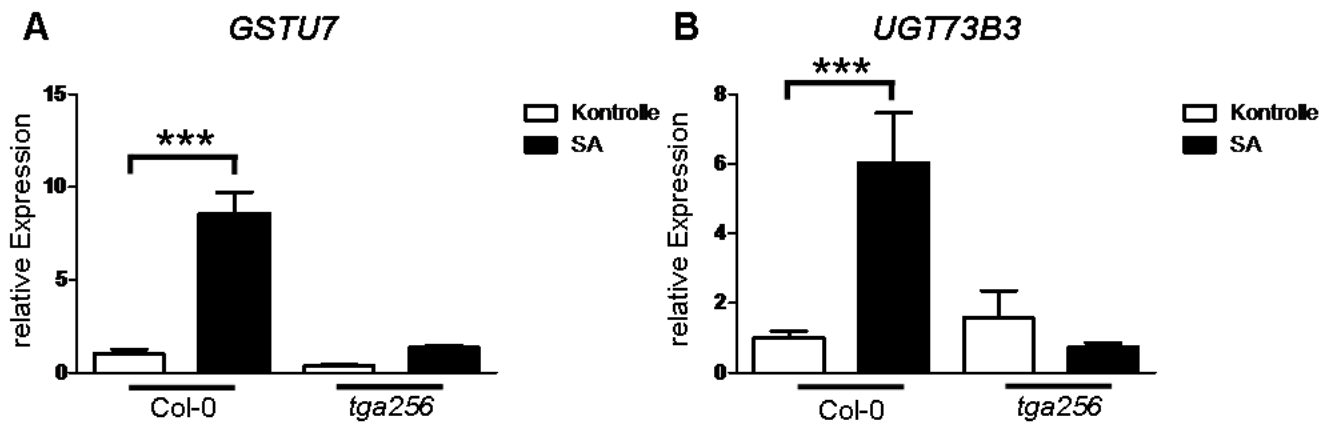

C

AT3G04130

D

AT5G61800
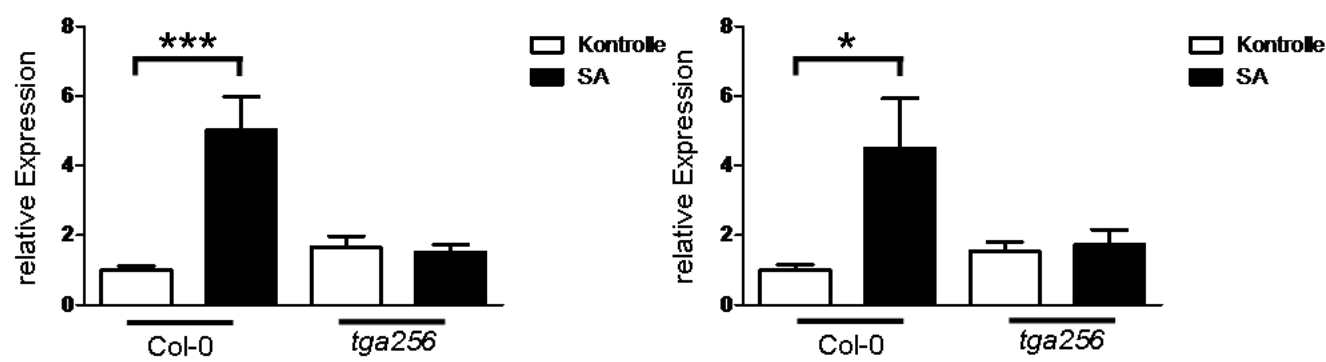

Abbildung 4.26: Expression der SCL14 Zielgene GSTU7, UGT73B3, AT3G04130 und AT5G61800 in der tga256 Mutante nach SA Behandlung.

Die Behandlung mit $1 \mathrm{mM} \mathrm{SA}$ erfolgte für vier Stunden an 10 Tage alten, in hydroponischen Kulturen unter Langtagbedingungen angezogenen Pflanzen. Die Extraktion der RNA erfolgte aus Wurzelmaterial. Die relativen Transkriptmengen von GSTU7, UGT73B3, AT3G04130 und AT5G61800 wurden mittels qRT-PCR bestimmt. Zur Normalisierung der Expression diente UBQ5. Die mittlere relative Expression der Wildtyp Kontrolle wurde gleich 1 gesetzt. Gezeigt sind die Mittelwerte von 8 9 Hydroponikkulturen ( \pm SEM) aus zwei unabhängigen Experimenten. $\left(^{*}: p \leq 0,05,{ }^{* * *}: p \leq 0,001\right.$; Oneway ANOVA)

\subsubsection{Das GFP-SCL14 Fusionsprotein komplementiert den Phänotyp der sc/14/33 Mutante}

$\mathrm{Da}$ ausgeschlossen werden sollte, dass das HA-GFP-SCL14 Fusionsprotein ein nichtfunktionales Protein ist, wurden transgene Pflanzen, die dieses Protein exprimieren, für 10 Tage unter Langtagbedingungen im hydroponischen System angezogen und für eine Stunde mit $1 \mathrm{mM} \mathrm{SA}$ behandelt und die Expression des SCL14 Zielgens GSTU7 mittels qRT-PCR analysiert.

Die Expression von GSTU7 ist in der transgenen Linie, nach der Behandlung mit SA, schwächer als im Wildtyp, jedoch signifikant erhöht gegenüber der Kontrolle, während in der sc/14/33 Mutante keine signifikante Induktion des Gens zu 
beobachten ist (Abb. 4.27). Die schwache Induktion in den transgenen Pflanzen kann ihre Ursache darin haben, dass das Fusionsprotein schwächer exprimiert ist als das endogene SCL14 Protein im Wildtyp. Wie auf dem Western Blot in Abb. $4.27 \mathrm{zu}$ erkennen ist, ist die Bande des endogenen Proteins wesentlich stärker als die des Transgens.

GSTU7
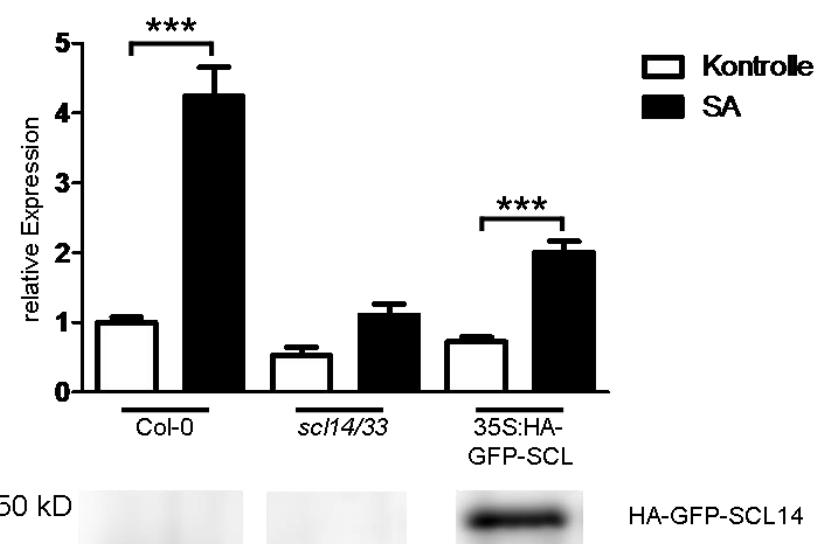

$130 \mathrm{kD}$

$100 \mathrm{kD}$
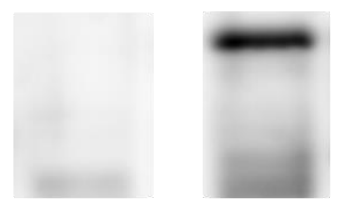

SCL14

$35 \mathrm{kD}$

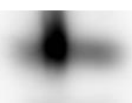

\#

Abbildung 4.27: Komplementation des GSTU7 Expressionsphänotyps in der sc/14/33 Mutante durch HA-GFP-SCL14.

Die Behandlung mit $1 \mathrm{mM}$ SA erfolgte für vier Stunden an 10 Tage alten, in hydroponischen Kulturen unter Langtagbedingungen angezogenen Pflanzen. Die Extraktion der RNA erfolgte aus Wurzelmaterial. Die relativen Transkriptmengen von GSTU7 wurden mittels qRT-PCR bestimmt. Zur Normalisierung der Expression diente UBQ5. Die mittlere relative Expression der Wildtyp Kontrolle wurde gleich 1 gesetzt. Gezeigt sind die Mittelwerte von 9 Hydroponikkulturen ( \pm SEM) aus drei unabhängigen Experimenten. Der Western Blot zeigt die Proteinmengen des endogenen SCL14 in Col-0 und des Transgens in sc/14/33 35S:HA-GFP-SCL. Die Detektion der Proteine erfolgte mittel eines gegen SCL14 gerichteten Antikörpers. \# markiert eine unspezifische Bande, die als Auftragkontrolle genutzt werden kann. ${ }^{* * *}$ : $p \leq 0,001$; One-way ANOVA)

Um den Effekt des HA-GFP-SCL Fusionsproteins auf die SA-induzierte Reduktion des Wurzelwachstums zu testen, wurden Pflanzen der Genotypen Col-0, sc/14/33 und sc/14/33 35S:HA-GFP-SCL14 auf Schrägagarplatten mit Murashige+Skoog Medium (MS) unter Langtagbedingungen angezogen. Nach sechs Tagen wurden die Pflanzen auf neue Schrägagarplatten mit oder ohne SA umgesetzt und die Wurzellänge gemessen. Nach weiteren sechs Tagen unter Langtagbedingungen wurde die Wurzellänge erneut gemessen und der relative Zuwachs berechnet (Abb. 4.28). Für den Wildtyp beträgt die Verringerung des Wurzelwachstums auf SA gegenüber der Kontrolle 72\%. Die sc/14/33 Mutante ist stärker betroffen, hier beträgt die Verminderung des Wurzelwachstums gegenüber der Kontrolle $85 \%$. In den 
transgenen Pflanzen beträgt die Reduktion des Wurzelwachstums gegenüber der Kontrolle $60 \%$ und ist damit sogar weniger stark als im Wildtyp. Somit ist das HAGFP-SCL14 Fusionsprotein in der Lage, sowohl den Genexpressionsphänotyp der sc/14/33 Mutante als auch die verstärkte SA-induzierte Reduktion des Wurzelwachstums zu komplemetieren. Es handelt sich bei diesem Fusionskonstrukt von SCL14 also um ein funktionelles Protein.

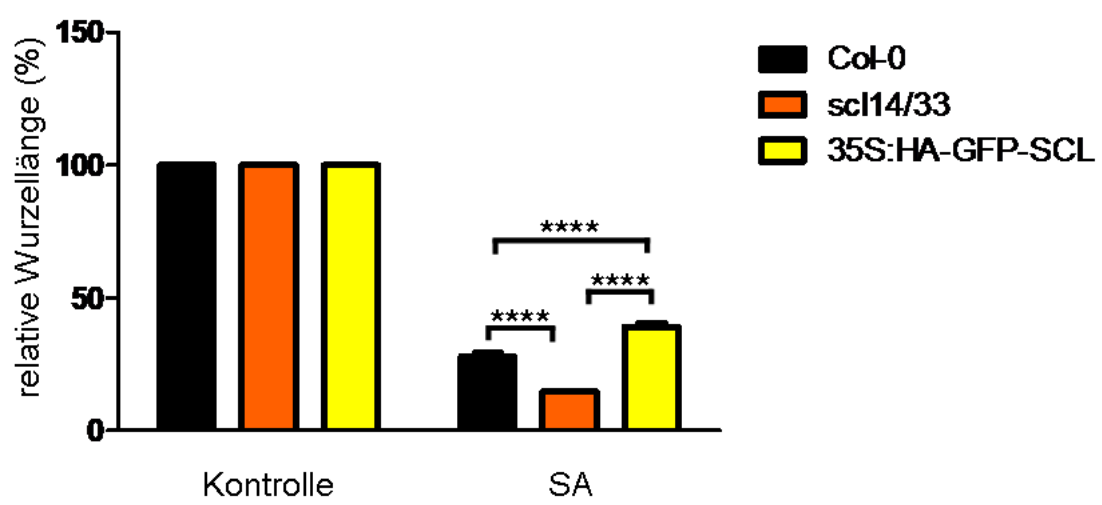

Abbildung 4.28: Relative Inhibition des Wurzelwachstums durch SA.

Die Pflanzen der Genotypen Col-0, sc/14/33 und sc/14/33 35S:HA-GFP-SCL14 wurden sechs Tage auf MS-Agar unter Langtagbedingungen angezogen. Anschließend wurden die Pflanzen auf MS-Agar ohne SA oder mit $100 \mu \mathrm{M}$ SA umgesetzt. Nach weiteren sechs Tagen wurde der relative Wurzelzuwachs bestimmt. Gezeigt sind die Mittelwerte von $30-40$ Pflanzen ( \pm SEM) aus zwei unabhängigen Experimenten $\left(^{* * * *}: p \leq 0,0001\right)$

\subsubsection{SCL14 akkumuliert auch im hydroponischen System nach SA Behandlung im Zellkern}

Da die Pflanzen für die Untersuchung der Genexpression unter anderen Bedingungen angezogen wurden als für die mikroskopische Analyse der Lokalisation von SCL14, wurde getestet, ob die Akkumulation von SCL14 im Zellkern auch unter den Anzucht- und Induktionsbedingungen stattfindet, die für die Analyse der Genexpression verwendet wurden. Hierfür wurden transgene Pflanzen, die das HAGFP-SCL14 Fusionsprotein exprimieren, für 10 Tage unter Langtagbedingungen im hydroponischen System angezogen und für eine Stunde mit $1 \mathrm{mM} \mathrm{SA}$ behandelt. Anschließend wurden die Wurzeln mittels konfokaler Lasermikroskopie analysiert.

In der Kontrolle ist keine Akkumulation der Fluoreszenz in den Zellkernen der untersuchten Wurzeln zu beobachten, in den mit SA behandelten Wurzeln kommt es jedoch zu einem Anstieg der Intensität der Fluoreszenz in den Zellkernen (Abb. 4.29). SCL14 akkumuliert also auch unter den Bedingungen, die für die Analyse der Genexpression gewählt wurden im Zellkern. 


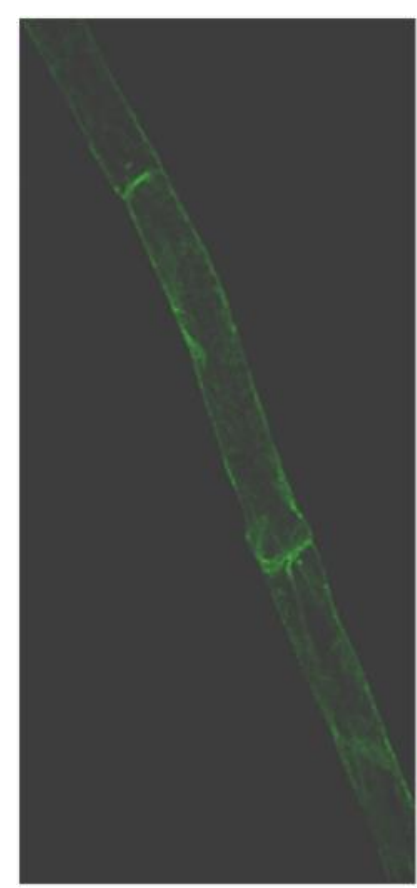

Kontrolle

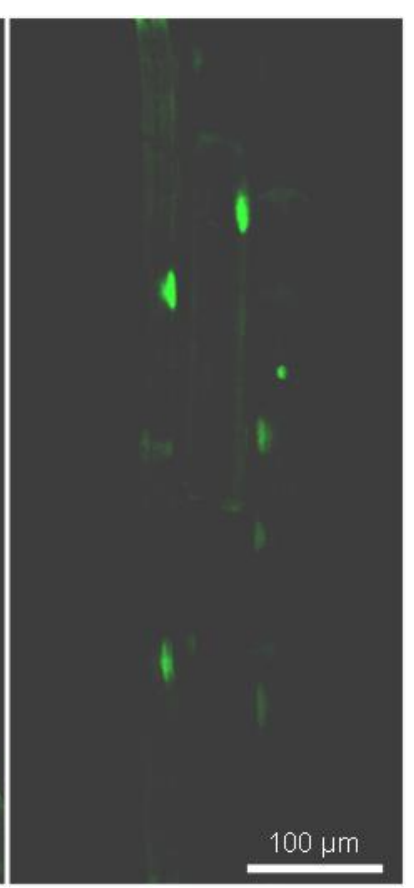

SA

Abbildung 4.29: HA-GFP-SCL14 akkumuliert im hydroponischen System nach SA Behandlung in Zellkernen von Arabidopsis thaliana Wurzelzellen.

10 Tage alte Pflanzen des Genotyps sc/14/33 35S:HA-GFP-SCL wurden mit 1 mM SA Behandelt. Als Kontrolle diente Wasser. Die Anzucht der Pflanzen erfolgte steril in hydroponischer Kultur unter Langtagbedingungen. Die Aufnahme der Fluoreszenzbilder erfolgte $60 \mathrm{~min}$ nach Beginn der Behandlung.

\subsection{SCL14 scheint nach der Behandlung von Arabidopsis Wurzeln mit SA oxidiert zu werden}

Um herauszufinden, ob SCL14 unter Bedingungen, unter denen die Akkumulation des Proteins im Zellkern zu beobachten ist, oxidativ modifiziert wird, wurden Col-0 Pflanzen im hydroponischen System angezogen und für eine Stunde mit $1 \mathrm{mM} \mathrm{SA}$ behandelt. Mit Proteinextrakten aus dem geernteten Wurzelmaterial wurde eine Markierung der Proteine mit Methoxypolyethylen Glycol Maleimid-5000 (mPEG-Mal5000) durchgeführt (Abschnitt 3.2.9). Hierbei werden zuerst reduzierte Cysteine durch eine Schutzgruppe maskiert. Anschließend werden oxidierte Cysteine reduziert und kovalent mit mPEG-Mal-5000 modifiziert. Diese Modifikation fügt dem Molekulargewicht eines Proteins $5 \mathrm{kDa}$ pro gebundenem Molekül mPEG-Mal-5000 hinzu, sodass sich das Laufverhalten eines Proteins in einem SDS-Polyacrylamidgel ändert. Sofern nach SA Behandlung eines oder mehrere der Cysteine in SCL14 oxidiert vorliegen, sollte sich daher das Laufverhalten des Proteins im Vergleich zur Kontrolle ändern. 
In der Kontrolle, die nicht mit DTT reduziert wurde, sollte kein mPEG-Mal-5000 an die Proteine gebunden haben, da alle reduzierten Cysteine mit einer Schutzgruppe maskiert wurden. In der reduzierten Kontrolle kann mPEG-Mal-5000 an das Protein gebunden haben, da nach der Reduktion mit DTT angreifbare Cysteine im Protein vorliegen, sofern sie vor dem Reduktionsschritt oxidiert waren. Die Proteinbande in dieser Spur (Col-0 Kontrolle, +DTT) läuft höher als in der Spur, in der die unreduzierte Kontrolle aufgetragen wurde (Col-0 Kontrolle, -DTT) (Abb. 4.30). Der Laufunterschied entspricht mit einem zusätzlichen Molekulargewicht von etwa $5 \mathrm{kDa}$ der Masse eines mPEG-Moleküls.

In dem SA-behandelten Ansatz ist der Laufunterschied zwischen der Probe nach Reduktion (Col-0 SA, +DTT) und der Probe, die vor dem Markierungsschritt mit mPEG-Mal-5000 nicht reduziert wurde (Col-0 SA, -DTT), größer. Er entspricht mit einem zusätzlichen Molekulargewicht von etwa 10 kDa der Masse von zwei mPEGMolekülen. SCL14 liegt also bereits im uninduzierten Zustand oxidiert vor, jedoch wird nach SA-Behandlung ein weiteres Cystein des Proteins oxidiert. Die hier gezeigten Daten bedürfen noch der Reproduktion, jedoch sind sie ein guter Hinweis darauf, dass die Oxidation von SCL14 das Signal für die Akkumulation des Proteins im Zellkern ist.
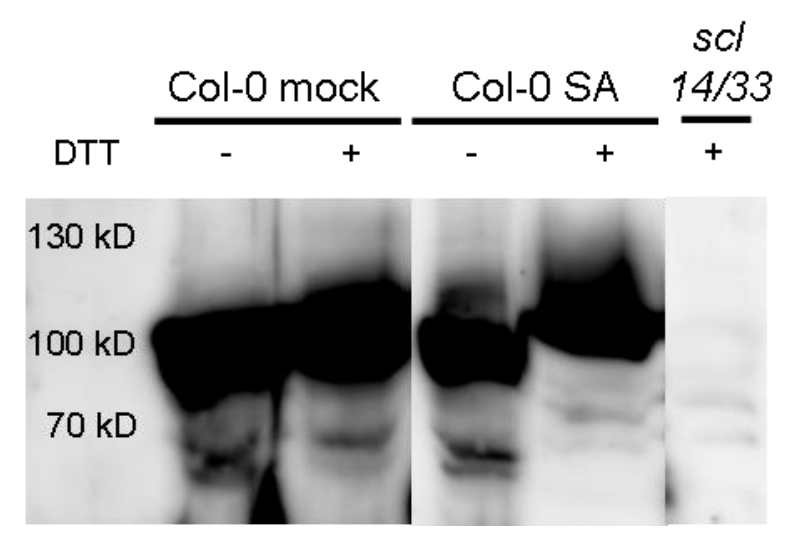

Abbildung 4.30: Induktion eines Laufunterschiedes von SCL14 in einem SDS-Polyacrylamidgel durch Markierung mit mPEG-Mal-5000.

Für die Markierung mit mPEG-Mal-5000 wurden Pflanzen der Genotypen Col-0 und sc/14/33 10 Tage lang in hydroponischen Kulturen unter Langtagbedingungen angezogen und eine Stunde mit $1 \mathrm{mM} \mathrm{SA}$ behandelt. Die Detektion des endogenen SCL14 Proteins im Western Blot erfolgte mit einem gegen SCL14 gerichteten Antikörper. 


\subsection{Suche nach Interaktionspartnern von SCL14 mit dem}

\section{Hefe-Zwei-Hybrid-System}

Um neue Interaktionspartner von SCL14 zu finden, wurde das Protein im Hefe-ZweiHybrid-System als Köderprotein angeboten. Da SCL14 bereits eine Aktivierungsdomäne besitzt, welche sich im N-Terminus befindet, wurde nur die GRAS-Domäne verwendet, um eine Autoaktivierung der Transkription durch SCL14 zu vermeiden. Als neuer Interaktionspartner konnte der Transkriptionsfaktor NAC017 gefunden werden, der zur Familie der NAC Transkriptionsfaktoren gehört, die eine der größten Familien pflanzenspezifischer Transkriptionsfaktoren darstellt. Die NAC Transkriptionsfaktoren werden durch ihre N-Terminale DNA Bindedomäne (NAC Domäne) charakterisiert, während ihr C-Terminus sehr variabel ist (Olsen et al. 2005).

Der Hefe-Zwei-Hybrid-Test sowie die Charakterisierung der erhaltenen cDNA Klone wurden von Polina Demeshko im Rahmen ihrer Bachelorarbeit durchgeführt.

\subsubsection{AtNAC017 interagiert mit der GRAS-Domäne von SCL14}

Für die Suche nach neuen Interaktionspartnern wurde die GRAS-Domäne von SCL14 in das Plasmid pGBKT7 kloniert. Die verwendete cDNA Bibliothek enthielt cDNAs aus Arabidopsis Suspensionszellkulturen im Plasmid pAct2 (Nemeth et al. 1998). Der Hefestamm PJ69-4A wurde mit dem Köderplasmid und der cDNA Bank transformiert und die Transformationsansätze auf Interaktionsmedium ausplattiert. Die Auswertung der Interaktionsplatten erfolgte nach vier Tagen bis zwei Wochen.

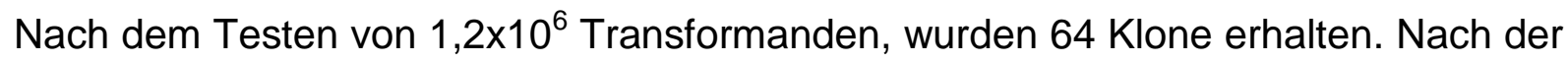
Isolation der cDNA-Klone aus der Hefe und der Retransformation zusammen mit pGBKT7-SCL14GRAS war jedoch nur bei 16 davon ein erneutes Wachstum auf Interaktionsmedium zu beobachten. Mit diesen 16 Klonen wurde ein oNPG-Test durchgeführt, um die Proteine herauszufinden, die die stärkste Interaktion mit der SCL14 GRAS-Domäne aufwiesen. Von den 16 getesteten Klonen wiesen $11 \mathrm{im}$ oNPG-Test eine, gegenüber der Kontrolle, mindestens zweifach erhöhte BGalaktosidaseaktivität auf, wobei Klon Nr.11 mit einer 20-fachen Erhöhung der BGalactosidaseaktivität eine wesentlich stärkere Interaktion zeigt als die übrigen Klone (Abb. 4.31). Die 11 Klone, die im oNPG-Test eine mindestens zweifach Erhöhung der 
ß-Galaktosidaseaktivität gegenüber der Kontrolle gezeigt haben, wurden sequenziert (siehe Tab. 4.4).

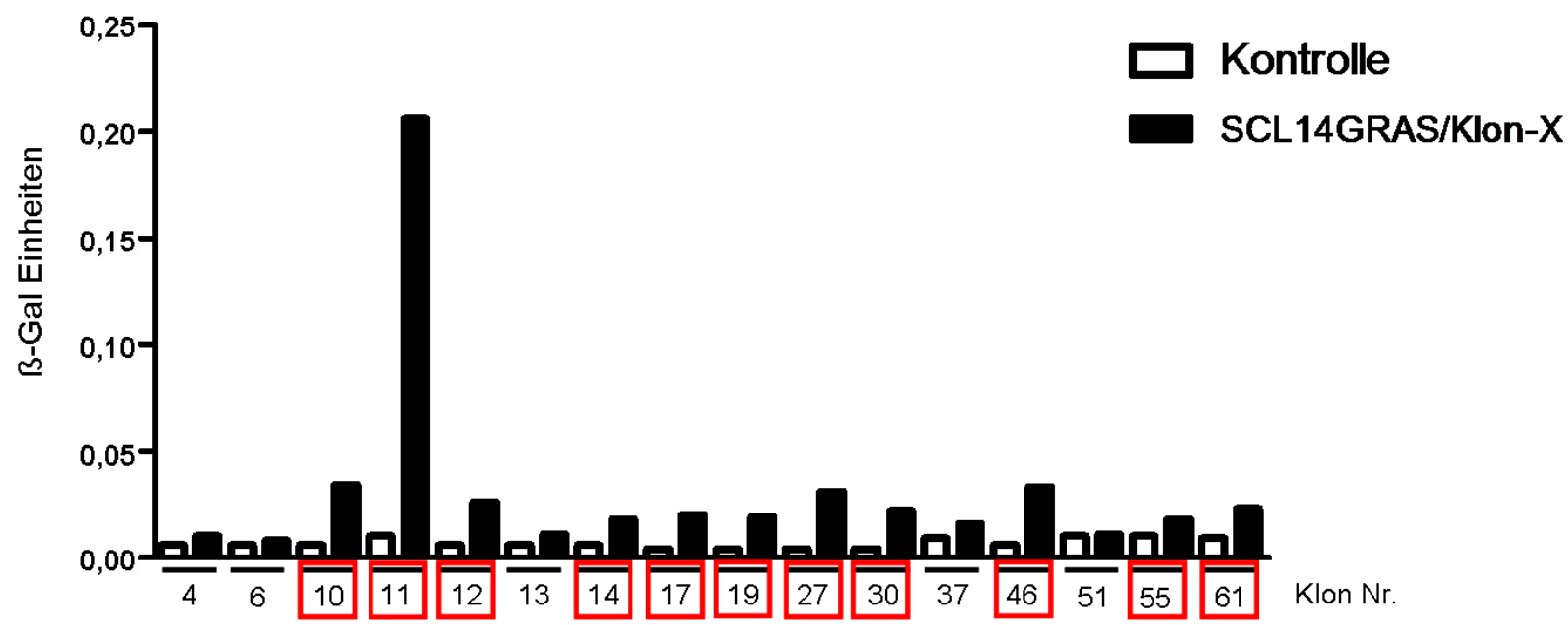

Abbildung 4.31: Quantifizierung der im Hefe-Zwei-Hybrid-System gefundenen Interaktionspartner der SCL14 GRAS-Domäne mittels oNPG-Test.

Interaktionen, die eine mindestens zweifache Steigerung der B-Galaktosidaseaktivität hervorrufen sind rot markiert. Für die genaue Bezeichnung der Interaktionspartner siehe Tabelle 1.3. Gezeigt ist der Mittelwert von 6 unabhängigen, biologischen Replikaten (Durchführung des Experiments von P. Demeshko im Rahmen ihrer Bachelorarbeit). 
Tabelle 4.4: Im Hefe-Zwei-Hybrid-System gefundene Interaktionspartner der SCL14 GRASDomäne

\begin{tabular}{|c|c|c|c|c|}
\hline Klon Nr. & $\begin{array}{c}\text { Erhöhung der ß- } \\
\text { Galaktosidaseaktivität }\end{array}$ & Gen & Proteinfunktion & Lokalisation \\
\hline 11 & 22,3 & At1G34190.1 & Transkriptionsfaktor & Zellkern \\
\hline 27 & 7,9 & At1G47128.1 & $\begin{array}{c}\text { Peptidligase, } \\
\text { Protease }\end{array}$ & $\begin{array}{l}\text { Vak., Chlp., } \\
\text { Apo. }\end{array}$ \\
\hline 10 & 5,5 & At4G35090.1 & Katalase & Chlp., Per. \\
\hline 30 & 5,3 & At1G20620 & Katalase & $\begin{array}{l}\text { Membran, } \\
\text { Vac., Chlp. }\end{array}$ \\
\hline 17 & 5,1 & At1G14700.1 & Phosphatase & Vac. \\
\hline 19 & 5,0 & At5G19090.3 & $\begin{array}{l}\text { Schwermetall Detoxifi- } \\
\text { kation, Metallionen } \\
\text { Bindung und Transport }\end{array}$ & $\begin{array}{l}\text { Plasmo- } \\
\text { desmata }\end{array}$ \\
\hline 12 & 4,2 & At1G29900.1 & $\begin{array}{c}\text { Carbamoylphosphat- } \\
\text { syntethase }\end{array}$ & $\begin{array}{l}\text { Membrane } \\
\text { Chlp. }\end{array}$ \\
\hline 46 & 3,6 & At5G40190.1 & Calmodulin Bindeprotein & Intrazellulär \\
\hline 14 & 2,9 & At5G63470.1 & Transkriptionsfaktor & Zellkern \\
\hline 61 & 2,5 & At4G49580.1 & $\begin{array}{c}\text { Reaktion auf } \\
\text { Schwefelmangel }\end{array}$ & unbekannt \\
\hline 55 & 2,0 & At1G01910 & $\begin{array}{c}\text { ATP Bindung, } \\
\text { Metallionen Homöstase }\end{array}$ & Membran \\
\hline
\end{tabular}

Bei Klon Nummer 11, der nach den Ergebnissen des oNPG-Tests von den gefundenen Interaktionspartnern die stärkste Interaktion mit der GRAS-Domäne von SCL14 darstellt, handelt es sich um den Transkriptionsfaktor NAC017. In den Promotoren der Gruppen 1 und 2 der SCL14 Zielgene sind Bindestellen für NACTranskriptionsfaktoren überrepräsentiert (Tab. 4.2) und die Promotoren der Gene GSTU7 und UGT73B3 enthalten potentielle NAC-Bindestellen. Da eine Kooperation der beiden Proteine an den Zielpromotoren möglich ist, wurden die Interaktion von NAC017 mit SCL14 und der Einfluss von NAC017 auf die Expression von SCL14 Zielgenen eingehender untersucht.

Der Klon enthielt nicht die vollständige cDNA, sondern ein Fragment, welches dem 3'-Ende von Nukleotid 1132 bis Nukleotid 1674 entspricht (Abb. 4.32). In diesem Fragment ist die NAC Domäne, welche die Bindung der NAC Transkriptionsfaktoren an die DNA vermittelt, nicht enthalten. 


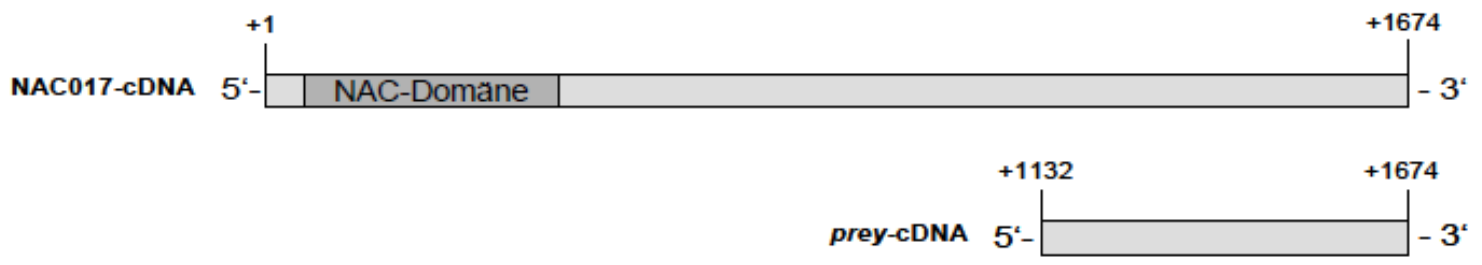

Abbildung 4.32: Struktur der im Hefe-Zwei-Hybrid-System gefundenen cDNA von NAC017 (P. Demeshko).

Das gefundene cDNA-Fragment umfasst das 3'-Ende von Nukleotid Nr. 1132 bis Nukleotid Nr. 1674 der vollständigen NAC017 cDNA und kodiert somit für den C-Terminus des NAC017-Proteins und beinhaltet daher nicht die NAC Domäne, welche die NAC Transkriptionsfaktoren charakterisiert und deren Bindung an die DNA vermittelt (Welner et al. 2012).

Um zu testen, ob auch der vollständige Transkriptionsfaktor NAC017 mit SCL14 interagiert, wurde die vollständige CDNA von NAC017 amplifiziert und in das Plasmid pAct2 kloniert. Es folgte die Kotransformation der Hefe PJ69-4A mit pAct2-NAC017 und pGBKT7-SCL14GRAS und das Ausplattieren der Transformationsansätze auf Selektions- und Interaktionsmedium sowie ein oNPG-Test. Nur die Hefen welche sowohl mit NAC017 als auch mit der SCL14 GRAS-Domäne transformiert worden sind, wachsen auf Interaktionsmedium, während kein Wachstum der Hefen zu beobachten ist, die nur SCL14 oder nur NAC017 beziehungsweise nur die Leerplasmide enthalten (Abb. 4.33).

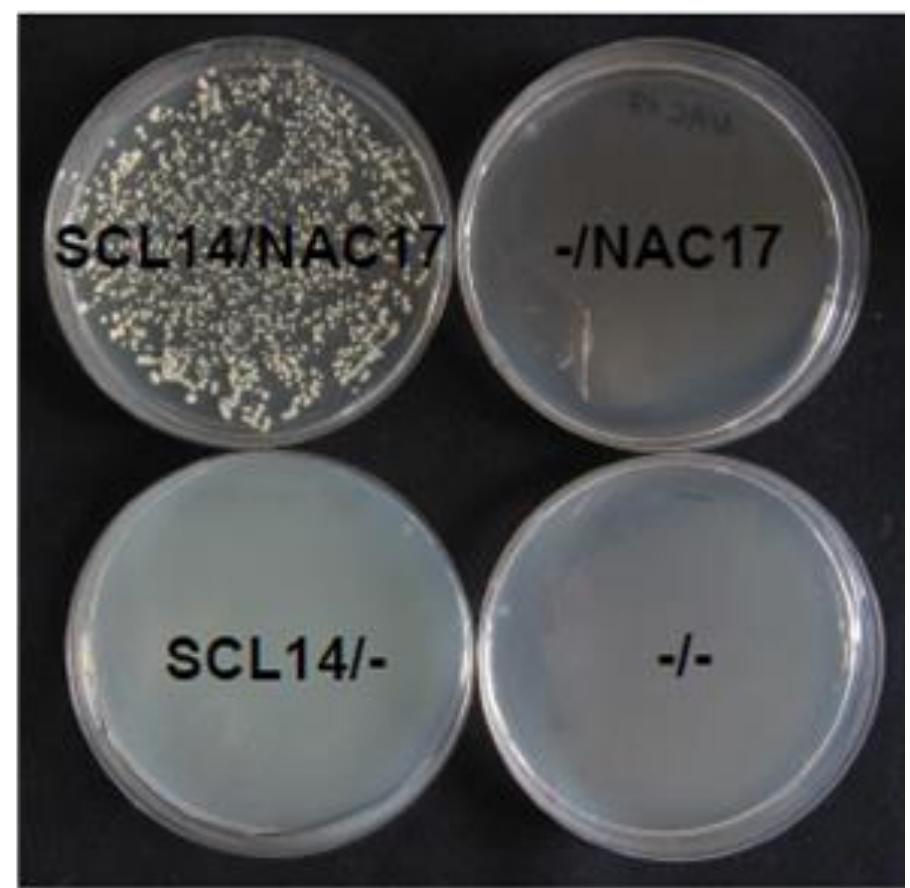

Abbildung 4.33: Wachstum von mit SCL14 und NAC017 transformierten Hefen des Stammes PJ69a auf Interaktionsmedium (P. Demeshko).

Im oNPG-Test wird deutlich, dass die Interaktion des C-Terminus von NAC017 mit der GRAS-Domäne von SCL14 um etwa den Faktor fünf stärker ist, als die 
Interaktion des vollständigen NAC017. Allerdings ist diese Interaktion wiederum um den Faktor fünf stärker als die Negativkotrolle (Abb. 4.34). Somit konnte gezeigt werden, dass auch der vollständige Transkriptionsfaktor NAC017 mit der GRASDomäne von SCL14 interagiert.

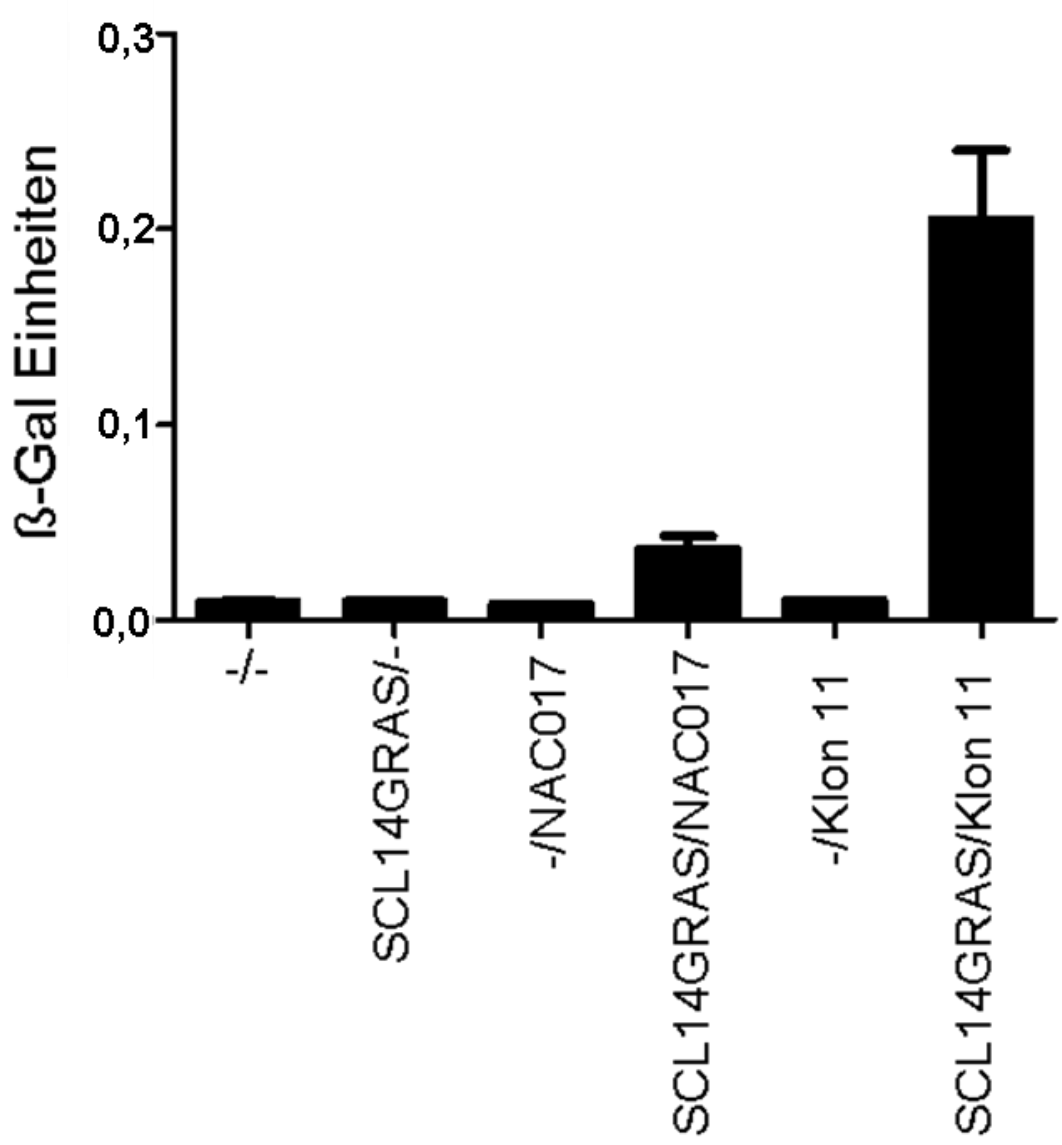

Abbildung 4.34: Quantifizierung der Interaktion der GRAS-Domäne von SCL14 mit dem im Hefe-Zwei-Hybrid-System gefundenen C-terminalen Teil von NAC017 und dem NAC017 Volllängenprotein mittel oNPG-Test.

Gezeigt ist der Mittelwert von drei unabhängigen, biologischen Replikaten ( \pm SEM). (Durchführung des Experiments von P. Demeshko im Rahmen ihrer Bachelorarbeit).

Um zu prüfen, ob SCL14 spezifisch mit NAC017 oder auch mit anderen NAC Faktoren interagiert, wurde die SCL14 GRAS-Domäne im Hefe-Zwei-Hybrid-System auf ihre Interaktion mit NAC002 und NAC032 getestet. Hierfür wurde der Hefestamm PJ69-4A mit der SCL14 GRAS-Domäne und jeweils einem der drei NAC Transkriptionsfaktoren NAC002, NAC017 und NAC032 kotransformiert. Im oNPGTest lässt sich wiederum eine Interaktion zwischen der SCL14 GRAS-Domäne und NAC017 beobachten, da in den Hefeklonen, die mit diesen beiden Proteinen transformiert wurden, eine Erhöhung der B-Galaktosidaseaktivität im Vergleich zur Negativkontrolle gemessen werden kann. Die Hefeklone, die NAC002 
beziehungsweise NAC032 enthalten, zeigen diese Erhöhung der B-Galaktosidaseaktivität nicht (Abb. 4.35). Es findet also keine Interaktion dieser beiden Proteine mit der SCL14 GRAS-Domäne statt. Da auch die Spezifität von NAC017 für die GRASDomäne von SCL14 getestet werden sollte, wurde die Interaktion des Proteins mit der GRAS-Domäne von SCL14 und der GRAS-Domäne des DELLA Proteins Repressor of GA1 (RGA) in einem oNPG-Test verglichen. Wie Abb. 4.35 zeigt, kann in den Hefeklonen, die mit NAC017 und der GRAS-Domäne von RGA transformiert wurden, keine Erhöhung der B-Galaktosidaseaktivität im Vergleich zur Negativkontrolle gemessen werden, während in den Hefeklonen, die NAC017 und die SCL14 GRAS-Domäne enthalten, wiederum eine Erhöhung der B-Galaktosidaseaktivität beobachtet werden kann. NAC017 interagiert also nicht mit der GRAS-Domäne von RGA. Die Interaktion von SCL14 und NAC017 kann somit als spezifisch angesehen werden.
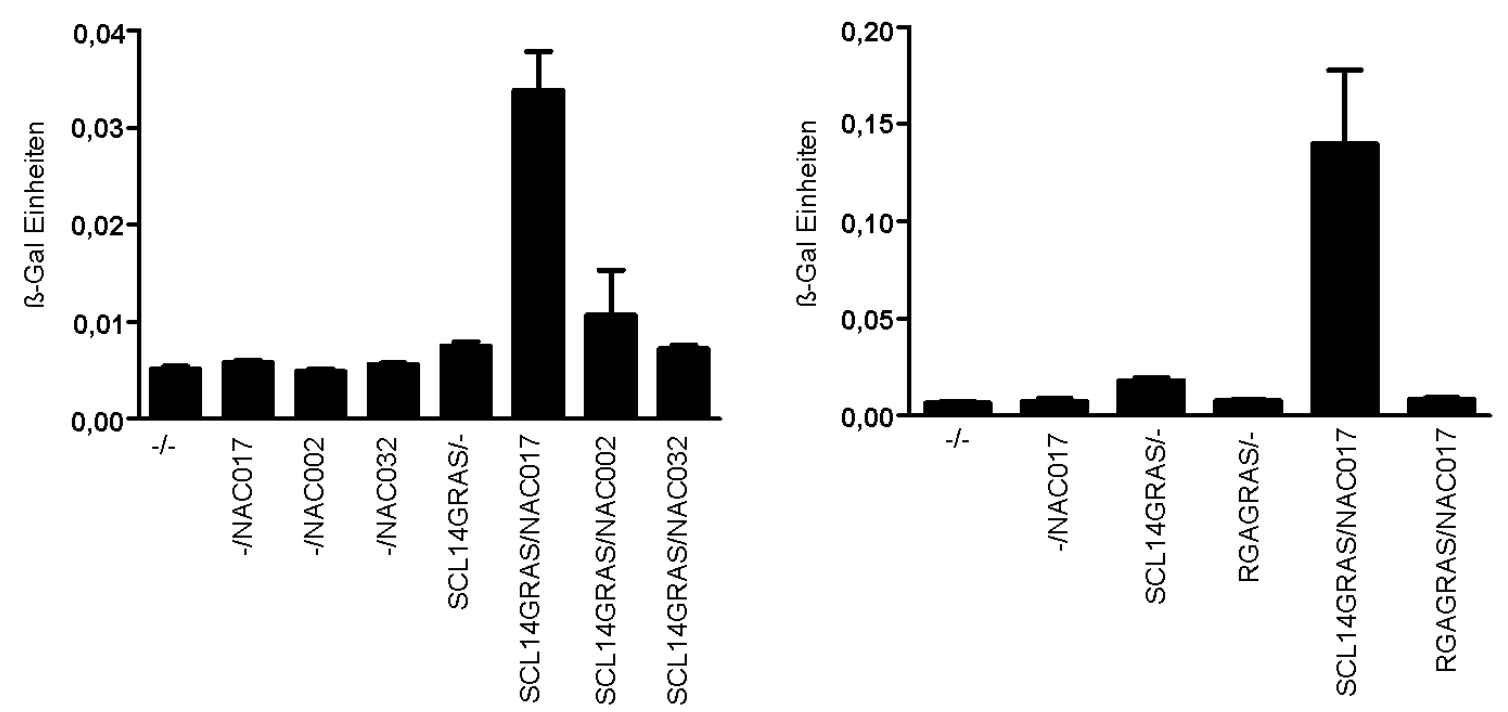

Abbildung 4.35: Quantifizierung der Interaktion zwischen der GRAS-Domäne von SCL14 mit den NAC Transkriptionsfaktoren NAC002, NAC017 und NAC032, sowie der GRAS-Domänen von SCL14 und RGA mit NAC017 mittels oNPG-Test.

Gezeigt ist der Mittelwert von 3 unabhängigen, biologischen Replikaten ( \pm SEM).

\subsubsection{Charakterisierung einer NAC017T-DNA Insertionslinie}

Um die Bedeutung von NAC017 für die Expression der Zielgene von SCL14 zu untersuchen, wurden zwei T-DNA Insertionslinien, SALK_025104 und SALK_117000 charakterisiert. Die Insertion in der Linie SALK_025104 befindet sich im 5'nichttranslatierten Bereich des NAC017 Gens, während sich die Insertion in der Linie SALK_177000 im zweiten Exon befindet (Abb. 4.36). Um festzustellen, ob es sich bei 
den beiden Linien um knockout Linien handelt, oder ob noch NAC017 mRNA in den Pflanzen gebildet wird, wurde eine quantitative RealTime PCR mit cDNA aus Pflanzen der beiden Insertionslinien als Amplifikationsvorlage durchgeführt. Bei den hierfür verwendeten Oligonukleotiden handelt es sich um Quantitect Primer ${ }^{\circledR}$ der Firma Quiagen. Das vorwärts gerichtete Oligonukleotid bindet am Ende des dritten Exons (QNAC017-fwd) und das rückwärts gerichtete Oligonukleotid bindet am Anfang des vierten Exons (QNAC017-rev) (Abb. 4.36).

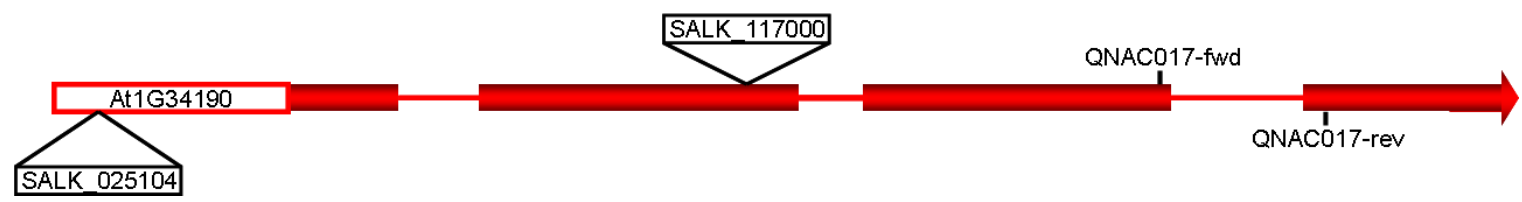

Abbildung 4.36: Intron/Exon Struktur des NAC017 Gens mit den Positionen der T-DNA Insertionen und der qRT-PCR Oligonukleotide.

Für die quantitative RealTime PCR wurde cDNA aus Pflanzen verwendet, die für vier Wochen unter Kurztagbedingungen auf Erde angezogen und für acht Stunden mit $100 \mu \mathrm{M}$ TIBA behandelt wurden. Die TIBA Behandlung erfolgte durch Besprühen der Blätter. Für die RNA-Extraktion und die anschließende cDNA-Synthese wurden die Blätter geerntet, in Stickstoff eingefroren und gemörsert.

In der T-DNA Insertionslinie SALK_025104 entspricht die Expression der NAC017 mRNA der im Wildtyp. Hier scheint die T-DNA Insertion keinen Einfluss auf die Expression des Gens zu haben. Diese Linie kann somit nicht verwendet werden, um die Bedeutung von NAC017 für die Expression der SCL14 Zielgene zu untersuchen. In der Linie SALK_117000 ist die Expression von NAC017 stark reduziert im Vergleich zum Wildtyp (Abb. 4.37). Da in dieser Insertionslinie das NAC017 Gen nicht mehr exprimiert wird, wird diese Linie für alle weiteren Experimente unter der Bezeichnung nac017 verwendet.

Wie ebenfalls aus Abb. 4.37 ersichtlich, ändert sich die Expression von NAC017 nach der Behandlung der Pflanzen mit TIBA nicht. Bedingungen, die zu einer Induktion der SCL14 Zielgene führen, rufen also keine Änderung der Expression des SCL14 Interaktionspartners NAC017 hervor. 


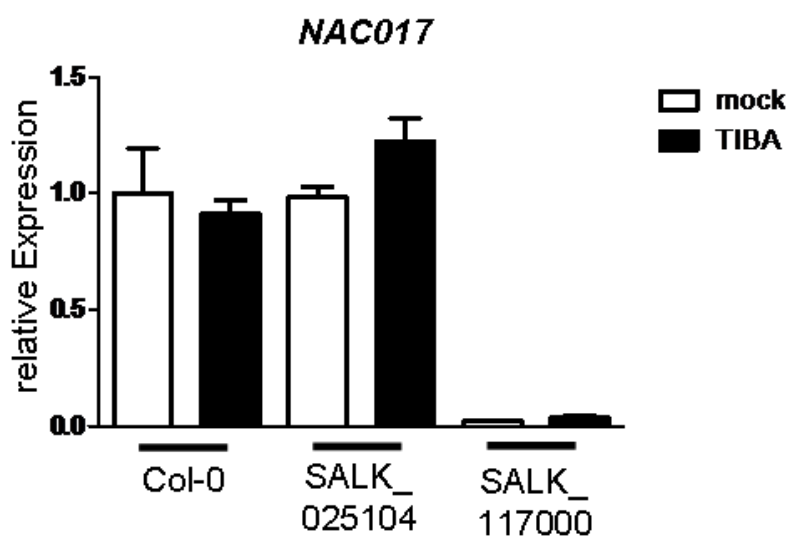

Abbildung 4.37: Expression von NAC017 in den T-DNA Insertionslinien SALK_025104 und SALK_117000 nach TIBA Behandlung.

Die Behandlung mit $100 \mu \mathrm{M}$ TIBA erfolgte für acht Stunden an vier Wochen alten, auf Erde unter Kurztagbedingungen angezogenen Pflanzen durch Sprühen. Geerntet wurde Blattmaterial. Die relativen Transkriptmengen von NAC017 wurden mittels qRT-PCR bestimmt. Zur Normalisierung der Expression diente UBQ5. Die mittlere relative Expression der Wildtyp Kontrolle wurde gleich 1 gesetzt. Gezeigt sind die Mittelwerte von 8 - 10 Hydroponikkulturen ( \pm SEM) aus zwei unabhängigen Experimenten.

\subsubsection{Expression von SCL14 Zielgenen in der nac017 Mutante}

Für die Analyse der Expression der SCL14 Zielgene in der nac017 Mutante wurden die Pflanzen für 10 Tage im hydroponischen System angezogen und für eine Stunde mit $1 \mathrm{mM}$ SA behandelt. Aus dem geernteten Wurzelmaterial wurde die RNA extrahiert und mittels qRT-PCR analysiert. Bei den drei Genen GSTU7, UGT73B3 und AT3G04130 ist kein deutlicher Unterschied der Expression in der nac017 Mutante, im Vergleich zum Wildtyp, zu beobachten. GSTU7 und AT3G04130 zeigen in beiden Genotypen nach SA-Behandlung eine signifikante Erhöhung der Expression (Abb. $4.38 \mathrm{~A}$ und C). Bei UGT73B3 ist ebenfalls eine Erhöhung der Expression nach SA-Behandlung $z u$ beobachten, jedoch ist diese in beiden Genotypen nicht signifikant (Abb. 4.38 B). Die Expression von AT5G61800 ist im Wildtyp ebenfalls nicht signifikant erhöht, in der nac017 Mutante hingegen schon (Abb.4.38 D). Somit scheint NAC017 einen Effekt auf die Expression dieses Gens zu haben. 
A

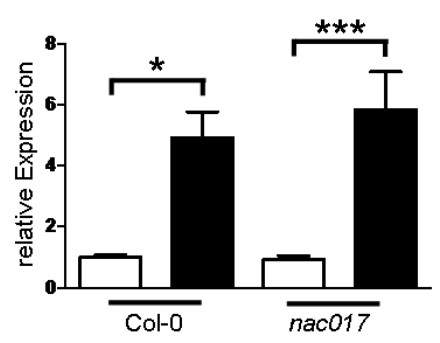

C

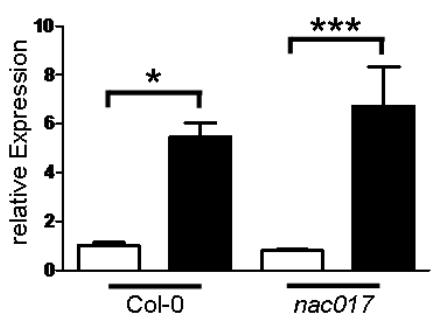

B
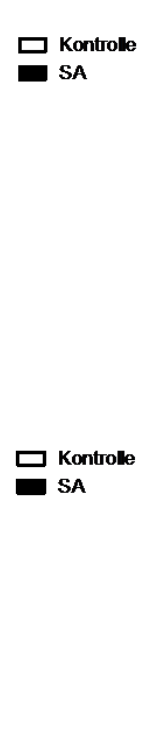

D
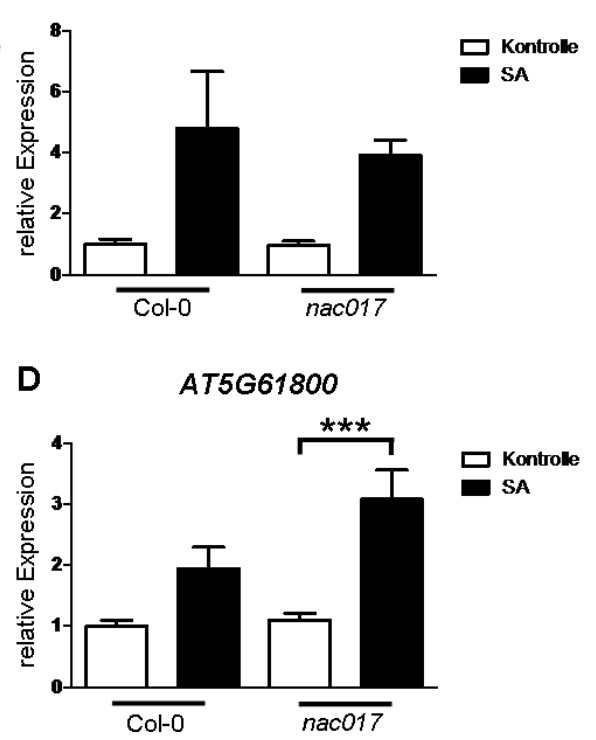

Abbildung 4.38: Expression der SCL14 Zielgene GSTU7, UGT73B3, AT3G04130 und AT5G61800 in der nac017 Mutante nach SA Behandlung.

Die Behandlung mit $1 \mathrm{mM}$ SA erfolgte für eine Stunde an 10 Tage alten, in hydroponischen Kulturen unter Langtagbedingungen angezogenen Pflanzen. Die relativen Transkriptmengen von GSTU7, UGT73B3, AT3G04130 und AT5G61800 wurden mittels qRT-PCR bestimmt. Zur Normalisierung der Expression diente UBQ5. Die mittlere relative Expression der Wildtyp Kontrolle wurde gleich 1 gesetzt. Gezeigt sind die Mittelwerte von 8 - 9 Pflanzen ( \pm SEM) aus zwei unabhängigen Experimenten. $\left({ }^{*}: p \leq 0,05,{ }^{* * *}: p \leq 0,001\right.$; One-way ANOVA) 


\section{Diskussion}

Die Detoxifikation xenobiotischer Substanzen in Pflanzen kann in drei Abschnitte unterteilt werden. Im ersten Abschnitt erfolgt die Aktivierung der Substanzen durch das Einfügen reaktiver Gruppen durch Enzyme wie Cytochrom P450 Monooxygenasen. Im zweiten Schritt erfolgt die eigentliche Entgiftung durch die Konjugation mit hydrophilen Molekülen wie Glutathion durch Glutathion STransferasen oder Glucose durch Glycosyltransferasen. Im dritten Schritt werden die konjugierten Substanzen durch ATP-abhängige Transporter in die Vakuole oder den apoplastischen Raum transportiert (Coleman et al. 1997). Die an diesem Entgiftungsprogramm beteiligten Gene werden durch chemischen Stress induziert und ein Teil davon wird durch das GRAS-Protein SCARECROW-like 14 (SCL14) reguliert. SCL14 wurde in einem Proteininteraktionsexperiment in der Hefe als Interaktionspartner des bZIP-Transkriptionsfaktors TGA2 gefunden (Fode et al. 2008). Für die Aktivierung der SCL14 Zielgene ist die Bildung des SCL14/TGA2Komplexes notwendig, da SCL14 keine DNA-Bindefähigkeit besitzt. Der SCL14/TGA2-Komplex bindet an as-1-ähnliche Sequenzen in den Promotoren seiner Zielgene. Dies allein führt jedoch noch nicht zur Aktivierung der Transkription, da der Komplex sowohl im uninduzierten als auch im induzierten Zustand an die DNA gebunden vorliegt (Fode et al. 2008). Da in Tabakprotoplasten ein konstanter Austausch des SCL14 Proteins zwischen dem Zellkern und dem Cytoplasma beobachtet werden konnte, wurde in dieser Arbeit der Fragestellung nachgegangen, ob dieser Austausch auch in Arabidopsis stattfindet und ob er eine Bedeutung für die Regulation von SCL14 hat. Des Weiteren konnte die Bedeutung von im Protein vorhandenen Cysteinen für die Aktivität von SCL14 nachgewiesen werden. In einem Hefe-Zwei-Hybrid Experiment, in dem die GRAS-Domäne von SCL14 als Köderprotein angeboten wurde, konnte der Transkriptionsfaktor NAC017 als neuer Interaktionspartner von SCL14 identifiziert werden.

Im Folgenden wird diskutiert, wie die drei xenobiotischen Substanzen SA, TIBA und OPDA zu einer Kernakkumulation von SCL14 führen können, welche Rolle die in SCL14 vorhandenen Cysteine dabei spielen können, wie sich diese Prozesse auf die Expression SCL14-abhängiger Gene auswirken und welche Rolle NAC017 bei der Regulation dieser Gene spielen könnte. 


\subsection{Unterschiedliche Substanzen führen zu einer}

\section{Akkumulation von SCL14 im Zellkern}

Die von Fode et al. beobachtete Akkumulation von SCL14 im Zellkern von Tabakprotoplasten durch die Inhibition des Kernexports mit LMB (Fode et al. 2008) konnte in dieser Arbeit ebenfalls in Wurzeln von Arabidopsis gezeigt werden (Abb. 4.2). Weiterhin erfolgte diese Akkumulation nach Behandlung der Pflanzen mit SA, TIBA und OPDA (Abb. 4.3 und 4.4), welche, im Gegensatz zu LMB, keine generellen Inhibitoren des Kernexports darstellen. Daraus ergeben sich die Fragen, ob die Akkumulation von SCL14 im Zellkern nach SA-, TIBA, und OPDA-Behandlung, wie bei LMB, eine Folge der Inhibition des Kernexports des Proteins ist, oder ob beispielsweise der Kernimport verstärkt wird, und welche gemeinsame Eigenschaft, die die drei Substanzen aufweisen, zu der beobachteten Akkumulation führen kann. Auf die Frage, ob die Akkumulation von SCL14 im Zellkern eine Folge des Kernimports oder des Kernexports ist, wird in Abschnitt 5.2 eingegangen.

Für die Beantwortung der Frage, durch welches gemeinsame Charakteristikum SA, TIBA und OPDA die Kernakkumulation von SCL14 auslösen können, ist es notwendig, sich mit den chemischen Eigenschaften dieser Substanzen zu beschäftigen. Bei allen dreien handelt es sich um reaktive Moleküle, die in höheren Konzentrationen zellschädigend wirken (Anderson et al. 1998; Berger et al. 2007; Fode et al. 2008) und sowohl SA und TIBA als auch OPDA induzieren die Expression von Genen, deren Genprodukte an der Entgiftung xenobiotischer Substanzen, aber auch an der Reparatur endogener Strukturen beteiligt sind (Uquillas et al. 2004; Fode et al. 2008; Mueller et al. 2008). Aufgrund ihrer strukturellen Heterogenität könnte es sein, dass die Wahrnehmung dieser Chemikalien und die daraus resultierende Aktivierung der Genexpression nicht über die direkte Erkennung der Chemikalien durch einen Rezeptor erfolgt, sondern dass vielmehr Schädigungen in der Zelle wahrgenommen werden. Für OPDA und SA wurde bereits untersucht, auf welche Art und Weise diese beiden Substanzen solch eine Zellschädigung hervorrufen können. Bei OPDA wird dieser schädigende Effekt auf die $\alpha, \beta$-ungesättigte Carbonylgruppe (Abb. 2.6) zurückgeführt (Mueller et al. 2008), welche in einer Michael-Addition mit nukleophilen Gruppen, wie zum Beispiel Thiolen von Proteinen, reagieren und dadurch oxidativen Stress hervorrufen kann (Abb. 5.1). 
A

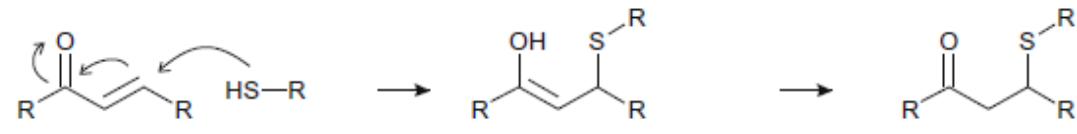

B

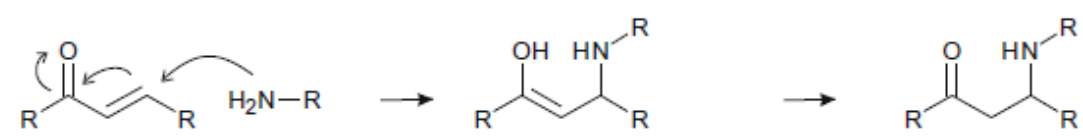

C

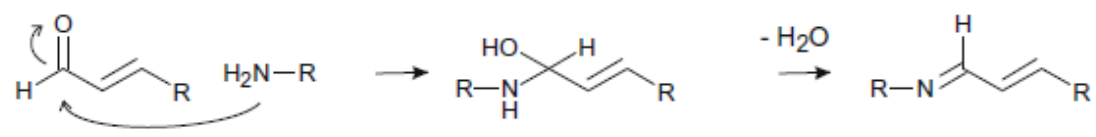

D

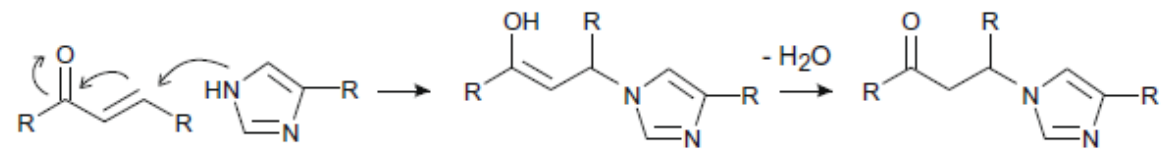

Abbildung 5.1: Reaktion von $\alpha, \beta$-ungesättigten Carbonylgruppen mit Thiolen und Aminen (Michael-Addition).

Thiolgruppen von Proteinen und Amine von Proteinen und Nukleinsäuren reagieren mit Molekülen, die eine $\alpha, \beta$-ungesättigten Carbonylgruppe enthalten. Dabei kann der Angriff entweder auf das $\beta$ Kohlenstoffatom erfolgen (A,B und D), oder auf das Carbonylkohlenstoffatom (D). (Mueller \& Berger 2009)

Der Effekt von SA verläuft vermutlich über die Bildung eines SA-Radikals. Dieses entsteht durch die Übertragung eines Elektrons des SA-Moleküls auf die Katalase, welche dadurch inaktiviert wird, was zur Akkumulation von Wasserstoffperoxid führt (Anderson et al. 1998) (Abb. 5.2). Das SA-Radikal kann dann wiederum die Oxidation von Membranlipiden zu Lipidperoxiden auslösen, welche sowohl in den Membranen akkumulieren und deren selektive Permeabilität stören, als auch aus den Membranen freigesetzt werden und selbst weitere Schäden hervorrufen können (Mueller 2004).

Die Oxidation der Lipide geschieht nicht durch das entstandene Wasserstoffperoxid, da eine Inhibition der Katalase durch 3-Aminotriazol (3-AT), was ebenfalls zu einer Ansammlung von Wasserstoffperoxid führt aber die Bildung des SA-Radikals verhindert, nicht zu einer verstärkten Bildung von Lipidperoxiden führte (Anderson et al. 1998). Auch Garretón et al. konnten zeigen, das die SA-vermittelte Aktivierung des as-1 Elementes durch oxidativen Stress erfolgt, da die Aktivierung des as-1 Elementes durch die Antioxidantien Dimethylthiourea (DMTU) und 3-t-butyl-4hydroxy-Anisol (BHA) verhindert werden konnte. Wie bereits Anderson et al., konnten auch Garretón et al. durch die Inhibition der Katalase mit 3-AT zeigen, dass der Effekt von SA nicht durch $\mathrm{H}_{2} \mathrm{O}_{2}$ vermittelt wird (Garretón et al. 2002). Ob DMTU und BHA die SA-induzierte Akkumulation von SCL14 im Zellkern unterbinden können, konnte in dieser Arbeit nicht überprüft werden, da durch diese beiden Substanzen die 
Fluoreszenz des GFP stark verringert wurde, sodass das HA-GFP-SCL14 Fusionsprotein im Fluoreszenzmikroskop nicht mehr sichtbar war.

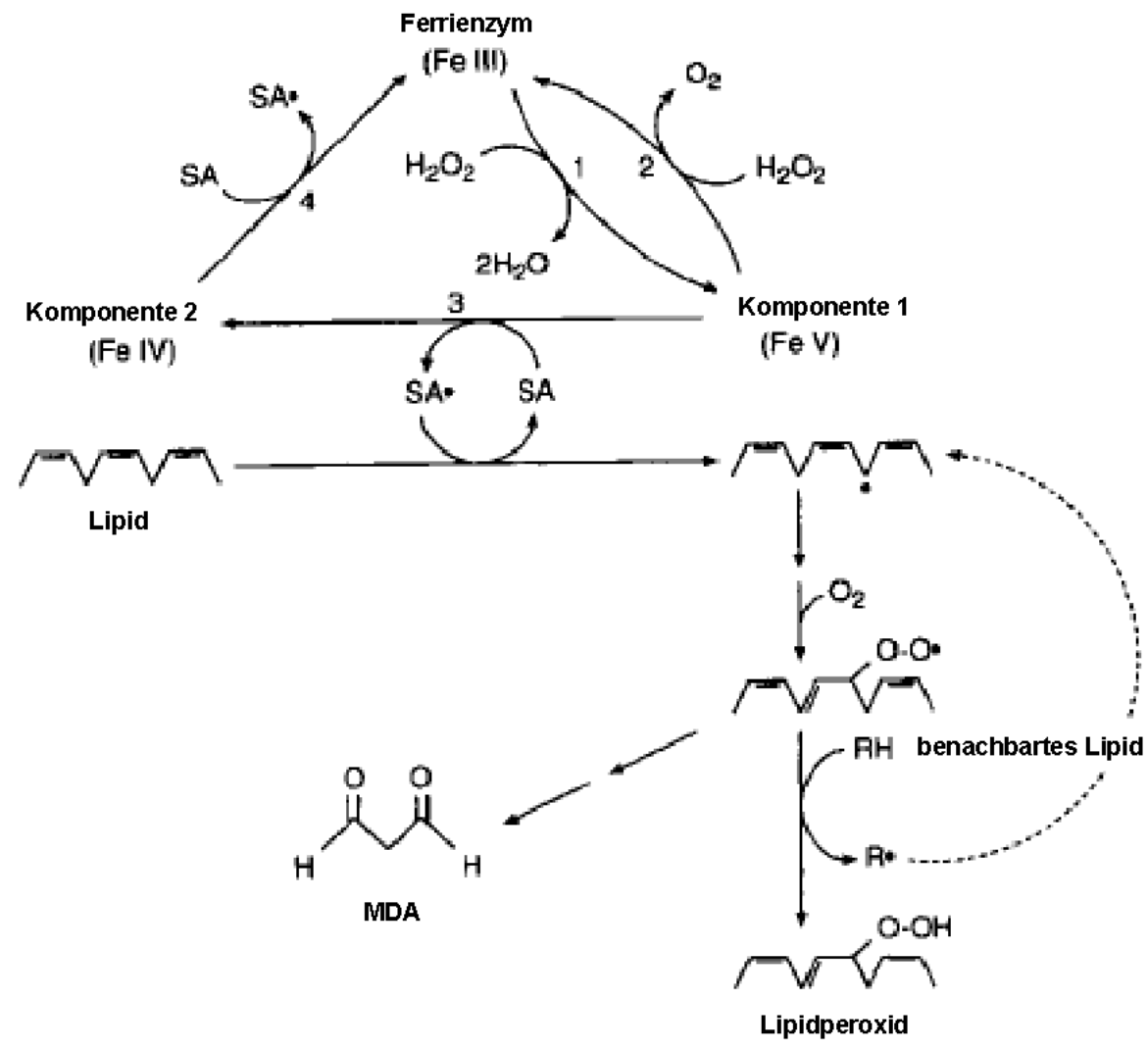

Abbildung 5.2: Mechanismus der Entstehung des SA-Radikals

Durch die Reduktion von $\mathrm{H}_{2} \mathrm{O}_{2}$ zu Wasser (1) wird die Katalase vom Ferrienzym zu Komponente 1 oxidiert. Durch die Oxidation von $\mathrm{H}_{2} \mathrm{O}_{2} \mathrm{zu} \mathrm{O}_{2}$ (2) wird das Ferrienzym regeneriert und der Katalytische Zyklus abgeschlossen. Durch die Übertragung eines Elektrons von SA auf Komponente 1 (3) wird diese in die inaktive Komponente 2 überführt und es entsteht ein SA-Radikal, welches mit einer ungesättigten Fettsäure reagieren kann, wodurch die Lipidperoxidationskettenreaktion in Gang gesetzt wird. Bei hohen $\mathrm{H}_{2} \mathrm{O}_{2}$ Konzentrationen kann Komponente 2 durch SA, unter erneuter Bildung eines SA-Radikals zum Ferrienzym regeneriert werden. Verändert nach (Anderson et al. 1998).

Die durch die Oxidation von Fettsäuren durch das SA-Radikal oder andere elektrophile Substanzen entstandenen Lipidderivate können ihre Wirkung in der Zelle potentiell auf zwei unterschiedliche Arten entfalten. Zum einen indirekt durch die Verschiebung des Redox-Gleichgewichtes, da für die Entgiftung dieser oxidierten Fettsäuren Reduktionsäquivalente in Form von NADPH und FMN verbraucht werden (Farmer \& Davoine 2007) und durch die direkte Reaktion mit der Thiolgruppe des Glutathions, wodurch in der Zelle ein oxidatives Millieu erzeugt wird. Zum Anderen können RES direkt nukleophile Gruppen in Biomolekülen oxidieren und diese so schädigen (Farmer \& Davoine 2007). 
Der genaue Wirkmechanismus von TIBA innerhalb der Zelle ist noch nicht bekannt, jedoch ist es durchaus wahrscheinlich, dass TIBA ebenfalls zur Verschiebung des Redox-Gleichgewichtes führt oder die Modifikation von Biomolekülen auslöst, da der Benzolring des Moleküls durch die drei Elektronen ziehenden lod-Substituenten einen elektrophilen Charakter erhält und in einer nukleophilen aromatischen Substitution mit nukleophilen Gruppen reagieren kann.

Das gemeinsame Charakteristikum von OPDA, SA und TIBA ist also, dass sie in der Zelle oxidativen Stress auslösen. Dieser Stress und eine daraus resultierende mögliche Redoxmodifikation reaktiver Cysteine von SCL14 könnte demnach das Ereignis sein, welches die Kernakkumulation von SCL14 auslöst.

Statt der kovalenten Modifikation reaktiver Cysteine könnte die Aktivierung von SCL14 auch durch die direkte, reversible Bindung von Xenobiotika und durch Xenobiotika-induzierte kleine Moleküle erfolgen. Für Pflanzen konnte solch ein Mechanismus der reversiblen, nichtkovalenten Bindung von Xenobiotika an Rezeptoren bisher noch nicht nachgewiesen werden, jedoch sind Beispiele aus dem Tierreich bekannt. So bindet der Aryl-Hydrocarbon-Rezeptor (AHR) aromatische Toxine, wie Dioxin, im Cytoplasma, was zur Translokation des Rezeptors in den Zellkern und der daraus resultierenden Aktivierung von Stressgenen wie Cytochrom P450 Monooxygenasen führt. AHRs sind sowohl aus Wirbellosen als auch aus Wirbeltieren bekannt (McMillan \& Bradfield 2007).

Zhang et al. postulierten, dass die pflanzlichen GRAS-Proteine nicht, wie bisher angenommen, mit den STAT-Proteinen verwand sind, sondern mit bakteriellen GRAS-Proteinen, welche Methyltransferasen darstellen (Zhang et al. 2012). Zwar hätten die pflanzlichen GRAS-Proteine größtenteils die Methyltransferaseaktivität verloren, jedoch seien die konservierten Aminosäuren, die für die Substratbindung notwendig seien, noch vorhanden. 


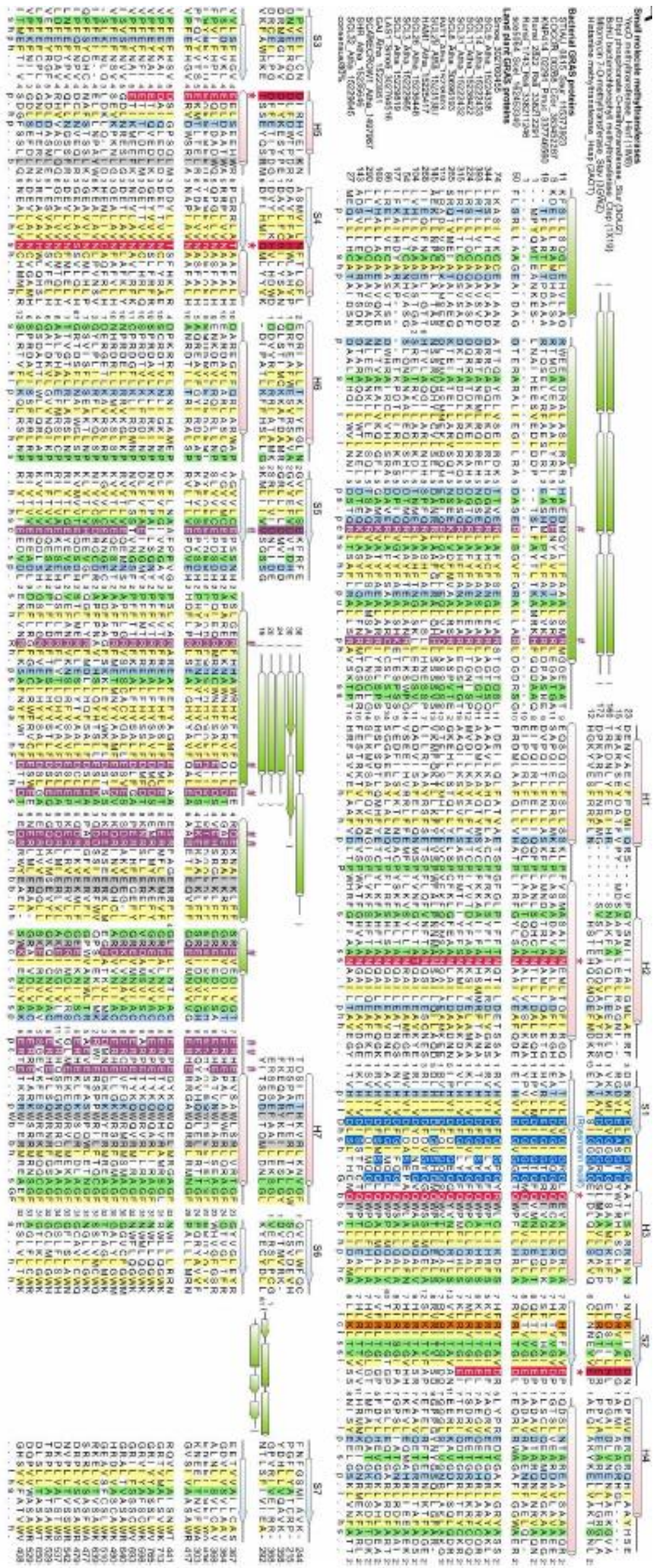


Abbildung 5.3: Sequenzvergleich von GRAS-Domänen pflanzlicher und bakterieller GRASProteine mit Methyltransferasen

Die konservierten Aminosäuren der Rossmannfalte sind blau, die für die Bindung des SAdenosylmethionins notwendigen Aminosäuren rot und die für die Substratbindung notwendigen Aminosäuren lila hinterlegt. Während die Aminosäuren der Rossmannfalte und die für die Substratbindung notwendigen Aminosäuren in den meisten pflanzlichen GRAS-Proteinen konserviert sind, sind die für die Bindung des S-Adenosylmethionins notwendigen Aminosäuren bei vielen pflanzlichen GRAS-Proteinen nicht mehr vorhanden (Zhang et al. 2012).

Somit könnten viele GRAS-Proteine noch eine Bindeaktivität für kleine Moleküle aufweisen. Daher könnte auch SCL14 möglicherweise in der Lage sein, kleine Moleküle wie SA oder TIBA zu binden, was dann zu einer Aktivierung des Proteins führen könnte. Allerdings würde eine Aktivierung durch eine breite Palette von Xenobiotika eine sehr geringe Substratspezifität erfordern, da Xenobiotika strukturell sehr divers sein können, wie zum Beispiel SA und OPDA. Es besteht jedoch auch die Möglichkeit, dass SCL14 nicht direkt die ursprünglichen Xenobiotika bindet, sondern die aufgrund deren Einwirkung entstandenen sekundären Substanzen. Zum Beispiel könnte Malondialdehyd (MDA) ein Kandidat für ein solches Sekundärmolekül sein. MDA ist eines der häufigsten Produkte der Lipidperoxidation in Pflanzenzellen und induziert die Expression von Stressassoziierten Genen wie GSTs (Weber et al. 2004). Die Hypothese, das Xenobiotika oder durch chemischen Stress induzierte Moleküle direkt an SCL14 binden, wurde in dieser Arbeit nicht überprüft, jedoch konnte gezeigt werden, dass zwei der im Protein vorhandenen Cysteine für die Funktionalität von SCL14 essentiell sind.

\subsection{Die Cysteine C400 und C691 sind essentiell für die Funktionalität von SCL14}

Wie im vorangehenden Abschnitt beschrieben, wird die Akkumulation von SCL14 im Zellkern durch Substanzen induziert, die in der Zelle oxidativen Stress auslösen können. Die Wahrnehmung dieses oxidativen Stresses durch Sensormoleküle kann durch die Redox-Modifikation von Cysteinen in diesen Proteinen erfolgen (Spoel \& Loake 2011; Spadaro et al. 2010). Allerdings sind nicht alle Cysteine in gleicher Weise empfänglich gegenüber solchen Modifikationen, da ihre Reaktivität auch durch die sie umgebenden Aminosäuren beeinflusst wird (Spoel \& Loake 2011). Um die mögliche Beteiligung der Cysteine von SCL14 an der Regulation des Proteins zu untersuchen, wurden Mutanten erstellt, bei denen eines oder mehrere Cysteine gegen die Aminosäure Serin ausgetauscht wurden. Durch die Mutation der fünf 
Cysteine in der GRAS-Domäne von SCL14 (Abb. 4.11) wurde ein Protein erstellt, welches nicht mehr in den Zellkern importiert wird (Abb. 4.18) und sowohl die Fähigkeit verloren hat, in einem transienten Protoplastensystem den GSTU7Promotor zu aktivieren (Abb. 4.13) als auch mit TGA2 und dem Kernexportrezeptor XPO1a zu interagieren (Abb. 4.16). Durch die Erstellung von Doppelmutanten konnte nachgewiesen werden, dass es sich bei den für die Aktivierung des GSTU7Promotors (Abb.4.15) und für die Interaktion mit TGA2 und XPO1a essentiellen Cysteinen um C400 und C691 handelt (Abb. 4.16). Ob diese Mutante genau wie die Mutante, in der alle fünf Cysteine der GRAS-Domäne mutiert waren, in der Kernlokalisation beeinträchtig ist, konnte bisher noch nicht getestet werden. Es stellt sich nun die Frage, auf welche Weise die beiden Cysteine die Aktivität von SCL14 beeinflussen können. Wie bereits im vorangehenden Abschnitt erwähnt, lösen SA, TIBA und OPDA oxidativen Stress aus, der zur Redox-Modifikation reaktiver Cysteine in Proteinen führen kann. Beispiele für die Regulation von Transkriptionsfaktoren bzw. Transkriptionskoaktivatoren durch solche RedoxModifikationen sind sowohl von Tieren und Pilzen, als auch von Bakterien bekannt. So wird der Säugetiertranskriptionsfaktor Nrf2 von seinem Interaktionspartner Keap1 im Cytoplasma zurückgehalten und für den Abbau durch das Proteasom markiert. Nach der Oxidation kritischer Cysteine in Keap1 wird die Interaktion der beiden Proteine unterbunden, wodurch Nrf2 stabilisiert wird und in den Zellkern gelangen kann um die Genexpression zu aktivieren (Satoh et al. 2006; Dinkova-Kostova et al. 2005). Solch einen Mechanismus könnte man sich ebenfalls für SCL14 vorstellen, wobei die Redox-Modifikation entweder an SCL14 oder an dem noch unbekannten interagierenden Protein stattfinden könnte. Allerdings ist diese Retention im Cytoplasma nicht vollständig, da SCL14 bereits im uninduzierten Zustand in den Kern transportiert wird, was daran zu erkennen ist, dass die Kernakkumulation allein durch LMB ohne zusätzlichen, oxidativen Stimulus hervorgerufen werden kann (Abb. 4.2) und das JA im Wildtyp und nicht in der sc/14/33 Mutante in der Lage ist, die Expression von GSTU7 zu induzieren, ohne das es zu einer Akkumulation von SCL14 im Zellkern kommt (Abb. 4.4 und 4.25). Dies könnte bedeuten, dass ein gewisser Prozentsatz von SCL14 und seinem Interaktionspartner bereits basal oxidiert ist, oder dass die Mengen des Retentionsfaktors limitiert sind.

In der Hefe Saccharomyces cerevisiae gibt es den Transkriptionsfaktor YAP1p, welcher für die Antwort auf oxidativen Stress verantwortlich ist. Im uninduzierten 
Zustand findet ein konstanter Austausch des Proteins zwischen dem Cytoplasma und dem Zellkern statt. Nach der Oxidation von vier Cysteinen unter oxidativem Stress und der daraus resultierenden Bildung von intramolekularen Disulfidbrücken wird das Kernexportsignal maskiert und YAP1p akkumuliert im Zellkern (Kuge et al. 1997; Menezes et al. 2004). Da sowohl YAP1p als auch SCL14 im uninduzierten Zustand kontinuierlich zwischen dem Zellkern und dem Cytoplasma hin und her wechseln und bei oxidativem Stress im Zellkern akkumulieren, ist es denkbar, dass auch bei der Regulation beider Proteine Parallelen gibt, dass also durch die Oxidation von Cysteinen die Kernexportsequenz von SCL14 nicht mehr für den Kernexportapparat zugänglich ist, was dann zur Kernakkumulation führt.

Aus Escherichia coli ist der durch Redox-Modifikationen regulierte Transkriptionsfaktor OxyR bekannt. Ein reaktives Cystein in diesem Protein kann durch unterschiedliche Substanzen oxidiert werden, wodurch eine Sulphensäure, ein gemischtes Disulfid oder ein Nitrosocystein gebildet werden, was jeweils zu unterschiedlichen DNA-Bindeeigenschaften führt (Kim et al. 2002). Auch diese Art der Regulation wäre für SCL14 vorstellbar. Zwar bindet SCL14 nicht selbst an DNA, jedoch könnte durch Konformationsänderungen, die durch eine Redox-Modifikation eines oder mehrerer Cysteine erfolgen, die Fähigkeit zur Interaktion mit anderen Proteinen positiv oder negativ beeinflusst werden. Zum Beispiel könnte die Interaktion mit dem Kernimportapparat erleichtert werden, was dann zu einem verstärkten Kernimport führen würde, oder die Interaktion mit dem Kernexportapparat könnte erschwert werden, was dann zu einer Herabsetzung des Kernexports führen würde, oder die Interaktion mit einem cytosolischen Retentionsfaktor könnte moduliert werden.

Da die Einzelmutanten nicht in messbarer Weise in der Aktivität beeinträchtigt waren, scheint die Funktion der beiden Cysteine redundant zu sein. Da jedoch ein Cystein bereits im uninduzierten Zustand oxidiert zu sein scheint und ein weiteres anscheinend nach oxidativem Stress oxidiert wird (Abb. 4.30), besteht auch die Möglichkeit, dass ein kooperativer Effekt der beiden Cysteine bei der Regulation der Aktivität von SCL14 vorliegt. Ein solcher kooperativer Effekt zweier Cysteine wurde bei dem bereits erwähnten Transkriptionsfaktor aus E. coli, OxyR, beobachtet (Kim et al. 2002). OxyR bindet bereits in seiner reduzierten Form an die DNA, was jedoch noch nicht zu einer Aktivierung der Genexpression führt (Kim et al. 2002). Diese wird erst nach der Oxidation von OxyR durch $\mathrm{H}_{2} \mathrm{O}_{2}$ oder GSNO aktiviert (Hausladen et al. 
1996). Bei der Aminosäure, die durch $\mathrm{H}_{2} \mathrm{O}_{2}$ oder $\mathrm{GSNO}$ oxidiert wird, handelt es sich um Cystein 199 und der Austausch dieser Aminosäure gegen ein Serin führt zum Verlust der Transkriptionsfaktoraktivität von OxyR. (Kim et al. 2002). Ebenfalls an der Regulation von OxyR beteiligt ist das Cystein 208. Allerdings wird diese Aminosäure nicht oxidativ modifiziert und ein Austausch führt auch nicht zu einem vollständigen Verlust der Aktivität, sondern nur zu deren Verminderung. Möglicherweise stabilisiert C208 die posttranslationale Modifikation von C199 auf chemische Weise oder durch einen Effekt auf die Konformation des Proteins (Kim et al. 2002).

Das Modell von OxyR ist nicht eins zu eins auf SCL14 übertragbar, da C400 und C691 in ihrer Funktion austauschbar zu sein scheinen, während dies bei OxyR nicht der Fall ist. Dennoch ist es denkbar, dass die Oxidation der beiden Cysteine in kooperativer Weise einen Einfluss auf die Konformation von SCL14 hat, welche die Interaktion mit anderen Proteinen beeinflussen könnte. Ein Modell für eine derartige Regulation wäre, dass bereits die Oxidation eines der beiden kritischen Cysteine für die Interaktion von SCL14 mit TGA-Faktoren, dem Kernimportapparat und dem Kernexportapparat sowohl notwendig als auch ausreichend ist. Dies wäre unter uninduzierten Bedingungen der Fall, wenn ein kontinuierlicher Austausch des Proteins zwischen Zellkern und Cytoplasma stattfindet. Durch die Einwirkung von oxidativem Stress wird das zweite Cystein oxidiert, wodurch die Interaktion mit dem Kernimportapparat erleichtert werden könnte, was dann, bei einer gleich bleibenden Exportrate, zu einer Akkumulation von SCL14 im Zellkern führen würde. Alternativ könnte die Oxidation des zweiten Cysteins auch dazu führen, dass die Interaktion mit dem Kernexportapparat verhindert wird, was bei gleich bleibendem Import ebenfalls zu einer Akkumulation von SCL14 im Zellkern führen würde.

Zwar konnte im Protoplastensystem kein Unterschied in der Fähigkeit der Einfachmutanten den GSTU7-Promotor zu aktivieren, im Vergleich zum Wildtypprotein festgestellt werden, jedoch ist für die Aktivierung dieses Promotors die basale Menge von SCL14 im Zellkern ausreichend, da JA zwar dessen Aktivierung in Abhängigkeit von SCL14 induziert (Abb. 4.25), nicht jedoch die Akkumulation von SCL14 im Zellkern (Abb. 4.4). In diesem Zusammenhang wäre es interessant zu testen, ob die C400S Mutante und die C691S Mutante noch mit TGA2 und XPO1a interagieren können, ob sie nach SA-, TIBA- oder OPDA-Stimulus noch im Zellkern akkumulieren und ob sie auch in der Lage sind, im Protoplastensystem den Promotor eines Gens zu aktivieren, welches nicht durch JA induziert wird, wie zum Beispiel 
UGT73B3, AT3G04130 oder AT5G61800 (Abb. 4.25). Sofern die beiden Einfachmutanten noch in der Lage sind, mit TGA2 und XPO1a zu interagieren, jedoch nicht mehr im Zellkern akkumulieren und auch keinen nicht durch JA induzierbaren Promotor aktivieren können, wäre dies ein Hinweis darauf, dass die Oxidation des zweiten Cysteins in der Tat für die Kernakkumulation und die daraus resultierende Aktivierung der Genexpression verantwortlich ist.

Die vollständige Reduktion des Proteins, die durch die gleichzeitige Mutation der beiden Cysteine C400 und C691 imitiert wird, könnte deswegen zu einem vollständigen Aktivitätsverlust von SCL14 führen, weil die Modifikation zumindest eines der beiden Cysteine notwendig ist, um die Interaktionsdomäne von SCL14 für andere Proteine zugänglich zu halten. Ein Protein, dessen Proteininteraktionsdomäne im reduzierten Zustand unzugänglich ist und nach der Oxidation des Proteins frei gelegt wird, ist die humane Protein Disulfid Isomerase (hPDI). Die hPDI ist ein Chaperon, welches unter anderem an der Formation, der Auflösung und der Reorganisation von Disulfidbrücken (Freedman et al. 2002) und der ER-gebundenen Degradation falsch gefalteter Proteine beteiligt ist (Molinari et al. 2002; Lee et al. 2010). Das Protein besteht aus den vier Thioredoxin-ähnlichen Domänen $a, b, a$ ' und b', einem $x$-Linker und einer C-terminalen sauren Schwanzdomäne (Alanen et al. 2003; Pirneskoski et al. 2004; Freedman et al. 1998). In ihrer reduzierten Form nimmt die hPDI eine dicht gepackte Konformation ein, was dazu führt, dass die Substrataffinität gering ist. Durch die Oxidation zweier Cysteine im aktiven Zentrum der a'-Domäne nimmt die hPDI eine offenere Konformation ein, wodurch die Substrataffinität und die katalytische Aktivität erhöht werden (Abb. 5.4) (Wang et al. 2012) 


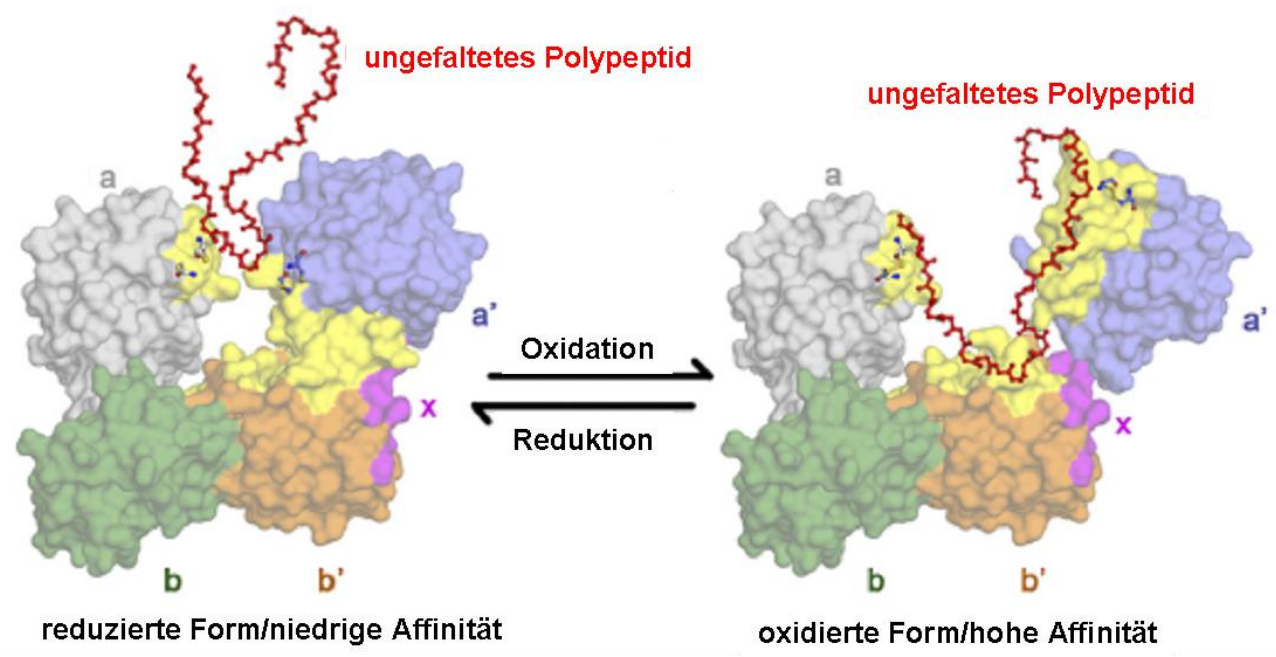

\begin{abstract}
Abbildung 5.4: Redox-induzierte Konformationsänderung der humanen Protein Disulfid Isomerase

Schematisches Modell der Redox-regulierten Chaperonaktivität der hPDI: Die reduzierte hDPI nimmt eine kompakte Konformation ein, wodurch nur kleine hydrophobe Bereiche für die Substratbindung exponiert werden. Oxidation des aktiven Zentrums der a'-Domäne induziert den Übergang in eine offenere Konformation, was zu einer verstärkten Exposition von hydrophoben Bereichen für die Substratbindung führt. Die a, a', b, b' und $x$ Domänen sind grau, blau, grün, orange und magenta dargestellt, hydrophobe Bereiche, die die Substratbindung vermitteln sind gelb dargestellt. Verändert nach (Wang et al. 2012).
\end{abstract}

Analog hierzu könnte sich bei SCL14 die Oxidation der Cysteine C400 und C691 auf die Position der GRAS-Domäne, relativ zum N-Terminus, auswirken. Dies würde erklären, warum sich die Mutation der beiden Cysteine, die sich in der C-terminalen GRAS-Domäne befinden, auf die Interaktion mit TGA2 und XPO1a auswirkt, obwohl die Interaktion von SCL14 mit diesen beiden Proteinen über den N-Terminus vermittelt wird (J. Oberdiek; unveröffentlichte Daten). Im reduzierten Zustand könnten der N-Terminus und die GRAS-Domäne von SCL14 in einer geschlossenen Konformation vorliegen, wodurch die für die Interaktion notwendigen Bereiche im NTerminus durch die GRAS-Domäne verdeckt würden. Durch die Oxidation eines der beiden Cysteine würde SCL14 in eine halb offene Konformation übergehen, wodurch die Interaktion mit TGA2, dem Kernimportapparat und XPO1a ermöglicht wird. Durch die Oxidation des zweiten Cysteins geht SCL14 in eine offene Konformation über, wodurch die Interaktion mit dem Kernimportapparat vereinfacht werden könnte, die in der halb offenen Konformation möglicherweise nur eingeschränkt möglich ist, während für die maximale Interaktion mit TGA2 und XPO1a bereits die halb offene Konformation ausreichend sein könnte (Abb. 5.5). Alternativ könnte die Oxidation des zweiten Cysteins eine Konformationsänderung von SCL14 auslösen, die die Interaktion mit XPO1a verhindert. 
A

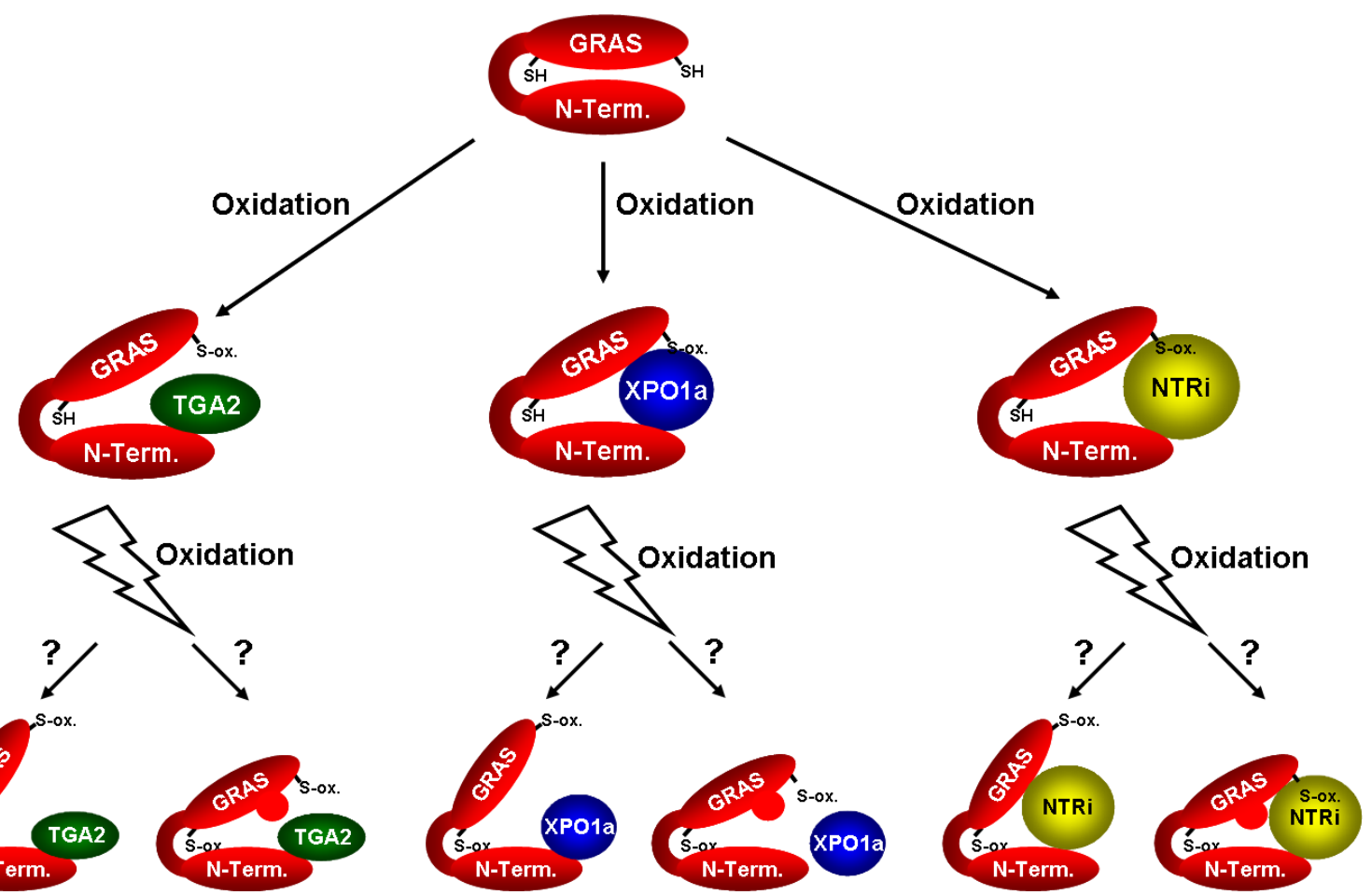

Abbildung 5.5: Schematisches Modell der kooperativen Regulation von SCL14 durch die Redox-Modifikation der Cysteine $\mathrm{C400}$ und $\mathrm{C691}$

A: Die reduzierte Form von SCL14 liegt in der geschlossenen Konformation vor, die weder mit TGA2 noch mit XPO1a noch mit dem Kernimportrezeptor (NTRi) interagieren und weder in den Kern noch zurück ins Cytoplasma transportiert werden kann. Da bereits im uninduzierten Zustand ein kontinuierlicher Austausch von SCL14 zwischen dem Zellkern und dem Cytoplasma stattfindet, liegt diese Form des Proteins vermutlich nur in geringer Menge oder gar nicht vor.

B: Nach der Oxidation eines der beiden Cysteine C400 oder C691 geht SCL14 in die halb offene Konformation über, was die Interaktion mit TGA2, XPO1a und NTRi den Austausch von SCL14 zwischen dem Zellkern und dem Cytoplasma ermöglicht.

C: Nach der Oxidation des zweiten Cysteins unter oxidativen Stressbedingungen könnte SCL14 in die offene Konformation übergehen. Die Interaktion von SCL14 mit TGA2 und XPO1a wird hierdurch nicht beeinflusst, da für diese die halb offene Konformation ausreichend ist. Die Interaktion mit NTRi ist in dieser Konformation, im Vergleich zur halb offenen Konformation jedoch erleichtert, was zu einer Verstärkung des Kernimports und dadurch zu einer Akkumulation von SCL14 im Zellkern führt. Alternativ könnte die Oxidation des zweiten Cysteins eine Konformationsänderung bei SCL14 auslösen, die die Interaktion mit XPO1a verhindert, die Interaktion mit TGA2 und NTRi jedoch nicht beeinflusst.

Alle vier Konformationen von SCL14 wurden bisher noch nicht beobachtet und sind somit rein hypothetisch.

SH: reduziertes Cystein; S-ox.: oxidiertes Cystein; GRAS: GRAS-Domäne von SCL14; N-Term.: NTerminus von SCL14; Die Blitze symbolisieren oxidativen Stress, der zur Oxidation des zweiten Cysteins führt.

Zumindest die Oxidation, die zum Übergang von der geschlossenen in die halb offene Konformation führt, muss auch in der Hefe möglich sein und erfolgen. Würde SCL14 in der Hefe vollständig reduziert vorliegen und sich deshalb in der geschlossenen Konformation befinden, könnte die Interaktion von SCL14 mit TGA2 und XPO1a nicht in einem Hefe-Zwei-Hybrid Experiment nachgewiesen werden. 


\subsection{SA induziert Gene der Stressantwort in Wurzeln von}

\section{Arabidopsis thaliana}

Fode et al. konnten zeigen, dass SCL14 in Blättern für die TIBA-induzierte Expression von Genen verantwortlich ist, die an der Antwort auf toxischen Stress beteiligt sind (Fode et al. 2008). Darunter waren Gene, die an den ersten beiden Abschnitten des pflanzlichen Detoxifikationsprogrammes beteiligt waren, wie die Cytochrom P450 Monooxygenase CYP81D11, die Glutathion S-Transferase GSTU7 und die Glykosyltransferase UGT73B3. In dieser Arbeit konnte gezeigt werden, dass SCL14 auch in Wurzeln an der Regulation solcher Gene beteiligt ist. Die drei genannten Gene und weitere, die zu den gleichen Genfamilien gehören, wurden in dem im Rahmen dieser Arbeit durchgeführten Microarray Experiment durch SA SCL14-abhängig induziert, jedoch konnte die Expression des Cytochrom CYP81D11 in Wurzeln nicht in unabhängigen Experimenten durch quantitative Realtime PCR bestätigt werden. Für GSTU7 und UGT73B3 wurde die Induktion durch SA jedoch mittels quantitativer Realtime PCR bestätigt und es konnte gezeigt werden, dass diese beiden Gene auch durch TIBA in der Wurzel induziert wurden.

Die in diesem Microarray Experiment in Col-0 durch SA SCL14-abhängig induzierten Gene können in zwei Gruppen eingeteilt werden. Die Expression der Gene der ersten Gruppe unterscheidet sich basal nicht zwischen Col-0 und der sc/14/33 Mutante und diese Gene werden in der Mutante nicht durch SA induziert (Abb. 4.22, Gruppe 1). Die SA-Induktion dieser Gene kann als strikt SCL14-abhängig bezeichnet werden. Die beiden Gene aus dieser Gruppe, deren Expression näher untersucht wurde, AT3G04130 und AT5G61800, werden zwar im Wildtyp durch SA und TIBA SCL14-abhängig induziert (Abb. 4.22 und 4.24), jedoch enthalten die Promotoren dieser beiden Gene keine Bindestellen für TGA-Faktoren (Tab. 4.3), obwohl diese um den Faktor 1,5 in den Promotoren der Gruppe 1 angereichert sind (Tab. 4.2). Die Regulation der beiden Gene durch den SCL14/TGA-Komplex muss also indirekt erfolgen. Dies könnte über Transkriptionsfaktoren aus der NAC-Familie geschehen, da in beiden Promotoren eine Bindestelle für NAC-Transkriptionsfaktoren vorhanden ist (Tab. 4.3) und mehrere NAC-Faktoren SCL14-abhängig reguliert werden. Beispielsweise konnte Neena Ratnakaran zeigen, das NAC102, ATAF2, NAC032 und ATAF1 durch TIBA SCL14-abhängig induziert werden (Ratnakaran 2014). Dabei zeigen NAC102 und ATAF2 ein Expressionsmuster, das dem der Gene der Gruppe 1 
entspricht. Somit könnten diese beiden Transkriptionsfaktoren die Verbindung zwischen SCL14 und AT3G04130 und AT5G61800 herstellen.

Die Expression der Gene der zweiten Gruppe ist in der Mutante, im Vergleich zum Wildtyp, bereits basal reduziert. Nach SA-Behandlung erfolgt bei diesen Genen auch in der Mutante eine Induktion der Expression. Die absolute Expressionsstärke dieser Gene ist in der Mutante im Vergleich zum Wildtyp verringert, jedoch ist der relative Induktionsfaktor in etwa gleich (Abb. 4.22, Gruppe 2). Interessanterweise sind in den Promotoren dieser Gruppe die TGA-Bindestellen 5,6-fach angereichert und im GSTU7 Promotor befindet sich sogar ein perfektes Palindrom. Dies könnte erklären, dass schon basale Mengen des SCL14/TGA-Komplexes die Aktivität dieser Promotoren beeinflussen. Da es im Wildtyp im Vergleich zur sc/14/33 Mutante nicht zu einer Hyperinduktion nach SA-Behandlung kommt, scheint SCL14 für diese Promotoren lediglich als Verstärker zu dienen, wobei das Ausmaß der Verstärkung unabhängig von der Kernakkumulation zu sein scheint. Somit müssen andere Transkriptionsfaktoren für die Aktivierung verantwortlich sein. In den Promotoren der Gene der Gruppe 2 sind G-Boxen und W-Boxen angereichert, die in den Promotoren der Gene der Gruppe 1 nicht angereichert sind (Tab. 4.2). Es könnten also G-Boxbindende Faktoren wie beispielsweise MYC2 und WRKY-Transkriptionsfaktoren, welche an die $W$-Box binden, für die unterschiedliche Regulation verantwortlich sein. Da die Promotoren von GSTU7 und UGT73B3 keine G-Box enthalten, kommen bei diesen beiden Genen lediglich WRKY- Transkriptionsfaktoren dafür in Frage.

Das Gen GSTU7 ist zusätzlich zu SA und TIBA auch durch JA induzierbar, wodurch es sich von UGT73B3, AT3G04130 und AT5G61800 unterscheidet (Abb. 4.25). Da der Promotor des Gens jedoch keine G-Box enthält, welche für die direkte Regulation durch JA notwendig ist (Köster et al. 2012), muss dieses indirekt geschehen. Auch hierfür kommen WRKY-Transkriptionsfaktoren in Frage, da deren Transkription häufig JA-reguliert ist (Pandey \& Somssich 2009). 


\subsection{SCL14 interagiert mit dem Transkriptionsfaktor NAC017}

Da die Transkriptmenge von SCL14 nach SA-Behandlung nicht zunimmt (Anhang Tab. 6.3), erfolgt die Aktivierung der SCL14 Zielgene nicht durch die Neusynthese von SCL14 unter induzierenden Bedingungen. Vielmehr scheint für diese Aktivierung eine Modifikation von SCL14 notwendig zu sein. Diese Modifikation kann in einer posttranslationalen Modifikation von SCL14 oder des TGA-Faktors, oder in der Interaktion des SCL14/TGA-Komplexes mit einem weiteren Protein bestehen. In dieser Arbeit konnte bisher gezeigt werden, dass die Cysteine C400 und C691 und wahrscheinlich deren Redox-Modifikation für die Regulation der Aktivität von SCL14 notwendig sind. Um Anhaltspunkte für die Regulation des SCL14/TGA-Komplexes durch die Interaktion mit einem weiteren Protein zu überprüfen, wurde mit dem HefeZwei-Hybrid System nach neuen Interaktionspartnern von SCL14 gesucht. Da SCL14 in diesem System bereits eine Autoaktivierung der Reportergene aufweist, wurde nur die C-terminale GRAS-Domäne als Köderprotein angeboten. In diesem Experiment wurde der Transkriptionsfaktor NAC017 als Interaktionspartner von SCL14 gefunden. Die Familie der NAC-Transkriptionsfaktoren zählt mit über 100 Mitgliedern zu den größten Familien pflanzenspezifischer Transkriptionsfaktoren. Entsprechend der Größe der Genfamilie sind NAC-Transkriptionsfaktoren an zahlreichen Prozessen wie Wachstum und Entwicklung, Organbildung, Seneszenz (Souer et al. 1996; Aida et al. 1997; Xie et al. 2000), Pathogenabwehr (Jensen et al. 2007; Jensen et al. 2008; X. Wang et al. 2009; Bu et al. 2008; Seo et al. 2010) und der Reaktion auf abiotischen Stress beteiligt (Hu et al. 2006; Jeong et al. 2010). Kürzlich konnten die beiden NAC-Transkriptionsfaktoren ATAF1 und NAC032 als Zielgene von SCL14 identifiziert und deren Beteiligung an der Regulation der pflanzlichen Antwort auf xenobiotischen Stress nachgewiesen werden (Fode et al. 2008; Ratnakaran 2014). Da auch die vier in dieser Arbeit untersuchten SCL14 Zielgene, GSTU7, UGT73B3, AT3G04130 und AT5G61800, in ihren Promotoren Bindemotive für NACTranskriptionsfaktoren aufweisen, wurde die Interaktion von SCL14 und NAC017 und der Einfluss von NAC017 auf die Expression dieser vier Gene eingehender untersucht. Der im Hefe-Zwei-Hybrid Experiment gefundene Klon enthielt nicht die komplette cDNA von NAC017, sondern nur ein Fragment, welches den C-terminalen Teil des Proteins kodiert (Abb. 4.32). Die GRAS-Domäne von SCL14 interagiert jedoch auch mit dem vollständigen NAC017-Protein (Abb. 4.34), allerdings ist diese Interaktion etwa um den Faktor fünf schwächer als die Interaktion mit dem 
C-terminalen Fragment (Abb. 4.34). Die NAC-Domäne, anhand welcher die Einordnung der Proteine in die Familie der NAC-Transkriptionsfaktoren erfolgt, befindet sich im N-Terminus der Proteine (Aida et al. 1997). Dieser Bereich der NACProteine ist stark konserviert und vermittelt sowohl die DNA-Bindung der NACFaktoren als auch die Dimerisierung verschiedener NAC-Proteine. Sie kann in die fünf Unterdomänen $A$ bis $E$ unterteilt werden, wobei die Unterdomänen $C$ und $D$ für die DNA-Bindung, die Unterdomäne A für die Dimerbildung und die Unterdomänen B und $E$ für die funktionelle Diversität verantwortlich sind (Abb. 2.6) (Puranik et al. 2012).

(i) $\mathrm{N}$-terminal

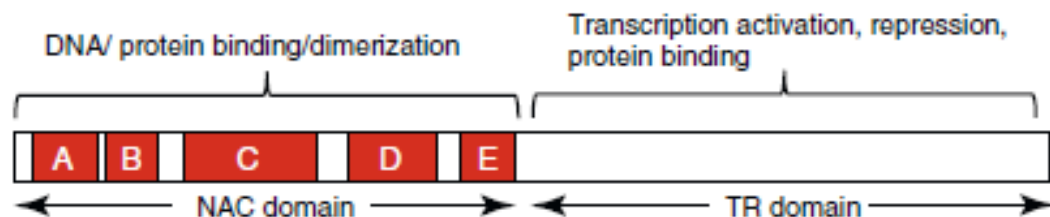

(ii)

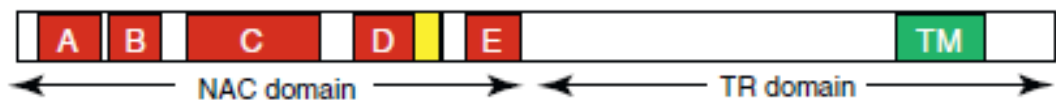

(iii)

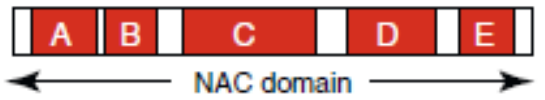

(iv)

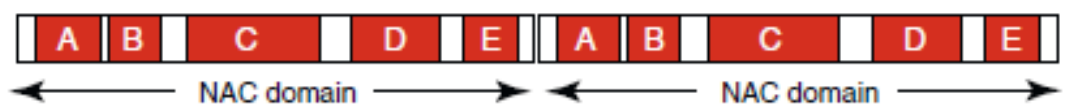

(v)

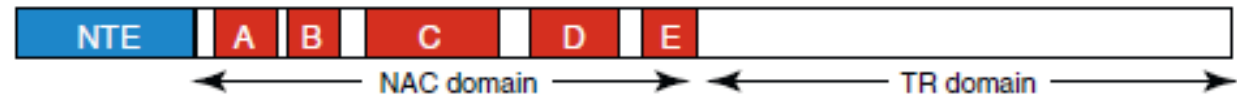

(vi)

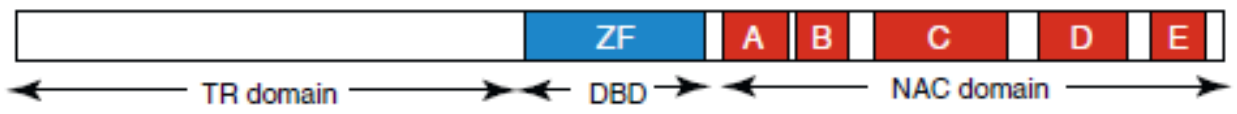

\section{Abbildung 5.6: Domänenstruktur der NAC-Transkriptionsfaktoren}

(i): Typisches NAC-Protein mit der konservierten NAC-Domäne im N-terminus, welche in fünf Unterdomänen (rot) unterteilt ist. Diese Domäne ist für die DNA-Bindung und Protein-Protein Interaktionen sowie Dimerbildung verantwortlich. Der C-Terminus ist weniger konserviert und dient als potentiell zur Regulation der Transkription und kann sowohl eine aktivierende als auch eine unterdrückende Funktion haben.

(ii): Manche NAC-Proteine weisen eine Repressordomäne (gelb) auf und der C-Terminus kann eine Transmembrandomäne enthalten (grün).

Einige NAC-Faktoren bestehen nur aus der NAC-Domäne (iii) oder einem Tandem aus zwei dieser Domänen (iv). Am N-Terminus kann der NAC-Domäne eine Extension vorgelagert sein (NTE) (v), oder die NAC-Domäne kann sich im C-Terminus befinden, während die Domäne zur Regulation der Transkription den C-Terminus bildet und ein Zinkfingermotiv (ZF) enthält, welches die DNA-Bindung vermittelt (vi). (Puranik et al. 2012)

Da die Interaktion zwischen dem vollständigen NAC-Protein und der SCL14 GRASDomäne schwächer ist als die Interaktion des C-Terminus mit der SCL14 GRAS- 
Domäne, scheint die NAC-Domäne für die Interaktion der beiden Proteine nicht notwendig zu sein. Die NAC-Domäne könnte auch zur Verringerung der Interaktionsstärke beitragen, da sich NAC-Dimere bilden könnten, deren Interaktion mit SCL14 aufgrund sterischer Behinderung möglicherweise schwächer ist. Der CTerminus der NAC-Transkriptionsfaktoren ist, im Gegensatz zur NAC-Domäne, kaum konserviert und für die Spezifität der Interaktion mit anderen Proteinen sowie für die Aktivierung bzw. die Repression der Genexpression verantwortlich. Um die Bedeutung von NAC017 für die Expression der SCL14 Zielgene zu überprüfen, wurde die Expression der SCL14 Zielgene GSTU7, UGT73B3, AT3G04130 und AT5G61800 in einer nac017 Knockoutmutante nach SA-Behandlung untersucht. Für die Gene GSTU7, UGT73B3 und AT3G04130 konnte kein Unterschied in der Genexpression zwischen dem Wildtyp und der Mutante beobachtet werden. Alle drei Gene werden sowohl im Wildtyp als auch in der Mutante durch die Behandlung mit SA induziert. Allerdings ist die Induktion von UGT73B3, im Gegensatz zu GSTU7 und AT3G04130, nicht signifikant (Abb. 4.38). Ein Unterschied in der Expression zwischen Col-0 und sc/14/33 ist jedoch für das Gen AT5G61800 zu beobachten, welches in der nac017 Mutante hyperinduziert ist. Die SA-Induktion dieses Gens scheint also durch NAC017 reprimiert zu werden. Eine leichte Tendenz zur Hyperinduktion ist auch bei GSTU7 und AT3G04130 zu beobachten, allerdings ist der Unterschied in der Induktion zwischen Wildtyp und Mutante für diese beiden Gene nicht signifikant. Ein deutlicherer Effekt wäre möglicherweise in einer Mehrfachmutante zu beobachten, da mehrere redundante NAC-Faktoren an der Regulation dieser Gene beteiligt sein könnten. So könnte beispielsweise NAC016 als nächster Verwandter die Rolle von NAC017 übernehmen. Die Erstellung einer nac016/017 Doppelmutante durch Kreuzung ist jedoch nicht möglich, da die beiden Gene auf Chromosom 1 direkt benachbart liegen, sodass die Wahrscheinlichkeit für ein Crossoverereignis zwischen den beiden Genen sehr gering ist. Eine weitere Möglichkeit, die Auswirkung von NAC017 auf die Expression der SCL14-Zielgene zu überprüfen, wäre die Herstellung von transgenen Pflanzen, die NAC017 überexprimieren. Sofern NAC017 wirklich einen negativen Regulator der SCL14 Zielgene darstellt, sollte die Expression der Gene nach SA-Behandlung in diesen Pflanzen, im Vergleich zum Wildtyp, verringert sein. 


\section{Anhang}

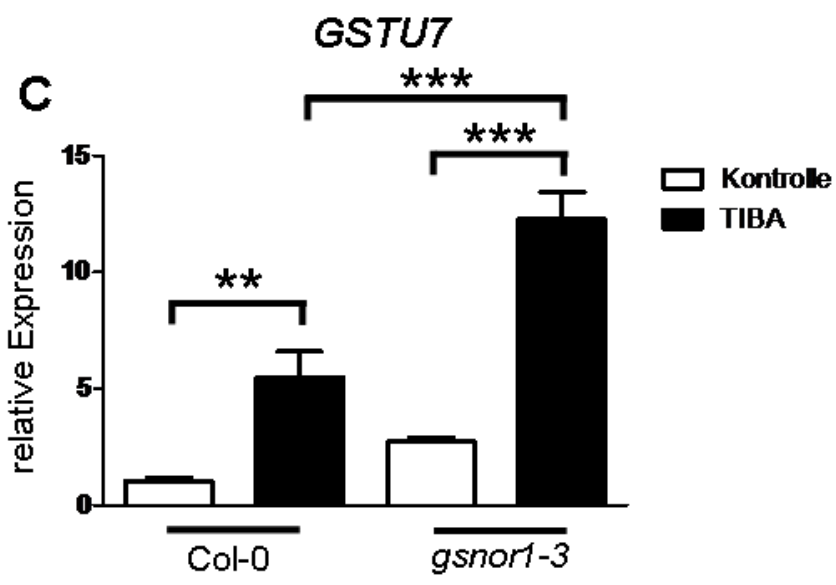

\section{Abbildung 6.1: Expression von GSTU7 in der gsnor1-3 Mutante nach TIBA-Behandlung}

Die Behandlung mit $100 \mu \mathrm{M}$ TIBA erfolgte für acht Stunden an 4 Wochen alten, auf Erde unter Kurztagbedingungen angezogenen Pflanzen. Die relativen Transkriptmengen von GSTU7 wurden mittels qRT-PCR bestimmt. Für die RNA-Extraktion wurde Blattmaterial verwendet. Zur Normalisierung der Expression diente UBQ5. Die mittlere relative Expression der Wildtyp Kontrolle wurde gleich 1 gesetzt. Gezeigt sind die Mittelwerte von $13-15$ Hydroponikkulturen ( \pm SEM) aus drei unabhängigen Experimenten. $\left({ }^{*}: p \leq 0,05,{ }^{* *}: p \leq 0,01,{ }^{* * *}: p \leq 0,001\right.$; Oneway ANOVA)

Tabelle 6.1: Nach SA-Behandlung in Col-0 induzierte Gene der Gruppe 1

Angegeben sind der Induktionsfaktor in Col-0 nach SA-Behandlung und der Unterschied der Expression zwischen Col-0 und sc/14/33 im uninduzierten Zustand, jeweils als log2-fache Induktion. Rot dargestellte Werte bedeuten eine Induktion, während grün dargestellte Werte eine Repression bedeuten. P-Werte über 0,05 sind gelb hinterlegt.

\begin{tabular}{|c|c|c|c|c|c|}
\hline AGICode & Beschreibung & $\begin{array}{l}\text { Col0 Kontr. } \\
\text { / Col0 SA }\end{array}$ & $\begin{array}{l}\text { adjusted } \\
\text { P-Value }\end{array}$ & $\begin{array}{l}\text { ColO Kontr. / } \\
\text { scl14/33 Kontr. }\end{array}$ & $\begin{array}{l}\text { adjusted } \\
\text { P-Value }\end{array}$ \\
\hline AT1G02880 & TPK1 & 1.43 & 0.03 & 0.28 & 0.69 \\
\hline AT1G04090 & $\begin{array}{l}\text { Plant protein of unknown function } \\
\text { (DUF946) }\end{array}$ & 1.02 & 0.00 & 0.00 & 0.99 \\
\hline AT1G05820 & SPPL5, ATSPPL5 & 1.02 & 0.01 & 0.16 & 0.65 \\
\hline AT1G06260 & $\begin{array}{l}\text { Cysteine proteinases superfamily } \\
\text { protein } \\
\end{array}$ & 1.17 & 0.00 & 0.07 & 0.85 \\
\hline AT1G09710 & $\begin{array}{l}\text { Homeodomainlike superfamily } \\
\text { protein }\end{array}$ & 1.79 & 0.02 & 0.78 & 0.29 \\
\hline AT1G10820 & $\begin{array}{c}\text { Protein of unknown function } \\
\text { (DUF3755) }\end{array}$ & 2.63 & 0.01 & 1.19 & 0.21 \\
\hline AT1G12770 & ISE1, EMB1586 & 1.17 & 0.00 & 0.32 & 0.26 \\
\hline AT1G12775 & $\begin{array}{c}\text { Pentatricopeptide repeat (PPR) } \\
\text { superfamily protein }\end{array}$ & 1.01 & 0.02 & 0.17 & 0.72 \\
\hline AT1G15125 & $\begin{array}{c}\text { SadenosylLmethioninedependent } \\
\text { methyltransferases superfamily } \\
\text { protein }\end{array}$ & 1.42 & 0.00 & 0.73 & 0.02 \\
\hline AT1G17147 & VQ motifcontaining protein & 1.68 & 0.00 & 0.65 & 0.02 \\
\hline AT1G17170 & ATGSTU24, GST, GSTU24 & 1.24 & 0.00 & 1.10 & 0.01 \\
\hline AT1G18250 & ATLP1 & 1.04 & 0.02 & 0.73 & 0.08 \\
\hline AT1G20150 & $\begin{array}{c}\text { Subtilisinlike serine endopeptidase } \\
\text { family protein }\end{array}$ & 1.08 & 0.00 & 0.43 & 0.15 \\
\hline
\end{tabular}




\begin{tabular}{|c|c|c|c|c|c|}
\hline AT1G20925 & Auxin efflux carrier family protein & 1.10 & 0.00 & 0.07 & 0.84 \\
\hline AT1G21680 & DPP6 Nterminal domainlike protein & 1.31 & 0.00 & 1.08 & 0.00 \\
\hline AT1G23460 & Pectin lyaselike superfamily protein & 1.13 & 0.00 & 0.10 & 0.76 \\
\hline AT1G23465 & $\begin{array}{l}\text { Peptidase S24/S26A/S26B/S26C } \\
\text { family protein }\end{array}$ & 1.10 & 0.03 & 0.13 & 0.83 \\
\hline AT1G26800 & RING/Ubox superfamily protein & 1.54 & 0.01 & 0.01 & 0.99 \\
\hline AT1G27921 & other RNA & 1.04 & 0.04 & 0.47 & 0.34 \\
\hline AT1G33030 & Omethyltransferase family protein & 1.01 & 0.01 & 0.57 & 0.09 \\
\hline AT1G54160 & NFYA5, NFYA5 & 1.13 & 0.03 & 0.23 & 0.66 \\
\hline AT1G63010 & $\begin{array}{l}\text { Major Facilitator Superfamily with } \\
\text { SPX (SYG1/Pho81/XPR1) } \\
\text { domaincontaining protein }\end{array}$ & 1.39 & 0.05 & 0.58 & 0.40 \\
\hline AT1G66080 & unknown protein & 1.00 & 0.01 & 0.37 & 0.23 \\
\hline AT1G69750 & COX192, ATCOX192 & 1.05 & 0.02 & 0.92 & 0.05 \\
\hline AT1G72416 & $\begin{array}{c}\text { Chaperone DnaJdomain } \\
\text { superfamily protein }\end{array}$ & 1.06 & 0.01 & 0.05 & 0.92 \\
\hline AT1G72660 & $\begin{array}{c}\text { Ploop containing nucleoside } \\
\text { triphosphate hydrolases } \\
\text { superfamily protein }\end{array}$ & 1.68 & 0.04 & 0.38 & 0.67 \\
\hline AT1G74310 & ATHSP101, HSP101, HOT1 & 1.48 & 0.01 & 0.91 & 0.07 \\
\hline AT1G75270 & DHAR2 & 1.20 & 0.00 & 0.29 & 0.41 \\
\hline AT1G76600 & unknown protein & 2.22 & 0.00 & 0.65 & 0.23 \\
\hline AT1G76680 & OPR1 & 1.94 & 0.00 & 0.48 & 0.31 \\
\hline AT1G76690 & OPR2, ATOPR2 & 1.74 & 0.00 & 0.34 & 0.32 \\
\hline AT1G77450 & anac032, NAC032 & 1.18 & 0.01 & 1.23 & 0.02 \\
\hline AT1G79710 & Major facilitator superfamily protein & 1.73 & 0.00 & 0.25 & 0.35 \\
\hline AT1G79790 & $\begin{array}{c}\text { Haloacid dehalogenaselike } \\
\text { hydrolase (HAD) superfamily } \\
\text { protein } \\
\end{array}$ & 1.83 & 0.01 & 0.52 & 0.37 \\
\hline AT1G79820 & SGB1 & 1.09 & 0.00 & 0.84 & 0.02 \\
\hline AT2G01200 & IAA32 & 1.02 & 0.00 & 0.23 & 0.32 \\
\hline AT2G04440 & MutT/nudix family protein & 1.02 & 0.00 & 0.09 & 0.72 \\
\hline AT2G14160 & $\begin{array}{l}\text { RNAbinding (RRM/RBD/RNP } \\
\text { motifs) family protein }\end{array}$ & 1.31 & 0.00 & 0.30 & 0.39 \\
\hline AT2G19310 & $\begin{array}{l}\text { HSP20like chaperones superfamily } \\
\text { protein }\end{array}$ & 1.26 & 0.00 & 0.17 & 0.64 \\
\hline AT2G28210 & ATACA2, ACA2 & 1.04 & 0.03 & 0.33 & 0.46 \\
\hline AT2G29480 & ATGSTU2, GST20, GSTU2 & 1.32 & 0.01 & 1.11 & 0.04 \\
\hline AT2G29490 & ATGSTU1, GST19, GSTU1 & 1.19 & 0.00 & 1.35 & 0.00 \\
\hline AT2G33100 & ATCSLD1, CSLD1 & 1.06 & 0.00 & 0.13 & 0.60 \\
\hline AT2G36355 & $\begin{array}{l}\text { Family of unknown function } \\
\text { (DUF662) }\end{array}$ & 1.65 & 0.01 & 0.60 & 0.27 \\
\hline AT2G36390 & SBE2.1, BE3 & 1.30 & 0.00 & 0.19 & 0.52 \\
\hline AT2G46320 & $\begin{array}{l}\text { Mitochondrial substrate carrier } \\
\text { family protein }\end{array}$ & 1.53 & 0.03 & 1.39 & 0.06 \\
\hline AT2G47895 & other RNA & 3.22 & 0.00 & 0.15 & 0.74 \\
\hline AT2G48121 & unknown protein & 1.00 & 0.00 & 0.01 & 0.99 \\
\hline AT3G01510 & \begin{tabular}{|l|l|} 
LSF1 like SEX4 1 \\
\end{tabular} & 1.51 & 0.00 & 0.24 & 0.28 \\
\hline AT3G01513 & unknown protein & 1.97 & 0.00 & 0.34 & 0.32 \\
\hline AT3G04130 & $\begin{array}{c}\text { Tetratricopeptide repeat (TPR)like } \\
\text { superfamily protein }\end{array}$ & 3.35 & 0.00 & 0.18 & 0.67 \\
\hline AT3G04140 & Ankyrin repeat family protein & 2.10 & 0.00 & 0.10 & 0.84 \\
\hline AT3G06400 & $\begin{array}{c}\text { CHR11 | chromatinremodeling } \\
\text { protein } 11 \\
\end{array}$ & 2.89 & 0.03 & 2.00 & 0.11 \\
\hline
\end{tabular}




\begin{tabular}{|c|c|c|c|c|c|}
\hline AT3G07740 & ADA2A & 1.17 & 0.04 & 1.12 & 0.06 \\
\hline AT3G11560 & LETM1like protein & 1.05 & 0.03 & 0.28 & 0.55 \\
\hline AT3G12580 & HSP70, ATHSP70 & 1.02 & 0.02 & 0.87 & 0.04 \\
\hline AT3G13030 & hAT transposon superfamily protein & 1.02 & 0.04 & 0.36 & 0.47 \\
\hline AT3G13065 & $\begin{array}{l}\text { SRF4 | STRUBBELIGreceptor } \\
\text { family } 4\end{array}$ & 1.39 & 0.00 & 0.33 & 0.29 \\
\hline AT3G14660 & CYP72A13 & 1.14 & 0.01 & 0.76 & 0.09 \\
\hline AT3G17340 & ARM repeat superfamily protein & 1.97 & 0.02 & 0.01 & 0.99 \\
\hline AT3G17660 & AGD15 & 1.06 & 0.00 & 0.20 & 0.43 \\
\hline AT3G17670 & $\begin{array}{l}\text { tetratricopeptide repeat } \\
\text { (TPR)containing protein }\end{array}$ & 1.18 & 0.04 & 0.77 & 0.16 \\
\hline AT3G19800 & $\begin{array}{c}\text { Protein of unknown function } \\
\text { (DUF177) }\end{array}$ & 1.30 & 0.00 & 0.76 & 0.03 \\
\hline AT3G24500 & MBF1C, ATMBF1C & 1.32 & 0.02 & 0.63 & 0.23 \\
\hline AT3G24560 & RSY3 & 1.29 & 0.00 & 0.34 & 0.24 \\
\hline AT3G28740 & CYP81D1 & 1.94 & 0.03 & 0.76 & 0.36 \\
\hline AT3G45730 & unknown protein & 1.32 & 0.00 & 0.11 & 0.80 \\
\hline AT3G47090 & $\begin{array}{l}\text { Leucinerich repeat protein kinase } \\
\text { family protein }\end{array}$ & 1.15 & 0.00 & 0.29 & 0.40 \\
\hline AT3G51760 & $\begin{array}{c}\text { Protein of unknown function } \\
\text { (DUF688) }\end{array}$ & 1.50 & 0.01 & 0.03 & 0.96 \\
\hline AT3G56830 & $\begin{array}{c}\text { Protein of unknown function } \\
\text { (DUF565) }\end{array}$ & 1.08 & 0.04 & 0.37 & 0.49 \\
\hline AT3G56980 & BHLH039, ORG3 & 1.17 & 0.00 & 0.25 & 0.42 \\
\hline AT3G60176 & other RNA & 1.24 & 0.00 & 0.82 & 0.02 \\
\hline AT4G03510 & RMA1, ATRMA1 & 1.22 & 0.01 & 0.05 & 0.93 \\
\hline AT4G12400 & Hop3 & 1.13 & 0.01 & 0.57 & 0.14 \\
\hline AT4G14030 & SBP1 & 1.29 & 0.00 & 0.07 & 0.87 \\
\hline AT4G14040 & EDA38, SBP2 & 1.39 & 0.00 & 0.37 & 0.31 \\
\hline AT4G17590 & unknown protein & 2.90 & 0.03 & 2.85 & 0.04 \\
\hline AT4G19060 & $\begin{array}{c}\text { Ploop containing nucleoside } \\
\text { triphosphate hydrolases } \\
\text { superfamily protein }\end{array}$ & 1.39 & 0.00 & 0.13 & 0.78 \\
\hline AT4G19070 & Putative membrane lipoprotein & 1.11 & 0.00 & 0.11 & 0.73 \\
\hline AT4G19880 & $\begin{array}{c}\text { Glutathione Stransferase family } \\
\text { protein }\end{array}$ & 1.71 & 0.04 & 1.02 & 0.20 \\
\hline AT4G21990 & APR3, PRH26, PRH26, ATAPR3 & 1.18 & 0.01 & 0.59 & 0.18 \\
\hline AT4G24460 & CLT2 & 1.69 & 0.03 & 0.97 & 0.18 \\
\hline AT4G25450 & ATNAP8, NAP8 & 2.33 & 0.01 & 2.50 & 0.02 \\
\hline AT4G27654 & unknown protein & 1.44 & 0.00 & 0.10 & 0.82 \\
\hline AT4G27657 & unknown protein & 1.19 & 0.00 & 0.20 & 0.53 \\
\hline AT4G28790 & $\begin{array}{c}\text { basic helixloophelix (bHLH) } \\
\text { DNAbinding superfamily protein }\end{array}$ & 1.24 & 0.02 & 0.44 & 0.40 \\
\hline AT4G29850 & $\begin{array}{l}\text { Eukaryotic protein of unknown } \\
\text { function (DUF872) }\end{array}$ & 2.16 & 0.04 & 1.19 & 0.23 \\
\hline AT4G32630 & $\begin{array}{l}\text { ArfGap/RecOlike zinc finger } \\
\text { domaincontaining protein }\end{array}$ & 1.16 & 0.00 & 0.03 & 0.95 \\
\hline AT4G33650 & ADL2, DRP3A & 2.00 & 0.00 & 1.32 & 0.04 \\
\hline AT4G34135 & UGT73B2 & 1.77 & 0.01 & 0.26 & 0.72 \\
\hline AT4G36040 & $\begin{array}{c}\text { Chaperone DnaJdomain } \\
\text { superfamily protein }\end{array}$ & 1.28 & 0.00 & 0.28 & 0.47 \\
\hline AT4G36052 & other RNA & 1.38 & 0.01 & 0.14 & 0.80 \\
\hline AT4G38490 & unknown protein & 1.21 & 0.00 & 0.13 & 0.61 \\
\hline AT5G05410 & DREB2A, DREB2 & 2.14 & 0.03 & 0.14 & 0.91 \\
\hline AT5G06820 & SRF2 & 1.09 & 0.01 & 0.16 & 0.70 \\
\hline
\end{tabular}




\begin{tabular}{|c|c|c|c|c|c|}
\hline AT5G07860 & $\begin{array}{l}\text { HXXXDtype acyltransferase family } \\
\text { protein }\end{array}$ & 1.96 & 0.00 & 0.15 & 0.76 \\
\hline AT5G07880 & SNAP29, ATSNAP29 & 1.29 & 0.00 & 0.04 & 0.92 \\
\hline AT5G07900 & $\begin{array}{c}\text { Mitochondrial transcription } \\
\text { termination factor family protein }\end{array}$ & 1.40 & 0.01 & 0.19 & 0.74 \\
\hline AT5G12280 & $\begin{array}{c}\text { SWAP } \\
\text { (SuppressorofWhiteAPricot)/surp } \\
\text { RNAbinding domaincontaining } \\
\text { protein }\end{array}$ & 1.35 & 0.02 & 0.19 & 0.77 \\
\hline AT5G13080 & WRKY75, ATWRKY75 & 1.01 & 0.05 & 0.80 & 0.12 \\
\hline AT5G14470 & GHMP kinase family protein & 2.29 & 0.01 & 0.19 & 0.84 \\
\hline AT5G14730 & unknown protein & 2.22 & 0.00 & 0.19 & 0.67 \\
\hline AT5G16300 & $\begin{array}{l}\text { Vps51/Vps67 family (components } \\
\text { of vesicular transport) protein }\end{array}$ & 1.47 & 0.00 & 0.61 & 0.17 \\
\hline AT5G18400 & $\begin{array}{l}\text { Cytokineinduced antiapoptosis } \\
\text { inhibitor } 1, \mathrm{FeS} \text { biogenesis }\end{array}$ & 1.33 & 0.05 & 1.23 & 0.07 \\
\hline AT5G26980 & SYP41, ATSYP41, ATTLG2A & 1.37 & 0.02 & 0.63 & 0.25 \\
\hline AT5G27010 & ARM repeat superfamily protein & 1.10 & 0.00 & 0.04 & 0.92 \\
\hline AT5G42965 & $\begin{array}{c}\text { Polynucleotidyl transferase, } \\
\text { ribonuclease Hlike superfamily } \\
\text { protein }\end{array}$ & 1.02 & 0.01 & 0.16 & 0.68 \\
\hline AT5G51440 & $\begin{array}{l}\text { HSP20like chaperones superfamily } \\
\text { protein }\end{array}$ & 1.12 & 0.02 & 1.25 & 0.02 \\
\hline AT5G57010 & calmodulinbinding family protein & 1.12 & 0.02 & 0.18 & 0.71 \\
\hline AT5G60410 & ATSIZ1, SIZ1 & 1.45 & 0.04 & 0.34 & 0.65 \\
\hline AT5G60440 & AGL62 | AGAMOUSlike 62 & 1.17 & 0.03 & 0.09 & 0.89 \\
\hline AT5G61495 & unknown protein & 1.77 & 0.00 & 0.52 & 0.10 \\
\hline AT5G61800 & $\begin{array}{c}\text { Pentatricopeptide repeat (PPR) } \\
\text { superfamily protein }\end{array}$ & 1.19 & 0.02 & 0.07 & 0.92 \\
\hline AT5G64150 & $\begin{array}{l}\text { RNA methyltransferase family } \\
\text { protein } \\
\end{array}$ & 1.01 & 0.02 & 0.23 & 0.61 \\
\hline AT5G64240 & AtMC3, MC3 & 1.11 & 0.02 & 0.20 & 0.67 \\
\hline AT5G64250 & $\begin{array}{l}\text { Aldolasetype TIM barrel family } \\
\text { protein } \\
\end{array}$ & 1.33 & 0.00 & 0.87 & 0.02 \\
\hline AT5G66985 & unknown protein & 1.30 & 0.01 & 0.36 & 0.39 \\
\hline
\end{tabular}


Tabelle 6.2: Nach SA-Behandlung in Col-0 induzierte Gene der Gruppe 2

Angegeben sind der Induktionsfaktor in Col-0 nach SA-Behandlung, der Unterschied der Expression zwischen Col-0 und sc/14/33 im uninduzierten Zustand, und der Induktionsfaktor in der sc/14/33 Mutante nach SA-Behandlung, jeweils als log2-fache Induktion. Rot dargestellte Werte bedeuten eine Induktion, während grün dargestellte Werte eine Repression bedeuten. P-Werte über 0,05 sind gelb hinterlegt.

\begin{tabular}{|l|c|c|c|c|c|c|c|}
\hline AGICode & Beschreibung & $\begin{array}{c}\text { Col-0 } \\
\text { Kontr. / } \\
\text { Col-0 SA }\end{array}$ & $\begin{array}{c}\text { adjusted } \\
\text { P-Value }\end{array}$ & $\begin{array}{c}\text { Col-0 } \\
\text { Kontr./ } \\
\text { scl14/33 } \\
\text { Kontr. }\end{array}$ & $\begin{array}{c}\text { adjusted } \\
\text { P-Value }\end{array}$ & $\begin{array}{c}\text { sc/14/33 } \\
\text { Kontr./ } \\
\text { scl14/33 } \\
\text { SA }\end{array}$ & $\begin{array}{c}\text { adjusted } \\
\text { P-Value }\end{array}$ \\
\hline AT1G01720 & ATAF1, ANAC002 & 1.074 & 0.014 & 1.297 & 0.012 & 1.342 & 0.008 \\
\hline AT1G17170 & $\begin{array}{c}\text { ATGSTU24, GST, } \\
\text { GSTU24 }\end{array}$ & 1.240 & 0.002 & 1.099 & 0.009 & 0.475 & 0.202 \\
\hline AT1G21680 & $\begin{array}{c}\text { DPP6 Nterminal } \\
\text { domainlike protein }\end{array}$ & 1.309 & 0.000 & 1.080 & 0.003 & 0.394 & 0.147 \\
\hline AT1G77450 & anac032, NAC032 & 1.176 & 0.015 & 1.226 & 0.020 & 0.562 & 0.287 \\
\hline AT2G29420 & $\begin{array}{c}\text { ATGSTU7, GST25, } \\
\text { GSTU7 }\end{array}$ & 4.089 & 0.000 & 1.005 & 0.021 & 2.116 & 0.000 \\
\hline AT2G29480 & $\begin{array}{c}\text { ATGSTU2, GST20, } \\
\text { GSTU2 }\end{array}$ & 1.320 & 0.013 & 1.108 & 0.039 & 0.508 & 0.404 \\
\hline AT2G29490 & $\begin{array}{c}\text { ATGSTU1, GST19, } \\
\text { GSTU1 }\end{array}$ & 1.192 & 0.002 & 1.349 & 0.003 & 0.283 & 0.447 \\
\hline AT4G15550 & $\begin{array}{c}\text { IAGLU indole3acetate } \\
\text { betaDglucosyltransferase }\end{array}$ & 2.468 & 0.000 & 1.399 & 0.013 & 2.371 & 0.001 \\
\hline AT4G34131 & UGT73B3 & 3.327 & 0.000 & 1.482 & 0.019 & 1.694 & 0.010 \\
\hline AT4G34135 & UGT73B2 & 2.741 & 0.001 & 1.547 & 0.034 & 0.690 & 0.393 \\
\hline AT5G63790 & ANAC102, NAC102 & 2.575 & 0.000 & 1.676 & 0.006 & 2.718 & 0.000 \\
\hline
\end{tabular}

Tabelle 6.3: Im uninduzierten Zustand in Col-0 stärker Exprimierte Gene als in der sc/14/33 Mutante

Angegeben sind der Unterschied der Expression zwischen Col-0 und sc/14/33 im uninduzierten Zustand, und der Induktionsfaktor in Col-0 nach SA-Behandlung, jeweils als log2-fache Induktion. Rot dargestellte Werte bedeuten eine Induktion, während grün dargestellte Werte eine Repression bedeuten. P-Werte über 0,05 sind gelb hinterlegt.

\begin{tabular}{|c|c|c|c|c|c|}
\hline AGI-Code & Beschreibung & $\begin{array}{c}\text { Col-0 Kontr. / } \\
\text { sc/14/33 } \\
\text { Kontr. }\end{array}$ & $\begin{array}{c}\text { adjusted } \\
\text { P-Value }\end{array}$ & $\begin{array}{c}\text { Col-0 Kontr./ } \\
\text { Col-0 SA }\end{array}$ & $\begin{array}{c}\text { adjusted } \\
\text { P-Value }\end{array}$ \\
\hline AT1G01560 & ATMPK11, MPK11 & 1.088 & 0.010 & 1.095 & 0.004 \\
\hline AT1G02850 & BGLU11 | beta glucosidase 11 & 1.207 & 0.004 & 0.628 & 0.028 \\
\hline AT1G07530 & SCL14, ATGRAS2, GRAS2 & 4.423 & 0.000 & 0.212 & 0.321 \\
\hline AT1G13590 & ATPSK1, PSK1 & 1.050 & 0.008 & 0.213 & 0.492 \\
\hline AT1G58320 & PLAC8 family protein & 1.277 & 0.028 & 0.119 & 0.851 \\
\hline AT1G60730 & $\begin{array}{c}\text { NAD(P)-linked oxidoreductase } \\
\text { superfamily protein }\end{array}$ & 1.156 & 0.029 & 0.502 & 0.278 \\
\hline AT1G67980 & $\begin{array}{c}\text { CCOAMT | caffeoyl-CoA 3-O- } \\
\text { methyltransferase }\end{array}$ & 1.917 & 0.023 & 0.378 & 0.632 \\
\hline AT1G68620 & $\begin{array}{c}\text { alpha/beta-Hydrolases } \\
\text { superfamily protein }\end{array}$ & 1.213 & 0.028 & 0.495 & 0.303 \\
\hline
\end{tabular}




\begin{tabular}{|c|c|c|c|c|c|}
\hline AT1G79410 & $\begin{array}{c}\text { AtOCT5, 5-Oct | organic } \\
\text { cation/carnitine transporter5 }\end{array}$ & 1.046 & 0.008 & 0.396 & 0.176 \\
\hline AT2G05400 & $\begin{array}{l}\text { Ubiquitin-specific protease } \\
\text { family C19-related protein }\end{array}$ & 1.392 & 0.013 & 0.751 & 0.090 \\
\hline AT2G05510 & Glycine-rich protein family & 1.720 & 0.004 & 0.254 & 0.546 \\
\hline AT2G15830 & unknown protein & 1.000 & 0.043 & 0.372 & 0.417 \\
\hline AT2G16430 & PAP10, ATPAP10 & 2.076 & 0.023 & 1.333 & 0.092 \\
\hline AT2G18750 & Calmodulin-binding protein & 1.999 & 0.016 & 1.344 & 0.053 \\
\hline AT2G19900 & ATNADP-ME1, NADP-ME1 & 1.126 & 0.015 & 0.084 & 0.861 \\
\hline AT2G20520 & $\begin{array}{c}\text { FLA6 | FASCICLIN-like } \\
\text { arabinogalactan } 6\end{array}$ & 1.775 & 0.039 & 1.760 & 0.030 \\
\hline AT2G25000 & WRKY60, ATWRKY60 & 1.402 & 0.007 & 0.213 & 0.605 \\
\hline AT2G29065 & $\begin{array}{l}\text { GRAS family transcription } \\
\text { factor }\end{array}$ & 1.180 & 0.006 & 0.143 & 0.670 \\
\hline AT2G29110 & ATGLR2.8, GLR2.8 & 1.111 & 0.043 & 0.325 & 0.533 \\
\hline AT2G32840 & proline-rich family protein & 1.803 & 0.034 & 1.787 & 0.026 \\
\hline AT2G35980 & YLS9, NHL10, ATNHL10 & 1.248 & 0.043 & 0.374 & 0.525 \\
\hline AT2G42850 & $\begin{array}{l}\text { CYP718 | cytochrome P450, } \\
\text { family } 718\end{array}$ & 1.173 & 0.047 & 0.789 & 0.142 \\
\hline AT2G47270 & UPB1 & 1.080 & 0.021 & 0.494 & 0.211 \\
\hline AT3G01345 & Expressed protein & 3.502 & 0.000 & 0.219 & 0.469 \\
\hline AT3G01970 & WRKY45, ATWRKY45 & 1.484 & 0.032 & 0.128 & 0.871 \\
\hline AT3G06435 & Expressed protein & 1.347 & 0.020 & 0.087 & 0.891 \\
\hline AT3G09270 & ATGSTU8, GSTU8 & 1.315 & 0.017 & 0.190 & 0.715 \\
\hline AT3G14075 & $\begin{array}{c}\text { Mono-/di-acylglycerol lipase, } \\
\text { N-terminal;Lipase, class } 3\end{array}$ & 1.522 & 0.013 & 0.026 & 0.969 \\
\hline AT3G23560 & $\begin{array}{l}\text { ALF5 | MATE efflux family } \\
\text { protein } \\
\end{array}$ & 1.135 & 0.007 & 0.224 & 0.485 \\
\hline AT3G25190 & $\begin{array}{c}\text { Vacuolar iron transporter (VIT) } \\
\text { family protein }\end{array}$ & 1.999 & 0.000 & 0.301 & 0.310 \\
\hline АT3G27940 & $\begin{array}{l}\text { LBD26 | LOB domain- } \\
\text { containing protein } 26\end{array}$ & 1.100 & 0.008 & 0.119 & 0.740 \\
\hline AT3G28345 & $\mathrm{ABC}$ transporter family protein & 2.123 & 0.000 & 0.398 & 0.168 \\
\hline AT3G29639 & unknown Protein & 1.427 & 0.034 & 1.129 & 0.065 \\
\hline AT3G29780 & RALFL27 | ralf-like 27 & 1.044 & 0.032 & 0.146 & 0.773 \\
\hline AT3G46340 & $\begin{array}{l}\text { Leucine-rich repeat protein } \\
\text { kinase family protein }\end{array}$ & 1.317 & 0.006 & 0.676 & 0.051 \\
\hline AT3G49960 & $\begin{array}{l}\text { Peroxidase superfamily } \\
\text { protein }\end{array}$ & 1.309 & 0.013 & 1.343 & 0.006 \\
\hline AT3G50970 & LTI30, XERO2 & 1.339 & 0.000 & 0.285 & 0.153 \\
\hline AT3G54580 & $\begin{array}{l}\text { Proline-rich extensin-like } \\
\text { family protein }\end{array}$ & 1.001 & 0.010 & 1.324 & 0.001 \\
\hline AT4G01870 & tolB protein-related & 1.225 & 0.006 & 0.958 & 0.007 \\
\hline AT4G02280 & SUS3, ATSUS3 & 1.120 & 0.004 & 0.283 & 0.285 \\
\hline AT4G03723 & unknown protein & 1.024 & 0.014 & 0.283 & 0.405 \\
\hline AT4G07960 & ATCSLC12, CSLC12 & 1.164 & 0.004 & 1.147 & 0.001 \\
\hline AT4G13180 & $\begin{array}{l}\text { NAD(P)-binding Rossmann- } \\
\text { fold superfamily protein }\end{array}$ & 1.435 & 0.007 & 0.582 & 0.134 \\
\hline AT4G13390 & $\begin{array}{l}\text { Proline-rich extensin-like } \\
\text { family protein }\end{array}$ & 1.090 & 0.035 & 1.093 & 0.026 \\
\hline AT4G25400 & $\begin{array}{l}\text { basic helix-loop-helix (bHLH) } \\
\text { DNA-binding superfamily } \\
\text { protein }\end{array}$ & 1.189 & 0.021 & 0.027 & 0.963 \\
\hline
\end{tabular}




\begin{tabular}{|l|c|c|c|c|c|}
\hline AT4G28040 & $\begin{array}{c}\text { nodulin MtN21 /EamA-like } \\
\text { transporter family protein }\end{array}$ & 1.099 & 0.013 & 0.988 & 0.011 \\
\hline AT4G28850 & XTH26, ATXTH26 & 1.563 & 0.005 & 1.581 & 0.001 \\
\hline AT4G34138 & UGT73B1 & 1.543 & 0.016 & 0.187 & 0.761 \\
\hline AT5G03545 & AT4, ATIPS2 & 1.330 & 0.032 & 0.318 & 0.583 \\
\hline AT5G06860 & PGIP1, ATPGIP1 & 1.669 & 0.014 & 0.200 & 0.754 \\
\hline AT5G25260 & $\begin{array}{c}\text { SPFH/Band 7/PHB domain- } \\
\text { containing membrane- } \\
\text { associated protein family }\end{array}$ & 1.076 & 0.047 & 0.022 & 0.974 \\
\hline AT5G34940 & AtGUS3, GUS3 & 1.307 & 0.021 & 0.182 & 0.743 \\
\hline AT5G57530 & XTH12, AtXTH12 & 1.008 & 0.016 & 1.190 & 0.004 \\
\hline AT5G61820 & unknown protein & 1.898 & 0.000 & 0.703 & 0.027 \\
\hline
\end{tabular}

Tabelle 6.4: In der sc/14/33 Mutante durch SA-Behandlung induzierte Gene

Angegeben sind der Induktionsfaktor in Col-0 und der sc/14/33 Mutante nach SA-Behandlung und der jeweils als log2-fache Induktion. Rot dargestellte Werte bedeuten eine Induktion, während grün dargestellte Werte eine Repression bedeuten. P-Werte über 0,05 sind gelb hinterlegt.

\begin{tabular}{|c|c|c|c|c|c|}
\hline AGI-Code & Beschreibung & $\begin{array}{l}\text { Col-0 Kontr. / } \\
\text { Col-0 SA }\end{array}$ & $\begin{array}{l}\text { adjusted } \\
\text { P-Value }\end{array}$ & $\begin{array}{l}\text { sc/14/33 Kontr. / } \\
\text { sc/14/33 SA }\end{array}$ & $\begin{array}{l}\text { adjusted } \\
\text { P-Value }\end{array}$ \\
\hline AT1G01720 & ATAF1, ANAC002 & 1.074 & 0.014 & 1.342 & 0.008 \\
\hline AT1G02230 & ANAC004, NAC004 & 2.340 & 0.001 & 3.165 & 0.000 \\
\hline AT1G02450 & NIMIN1, NIMIN-1 & 1.002 & 0.104 & 2.442 & 0.003 \\
\hline AT1G03850 & Glutaredoxin family protein & 0.925 & 0.084 & 1.366 & 0.029 \\
\hline AT1G05560 & UGT1, UGT75B1 & 1.787 & 0.008 & 2.209 & 0.004 \\
\hline AT1G06645 & $\begin{array}{c}\text { 2-oxoglutarate (2OG) and Fe(II)- } \\
\text { dependent oxygenase superfamily } \\
\text { protein }\end{array}$ & 0.798 & 0.013 & 1.279 & 0.002 \\
\hline AT1G07590 & $\begin{array}{c}\text { Tetratricopeptide repeat (TPR)-like } \\
\text { superfamily protein }\end{array}$ & 1.299 & 0.000 & 1.008 & 0.003 \\
\hline AT1G15260 & unknown protein & 1.395 & 0.012 & 1.460 & 0.016 \\
\hline AT1G18265 & $\begin{array}{c}\text { Protein of unknown function, } \\
\text { DUF593 }\end{array}$ & 1.922 & 0.002 & 1.683 & 0.007 \\
\hline AT1G18990 & $\begin{array}{c}\text { Protein of unknown function, } \\
\text { DUF593 }\end{array}$ & 1.374 & 0.015 & 1.636 & 0.011 \\
\hline AT1G19540 & $\begin{array}{c}\text { NmrA-like negative transcriptional } \\
\text { regulator family protein }\end{array}$ & 1.946 & 0.003 & 2.092 & 0.004 \\
\hline AT1G21270 & WAK2 | wall-associated kinase 2 & 0.557 & 0.159 & 1.102 & 0.021 \\
\hline AT1G23450 & $\begin{array}{c}\text { Tetratricopeptide repeat (TPR)-like } \\
\text { superfamily protein }\end{array}$ & 3.194 & 0.000 & 1.413 & 0.009 \\
\hline AT1G27970 & $\begin{array}{c}\text { NTF2B | nuclear transport factor } \\
\text { 2B }\end{array}$ & 0.757 & 0.077 & 1.053 & 0.035 \\
\hline AT1G28480 & GRX480, roxy19 & 3.117 & 0.000 & 2.575 & 0.001 \\
\hline AT1G29510 & SAUR68 & 0.191 & 0.522 & 1.289 & 0.001 \\
\hline AT1G30455 & $\begin{array}{c}\text { transcription regulators;translation } \\
\text { initiation factors;zinc ion } \\
\text { binding;transcription activators } \\
\end{array}$ & 1.957 & 0.002 & 2.577 & 0.001 \\
\hline AT1G30473 & $\begin{array}{c}\text { Heavy metal } \\
\text { transport/detoxification superfamily }\end{array}$ & 2.145 & 0.001 & 1.741 & 0.006 \\
\hline
\end{tabular}




\begin{tabular}{|c|c|c|c|c|c|}
\hline & protein & & & & \\
\hline AT1G33600 & $\begin{array}{l}\text { Leucine-rich repeat (LRR) family } \\
\text { protein }\end{array}$ & 0.006 & 0.992 & 1.014 & 0.036 \\
\hline AT1G48405 & $\begin{array}{l}\text { Kinase interacting (KIP1-like) } \\
\text { family protein }\end{array}$ & 1.432 & 0.000 & 1.359 & 0.001 \\
\hline AT1G48560 & unknown protein & 2.702 & 0.003 & 3.129 & 0.003 \\
\hline AT1G48830 & $\begin{array}{c}\text { Ribosomal protein S7e family } \\
\text { protein }\end{array}$ & 0.682 & 0.275 & 1.644 & 0.025 \\
\hline AT1G49160 & WNK7 & 0.482 & 0.315 & 1.158 & 0.039 \\
\hline AT1G49750 & $\begin{array}{l}\text { Leucine-rich repeat (LRR) family } \\
\text { protein }\end{array}$ & 0.064 & 0.934 & 1.381 & 0.043 \\
\hline AT1G50190 & $\begin{array}{l}\text { Cysteine/Histidine-rich C1 domain } \\
\text { family protein }\end{array}$ & 1.177 & 0.001 & 1.033 & 0.004 \\
\hline AT1G52370 & $\begin{array}{l}\text { Ribosomal protein L22p/L17e } \\
\text { family protein }\end{array}$ & 1.112 & 0.012 & 1.034 & 0.028 \\
\hline AT1G59660 & Nucleoporin autopeptidase & 1.237 & 0.010 & 1.533 & 0.005 \\
\hline AT1G62880 & Cornichon family protein & 2.170 & 0.001 & 1.267 & 0.038 \\
\hline AT1G62886 & $\begin{array}{c}\text { Nucleotide excision repair, TFIIH, } \\
\text { subunit TTDA }\end{array}$ & 2.845 & 0.000 & 2.824 & 0.000 \\
\hline AT1G72930 & TIR | toll/interleukin-1 receptor-like & 0.048 & 0.937 & 1.192 & 0.027 \\
\hline AT1G74830 & $\begin{array}{c}\text { Protein of unknown function, } \\
\text { DUF593 }\end{array}$ & 1.398 & 0.002 & 1.848 & 0.001 \\
\hline AT1G78995 & unknown protein & 2.993 & 0.000 & 2.806 & 0.001 \\
\hline AT1G80030 & $\begin{array}{l}\text { Molecular chaperone Hsp40/DnaJ } \\
\text { family protein } \\
\end{array}$ & 0.911 & 0.020 & 1.269 & 0.006 \\
\hline AT1G80660 & HA9 | H(+)-ATPase 9 & 0.582 & 0.031 & 1.420 & 0.000 \\
\hline AT2G05720 & $\begin{array}{l}\text { Transducin/WD40 repeat-like } \\
\text { superfamily protein }\end{array}$ & 3.312 & 0.000 & 3.019 & 0.001 \\
\hline AT2G11270 & citrate synthase-related & 1.139 & 0.000 & 1.169 & 0.001 \\
\hline AT2G21900 & WRKY59, ATWRKY59 & 0.928 & 0.116 & 1.388 & 0.045 \\
\hline AT2G23170 & $\begin{array}{c}\text { GH3.3 | Auxin-responsive GH3 } \\
\text { family protein }\end{array}$ & 1.201 & 0.003 & 1.360 & 0.003 \\
\hline AT2G25510 & unknown protein & 0.588 & 0.293 & 1.292 & 0.046 \\
\hline AT2G29420 & ATGSTU7, GST25, GSTU7 & 4.089 & 0.000 & 2.116 & 0.000 \\
\hline AT2G32235 & unknown protein & 1.161 & 0.029 & 1.382 & 0.021 \\
\hline AT2G32340 & TraB family protein & 1.280 & 0.009 & 1.015 & 0.045 \\
\hline AT2G35640 & $\begin{array}{l}\text { Homeodomain-like superfamily } \\
\text { protein }\end{array}$ & 1.243 & 0.007 & 1.405 & 0.006 \\
\hline AT2G36800 & DOGT1, UGT73C5 & 1.278 & 0.008 & 1.453 & 0.007 \\
\hline AT2G40750 & WRKY54, ATWRKY54 & 1.233 & 0.009 & 1.378 & 0.008 \\
\hline AT2G40925 & $\begin{array}{l}\text { F-box and associated interaction } \\
\text { domains-containing protein }\end{array}$ & 2.406 & 0.000 & 2.113 & 0.000 \\
\hline AT2G41090 & $\begin{array}{l}\text { Calcium-binding EF-hand family } \\
\text { protein }\end{array}$ & 0.091 & 0.904 & 1.498 & 0.028 \\
\hline AT2G45150 & $\begin{array}{c}\text { cytidinediphosphate diacylglycerol } \\
\text { synthase } 4\end{array}$ & 1.349 & 0.012 & 1.368 & 0.019 \\
\hline AT3G06280 & $\begin{array}{l}\text { F-box associated ubiquitination } \\
\text { effector family protein }\end{array}$ & 1.371 & 0.001 & 1.324 & 0.003 \\
\hline AT3G07150 & unknown protein & 1.392 & 0.000 & 1.115 & 0.003 \\
\hline AT3G09240 & $\begin{array}{l}\text { Protein kinase protein with } \\
\text { tetratricopeptide repeat domain }\end{array}$ & 1.189 & 0.006 & 1.332 & 0.005 \\
\hline AT3G13062 & $\begin{array}{l}\text { Polyketide cyclase/dehydrase and } \\
\text { lipid transport superfamily protein }\end{array}$ & 0.817 & 0.086 & 1.391 & 0.015 \\
\hline AT3G14735 & U6-1| U6-1; snRNA & 1.089 & 0.008 & 1.074 & 0.014 \\
\hline AT3G16660 & $\begin{array}{l}\text { Pollen Ole e } 1 \text { allergen and } \\
\text { extensin family protein }\end{array}$ & 0.082 & 0.917 & 1.397 & 0.045 \\
\hline
\end{tabular}




\begin{tabular}{|c|c|c|c|c|c|}
\hline AT3G20520 & SVL3 | SHV3-like 3 & 0.876 & 0.003 & 1.082 & 0.002 \\
\hline AT3G22231 & $\begin{array}{c}\text { PCC1 | pathogen and circadian } \\
\text { controlled } 1\end{array}$ & 0.829 & 0.159 & 2.947 & 0.001 \\
\hline AT3G51910 & AT-HSFA7A, HSFA7A & 1.314 & 0.011 & 1.303 & 0.020 \\
\hline AT3G54280 & $\begin{array}{l}\text { CHR16, CHA16, RGD3, } \\
\text { ATBTAF1, BTAF1 }\end{array}$ & 1.496 & 0.003 & 1.567 & 0.004 \\
\hline AT3G56400 & WRKY70, ATWRKY70 & 0.991 & 0.029 & 2.017 & 0.001 \\
\hline AT3G56600 & Protein kinase superfamily protein & 0.631 & 0.063 & 1.282 & 0.004 \\
\hline AT3G56790 & RNA splicing factor-related & 1.404 & 0.006 & 1.763 & 0.003 \\
\hline AT3G60760 & unknown protein & 1.668 & 0.000 & 1.957 & 0.000 \\
\hline АT3G62320 & $\begin{array}{c}\text { Polynucleotidyl transferase, } \\
\text { ribonuclease } \mathrm{H} \text {-like superfamily } \\
\text { protein }\end{array}$ & 0.752 & 0.070 & 1.163 & 0.018 \\
\hline AT3G62350 & unknown protein & 1.111 & 0.039 & 1.413 & 0.022 \\
\hline AT3G63320 & $\begin{array}{l}\text { Protein phosphatase } 2 \mathrm{C} \text { family } \\
\text { protein }\end{array}$ & 1.246 & 0.000 & 1.625 & 0.000 \\
\hline AT4G04730 & unknown protein & 1.208 & 0.015 & 1.050 & 0.048 \\
\hline AT4G10410 & $\begin{array}{l}\text { Leucine-rich repeat (LRR) family } \\
\text { protein }\end{array}$ & 1.564 & 0.009 & 1.317 & 0.033 \\
\hline AT4G12400 & $\begin{array}{c}\text { Hop3 | stress-inducible protein, } \\
\text { putative }\end{array}$ & 1.490 & 0.017 & 2.134 & 0.004 \\
\hline AT4G14368 & $\begin{array}{c}\text { Regulator of chromosome } \\
\text { condensation (RCC1) family } \\
\text { protein }\end{array}$ & 1.424 & 0.011 & 1.323 & 0.025 \\
\hline AT4G15550 & $\begin{array}{l}\text { IAGLU | indole-3-acetate beta-D- } \\
\text { glucosyltransferase }\end{array}$ & 2.468 & 0.000 & 2.371 & 0.001 \\
\hline AT4G19080 & $\begin{array}{c}\text { Protein of unknown function } \\
\text { (DUF594) }\end{array}$ & 2.511 & 0.000 & 1.100 & 0.032 \\
\hline AT4G19095 & unknown protein & 2.088 & 0.000 & 1.024 & 0.035 \\
\hline AT4G19645 & $\begin{array}{l}\text { TRAM, LAG1 and CLN8 (TLC) } \\
\text { lipid-sensing domain containing } \\
\text { protein } \\
\end{array}$ & 2.079 & 0.003 & 1.509 & 0.024 \\
\hline AT4G19865 & $\begin{array}{l}\text { Galactose oxidase/kelch repeat } \\
\text { superfamily protein }\end{array}$ & 4.552 & 0.000 & 2.103 & 0.001 \\
\hline AT4G19870 & $\begin{array}{c}\text { Galactose oxidase/kelch repeat } \\
\text { superfamily protein }\end{array}$ & 4.140 & 0.001 & 2.101 & 0.042 \\
\hline AT4G25434 & $\begin{array}{l}\text { ATNUDT10, NUDT10 | nudix } \\
\text { hydrolase homolog } 10\end{array}$ & 0.604 & 0.227 & 1.377 & 0.021 \\
\hline AT4G27652 & unknown protein & 1.818 & 0.000 & 1.181 & 0.005 \\
\hline AT4G29880 & PIRL7 & 2.557 & 0.000 & 2.685 & 0.000 \\
\hline AT4G31196 & oxidoreductases & 1.098 & 0.009 & 1.224 & 0.008 \\
\hline AT4G31800 & WRKY18 & 0.585 & 0.026 & 1.070 & 0.002 \\
\hline AT4G34131 & UGT73B3 & 3.327 & 0.000 & 1.694 & 0.010 \\
\hline AT4G35180 & LHT7 | LYS/HIS transporter 7 & 0.583 & 0.091 & 1.537 & 0.001 \\
\hline AT4G38215 & other RNA & 1.683 & 0.000 & 1.165 & 0.001 \\
\hline AT4G38480 & $\begin{array}{l}\text { Transducin/WD40 repeat-like } \\
\text { superfamily protein }\end{array}$ & 1.697 & 0.000 & 1.409 & 0.001 \\
\hline AT5G01900 & WRKY62, ATWRKY62 & 1.919 & 0.001 & 1.848 & 0.003 \\
\hline AT5G03350 & Legume lectin family protein & 0.150 & 0.783 & 3.006 & 0.000 \\
\hline AT5G07100 & WRKY26 & 0.162 & 0.774 & 1.251 & 0.025 \\
\hline AT5G0 & $\begin{array}{l}\text { HXXXD-type acyl-transferase } \\
\text { family protein }\end{array}$ & 3.110 & 0.000 & 1.863 & 0.001 \\
\hline AT5G08790 & ATAF2, anac081 & 2.156 & 0.000 & 1.471 & 0.006 \\
\hline AT5G14890 & $\mathrm{NHL}$ domain-containing protein & 1.364 & 0.000 & 1.166 & 0.000 \\
\hline AT5G20935 & unknown protein & 1.235 & 0.000 & 1.025 & 0.001 \\
\hline AT5G21920 & YLMG2 & 0.806 & 0.094 & 1.202 & 0.034 \\
\hline
\end{tabular}




\begin{tabular}{|l|c|c|c|c|c|}
\hline AT5G22570 & WRKY38, ATWRKY38 & 2.068 & 0.008 & 2.492 & 0.005 \\
\hline AT5G25450 & $\begin{array}{c}\text { Cytochrome bd ubiquinol oxidase, } \\
\text { 14kDa subunit }\end{array}$ & 1.347 & 0.011 & 1.376 & 0.016 \\
\hline AT5G35688 & unknown protein & 3.174 & 0.000 & 1.590 & 0.015 \\
\hline AT5G44568 & unknown protein & 0.236 & 0.526 & 1.526 & 0.002 \\
\hline AT5G45110 & NPR3, ATNPR3 & 1.449 & 0.003 & 1.147 & 0.021 \\
\hline AT5G48400 & ATGLR1.2, GLR1.2 & 0.926 & 0.037 & 1.634 & 0.004 \\
\hline AT5G53470 & ACBP1, ACBP & 2.079 & 0.000 & 1.863 & 0.000 \\
\hline AT5G58120 & $\begin{array}{c}\text { Disease resistance protein (TIR- } \\
\text { NBS-LRR class) family }\end{array}$ & 1.084 & 0.011 & 1.043 & 0.021 \\
\hline AT5G59160 & TOPP2, PPO & 2.150 & 0.002 & 2.330 & 0.003 \\
\hline AT5G59820 & RHL41, ZAT12 & 2.099 & 0.000 & 1.189 & 0.005 \\
\hline AT5G60380 & $\begin{array}{c}\text { Protein of Unknown Function } \\
\text { (DUF239) }\end{array}$ & 1.220 & 0.006 & 1.325 & 0.007 \\
\hline AT5G63790 & ANAC102, NAC102 & 2.575 & 0.000 & 2.718 & 0.000 \\
\hline AT5G64240 & AtMC3, MC3 metacaspase 3 & 2.426 & 0.003 & 1.503 & 0.049 \\
\hline AT5G64810 & WRKY51, ATWRKY51 & 1.377 & 0.011 & 1.453 & 0.015 \\
\hline AT5G66110 & HIPP27 & 1.294 & 0.003 & 1.170 & 0.010 \\
\hline
\end{tabular}

\section{Tabelle 6.5: In Col-0 durch SA-Behandlung induzierte Gene}

Angegeben sind der Induktionsfaktor in Col-0 und der sc/14/33 Mutante nach SA-Behandlung und der jeweils als log2-fache Induktion. Rot dargestellte Werte bedeuten eine Induktion, während grün dargestellte Werte eine Repression bedeuten. P-Werte über 0,05 sind gelb hinterlegt.

\begin{tabular}{|c|c|c|c|c|c|}
\hline AGI-Code & Beschreibung & $\begin{array}{c}\text { Col-0 } \\
\text { Kontr. / } \\
\text { Col-0 SA }\end{array}$ & $\begin{array}{c}\text { adjusted } \\
\text { P-Value }\end{array}$ & $\begin{array}{c}\text { scl14/33 } \\
\text { Kontr. / } \\
\text { scl14/33 SA }\end{array}$ & $\begin{array}{c}\text { adjusted } \\
\text { P-Value }\end{array}$ \\
\hline AT1G01720 & ATAF1, ANAC002 & 1.074 & 0.014 & 1.342 & 0.008 \\
\hline AT1G02230 & ANAC004, NAC004 & 2.340 & 0.001 & 3.165 & 0.000 \\
\hline AT1G02880 & $\begin{array}{c}\text { TPK1 | thiamin } \\
\text { pyrophosphokinase1 }\end{array}$ & 1.432 & 0.031 & 0.531 & 0.525 \\
\hline AT1G04090 & $\begin{array}{c}\text { Plant protein of unknown function } \\
\text { (DUF946) }\end{array}$ & 1.019 & 0.002 & 0.810 & 0.011 \\
\hline AT1G05560 & $\begin{array}{c}\text { UGT1, UGT75B1 | UDP- } \\
\text { glucosyltransferase 75B1 }\end{array}$ & 1.787 & 0.008 & 2.209 & 0.004 \\
\hline AT1G05820 & $\begin{array}{c}\text { SPPL5, ATSPPL5 | SIGNAL } \\
\text { PEPTIDE PEPTIDASE-LIKE 5 }\end{array}$ & 1.021 & 0.007 & 0.816 & 0.035 \\
\hline AT1G06260 & $\begin{array}{c}\text { Cysteine proteinases superfamily } \\
\text { protein }\end{array}$ & 1.167 & 0.002 & 0.955 & 0.012 \\
\hline AT1G07590 & $\begin{array}{c}\text { Tetratricopeptide repeat (TPR)-like } \\
\text { superfamily protein }\end{array}$ & 1.299 & 0.000 & 1.008 & 0.003 \\
\hline AT1G09710 & $\begin{array}{c}\text { Homeodomain-like superfamily } \\
\text { protein }\end{array}$ & 1.788 & 0.022 & 0.545 & 0.579 \\
\hline AT1G10820 & $\begin{array}{c}\text { Protein of unknown function } \\
\text { (DUF3755) }\end{array}$ & 2.633 & 0.011 & 0.202 & 0.908 \\
\hline AT1G12770 & ISE1, EMB1586 & 1.166 & 0.002 & 0.893 & 0.012 \\
\hline AT1G12775 & $\begin{array}{c}\text { Pentatricopeptide repeat (PPR) } \\
\text { superfamily protein }\end{array}$ & 1.015 & 0.024 & 0.961 & 0.049 \\
\hline AT1G15125 & $\begin{array}{c}\text { S-adenosyl-L-methionine- } \\
\text { dependent methyltransferases } \\
\text { superfamily protein }\end{array}$ & 1.417 & 0.000 & 0.884 & 0.009 \\
\hline AT1G15260 & unknown protein & 1.395 & 0.012 & 1.460 & 0.016 \\
\hline
\end{tabular}




\begin{tabular}{|c|c|c|c|c|c|}
\hline AT1G17147 & VQ motif-containing protein & 1.679 & 0.000 & 0.496 & 0.049 \\
\hline AT1G17170 & ATGSTU24, GST, GSTU24 & 1.240 & 0.002 & 0.475 & 0.202 \\
\hline AT1G18250 & $\begin{array}{l}\text { ATLP-1 | Pathogenesis-related } \\
\text { thaumatin superfamily protein }\end{array}$ & 1.037 & 0.016 & 0.544 & 0.242 \\
\hline AT1G18265 & $\begin{array}{c}\text { Protein of unknown function, } \\
\text { DUF593 }\end{array}$ & 1.922 & 0.002 & 1.683 & 0.007 \\
\hline AT1G18990 & $\begin{array}{c}\text { Protein of unknown function, } \\
\text { DUF593 }\end{array}$ & 1.374 & 0.015 & 1.636 & 0.011 \\
\hline AT1G19115 & unknown protein; & 1.947 & 0.047 & 1.021 & 0.388 \\
\hline AT1G19540 & $\begin{array}{l}\text { NmrA-like negative transcriptional } \\
\text { regulator family protein }\end{array}$ & 1.946 & 0.003 & 2.092 & 0.004 \\
\hline AT1G20150 & $\begin{array}{l}\text { Subtilisin-like serine endopeptidase } \\
\text { family protein }\end{array}$ & 1.083 & 0.003 & 0.356 & 0.316 \\
\hline AT1G20925 & Auxin efflux carrier family protein & 1.100 & 0.002 & 0.957 & 0.007 \\
\hline AT1G21680 & $\begin{array}{l}\text { DPP6 N-terminal domain-like } \\
\text { protein }\end{array}$ & 1.309 & 0.000 & 0.394 & 0.147 \\
\hline AT1G23450 & $\begin{array}{c}\text { Tetratricopeptide repeat (TPR)-like } \\
\text { superfamily protein }\end{array}$ & 3.194 & 0.000 & 1.413 & 0.009 \\
\hline AT1G23460 & $\begin{array}{l}\text { Pectin lyase-like superfamily } \\
\text { protein }\end{array}$ & 1.129 & 0.002 & 0.306 & 0.416 \\
\hline AT1G23465 & $\begin{array}{l}\text { Peptidase S24/S26A/S26B/S26C } \\
\text { family protein }\end{array}$ & 1.095 & 0.035 & 0.656 & 0.266 \\
\hline AT1G26800 & RING/U-box superfamily protein & 1.539 & 0.005 & 0.996 & 0.063 \\
\hline AT1G27921 & other RNA & 1.039 & 0.042 & 0.582 & 0.330 \\
\hline AT1G28480 & $\begin{array}{l}\text { GRX480, roxy19 | Thioredoxin } \\
\text { superfamily protein } \\
\end{array}$ & 3.117 & 0.000 & 2.575 & 0.001 \\
\hline AT1G30455 & $\begin{array}{c}\text { transcription regulators;translation } \\
\text { initiation factors;zinc ion } \\
\text { binding;transcription activators }\end{array}$ & 1.957 & 0.002 & 2.577 & 0.001 \\
\hline AT1G30473 & $\begin{array}{l}\text { Heavy metal transport/detoxification } \\
\text { superfamily protein }\end{array}$ & 2.145 & 0.001 & 1.741 & 0.006 \\
\hline AT1G33030 & O-methyltransferase family protein & 1.005 & 0.007 & 0.919 & 0.019 \\
\hline AT1G48405 & $\begin{array}{l}\text { Kinase interacting (KIP1-like) family } \\
\text { protein }\end{array}$ & 1.432 & 0.000 & 1.359 & 0.001 \\
\hline AT1G48560 & unknown protein & 2.702 & 0.003 & 3.129 & 0.003 \\
\hline AT1G50190 & $\begin{array}{l}\text { Cysteine/Histidine-rich C1 domain } \\
\text { family protein }\end{array}$ & 1.177 & 0.001 & 1.033 & 0.004 \\
\hline AT1G52370 & $\begin{array}{l}\text { Ribosomal protein } \mathrm{L} 22 \mathrm{p} / \mathrm{L} 17 \mathrm{e} \\
\text { family protein }\end{array}$ & 1.112 & 0.012 & 1.034 & 0.028 \\
\hline AT1G54160 & $\begin{array}{c}\text { NFYA5, NF-YA5 | nuclear factor Y, } \\
\text { subunit A5 }\end{array}$ & 1.128 & 0.028 & 0.846 & 0.132 \\
\hline AT1G59660 & Nucleoporin autopeptidase & 1.237 & 0.010 & 1.533 & 0.005 \\
\hline AT1G62880 & Cornichon family protein & 2.170 & 0.001 & 1.267 & 0.038 \\
\hline AT1G62886 & $\begin{array}{c}\text { Nucleotide excision repair, TFIIH, } \\
\text { subunit TTDA }\end{array}$ & 2.845 & 0.000 & 2.824 & 0.000 \\
\hline AT1G63010 & $\begin{array}{l}\text { Major Facilitator Superfamily with } \\
\text { SPX (SYG1/Pho81/XPR1) domain- } \\
\text { containing protein }\end{array}$ & 1.391 & 0.049 & 0.627 & 0.481 \\
\hline AT1G66080 & unknown protein & 1.000 & 0.006 & 0.555 & 0.120 \\
\hline AT1G69750 & $\begin{array}{c}\text { COX19-2, ATCOX19-2 | } \\
\text { cytochrome c oxidase 19-2 }\end{array}$ & 1.048 & 0.024 & 0.208 & 0.758 \\
\hline AT1G72416 & $\begin{array}{l}\text { Chaperone DnaJ-domain } \\
\text { superfamily protein }\end{array}$ & 1.062 & 0.008 & 0.629 & 0.124 \\
\hline
\end{tabular}




\begin{tabular}{|c|c|c|c|c|c|}
\hline AT1G72660 & $\begin{array}{l}\text { P-loop containing nucleoside } \\
\text { triphosphate hydrolases } \\
\text { superfamily protein }\end{array}$ & 1.677 & 0.044 & 0.800 & 0.431 \\
\hline AT1G74310 & ATHSP101, HSP101, HOT1 & 1.478 & 0.007 & 0.965 & 0.075 \\
\hline AT1G74830 & $\begin{array}{c}\text { Protein of unknown function, } \\
\text { DUF593 }\end{array}$ & 1.398 & 0.002 & 1.848 & 0.001 \\
\hline AT1G75270 & $\begin{array}{c}\text { DHAR2 | dehydroascorbate } \\
\text { reductase } 2\end{array}$ & 1.203 & 0.004 & 0.244 & 0.616 \\
\hline AT1G76600 & unknown protein & 2.216 & 0.001 & 0.476 & 0.500 \\
\hline AT1G76680 & $\begin{array}{c}\text { OPR1 | } 12 \text {-oxophytodienoate } \\
\text { reductase } 1\end{array}$ & 1.937 & 0.001 & 0.926 & 0.084 \\
\hline AT1G76690 & $\begin{array}{c}\text { OPR2, ATOPR2 | } 12- \\
\text { oxophytodienoate reductase } 2\end{array}$ & 1.735 & 0.000 & 0.499 & 0.209 \\
\hline AT1G77450 & anac032, NAC032 & 1.176 & 0.015 & 0.562 & 0.287 \\
\hline AT1G78995 & unknown protein & 2.993 & 0.000 & 2.806 & 0.001 \\
\hline AT1G79710 & Major facilitator superfamily protein & 1.733 & 0.000 & 0.148 & 0.696 \\
\hline AT1G79790 & $\begin{array}{l}\text { Haloacid dehalogenase-like } \\
\text { hydrolase (HAD) superfamily } \\
\text { protein } \\
\end{array}$ & 1.825 & 0.006 & 0.873 & 0.192 \\
\hline AT1G79820 & $\begin{array}{l}\text { SGB1 | Major facilitator superfamily } \\
\text { protein }\end{array}$ & 1.090 & 0.002 & 0.318 & 0.369 \\
\hline AT2G01100 & unknown protein & 1.462 & 0.015 & 1.088 & 0.087 \\
\hline AT2G01200 & $\begin{array}{c}\text { IAA32 | indole-3-acetic acid } \\
\text { inducible } 32\end{array}$ & 1.017 & 0.001 & 0.741 & 0.010 \\
\hline AT2G04440 & MutT/nudix family protein & 1.022 & 0.001 & 0.841 & 0.004 \\
\hline AT2G05720 & $\begin{array}{l}\text { Transducin/WD40 repeat-like } \\
\text { superfamily protein }\end{array}$ & 3.312 & 0.000 & 3.019 & 0.001 \\
\hline AT2G11270 & citrate synthase-related & 1.139 & 0.000 & 1.169 & 0.001 \\
\hline AT2G14160 & $\begin{array}{l}\text { RNA-binding (RRM/RBD/RNP } \\
\text { motifs) family protein }\end{array}$ & 1.308 & 0.002 & 0.975 & 0.018 \\
\hline AT2G15490 & $\begin{array}{c}\text { UGT73B4 | UDP- } \\
\text { glycosyltransferase 73B4 }\end{array}$ & 1.477 & 0.023 & 1.206 & 0.085 \\
\hline AT2G19310 & $\begin{array}{l}\text { HSP20-like chaperones superfamily } \\
\text { protein }\end{array}$ & 1.264 & 0.002 & 0.167 & 0.747 \\
\hline AT2G23170 & $\begin{array}{l}\text { GH3.3 | Auxin-responsive GH3 } \\
\text { family protein }\end{array}$ & 1.201 & 0.003 & 1.360 & 0.003 \\
\hline AT2G28210 & $\begin{array}{l}\text { ATACA2, ACA2 | alpha carbonic } \\
\text { anhydrase } 2 \\
\end{array}$ & 1.037 & 0.026 & 0.277 & 0.652 \\
\hline AT2G29420 & $\begin{array}{c}\text { ATGSTU7, GST25, GSTU7 | } \\
\text { glutathione S-transferase tau } 7\end{array}$ & 4.089 & 0.000 & 2.116 & 0.000 \\
\hline AT2G29480 & $\begin{array}{l}\text { ATGSTU2, GST20, GSTU2 | } \\
\text { glutathione S-transferase tau } 2\end{array}$ & 1.320 & 0.013 & 0.508 & 0.404 \\
\hline AT2G29490 & $\begin{array}{c}\text { ATGSTU1, GST19, GSTU1 | } \\
\text { glutathione S-transferase TAU } 1\end{array}$ & 1.192 & 0.002 & 0.283 & 0.447 \\
\hline AT2G31981 & unknown protein & 1.219 & 0.046 & 1.165 & 0.086 \\
\hline AT2G32235 & unknown protein & 1.161 & 0.029 & 1.382 & 0.021 \\
\hline AT2G32340 & TraB family protein & 1.280 & 0.009 & 1.015 & 0.045 \\
\hline AT2G33100 & $\begin{array}{l}\text { ATCSLD1, CSLD1 | cellulose } \\
\text { synthase-like D1 }\end{array}$ & 1.065 & 0.001 & 0.926 & 0.003 \\
\hline AT2G35640 & $\begin{array}{l}\text { Homeodomain-like superfamily } \\
\text { protein }\end{array}$ & 1.243 & 0.007 & 1.405 & 0.006 \\
\hline AT2G36355 & $\begin{array}{l}\text { Family of unknown function } \\
\text { (DUF662) }\end{array}$ & 1.648 & 0.008 & 0.784 & 0.219 \\
\hline
\end{tabular}




\begin{tabular}{|c|c|c|c|c|c|}
\hline AT2G36390 & $\begin{array}{c}\text { SBE2.1, BE3 | starch branching } \\
\text { enzyme } 2.1\end{array}$ & 1.296 & 0.001 & 0.708 & 0.035 \\
\hline AT2G36800 & $\begin{array}{l}\text { DOGT1, UGT73C5 | don- } \\
\text { glucosyltransferase } 1\end{array}$ & 1.278 & 0.008 & 1.453 & 0.007 \\
\hline AT2G38255 & $\begin{array}{c}\text { Protein of Unknown Function } \\
\text { (DUF239) }\end{array}$ & 1.685 & 0.011 & 1.219 & 0.076 \\
\hline AT2G40750 & WRKY54, ATWRKY54 & 1.233 & 0.009 & 1.378 & 0.008 \\
\hline AT2G40925 & $\begin{array}{l}\text { F-box and associated interaction } \\
\text { domains-containing protein }\end{array}$ & 2.406 & 0.000 & 2.113 & 0.000 \\
\hline AT2G45150 & $\begin{array}{c}\text { cytidinediphosphate diacylglycerol } \\
\text { synthase } 4\end{array}$ & 1.349 & 0.012 & 1.368 & 0.019 \\
\hline AT2G46320 & $\begin{array}{l}\text { Mitochondrial substrate carrier } \\
\text { family protein }\end{array}$ & 1.527 & 0.034 & 0.366 & 0.719 \\
\hline AT2G47895 & other RNA & 3.225 & 0.000 & 0.730 & 0.116 \\
\hline AT2G48121 & unknown protein & 1.003 & 0.004 & 0.870 & 0.015 \\
\hline AT3G01510 & LSF1 | like SEX4 1 & 1.506 & 0.000 & 0.439 & 0.085 \\
\hline AT3G01513 & unknown protein & 1.970 & 0.000 & 0.313 & 0.471 \\
\hline AT3G04130 & \begin{tabular}{|c|}
$\begin{array}{c}\text { Tetratricopeptide repeat (TPR)-like } \\
\text { superfamily protein }\end{array}$ \\
\end{tabular} & 3.352 & 0.000 & 0.583 & 0.211 \\
\hline AT3G04140 & Ankyrin repeat family protein & 2.102 & 0.000 & 0.162 & 0.807 \\
\hline AT3G06280 & $\begin{array}{c}\text { F-box associated ubiquitination } \\
\text { effector family protein }\end{array}$ & 1.371 & 0.001 & 1.324 & 0.003 \\
\hline AT3G06400 & $\begin{array}{l}\text { CHR11 | chromatin-remodeling } \\
\text { protein } 11\end{array}$ & 2.890 & 0.028 & 0.574 & 0.767 \\
\hline AT3G07150 & unknown protein & 1.392 & 0.000 & 1.115 & 0.003 \\
\hline AT3G07740 & $\begin{array}{c}\text { ADA2A, ATADA2A, HAC10, } \\
\text { HXA02, HXA2 | homolog of yeast } \\
\text { ADA2 2A }\end{array}$ & 1.170 & 0.039 & 0.175 & 0.855 \\
\hline AT3G09240 & $\begin{array}{l}\text { Protein kinase protein with } \\
\text { tetratricopeptide repeat domain }\end{array}$ & 1.189 & 0.006 & 1.332 & 0.005 \\
\hline AT3G11560 & LETM1-like protein & 1.049 & 0.028 & 0.637 & 0.228 \\
\hline AT3G12580 & $\begin{array}{l}\text { HSP70, ATHSP70 | heat shock } \\
\text { protein } 70\end{array}$ & 1.021 & 0.017 & 0.300 & 0.576 \\
\hline AT3G13030 & hAT transposon superfamily protein & 1.023 & 0.042 & 0.595 & 0.311 \\
\hline AT3G13065 & $\begin{array}{l}\text { SRF4 | STRUBBELIG-receptor } \\
\text { family } 4\end{array}$ & 1.385 & 0.001 & 0.852 & 0.021 \\
\hline AT3G14660 & CYP72A13 & 1.142 & 0.014 & 0.399 & 0.468 \\
\hline AT3G14735 & U6-1| U6-1; snRNA & 1.089 & 0.008 & 1.074 & 0.014 \\
\hline AT3G17340 & ARM repeat superfamily protein & 1.973 & 0.023 & 0.940 & 0.341 \\
\hline AT3G17660 & AGD15 | ARF-GAP domain 15 & 1.064 & 0.001 & 0.649 & 0.024 \\
\hline AT3G17670 & $\begin{array}{l}\text { tetratricopeptide repeat (TPR)- } \\
\text { containing protein }\end{array}$ & 1.183 & 0.036 & 0.352 & 0.642 \\
\hline AT3G19800 & $\begin{array}{l}\text { Protein of unknown function } \\
\text { (DUF177) }\end{array}$ & 1.303 & 0.001 & 0.990 & 0.008 \\
\hline AT3G24500 & $\begin{array}{l}\text { MBF1C, ATMBF1C I multiprotein } \\
\text { bridging factor } 1 \mathrm{C}\end{array}$ & 1.319 & 0.019 & 0.642 & 0.304 \\
\hline AT3G24560 & $\begin{array}{l}\text { RSY3 | Adenine nucleotide alpha } \\
\text { hydrolases-like superfamily protein }\end{array}$ & 1.288 & 0.001 & 0.755 & 0.026 \\
\hline AT3G28740 & $\begin{array}{l}\text { CYP81D1 | Cytochrome P450 } \\
\text { superfamily protein }\end{array}$ & 1.945 & 0.026 & 0.238 & 0.872 \\
\hline AT3G45730 & unknown protein & 1.325 & 0.003 & 0.850 & 0.051 \\
\hline AT3G47090 & $\begin{array}{l}\text { Leucine-rich repeat protein kinase } \\
\text { family protein }\end{array}$ & 1.153 & 0.004 & 0.753 & 0.053 \\
\hline
\end{tabular}




\begin{tabular}{|c|c|c|c|c|c|}
\hline AT3G51760 & $\begin{array}{c}\text { Protein of unknown function } \\
\text { (DUF688) }\end{array}$ & 1.500 & 0.008 & 0.792 & 0.171 \\
\hline AT3G51910 & AT-HSFA7A, HSFA7A & 1.314 & 0.011 & 1.303 & 0.020 \\
\hline AT3G54280 & $\begin{array}{c}\text { CHR16, CHA16, RGD3, ATBTAF1, } \\
\text { BTAF1 }\end{array}$ & 1.496 & 0.003 & 1.567 & 0.004 \\
\hline AT3G56790 & RNA splicing factor-related & 1.404 & 0.006 & 1.763 & 0.003 \\
\hline AT3G56830 & $\begin{array}{c}\text { Protein of unknown function } \\
\text { (DUF565) }\end{array}$ & 1.078 & 0.041 & 0.647 & 0.287 \\
\hline AT3G56980 & $\begin{array}{c}\text { BHLH039, ORG3 | basic helix-loop- } \\
\text { helix (bHLH) DNA-binding } \\
\text { superfamily protein }\end{array}$ & 1.165 & 0.002 & 0.265 & 0.508 \\
\hline AT3G60176 & other RNA & 1.239 & 0.001 & 0.619 & 0.057 \\
\hline AT3G60760 & unknown protein & 1.668 & 0.000 & 1.957 & 0.000 \\
\hline AT3G62350 & unknown protein & 1.111 & 0.039 & 1.413 & 0.022 \\
\hline AT3G63320 & $\begin{array}{c}\text { Protein phosphatase } 2 \mathrm{C} \text { family } \\
\text { protein }\end{array}$ & 1.246 & 0.000 & 1.625 & 0.000 \\
\hline AT4G03510 & $\begin{array}{l}\text { RMA1, ATRMA1 | RING } \\
\text { membrane-anchor } 1\end{array}$ & 1.218 & 0.009 & 0.512 & 0.303 \\
\hline AT4G04730 & unknown protein & 1.208 & 0.015 & 1.050 & 0.048 \\
\hline AT4G10410 & $\begin{array}{l}\text { Leucine-rich repeat (LRR) family } \\
\text { protein }\end{array}$ & 1.564 & 0.009 & 1.317 & 0.033 \\
\hline AT4G12400 & $\begin{array}{c}\text { Hop3 | stress-inducible protein, } \\
\text { putative }\end{array}$ & 1.490 & 0.017 & 2.134 & 0.004 \\
\hline AT4G14030 & SBP1 | selenium-binding protein 1 & 1.286 & 0.002 & 0.165 & 0.730 \\
\hline AT4G14040 & $\begin{array}{l}\text { EDA38, SBP2 | selenium-binding } \\
\text { protein } 2 \\
\end{array}$ & 1.391 & 0.002 & 0.192 & 0.725 \\
\hline AT4G14368 & $\begin{array}{c}\text { Regulator of chromosome } \\
\text { condensation (RCC1) family protein }\end{array}$ & 1.424 & 0.011 & 1.323 & 0.025 \\
\hline AT4G15550 & $\begin{array}{l}\text { IAGLU | indole-3-acetate beta-D- } \\
\text { glucosyltransferase }\end{array}$ & 2.468 & 0.000 & 2.371 & 0.001 \\
\hline AT4G17590 & unknown protein & 2.898 & 0.028 & 0.275 & 0.905 \\
\hline AT4G19060 & $\begin{array}{l}\text { P-loop containing nucleoside } \\
\text { triphosphate hydrolases } \\
\text { superfamily protein }\end{array}$ & 1.390 & 0.004 & 0.861 & 0.067 \\
\hline AT4G19070 & Putative membrane lipoprotein & 1.110 & 0.002 & 0.643 & 0.055 \\
\hline AT4G19080 & $\begin{array}{l}\text { Protein of unknown function } \\
\text { (DUF594) }\end{array}$ & 2.511 & 0.000 & 1.100 & 0.032 \\
\hline AT4G19095 & unknown protein & 2.088 & 0.000 & 1.024 & 0.035 \\
\hline AT4G19110 & Protein kinase superfamily protein & 3.041 & 0.036 & 1.201 & 0.513 \\
\hline AT4G19645 & $\begin{array}{l}\text { TRAM, LAG1 and CLN8 (TLC) } \\
\text { lipid-sensing domain containing } \\
\text { protein } \\
\end{array}$ & 2.079 & 0.003 & 1.509 & 0.024 \\
\hline AT4G19865 & $\begin{array}{c}\text { Galactose oxidase/kelch repeat } \\
\text { superfamily protein }\end{array}$ & 4.552 & 0.000 & 2.103 & 0.001 \\
\hline AT4G19870 & $\begin{array}{c}\text { Galactose oxidase/kelch repeat } \\
\text { superfamily protein }\end{array}$ & 4.140 & 0.001 & 2.101 & 0.042 \\
\hline AT4G19880 & $\begin{array}{c}\text { Glutathione S-transferase family } \\
\text { protein }\end{array}$ & 1.710 & 0.038 & 0.226 & 0.874 \\
\hline AT4G21990 & $\begin{array}{c}\text { APR3, PRH-26, PRH26, ATAPR3 } \\
\text { APS reductase } 3\end{array}$ & 1.177 & 0.014 & 0.187 & 0.792 \\
\hline AT4G24460 & $\begin{array}{c}\text { CLT2 | CRT (chloroquine- } \\
\text { resistance transporter)-like } \\
\text { transporter } 2 \\
\end{array}$ & 1.687 & 0.028 & 0.656 & 0.485 \\
\hline
\end{tabular}




\begin{tabular}{|c|c|c|c|c|c|}
\hline AT4G25450 & $\begin{array}{l}\text { ATNAP8, NAP8 | non-intrinsic ABC } \\
\text { protein } 8\end{array}$ & 2.329 & 0.014 & 0.225 & 0.886 \\
\hline AT4G27652 & unknown protein & 1.818 & 0.000 & 1.181 & 0.005 \\
\hline AT4G27654 & unknown protein & 1.441 & 0.002 & 0.564 & 0.202 \\
\hline AT4G27657 & unknown protein & 1.193 & 0.002 & 0.447 & 0.198 \\
\hline AT4G28790 & $\begin{array}{l}\text { basic helix-loop-helix (bHLH) DNA- } \\
\text { binding superfamily protein }\end{array}$ & 1.237 & 0.025 & 0.195 & 0.821 \\
\hline AT4G29850 & $\begin{array}{l}\text { Eukaryotic protein of unknown } \\
\text { function (DUF872) }\end{array}$ & 2.165 & 0.038 & 0.151 & 0.939 \\
\hline AT4G29880 & $\begin{array}{l}\text { PIRL7 | plant intracellular ras } \\
\text { group-related LRR } 7\end{array}$ & 2.557 & 0.000 & 2.685 & 0.000 \\
\hline AT4G31196 & oxidoreductases & 1.098 & 0.009 & 1.224 & 0.008 \\
\hline AT4G32630 & $\begin{array}{l}\text { ArfGap/RecO-like zinc finger } \\
\text { domain-containing protein }\end{array}$ & 1.157 & 0.003 & 0.959 & 0.013 \\
\hline AT4G33650 & $\begin{array}{l}\text { ADL2, DRP3A | dynamin-related } \\
\text { protein } 3 A\end{array}$ & 2.005 & 0.003 & 0.720 & 0.284 \\
\hline AT4G34131 & $\begin{array}{l}\text { UGT73B3 | UDP-glucosyl } \\
\text { transferase 73B3 }\end{array}$ & 3.327 & 0.000 & 1.694 & 0.010 \\
\hline AT4G34135 & $\begin{array}{c}\text { UGT73B2 | UDP- } \\
\text { glucosyltransferase 73B2 }\end{array}$ & 1.770 & 0.012 & 0.150 & 0.897 \\
\hline AT4G36040 & $\begin{array}{l}\text { Chaperone DnaJ-domain } \\
\text { superfamily protein }\end{array}$ & 1.283 & 0.005 & 0.240 & 0.659 \\
\hline AT4G36052 & other RNA & 1.382 & 0.008 & 0.109 & 0.897 \\
\hline AT4G38215 & other RNA & 1.683 & 0.000 & 1.165 & 0.001 \\
\hline AT4G38480 & $\begin{array}{l}\text { Transducin/WD40 repeat-like } \\
\text { superfamily protein }\end{array}$ & 1.697 & 0.000 & 1.409 & 0.001 \\
\hline AT4G38490 & unknown protein & 1.215 & 0.000 & 0.944 & 0.003 \\
\hline AT5G01900 & WRKY62, ATWRKY62 & 1.919 & 0.001 & 1.848 & 0.003 \\
\hline AT5G05410 & $\begin{array}{l}\text { DREB2A, DREB2 | DRE-binding } \\
\text { protein } 2 A \\
\end{array}$ & 2.144 & 0.028 & 0.449 & 0.752 \\
\hline AT5G06820 & $\begin{array}{l}\text { SRF2 | STRUBBELIG-receptor } \\
\text { family } 2 \\
\end{array}$ & 1.086 & 0.009 & 0.990 & 0.023 \\
\hline AT5G07860 & $\begin{array}{c}\text { HXXXD-type acyl-transferase } \\
\text { family protein }\end{array}$ & 1.964 & 0.001 & 0.909 & 0.061 \\
\hline AT5G07870 & $\begin{array}{l}\text { HXXXD-type acyl-transferase } \\
\text { family protein } \\
\end{array}$ & 3.110 & 0.000 & 1.863 & 0.001 \\
\hline AT5G07880 & $\begin{array}{l}\text { SNAP29, ATSNAP29 | } \\
\text { synaptosomal-associated protein } \\
\text { SNAP25-like } 29\end{array}$ & 1.293 & 0.001 & 0.673 & 0.043 \\
\hline AT5G07900 & $\begin{array}{l}\text { Mitochondrial transcription } \\
\text { termination factor family protein }\end{array}$ & 1.404 & 0.011 & 0.199 & 0.806 \\
\hline AT5G08790 & ATAF2, anac081 & 2.156 & 0.000 & 1.471 & 0.006 \\
\hline AT5G12280 & $\begin{array}{l}\text { SWAP (Suppressor-of-White- } \\
\text { APricot)/surp RNA-binding domain- } \\
\text { containing protein }\end{array}$ & 1.349 & 0.023 & 0.785 & 0.225 \\
\hline AT5G13080 & WRKY75, ATWRKY75 & 1.008 & 0.049 & 0.396 & 0.553 \\
\hline AT5G14270 & ATBET9, BET9 & 2.927 & 0.012 & 1.816 & 0.138 \\
\hline AT5G14470 & GHMP kinase family protein & 2.286 & 0.007 & 0.368 & 0.739 \\
\hline AT5G14730 & unknown protein & 2.216 & 0.000 & 0.640 & 0.176 \\
\hline AT5G14890 & $\mathrm{NHL}$ domain-containing protein & 1.364 & 0.000 & 1.166 & 0.000 \\
\hline AT5G16300 & $\begin{array}{l}\text { Vps51/Vps67 family (components } \\
\text { of vesicular transport) protein }\end{array}$ & 1.472 & 0.005 & 0.467 & 0.396 \\
\hline
\end{tabular}




\begin{tabular}{|c|c|c|c|c|c|}
\hline AT5G18400 & $\begin{array}{l}\text { Cytokine-induced anti-apoptosis } \\
\text { inhibitor } 1, \text { Fe-S biogenesis }\end{array}$ & 1.333 & 0.046 & 0.484 & 0.582 \\
\hline AT5G20935 & unknown protein & 1.235 & 0.000 & 1.025 & 0.001 \\
\hline AT5G22570 & WRKY38, ATWRKY38 & 2.068 & 0.008 & 2.492 & 0.005 \\
\hline AT5G25450 & $\begin{array}{c}\text { Cytochrome bd ubiquinol oxidase, } \\
14 \mathrm{kDa} \text { subunit }\end{array}$ & 1.347 & 0.011 & 1.376 & 0.016 \\
\hline AT5G26980 & SYP41, ATSYP41, ATTLG2A & 1.366 & 0.021 & 0.341 & 0.661 \\
\hline AT5G27010 & ARM repeat superfamily protein & 1.103 & 0.003 & 0.964 & 0.013 \\
\hline AT5G27030 & TPR3 | TOPLESS-related 3 & 2.470 & 0.048 & 2.145 & 0.127 \\
\hline AT5G35688 & unknown protein & 3.174 & 0.000 & 1.590 & 0.015 \\
\hline AT5G42965 & $\begin{array}{c}\text { Polynucleotidyl transferase, } \\
\text { ribonuclease H-like superfamily } \\
\text { protein }\end{array}$ & 1.023 & 0.010 & 0.841 & 0.041 \\
\hline AT5G45110 & NPR3, ATNPR3 & 1.449 & 0.003 & 1.147 & 0.021 \\
\hline AT5G51440 & $\begin{array}{c}\text { HSP20-like chaperones superfamily } \\
\text { protein }\end{array}$ & 1.116 & 0.016 & 0.024 & 0.979 \\
\hline AT5G52100 & $\begin{array}{l}\text { crr1 | Dihydrodipicolinate } \\
\text { reductase, bacterial/plant }\end{array}$ & 1.505 & 0.012 & 1.150 & 0.067 \\
\hline AT5G53470 & $\begin{array}{l}\text { ACBP1, ACBP | acyl-CoA binding } \\
\text { protein } 1\end{array}$ & 2.079 & 0.000 & 1.863 & 0.000 \\
\hline AT5G57010 & calmodulin-binding family protein & 1.124 & 0.016 & 0.003 & 0.998 \\
\hline AT5G58120 & $\begin{array}{l}\text { Disease resistance protein (TIR- } \\
\text { NBS-LRR class) family }\end{array}$ & 1.084 & 0.011 & 1.043 & 0.021 \\
\hline AT5G59160 & TOPP2, PPO & 2.150 & 0.002 & 2.330 & 0.003 \\
\hline AT5G59820 & $\begin{array}{l}\mathrm{RHL} 41, \mathrm{ZAT} 12 \mid \mathrm{C} 2 \mathrm{H} 2 \text {-type zinc } \\
\text { finger family protein }\end{array}$ & 2.099 & 0.000 & 1.189 & 0.005 \\
\hline AT5G60380 & $\begin{array}{c}\text { Protein of Unknown Function } \\
\text { (DUF239) }\end{array}$ & 1.220 & 0.006 & 1.325 & 0.007 \\
\hline AT5G60410 & ATSIZ1, SIZ1 & 1.445 & 0.044 & 0.662 & 0.459 \\
\hline AT5G60440 & AGL62 & 1.165 & 0.026 & 0.830 & 0.145 \\
\hline AT5G61495 & unknown protein & 1.765 & 0.000 & 0.967 & 0.011 \\
\hline AT5G61800 & $\begin{array}{l}\text { Pentatricopeptide repeat (PPR) } \\
\text { superfamily protein }\end{array}$ & 1.192 & 0.025 & 0.059 & 0.953 \\
\hline AT5G63790 & ANAC102, NAC102 & 2.575 & 0.000 & 2.718 & 0.000 \\
\hline AT5G64150 & $\begin{array}{l}\text { RNA methyltransferase family } \\
\text { protein }\end{array}$ & 1.008 & 0.023 & 0.634 & 0.188 \\
\hline AT5G64240 & AtMC3, MC3 | metacaspase 3 & 2.426 & 0.003 & 1.503 & 0.049 \\
\hline AT5G64250 & $\begin{array}{l}\text { Aldolase-type TIM barrel family } \\
\text { protein }\end{array}$ & 1.330 & 0.002 & 0.673 & 0.077 \\
\hline AT5G64810 & WRKY51, ATWRKY51 & 1.377 & 0.011 & 1.453 & 0.015 \\
\hline AT5G66045 & MIR170 | MIR170; miRNA & 1.637 & 0.035 & 1.264 & 0.142 \\
\hline AT5G66110 & HIPP27 & 1.294 & 0.003 & 1.170 & 0.010 \\
\hline AT5G66985 & unknown protein & 1.296 & 0.007 & 0.168 & 0.806 \\
\hline
\end{tabular}


Tabelle 6.6:Liste der 516 SA-beeinflussten Gene aus der MarVis Analyse

Normalized Profile gibt die Relative Expression der einzelnen Gene unter den angegebenen Bedingungen an. PrototypeProfile gibt die durchschnittliche Relative Expression der Gene in einem Prototyp an. Die Cluster Number entspricht der Nummer des Prototyps, in den die Gene eingeordnet wurden.

\begin{tabular}{|c|c|c|c|c|c|c|c|c|c|c|}
\hline \multirow[t]{2}{*}{ AGI-Code } & \multirow[t]{2}{*}{ Beschreibung } & \multicolumn{4}{|c|}{ NormalizedProfile } & \multirow{2}{*}{$\begin{array}{c}\text { Cluster } \\
\text { Number }\end{array}$} & \multicolumn{4}{|c|}{ PrototypeProfile } \\
\hline & & $\begin{array}{c}\text { Col-0 } \\
\text { SA }\end{array}$ & $\begin{array}{l}\text { Col-0 } \\
\text { Kontr. }\end{array}$ & $\begin{array}{c}s c / 14 / 33 \\
\text { SA }\end{array}$ & $\begin{array}{l}\text { scl14/33 } \\
\text { Kontr. }\end{array}$ & & $\begin{array}{c}\text { Col-0 } \\
\text { SA }\end{array}$ & $\begin{array}{l}\text { Col-0 } \\
\text { Kontr. }\end{array}$ & $\begin{array}{c}s c / 14 / 33 \\
\text { SA }\end{array}$ & $\begin{array}{l}\text { scl14/33 } \\
\text { Kontr. }\end{array}$ \\
\hline AT1G13360.1 & unknown protein & 0,727 & 0,369 & 0,506 & 0,283 & 1 & 0,695 & 0,358 & 0,545 & 0,291 \\
\hline AT1G18879.1 & $\begin{array}{c}\text { MIR837A MIR837a; } \\
\text { miRNA }\end{array}$ & 0,675 & 0,346 & 0,599 & 0,258 & 1 & 0,695 & 0,358 & 0,545 & 0,291 \\
\hline AT1G45545.1 & $\begin{array}{l}\text { Plant protein of } \\
\text { unknown function } \\
\text { (DUF827) }\end{array}$ & 0,695 & 0,326 & 0,529 & 0,363 & 1 & 0,695 & 0,358 & 0,545 & 0,291 \\
\hline AT1G48267.1 & $\begin{array}{c}\text { MIR161 MIR161; } \\
\text { miRNA }\end{array}$ & 0,701 & 0,345 & 0,518 & 0,347 & 1 & 0,695 & 0,358 & 0,545 & 0,291 \\
\hline AT1G56700.2 & $\begin{array}{l}\text { Peptidase C15 } \\
\text { pyroglutamyl } \\
\text { peptidase I-like }\end{array}$ & 0,708 & 0,311 & 0,542 & 0,329 & 1 & 0,695 & 0,358 & 0,545 & 0,291 \\
\hline AT1G63930.1 & $\begin{array}{c}\text { ROH1 from the } \\
\text { Czech 'roh' meaning } \\
\text { 'corner' }\end{array}$ & 0,720 & 0,356 & 0,504 & 0,316 & 1 & 0,695 & 0,358 & 0,545 & 0,291 \\
\hline AT1G65570.1 & $\begin{array}{l}\text { Pectin lyase-like } \\
\text { superfamily protein }\end{array}$ & 0,694 & 0,346 & 0,520 & 0,358 & 1 & 0,695 & 0,358 & 0,545 & 0,291 \\
\hline AT1G70460.1 & $\begin{array}{l}\text { RHS10 root hair } \\
\text { specific } 10 \\
\end{array}$ & 0,743 & 0,331 & 0,506 & 0,288 & 1 & 0,695 & 0,358 & 0,545 & 0,291 \\
\hline AT2G22850.1 & $\begin{array}{l}\text { AtbZIP6 bZIP6 basic } \\
\text { leucine-zipper } 6\end{array}$ & 0,656 & 0,473 & 0,535 & 0,245 & 1 & 0,695 & 0,358 & 0,545 & 0,291 \\
\hline AT2G23290.1 & $\begin{array}{c}\text { AtMYB70 MYB70 } \\
\text { myb domain protein } \\
70 \\
\end{array}$ & 0,688 & 0,321 & 0,537 & 0,368 & 1 & 0,695 & 0,358 & 0,545 & 0,291 \\
\hline AT2G37820.1 & $\begin{array}{l}\text { Cysteine/Histidine- } \\
\text { rich C1 domain family } \\
\text { protein }\end{array}$ & 0,680 & 0,333 & 0,561 & 0,335 & 1 & 0,695 & 0,358 & 0,545 & 0,291 \\
\hline AT2G46685.1 & $\begin{array}{c}\text { MIR166A MIR166 } \\
\text { MIR166/MIR166A; } \\
\text { miRNA }\end{array}$ & 0,694 & 0,302 & 0,543 & 0,363 & 1 & 0,695 & 0,358 & 0,545 & 0,291 \\
\hline АТ3G08710.1 & $\begin{array}{l}\text { ATH9 TRX H9 TH9 } \\
\text { thioredoxin H-type } 9\end{array}$ & 0,655 & 0,411 & 0,574 & 0,272 & 1 & 0,695 & 0,358 & 0,545 & 0,291 \\
\hline AT3G16857.1 & $\begin{array}{l}\text { ARR1 RR1 response } \\
\text { regulator } 1\end{array}$ & 0,674 & 0,356 & 0,593 & 0,260 & 1 & 0,695 & 0,358 & 0,545 & 0,291 \\
\hline AT3G18773.1 & $\begin{array}{c}\text { RING/U-box } \\
\text { superfamily protein }\end{array}$ & 0,718 & 0,294 & 0,568 & 0,275 & 1 & 0,695 & 0,358 & 0,545 & 0,291 \\
\hline AT3G23870.1 & $\begin{array}{l}\text { Protein of unknown } \\
\text { function (DUF803) }\end{array}$ & 0,719 & 0,354 & 0,504 & 0,321 & 1 & 0,695 & 0,358 & 0,545 & 0,291 \\
\hline AT4G31408.1 & other RNA & 0,721 & 0,307 & 0,539 & 0,309 & 1 & 0,695 & 0,358 & 0,545 & 0,291 \\
\hline AT4G32440.1 & $\begin{array}{l}\text { Plant Tudor-like RNA- } \\
\text { binding protein }\end{array}$ & 0,654 & 0,418 & 0,586 & 0,233 & 1 & 0,695 & 0,358 & 0,545 & 0,291 \\
\hline AT4G35030.2 & $\begin{array}{c}\text { Protein kinase } \\
\text { superfamily protein }\end{array}$ & 0,719 & 0,329 & 0,545 & 0,280 & 1 & 0,695 & 0,358 & 0,545 & 0,291 \\
\hline AT4G37890.1 & $\begin{array}{l}\text { EDA40 Zinc finger } \\
\text { (C3HC4-type RING } \\
\text { finger) family protein }\end{array}$ & 0,699 & 0,325 & 0,554 & 0,313 & 1 & 0,695 & 0,358 & 0,545 & 0,291 \\
\hline AT4G38810.1 & $\begin{array}{l}\text { Calcium-binding EF- } \\
\text { hand family protein }\end{array}$ & 0,727 & 0,402 & 0,532 & 0,166 & 1 & 0,695 & 0,358 & 0,545 & 0,291 \\
\hline AT4G39780.1 & $\begin{array}{c}\text { Integrase-type DNA- } \\
\text { binding superfamily } \\
\text { protein }\end{array}$ & 0,726 & 0,347 & 0,529 & 0,272 & 1 & 0,695 & 0,358 & 0,545 & 0,291 \\
\hline AT5G10990.1 & $\begin{array}{c}\text { SAUR-like auxin- } \\
\text { responsive protein } \\
\text { family }\end{array}$ & 0,674 & 0,322 & 0,596 & 0,296 & 1 & 0,695 & 0,358 & 0,545 & 0,291 \\
\hline AT5G16510.1 & $\begin{array}{l}\text { Alpha-14-glucan- } \\
\text { protein synthase } \\
\text { family protein }\end{array}$ & 0,693 & 0,336 & 0,573 & 0,281 & 1 & 0,695 & 0,358 & 0,545 & 0,291 \\
\hline AT5G41680.1 & $\begin{array}{c}\text { Protein kinase } \\
\text { superfamily protein }\end{array}$ & 0,625 & 0,462 & 0,575 & 0,257 & 1 & 0,695 & 0,358 & 0,545 & 0,291 \\
\hline
\end{tabular}


Anhang

\begin{tabular}{|c|c|c|c|c|c|c|c|c|c|c|}
\hline AT5G46845.1 & $\begin{array}{c}\text { MIR160C MIR160 } \\
\text { MIR160/MIR160C } \\
\text { (MICRORNA160); } \\
\text { miRNA }\end{array}$ & 0,676 & 0,501 & 0,498 & 0,212 & 1 & 0,695 & 0,358 & 0,545 & 0,291 \\
\hline AT5G60680.1 & $\begin{array}{l}\text { Protein of unknown } \\
\text { function DUF584 }\end{array}$ & 0,710 & 0,338 & 0,562 & 0,259 & 1 & 0,695 & 0,358 & 0,545 & 0,291 \\
\hline AT1G12040.1 & $\begin{array}{l}\text { LRX1 leucine-rich } \\
\text { repeat/extensin } 1\end{array}$ & 0,808 & 0,240 & 0,479 & 0,245 & 2 & 0,765 & 0,254 & 0,524 & 0,270 \\
\hline AT1G12650.1 & unknown protein & 0,732 & 0,240 & 0,558 & 0,307 & 2 & 0,765 & 0,254 & 0,524 & 0,270 \\
\hline AT1G15240.1 & $\begin{array}{c}\text { Phox-associated } \\
\text { domain;Phox- } \\
\text { like;Sorting nexin C- } \\
\text { terminal } \\
\end{array}$ & 0,775 & 0,237 & 0,531 & 0,248 & 2 & 0,765 & 0,254 & 0,524 & 0,270 \\
\hline AT1G28330.3 & $\begin{array}{l}\text { DYL1 dormancy- } \\
\text { associated protein- } \\
\text { like } 1\end{array}$ & 0,758 & 0,322 & 0,503 & 0,262 & 2 & 0,765 & 0,254 & 0,524 & 0,270 \\
\hline AT1G48930.1 & $\begin{array}{c}\text { AtGH9C1 GH9C1 } \\
\text { glycosyl hydrolase } \\
9 \mathrm{C} 1 \\
\end{array}$ & 0,787 & 0,234 & 0,513 & 0,250 & 2 & 0,765 & 0,254 & 0,524 & 0,270 \\
\hline AT1G63600.1 & $\begin{array}{c}\text { Receptor-like protein } \\
\text { kinase-related family } \\
\text { protein } \\
\end{array}$ & 0,799 & 0,243 & 0,470 & 0,284 & 2 & 0,765 & 0,254 & 0,524 & 0,270 \\
\hline AT1G66173.1 & other RNA & 0,749 & 0,237 & 0,580 & 0,215 & 2 & 0,765 & 0,254 & 0,524 & 0,270 \\
\hline AT1G74960.1 & $\begin{array}{c}\text { FAB1 KAS2 ATKAS2 } \\
\text { fatty acid } \\
\text { biosynthesis } 1\end{array}$ & 0,769 & 0,276 & 0,486 & 0,310 & 2 & 0,765 & 0,254 & 0,524 & 0,270 \\
\hline AT1G75180.2 & $\begin{array}{c}\text { Erythronate-4- } \\
\text { phosphate } \\
\text { dehydrogenase } \\
\text { family protein } \\
\end{array}$ & 0,725 & 0,241 & 0,564 & 0,312 & 2 & 0,765 & 0,254 & 0,524 & 0,270 \\
\hline AT2G21270.2 & $\begin{array}{c}\text { UFD1 ubiquitin } \\
\text { fusion degradation } 1\end{array}$ & 0,799 & 0,196 & 0,517 & 0,235 & 2 & 0,765 & 0,254 & 0,524 & 0,270 \\
\hline AT2G47275.1 & $\begin{array}{c}\text { MIR403 MIR403; } \\
\text { miRNA }\end{array}$ & 0,776 & 0,286 & 0,520 & 0,216 & 2 & 0,765 & 0,254 & 0,524 & 0,270 \\
\hline AT3G06330.2 & $\begin{array}{c}\text { RING/U-box } \\
\text { superfamily protein }\end{array}$ & 0,748 & 0,297 & 0,530 & 0,266 & 2 & 0,765 & 0,254 & 0,524 & 0,270 \\
\hline AT3G07070.1 & $\begin{array}{c}\text { Protein kinase } \\
\text { superfamily protein }\end{array}$ & 0,786 & 0,270 & 0,466 & 0,303 & 2 & 0,765 & 0,254 & 0,524 & 0,270 \\
\hline AT3G18240.1 & $\begin{array}{c}\text { Ribosomal protein } \\
\text { S24/S35 } \\
\text { mitochondrial } \\
\end{array}$ & 0,759 & 0,217 & 0,506 & 0,348 & 2 & 0,765 & 0,254 & 0,524 & 0,270 \\
\hline AT4G00355.3 & unknown protein & 0,769 & 0,258 & 0,536 & 0,235 & 2 & 0,765 & 0,254 & 0,524 & 0,270 \\
\hline AT5G19560.1 & $\begin{array}{c}\text { ATROPGEF10 } \\
\text { ROPGEF10 ROP } \\
\text { uanine nucleotide } \\
\text { exchange factor } 10\end{array}$ & 0,719 & 0,278 & 0,559 & 0,304 & 2 & 0,765 & 0,254 & 0,524 & 0,270 \\
\hline AT5G20300.2 & $\begin{array}{l}\text { Avirulence induced } \\
\text { gene (AIG1) family } \\
\text { protein } \\
\end{array}$ & 0,733 & 0,260 & 0,562 & 0,282 & 2 & 0,765 & 0,254 & 0,524 & 0,270 \\
\hline AT5G45410.2 & unknown protein & 0,800 & 0,220 & 0,498 & 0,251 & 2 & 0,765 & 0,254 & 0,524 & 0,270 \\
\hline AT5G48657.1 & $\begin{array}{l}\text { defense protein- } \\
\text { related }\end{array}$ & 0,760 & 0,236 & 0,557 & 0,236 & 2 & 0,765 & 0,254 & 0,524 & 0,270 \\
\hline AT5G61350.1 & $\begin{array}{c}\text { Protein kinase } \\
\text { superfamily protein }\end{array}$ & 0,740 & 0,287 & 0,537 & 0,284 & 2 & 0,765 & 0,254 & 0,524 & 0,270 \\
\hline AT1G01560.1 & $\begin{array}{l}\text { ATMPK11 MPK11 } \\
\text { MAP kinase } 11\end{array}$ & 0,767 & 0,357 & 0,361 & 0,393 & 3 & 0,750 & 0,335 & 0,453 & 0,341 \\
\hline AT1G05990.1 & $\begin{array}{l}\text { RHS1 EF hand } \\
\text { calcium-binding } \\
\text { protein family } \\
\end{array}$ & 0,734 & 0,350 & 0,443 & 0,377 & 3 & 0,750 & 0,335 & 0,453 & 0,341 \\
\hline AT1G19900.1 & $\begin{array}{l}\text { glyoxal oxidase- } \\
\text { related protein }\end{array}$ & 0,738 & 0,370 & 0,430 & 0,365 & 3 & 0,750 & 0,335 & 0,453 & 0,341 \\
\hline AT1G59850.1 & $\begin{array}{c}\text { ARM repeat } \\
\text { superfamily protein }\end{array}$ & 0,718 & 0,330 & 0,500 & 0,354 & 3 & 0,750 & 0,335 & 0,453 & 0,341 \\
\hline AT2G03720.1 & $\begin{array}{l}\text { MRH6 Adenine } \\
\text { nucleotide alpha } \\
\text { hydrolases-like } \\
\text { superfamily protein }\end{array}$ & 0,757 & 0,312 & 0,487 & 0,305 & 3 & 0,750 & 0,335 & 0,453 & 0,341 \\
\hline AT2G18350.1 & $\begin{array}{l}\text { AtHB24 HB24 ZHD6 } \\
\text { homeobox protein } 24\end{array}$ & 0,747 & 0,365 & 0,428 & 0,355 & 3 & 0,750 & 0,335 & 0,453 & 0,341 \\
\hline AT3G10710.1 & $\begin{array}{l}\text { RHS12 root hair } \\
\text { specific } 12\end{array}$ & 0,777 & 0,342 & 0,433 & 0,303 & 3 & 0,750 & 0,335 & 0,453 & 0,341 \\
\hline
\end{tabular}


Anhang

\begin{tabular}{|c|c|c|c|c|c|c|c|c|c|c|}
\hline AT3G20850.1 & $\begin{array}{l}\text { proline-rich family } \\
\text { protein }\end{array}$ & 0,758 & 0,353 & 0,440 & 0,327 & 3 & 0,750 & 0,335 & 0,453 & 0,341 \\
\hline AT4G20840.1 & $\begin{array}{c}\text { FAD-binding } \\
\text { Berberine family } \\
\text { protein }\end{array}$ & 0,755 & 0,336 & 0,490 & 0,276 & 3 & 0,750 & 0,335 & 0,453 & 0,341 \\
\hline AT4G29180.2 & $\begin{array}{l}\text { RHS16 root hair } \\
\text { specific } 16\end{array}$ & 0,724 & 0,344 & 0,477 & 0,360 & 3 & 0,750 & 0,335 & 0,453 & 0,341 \\
\hline AT4G30320.1 & \begin{tabular}{|} 
CAP (Cysteine-rich \\
secretory proteins \\
Antigen 5 and \\
Pathogenesis-related \\
1 protein) superfamily \\
protein \\
\end{tabular} & 0,742 & 0,332 & 0,490 & 0,315 & 3 & 0,750 & 0,335 & 0,453 & 0,341 \\
\hline AT5G04960.1 & $\begin{array}{l}\text { Plant invertase/pectin } \\
\text { methylesterase } \\
\text { inhibitor superfamily }\end{array}$ & 0,765 & 0,332 & 0,475 & 0,280 & 3 & 0,750 & 0,335 & 0,453 & 0,341 \\
\hline AT5G06630.1 & $\begin{array}{l}\text { proline-rich extensin- } \\
\text { like family protein }\end{array}$ & 0,733 & 0,358 & 0,464 & 0,345 & 3 & 0,750 & 0,335 & 0,453 & 0,341 \\
\hline AT5G22410.1 & $\begin{array}{l}\text { RHS18 root hair } \\
\text { specific } 18\end{array}$ & 0,734 & 0,335 & 0,465 & 0,364 & 3 & 0,750 & 0,335 & 0,453 & 0,341 \\
\hline AT5G23870.2 & $\begin{array}{l}\text { Pectinacetylesterase } \\
\text { family protein }\end{array}$ & 0,755 & 0,287 & 0,393 & 0,439 & 3 & 0,750 & 0,335 & 0,453 & 0,341 \\
\hline AT5G26080.1 & $\begin{array}{l}\text { proline-rich family } \\
\text { protein }\end{array}$ & 0,770 & 0,358 & 0,426 & 0,313 & 3 & 0,750 & 0,335 & 0,453 & 0,341 \\
\hline AT5G35190.1 & $\begin{array}{l}\text { proline-rich extensin- } \\
\text { like family protein }\end{array}$ & 0,747 & 0,336 & 0,481 & 0,313 & 3 & 0,750 & 0,335 & 0,453 & 0,341 \\
\hline AT5G38700.1 & unknown protein & 0,771 & 0,337 & 0,418 & 0,341 & 3 & 0,750 & 0,335 & 0,453 & 0,341 \\
\hline AT5G40580.1 & $\begin{array}{c}\text { PBB2 20S } \\
\text { proteasome beta } \\
\text { subunit PBB2 }\end{array}$ & 0,740 & 0,289 & 0,506 & 0,338 & 3 & 0,750 & 0,335 & 0,453 & 0,341 \\
\hline AT5G51270.1 & $\begin{array}{c}\text { U-box domain- } \\
\text { containing protein } \\
\text { kinase family protein }\end{array}$ & 0,750 & 0,363 & 0,419 & 0,360 & 3 & 0,750 & 0,335 & 0,453 & 0,341 \\
\hline AT5G54940.1 & $\begin{array}{c}\text { Translation initiation } \\
\text { factor SUl1 family } \\
\text { protein } \\
\end{array}$ & 0,738 & 0,302 & 0,495 & 0,346 & 3 & 0,750 & 0,335 & 0,453 & 0,341 \\
\hline AT5G57540.1 & \begin{tabular}{|c|} 
XTH13 AtXTH13 \\
xyloglucan \\
endotransglucosylase \\
/hydrolase 13
\end{tabular} & 0,781 & 0,284 & 0,446 & 0,332 & 3 & 0,750 & 0,335 & 0,453 & 0,341 \\
\hline AT1G31930.1 & $\begin{array}{c}\text { XLG3 extra-large } \\
\text { GTP-binding protein } \\
3 \\
\end{array}$ & 0,838 & 0,237 & 0,409 & 0,272 & 4 & 0,811 & 0,311 & 0,393 & 0,293 \\
\hline AT1G36050.1 & $\begin{array}{c}\text { Endoplasmic } \\
\text { reticulum vesicle } \\
\text { transporter protein }\end{array}$ & 0,828 & 0,180 & 0,414 & 0,333 & 4 & 0,811 & 0,311 & 0,393 & 0,293 \\
\hline АT3G49960.1 & $\begin{array}{c}\text { Peroxidase } \\
\text { superfamily protein } \\
\end{array}$ & 0,834 & 0,331 & 0,330 & 0,292 & 4 & 0,811 & 0,311 & 0,393 & 0,293 \\
\hline AT3G54580.1 & $\begin{array}{l}\text { Proline-rich extensin- } \\
\text { like family protein }\end{array}$ & 0,812 & 0,323 & 0,402 & 0,274 & 4 & 0,811 & 0,311 & 0,393 & 0,293 \\
\hline AT4G07960.1 & $\begin{array}{c}\text { ATCSLC12 CSLC12 } \\
\text { Cellulose-synthase- } \\
\text { like C12 }\end{array}$ & 0,800 & 0,361 & 0,354 & 0,322 & 4 & 0,811 & 0,311 & 0,393 & 0,293 \\
\hline AT4G13390.1 & $\begin{array}{l}\text { Proline-rich extensin- } \\
\text { like family protein }\end{array}$ & 0,811 & 0,373 & 0,370 & 0,258 & 4 & 0,811 & 0,311 & 0,393 & 0,293 \\
\hline AT4G25220.1 & $\begin{array}{l}\text { RHS15 root hair } \\
\text { specific } 15\end{array}$ & 0,789 & 0,318 & 0,432 & 0,299 & 4 & 0,811 & 0,311 & 0,393 & 0,293 \\
\hline AT5G19800.1 & $\begin{array}{l}\text { hydroxyproline-rich } \\
\text { glycoprotein family } \\
\text { protein }\end{array}$ & 0,792 & 0,327 & 0,431 & 0,283 & 4 & 0,811 & 0,311 & 0,393 & 0,293 \\
\hline AT5G57530.1 & \begin{tabular}{|c|} 
XTH12 AtXTH12 \\
xyloglucan \\
endotransglucosylase \\
/hydrolase 12
\end{tabular} & 0,798 & 0,346 & 0,391 & 0,302 & 4 & 0,811 & 0,311 & 0,393 & 0,293 \\
\hline AT1G54970.1 & \begin{tabular}{|l|} 
ATPRP1 RHS7 PRP1 \\
proline-rich protein 1
\end{tabular} & 0,921 & 0,192 & 0,271 & 0,203 & 5 & 0,898 & 0,238 & 0,272 & 0,239 \\
\hline AT2G20520.1 & \begin{tabular}{|c|} 
FLA6 FASCICLIN- \\
like arabinogalactan 6
\end{tabular} & 0,912 & 0,252 & 0,247 & 0,208 & 5 & 0,898 & 0,238 & 0,272 & 0,239 \\
\hline AT2G32840.1 & proline-rich family & 0,925 & 0,248 & 0,249 & 0,147 & 5 & 0,898 & 0,238 & 0,272 & 0,239 \\
\hline
\end{tabular}


Anhang

\begin{tabular}{|c|c|c|c|c|c|c|c|c|c|c|}
\hline & protein & & & & & & & & & \\
\hline AT3G53420.1 & $\begin{array}{l}\text { PIP2A PIP2 PIP2; } 1 \\
\text { plasma membrane } \\
\text { intrinsic protein } 2 \mathrm{~A}\end{array}$ & 0,884 & 0,242 & 0,308 & 0,257 & 5 & 0,898 & 0,238 & 0,272 & 0,239 \\
\hline AT4G28850.1 & $\begin{array}{c}\text { XTH26 ATXTH26 } \\
\text { xyloglucan } \\
\text { endotransglucosylase } \\
\text { /hydrolase } 26\end{array}$ & 0,870 & 0,292 & 0,291 & 0,270 & 5 & 0,898 & 0,238 & 0,272 & 0,239 \\
\hline AT5G30495.1 & $\begin{array}{c}\text { Fcf2 pre-rRNA } \\
\text { processing protein }\end{array}$ & 0,875 & 0,202 & 0,267 & 0,349 & 5 & 0,898 & 0,238 & 0,272 & 0,239 \\
\hline AT2G28800.2 & $\begin{array}{c}\text { ALB3 } 63 \mathrm{kDa} \text { inner } \\
\text { membrane family } \\
\text { protein }\end{array}$ & 0,846 & 0,206 & 0,449 & 0,199 & 6 & 0,872 & 0,154 & 0,434 & 0,142 \\
\hline AT4G05050.2 & UBQ11 ubiquitin 11 & 0,888 & 0,051 & 0,434 & 0,141 & 6 & 0,872 & 0,154 & 0,434 & 0,142 \\
\hline AT4G27410.1 & $\begin{array}{c}\text { RD26 NAC (No } \\
\text { Apical Meristem) } \\
\text { domain } \\
\text { transcriptional } \\
\text { regulator superfamily } \\
\text { protein } \\
\end{array}$ & 0,906 & 0,073 & 0,408 & 0,079 & 6 & 0,872 & 0,154 & 0,434 & 0,142 \\
\hline AT5G11870.1 & $\begin{array}{c}\text { Alkaline } \\
\text { phytoceramidase } \\
\text { (aPHC) }\end{array}$ & 0,872 & 0,212 & 0,422 & 0,127 & 6 & 0,872 & 0,154 & 0,434 & 0,142 \\
\hline AT5G41700.3 & $\begin{array}{c}\text { UBC8 ATUBC8 } \\
\text { ubiquitin conjugating } \\
\text { enzyme } 8 \\
\end{array}$ & 0,845 & 0,227 & 0,455 & 0,165 & 6 & 0,872 & 0,154 & 0,434 & 0,142 \\
\hline AT1G13360.2 & unknown protein & 0,795 & 0,172 & 0,570 & 0,116 & 7 & 0,791 & 0,175 & 0,569 & 0,128 \\
\hline AT2G02390.2 & $\begin{array}{c}\text { ATGSTZ1 GST18 } \\
\text { GSTZ1 glutathione } \\
\text { S-transferase zeta } 1\end{array}$ & 0,767 & 0,166 & 0,599 & 0,159 & 7 & 0,791 & 0,175 & 0,569 & 0,128 \\
\hline AT3G62400.1 & unknown protein & 0,808 & 0,105 & 0,559 & 0,151 & 7 & 0,791 & 0,175 & 0,569 & 0,128 \\
\hline AT5G03240.2 & UBQ3 polyubiquitin 3 & 0,792 & 0,256 & 0,548 & 0,086 & 7 & 0,791 & 0,175 & 0,569 & 0,128 \\
\hline AT1G61660.2 & $\begin{array}{l}\text { basic helix-loop-helix } \\
\text { (bHLH) DNA-binding } \\
\text { superfamily protein }\end{array}$ & 0,728 & 0,119 & 0,664 & 0,119 & 8 & 0,745 & 0,067 & 0,651 & 0,111 \\
\hline AT1G66240.2 & $\begin{array}{l}\text { ATX1 ATATX1 } \\
\text { homolog of anti- } \\
\text { oxidant } 1 \\
\end{array}$ & 0,750 & 0,085 & 0,640 & 0,144 & 8 & 0,745 & 0,067 & 0,651 & 0,111 \\
\hline AT2G32700.3 & $\begin{array}{c}\text { LUH } \\
\text { LEUNIG_homolog }\end{array}$ & 0,713 & 0,054 & 0,693 & 0,095 & 8 & 0,745 & 0,067 & 0,651 & 0,111 \\
\hline AT2G41430.4 & $\begin{array}{c}\text { ERD15 LSR1 CID1 } \\
\text { dehydration-induced } \\
\text { protein (ERD15) }\end{array}$ & 0,764 & 0,078 & 0,631 & 0,113 & 8 & 0,745 & 0,067 & 0,651 & 0,111 \\
\hline AT3G01316.1 & snoRNA & 0,692 & 0,047 & 0,705 & 0,146 & 8 & 0,745 & 0,067 & 0,651 & 0,111 \\
\hline AT3G02470.1 & $\begin{array}{c}\text { SAMDC S- } \\
\text { adenosylmethionine } \\
\text { decarboxylase }\end{array}$ & 0,796 & 0,044 & 0,598 & 0,085 & 8 & 0,745 & 0,067 & 0,651 & 0,111 \\
\hline AT4G29160.2 & $\begin{array}{c}\text { SNF7.1 SNF7 family } \\
\text { protein }\end{array}$ & 0,738 & 0,074 & 0,665 & 0,092 & 8 & 0,745 & 0,067 & 0,651 & 0,111 \\
\hline AT5G45775.1 & $\begin{array}{c}\text { Ribosomal L5P family } \\
\text { protein }\end{array}$ & 0,702 & 0,062 & 0,696 & 0,139 & 8 & 0,745 & 0,067 & 0,651 & 0,111 \\
\hline AT5G53160.1 & $\begin{array}{c}\text { RCAR3 PYL8 } \\
\text { regulatory } \\
\text { components of ABA } \\
\text { receptor } 3 \\
\end{array}$ & 0,779 & 0,040 & 0,622 & 0,073 & 8 & 0,745 & 0,067 & 0,651 & 0,111 \\
\hline AT5G55970.1 & $\begin{array}{c}\mathrm{RING/U-box} \\
\text { superfamily protein } \\
\end{array}$ & 0,791 & 0,062 & 0,600 & 0,104 & 8 & 0,745 & 0,067 & 0,651 & 0,111 \\
\hline AT1G10670.3 & $\begin{array}{c}\text { ACLA-1 ATP-citrate } \\
\text { lyase A-1 }\end{array}$ & 0,752 & 0,106 & 0,609 & 0,231 & 9 & 0,716 & 0,145 & 0,654 & 0,184 \\
\hline AT1G26235.1 & other RNA & 0,723 & 0,098 & 0,665 & 0,163 & 9 & 0,716 & 0,145 & 0,654 & 0,184 \\
\hline AT1G27760.2 & SAT32 ATSAT32 & 0,683 & 0,225 & 0,666 & 0,200 & 9 & 0,716 & 0,145 & 0,654 & 0,184 \\
\hline AT1G54730.1 & $\begin{array}{c}\text { Major facilitator } \\
\text { superfamily protein }\end{array}$ & 0,728 & 0,128 & 0,632 & 0,233 & 9 & 0,716 & 0,145 & 0,654 & 0,184 \\
\hline AT2G41430.3 & $\begin{array}{c}\text { ERD15 LSR1 CID1 } \\
\text { dehydration-induced } \\
\text { protein (ERD15) }\end{array}$ & 0,708 & 0,063 & 0,678 & 0,189 & 9 & 0,716 & 0,145 & 0,654 & 0,184 \\
\hline AT2G41600.1 & $\begin{array}{c}\text { Mitochondrial } \\
\text { glycoprotein family } \\
\text { protein }\end{array}$ & 0,712 & 0,181 & 0,658 & 0,166 & 9 & 0,716 & 0,145 & 0,654 & 0,184 \\
\hline
\end{tabular}


Anhang

\begin{tabular}{|c|c|c|c|c|c|c|c|c|c|c|}
\hline AT3G60410.2 & $\begin{array}{l}\text { Protein of unknown } \\
\text { function (DUF1639) }\end{array}$ & 0,698 & 0,119 & 0,678 & 0,195 & 9 & 0,716 & 0,145 & 0,654 & 0,184 \\
\hline AT4G20320.1 & $\begin{array}{l}\text { CTP synthase family } \\
\text { protein }\end{array}$ & 0,717 & 0,096 & 0,666 & 0,181 & 9 & 0,716 & 0,145 & 0,654 & 0,184 \\
\hline AT4G33050.2 & $\begin{array}{l}\text { EDA39 calmodulin- } \\
\text { binding family protein }\end{array}$ & 0,699 & 0,147 & 0,683 & 0,153 & 9 & 0,716 & 0,145 & 0,654 & 0,184 \\
\hline AT5G14420.1 & $\begin{array}{l}\text { RGLG2 RING } \\
\text { domain ligase2 }\end{array}$ & 0,715 & 0,178 & 0,652 & 0,179 & 9 & 0,716 & 0,145 & 0,654 & 0,184 \\
\hline AT5G20570.2 & $\begin{array}{c}\text { ROC1 RBX1 HRT1 } \\
\text { ATRBX1 RING-box } 1\end{array}$ & 0,742 & 0,165 & 0,605 & 0,234 & 9 & 0,716 & 0,145 & 0,654 & 0,184 \\
\hline AT5G57340.2 & unknown protein & 0,731 & 0,184 & 0,630 & 0,185 & 9 & 0,716 & 0,145 & 0,654 & 0,184 \\
\hline AT5G59613.1 & unknown protein & 0,725 & 0,153 & 0,656 & 0,146 & 9 & 0,716 & 0,145 & 0,654 & 0,184 \\
\hline AT5G65210.2 & $\begin{array}{c}\text { TGA1 bZIP } \\
\text { transcription factor } \\
\text { family protein }\end{array}$ & 0,683 & 0,157 & 0,699 & 0,139 & 9 & 0,716 & 0,145 & 0,654 & 0,184 \\
\hline AT5G65210.4 & $\begin{array}{l}\text { TGA1 bZIP } \\
\text { transcription factor } \\
\text { family protein }\end{array}$ & 0,729 & 0,177 & 0,639 & 0,173 & 9 & 0,716 & 0,145 & 0,654 & 0,184 \\
\hline AT1G26233.1 & $\begin{array}{c}\text { SNOR95 SNOR95; } \\
\text { snoRNA }\end{array}$ & 0,652 & 0,178 & 0,682 & 0,281 & 10 & 0,660 & 0,153 & 0,664 & 0,308 \\
\hline AT2G30520.2 & $\begin{array}{l}\text { RPT2 Phototropic- } \\
\text { responsive NPH3 } \\
\text { family protein } \\
\end{array}$ & 0,636 & 0,064 & 0,684 & 0,351 & 10 & 0,660 & 0,153 & 0,664 & 0,308 \\
\hline AT2G42130.1 & $\begin{array}{c}\text { Plastid-lipid } \\
\text { associated protein } \\
\text { PAP / fibrillin family } \\
\text { protein } \\
\end{array}$ & 0,713 & 0,127 & 0,599 & 0,341 & 10 & 0,660 & 0,153 & 0,664 & 0,308 \\
\hline AT3G61898.1 & unknown protein & 0,621 & 0,149 & 0,699 & 0,321 & 10 & 0,660 & 0,153 & 0,664 & 0,308 \\
\hline AT5G12240.1 & unknown protein & 0,677 & 0,108 & 0,673 & 0,278 & 10 & 0,660 & 0,153 & 0,664 & 0,308 \\
\hline AT5G14930.1 & \begin{tabular}{c|} 
SAG101 \\
senescence- \\
associated gene 101
\end{tabular} & 0,665 & 0,191 & 0,644 & 0,325 & 10 & 0,660 & 0,153 & 0,664 & 0,308 \\
\hline AT5G62760.1 & $\begin{array}{c}\text { P-loop containing } \\
\text { nucleoside } \\
\text { triphosphate } \\
\text { hydrolases } \\
\text { superfamily protein } \\
\end{array}$ & 0,646 & 0,207 & 0,672 & 0,297 & 10 & 0,660 & 0,153 & 0,664 & 0,308 \\
\hline AT5G66564.1 & snoRNA & 0,667 & 0,205 & 0,662 & 0,274 & 10 & 0,660 & 0,153 & 0,664 & 0,308 \\
\hline AT1G01183.1 & $\begin{array}{c}\text { MIR165A MIR165 } \\
\text { MIR165/MIR165A; } \\
\text { miRNA }\end{array}$ & 0,633 & 0,170 & 0,731 & 0,191 & 11 & 0,624 & 0,183 & 0,727 & 0,212 \\
\hline AT1G16840.2 & unknown protein & 0,608 & 0,160 & 0,755 & 0,186 & 11 & 0,624 & 0,183 & 0,727 & 0,212 \\
\hline AT1G56010.1 & $\begin{array}{c}\text { NAC1 anac021 NAC } \\
\text { domain containing } \\
\text { protein } 1\end{array}$ & 0,673 & 0,211 & 0,678 & 0,206 & 11 & 0,624 & 0,183 & 0,727 & 0,212 \\
\hline AT1G69510.2 & $\begin{array}{l}\text { cAMP-regulated } \\
\text { phosphoprotein 19- } \\
\text { related protein }\end{array}$ & 0,597 & 0,201 & 0,739 & 0,240 & 11 & 0,624 & 0,183 & 0,727 & 0,212 \\
\hline AT1G72360.1 & $\begin{array}{l}\text { HRE1 Integrase-type } \\
\text { DNA-binding } \\
\text { superfamily protein } \\
\end{array}$ & 0,624 & 0,187 & 0,733 & 0,195 & 11 & 0,624 & 0,183 & 0,727 & 0,212 \\
\hline AT2G04880.1 & $\begin{array}{c}\text { ZAP1 ATWRKY1 } \\
\text { WRKY1 zinc- } \\
\text { dependent activator } \\
\text { protein-1 }\end{array}$ & 0,600 & 0,167 & 0,740 & 0,254 & 11 & 0,624 & 0,183 & 0,727 & 0,212 \\
\hline AT2G10606.1 & $\begin{array}{c}\text { MIR396A MIR396A; } \\
\text { miRNA }\end{array}$ & 0,645 & 0,136 & 0,723 & 0,209 & 11 & 0,624 & 0,183 & 0,727 & 0,212 \\
\hline AT2G45070.2 & $\begin{array}{c}\text { SEC61 BETA } \\
\text { Preprotein } \\
\text { translocase Sec } \\
\text { Sec61-beta subunit } \\
\text { protein }\end{array}$ & 0,649 & 0,201 & 0,704 & 0,207 & 11 & 0,624 & 0,183 & 0,727 & 0,212 \\
\hline AT2G45960.2 & $\begin{array}{c}\text { PIP1B TMP-A } \\
\text { ATHH2 PIP1;2 } \\
\text { plasma membrane } \\
\text { intrinsic protein 1B }\end{array}$ & 0,616 & 0,218 & 0,744 & 0,142 & 11 & 0,624 & 0,183 & 0,727 & 0,212 \\
\hline AT3G02832.1 & unknown & 0,600 & 0,220 & 0,724 & 0,260 & 11 & 0,624 & 0,183 & 0,727 & 0,212 \\
\hline AT3G05410.1 & $\begin{array}{c}\text { Photosystem II } \\
\text { reaction center PsbP } \\
\text { family protein }\end{array}$ & 0,636 & 0,184 & 0,702 & 0,262 & 11 & 0,624 & 0,183 & 0,727 & 0,212 \\
\hline
\end{tabular}


Anhang

\begin{tabular}{|c|c|c|c|c|c|c|c|c|c|c|}
\hline AT3G61850.2 & $\begin{array}{l}\text { DAG1 Dof-type zinc } \\
\text { finger DNA-binding } \\
\text { family protein }\end{array}$ & 0,586 & 0,140 & 0,759 & 0,246 & 11 & 0,624 & 0,183 & 0,727 & 0,212 \\
\hline AT4G24290.1 & $\begin{array}{c}\text { MAC/Perforin } \\
\text { domain-containing } \\
\text { protein } \\
\end{array}$ & 0,629 & 0,174 & 0,723 & 0,228 & 11 & 0,624 & 0,183 & 0,727 & 0,212 \\
\hline AT5G10450.3 & $\begin{array}{l}\text { GRF6 G-box } \\
\text { regulating factor } 6\end{array}$ & 0,588 & 0,216 & 0,748 & 0,218 & 11 & 0,624 & 0,183 & 0,727 & 0,212 \\
\hline AT5G47820.1 & $\begin{array}{c}\text { FRA1 P-loop } \\
\text { containing nucleoside } \\
\text { triphosphate } \\
\text { hydrolases } \\
\text { superfamily protein } \\
\end{array}$ & 0,594 & 0,188 & 0,762 & 0,174 & 11 & 0,624 & 0,183 & 0,727 & 0,212 \\
\hline AT5G51300.2 & splicing factor-related & 0,639 & 0,132 & 0,724 & 0,225 & 11 & 0,624 & 0,183 & 0,727 & 0,212 \\
\hline AT5G57150.3 & $\begin{array}{l}\text { basic helix-loop-helix } \\
\text { (bHLH) DNA-binding } \\
\text { superfamily protein }\end{array}$ & 0,675 & 0,245 & 0,674 & 0,175 & 11 & 0,624 & 0,183 & 0,727 & 0,212 \\
\hline AT5G61920.1 & unknown protein & 0,640 & 0,142 & 0,730 & 0,191 & 11 & 0,624 & 0,183 & 0,727 & 0,212 \\
\hline AT1G01100.1 & $\begin{array}{c}60 S \text { acidic ribosomal } \\
\text { protein family }\end{array}$ & 0,586 & 0,180 & 0,773 & 0,163 & 12 & 0,596 & 0,121 & 0,777 & 0,149 \\
\hline AT1G53543.1 & unknown protein & 0,580 & 0,111 & 0,781 & 0,204 & 12 & 0,596 & 0,121 & 0,777 & 0,149 \\
\hline AT2G15390.1 & $\begin{array}{c}\text { FUT4 atfut4 } \\
\text { fucosyltransferase } 4\end{array}$ & 0,608 & 0,092 & 0,785 & 0,077 & 12 & 0,596 & 0,121 & 0,777 & 0,149 \\
\hline AT3G24614.1 & snoRNA & 0,577 & 0,119 & 0,786 & 0,189 & 12 & 0,596 & 0,121 & 0,777 & 0,149 \\
\hline AT3G55880.1 & $\begin{array}{l}\text { SUE4 Alpha/beta } \\
\text { hydrolase related } \\
\text { protein }\end{array}$ & 0,663 & 0,109 & 0,731 & 0,123 & 12 & 0,596 & 0,121 & 0,777 & 0,149 \\
\hline AT5G48000.4 & $\begin{array}{l}\text { CYP708A2 THAH } \\
\text { THAH1 cytochrome } \\
\text { P450 family } 708 \\
\text { subfamily A } \\
\text { polypeptide } 2\end{array}$ & 0,563 & 0,146 & 0,805 & 0,116 & 12 & 0,596 & 0,121 & 0,777 & 0,149 \\
\hline AT5G55550.3 & $\begin{array}{c}\text { RNA-binding } \\
\text { (RRM/RBD/RNP } \\
\text { motifs) family protein }\end{array}$ & 0,596 & 0,140 & 0,775 & 0,158 & 12 & 0,596 & 0,121 & 0,777 & 0,149 \\
\hline AT5G62890.1 & $\begin{array}{c}\text { Xanthine/uracil } \\
\text { permease family } \\
\text { protein }\end{array}$ & 0,568 & 0,113 & 0,790 & 0,202 & 12 & 0,596 & 0,121 & 0,777 & 0,149 \\
\hline $\begin{array}{c}\text { ATMG01340. } \\
1\end{array}$ & TRNM.2 tRNA-Met & 0,628 & 0,084 & 0,766 & 0,111 & 12 & 0,596 & 0,121 & 0,777 & 0,149 \\
\hline AT1G16635.1 & unknown & 0,474 & 0,131 & 0,852 & 0,182 & 13 & 0,504 & 0,121 & 0,835 & 0,171 \\
\hline AT1G78206.1 & $\begin{array}{c}\text { MIR775A MIR775a; } \\
\text { miRNA }\end{array}$ & 0,551 & 0,056 & 0,818 & 0,156 & 13 & 0,504 & 0,121 & 0,835 & 0,171 \\
\hline AT3G58193.1 & snoRNA & 0,499 & 0,088 & 0,843 & 0,178 & 13 & 0,504 & 0,121 & 0,835 & 0,171 \\
\hline AT3G59970.1 & $\begin{array}{c}\text { MTHFR1 } \\
\text { methylenetetrahydrof } \\
\text { olate reductase } 1\end{array}$ & 0,481 & 0,114 & 0,864 & 0,092 & 13 & 0,504 & 0,121 & 0,835 & 0,171 \\
\hline AT5G57150.2 & $\begin{array}{l}\text { basic helix-loop-helix } \\
\text { (bHLH) DNA-binding } \\
\text { superfamily protein }\end{array}$ & 0,498 & 0,158 & 0,830 & 0,194 & 13 & 0,504 & 0,121 & 0,835 & 0,171 \\
\hline $\begin{array}{c}\text { ATMG00190. } \\
1\end{array}$ & TRNG tRNA-Gly & 0,519 & 0,179 & 0,805 & 0,224 & 13 & 0,504 & 0,121 & 0,835 & 0,171 \\
\hline AT1G55500.1 & $\begin{array}{c}\text { ECT4 evolutionarily } \\
\text { conserved C-terminal } \\
\text { region } 4\end{array}$ & 0,378 & 0,118 & 0,897 & 0,196 & 14 & 0,419 & 0,149 & 0,864 & 0,220 \\
\hline AT3G16450.1 & $\begin{array}{l}\text { Mannose-binding } \\
\text { lectin superfamily } \\
\text { protein }\end{array}$ & 0,394 & 0,139 & 0,877 & 0,236 & 14 & 0,419 & 0,149 & 0,864 & 0,220 \\
\hline AT4G10000.1 & $\begin{array}{c}\text { Thioredoxin family } \\
\text { protein }\end{array}$ & 0,469 & 0,247 & 0,834 & 0,156 & 14 & 0,419 & 0,149 & 0,864 & 0,220 \\
\hline AT4G36690.2 & $\begin{array}{l}\text { ATU2AF65A U2 } \\
\text { snRNP auxilliary } \\
\text { factor large subunit } \\
\text { splicing factor }\end{array}$ & 0,407 & 0,082 & 0,879 & 0,233 & 14 & 0,419 & 0,149 & 0,864 & 0,220 \\
\hline AT5G44286.1 & snoRNA & 0,447 & 0,160 & 0,835 & 0,278 & 14 & 0,419 & 0,149 & 0,864 & 0,220 \\
\hline AT2G28760.1 & $\begin{array}{c}\text { UXS6 UDP-XYL } \\
\text { synthase } 6\end{array}$ & 0,319 & 0,390 & 0,829 & 0,243 & 15 & 0,363 & 0,276 & 0,835 & 0,295 \\
\hline AT3G13060.1 & $\begin{array}{c}\text { ECT5 evolutionarily } \\
\text { conserved C-terminal } \\
\text { region } 5\end{array}$ & 0,355 & 0,336 & 0,820 & 0,297 & 15 & 0,363 & 0,276 & 0,835 & 0,295 \\
\hline
\end{tabular}


Anhang

\begin{tabular}{|c|c|c|c|c|c|c|c|c|c|c|}
\hline AT3G41762.1 & unknown protein. & 0,419 & 0,219 & 0,832 & 0,292 & 15 & 0,363 & 0,276 & 0,835 & 0,295 \\
\hline AT4G03292.1 & $\begin{array}{c}\text { Polynucleotidyl } \\
\text { transferase } \\
\text { ribonuclease } \mathrm{H} \text {-like } \\
\text { superfamily protein }\end{array}$ & 0,398 & 0,228 & 0,830 & 0,319 & 15 & 0,363 & 0,276 & 0,835 & 0,295 \\
\hline AT4G20440.2 & $\begin{array}{l}\text { smB small nuclear } \\
\text { ribonucleoprotein } \\
\text { associated protein B }\end{array}$ & 0,341 & 0,250 & 0,876 & 0,231 & 15 & 0,363 & 0,276 & 0,835 & 0,295 \\
\hline AT5G47980.1 & $\begin{array}{l}\text { HXXXD-type acyl- } \\
\text { transferase family } \\
\text { protein }\end{array}$ & 0,362 & 0,274 & 0,822 & 0,343 & 15 & 0,363 & 0,276 & 0,835 & 0,295 \\
\hline AT5G56030.1 & $\begin{array}{c}\text { HSP81-2 ERD8 } \\
\text { HSP90.2 AtHsp90.2 } \\
\text { heat shock protein } \\
81-2\end{array}$ & 0,306 & 0,272 & 0,829 & 0,380 & 15 & 0,363 & 0,276 & 0,835 & 0,295 \\
\hline AT5G61310.2 & $\begin{array}{c}\text { Cytochrome c } \\
\text { oxidase subunit Vc } \\
\text { family protein }\end{array}$ & 0,408 & 0,235 & 0,844 & 0,258 & 15 & 0,363 & 0,276 & 0,835 & 0,295 \\
\hline AT1G15002.1 & $\begin{array}{c}\text { Potential natural } \\
\text { antisense gene locus } \\
\text { overlaps with } \\
\text { AT1G15000 }\end{array}$ & 0,471 & 0,203 & 0,791 & 0,333 & 16 & 0,484 & 0,276 & 0,759 & 0,329 \\
\hline AT1G19376.1 & snoRNA & 0,479 & 0,259 & 0,759 & 0,358 & 16 & 0,484 & 0,276 & 0,759 & 0,329 \\
\hline AT1G70410.1 & $\begin{array}{c}\text { ATBCA4 BCA4 CA4 } \\
\text { beta carbonic } \\
\text { anhydrase } 4 \\
\end{array}$ & 0,484 & 0,264 & 0,749 & 0,369 & 16 & 0,484 & 0,276 & 0,759 & 0,329 \\
\hline AT2G35658.2 & unknown protein & 0,473 & 0,364 & 0,727 & 0,340 & 16 & 0,484 & 0,276 & 0,759 & 0,329 \\
\hline AT2G39681.1 & $\begin{array}{l}\text { TAS2 TAS2; other } \\
\text { RNA } \\
\end{array}$ & 0,516 & 0,265 & 0,737 & 0,347 & 16 & 0,484 & 0,276 & 0,759 & 0,329 \\
\hline AT2G43137.1 & snoRNA & 0,499 & 0,231 & 0,770 & 0,325 & 16 & 0,484 & 0,276 & 0,759 & 0,329 \\
\hline AT3G06700.2 & $\begin{array}{l}\text { Ribosomal L29e } \\
\text { protein family }\end{array}$ & 0,460 & 0,384 & 0,740 & 0,306 & 16 & 0,484 & 0,276 & 0,759 & 0,329 \\
\hline AT5G52471.1 & $\begin{array}{l}\text { U60.1F U60.1F; } \\
\text { snoRNA }\end{array}$ & 0,464 & 0,272 & 0,789 & 0,296 & 16 & 0,484 & 0,276 & 0,759 & 0,329 \\
\hline $\begin{array}{c}\text { ATMG00250. } \\
1\end{array}$ & TRNM.1 tRNA-Met & 0,514 & 0,239 & 0,771 & 0,291 & 16 & 0,484 & 0,276 & 0,759 & 0,329 \\
\hline AT1G03746.1 & snoRNA & 0,551 & 0,234 & 0,737 & 0,312 & 17 & 0,566 & 0,209 & 0,724 & 0,327 \\
\hline AT1G45474.1 & $\begin{array}{l}\text { LHCA5 photosystem } \\
\text { I light harvesting } \\
\text { complex gene } 5 \\
\end{array}$ & 0,554 & 0,161 & 0,709 & 0,405 & 17 & 0,566 & 0,209 & 0,724 & 0,327 \\
\hline AT1G65960.1 & $\begin{array}{l}\text { GAD2 glutamate } \\
\text { decarboxylase } 2\end{array}$ & 0,576 & 0,212 & 0,698 & 0,369 & 17 & 0,566 & 0,209 & 0,724 & 0,327 \\
\hline AT1G75166.1 & snoRNA & 0,611 & 0,215 & 0,704 & 0,292 & 17 & 0,566 & 0,209 & 0,724 & 0,327 \\
\hline AT1G77930.1 & $\begin{array}{c}\text { Chaperone DnaJ- } \\
\text { domain superfamily } \\
\text { protein }\end{array}$ & 0,574 & 0,189 & 0,721 & 0,339 & 17 & 0,566 & 0,209 & 0,724 & 0,327 \\
\hline AT2G20722.1 & snoRNA & 0,543 & 0,213 & 0,772 & 0,254 & 17 & 0,566 & 0,209 & 0,724 & 0,327 \\
\hline AT2G31110.1 & $\begin{array}{c}\text { TBL40 Plant protein } \\
\text { of unknown function } \\
\text { (DUF828) }\end{array}$ & 0,558 & 0,181 & 0,713 & 0,383 & 17 & 0,566 & 0,209 & 0,724 & 0,327 \\
\hline AT2G41100.3 & $\begin{array}{c}\text { TCH3 ATCAL4 } \\
\text { Calcium-binding EF } \\
\text { hand family protein }\end{array}$ & 0,571 & 0,190 & 0,705 & 0,375 & 17 & 0,566 & 0,209 & 0,724 & 0,327 \\
\hline AT3G41761.1 & other RNA & 0,518 & 0,167 & 0,741 & 0,393 & 17 & 0,566 & 0,209 & 0,724 & 0,327 \\
\hline AT3G63110.1 & $\begin{array}{c}\text { ATIPT3 IPT3 } \\
\text { isopentenyltransferas } \\
\text { e } 3 \\
\end{array}$ & 0,533 & 0,242 & 0,736 & 0,340 & 17 & 0,566 & 0,209 & 0,724 & 0,327 \\
\hline AT4G20980.2 & $\begin{array}{l}\text { Eukaryotic translation } \\
\text { initiation factor } 3 \\
\text { subunit } 7 \text { (elF-3) } \\
\end{array}$ & 0,520 & 0,177 & 0,781 & 0,295 & 17 & 0,566 & 0,209 & 0,724 & 0,327 \\
\hline AT5G06265.2 & $\begin{array}{c}\text { hyaluronan mediated } \\
\text { motility receptor- } \\
\text { related } \\
\end{array}$ & 0,575 & 0,241 & 0,719 & 0,307 & 17 & 0,566 & 0,209 & 0,724 & 0,327 \\
\hline AT5G15022.1 & $\begin{array}{c}\text { Potential natural } \\
\text { antisense gene locus } \\
\text { overlaps with } \\
\text { AT5G15030 } \\
\end{array}$ & 0,612 & 0,242 & 0,701 & 0,275 & 17 & 0,566 & 0,209 & 0,724 & 0,327 \\
\hline AT5G28850.1 & $\begin{array}{l}\text { Calcium-binding EF- } \\
\text { hand family protein }\end{array}$ & 0,568 & 0,248 & 0,728 & 0,292 & 17 & 0,566 & 0,209 & 0,724 & 0,327 \\
\hline
\end{tabular}




\begin{tabular}{|c|c|c|c|c|c|c|c|c|c|c|}
\hline AT5G60300.1 & $\begin{array}{l}\text { Concanavalin A-like } \\
\text { lectin protein kinase } \\
\text { family protein }\end{array}$ & 0,603 & 0,214 & 0,714 & 0,285 & 17 & 0,566 & 0,209 & 0,724 & 0,327 \\
\hline AT5G65860.1 & $\begin{array}{l}\text { ankyrin repeat family } \\
\text { protein }\end{array}$ & 0,596 & 0,220 & 0,702 & 0,322 & 17 & 0,566 & 0,209 & 0,724 & 0,327 \\
\hline AT1G08920.2 & $\begin{array}{c}\text { ESL1 ERD (early } \\
\text { response to } \\
\text { dehydration) six-like 1 }\end{array}$ & 0,564 & 0,346 & 0,669 & 0,338 & 18 & 0,565 & 0,317 & 0,686 & 0,326 \\
\hline AT1G20070.1 & unknown protein & 0,587 & 0,337 & 0,673 & 0,299 & 18 & 0,565 & 0,317 & 0,686 & 0,326 \\
\hline AT1G73770.1 & $\begin{array}{l}\text { BEST Arabidopsis } \\
\text { thaliana protein } \\
\text { match: Ribosomal } \\
\text { protein S24/S35 } \\
\text { mitochondrial } \\
\text { (TAIR:AT3G18240.2) }\end{array}$ & 0,575 & 0,313 & 0,678 & 0,334 & 18 & 0,565 & 0,317 & 0,686 & 0,326 \\
\hline AT1G75295.2 & other RNA & 0,518 & 0,357 & 0,710 & 0,316 & 18 & 0,565 & 0,317 & 0,686 & 0,326 \\
\hline AT2G24755.1 & other RNA & 0,576 & 0,278 & 0,671 & 0,375 & 18 & 0,565 & 0,317 & 0,686 & 0,326 \\
\hline AT2G39175.1 & $\begin{array}{l}\text { MIR160A MIR160 } \\
\text { FOC } \\
\text { MIR160/MIR160A; } \\
\text { miRNA }\end{array}$ & 0,548 & 0,356 & 0,682 & 0,329 & 18 & 0,565 & 0,317 & 0,686 & 0,326 \\
\hline AT2G46192.1 & other RNA & 0,580 & 0,272 & 0,683 & 0,350 & 18 & 0,565 & 0,317 & 0,686 & 0,326 \\
\hline AT3G50340.1 & unknown protein & 0,549 & 0,309 & 0,711 & 0,312 & 18 & 0,565 & 0,317 & 0,686 & 0,326 \\
\hline AT3G50825.1 & snoRNA & 0,572 & 0,282 & 0,694 & 0,334 & 18 & 0,565 & 0,317 & 0,686 & 0,326 \\
\hline AT4G17788.1 & $\begin{array}{c}\text { MIR160B MIR160 } \\
\text { MIR160/MIR160B; } \\
\text { miRNA }\end{array}$ & 0,519 & 0,398 & 0,699 & 0,288 & 18 & 0,565 & 0,317 & 0,686 & 0,326 \\
\hline AT4G18975.3 & $\begin{array}{c}\text { Pentatricopeptide } \\
\text { repeat (PPR) } \\
\text { superfamily protein } \\
\end{array}$ & 0,533 & 0,324 & 0,705 & 0,337 & 18 & 0,565 & 0,317 & 0,686 & 0,326 \\
\hline AT4G26365.1 & snoRNA & 0,601 & 0,277 & 0,692 & 0,288 & 18 & 0,565 & 0,317 & 0,686 & 0,326 \\
\hline AT5G28020.1 & \begin{tabular}{|c|} 
CYSD2 ATCYSD2 \\
cysteine synthase D2
\end{tabular} & 0,597 & 0,258 & 0,674 & 0,350 & 18 & 0,565 & 0,317 & 0,686 & 0,326 \\
\hline AT5G50120.1 & $\begin{array}{l}\text { Transducin/WD40 } \\
\text { repeat-like } \\
\text { superfamily protein }\end{array}$ & 0,575 & 0,323 & 0,679 & 0,322 & 18 & 0,565 & 0,317 & 0,686 & 0,326 \\
\hline $\begin{array}{c}\text { ATMG00350. } \\
1\end{array}$ & $\begin{array}{l}\text { TRNP Mitochondrial- } \\
\text { encoded proline- } \\
\text { accepting tRNA. }\end{array}$ & 0,585 & 0,324 & 0,675 & 0,312 & 18 & 0,565 & 0,317 & 0,686 & 0,326 \\
\hline AT1G05710.1 & $\begin{array}{l}\text { basic helix-loop-helix } \\
\text { (bHLH) DNA-binding } \\
\text { superfamily protein }\end{array}$ & 0,606 & 0,324 & 0,665 & 0,291 & 19 & 0,634 & 0,321 & 0,651 & 0,259 \\
\hline AT1G15920.1 & $\begin{array}{c}\text { Polynucleotidyl } \\
\text { transferase } \\
\text { ribonuclease } \mathrm{H} \text {-like } \\
\text { superfamily protein }\end{array}$ & 0,675 & 0,245 & 0,657 & 0,231 & 19 & 0,634 & 0,321 & 0,651 & 0,259 \\
\hline AT1G28310.1 & $\begin{array}{c}\text { Dof-type zinc finger } \\
\text { DNA-binding family } \\
\text { protein }\end{array}$ & 0,603 & 0,343 & 0,655 & 0,301 & 19 & 0,634 & 0,321 & 0,651 & 0,259 \\
\hline AT1G69760.1 & unknown protein & 0,619 & 0,305 & 0,658 & 0,302 & 19 & 0,634 & 0,321 & 0,651 & 0,259 \\
\hline AT1G77235.1 & $\begin{array}{c}\text { MIR402 MIR402; } \\
\text { miRNA }\end{array}$ & 0,639 & 0,254 & 0,685 & 0,242 & 19 & 0,634 & 0,321 & 0,651 & 0,259 \\
\hline AT1G78080.1 & $\begin{array}{c}\text { RAP2.4 related to } \\
\text { AP2 } 4\end{array}$ & 0,637 & 0,322 & 0,632 & 0,302 & 19 & 0,634 & 0,321 & 0,651 & 0,259 \\
\hline AT2G03810.1 & $\begin{array}{l}\text { 18S pre-ribosomal } \\
\text { assembly protein } \\
\text { gar2-related }\end{array}$ & 0,650 & 0,310 & 0,678 & 0,148 & 19 & 0,634 & 0,321 & 0,651 & 0,259 \\
\hline AT2G09795.2 & other RNA & 0,662 & 0,313 & 0,628 & 0,264 & 19 & 0,634 & 0,321 & 0,651 & 0,259 \\
\hline AT2G25250.1 & unknown protein & 0,623 & 0,357 & 0,626 & 0,304 & 19 & 0,634 & 0,321 & 0,651 & 0,259 \\
\hline AT3G21710.1 & unknown protein & 0,630 & 0,330 & 0,661 & 0,240 & 19 & 0,634 & 0,321 & 0,651 & 0,259 \\
\hline AT3G27270.1 & $\begin{array}{l}\text { TRAM LAG1 and } \\
\text { CLN8 (TLC) lipid- } \\
\text { sensing domain } \\
\text { containing protein }\end{array}$ & 0,650 & 0,369 & 0,616 & 0,250 & 19 & 0,634 & 0,321 & 0,651 & 0,259 \\
\hline AT3G28690.1 & $\begin{array}{c}\text { Protein kinase } \\
\text { superfamily protein }\end{array}$ & 0,666 & 0,326 & 0,631 & 0,227 & 19 & 0,634 & 0,321 & 0,651 & 0,259 \\
\hline
\end{tabular}


Anhang

\begin{tabular}{|c|c|c|c|c|c|c|c|c|c|c|}
\hline AT3G43790.2 & $\begin{array}{l}\text { ZIFL2 zinc induced } \\
\text { facilitator-like } 2\end{array}$ & 0,587 & 0,397 & 0,654 & 0,264 & 19 & 0,634 & 0,321 & 0,651 & 0,259 \\
\hline AT3G47810.2 & $\begin{array}{l}\text { MAG1 Calcineurin- } \\
\text { like metallo- } \\
\text { phosphoesterase } \\
\text { superfamily protein }\end{array}$ & 0,695 & 0,262 & 0,627 & 0,235 & 19 & 0,634 & 0,321 & 0,651 & 0,259 \\
\hline AT3G53570.1 & $\begin{array}{c}\text { AFC1 AME2 FC1 } \\
\text { FUS3-complementing } \\
\text { gene } 1\end{array}$ & 0,596 & 0,435 & 0,603 & 0,302 & 19 & 0,634 & 0,321 & 0,651 & 0,259 \\
\hline AT3G56410.1 & $\begin{array}{l}\text { Protein of unknown } \\
\text { function (DUF3133) }\end{array}$ & 0,647 & 0,296 & 0,650 & 0,267 & 19 & 0,634 & 0,321 & 0,651 & 0,259 \\
\hline AT4G02005.1 & other RNA & 0,646 & 0,265 & 0,684 & 0,212 & 19 & 0,634 & 0,321 & 0,651 & 0,259 \\
\hline AT4G36090.1 & $\begin{array}{l}\text { oxidoreductase 2OG- } \\
\text { Fe(II) oxygenase } \\
\text { family protein }\end{array}$ & 0,657 & 0,267 & 0,668 & 0,226 & 19 & 0,634 & 0,321 & 0,651 & 0,259 \\
\hline AT5G11090.1 & $\begin{array}{l}\text { serine-rich protein- } \\
\text { related }\end{array}$ & 0,646 & 0,342 & 0,614 & 0,298 & 19 & 0,634 & 0,321 & 0,651 & 0,259 \\
\hline AT5G18780.1 & $\begin{array}{c}\text { F-box/RNI-like } \\
\text { superfamily protein }\end{array}$ & 0,584 & 0,376 & 0,665 & 0,276 & 19 & 0,634 & 0,321 & 0,651 & 0,259 \\
\hline AT5G26600.1 & $\begin{array}{l}\text { Pyridoxal phosphate } \\
\text { (PLP)-dependent } \\
\text { transferases } \\
\text { superfamily protein } \\
\end{array}$ & 0,589 & 0,311 & 0,703 & 0,249 & 19 & 0,634 & 0,321 & 0,651 & 0,259 \\
\hline AT1G15930.1 & $\begin{array}{c}\text { Ribosomal protein } \\
\text { L7Ae/L30e/S12e/Gad } \\
\text { d45 family protein }\end{array}$ & 0,680 & 0,234 & 0,627 & 0,298 & 20 & 0,668 & 0,263 & 0,613 & 0,327 \\
\hline AT1G48490.2 & $\begin{array}{c}\text { Protein kinase } \\
\text { superfamily protein }\end{array}$ & 0,683 & 0,289 & 0,575 & 0,346 & 20 & 0,668 & 0,263 & 0,613 & 0,327 \\
\hline AT1G73390.1 & $\begin{array}{l}\text { Endosomal targeting } \\
\text { BRO1-like domain- } \\
\text { containing protein } \\
\end{array}$ & 0,644 & 0,284 & 0,614 & 0,357 & 20 & 0,668 & 0,263 & 0,613 & 0,327 \\
\hline AT2G30120.1 & unknown protein & 0,654 & 0,247 & 0,638 & 0,324 & 20 & 0,668 & 0,263 & 0,613 & 0,327 \\
\hline AT3G28140.2 & $\begin{array}{l}\text { RNA ligase/cyclic } \\
\text { nucleotide } \\
\text { phosphodiesterase } \\
\text { family protein } \\
\end{array}$ & 0,652 & 0,295 & 0,630 & 0,302 & 20 & 0,668 & 0,263 & 0,613 & 0,327 \\
\hline AT3G49010.1 & $\begin{array}{c}\text { ATBBC1 BBC1 RSU2 } \\
\text { breast basic } \\
\text { conserved } 1\end{array}$ & 0,682 & 0,297 & 0,583 & 0,326 & 20 & 0,668 & 0,263 & 0,613 & 0,327 \\
\hline AT3G50760.1 & \begin{tabular}{|c|} 
GATL2 \\
galacturonosyltransfe \\
rase-like 2 \\
\end{tabular} & 0,622 & 0,269 & 0,644 & 0,355 & 20 & 0,668 & 0,263 & 0,613 & 0,327 \\
\hline AT3G62680.1 & $\begin{array}{c}\text { PRP3 ATPRP3 } \\
\text { proline-rich protein } 3\end{array}$ & 0,670 & 0,212 & 0,631 & 0,328 & 20 & 0,668 & 0,263 & 0,613 & 0,327 \\
\hline AT4G02890.3 & $\begin{array}{l}\text { UBQ14 Ubiquitin } \\
\text { family protein }\end{array}$ & 0,701 & 0,283 & 0,562 & 0,335 & 20 & 0,668 & 0,263 & 0,613 & 0,327 \\
\hline AT4G05000.1 & $\begin{array}{l}\text { VPS28-2 Vacuolar } \\
\text { protein sorting- } \\
\text { associated protein } \\
\text { VPS28 family protein } \\
\end{array}$ & 0,666 & 0,212 & 0,625 & 0,347 & 20 & 0,668 & 0,263 & 0,613 & 0,327 \\
\hline AT4G40030.3 & $\begin{array}{l}\text { Histone superfamily } \\
\text { protein }\end{array}$ & 0,694 & 0,268 & 0,609 & 0,276 & 20 & 0,668 & 0,263 & 0,613 & 0,327 \\
\hline AT1G27370.1 & $\begin{array}{l}\text { SPL10 squamosa } \\
\text { promoter binding } \\
\text { protein-like } 10\end{array}$ & 0,632 & 0,302 & 0,592 & 0,399 & 21 & 0,611 & 0,286 & 0,614 & 0,407 \\
\hline AT1G31070.1 & \begin{tabular}{|c|} 
GlcNAc1pUT1 N- \\
acetylglucosamine-1- \\
phosphate \\
uridylyltransferase 1 \\
\end{tabular} & 0,614 & 0,296 & 0,572 & 0,456 & 21 & 0,611 & 0,286 & 0,614 & 0,407 \\
\hline AT1G50055.1 & \begin{tabular}{|c|} 
TAS1B TAS1B; other \\
RNA \\
\end{tabular} & 0,586 & 0,268 & 0,656 & 0,393 & 21 & 0,611 & 0,286 & 0,614 & 0,407 \\
\hline AT1G65010.1 & $\begin{array}{l}\text { Plant protein of } \\
\text { unknown function } \\
\text { (DUF827) }\end{array}$ & 0,596 & 0,287 & 0,631 & 0,405 & 21 & 0,611 & 0,286 & 0,614 & 0,407 \\
\hline AT2G39675.1 & $\begin{array}{c}\text { TAS1C TAS1C; } \\
\text { other RNA }\end{array}$ & 0,608 & 0,252 & 0,636 & 0,403 & 21 & 0,611 & 0,286 & 0,614 & 0,407 \\
\hline AT3G02180.2 & $\begin{array}{l}\text { SP1L3 SPIRAL1- } \\
\text { like3 }\end{array}$ & 0,656 & 0,316 & 0,566 & 0,387 & 21 & 0,611 & 0,286 & 0,614 & 0,407 \\
\hline AT3G12560.1 & $\begin{array}{l}\text { TRFL9 ATTBP2 } \\
\text { TRF-like } 9\end{array}$ & 0,632 & 0,299 & 0,610 & 0,372 & 21 & 0,611 & 0,286 & 0,614 & 0,407 \\
\hline
\end{tabular}


Anhang

\begin{tabular}{|c|c|c|c|c|c|c|c|c|c|c|}
\hline AT3G22790.1 & $\begin{array}{c}\text { Kinase interacting } \\
\text { (KIP1-like) family } \\
\text { protein }\end{array}$ & 0,563 & 0,268 & 0,648 & 0,438 & 21 & 0,611 & 0,286 & 0,614 & 0,407 \\
\hline AT3G56860.2 & $\begin{array}{c}\text { UBA2A UBP1- } \\
\text { associated protein 2A }\end{array}$ & 0,594 & 0,295 & 0,617 & 0,422 & 21 & 0,611 & 0,286 & 0,614 & 0,407 \\
\hline AT3G60330.2 & HA7 H(+)-ATPase 7 & 0,636 & 0,291 & 0,600 & 0,389 & 21 & 0,611 & 0,286 & 0,614 & 0,407 \\
\hline AT4G35920.2 & $\begin{array}{l}\text { MCA1 PLAC8 family } \\
\text { protein }\end{array}$ & 0,607 & 0,280 & 0,628 & 0,399 & 21 & 0,611 & 0,286 & 0,614 & 0,407 \\
\hline AT5G06165.1 & unknown & 0,593 & 0,272 & 0,659 & 0,374 & 21 & 0,611 & 0,286 & 0,614 & 0,407 \\
\hline AT5G35732.1 & unknown protein & 0,634 & 0,302 & 0,579 & 0,415 & 21 & 0,611 & 0,286 & 0,614 & 0,407 \\
\hline $\begin{array}{c}\text { ATMG00380. } \\
1\end{array}$ & TRNN tRNA-Asn & 0,600 & 0,277 & 0,606 & 0,443 & 21 & 0,611 & 0,286 & 0,614 & 0,407 \\
\hline AT1G29890.1 & $\begin{array}{c}\text { O-acetyltransferase } \\
\text { family protein }\end{array}$ & 0,741 & 0,194 & 0,478 & 0,431 & 22 & 0,671 & 0,271 & 0,521 & 0,446 \\
\hline AT1G63400.1 & $\begin{array}{l}\text { Pentatricopeptide } \\
\text { repeat (PPR) } \\
\text { superfamily protein }\end{array}$ & 0,666 & 0,326 & 0,518 & 0,426 & 22 & 0,671 & 0,271 & 0,521 & 0,446 \\
\hline AT1G66783.1 & $\begin{array}{l}\text { MIR157A MIR157A; } \\
\text { miRNA }\end{array}$ & 0,681 & 0,340 & 0,514 & 0,395 & 22 & 0,671 & 0,271 & 0,521 & 0,446 \\
\hline AT2G23450.1 & $\begin{array}{c}\text { Protein kinase } \\
\text { superfamily protein }\end{array}$ & 0,691 & 0,248 & 0,495 & 0,465 & 22 & 0,671 & 0,271 & 0,521 & 0,446 \\
\hline AT3G14840.1 & $\begin{array}{c}\text { Leucine-rich repeat } \\
\text { transmembrane } \\
\text { protein kinase }\end{array}$ & 0,666 & 0,300 & 0,503 & 0,462 & 22 & 0,671 & 0,271 & 0,521 & 0,446 \\
\hline AT5G41760.1 & $\begin{array}{c}\text { Nucleotide-sugar } \\
\text { transporter family } \\
\text { protein }\end{array}$ & 0,643 & 0,234 & 0,574 & 0,450 & 22 & 0,671 & 0,271 & 0,521 & 0,446 \\
\hline $\begin{array}{c}\text { ATCG01140. } \\
1 \\
\end{array}$ & TRNN.2 tRNA-Asn & 0,611 & 0,256 & 0,565 & 0,492 & 22 & 0,671 & 0,271 & 0,521 & 0,446 \\
\hline AT2G16200.1 & structural molecules & 0,606 & 0,284 & 0,389 & 0,633 & 23 & 0,654 & 0,266 & 0,378 & 0,596 \\
\hline AT5G43310.1 & $\begin{array}{l}\text { COP1-interacting } \\
\text { protein-related }\end{array}$ & 0,701 & 0,247 & 0,368 & 0,559 & 23 & 0,654 & 0,266 & 0,378 & 0,596 \\
\hline $\begin{array}{c}\text { ATCG00030. } \\
1\end{array}$ & $\begin{array}{c}\text { TRNK TRNK-UUU } \\
\text { TRNA LYS Lysine } \\
\text { tRNA } \\
\end{array}$ & 0,455 & 0,226 & 0,560 & 0,655 & 24 & 0,481 & 0,173 & 0,582 & 0,628 \\
\hline $\begin{array}{c}\text { ATCG00240. } \\
1 \\
\end{array}$ & TRNY tRNA-Tyr & 0,455 & 0,084 & 0,591 & 0,661 & 24 & 0,481 & 0,173 & 0,582 & 0,628 \\
\hline $\begin{array}{c}\text { ATCG00250. } \\
1\end{array}$ & $\begin{array}{c}\text { TRNE this } \\
\text { chloroplast gene } \\
\text { encodes a UUC tRNA } \\
\text { whose expression is } \\
\text { regulated by SIG2. }\end{array}$ & 0,481 & 0,127 & 0,588 & 0,638 & 24 & 0,481 & 0,173 & 0,582 & 0,628 \\
\hline $\begin{array}{c}\text { ATCG00400. } \\
1 \\
\end{array}$ & TRNL. 1 tRNA-Leu & 0,549 & 0,181 & 0,608 & 0,544 & 24 & 0,481 & 0,173 & 0,582 & 0,628 \\
\hline $\begin{array}{c}\text { ATCG00410. } \\
1 \\
\end{array}$ & $\begin{array}{c}\text { TRNF chloroplast } \\
\text { TRNF }\end{array}$ & 0,480 & 0,208 & 0,552 & 0,649 & 24 & 0,481 & 0,173 & 0,582 & 0,628 \\
\hline $\begin{array}{c}\text { ATCG00440. } \\
1\end{array}$ & $\begin{array}{c}\text { NDHC } \\
\text { NADH:ubiquinone/pla } \\
\text { stoquinone } \\
\text { oxidoreductase chain } \\
3 \text { protein } \\
\end{array}$ & 0,436 & 0,185 & 0,579 & 0,664 & 24 & 0,481 & 0,173 & 0,582 & 0,628 \\
\hline $\begin{array}{c}\text { ATCG00450. } \\
1\end{array}$ & TRNV.1 tRNA-Val & 0,523 & 0,168 & 0,639 & 0,539 & 24 & 0,481 & 0,173 & 0,582 & 0,628 \\
\hline $\begin{array}{c}\text { ATCG01150. } \\
1 \\
\end{array}$ & TRNR.3 tRNA-Arg & 0,469 & 0,203 & 0,537 & 0,672 & 24 & 0,481 & 0,173 & 0,582 & 0,628 \\
\hline AT1G21270.1 & $\begin{array}{c}\text { WAK2 wall- } \\
\text { associated kinase } 2\end{array}$ & 0,247 & 0,361 & 0,378 & 0,816 & 26 & 0,288 & 0,320 & 0,356 & 0,828 \\
\hline AT1G29510.1 & $\begin{array}{c}\text { SAUR68 SAUR-like } \\
\text { auxin-responsive } \\
\text { protein family }\end{array}$ & 0,295 & 0,333 & 0,338 & 0,830 & 26 & 0,288 & 0,320 & 0,356 & 0,828 \\
\hline AT1G33600.1 & $\begin{array}{l}\text { Leucine-rich repeat } \\
\text { (LRR) family protein }\end{array}$ & 0,317 & 0,318 & 0,387 & 0,805 & 26 & 0,288 & 0,320 & 0,356 & 0,828 \\
\hline AT3G16660.1 & $\begin{array}{c}\text { Pollen Ole e } 1 \\
\text { allergen and extensin } \\
\text { family protein } \\
\end{array}$ & 0,303 & 0,277 & 0,313 & 0,857 & 26 & 0,288 & 0,320 & 0,356 & 0,828 \\
\hline AT5G07100.1 & $\begin{array}{c}\text { WRKY26 WRKY } \\
\text { DNA-binding protein } \\
26 \\
\end{array}$ & 0,278 & 0,309 & 0,366 & 0,832 & 26 & 0,288 & 0,320 & 0,356 & 0,828 \\
\hline AT1G49750.1 & $\begin{array}{l}\text { Leucine-rich repeat } \\
\text { (LRR) family protein }\end{array}$ & 0,141 & 0,130 & 0,336 & 0,922 & 27 & 0,211 & 0,216 & 0,313 & 0,896 \\
\hline
\end{tabular}


Anhang

\begin{tabular}{|c|c|c|c|c|c|c|c|c|c|c|}
\hline AT2G41090.1 & $\begin{array}{l}\text { Calcium-binding EF- } \\
\text { hand family protein }\end{array}$ & 0,248 & 0,230 & 0,301 & 0,891 & 27 & 0,211 & 0,216 & 0,313 & 0,896 \\
\hline AT5G44568.1 & unknown protein & 0,245 & 0,289 & 0,300 & 0,875 & 27 & 0,211 & 0,216 & 0,313 & 0,896 \\
\hline AT3G22231.1 & $\begin{array}{l}\text { PCC1 pathogen and } \\
\text { circadian controlled } 1\end{array}$ & 0,132 & 0,242 & 0,119 & 0,954 & 28 & 0,112 & 0,242 & 0,134 & 0,951 \\
\hline AT5G03350.1 & $\begin{array}{c}\text { Legume lectin family } \\
\text { protein }\end{array}$ & 0,131 & 0,146 & 0,118 & 0,974 & 28 & 0,112 & 0,242 & 0,134 & 0,951 \\
\hline AT5G22570.1 & $\begin{array}{c}\text { WRKY38 } \\
\text { ATWRKY38 WRKY } \\
\text { DNA-binding protein } \\
38\end{array}$ & 0,074 & 0,337 & 0,164 & 0,924 & 28 & 0,112 & 0,242 & 0,134 & 0,951 \\
\hline AT1G02230.1 & ANAC004 NAC004 & 0,097 & 0,490 & 0,096 & 0,861 & 29 & 0,123 & 0,453 & 0,173 & 0,861 \\
\hline AT1G02450.1 & $\begin{array}{l}\text { NIMIN1 NIMIN-1 } \\
\text { NIM1-interacting } 1\end{array}$ & 0,200 & 0,396 & 0,162 & 0,882 & 29 & 0,123 & 0,453 & 0,173 & 0,861 \\
\hline AT5G01900.1 & $\begin{array}{c}\text { WRKY62 } \\
\text { ATWRKY62 WRKY } \\
\text { DNA-binding protein } \\
62 \\
\end{array}$ & 0,107 & 0,412 & 0,243 & 0,871 & 29 & 0,123 & 0,453 & 0,173 & 0,861 \\
\hline AT5G27030.1 & $\begin{array}{c}\text { TPR3 TOPLESS- } \\
\text { related } 3\end{array}$ & 0,089 & 0,514 & 0,190 & 0,832 & 29 & 0,123 & 0,453 & 0,173 & 0,861 \\
\hline AT1G15260.1 & unknown protein & 0,195 & 0,510 & 0,285 & 0,788 & 30 & 0,243 & 0,457 & 0,273 & 0,807 \\
\hline AT1G48830.1 & $\begin{array}{l}\text { Ribosomal protein } \\
\text { S7e family protein }\end{array}$ & 0,283 & 0,442 & 0,260 & 0,811 & 30 & 0,243 & 0,457 & 0,273 & 0,807 \\
\hline AT1G80660.2 & HA9 H(+)-ATPase 9 & 0,285 & 0,430 & 0,301 & 0,802 & 30 & 0,243 & 0,457 & 0,273 & 0,807 \\
\hline AT2G21900.1 & $\begin{array}{c}\text { WRKY59 } \\
\text { ATWRKY59 WRKY } \\
\text { DNA-binding protein } \\
59 \\
\end{array}$ & 0,243 & 0,445 & 0,307 & 0,805 & 30 & 0,243 & 0,457 & 0,273 & 0,807 \\
\hline AT2G25510.2 & unknown protein & 0,268 & 0,400 & 0,325 & 0,814 & 30 & 0,243 & 0,457 & 0,273 & 0,807 \\
\hline AT2G40750.1 & $\begin{array}{c}\text { WRKY54 } \\
\text { ATWRKY54 WRKY } \\
\text { DNA-binding protein } \\
54 \\
\end{array}$ & 0,188 & 0,449 & 0,314 & 0,815 & 30 & 0,243 & 0,457 & 0,273 & 0,807 \\
\hline AT3G56400.1 & $\begin{array}{c}\text { WRKY70 } \\
\text { ATWRKY70 WRKY } \\
\text { DNA-binding protein } \\
70 \\
\end{array}$ & 0,238 & 0,472 & 0,202 & 0,825 & 30 & 0,243 & 0,457 & 0,273 & 0,807 \\
\hline AT4G12400.1 & $\begin{array}{c}\text { Hop3 stress- } \\
\text { inducible protein } \\
\text { putative }\end{array}$ & 0,200 & 0,538 & 0,187 & 0,797 & 30 & 0,243 & 0,457 & 0,273 & 0,807 \\
\hline AT4G35180.1 & $\begin{array}{l}\text { LHT7 LYS/HIS } \\
\text { transporter } 7\end{array}$ & 0,289 & 0,430 & 0,276 & 0,810 & 30 & 0,243 & 0,457 & 0,273 & 0,807 \\
\hline AT1G03850.1 & $\begin{array}{c}\text { Glutaredoxin family } \\
\text { protein }\end{array}$ & 0,297 & 0,554 & 0,291 & 0,722 & 31 & 0,326 & 0,503 & 0,312 & 0,734 \\
\hline AT1G72930.2 & $\begin{array}{l}\text { TIR toll/interleukin-1 } \\
\text { receptor-like }\end{array}$ & 0,409 & 0,430 & 0,311 & 0,742 & 31 & 0,326 & 0,503 & 0,312 & 0,734 \\
\hline AT3G62320.1 & $\begin{array}{c}\text { Polynucleotidyl } \\
\text { transferase } \\
\text { ribonuclease } \mathrm{H} \text {-like } \\
\text { superfamily protein }\end{array}$ & 0,312 & 0,530 & 0,321 & 0,721 & 31 & 0,326 & 0,503 & 0,312 & 0,734 \\
\hline AT4G25434.2 & $\begin{array}{c}\text { ATNUDT10 NUDT10 } \\
\text { nudix hydrolase } \\
\text { homolog } 10 \\
\end{array}$ & 0,339 & 0,510 & 0,284 & 0,737 & 31 & 0,326 & 0,503 & 0,312 & 0,734 \\
\hline AT4G31800.2 & $\begin{array}{c}\text { WRKY18 WRKY } \\
\text { DNA-binding protein } \\
18 \\
\end{array}$ & 0,298 & 0,447 & 0,359 & 0,763 & 31 & 0,326 & 0,503 & 0,312 & 0,734 \\
\hline AT5G21920.2 & $\begin{array}{c}\text { YLMG2 YGGT family } \\
\text { protein }\end{array}$ & 0,302 & 0,546 & 0,307 & 0,719 & 31 & 0,326 & 0,503 & 0,312 & 0,734 \\
\hline AT1G59660.1 & $\begin{array}{c}\text { Nucleoporin } \\
\text { autopeptidase }\end{array}$ & 0,238 & 0,575 & 0,257 & 0,740 & 32 & 0,235 & 0,577 & 0,286 & 0,724 \\
\hline AT1G74310.1 & $\begin{array}{l}\text { ATHSP101 HSP101 } \\
\text { HOT1 heat shock } \\
\text { protein } 101\end{array}$ & 0,197 & 0,537 & 0,362 & 0,736 & 32 & 0,235 & 0,577 & 0,286 & 0,724 \\
\hline AT1G80030.2 & $\begin{array}{c}\text { Molecular chaperone } \\
\text { Hsp40/DnaJ family } \\
\text { protein }\end{array}$ & 0,310 & 0,586 & 0,289 & 0,691 & 32 & 0,235 & 0,577 & 0,286 & 0,724 \\
\hline AT2G45150.2 & $\begin{array}{c}\text { cytidinediphosphate } \\
\text { diacylglycerol } \\
\text { synthase } 4 \\
\end{array}$ & 0,235 & 0,576 & 0,288 & 0,728 & 32 & 0,235 & 0,577 & 0,286 & 0,724 \\
\hline
\end{tabular}


Anhang

\begin{tabular}{|c|c|c|c|c|c|c|c|c|c|c|}
\hline AT3G19800.2 & $\begin{array}{l}\text { Protein of unknown } \\
\text { function (DUF177) }\end{array}$ & 0,219 & 0,534 & 0,367 & 0,730 & 32 & 0,235 & 0,577 & 0,286 & 0,724 \\
\hline AT3G60760.1 & unknown protein & 0,185 & 0,582 & 0,197 & 0,767 & 32 & 0,235 & 0,577 & 0,286 & 0,724 \\
\hline AT3G63320.1 & $\begin{array}{l}\text { Protein phosphatase } \\
2 \mathrm{C} \text { family protein }\end{array}$ & 0,256 & 0,603 & 0,234 & 0,719 & 32 & 0,235 & 0,577 & 0,286 & 0,724 \\
\hline AT4G31196.1 & oxidoreductases & 0,275 & 0,568 & 0,306 & 0,713 & 32 & 0,235 & 0,577 & 0,286 & 0,724 \\
\hline AT5G25450.1 & $\begin{array}{l}\text { Cytochrome bd } \\
\text { ubiquinol oxidase } \\
14 \mathrm{kDa} \text { subunit }\end{array}$ & 0,240 & 0,613 & 0,263 & 0,705 & 32 & 0,235 & 0,577 & 0,286 & 0,724 \\
\hline AT5G52100.1 & $\begin{array}{c}\text { crr1 } \\
\text { Dihydrodipicolinate } \\
\text { reductase } \\
\text { bacterial/plant }\end{array}$ & 0,195 & 0,565 & 0,327 & 0,732 & 32 & 0,235 & 0,577 & 0,286 & 0,724 \\
\hline AT5G64810.1 & $\begin{array}{c}\text { WRKY51 } \\
\text { ATWRKY51 WRKY } \\
\text { DNA-binding protein } \\
51 \\
\end{array}$ & 0,240 & 0,610 & 0,260 & 0,709 & 32 & 0,235 & 0,577 & 0,286 & 0,724 \\
\hline AT1G12770.1 & ISE1 EMB1586 & 0,275 & 0,624 & 0,345 & 0,645 & 33 & 0,243 & 0,603 & 0,393 & 0,648 \\
\hline AT1G15125.1 & $\begin{array}{c}\text { S-adenosyl-L- } \\
\text { methionine- } \\
\text { dependent } \\
\text { methyltransferases } \\
\text { superfamily protein } \\
\end{array}$ & 0,222 & 0,592 & 0,371 & 0,680 & 33 & 0,243 & 0,603 & 0,393 & 0,648 \\
\hline AT1G18250.2 & $\begin{array}{c}\text { ATLP-1 } \\
\text { Pathogenesis-related } \\
\text { thaumatin } \\
\text { superfamily protein }\end{array}$ & 0,266 & 0,563 & 0,443 & 0,644 & 33 & 0,243 & 0,603 & 0,393 & 0,648 \\
\hline AT3G24500.1 & $\begin{array}{c}\text { MBF1C ATMBF1C } \\
\text { multiprotein bridging } \\
\text { factor } 1 \mathrm{C}\end{array}$ & 0,252 & 0,624 & 0,398 & 0,624 & 33 & 0,243 & 0,603 & 0,393 & 0,648 \\
\hline AT3G24500.2 & $\begin{array}{l}\text { MBF1C multiprotein } \\
\text { bridging factor } 1 \mathrm{C}\end{array}$ & 0,285 & 0,582 & 0,370 & 0,666 & 33 & 0,243 & 0,603 & 0,393 & 0,648 \\
\hline AT3G60176.1 & other RNA & 0,243 & 0,574 & 0,426 & 0,656 & 33 & 0,243 & 0,603 & 0,393 & 0,648 \\
\hline AT4G12400.2 & $\begin{array}{c}\text { Hop3 stress- } \\
\text { inducible protein } \\
\text { putative }\end{array}$ & 0,277 & 0,598 & 0,408 & 0,632 & 33 & 0,243 & 0,603 & 0,393 & 0,648 \\
\hline AT4G24460.1 & $\begin{array}{l}\text { CLT2 CRT } \\
\text { (chloroquine- } \\
\text { resistance } \\
\text { transporter)-like } \\
\text { transporter } 2\end{array}$ & 0,201 & 0,635 & 0,381 & 0,642 & 33 & 0,243 & 0,603 & 0,393 & 0,648 \\
\hline AT4G33650.1 & $\begin{array}{c}\text { ADL2 DRP3A } \\
\text { dynamin-related } \\
\text { protein } 3 A\end{array}$ & 0,161 & 0,636 & 0,399 & 0,640 & 33 & 0,243 & 0,603 & 0,393 & 0,648 \\
\hline AT1G69750.1 & $\begin{array}{c}\text { COX19-2 ATCOX19- } \\
2 \text { cytochrome c } \\
\text { oxidase 19-2 }\end{array}$ & 0,268 & 0,563 & 0,505 & 0,597 & 34 & 0,220 & 0,569 & 0,545 & 0,565 \\
\hline AT1G79820.3 & $\begin{array}{c}\text { SGB1 Major } \\
\text { facilitator superfamily } \\
\text { protein }\end{array}$ & 0,272 & 0,571 & 0,482 & 0,606 & 34 & 0,220 & 0,569 & 0,545 & 0,565 \\
\hline AT2G46320.2 & $\begin{array}{c}\text { Mitochondrial } \\
\text { substrate carrier } \\
\text { family protein }\end{array}$ & 0,186 & 0,547 & 0,505 & 0,641 & 34 & 0,220 & 0,569 & 0,545 & 0,565 \\
\hline AT3G07740.2 & $\begin{array}{c}\text { ADA2A ATADA2A } \\
\text { HAC10 HXA02 HXA2 } \\
\text { homolog of yeast } \\
\text { ADA2 2A } \\
\end{array}$ & 0,278 & 0,586 & 0,571 & 0,503 & 34 & 0,220 & 0,569 & 0,545 & 0,565 \\
\hline AT3G12580.1 & $\begin{array}{c}\text { HSP70 ATHSP70 } \\
\text { heat shock protein } 70\end{array}$ & 0,274 & 0,548 & 0,492 & 0,619 & 34 & 0,220 & 0,569 & 0,545 & 0,565 \\
\hline AT4G17590.1 & unknown protein & 0,103 & 0,608 & 0,572 & 0,541 & 34 & 0,220 & 0,569 & 0,545 & 0,565 \\
\hline AT4G25450.2 & $\begin{array}{c}\text { ATNAP8 NAP8 non- } \\
\text { intrinsic ABC protein } \\
8 \\
\end{array}$ & 0,118 & 0,549 & 0,606 & 0,563 & 34 & 0,220 & 0,569 & 0,545 & 0,565 \\
\hline AT5G18400.2 & $\begin{array}{c}\text { Cytokine-induced } \\
\text { anti-apoptosis } \\
\text { inhibitor } 1 \mathrm{Fe}-\mathrm{S} \\
\text { biogenesis } \\
\end{array}$ & 0,244 & 0,631 & 0,606 & 0,417 & 34 & 0,220 & 0,569 & 0,545 & 0,565 \\
\hline AT5G51440.1 & $\begin{array}{c}\text { HSP20-like } \\
\text { chaperones } \\
\text { superfamily protein }\end{array}$ & 0,237 & 0,518 & 0,564 & 0,598 & 34 & 0,220 & 0,569 & 0,545 & 0,565 \\
\hline
\end{tabular}


Anhang

\begin{tabular}{|c|c|c|c|c|c|c|c|c|c|c|}
\hline AT1G20150.1 & $\begin{array}{c}\begin{array}{c}\text { Subtilisin-like serine } \\
\text { endopeptidase family } \\
\text { protein }\end{array} \\
\end{array}$ & 0,313 & 0,663 & 0,419 & 0,535 & 35 & 0,307 & 0,647 & 0,403 & 0,567 \\
\hline AT1G23465.1 & $\begin{array}{c}\text { Peptidase } \\
\text { S24/S26A/S26B/S26 } \\
\text { C family protein } \\
\end{array}$ & 0,334 & 0,679 & 0,349 & 0,553 & 35 & 0,307 & 0,647 & 0,403 & 0,567 \\
\hline AT1G27921.1 & other RNA & 0,305 & 0,612 & 0,406 & 0,607 & 35 & 0,307 & 0,647 & 0,403 & 0,567 \\
\hline AT1G66080.1 & unknown protein & 0,312 & 0,620 & 0,408 & 0,593 & 35 & 0,307 & 0,647 & 0,403 & 0,567 \\
\hline AT2G28210.1 & $\begin{array}{l}\text { ATACA2 ACA2 } \\
\text { alpha carbonic } \\
\text { anhydrase } 2 \\
\end{array}$ & 0,324 & 0,691 & 0,410 & 0,500 & 35 & 0,307 & 0,647 & 0,403 & 0,567 \\
\hline AT2G36355.3 & $\begin{array}{l}\text { Family of unknown } \\
\text { function (DUF662) }\end{array}$ & 0,295 & 0,638 & 0,464 & 0,538 & 35 & 0,307 & 0,647 & 0,403 & 0,567 \\
\hline AT3G11560.2 & LETM1-like protein & 0,317 & 0,636 & 0,376 & 0,595 & 35 & 0,307 & 0,647 & 0,403 & 0,567 \\
\hline AT3G13030.2 & $\begin{array}{l}\text { hAT transposon } \\
\text { superfamily protein }\end{array}$ & 0,303 & 0,642 & 0,391 & 0,587 & 35 & 0,307 & 0,647 & 0,403 & 0,567 \\
\hline AT3G17660.1 & $\begin{array}{l}\text { AGD15 ARF-GAP } \\
\text { domain } 15\end{array}$ & 0,317 & 0,663 & 0,365 & 0,571 & 35 & 0,307 & 0,647 & 0,403 & 0,567 \\
\hline AT3G17670.1 & $\begin{array}{l}\text { tetratricopeptide } \\
\text { repeat (TPR)- } \\
\text { containing protein } \\
\end{array}$ & 0,279 & 0,604 & 0,464 & 0,585 & 35 & 0,307 & 0,647 & 0,403 & 0,567 \\
\hline AT3G47090.1 & $\begin{array}{c}\text { Leucine-rich repeat } \\
\text { protein kinase family } \\
\text { protein }\end{array}$ & 0,294 & 0,648 & 0,360 & 0,603 & 35 & 0,307 & 0,647 & 0,403 & 0,567 \\
\hline AT3G56830.2 & $\begin{array}{l}\text { Protein of unknown } \\
\text { function (DUF565) }\end{array}$ & 0,303 & 0,630 & 0,385 & 0,603 & 35 & 0,307 & 0,647 & 0,403 & 0,567 \\
\hline AT4G21990.1 & $\begin{array}{c}\text { APR3 PRH-26 } \\
\text { PRH26 ATAPR3 } \\
\text { APS reductase } 3 \\
\end{array}$ & 0,296 & 0,675 & 0,445 & 0,509 & 35 & 0,307 & 0,647 & 0,403 & 0,567 \\
\hline AT4G21990.2 & $\begin{array}{l}\text { APR3 APS } \\
\text { reductase } 3\end{array}$ & 0,288 & 0,659 & 0,427 & 0,548 & 35 & 0,307 & 0,647 & 0,403 & 0,567 \\
\hline AT5G64150.1 & $\begin{array}{c}\mathrm{RNA} \\
\text { methyltransferase } \\
\text { family protein }\end{array}$ & 0,327 & 0,649 & 0,371 & 0,578 & 35 & 0,307 & 0,647 & 0,403 & 0,567 \\
\hline AT1G09710.1 & $\begin{array}{l}\text { Homeodomain-like } \\
\text { superfamily protein }\end{array}$ & 0,218 & 0,722 & 0,366 & 0,545 & 36 & 0,262 & 0,712 & 0,337 & 0,554 \\
\hline AT1G63010.1 & $\begin{array}{c}\text { Major Facilitator } \\
\text { Superfamily with SPX } \\
\text { (SYG1/Pho81/XPR1) } \\
\text { domain-containing } \\
\text { protein }\end{array}$ & 0,247 & 0,699 & 0,359 & 0,567 & 36 & 0,262 & 0,712 & 0,337 & 0,554 \\
\hline AT1G72416.4 & $\begin{array}{c}\text { Chaperone DnaJ- } \\
\text { domain superfamily } \\
\text { protein }\end{array}$ & 0,334 & 0,694 & 0,347 & 0,536 & 36 & 0,262 & 0,712 & 0,337 & 0,554 \\
\hline AT1G72660.1 & $\begin{array}{l}\text { P-loop containing } \\
\text { nucleoside } \\
\text { triphosphate } \\
\text { hydrolases } \\
\text { superfamily protein }\end{array}$ & 0,268 & 0,740 & 0,299 & 0,540 & 36 & 0,262 & 0,712 & 0,337 & 0,554 \\
\hline AT1G79790.1 & $\begin{array}{c}\text { Haloacid } \\
\text { dehalogenase-like } \\
\text { hydrolase (HAD) } \\
\text { superfamily protein } \\
\end{array}$ & 0,216 & 0,749 & 0,307 & 0,546 & 36 & 0,262 & 0,712 & 0,337 & 0,554 \\
\hline AT2G36355.2 & $\begin{array}{l}\text { Family of unknown } \\
\text { function (DUF662) }\end{array}$ & 0,232 & 0,700 & 0,338 & 0,584 & 36 & 0,262 & 0,712 & 0,337 & 0,554 \\
\hline AT2G36390.1 & $\begin{array}{c}\text { SBE2.1 BE3 starch } \\
\text { branching enzyme } \\
2.1 \\
\end{array}$ & 0,291 & 0,718 & 0,330 & 0,539 & 36 & 0,262 & 0,712 & 0,337 & 0,554 \\
\hline AT3G06400.1 & $\begin{array}{l}\text { CHR11 chromatin- } \\
\text { remodeling protein } 11\end{array}$ & 0,143 & 0,716 & 0,387 & 0,563 & 36 & 0,262 & 0,712 & 0,337 & 0,554 \\
\hline AT3G13065.1 & $\begin{array}{c}\text { SRF4 } \\
\text { STRUBBELIG- } \\
\text { receptor family } 4\end{array}$ & 0,262 & 0,691 & 0,326 & 0,589 & 36 & 0,262 & 0,712 & 0,337 & 0,554 \\
\hline AT3G24560.3 & $\begin{array}{l}\text { RSY3 Adenine } \\
\text { nucleotide alpha } \\
\text { hydrolases-like } \\
\text { superfamily protein }\end{array}$ & 0,278 & 0,674 & 0,348 & 0,589 & 36 & 0,262 & 0,712 & 0,337 & 0,554 \\
\hline AT4G19060.1 & $\begin{array}{l}\text { P-loop containing } \\
\text { nucleoside } \\
\text { triphosphate }\end{array}$ & 0,273 & 0,736 & 0,299 & 0,543 & 36 & 0,262 & 0,712 & 0,337 & 0,554 \\
\hline
\end{tabular}




\begin{tabular}{|c|c|c|c|c|c|c|c|c|c|c|}
\hline & $\begin{array}{c}\text { hydrolases } \\
\text { superfamily protein }\end{array}$ & & & & & & & & & \\
\hline AT4G19070.1 & $\begin{array}{l}\text { Putative membrane } \\
\text { lipoprotein }\end{array}$ & 0,318 & 0,700 & 0,344 & 0,538 & 36 & 0,262 & 0,712 & 0,337 & 0,554 \\
\hline AT5G12280.1 & $\begin{array}{l}\text { SWAP (Suppressor- } \\
\text { of-White- } \\
\text { APricot)/surp RNA- } \\
\text { binding domain- } \\
\text { containing protein }\end{array}$ & 0,272 & 0,732 & 0,312 & 0,541 & 36 & 0,262 & 0,712 & 0,337 & 0,554 \\
\hline AT5G26980.1 & $\begin{array}{l}\text { SYP41 ATSYP41 } \\
\text { ATTLG2A syntaxin } \\
\text { of plants } 41\end{array}$ & 0,258 & 0,715 & 0,399 & 0,513 & 36 & 0,262 & 0,712 & 0,337 & 0,554 \\
\hline AT5G60410.3 & ATSIZ1 SIZ1 & 0,285 & 0,722 & 0,341 & 0,530 & 36 & 0,262 & 0,712 & 0,337 & 0,554 \\
\hline AT5G60440.1 & $\begin{array}{l}\text { AGL62 AGAMOUS- } \\
\text { like } 62\end{array}$ & 0,300 & 0,704 & 0,315 & 0,561 & 36 & 0,262 & 0,712 & 0,337 & 0,554 \\
\hline AT5G61495.1 & unknown protein & 0,210 & 0,723 & 0,300 & 0,586 & 36 & 0,262 & 0,712 & 0,337 & 0,554 \\
\hline AT5G64240.2 & $\begin{array}{c}\text { AtMC3 MC3 } \\
\text { metacaspase } 3\end{array}$ & 0,307 & 0,688 & 0,352 & 0,556 & 36 & 0,262 & 0,712 & 0,337 & 0,554 \\
\hline AT1G04090.1 & $\begin{array}{l}\text { Plant protein of } \\
\text { unknown function } \\
\text { (DUF946) }\end{array}$ & 0,331 & 0,670 & 0,328 & 0,578 & 37 & 0,335 & 0,635 & 0,314 & 0,619 \\
\hline AT1G05820.2 & $\begin{array}{l}\text { SPPL5 ATSPPL5 } \\
\text { SIGNAL PEPTIDE } \\
\text { PEPTIDASE-LIKE } 5\end{array}$ & 0,311 & 0,639 & 0,346 & 0,613 & 37 & 0,335 & 0,635 & 0,314 & 0,619 \\
\hline AT1G06645.1 & $\begin{array}{l}\text { 2-oxoglutarate (2OG) } \\
\text { and Fe(II)-dependent } \\
\text { oxygenase } \\
\text { superfamily protein }\end{array}$ & 0,362 & 0,632 & 0,264 & 0,633 & 37 & 0,335 & 0,635 & 0,314 & 0,619 \\
\hline AT1G12775.1 & $\begin{array}{l}\text { Pentatricopeptide } \\
\text { repeat (PPR) } \\
\text { superfamily protein } \\
\end{array}$ & 0,344 & 0,676 & 0,298 & 0,580 & 37 & 0,335 & 0,635 & 0,314 & 0,619 \\
\hline AT1G27970.1 & $\begin{array}{l}\text { NTF2B nuclear } \\
\text { transport factor 2B }\end{array}$ & 0,350 & 0,599 & 0,320 & 0,645 & 37 & 0,335 & 0,635 & 0,314 & 0,619 \\
\hline AT1G49160.1 & $\begin{array}{c}\text { WNK7 Protein } \\
\text { kinase superfamily } \\
\text { protein }\end{array}$ & 0,431 & 0,594 & 0,281 & 0,619 & 37 & 0,335 & 0,635 & 0,314 & 0,619 \\
\hline AT1G52370.1 & $\begin{array}{c}\text { Ribosomal protein } \\
\text { L22p/L17e family } \\
\text { protein }\end{array}$ & 0,304 & 0,642 & 0,311 & 0,631 & 37 & 0,335 & 0,635 & 0,314 & 0,619 \\
\hline AT1G54160.1 & $\begin{array}{c}\text { NFYA5 NF-YA5 } \\
\text { nuclear factor Y } \\
\text { subunit A5 }\end{array}$ & 0,293 & 0,647 & 0,348 & 0,612 & 37 & 0,335 & 0,635 & 0,314 & 0,619 \\
\hline AT2G01200.2 & $\begin{array}{c}\text { IAA32 indole-3- } \\
\text { acetic acid inducible } \\
32 \\
\end{array}$ & 0,313 & 0,631 & 0,364 & 0,609 & 37 & 0,335 & 0,635 & 0,314 & 0,619 \\
\hline AT2G04440.1 & $\begin{array}{l}\text { MutT/nudix family } \\
\text { protein }\end{array}$ & 0,318 & 0,646 & 0,340 & 0,605 & 37 & 0,335 & 0,635 & 0,314 & 0,619 \\
\hline AT2G33100.1 & $\begin{array}{l}\text { ATCSLD1 CSLD1 } \\
\text { cellulose synthase- } \\
\text { like D1 }\end{array}$ & 0,303 & 0,634 & 0,331 & 0,630 & 37 & 0,335 & 0,635 & 0,314 & 0,619 \\
\hline AT2G48121.1 & $\begin{array}{c}\text { BEST Arabidopsis } \\
\text { thaliana protein } \\
\text { match: Ribonuclease } \\
\text { III family protein } \\
\text { (TAIR:AT4G37510.1). }\end{array}$ & 0,328 & 0,655 & 0,325 & 0,598 & 37 & 0,335 & 0,635 & 0,314 & 0,619 \\
\hline AT3G13062.2 & $\begin{array}{c}\text { Polyketide } \\
\text { cyclase/dehydrase } \\
\text { and lipid transport } \\
\text { superfamily protein }\end{array}$ & 0,349 & 0,595 & 0,258 & 0,676 & 37 & 0,335 & 0,635 & 0,314 & 0,619 \\
\hline AT3G20520.1 & SVL3 SHV3-like 3 & 0,353 & 0,648 & 0,290 & 0,609 & 37 & 0,335 & 0,635 & 0,314 & 0,619 \\
\hline AT3G56600.2 & $\begin{array}{c}\text { Protein kinase } \\
\text { superfamily protein }\end{array}$ & 0,386 & 0,597 & 0,266 & 0,651 & 37 & 0,335 & 0,635 & 0,314 & 0,619 \\
\hline AT5G27010.1 & $\begin{array}{c}\text { ARM repeat } \\
\text { superfamily protein }\end{array}$ & 0,308 & 0,655 & 0,317 & 0,613 & 37 & 0,335 & 0,635 & 0,314 & 0,619 \\
\hline AT5G42965.1 & $\begin{array}{c}\text { Polynucleotidyl } \\
\text { transferase } \\
\text { ribonuclease } \mathrm{H} \text {-like } \\
\text { superfamily protein }\end{array}$ & 0,308 & 0,630 & 0,346 & 0,623 & 37 & 0,335 & 0,635 & 0,314 & 0,619 \\
\hline
\end{tabular}


Anhang

\begin{tabular}{|c|c|c|c|c|c|c|c|c|c|c|}
\hline AT1G06260.1 & $\begin{array}{l}\text { Cysteine proteinases } \\
\text { superfamily protein }\end{array}$ & 0,311 & 0,703 & 0,293 & 0,569 & 38 & 0,285 & 0,687 & 0,284 & 0,604 \\
\hline AT1G07590.1 & $\begin{array}{l}\text { Tetratricopeptide } \\
\text { repeat (TPR)-like } \\
\text { superfamily protein } \\
\end{array}$ & 0,277 & 0,681 & 0,301 & 0,608 & 38 & 0,285 & 0,687 & 0,284 & 0,604 \\
\hline AT1G20925.1 & $\begin{array}{l}\text { Auxin efflux carrier } \\
\text { family protein }\end{array}$ & 0,317 & 0,685 & 0,301 & 0,583 & 38 & 0,285 & 0,687 & 0,284 & 0,604 \\
\hline AT1G48405.1 & $\begin{array}{c}\begin{array}{c}\text { Kinase interacting } \\
\text { (KIP1-like) family } \\
\text { protein }\end{array} \\
\end{array}$ & 0,269 & 0,726 & 0,230 & 0,590 & 38 & 0,285 & 0,687 & 0,284 & 0,604 \\
\hline AT2G11270.1 & $\begin{array}{l}\text { citrate synthase- } \\
\text { related }\end{array}$ & 0,309 & 0,679 & 0,270 & 0,609 & 38 & 0,285 & 0,687 & 0,284 & 0,604 \\
\hline AT2G14160.1 & $\begin{array}{c}\text { RNA-binding } \\
\text { (RRM/RBD/RNP } \\
\text { motifs) family protein }\end{array}$ & 0,266 & 0,650 & 0,322 & 0,634 & 38 & 0,285 & 0,687 & 0,284 & 0,604 \\
\hline AT2G31981.1 & unknown protein & 0,272 & 0,673 & 0,278 & 0,629 & 38 & 0,285 & 0,687 & 0,284 & 0,604 \\
\hline AT2G32340.1 & TraB family protein & 0,271 & 0,676 & 0,307 & 0,612 & 38 & 0,285 & 0,687 & 0,284 & 0,604 \\
\hline AT2G38255.1 & $\begin{array}{l}\text { Protein of Unknown } \\
\text { Function (DUF239) }\end{array}$ & 0,220 & 0,701 & 0,278 & 0,619 & 38 & 0,285 & 0,687 & 0,284 & 0,604 \\
\hline AT3G06280.1 & $\begin{array}{c}\text { F-box associated } \\
\text { ubiquitination effector } \\
\text { family protein } \\
\end{array}$ & 0,274 & 0,717 & 0,238 & 0,595 & 38 & 0,285 & 0,687 & 0,284 & 0,604 \\
\hline AT3G07150.1 & unknown protein & 0,269 & 0,701 & 0,277 & 0,600 & 38 & 0,285 & 0,687 & 0,284 & 0,604 \\
\hline AT4G04730.1 & unknown protein & 0,302 & 0,677 & 0,293 & 0,605 & 38 & 0,285 & 0,687 & 0,284 & 0,604 \\
\hline AT4G32630.2 & $\begin{array}{l}\text { ArfGap/RecO-like } \\
\text { zinc finger domain- } \\
\text { containing protein }\end{array}$ & 0,310 & 0,688 & 0,301 & 0,583 & 38 & 0,285 & 0,687 & 0,284 & 0,604 \\
\hline AT4G38490.1 & unknown protein & 0,288 & 0,669 & 0,316 & 0,608 & 38 & 0,285 & 0,687 & 0,284 & 0,604 \\
\hline AT5G06820.1 & $\begin{array}{c}\text { SRF2 } \\
\text { STRUBBELIG- } \\
\text { receptor family } 2 \\
\end{array}$ & 0,325 & 0,688 & 0,296 & 0,577 & 38 & 0,285 & 0,687 & 0,284 & 0,604 \\
\hline AT5G14890.1 & $\begin{array}{c}\mathrm{NHL} \text { domain- } \\
\text { containing protein }\end{array}$ & 0,271 & 0,699 & 0,270 & 0,605 & 38 & 0,285 & 0,687 & 0,284 & 0,604 \\
\hline AT5G20935.1 & unknown protein & 0,282 & 0,664 & 0,306 & 0,621 & 38 & 0,285 & 0,687 & 0,284 & 0,604 \\
\hline AT5G60380.1 & $\begin{array}{l}\text { Protein of Unknown } \\
\text { Function (DUF239) }\end{array}$ & 0,291 & 0,685 & 0,247 & 0,620 & 38 & 0,285 & 0,687 & 0,284 & 0,604 \\
\hline AT5G66110.1 & $\begin{array}{l}\text { HIPP27 Heavy metal } \\
\text { transport/detoxificatio } \\
\text { n superfamily protein }\end{array}$ & 0,284 & 0,698 & 0,266 & 0,601 & 38 & 0,285 & 0,687 & 0,284 & 0,604 \\
\hline AT1G18990.1 & $\begin{array}{l}\text { Protein of unknown } \\
\text { function DUF593 }\end{array}$ & 0,274 & 0,686 & 0,202 & 0,643 & 39 & 0,261 & 0,660 & 0,246 & 0,658 \\
\hline AT1G74830.1 & $\begin{array}{l}\text { Protein of unknown } \\
\text { function DUF593 }\end{array}$ & 0,256 & 0,678 & 0,185 & 0,664 & 39 & 0,261 & 0,660 & 0,246 & 0,658 \\
\hline AT2G23170.1 & $\begin{array}{l}\text { GH3.3 Auxin- } \\
\text { responsive GH3 } \\
\text { family protein }\end{array}$ & 0,277 & 0,629 & 0,265 & 0,677 & 39 & 0,261 & 0,660 & 0,246 & 0,658 \\
\hline AT2G32235.1 & unknown protein & 0,292 & 0,652 & 0,258 & 0,651 & 39 & 0,261 & 0,660 & 0,246 & 0,658 \\
\hline AT2G35640.1 & $\begin{array}{l}\text { Homeodomain-like } \\
\text { superfamily protein }\end{array}$ & 0,297 & 0,676 & 0,238 & 0,630 & 39 & 0,261 & 0,660 & 0,246 & 0,658 \\
\hline AT2G36800.1 & $\begin{array}{c}\text { DOGT1 UGT73C5 } \\
\text { don- } \\
\text { glucosyltransferase 1 }\end{array}$ & 0,263 & 0,630 & 0,255 & 0,684 & 39 & 0,261 & 0,660 & 0,246 & 0,658 \\
\hline AT3G09240.1 & $\begin{array}{c}\text { Protein kinase protein } \\
\text { with tetratricopeptide } \\
\text { repeat domain }\end{array}$ & 0,281 & 0,647 & 0,262 & 0,659 & 39 & 0,261 & 0,660 & 0,246 & 0,658 \\
\hline AT3G51910.1 & $\begin{array}{c}\text { AT-HSFA7A HSFA7A } \\
\text { heat shock } \\
\text { transcription factor } \\
\text { A7A } \\
\end{array}$ & 0,259 & 0,636 & 0,273 & 0,674 & 39 & 0,261 & 0,660 & 0,246 & 0,658 \\
\hline AT3G54280.1 & $\begin{array}{c}\text { CHR16 CHA16 } \\
\text { RGD3 ATBTAF1 } \\
\text { BTAF1 } \\
\end{array}$ & 0,237 & 0,679 & 0,226 & 0,657 & 39 & 0,261 & 0,660 & 0,246 & 0,658 \\
\hline AT3G56790.1 & $\begin{array}{l}\text { RNA splicing factor- } \\
\text { related }\end{array}$ & 0,237 & 0,633 & 0,210 & 0,707 & 39 & 0,261 & 0,660 & 0,246 & 0,658 \\
\hline
\end{tabular}


Anhang

\begin{tabular}{|c|c|c|c|c|c|c|c|c|c|c|}
\hline AT3G62350.1 & $\begin{array}{c}\text { BEST Arabidopsis } \\
\text { thaliana protein } \\
\text { match: F-box family } \\
\text { protein } \\
\text { (TAIR:AT1G71320.1) }\end{array}$ & 0,306 & 0,657 & 0,251 & 0,642 & 39 & 0,261 & 0,660 & 0,246 & 0,658 \\
\hline AT4G38215.1 & other RNA & 0,214 & 0,683 & 0,285 & 0,637 & 39 & 0,261 & 0,660 & 0,246 & 0,658 \\
\hline AT4G38480.1 & $\begin{array}{l}\text { Transducin/WD40 } \\
\text { repeat-like } \\
\text { superfamily protein }\end{array}$ & 0,218 & 0,702 & 0,238 & 0,635 & 39 & 0,261 & 0,660 & 0,246 & 0,658 \\
\hline AT5G45110.1 & $\begin{array}{c}\text { NPR3 ATNPR3 } \\
\text { NPR1-like protein } 3\end{array}$ & 0,242 & 0,652 & 0,299 & 0,654 & 39 & 0,261 & 0,660 & 0,246 & 0,658 \\
\hline AT1G05560.1 & $\begin{array}{c}\text { UGT1 UGT75B1 } \\
\text { UDP- } \\
\text { glucosyltransferase } \\
\text { 75B1 }\end{array}$ & 0,196 & 0,722 & 0,141 & 0,648 & 40 & 0,135 & 0,719 & 0,119 & 0,668 \\
\hline AT1G30455.1 & $\begin{array}{c}\text { transcription } \\
\text { regulators;translation } \\
\text { initiation factors;zinc } \\
\text { ion } \\
\text { binding;transcription } \\
\text { activators } \\
\end{array}$ & 0,186 & 0,678 & 0,117 & 0,701 & 40 & 0,135 & 0,719 & 0,119 & 0,668 \\
\hline AT1G48560.1 & unknown protein & 0,099 & 0,658 & 0,085 & 0,742 & 40 & 0,135 & 0,719 & 0,119 & 0,668 \\
\hline AT1G62886.1 & $\begin{array}{c}\text { Nucleotide excision } \\
\text { repair TFIlH subunit } \\
\text { TTDA } \\
\end{array}$ & 0,105 & 0,753 & 0,092 & 0,643 & 40 & 0,135 & 0,719 & 0,119 & 0,668 \\
\hline AT1G78995.1 & unknown protein & 0,097 & 0,731 & 0,095 & 0,669 & 40 & 0,135 & 0,719 & 0,119 & 0,668 \\
\hline AT2G05720.1 & $\begin{array}{l}\text { Transducin/WD40 } \\
\text { repeat-like } \\
\text { superfamily protein } \\
\end{array}$ & 0,079 & 0,770 & 0,082 & 0,628 & 40 & 0,135 & 0,719 & 0,119 & 0,668 \\
\hline AT2G40925.1 & $\begin{array}{c}\text { F-box and associated } \\
\text { interaction domains- } \\
\text { containing protein } \\
\end{array}$ & 0,138 & 0,733 & 0,149 & 0,649 & 40 & 0,135 & 0,719 & 0,119 & 0,668 \\
\hline AT4G29880.1 & $\begin{array}{c}\text { PIRL7 plant } \\
\text { intracellular ras } \\
\text { group-related LRR } 7 \\
\end{array}$ & 0,128 & 0,756 & 0,098 & 0,634 & 40 & 0,135 & 0,719 & 0,119 & 0,668 \\
\hline AT5G53470.1 & $\begin{array}{l}\text { ACBP1 ACBP acyl- } \\
\text { CoA binding protein } 1\end{array}$ & 0,166 & 0,704 & 0,182 & 0,666 & 40 & 0,135 & 0,719 & 0,119 & 0,668 \\
\hline AT5G59160.1 & $\begin{array}{c}\text { TOPP2 PPO type } \\
\text { one serine/threonine } \\
\text { protein phosphatase } \\
2 \\
\end{array}$ & 0,159 & 0,683 & 0,146 & 0,698 & 40 & 0,135 & 0,719 & 0,119 & 0,668 \\
\hline AT1G18265.1 & $\begin{array}{l}\text { Protein of unknown } \\
\text { function DUF593 }\end{array}$ & 0,194 & 0,739 & 0,192 & 0,616 & 41 & 0,169 & 0,759 & 0,172 & 0,603 \\
\hline AT1G19540.1 & $\begin{array}{c}\text { NmrA-like negative } \\
\text { transcriptional } \\
\text { regulator family } \\
\text { protein } \\
\end{array}$ & 0,191 & 0,751 & 0,142 & 0,616 & 41 & 0,169 & 0,759 & 0,172 & 0,603 \\
\hline AT1G30473.1 & $\begin{array}{c}\text { Heavy metal } \\
\text { transport/detoxificatio } \\
\mathrm{n} \text { superfamily protein }\end{array}$ & 0,172 & 0,748 & 0,185 & 0,614 & 41 & 0,169 & 0,759 & 0,172 & 0,603 \\
\hline AT5G14270.1 & $\begin{array}{c}\text { ATBET9 BET9 } \\
\text { bromodomain and } \\
\text { extraterminal domain } \\
\text { protein } 9 \\
\end{array}$ & 0,119 & 0,799 & 0,170 & 0,565 & 41 & 0,169 & 0,759 & 0,172 & 0,603 \\
\hline AT1G26800.1 & $\begin{array}{c}\text { RING/U-box } \\
\text { superfamily protein }\end{array}$ & 0,264 & 0,758 & 0,266 & 0,534 & 42 & 0,295 & 0,759 & 0,251 & 0,519 \\
\hline AT1G33030.1 & $\begin{array}{c}\text { O-methyltransferase } \\
\text { family protein }\end{array}$ & 0,375 & 0,751 & 0,253 & 0,481 & 42 & 0,295 & 0,759 & 0,251 & 0,519 \\
\hline AT1G50190.1 & $\begin{array}{l}\text { Cysteine/Histidine- } \\
\text { rich C1 domain family } \\
\text { protein } \\
\end{array}$ & 0,317 & 0,720 & 0,271 & 0,555 & 42 & 0,295 & 0,759 & 0,251 & 0,519 \\
\hline AT2G01100.1 & unknown protein & 0,273 & 0,755 & 0,241 & 0,545 & 42 & 0,295 & 0,759 & 0,251 & 0,519 \\
\hline AT3G14735.1 & U6-1 U6-1; snRNA & 0,346 & 0,725 & 0,256 & 0,537 & 42 & 0,295 & 0,759 & 0,251 & 0,519 \\
\hline AT3G45730.1 & unknown protein & 0,300 & 0,764 & 0,278 & 0,499 & 42 & 0,295 & 0,759 & 0,251 & 0,519 \\
\hline AT3G51760.1 & $\begin{array}{l}\text { Protein of unknown } \\
\text { function (DUF688) }\end{array}$ & 0,270 & 0,795 & 0,272 & 0,470 & 42 & 0,295 & 0,759 & 0,251 & 0,519 \\
\hline AT4G10410.1 & $\begin{array}{l}\text { Leucine-rich repeat } \\
\text { (LRR) family protein }\end{array}$ & 0,270 & 0,818 & 0,191 & 0,470 & 42 & 0,295 & 0,759 & 0,251 & 0,519 \\
\hline
\end{tabular}


Anhang

\begin{tabular}{|c|c|c|c|c|c|c|c|c|c|c|}
\hline AT4G14368.1 & $\begin{array}{c}\text { Regulator of } \\
\text { chromosome } \\
\text { condensation (RCC1) } \\
\text { family protein } \\
\end{array}$ & 0,287 & 0,769 & 0,210 & 0,532 & 42 & 0,295 & 0,759 & 0,251 & 0,519 \\
\hline AT4G27652.1 & unknown protein & 0,217 & 0,760 & 0,248 & 0,560 & 42 & 0,295 & 0,759 & 0,251 & 0,519 \\
\hline AT5G07880.1 & $\begin{array}{l}\text { SNAP29 ATSNAP29 } \\
\text { synaptosomal- } \\
\text { associated protein } \\
\text { SNAP25-like } 29 \\
\end{array}$ & 0,306 & 0,748 & 0,312 & 0,499 & 42 & 0,295 & 0,759 & 0,251 & 0,519 \\
\hline AT5G58120.1 & $\begin{array}{l}\text { Disease resistance } \\
\text { protein (TIR-NBS- } \\
\text { LRR class) family }\end{array}$ & 0,350 & 0,711 & 0,267 & 0,549 & 42 & 0,295 & 0,759 & 0,251 & 0,519 \\
\hline AT5G66045.1 & $\begin{array}{c}\text { MIR170 MIR170; } \\
\text { miRNA }\end{array}$ & 0,257 & 0,792 & 0,201 & 0,517 & 42 & 0,295 & 0,759 & 0,251 & 0,519 \\
\hline AT1G10820.1 & $\begin{array}{l}\text { Protein of unknown } \\
\text { function (DUF3755) }\end{array}$ & 0,144 & 0,860 & 0,312 & 0,378 & 43 & 0,190 & 0,853 & 0,225 & 0,425 \\
\hline AT1G19115.1 & unknown protein & 0,214 & 0,843 & 0,193 & 0,453 & 43 & 0,190 & 0,853 & 0,225 & 0,425 \\
\hline AT1G62880.2 & $\begin{array}{c}\text { Cornichon family } \\
\text { protein }\end{array}$ & 0,184 & 0,826 & 0,212 & 0,489 & 43 & 0,190 & 0,853 & 0,225 & 0,425 \\
\hline AT3G01513.1 & unknown protein & 0,224 & 0,866 & 0,278 & 0,349 & 43 & 0,190 & 0,853 & 0,225 & 0,425 \\
\hline AT3G17340.1 & $\begin{array}{c}\text { ARM repeat } \\
\text { superfamily protein }\end{array}$ & 0,238 & 0,844 & 0,220 & 0,427 & 43 & 0,190 & 0,853 & 0,225 & 0,425 \\
\hline AT4G19080.1 & $\begin{array}{l}\text { Protein of unknown } \\
\text { function (DUF594) }\end{array}$ & 0,151 & 0,882 & 0,190 & 0,403 & 43 & 0,190 & 0,853 & 0,225 & 0,425 \\
\hline AT5G07860.1 & $\begin{array}{c}\text { HXXXD-type acyl- } \\
\text { transferase family } \\
\text { protein }\end{array}$ & 0,212 & 0,844 & 0,231 & 0,436 & 43 & 0,190 & 0,853 & 0,225 & 0,425 \\
\hline AT5G64240.1 & $\begin{array}{c}\text { AtMC3 MC3 } \\
\text { metacaspase } 3 \\
\end{array}$ & 0,155 & 0,856 & 0,162 & 0,466 & 43 & 0,190 & 0,853 & 0,225 & 0,425 \\
\hline AT1G02880.1 & $\begin{array}{c}\text { TPK1 thiamin } \\
\text { pyrophosphokinase1 }\end{array}$ & 0,286 & 0,748 & 0,354 & 0,483 & 44 & 0,299 & 0,777 & 0,351 & 0,421 \\
\hline AT1G23460.1 & $\begin{array}{l}\text { Pectin lyase-like } \\
\text { superfamily protein }\end{array}$ & 0,351 & 0,779 & 0,326 & 0,403 & 44 & 0,299 & 0,777 & 0,351 & 0,421 \\
\hline AT2G19310.1 & $\begin{array}{c}\text { HSP20-like } \\
\text { chaperones } \\
\text { superfamily protein }\end{array}$ & 0,322 & 0,772 & 0,361 & 0,413 & 44 & 0,299 & 0,777 & 0,351 & 0,421 \\
\hline AT3G01510.1 & LSF1 like SEX4 1 & 0,278 & 0,787 & 0,327 & 0,443 & 44 & 0,299 & 0,777 & 0,351 & 0,421 \\
\hline AT4G03510.1 & $\begin{array}{l}\text { RMA1 ATRMA1 } \\
\text { RING membrane- } \\
\text { anchor } 1\end{array}$ & 0,331 & 0,763 & 0,321 & 0,452 & 44 & 0,299 & 0,777 & 0,351 & 0,421 \\
\hline AT4G14040.1 & $\begin{array}{c}\text { EDA38 SBP2 } \\
\text { selenium-binding } \\
\text { protein } 2 \\
\end{array}$ & 0,290 & 0,767 & 0,377 & 0,431 & 44 & 0,299 & 0,777 & 0,351 & 0,421 \\
\hline AT4G27654.1 & unknown protein & 0,295 & 0,819 & 0,274 & 0,409 & 44 & 0,299 & 0,777 & 0,351 & 0,421 \\
\hline AT4G27657.1 & unknown protein & 0,345 & 0,787 & 0,304 & 0,411 & 44 & 0,299 & 0,777 & 0,351 & 0,421 \\
\hline AT4G28790.2 & $\begin{array}{l}\text { basic helix-loop-helix } \\
\text { (bHLH) DNA-binding } \\
\text { superfamily protein }\end{array}$ & 0,306 & 0,721 & 0,412 & 0,467 & 44 & 0,299 & 0,777 & 0,351 & 0,421 \\
\hline AT4G29850.1 & $\begin{array}{c}\text { Eukaryotic protein of } \\
\text { unknown function } \\
\text { (DUF872) }\end{array}$ & 0,209 & 0,772 & 0,399 & 0,448 & 44 & 0,299 & 0,777 & 0,351 & 0,421 \\
\hline AT5G07900.1 & $\begin{array}{l}\text { Mitochondrial } \\
\text { transcription } \\
\text { termination factor } \\
\text { family protein }\end{array}$ & 0,289 & 0,816 & 0,329 & 0,378 & 44 & 0,299 & 0,777 & 0,351 & 0,421 \\
\hline AT5G16300.2 & $\begin{array}{l}\text { Vps51/Vps67 family } \\
\text { (components of } \\
\text { vesicular transport) } \\
\text { protein } \\
\end{array}$ & 0,288 & 0,797 & 0,429 & 0,313 & 44 & 0,299 & 0,777 & 0,351 & 0,421 \\
\hline AT1G01720.1 & ATAF1 ANAC002 & 0,388 & 0,817 & 0,156 & 0,396 & 45 & 0,365 & 0,827 & 0,260 & 0,329 \\
\hline AT1G75270.1 & $\begin{array}{c}\text { DHAR2 } \\
\text { dehydroascorbate } \\
\text { reductase } 2\end{array}$ & 0,363 & 0,847 & 0,297 & 0,250 & 45 & 0,365 & 0,827 & 0,260 & 0,329 \\
\hline AT3G14660.1 & $\begin{array}{c}\text { CYP72A13 } \\
\text { cytochrome P450 } \\
\text { family } 72 \text { subfamily A } \\
\text { polypeptide } 13\end{array}$ & 0,394 & 0,841 & 0,224 & 0,295 & 45 & 0,365 & 0,827 & 0,260 & 0,329 \\
\hline
\end{tabular}


Anhang

\begin{tabular}{|c|c|c|c|c|c|c|c|c|c|c|}
\hline AT3G56980.1 & $\begin{array}{c}\text { BHLH039 ORG3 } \\
\text { basic helix-loop-helix } \\
\text { (bHLH) DNA-binding } \\
\text { superfamily protein } \\
\end{array}$ & 0,357 & 0,809 & 0,298 & 0,359 & 45 & 0,365 & 0,827 & 0,260 & 0,329 \\
\hline AT4G14030.1 & $\begin{array}{l}\text { SBP1 selenium- } \\
\text { binding protein } 1\end{array}$ & 0,339 & 0,832 & 0,326 & 0,293 & 45 & 0,365 & 0,827 & 0,260 & 0,329 \\
\hline AT4G19880.3 & $\begin{array}{c}\text { Glutathione S- } \\
\text { transferase family } \\
\text { protein }\end{array}$ & 0,372 & 0,830 & 0,216 & 0,355 & 45 & 0,365 & 0,827 & 0,260 & 0,329 \\
\hline AT4G36040.1 & $\begin{array}{c}\text { Chaperone DnaJ- } \\
\text { domain superfamily } \\
\text { protein }\end{array}$ & 0,343 & 0,831 & 0,284 & 0,333 & 45 & 0,365 & 0,827 & 0,260 & 0,329 \\
\hline AT4G36052.1 & other RNA & 0,316 & 0,850 & 0,288 & 0,308 & 45 & 0,365 & 0,827 & 0,260 & 0,329 \\
\hline AT5G13080.1 & $\begin{array}{c}\text { WRKY75 } \\
\text { ATWRKY75 WRKY } \\
\text { DNA-binding protein } \\
75\end{array}$ & 0,411 & 0,823 & 0,235 & 0,314 & 45 & 0,365 & 0,827 & 0,260 & 0,329 \\
\hline AT5G48400.1 & $\begin{array}{c}\text { ATGLR1.2 GLR1.2 } \\
\text { Glutamate receptor } \\
\text { family protein }\end{array}$ & 0,405 & 0,795 & 0,137 & 0,431 & 45 & 0,365 & 0,827 & 0,260 & 0,329 \\
\hline AT5G57010.1 & $\begin{array}{l}\text { calmodulin-binding } \\
\text { family protein }\end{array}$ & 0,376 & 0,804 & 0,323 & 0,328 & 45 & 0,365 & 0,827 & 0,260 & 0,329 \\
\hline AT5G61800.1 & $\begin{array}{l}\text { Pentatricopeptide } \\
\text { repeat (PPR) } \\
\text { superfamily protein }\end{array}$ & 0,344 & 0,819 & 0,328 & 0,320 & 45 & 0,365 & 0,827 & 0,260 & 0,329 \\
\hline AT5G66985.1 & unknown protein & 0,339 & 0,854 & 0,262 & 0,295 & 45 & 0,365 & 0,827 & 0,260 & 0,329 \\
\hline AT1G17170.1 & $\begin{array}{c}\text { ATGSTU24 GST } \\
\text { GSTU24 glutathione } \\
\text { S-transferase TAU } 24\end{array}$ & 0,369 & 0,881 & 0,175 & 0,240 & 46 & 0,367 & 0,883 & 0,168 & 0,237 \\
\hline AT1G21680.1 & $\begin{array}{c}\text { DPP6 N-terminal } \\
\text { domain-like protein }\end{array}$ & 0,360 & 0,890 & 0,170 & 0,224 & 46 & 0,367 & 0,883 & 0,168 & 0,237 \\
\hline AT1G77450.1 & $\begin{array}{c}\text { anac032 NAC032 } \\
\text { NAC domain } \\
\text { containing protein } 32\end{array}$ & 0,392 & 0,871 & 0,166 & 0,245 & 46 & 0,367 & 0,883 & 0,168 & 0,237 \\
\hline AT2G29480.1 & $\begin{array}{l}\text { ATGSTU2 GST20 } \\
\text { GSTU2 glutathione } \\
\text { S-transferase tau } 2\end{array}$ & 0,345 & 0,896 & 0,160 & 0,231 & 46 & 0,367 & 0,883 & 0,168 & 0,237 \\
\hline AT2G29490.1 & $\begin{array}{c}\text { ATGSTU1 GST19 } \\
\text { GSTU1 glutathione } \\
\text { S-transferase TAU } 1 \\
\end{array}$ & 0,389 & 0,890 & 0,151 & 0,184 & 46 & 0,367 & 0,883 & 0,168 & 0,237 \\
\hline AT5G64250.2 & $\begin{array}{c}\text { Aldolase-type TIM } \\
\text { barrel family protein }\end{array}$ & 0,344 & 0,870 & 0,187 & 0,298 & 46 & 0,367 & 0,883 & 0,168 & 0,237 \\
\hline AT1G17147.1 & $\begin{array}{l}\text { VQ motif-containing } \\
\text { protein }\end{array}$ & 0,283 & 0,907 & 0,181 & 0,254 & 47 & 0,226 & 0,933 & 0,171 & 0,211 \\
\hline AT1G76600.1 & unknown protein & 0,195 & 0,957 & 0,128 & 0,175 & 47 & 0,226 & 0,933 & 0,171 & 0,211 \\
\hline AT1G79710.1 & $\begin{array}{c}\text { Major facilitator } \\
\text { superfamily protein }\end{array}$ & 0,271 & 0,901 & 0,229 & 0,252 & 47 & 0,226 & 0,933 & 0,171 & 0,211 \\
\hline AT3G04140.1 & $\begin{array}{c}\text { Ankyrin repeat family } \\
\text { protein }\end{array}$ & 0,216 & 0,928 & 0,202 & 0,226 & 47 & 0,226 & 0,933 & 0,171 & 0,211 \\
\hline AT3G28740.1 & $\begin{array}{c}\text { CYP81D1 } \\
\text { Cytochrome P450 } \\
\text { superfamily protein }\end{array}$ & 0,204 & 0,961 & 0,120 & 0,142 & 47 & 0,226 & 0,933 & 0,171 & 0,211 \\
\hline AT4G19880.2 & $\begin{array}{c}\text { Glutathione S- } \\
\text { transferase family } \\
\text { protein }\end{array}$ & 0,274 & 0,942 & 0,128 & 0,149 & 47 & 0,226 & 0,933 & 0,171 & 0,211 \\
\hline AT4G34135.1 & $\begin{array}{c}\text { UGT73B2 UDP- } \\
\text { glucosyltransferase } \\
\text { 73B2 } \\
\end{array}$ & 0,249 & 0,926 & 0,214 & 0,187 & 47 & 0,226 & 0,933 & 0,171 & 0,211 \\
\hline AT5G05410.1 & $\begin{array}{c}\text { DREB2A DREB2 } \\
\text { DRE-binding protein } \\
2 \mathrm{~A} \\
\end{array}$ & 0,200 & 0,927 & 0,183 & 0,259 & 47 & 0,226 & 0,933 & 0,171 & 0,211 \\
\hline AT5G14470.1 & $\begin{array}{l}\text { GHMP kinase family } \\
\text { protein }\end{array}$ & 0,173 & 0,953 & 0,153 & 0,196 & 47 & 0,226 & 0,933 & 0,171 & 0,211 \\
\hline AT5G14730.1 & unknown protein & 0,197 & 0,928 & 0,171 & 0,266 & 47 & 0,226 & 0,933 & 0,171 & 0,211 \\
\hline AT1G76680.2 & $\begin{array}{c}\text { OPR1 12- } \\
\text { oxophytodienoate } \\
\text { reductase } 1\end{array}$ & 0,234 & 0,906 & 0,165 & 0,312 & 48 & 0,229 & 0,899 & 0,160 & 0,333 \\
\hline AT1G76690.1 & $\begin{array}{l}\text { OPR2 ATOPR2 12- } \\
\text { oxophytodienoate } \\
\text { reductase } 2\end{array}$ & 0,263 & 0,895 & 0,207 & 0,294 & 48 & 0,229 & 0,899 & 0,160 & 0,333 \\
\hline
\end{tabular}


Anhang

\begin{tabular}{|c|c|c|c|c|c|c|c|c|c|c|}
\hline AT2G15490.3 & $\begin{array}{c}\text { UGT73B4 UDP- } \\
\text { glycosyltransferase } \\
\text { 73B4 } \\
\end{array}$ & 0,298 & 0,882 & 0,146 & 0,335 & 48 & 0,229 & 0,899 & 0,160 & 0,333 \\
\hline AT4G19095.1 & unknown protein & 0,206 & 0,896 & 0,176 & 0,352 & 48 & 0,229 & 0,899 & 0,160 & 0,333 \\
\hline AT4G19645.2 & $\begin{array}{l}\text { TRAM LAG1 and } \\
\text { CLN8 (TLC) lipid- } \\
\text { sensing domain } \\
\text { containing protein }\end{array}$ & 0,198 & 0,899 & 0,129 & 0,369 & 48 & 0,229 & 0,899 & 0,160 & 0,333 \\
\hline AT5G05410.2 & $\begin{array}{c}\text { DREB2A DREB2 } \\
\text { DRE-binding protein } \\
2 A \\
\end{array}$ & 0,222 & 0,909 & 0,183 & 0,302 & 48 & 0,229 & 0,899 & 0,160 & 0,333 \\
\hline AT5G08790.1 & ATAF2 anac081 & 0,199 & 0,910 & 0,122 & 0,342 & 48 & 0,229 & 0,899 & 0,160 & 0,333 \\
\hline AT5G59820.1 & $\begin{array}{c}\text { RHL41 ZAT12 } \\
\text { C2H2-type zinc finger } \\
\text { family protein } \\
\end{array}$ & 0,211 & 0,898 & 0,155 & 0,354 & 48 & 0,229 & 0,899 & 0,160 & 0,333 \\
\hline AT1G23450.1 & $\begin{array}{c}\text { Tetratricopeptide } \\
\text { repeat (TPR)-like } \\
\text { superfamily protein } \\
\end{array}$ & 0,100 & 0,950 & 0,104 & 0,277 & 49 & 0,123 & 0,930 & 0,090 & 0,328 \\
\hline AT1G28480.1 & $\begin{array}{c}\text { GRX480 roxy19 } \\
\text { Thioredoxin } \\
\text { superfamily protein }\end{array}$ & 0,099 & 0,895 & 0,072 & 0,429 & 49 & 0,123 & 0,930 & 0,090 & 0,328 \\
\hline AT4G15550.1 & $\begin{array}{l}\text { IAGLU indole-3- } \\
\text { acetate beta-D- } \\
\text { glucosyltransferase }\end{array}$ & 0,169 & 0,927 & 0,064 & 0,329 & 49 & 0,123 & 0,930 & 0,090 & 0,328 \\
\hline AT4G19110.3 & $\begin{array}{c}\text { Protein kinase } \\
\text { superfamily protein }\end{array}$ & 0,130 & 0,945 & 0,137 & 0,266 & 49 & 0,123 & 0,930 & 0,090 & 0,328 \\
\hline AT5G07870.1 & $\begin{array}{c}\text { HXXXD-type acyl- } \\
\text { transferase family } \\
\text { protein }\end{array}$ & 0,103 & 0,909 & 0,107 & 0,388 & 49 & 0,123 & 0,930 & 0,090 & 0,328 \\
\hline AT5G35688.1 & unknown protein & 0,101 & 0,947 & 0,100 & 0,289 & 49 & 0,123 & 0,930 & 0,090 & 0,328 \\
\hline AT5G63790.1 & $\begin{array}{l}\text { ANAC102 NAC102 } \\
\text { NAC domain } \\
\text { containing protein } \\
102 \\
\end{array}$ & 0,156 & 0,935 & 0,048 & 0,316 & 49 & 0,123 & 0,930 & 0,090 & 0,328 \\
\hline AT2G29420.1 & $\begin{array}{l}\text { ATGSTU7 GST25 } \\
\text { GSTU7 glutathione } \\
\text { S-transferase tau } 7 \\
\end{array}$ & 0,058 & 0,990 & 0,029 & 0,125 & 50 & 0,077 & 0,982 & 0,056 & 0,149 \\
\hline AT2G47895.1 & other RNA & 0,100 & 0,971 & 0,112 & 0,184 & 50 & 0,077 & 0,982 & 0,056 & 0,149 \\
\hline AT3G04130.2 & $\begin{array}{c}\text { Tetratricopeptide } \\
\text { repeat (TPR)-like } \\
\text { superfamily protein }\end{array}$ & 0,093 & 0,985 & 0,082 & 0,123 & 50 & 0,077 & 0,982 & 0,056 & 0,149 \\
\hline AT4G19865.1 & $\begin{array}{c}\text { Galactose } \\
\text { oxidase/kelch repeat } \\
\text { superfamily protein } \\
\end{array}$ & 0,040 & 0,980 & 0,044 & 0,188 & 50 & 0,077 & 0,982 & 0,056 & 0,149 \\
\hline AT4G19870.1 & $\begin{array}{c}\text { Galactose } \\
\text { oxidase/kelch repeat } \\
\text { superfamily protein } \\
\end{array}$ & 0,059 & 0,982 & 0,042 & 0,172 & 50 & 0,077 & 0,982 & 0,056 & 0,149 \\
\hline AT4G19870.2 & $\begin{array}{c}\text { Galactose } \\
\text { oxidase/kelch repeat } \\
\text { superfamily protein } \\
\end{array}$ & 0,037 & 0,974 & 0,059 & 0,217 & 50 & 0,077 & 0,982 & 0,056 & 0,149 \\
\hline AT4G34131.1 & $\begin{array}{c}\text { UGT73B3 UDP- } \\
\text { glucosyl transferase } \\
\text { 73B3 }\end{array}$ & 0,093 & 0,989 & 0,033 & 0,108 & 50 & 0,077 & 0,982 & 0,056 & 0,149 \\
\hline AT4G34135.2 & $\begin{array}{c}\text { UGT73B2 UDP- } \\
\text { glucosyltransferase } \\
\text { 73B2 }\end{array}$ & 0,138 & 0,986 & 0,049 & 0,077 & 50 & 0,077 & 0,982 & 0,056 & 0,149 \\
\hline
\end{tabular}


Tabelle 6.7: Liste der 620 in den Genotypen Col-0 und sc/14/33 unterschiedlich exprimierten Gene aus der MarVis Analyse

Normalized Profile gibt die Relative Expression der einzelnen Gene unter den angegebenen Bedingungen an. PrototypeProfile gibt die durchschnittliche Relative Expression der Gene in einem Prototyp an. Die Cluster Number entspricht der Nummer des Prototyps, in den die Gene eingeordnet wurden.

\begin{tabular}{|c|c|c|c|c|c|c|c|c|c|c|}
\hline \multirow[t]{2}{*}{ AGI-Code } & \multirow[t]{2}{*}{ Beschreibung } & \multicolumn{3}{|c|}{ NormalizedProfile } & \multirow[b]{2}{*}{$\begin{array}{l}s c / 14 / 33 \\
\text { Kontr. }\end{array}$} & \multirow[t]{2}{*}{$\begin{array}{l}\text { Cluster } \\
\text { Number }\end{array}$} & \multicolumn{4}{|c|}{ PrototypeProfile } \\
\hline & & $\begin{array}{c}\text { Col-0 } \\
\text { SA }\end{array}$ & $\begin{array}{l}\text { Col-0 } \\
\text { Kontr. }\end{array}$ & $\begin{array}{l}s c / 14 / 33 \\
\text { SA }\end{array}$ & & & $\begin{array}{c}\text { Col-0 } \\
\text { SA }\end{array}$ & $\begin{array}{l}\text { Col-0 } \\
\text { Kontr. }\end{array}$ & $\begin{array}{l}s c / 14 / 33 \\
\text { SA }\end{array}$ & $\begin{array}{l}s c / 14 / 33 \\
\text { Kontr. }\end{array}$ \\
\hline AT4G34135.2 & $\begin{array}{c}\text { UGT73B2 UDP- } \\
\text { glucosyltransferase 73B2 }\end{array}$ & 0,138 & 0,986 & 0,049 & 0,077 & 1 & 0,077 & 0,982 & 0,056 & 0,149 \\
\hline AT4G34131.1 & $\begin{array}{l}\text { UGT73B3 UDP-glucosyl } \\
\text { transferase 73B3 }\end{array}$ & 0,093 & 0,989 & 0,033 & 0,108 & 1 & 0,077 & 0,982 & 0,056 & 0,149 \\
\hline AT2G29420.1 & $\begin{array}{l}\text { ATGSTU7 GST25 GSTU7 } \\
\text { glutathione S-transferase } \\
\text { tau } 7\end{array}$ & 0,058 & 0,990 & 0,029 & 0,125 & 1 & 0,077 & 0,982 & 0,056 & 0,149 \\
\hline AT3G04130.2 & $\begin{array}{l}\text { Tetratricopeptide repeat } \\
\text { (TPR)-like superfamily } \\
\text { protein }\end{array}$ & 0,093 & 0,985 & 0,082 & 0,123 & 1 & 0,077 & 0,982 & 0,056 & 0,149 \\
\hline AT4G19870.1 & $\begin{array}{l}\text { Galactose } \\
\text { repeat supe }\end{array}$ & 0,059 & 0,982 & 0,042 & 0,172 & 1 & 0,077 & 0,982 & 0,056 & 0,149 \\
\hline AT4G19865.1 & $\begin{array}{l}\text { Galactose oxidase/kelch } \\
\text { repeat superfamily protein }\end{array}$ & 0,040 & 0,980 & 0,044 & 0,188 & 1 & 0,077 & 0,982 & 0,056 & 0,149 \\
\hline AT2G47895.1 & other RNA & 0,100 & 0,971 & 0,112 & 0,184 & 1 & 0,077 & 0,982 & 0,056 & 0,149 \\
\hline AT4G19870.2 & $\begin{array}{l}\text { Galactose ox } \\
\text { repeat superf }\end{array}$ & 0,037 & 0,974 & 0,059 & 0,217 & 1 & 0,077 & 0,982 & 0,056 & 0,149 \\
\hline AT4G19880.2 & $\begin{array}{r}\text { Glutathione } S \\
\text { family } \mathrm{P}\end{array}$ & 0,274 & 0,942 & 0,128 & 0,149 & 2 & 0,211 & 0,953 & 0,132 & 0,165 \\
\hline AT3G28740.1 & $\begin{array}{l}\text { CYP81D1 Cytochrome } \\
\text { P450 superfamily protein }\end{array}$ & 0,204 & 0,961 & 0,120 & 0,142 & 2 & 0,211 & 0,953 & 0,132 & 0,165 \\
\hline AT1G76600.1 & unknown protein & 0,195 & 0,957 & 0,128 & 0,175 & 2 & 0,211 & 0,953 & 0,132 & 0,165 \\
\hline AT5G14470.1 & GHMP kinase family protein & 0,173 & 0,953 & 0,153 & 0,196 & 2 & 0,211 & 0,953 & 0,132 &, 165 \\
\hline AT1G23450.1 & $\begin{array}{l}\text { Tetratricopeptide repeat } \\
\text { (TPR)-like superfamily } \\
\text { protein }\end{array}$ & 0,100 & 0,950 & 0,104 & 0,277 & 3 & 0,126 & 0,934 & 0,084 & 0,320 \\
\hline AT5G35688.1 & unknown protein & 101 & 947 & 210 & 0,289 & 2 & 126 &, 934 & 0,084 & 0,320 \\
\hline 790.1 & $\begin{array}{c}\text { ANAC102 NAC102 NAC } \\
\text { domain containing protein } \\
102 \\
\end{array}$ & 0,156 & 0,935 & 0,048 & 6 & 3 & 0,126 & 0,934 & 0,084 & ,320 \\
\hline AT4G15550.1 & $\begin{array}{r}\text { IAGLU indol } \\
\text { beta-D-glucos }\end{array}$ & 0,169 & 0,927 & 0,064 & 0,329 & 3 & 0,126 & 0,934 & 0,084 & 0,320 \\
\hline AT5G07870.1 & $\begin{array}{c}\text { HXXXD-type acyl- } \\
\text { transferase family protein }\end{array}$ & 0,103 & 0,909 & 0,107 & 0,388 & 3 & 0,126 & 0,934 & 0,084 & 0,320 \\
\hline AT5G05410.2 & $\begin{array}{l}\text { DREB2A DREB2 DRE- } \\
\text { binding protein } 2 \mathrm{~A} \\
\end{array}$ & 222 & 909 & 0 & 0,302 & 4 & 0,215 & 0,898 & 158 & 346 \\
\hline AT1G76680.2 & $\begin{array}{c}\text { OPR1 12- } \\
\text { oxophytodienoate reductase } \\
1\end{array}$ & 0,234 & 0,906 & 0,165 & 0,312 & 4 & 0,215 & 0,898 & 0,158 & 0,346 \\
\hline AT5G08790.1 & ATAF2 anac081 & 0,199 & 0,910 & 0,122 & 0,342 & 4 & 0,215 & 0,898 & 158 & 0,346 \\
\hline AT5G59820.1 & $\begin{array}{l}\text { RHL41 ZAT12 C2H2-type } \\
\text { zinc finger family protein }\end{array}$ & 0,211 & 0,898 & 0,155 & 0,354 & 4 & 0,215 & 0,898 & 0,158 & 0,346 \\
\hline AT4G19095.1 & unknown protein & 0,206 & 0,896 & 0,176 & 0,352 & 4 & 0,215 & \begin{tabular}{|l|}
0,898 \\
\end{tabular} & 0,158 & 0,346 \\
\hline AT2G15490.3 & $\begin{array}{r}\text { UGT7 } \\
\text { glycosyltre }\end{array}$ & 0,298 & 0,882 & 0,146 & 0,335 & 4 & 0,215 & 0,898 & 0,158 & 0,346 \\
\hline AT4G19645.2 & $\begin{array}{c}\text { TRAM LAG1 and CLN8 } \\
\text { (TLC) lipid-sensing domain } \\
\text { containing protein }\end{array}$ & 0,198 & 0,899 & 0,129 & 0,369 & 4 & 0,215 & 0,898 & 0,158 & 0,346 \\
\hline AT4G19080.1 & $\begin{array}{c}\text { Protein of unknown function } \\
\text { (DUF594) }\end{array}$ & 0,151 & 0,882 & 0,190 & 403 & 4 & 0,215 & 0,898 & 0,158 & 0,346 \\
\hline AT4G34135.1 & $\begin{array}{c}\text { UGT73B2 UDP- } \\
\text { glucosyltransferase 73B2 }\end{array}$ & 0,249 & 0,926 & 0,214 & 0,187 & 5 & 0,243 & 0,907 & 0,212 & 0,261 \\
\hline AT3G04140.1 & $\begin{array}{c}\text { Ankyrin repeat family } \\
\text { protein }\end{array}$ & 0,216 & 0,928 & 0,202 & 0,226 & 5 & 0,243 & 0,907 & 0,212 & 0,261 \\
\hline G79710.1 & $\begin{array}{l}\text { Major facilitator superfamily } \\
\text { protein }\end{array}$ & 0,271 & 0,901 & 0,229 & 0,252 & 5 & 0,243 & 0,907 & 0,212 & 0,261 \\
\hline
\end{tabular}




\begin{tabular}{|c|c|c|c|c|c|c|c|c|c|c|}
\hline AT1G17147.1 & VQ motif-containing protein & 0,283 & 0,907 & 0,181 & 0,254 & 5 & 0,243 & 0,907 & 0,212 & 0,261 \\
\hline AT5G14730.1 & unknown protein & 0,197 & 0,928 & 0,171 & 0,266 & 5 & 0,243 & 0,907 & 0,212 & 0,261 \\
\hline AT1G76690.1 & $\begin{array}{c}\text { OPR2 ATOPR2 12- } \\
\text { oxophytodienoate reductase } \\
2 \\
\end{array}$ & 0,263 & 0,895 & 0,207 & 0,294 & 5 & 0,243 & 0,907 & 0,212 & 0,261 \\
\hline AT3G01513.1 & unknown protein & 0,224 & 0,866 & 0,278 & 0,349 & 5 & 0,243 & 0,907 & 0,212 & 0,261 \\
\hline AT2G29490.1 & $\begin{array}{c}\text { ATGSTU1 GST19 GSTU1 } \\
\text { glutathione S-transferase } \\
\text { TAU } 1 \\
\end{array}$ & 0,389 & 0,890 & 0,151 & 0,184 & 6 & 0,367 & 0,883 & 0,168 & 0,237 \\
\hline AT1G21680.1 & $\begin{array}{l}\text { DPP6 N-terminal domain- } \\
\text { like protein }\end{array}$ & 0,360 & 0,890 & 0,170 & 0,224 & 6 & 0,367 & 0,883 & 0,168 & 0,237 \\
\hline AT2G29480.1 & $\begin{array}{c}\text { ATGSTU2 GST20 GSTU2 } \\
\text { glutathione S-transferase } \\
\text { tau } 2 \\
\end{array}$ & 0,345 & 0,896 & 0,160 & 0,231 & 6 & 0,367 & 0,883 & 0,168 & 0,237 \\
\hline AT1G17170.1 & $\begin{array}{c}\text { ATGSTU24 GST GSTU24 } \\
\text { glutathione S-transferase } \\
\text { TAU } 24 \\
\end{array}$ & 0,369 & 0,881 & 0,175 & 0,240 & 6 & 0,367 & 0,883 & 0,168 & 0,237 \\
\hline AT1G77450.1 & $\begin{array}{c}\text { anac032 NAC032 NAC } \\
\text { domain containing protein } \\
32 \\
\end{array}$ & 0,392 & 0,871 & 0,166 & 0,245 & 6 & 0,367 & 0,883 & 0,168 & 0,237 \\
\hline AT5G64250.2 & $\begin{array}{c}\text { Aldolase-type TIM barrel } \\
\text { family protein }\end{array}$ & 0,344 & 0,870 & 0,187 & 0,298 & 6 & 0,367 & 0,883 & 0,168 & 0,237 \\
\hline AT1G75270.1 & $\begin{array}{l}\text { DHAR2 dehydroascorbate } \\
\text { reductase } 2\end{array}$ & 0,363 & 0,847 & 0,297 & 0,250 & 7 & 0,336 & 0,826 & 0,317 & 0,318 \\
\hline AT4G14030.1 & $\begin{array}{l}\text { SBP1 selenium-binding } \\
\text { protein } 1\end{array}$ & 0,339 & 0,832 & 0,326 & 0,293 & 7 & 0,336 & 0,826 & 0,317 & 0,318 \\
\hline AT5G66985.1 & unknown protein & 0,339 & 0,854 & 0,262 & 0,295 & 7 & 0,336 & 0,826 & 0,317 & 0,318 \\
\hline AT4G36052.1 & other RNA & 0,316 & 0,850 & 0,288 & 0,308 & 7 & 0,336 & 0,826 & 0,317 & 0,318 \\
\hline AT5G16300.2 & $\begin{array}{l}\text { Vps51/Vps67 family } \\
\text { (components of vesicular } \\
\text { transport) protein }\end{array}$ & 0,288 & 0,797 & 0,429 & 0,313 & 7 & 0,336 & 0,826 & 0,317 & 0,318 \\
\hline AT4G36040.1 & $\begin{array}{c}\text { Chaperone DnaJ-domain } \\
\text { superfamily protein }\end{array}$ & 0,343 & 0,831 & 0,284 & 0,333 & 7 & 0,336 & 0,826 & 0,317 & 0,318 \\
\hline AT5G61800.1 & $\begin{array}{l}\text { Pentatricopeptide repeat } \\
\text { (PPR) superfamily protein }\end{array}$ & 0,344 & 0,819 & 0,328 & 0,320 & 7 & 0,336 & 0,826 & 0,317 & 0,318 \\
\hline AT5G57010.1 & $\begin{array}{l}\text { calmodulin-binding family } \\
\text { protein }\end{array}$ & 0,376 & 0,804 & 0,323 & 0,328 & 7 & 0,336 & 0,826 & 0,317 & 0,318 \\
\hline AT3G56980.1 & $\begin{array}{l}\text { BHLH039 ORG3 basic } \\
\text { helix-loop-helix (bHLH) } \\
\text { DNA-binding superfamily } \\
\text { protein } \\
\end{array}$ & 0,357 & 0,809 & 0,298 & 0,359 & 7 & 0,336 & 0,826 & 0,317 & 0,318 \\
\hline AT5G07900.1 & $\begin{array}{c}\text { Mitochondrial transcription } \\
\text { termination factor family } \\
\text { protein } \\
\end{array}$ & 0,289 & 0,816 & 0,329 & 0,378 & 7 & 0,336 & 0,826 & 0,317 & 0,318 \\
\hline AT5G61820.1 & unknown & 0,507 & 0,829 & 0,136 & 0,192 & 8 & 0,433 & 0,817 & 0,204 & 0,309 \\
\hline AT1G60730.2 & $\begin{array}{c}\mathrm{NAD}(\mathrm{P}) \text {-linked } \\
\begin{array}{c}\text { oxidoreductase superfamily } \\
\text { protein }\end{array} \\
\end{array}$ & 0,498 & 0,811 & 0,201 & 0,230 & 8 & 0,433 & 0,817 & 0,204 & 0,309 \\
\hline AT4G01870.1 & tolB protein-related & 0,431 & 0,842 & 0,183 & 0,267 & 8 & 0,433 & 0,817 & 0,204 & 0,309 \\
\hline AT2G15480.2 & $\begin{array}{l}\text { UGT73B5 UDP-glucosyl } \\
\text { transferase 73B5 }\end{array}$ & 0,435 & 0,822 & 0,254 & 0,265 & 8 & 0,433 & 0,817 & 0,204 & 0,309 \\
\hline AT3G14660.1 & $\begin{array}{c}\text { CYP72A13 cytochrome } \\
\text { P450 family } 72 \text { subfamily A } \\
\text { polypeptide } 13\end{array}$ & 0,394 & 0,841 & 0,224 & 0,295 & 8 & 0,433 & 0,817 & 0,204 & 0,309 \\
\hline AT2G05400.2 & $\begin{array}{l}\text { Ubiquitin-specific protease } \\
\text { family C19-related protein }\end{array}$ & 0,484 & 0,802 & 0,181 & 0,299 & 8 & 0,433 & 0,817 & 0,204 & 0,309 \\
\hline AT5G13080.1 & $\begin{array}{c}\text { WRKY75 ATWRKY75 } \\
\text { WRKY DNA-binding protein } \\
75 \\
\end{array}$ & 0,411 & 0,823 & 0,235 & 0,314 & 8 & 0,433 & 0,817 & 0,204 & 0,309 \\
\hline AT1G78380.1 & $\begin{array}{c}\text { ATGSTU19 GST8 GSTU19 } \\
\text { glutathione S-transferase } \\
\text { TAU } 19\end{array}$ & 0,441 & 0,793 & 0,246 & 0,341 & 8 & 0,433 & 0,817 & 0,204 & 0,309 \\
\hline AT4G02380.1 & $\begin{array}{c}\text { SAG21 AtLEA5 } \\
\text { senescence-associated } \\
\text { gene } 21 \\
\end{array}$ & 0,434 & 0,795 & 0,275 & 0,322 & 8 & 0,433 & 0,817 & 0,204 & 0,309 \\
\hline AT4G19880.3 & $\begin{array}{c}\text { Glutathione S-transferase } \\
\text { family protein }\end{array}$ & 0,372 & 0,830 & 0,216 & 0,355 & 8 & 0,433 & 0,817 & 0,204 & 0,309 \\
\hline AT1G01720.1 & ATAF1 ANAC002 & 0,388 & 0,817 & 0,156 & 0,396 & 8 & 0,433 & 0,817 & 0,204 & 0,309 \\
\hline AT5G48400.1 & $\begin{array}{c}\text { ATGLR1.2 GLR1.2 } \\
\text { Glutamate receptor family }\end{array}$ & 0,405 & 0,795 & 0,137 & 0,431 & 8 & 0,433 & 0,817 & 0,204 & 0,309 \\
\hline
\end{tabular}


Anhang

\begin{tabular}{|c|c|c|c|c|c|c|c|c|c|c|}
\hline & protein & & & & & & & & & \\
\hline AT1G78340.1 & $\begin{array}{c}\text { ATGSTU22 GSTU22 } \\
\text { glutathione S-transferase } \\
\text { TAU } 22 \\
\end{array}$ & 0,489 & 0,792 & 0,276 & 0,240 & 9 & 0,519 & 0,750 & 0,258 & 0,313 \\
\hline AT2G02930.1 & $\begin{array}{c}\text { ATGSTF3 GST16 GSTF3 } \\
\text { glutathione S-transferase } \\
\text { F3 }\end{array}$ & 0,551 & 0,761 & 0,213 & 0,270 & 9 & 0,519 & 0,750 & 0,258 & 0,313 \\
\hline AT2G47890.2 & $\begin{array}{l}\text { B-box type zinc finger } \\
\text { protein with CCT domain }\end{array}$ & 0,531 & 0,739 & 0,301 & 0,286 & 9 & 0,519 & 0,750 & 0,258 & 0,313 \\
\hline AT3G44300.1 & NIT2 AtNIT2 nitrilase 2 & 0,475 & 0,766 & 0,307 & 0,306 & 9 & 0,519 & 0,750 & 0,258 & 0,313 \\
\hline AT1G68620.1 & $\begin{array}{l}\text { alpha/beta-Hydrolases } \\
\text { superfamily protein }\end{array}$ & 0,539 & 0,748 & 0,230 & 0,311 & 9 & 0,519 & 0,750 & 0,258 & 0,313 \\
\hline AT2G05400.1 & $\begin{array}{l}\text { Ubiquitin-specific protease } \\
\text { family C19-related protein }\end{array}$ & 0,538 & 0,755 & 0,227 & 0,300 & 9 & 0,519 & 0,750 & 0,258 & 0,313 \\
\hline AT5G13750.3 & $\begin{array}{l}\text { ZIFL1 zinc induced } \\
\text { facilitator-like } 1\end{array}$ & 0,496 & 0,762 & 0,279 & 0,310 & 9 & 0,519 & 0,750 & 0,258 & 0,313 \\
\hline AT1G60730.3 & $\begin{array}{c}\mathrm{NAD}(\mathrm{P}) \text {-linked } \\
\text { oxidoreductase superfamily } \\
\text { protein } \\
\end{array}$ & 0,542 & 0,747 & 0,234 & 0,306 & 9 & 0,519 & 0,750 & 0,258 & 0,313 \\
\hline AT1G76520.2 & $\begin{array}{l}\text { Auxin efflux carrier family } \\
\text { protein }\end{array}$ & 0,541 & 0,735 & 0,266 & 0,310 & 9 & 0,519 & 0,750 & 0,258 & 0,313 \\
\hline AT1G79410.1 & $\begin{array}{c}\text { AtOCT5 5-Oct organic } \\
\text { cation/carnitine transporter5 }\end{array}$ & 0,557 & 0,721 & 0,267 & 0,314 & 9 & 0,519 & 0,750 & 0,258 & 0,313 \\
\hline AT2G33710.1 & $\begin{array}{c}\text { Integrase-type DNA-binding } \\
\text { superfamily protein }\end{array}$ & 0,539 & 0,719 & 0,302 & 0,318 & 9 & 0,519 & 0,750 & 0,258 & 0,313 \\
\hline AT1G02850.5 & $\begin{array}{c}\text { BGLU11 beta glucosidase } \\
11\end{array}$ & 0,496 & 0,768 & 0,217 & 0,344 & 9 & 0,519 & 0,750 & 0,258 & 0,313 \\
\hline AT4G13180.1 & $\begin{array}{l}\text { NAD(P)-binding Rossmann- } \\
\text { fold superfamily protein }\end{array}$ & 0,513 & 0,760 & 0,189 & 0,352 & 9 & 0,519 & 0,750 & 0,258 & 0,313 \\
\hline AT3G53480.1 & $\begin{array}{c}\text { PIS1 PDR9 ATPDR9 } \\
\text { ABCG37 pleiotropic drug } \\
\text { resistance } 9\end{array}$ & 0,487 & 0,739 & 0,293 & 0,363 & 9 & 0,519 & 0,750 & 0,258 & 0,313 \\
\hline AT3G14990.3 & $\begin{array}{c}\text { Class I glutamine } \\
\text { amidotransferase-like } \\
\text { superfamily protein }\end{array}$ & 0,496 & 0,740 & 0,265 & 0,368 & 9 & 0,519 & 0,750 & 0,258 & 0,313 \\
\hline AT3G45100.1 & $\begin{array}{c}\text { SETH2 UDP- } \\
\text { Glycosyltransferase } \\
\text { superfamily protein }\end{array}$ & 0,518 & 0,705 & 0,359 & 0,325 & 10 & 0,508 & 0,692 & 0,374 & 0,335 \\
\hline AT1G65690.1 & $\begin{array}{l}\text { Late embryogenesis } \\
\text { abundant (LEA) } \\
\text { hydroxyproline-rich } \\
\text { glycoprotein family }\end{array}$ & 0,556 & 0,685 & 0,338 & 0,327 & 10 & 0,508 & 0,692 & 0,374 & 0,335 \\
\hline AT4G37030.1 & unknown protein & 0,498 & 0,713 & 0,361 & 0,337 & 10 & 0,508 & 0,692 & 0,374 & 0,335 \\
\hline AT1G13520.1 & $\begin{array}{c}\text { Protein of unknown function } \\
\text { (DUF1262) }\end{array}$ & 0,566 & 0,663 & 0,363 & 0,329 & 10 & 0,508 & 0,692 & 0,374 & 0,335 \\
\hline AT4G23880.1 & unknown protein & 0,418 & 0,738 & 0,385 & 0,365 & 10 & 0,508 & 0,692 & 0,374 & 0,335 \\
\hline AT1G53850.1 & $\begin{array}{c}\text { PAE1 ATPAE1 20S } \\
\text { proteasome alpha subunit } \\
\text { E1 }\end{array}$ & 0,576 & 0,660 & 0,364 & 0,317 & 10 & 0,508 & 0,692 & 0,374 & 0,335 \\
\hline AT5G22140.2 & $\begin{array}{l}\text { FAD/NAD(P)-binding } \\
\text { oxidoreductase family } \\
\text { protein } \\
\end{array}$ & 0,443 & 0,750 & 0,333 & 0,361 & 10 & 0,508 & 0,692 & 0,374 & 0,335 \\
\hline AT4G24160.2 & $\begin{array}{l}\text { alpha/beta-Hydrolases } \\
\text { superfamily protein }\end{array}$ & 0,522 & 0,712 & 0,315 & 0,349 & 10 & 0,508 & 0,692 & 0,374 & 0,335 \\
\hline AT1G69600.1 & $\begin{array}{c}\text { ZFHD1 ATHB29 ZHD11 } \\
\text { zinc finger homeodomain } 1\end{array}$ & 0,570 & 0,666 & 0,349 & 0,332 & 10 & 0,508 & 0,692 & 0,374 & 0,335 \\
\hline AT5G08350.1 & $\begin{array}{c}\text { GRAM domain-containing } \\
\text { protein / ABA-responsive } \\
\text { protein-related } \\
\end{array}$ & 0,412 & 0,633 & 0,577 & 0,312 & 10 & 0,508 & 0,692 & 0,374 & 0,335 \\
\hline AT4G25400.1 & $\begin{array}{l}\text { basic helix-loop-helix } \\
\text { (bHLH) DNA-binding } \\
\text { superfamily protein }\end{array}$ & 0,656 & 0,658 & 0,287 & 0,233 & 11 & 0,612 & 0,677 & 0,287 & 0,286 \\
\hline AT1G18970.1 & GLP4 germin-like protein 4 & 0,586 & 0,719 & 0,264 & 0,264 & 11 & 0,612 & 0,677 & 0,287 & 0,286 \\
\hline AT3G21260.2 & $\begin{array}{l}\text { GLTP3 Glycolipid transfer } \\
\text { protein (GLTP) family } \\
\text { protein } \\
\end{array}$ & 0,576 & 0,693 & 0,338 & 0,272 & 11 & 0,612 & 0,677 & 0,287 & 0,286 \\
\hline AT5G13320.1 & $\begin{array}{c}\text { PBS3 GDG1 WIN3 GH3.12 } \\
\text { Auxin-responsive GH3 } \\
\text { family protein } \\
\end{array}$ & 0,628 & 0,686 & 0,266 & 0,253 & 11 & 0,612 & 0,677 & 0,287 & 0,286 \\
\hline AT1G21120.1 & $\begin{array}{c}\text { O-methyltransferase family } \\
\text { protein }\end{array}$ & 0,638 & 0,658 & 0,304 & 0,261 & 11 & 0,612 & 0,677 & 0,287 & 0,286 \\
\hline
\end{tabular}




\begin{tabular}{|c|c|c|c|c|c|c|c|c|c|c|}
\hline AT3G23560.1 & $\begin{array}{l}\text { ALF5 MATE efflux family } \\
\text { protein }\end{array}$ & 0,597 & 0,696 & 0,273 & 0,290 & 11 & 0,612 & 0,677 & 0,287 & 0,286 \\
\hline AT1G58320.1 & PLAC8 family protein & 0,631 & 0,671 & 0,257 & 0,292 & 11 & 0,612 & 0,677 & 0,287 & 0,286 \\
\hline AT1G13590.1 & $\begin{array}{c}\text { ATPSK1 PSK1 } \\
\text { phytosulfokine } 1 \text { precursor }\end{array}$ & 0,595 & 0,689 & 0,287 & 0,298 & 11 & 0,612 & 0,677 & 0,287 & 0,286 \\
\hline AT3G14075.1 & $\begin{array}{c}\text { Mono-/di-acylglycerol lipase } \\
\text { N-terminal;Lipase class } 3\end{array}$ & 0,655 & 0,658 & 0,226 & 0,295 & 11 & 0,612 & 0,677 & 0,287 & 0,286 \\
\hline AT5G26920.2 & $\begin{array}{l}\text { CBP60G Cam-binding } \\
\text { protein } 60 \text {-like G }\end{array}$ & 0,610 & 0,660 & 0,319 & 0,300 & 11 & 0,612 & 0,677 & 0,287 & 0,286 \\
\hline AT5G24090.1 & ATCHIA CHIA chitinase A & 0,582 & 0,687 & 0,300 & 0,315 & 11 & 0,612 & 0,677 & 0,287 & 0,286 \\
\hline AT5G45380.1 & $\begin{array}{l}\text { ATDUR3 DUR3 } \\
\text { solute:sodium } \\
\text { symporters;urea } \\
\text { transmembrane } \\
\text { transporters }\end{array}$ & 0,600 & 0,664 & 0,312 & 0,320 & 11 & 0,612 & 0,677 & 0,287 & 0,286 \\
\hline AT1G67810.1 & SUFE2 sulfur E2 & 0,599 & 0,666 & 0,302 & 0,327 & 11 & 0,612 & 0,677 & 0,287 & 0,286 \\
\hline AT3G25190.1 & $\begin{array}{c}\text { Vacuolar iron transporter } \\
\text { (VIT) family protein }\end{array}$ & 0,610 & 0,754 & 0,153 & 0,191 & 12 & 0,619 & 0,719 & 0,218 & 0,223 \\
\hline AT2G15480.1 & $\begin{array}{l}\text { UGT73B5 UDP-glucosyl } \\
\text { transferase 73B5 }\end{array}$ & 0,607 & 0,734 & 0,244 & 0,183 & 12 & 0,619 & 0,719 & 0,218 & 0,223 \\
\hline AT4G34138.1 & $\begin{array}{l}\text { UGT73B1 UDP-glucosyl } \\
\text { transferase 73B1 }\end{array}$ & 0,632 & 0,710 & 0,215 & 0,224 & 12 & 0,619 & 0,719 & 0,218 & 0,223 \\
\hline AT5G06860.1 & $\begin{array}{c}\text { PGIP1 ATPGIP1 } \\
\text { polygalacturonase inhibiting } \\
\text { protein } 1\end{array}$ & 0,611 & 0,735 & 0,190 & 0,223 & 12 & 0,619 & 0,719 & 0,218 & 0,223 \\
\hline AT3G09270.1 & $\begin{array}{c}\text { ATGSTU8 GSTU8 } \\
\text { glutathione S-transferase } \\
\text { TAU } 8 \\
\end{array}$ & 0,627 & 0,699 & 0,248 & 0,238 & 12 & 0,619 & 0,719 & 0,218 & 0,223 \\
\hline AT2G25000.1 & $\begin{array}{c}\text { WRKY60 ATWRKY60 } \\
\text { WRKY DNA-binding protein } \\
60 \\
\end{array}$ & 0,622 & 0,704 & 0,229 & 0,256 & 12 & 0,619 & 0,719 & 0,218 & 0,223 \\
\hline AT3G06435.1 & Expressed protein & 0,623 & 0,700 & 0,247 & 0,246 & 12 & 0,619 & 0,719 & 0,218 & 0,223 \\
\hline AT1G07530.1 & $\begin{array}{l}\text { SCL14 ATGRAS2 GRAS2 } \\
\text { SCARECROW-like } 14\end{array}$ & 0,653 & 0,756 & 0,031 & 0,033 & 13 & 0,705 & 0,701 & 0,048 & 0,061 \\
\hline AT3G01345.1 & Expressed protein & 0,756 & 0,645 & 0,066 & 0,088 & 13 & 0,705 & 0,701 & 0,048 & 0,061 \\
\hline AT1G26390.1 & $\begin{array}{l}\text { FAD-binding Berberine } \\
\text { family protein }\end{array}$ & 0,676 & 0,627 & 0,319 & 0,221 & 14 & 0,706 & 0,596 & 0,269 & 0,261 \\
\hline AT3G28345.1 & $\begin{array}{l}\text { ABC transporter family } \\
\text { protein } \\
\end{array}$ & 0,765 & 0,581 & 0,177 & 0,212 & 14 & 0,706 & 0,596 & 0,269 & 0,261 \\
\hline AT2G35980.1 & YLS9 NHL10 ATNHL10 & 0,736 & 0,565 & 0,307 & 0,210 & 14 & 0,706 & 0,596 & 0,269 & 0,261 \\
\hline AT2G05510.6 & Glycine-rich protein family & 0,718 & 0,612 & 0,218 & 0,248 & 14 & 0,706 & 0,596 & 0,269 & 0,261 \\
\hline AT3G01970.1 & $\begin{array}{c}\text { WRKY45 ATWRKY45 } \\
\text { WRKY DNA-binding protein } \\
45\end{array}$ & 0,683 & 0,634 & 0,240 & 0,272 & 14 & 0,706 & 0,596 & 0,269 & 0,261 \\
\hline AT3G27940.1 & $\begin{array}{l}\text { LBD26 LOB domain- } \\
\text { containing protein } 26 \\
\end{array}$ & 0,672 & 0,617 & 0,312 & 0,267 & 14 & 0,706 & 0,596 & 0,269 & 0,261 \\
\hline AT3G47480.1 & $\begin{array}{c}\text { Calcium-binding EF-hand } \\
\text { family protein }\end{array}$ & 0,690 & 0,580 & 0,348 & 0,260 & 14 & 0,706 & 0,596 & 0,269 & 0,261 \\
\hline AT1G53625.1 & unknown protein & 0,680 & 0,612 & 0,293 & 0,278 & 14 & 0,706 & 0,596 & 0,269 & 0,261 \\
\hline AT5G34940.2 & $\begin{array}{l}\text { AtGUS3 GUS3 } \\
\text { glucuronidase } 3\end{array}$ & 0,690 & 0,600 & 0,279 & 0,294 & 14 & 0,706 & 0,596 & 0,269 & 0,261 \\
\hline AT3G50970.1 & $\begin{array}{l}\text { LTI30 XERO2 dehydrin } \\
\text { family protein }\end{array}$ & 0,708 & 0,581 & 0,279 & 0,289 & 14 & 0,706 & 0,596 & 0,269 & 0,261 \\
\hline AT1G67980.1 & $\begin{array}{c}\text { CCOAMT caffeoyl-CoA 3- } \\
\text { O-methyltransferase }\end{array}$ & 0,750 & 0,546 & 0,183 & 0,325 & 14 & 0,706 & 0,596 & 0,269 & 0,261 \\
\hline AT5G57220.1 & $\begin{array}{c}\text { CYP81F2 cytochrome } \\
\text { P450 family } 81 \text { subfamily F } \\
\text { polypeptide } 2 \\
\end{array}$ & 0,659 & 0,611 & 0,324 & 0,296 & 15 & 0,666 & 0,574 & 0,317 & 0,351 \\
\hline AT2G47485.1 & unknown protein & 0,637 & 0,601 & 0,380 & 0,298 & 15 & 0,666 & 0,574 & 0,317 & 0,351 \\
\hline AT3G29780.1 & RALFL27 ralf-like 27 & 0,656 & 0,602 & 0,316 & 0,328 & 15 & 0,666 & 0,574 & 0,317 & 0,351 \\
\hline AT5G25260.1 & $\begin{array}{c}\text { SPFH/Band 7/PHB domain- } \\
\text { containing membrane- } \\
\text { associated protein family } \\
\end{array}$ & 0,643 & 0,617 & 0,302 & 0,339 & 15 & 0,666 & 0,574 & 0,317 & 0,351 \\
\hline AT2G19900.1 & $\begin{array}{l}\text { ATNADP-ME1 NADP-ME1 } \\
\text { NADP-malic enzyme } 1\end{array}$ & 0,652 & 0,606 & 0,293 & 0,349 & 15 & 0,666 & 0,574 & 0,317 & 0,351 \\
\hline AT2G29110.1 & $\begin{array}{c}\text { ATGLR2.8 GLR2.8 } \\
\text { glutamate receptor } 2.8\end{array}$ & 0,686 & 0,566 & 0,322 & 0,324 & 15 & 0,666 & 0,574 & 0,317 & 0,351 \\
\hline AT4G02280.1 & $\begin{array}{c}\text { SUS3 ATSUS3 sucrose } \\
\text { synthase } 3 \\
\end{array}$ & 0,679 & 0,565 & 0,313 & 0,349 & 15 & 0,666 & 0,574 & 0,317 & 0,351 \\
\hline
\end{tabular}


Anhang

\begin{tabular}{|c|c|c|c|c|c|c|c|c|c|c|}
\hline AT2G29065.1 & $\begin{array}{l}\text { GRAS family transcription } \\
\text { factor }\end{array}$ & 0,656 & 0,591 & 0,287 & 0,371 & 15 & 0,666 & 0,574 & 0,317 & 0,351 \\
\hline AT5G03545.1 & AT4 ATIPS2 & 0,692 & 0,563 & 0,276 & 0,357 & 15 & 0,666 & 0,574 & 0,317 & 0,351 \\
\hline AT2G47270.1 & $\begin{array}{l}\text { UPB1 sequence-specific } \\
\text { DNA binding transcription } \\
\text { factors;transcription } \\
\text { regulators }\end{array}$ & 0,711 & 0,503 & 0,339 & 0,356 & 15 & 0,666 & 0,574 & 0,317 & 0,351 \\
\hline AT2G15830.1 & unknown protein & 0,681 & 0,533 & 0,338 & 0,371 & 15 & 0,666 & 0,574 & 0,317 & 0,351 \\
\hline AT4G03723.1 & $\begin{array}{l}\text { BEST Arabidopsis thaliana } \\
\text { protein match: zinc ion } \\
\text { binding } \\
\text { (TAIR:AT4G04775.1) }\end{array}$ & 0,636 & 0,525 & 0,311 & 0,472 & 15 & 0,666 & 0,574 & 0,317 & 0,351 \\
\hline AT5G46845.1 & $\begin{array}{c}\text { MIR160C MIR160 } \\
\text { MIR160/MIR160C } \\
\text { (MICRORNA160); miRNA }\end{array}$ & 0,676 & 0,501 & 0,498 & 0,212 & 16 & 0,676 & 0,501 & 0,498 & 0,212 \\
\hline AT2G42850.1 & $\begin{array}{c}\text { CYP718 cytochrome P450 } \\
\text { family } 718\end{array}$ & 0,789 & 0,447 & 0,335 & 0,257 & 17 & 0,777 & 0,465 & 0,321 & 0,277 \\
\hline AT3G46340.1 & $\begin{array}{c}\text { Leucine-rich repeat protein } \\
\text { kinase family protein }\end{array}$ & 0,765 & 0,482 & 0,307 & 0,297 & 17 & 0,777 & 0,465 & 0,321 & 0,277 \\
\hline AT4G28040.4 & $\begin{array}{l}\text { nodulin MtN21 /EamA-like } \\
\text { transporter family protein }\end{array}$ & 0,806 & 0,405 & 0,375 & 0,217 & 18 & 0,807 & 0,359 & 0,362 & 0,290 \\
\hline AT4G13390.1 & $\begin{array}{c}\text { Proline-rich extensin-like } \\
\text { family protein } \\
\end{array}$ & 0,811 & 0,373 & 0,370 & 0,258 & 18 & 0,807 & 0,359 & 0,362 & 0,290 \\
\hline AT3G29639.1 & unknown protein & 0,831 & 0,375 & 0,316 & 0,263 & 18 & 0,807 & 0,359 & 0,362 & 0,290 \\
\hline AT3G54580.1 & $\begin{array}{l}\text { Proline-rich extensin-like } \\
\text { family protein }\end{array}$ & 0,812 & 0,323 & 0,402 & 0,274 & 18 & 0,807 & 0,359 & 0,362 & 0,290 \\
\hline AT5G57530.1 & $\begin{array}{c}\text { XTH12 AtXTH12 } \\
\text { xyloglucan } \\
\text { endotransglucosylase/hydro } \\
\text { lase } 12 \\
\end{array}$ & 0,798 & 0,346 & 0,391 & 0,302 & 18 & 0,807 & 0,359 & 0,362 & 0,290 \\
\hline AT4G07960.1 & $\begin{array}{c}\text { ATCSLC12 CSLC12 } \\
\text { Cellulose-synthase-like C12 }\end{array}$ & 0,800 & 0,361 & 0,354 & 0,322 & 18 & 0,807 & 0,359 & 0,362 & 0,290 \\
\hline AT3G49960.1 & $\begin{array}{c}\text { Peroxidase superfamily } \\
\text { protein }\end{array}$ & 0,834 & 0,331 & 0,330 & 0,292 & 18 & 0,807 & 0,359 & 0,362 & 0,290 \\
\hline AT1G01560.1 & $\begin{array}{c}\text { ATMPK11 MPK11 MAP } \\
\text { kinase } 11\end{array}$ & 0,767 & 0,357 & 0,361 & 0,393 & 18 & 0,807 & 0,359 & 0,362 & 0,290 \\
\hline AT2G32840.1 & proline-rich family protein & 0,925 & 0,248 & 0,249 & 0,147 & 19 & 0,890 & 0,297 & 0,245 & 0,233 \\
\hline AT2G16430.1 & $\begin{array}{l}\text { PAP10 ATPAP10 purple } \\
\text { acid phosphatase } 10\end{array}$ & 0,882 & 0,344 & 0,206 & 0,247 & 19 & 0,890 & 0,297 & 0,245 & 0,233 \\
\hline AT2G18750.2 & Calmodulin-binding protein & 0,860 & 0,349 & 0,231 & 0,293 & 19 & 0,890 & 0,297 & 0,245 & 0,233 \\
\hline AT2G20520.1 & $\begin{array}{c}\text { FLA6 FASCICLIN-like } \\
\text { arabinogalactan } 6\end{array}$ & 0,912 & 0,252 & 0,247 & 0,208 & 19 & 0,890 & 0,297 & 0,245 & 0,233 \\
\hline AT4G28850.1 & $\begin{array}{c}\text { XTH26 ATXTH26 } \\
\text { xyloglucan } \\
\text { endotransglucosylase/hydro } \\
\text { lase } 26 \\
\end{array}$ & 0,870 & 0,292 & 0,291 & 0,270 & 19 & 0,890 & 0,297 & 0,245 & 0,233 \\
\hline AT4G38810.1 & $\begin{array}{c}\text { Calcium-binding EF-hand } \\
\text { family protein }\end{array}$ & 0,727 & 0,402 & 0,532 & 0,166 & 20 & 0,727 & 0,402 & 0,532 & 0,166 \\
\hline AT5G03240.2 & UBQ3 polyubiquitin 3 & 0,792 & 0,256 & 0,548 & 0,086 & 21 & 0,792 & 0,256 & 0,548 & 0,086 \\
\hline AT2G42130.1 & $\begin{array}{c}\text { Plastid-lipid associated } \\
\text { protein PAP / fibrillin family } \\
\text { protein } \\
\end{array}$ & 0,713 & 0,127 & 0,599 & 0,341 & 22 & 0,713 & 0,127 & 0,599 & 0,341 \\
\hline AT3G61898.1 & unknown protein & 0,621 & 0,149 & 0,699 & 0,321 & 23 & 0,664 & 0,081 & 0,692 & 0,252 \\
\hline AT3G01316.1 & snoRNA & 0,692 & 0,047 & 0,705 & 0,146 & 23 & 0,664 & 0,081 & 0,692 & 0,252 \\
\hline AT2G41430.3 & $\begin{array}{c}\text { ERD15 LSR1 CID1 } \\
\text { dehydration-induced protein } \\
\text { (ERD15) } \\
\end{array}$ & 0,708 & 0,063 & 0,678 & 0,189 & 23 & 0,664 & 0,081 & 0,692 & 0,252 \\
\hline AT2G30520.2 & $\begin{array}{c}\text { RPT2 Phototropic- } \\
\text { responsive NPH3 family } \\
\text { protein } \\
\end{array}$ & 0,636 & 0,064 & 0,684 & 0,351 & 23 & 0,664 & 0,081 & 0,692 & 0,252 \\
\hline AT3G58193.1 & snoRNA & 0,499 & 0,088 & 0,843 & 0,178 & 24 & 0,525 & 0,072 & 0,831 & 0,167 \\
\hline AT1G78206.1 & MIR775A MIR775a; miRNA & 0,551 & 0,056 & 0,818 & 0,156 & 24 & 0,525 & 0,072 & 0,831 & 0,167 \\
\hline AT3G41761.1 & other RNA & 0,518 & 0,167 & 0,741 & 0,393 & 25 & 0,463 & 0,124 & 0,810 & 0,313 \\
\hline AT4G36690.2 & $\begin{array}{l}\text { ATU2AF65A U2 snRNP } \\
\text { auxilliary factor large } \\
\text { subunit splicing factor }\end{array}$ & 0,407 & 0,082 & 0,879 & 0,233 & 25 & 0,463 & 0,124 & 0,810 & 0,313 \\
\hline AT1G65620.2 & $\begin{array}{c}\text { AS2 Lateral organ } \\
\text { boundaries (LOB) domain } \\
\text { family protein }\end{array}$ & 0,261 & 0,309 & 0,842 & 0,357 & 26 & 0,326 & 0,248 & 0,827 & 0,374 \\
\hline
\end{tabular}


Anhang

\begin{tabular}{|c|c|c|c|c|c|c|c|c|c|c|}
\hline AT5G47980.1 & $\begin{array}{c}\text { HXXXD-type acyl- } \\
\text { transferase family protein }\end{array}$ & 0,362 & 0,274 & 0,822 & 0,343 & 26 & 0,326 & 0,248 & 0,827 & 0,374 \\
\hline AT5G56030.1 & $\begin{array}{l}\text { HSP81-2 ERD8 HSP90.2 } \\
\text { AtHsp90.2 heat shock } \\
\text { protein } 81-2\end{array}$ & 0,306 & 0,272 & 0,829 & 0,380 & 26 & 0,326 & 0,248 & 0,827 & 0,374 \\
\hline AT4G03292.1 & $\begin{array}{c}\text { Polynucleotidyl transferase } \\
\text { ribonuclease } \mathrm{H} \text {-like } \\
\text { superfamily protein }\end{array}$ & 0,398 & 0,228 & 0,830 & 0,319 & 26 & 0,326 & 0,248 & 0,827 & 0,374 \\
\hline AT5G61420.1 & $\begin{array}{c}\text { MYB28 HAG1 AtMYB28 } \\
\text { PMG1 myb domain protein } \\
28 \\
\end{array}$ & 0,303 & 0,158 & 0,813 & 0,471 & 26 & 0,326 & 0,248 & 0,827 & 0,374 \\
\hline AT1G63380.2 & $\begin{array}{c}\text { NAD(P)-binding Rossmann- } \\
\text { fold superfamily protein }\end{array}$ & 0,289 & 0,533 & 0,736 & 0,301 & 27 & 0,321 & 0,420 & 0,795 & 0,280 \\
\hline AT2G28760.1 & $\begin{array}{c}\text { UXS6 UDP-XYL synthase } \\
6\end{array}$ & 0,319 & 0,390 & 0,829 & 0,243 & 27 & 0,321 & 0,420 & 0,795 & 0,280 \\
\hline AT3G13060.1 & \begin{tabular}{|c|} 
ECT5 evolutionarily \\
conserved C-terminal region \\
5 \\
\end{tabular} & 0,355 & 0,336 & 0,820 & 0,297 & 27 & 0,321 & 0,420 & 0,795 & 0,280 \\
\hline AT2G25880.1 & AtAUR2 AUR2 ataurora2 & 0,337 & 0,398 & 0,736 & 0,432 & 28 & 0,314 & 0,342 & 0,749 & 0,469 \\
\hline AT1G54440.1 & $\begin{array}{c}\text { Polynucleotidyl transferase } \\
\text { ribonuclease } \mathrm{H} \text { fold protein } \\
\text { with HRDC domain }\end{array}$ & 0,265 & 0,349 & 0,781 & 0,445 & 28 & 0,314 & 0,342 & 0,749 & 0,469 \\
\hline AT2G26150.2 & $\begin{array}{c}\text { ATHSFA2 HSFA2 heat } \\
\text { shock transcription factor } \\
\text { A2 } \\
\end{array}$ & 0,336 & 0,346 & 0,746 & 0,460 & 28 & 0,314 & 0,342 & 0,749 & 0,469 \\
\hline AT4G35790.1 & $\begin{array}{c}\text { ATPLDDELTA PLDDELTA } \\
\text { phospholipase D delta }\end{array}$ & 0,297 & 0,332 & 0,779 & 0,442 & 28 & 0,314 & 0,342 & 0,749 & 0,469 \\
\hline AT3G47540.1 & Chitinase family protein & 0,267 & 0,375 & 0,748 & 0,477 & 28 & 0,314 & 0,342 & 0,749 & 0,469 \\
\hline AT3G62760.1 & $\begin{array}{l}\text { ATGSTF13 Glutathione S- } \\
\text { transferase family protein } \\
\end{array}$ & 0,348 & 0,356 & 0,706 & 0,503 & 28 & 0,314 & 0,342 & 0,749 & 0,469 \\
\hline AT3G57490.1 & $\begin{array}{c}\text { Ribosomal protein S5 family } \\
\text { protein }\end{array}$ & 0,349 & 0,347 & 0,717 & 0,494 & 28 & 0,314 & 0,342 & 0,749 & 0,469 \\
\hline AT5G48000.5 & $\begin{array}{c}\text { CYP708A2 THAH THAH1 } \\
\text { cytochrome P450 family } \\
708 \text { subfamily A polypeptide } \\
2 \\
\end{array}$ & 0,257 & 0,311 & 0,804 & 0,437 & 28 & 0,314 & 0,342 & 0,749 & 0,469 \\
\hline AT4G15393.3 & $\begin{array}{c}\text { CYP702A5 cytochrome } \\
\text { P450 family } 702 \text { subfamily } \\
\text { A polypeptide } 5 \\
\end{array}$ & 0,341 & 0,293 & 0,770 & 0,452 & 28 & 0,314 & 0,342 & 0,749 & 0,469 \\
\hline AT5G59990.2 & CCT motif family protein & 0,345 & 0,326 & 0,725 & 0,499 & 28 & 0,314 & 0,342 & 0,749 & 0,469 \\
\hline AT5G52710.1 & $\begin{array}{l}\text { Copper transport protein } \\
\text { family }\end{array}$ & 0,314 & 0,325 & 0,725 & 0,520 & 28 & 0,314 & 0,342 & 0,749 & 0,469 \\
\hline AT5G33355.1 & $\begin{array}{c}\text { Defensin-like (DEFL) family } \\
\text { protein }\end{array}$ & 0,310 & 0,452 & 0,646 & 0,532 & 29 & 0,310 & 0,410 & 0,661 & 0,544 \\
\hline AT3G61400.1 & $\begin{array}{c}\text { 2-oxoglutarate (2OG) and } \\
\mathrm{Fe}(\mathrm{II}) \text {-dependent oxygenase } \\
\text { superfamily protein }\end{array}$ & 0,312 & 0,449 & 0,653 & 0,524 & 29 & 0,310 & 0,410 & 0,661 & 0,544 \\
\hline AT1G48510.1 & $\begin{array}{c}\text { Surfeit locus } 1 \text { cytochrome c } \\
\text { oxidase biogenesis protein }\end{array}$ & 0,303 & 0,457 & 0,622 & 0,559 & 29 & 0,310 & 0,410 & 0,661 & 0,544 \\
\hline AT4G31355.1 & unknown protein & 0,292 & 0,425 & 0,682 & 0,519 & 29 & 0,310 & 0,410 & 0,661 & 0,544 \\
\hline AT3G45720.1 & $\begin{array}{c}\text { Major facilitator superfamily } \\
\text { protein }\end{array}$ & 0,281 & 0,417 & 0,680 & 0,534 & 29 & 0,310 & 0,410 & 0,661 & 0,544 \\
\hline AT3G03190.1 & $\begin{array}{c}\text { ATGSTF11 ATGSTF6 } \\
\text { GSTF11 glutathione S- } \\
\text { transferase F11 }\end{array}$ & 0,337 & 0,374 & 0,687 & 0,524 & 29 & 0,310 & 0,410 & 0,661 & 0,544 \\
\hline AT1G09530.2 & $\begin{array}{c}\text { PIF3 POC1 PAP3 } \\
\text { phytochrome interacting } \\
\text { factor } 3\end{array}$ & 0,324 & 0,356 & 0,661 & 0,576 & 29 & 0,310 & 0,410 & 0,661 & 0,544 \\
\hline AT3G29250.2 & \begin{tabular}{|c|}
$\begin{array}{l}\text { NAD(P)-binding Rossmann- } \\
\text { fold superfamily protein }\end{array}$ \\
\end{tabular} & 0,322 & 0,352 & 0,660 & 0,581 & 29 & 0,310 & 0,410 & 0,661 & 0,544 \\
\hline AT4G17590.1 & unknown protein & 0,103 & 0,608 & 0,572 & 0,541 & 30 & 0,155 & 0,578 & 0,535 & 0,586 \\
\hline AT4G25450.2 & $\begin{array}{c}\text { ATNAP8 NAP8 non- } \\
\text { intrinsic ABC protein } 8 \\
\end{array}$ & 0,118 & 0,549 & 0,606 & 0,563 & 30 & 0,155 & 0,578 & 0,535 & 0,586 \\
\hline AT4G33650.1 & $\begin{array}{l}\text { ADL2 DRP3A dynamin- } \\
\text { related protein } 3 \mathrm{~A}\end{array}$ & 0,161 & 0,636 & 0,399 & 0,640 & 30 & 0,155 & 0,578 & 0,535 & 0,586 \\
\hline AT5G51440.1 & $\begin{array}{l}\text { HSP20-like chaperones } \\
\text { superfamily protein }\end{array}$ & 0,237 & 0,518 & 0,564 & 0,598 & 30 & 0,155 & 0,578 & 0,535 & 0,586 \\
\hline AT5G09710.1 & $\begin{array}{l}\text { Magnesium transporter } \\
\text { CorA-like family protein }\end{array}$ & 0,258 & 0,441 & 0,535 & 0,673 & 31 & 0,284 & 0,345 & 0,612 & 0,651 \\
\hline AT5G38100.2 & $\begin{array}{l}\text { S-adenosyl-L-methionine- } \\
\text { dependent }\end{array}$ & 0,292 & 0,344 & 0,657 & 0,605 & 31 & 0,284 & 0,345 & 0,612 & 0,651 \\
\hline
\end{tabular}




\begin{tabular}{|c|c|c|c|c|c|c|c|c|c|c|}
\hline & $\begin{array}{l}\text { methyltransferases } \\
\text { superfamily protein }\end{array}$ & & & & & & & & & \\
\hline AT1G15610.2 & unknown protein & 0,317 & 0,361 & 0,613 & 0,627 & 31 & 0,284 & 0,345 & 0,612 & 0,651 \\
\hline AT4G22212.1 & $\begin{array}{l}\text { Arabidopsis defensin-like } \\
\text { protein }\end{array}$ & 0,239 & 0,364 & 0,637 & 0,636 & 31 & 0,284 & 0,345 & 0,612 & 0,651 \\
\hline AT5G22555.1 & unknown protein & 0,298 & 0,366 & 0,614 & 0,632 & 31 & 0,284 & 0,345 & 0,612 & 0,651 \\
\hline AT5G14200.3 & $\begin{array}{l}\text { isopropylmalate } \\
\text { dehydrogenase } 1\end{array}$ & 0,311 & 0,345 & 0,641 & 0,611 & 31 & 0,284 & 0,345 & 0,612 & 0,651 \\
\hline AT4G30250.1 & $\begin{array}{c}\text { P-loop containing } \\
\text { nucleoside triphosphate } \\
\text { hydrolases superfamily } \\
\text { protein } \\
\end{array}$ & 0,278 & 0,377 & 0,569 & 0,676 & 31 & 0,284 & 0,345 & 0,612 & 0,651 \\
\hline AT2G43100.1 & $\begin{array}{c}\text { IPMI2 ATLEUD1 } \\
\text { isopropylmalate isomerase } \\
2 \\
\end{array}$ & 0,310 & 0,348 & 0,618 & 0,633 & 31 & 0,284 & 0,345 & 0,612 & 0,651 \\
\hline AT2G18193.1 & $\begin{array}{c}\text { P-loop containing } \\
\text { nucleoside triphosphate } \\
\text { hydrolases superfamily } \\
\text { protein }\end{array}$ & 0,291 & 0,356 & 0,610 & 0,646 & 31 & 0,284 & 0,345 & 0,612 & 0,651 \\
\hline AT3G62530.1 & $\begin{array}{l}\text { ARM repeat superfamily } \\
\text { protein }\end{array}$ & 0,296 & 0,349 & 0,605 & 0,651 & 31 & 0,284 & 0,345 & 0,612 & 0,651 \\
\hline AT3G23510.1 & $\begin{array}{l}\text { Cyclopropane-fatty-acyl- } \\
\text { phospholipid synthase }\end{array}$ & 0,304 & 0,340 & 0,620 & 0,638 & 31 & 0,284 & 0,345 & 0,612 & 0,651 \\
\hline AT3G58270.2 & \begin{tabular}{|c|} 
Arabidopsis phospholipase- \\
like protein (PEARLI 4) with \\
TRAF-like domain \\
\end{tabular} & 0,298 & 0,329 & 0,639 & 0,628 & 31 & 0,284 & 0,345 & 0,612 & 0,651 \\
\hline AT2G26370.1 & $\begin{array}{l}\text { MD-2-related lipid } \\
\text { recognition domain- } \\
\text { containing protein } \\
\end{array}$ & 0,296 & 0,325 & 0,634 & 0,637 & 31 & 0,284 & 0,345 & 0,612 & 0,651 \\
\hline AT1G65370.1 & TRAF-like family protein & 0,245 & 0,345 & 0,587 & 0,690 & 31 & 0,284 & 0,345 & 0,612 & 0,651 \\
\hline AT1G45015.2 & $\begin{array}{l}\text { MD-2-related lipid } \\
\text { recognition domain- } \\
\text { containing protein } \\
\end{array}$ & 0,313 & 0,323 & 0,628 & 0,635 & 31 & 0,284 & 0,345 & 0,612 & 0,651 \\
\hline AT1G23310.1 & $\begin{array}{l}\text { GGT1 AOAT1 GGAT1 } \\
\text { glutamate:glyoxylate } \\
\text { aminotransferase } \\
\end{array}$ & 0,221 & 0,350 & 0,581 & 0,701 & 31 & 0,284 & 0,345 & 0,612 & 0,651 \\
\hline AT4G12550.1 & $\begin{array}{l}\text { AIR1 Auxin-Induced in } \\
\text { Root cultures } 1\end{array}$ & 0,240 & 0,329 & 0,643 & 0,649 & 31 & 0,284 & 0,345 & 0,612 & 0,651 \\
\hline AT4G12870.1 & $\begin{array}{c}\text { Gamma interferon } \\
\text { responsive lysosomal thiol } \\
(\text { GILT) reductase family } \\
\text { protein } \\
\end{array}$ & 0,300 & 0,333 & 0,605 & 0,658 & 31 & 0,284 & 0,345 & 0,612 & 0,651 \\
\hline AT3G50440.1 & $\begin{array}{l}\text { ATMES10 MES10 methyl } \\
\text { esterase } 10\end{array}$ & 0,294 & 0,326 & 0,624 & 0,646 & 31 & 0,284 & 0,345 & 0,612 & 0,651 \\
\hline AT2G28950.1 & $\begin{array}{l}\text { ATEXPA6 ATEXP6 } \\
\text { ATHEXP ALPHA } 1.8 \\
\text { EXPA6 expansin A6 } \\
\end{array}$ & 0,326 & 0,328 & 0,596 & 0,657 & 31 & 0,284 & 0,345 & 0,612 & 0,651 \\
\hline AT1G35290.1 & $\begin{array}{l}\text { Thioesterase superfamily } \\
\text { protein }\end{array}$ & 0,288 & 0,332 & 0,599 & 0,669 & 31 & 0,284 & 0,345 & 0,612 & 0,651 \\
\hline AT5G23010.1 & $\begin{array}{c}\text { MAM1 IMS3 } \\
\text { methylthioalkylmalate } \\
\text { synthase } 1 \\
\end{array}$ & 0,258 & 0,309 & 0,610 & 0,682 & 31 & 0,284 & 0,345 & 0,612 & 0,651 \\
\hline AT3G45160.1 & $\begin{array}{l}\text { Putative membrane } \\
\text { lipoprotein }\end{array}$ & 0,267 & 0,304 & 0,603 & 0,687 & 31 & 0,284 & 0,345 & 0,612 & 0,651 \\
\hline AT2G46650.1 & $\begin{array}{l}\text { B5 \#1 ATCB5-C CB5-C } \\
\text { cytochrome B5 isoform C }\end{array}$ & 0,327 & 0,334 & 0,667 & 0,580 & 32 & 0,280 & 0,276 & 0,706 & 0,585 \\
\hline AT4G21903.2 & MATE efflux family protein & 0,270 & 0,321 & 0,698 & 0,581 & 32 & 0,280 & 0,276 & 0,706 & 0,585 \\
\hline AT1G35625.1 & $\begin{array}{l}\text { RING/U-box superfamily } \\
\text { protein }\end{array}$ & 0,303 & 0,323 & 0,678 & 0,587 & 32 & 0,280 & 0,276 & 0,706 & 0,585 \\
\hline AT5G23840.2 & $\begin{array}{l}\text { MD-2-related lipid } \\
\text { recognition domain- } \\
\text { containing protein }\end{array}$ & 0,259 & 0,308 & 0,678 & 0,615 & 32 & 0,280 & 0,276 & 0,706 & 0,585 \\
\hline AT2G39700.1 & $\begin{array}{l}\text { ATEXPA4 ATEXP4 } \\
\text { ATHEXP ALPHA } 1.6 \\
\text { EXPA4 expansin A4 } \\
\end{array}$ & 0,332 & 0,311 & 0,667 & 0,590 & 32 & 0,280 & 0,276 & 0,706 & 0,585 \\
\hline AT1G66800.1 & $\begin{array}{l}\text { NAD(P)-binding Rossmann- } \\
\text { fold superfamily protein }\end{array}$ & 0,305 & 0,302 & 0,673 & 0,602 & 32 & 0,280 & 0,276 & 0,706 & 0,585 \\
\hline AT1G03410.1 & $\begin{array}{c}\text { 2A6 2-oxoglutarate (2OG) } \\
\text { and Fe(II)-dependent } \\
\text { oxygenase superfamily } \\
\text { protein } \\
\end{array}$ & 0,267 & 0,296 & 0,691 & 0,603 & 32 & 0,280 & 0,276 & 0,706 & 0,585 \\
\hline
\end{tabular}


Anhang

\begin{tabular}{|c|c|c|c|c|c|c|c|c|c|c|}
\hline AT5G47990.1 & $\begin{array}{c}\text { CYP705A5 THAD THAD1 } \\
\text { cytochrome P450 family } \\
705 \text { subfamily A polypeptide } \\
5\end{array}$ & 0,208 & 0,276 & 0,778 & 0,525 & 32 & 0,280 & 0,276 & 0,706 & 0,585 \\
\hline AT3G20940.1 & $\begin{array}{c}\text { CYP705A30 cytochrome } \\
\text { P450 family } 705 \text { subfamily } \\
\text { A polypeptide } 30 \\
\end{array}$ & 0,267 & 0,276 & 0,738 & 0,555 & 32 & 0,280 & 0,276 & 0,706 & 0,585 \\
\hline AT3G59730.1 & $\begin{array}{c}\text { Concanavalin A-like lectin } \\
\text { protein kinase family protein }\end{array}$ & 0,360 & 0,267 & 0,712 & 0,540 & 32 & 0,280 & 0,276 & 0,706 & 0,585 \\
\hline AT4G37850.1 & $\begin{array}{l}\text { basic helix-loop-helix } \\
\text { (bHLH) DNA-binding } \\
\text { superfamily protein }\end{array}$ & 0,271 & 0,291 & 0,705 & 0,587 & 32 & 0,280 & 0,276 & 0,706 & 0,585 \\
\hline AT1G16400.1 & $\begin{array}{c}\text { CYP79F2 cytochrome } \\
\text { P450 family } 79 \text { subfamily F } \\
\text { polypeptide } 2\end{array}$ & 0,340 & 0,269 & 0,681 & 0,590 & 32 & 0,280 & 0,276 & 0,706 & 0,585 \\
\hline AT4G13770.1 & $\begin{array}{c}\text { CYP83A1 REF2 } \\
\text { cytochrome P450 family } 83 \\
\text { subfamily A polypeptide } 1\end{array}$ & 0,280 & 0,270 & 0,694 & 0,606 & 32 & 0,280 & 0,276 & 0,706 & 0,585 \\
\hline AT5G61290.1 & $\begin{array}{c}\text { Flavin-binding } \\
\text { monooxygenase family } \\
\text { protein }\end{array}$ & 0,233 & 0,260 & 0,718 & 0,602 & 32 & 0,280 & 0,276 & 0,706 & 0,585 \\
\hline AT5G42590.1 & $\begin{array}{c}\text { CYP71A16 cytochrome } \\
\text { P450 family } 71 \text { subfamily A } \\
\text { polypeptide } 16\end{array}$ & 0,231 & 0,226 & 0,757 & 0,568 & 32 & 0,280 & 0,276 & 0,706 & 0,585 \\
\hline AT3G58990.1 & $\begin{array}{l}\text { IPMI1 isopropylmalate } \\
\text { isomerase } 1\end{array}$ & 0,263 & 0,251 & 0,695 & 0,620 & 32 & 0,280 & 0,276 & 0,706 & 0,585 \\
\hline AT3G02020.1 & AK3 aspartate kinase 3 & 0,248 & 0,234 & 0,701 & 0,627 & 32 & 0,280 & 0,276 & 0,706 & 0,585 \\
\hline AT4G36220.1 & $\begin{array}{c}\text { FAH1 CYP84A1 ferulic acid } \\
\text { 5-hydroxylase } 1\end{array}$ & 0,286 & 0,223 & 0,728 & 0,582 & 32 & 0,280 & 0,276 & 0,706 & 0,585 \\
\hline AT1G70830.4 & MLP28 MLP-like protein 28 & 0,277 & 0,208 & 0,755 & 0,558 & 32 & 0,280 & 0,276 & 0,706 & 0,585 \\
\hline AT3G61830.1 & $\begin{array}{l}\text { ARF18 auxin response } \\
\text { factor } 18\end{array}$ & 0,376 & 0,262 & 0,677 & 0,576 & 33 & 0,351 & 0,209 & 0,674 & 0,612 \\
\hline AT4G32460.2 & \begin{tabular}{|c|}
$\begin{array}{c}\text { Protein of unknown function } \\
\text { DUF642 }\end{array}$ \\
\end{tabular} & 0,375 & 0,266 & 0,640 & 0,615 & 33 & 0,351 & 0,209 & 0,674 & 0,612 \\
\hline AT1G64390.1 & $\begin{array}{c}\text { AtGH9C2 GH9C2 glycosyl } \\
\text { hydrolase } 9 \mathrm{C} 2\end{array}$ & 0,347 & 0,245 & 0,660 & 0,620 & 33 & 0,351 & 0,209 & 0,674 & 0,612 \\
\hline AT2G34490.1 & $\begin{array}{l}\text { CYP710A2 cytochrome } \\
\text { P450 family } 710 \text { subfamily } \\
\text { A polypeptide } 2\end{array}$ & 0,298 & 0,221 & 0,683 & 0,629 & 33 & 0,351 & 0,209 & 0,674 & 0,612 \\
\hline AT5G58960.1 & $\begin{array}{c}\text { GIL1 Plant protein of } \\
\text { unknown function (DUF641) }\end{array}$ & 0,360 & 0,187 & 0,676 & 0,615 & 33 & 0,351 & 0,209 & 0,674 & 0,612 \\
\hline AT4G11190.1 & $\begin{array}{l}\text { Disease resistance- } \\
\text { responsive (dirigent-like } \\
\text { protein) family protein }\end{array}$ & 0,304 & 0,177 & 0,711 & 0,609 & 33 & 0,351 & 0,209 & 0,674 & 0,612 \\
\hline AT4G27440.1 & $\begin{array}{l}\text { PORB protochlorophyllide } \\
\text { oxidoreductase B }\end{array}$ & 0,395 & 0,102 & 0,668 & 0,622 & 33 & 0,351 & 0,209 & 0,674 & 0,612 \\
\hline AT3G28040.1 & $\begin{array}{c}\text { Leucine-rich receptor-like } \\
\text { protein kinase family protein }\end{array}$ & 0,480 & 0,262 & 0,617 & 0,566 & 34 & 0,487 & 0,178 & 0,591 & 0,613 \\
\hline $\begin{array}{c}\text { ATCG00400. } \\
1\end{array}$ & TRNL. 1 tRNA-Leu & 0,549 & 0,181 & 0,608 & 0,544 & 34 & 0,487 & 0,178 & 0,591 & 0,613 \\
\hline $\begin{array}{c}\text { ATCG00410. } \\
1 \\
\end{array}$ & TRNF chloroplast TRNF & 0,480 & 0,208 & 0,552 & 0,649 & 34 & 0,487 & 0,178 & 0,591 & 0,613 \\
\hline AT1G55120.2 & $\begin{array}{l}\text { ATFRUCT5 FRUCT5 beta- } \\
\text { fructofuranosidase } 5\end{array}$ & 0,491 & 0,188 & 0,594 & 0,609 & 34 & 0,487 & 0,178 & 0,591 & 0,613 \\
\hline AT1G26230.1 & $\begin{array}{l}\text { TCP-1/cpn60 chaperonin } \\
\text { family protein }\end{array}$ & 0,492 & 0,205 & 0,548 & 0,645 & 34 & 0,487 & 0,178 & 0,591 & 0,613 \\
\hline $\begin{array}{c}\text { ATCG00450. } \\
1 \\
\end{array}$ & TRNV.1 tRNA-Val & 0,523 & 0,168 & 0,639 & 0,539 & 34 & 0,487 & 0,178 & 0,591 & 0,613 \\
\hline $\begin{array}{c}\text { ATCG00440. } \\
1\end{array}$ & \begin{tabular}{|c|}
$\mathrm{NDHC}$ \\
$\mathrm{NADH}$ :ubiquinone/plastoqui \\
none oxidoreductase chain \\
3 protein \\
\end{tabular} & 0,436 & 0,185 & 0,579 & 0,664 & 34 & 0,487 & 0,178 & 0,591 & 0,613 \\
\hline $\begin{array}{c}\text { ATCG00250. } \\
1\end{array}$ & $\begin{array}{c}\text { TRNE this chloroplast gene } \\
\text { encodes a UUC tRNA } \\
\text { whose expression is } \\
\text { regulated by SIG2. }\end{array}$ & 0,481 & 0,127 & 0,588 & 0,638 & 34 & 0,487 & 0,178 & 0,591 & 0,613 \\
\hline $\begin{array}{c}\text { ATCG00240. } \\
1 \\
\end{array}$ & TRNY tRNA-Tyr & 0,455 & 0,084 & 0,591 & 0,661 & 34 & 0,487 & 0,178 & 0,591 & 0,613 \\
\hline AT4G18390.2 & $\begin{array}{c}\text { TCP2 TEOSINTE } \\
\text { BRANCHED 1 cycloidea } \\
\text { and PCF transcription factor } \\
2 \\
\end{array}$ & 0,490 & 0,315 & 0,495 & 0,645 & 35 & 0,489 & 0,271 & 0,509 & 0,648 \\
\hline AT4G27120.1 & unknown & 0,535 & 0,335 & 0,424 & 0,650 & 35 & 0,489 & 0,271 & 0,509 & 0,648 \\
\hline
\end{tabular}




\begin{tabular}{|c|c|c|c|c|c|c|c|c|c|c|}
\hline AT1G67910.1 & unknown protein & 0,553 & 0,291 & 0,498 & 0,601 & 35 & 0,489 & 0,271 & 0,509 & 0,648 \\
\hline AT4G33010.2 & $\begin{array}{l}\text { AtGLDP1 GLDP1 glycine } \\
\text { decarboxylase P-protein } 1\end{array}$ & 0,470 & 0,285 & 0,569 & 0,612 & 35 & 0,489 & 0,271 & 0,509 & 0,648 \\
\hline AT2G16200.1 & structural molecules & 0,606 & 0,284 & 0,389 & 0,633 & 35 & 0,489 & 0,271 & 0,509 & 0,648 \\
\hline $\begin{array}{c}\text { ATCG01040. } \\
1\end{array}$ & $\begin{array}{l}\text { YCF5 Cytochrome C } \\
\text { assembly protein }\end{array}$ & 0,482 & 0,266 & 0,549 & 0,629 & 35 & 0,489 & 0,271 & 0,509 & 0,648 \\
\hline AT3G23810.1 & $\begin{array}{l}\text { SAHH2 ATSAHH2 S- } \\
\text { adenosyl-I-homocysteine } \\
\text { (SAH) hydrolase } 2\end{array}$ & 0,434 & 0,280 & 0,587 & 0,624 & 35 & 0,489 & 0,271 & 0,509 & 0,648 \\
\hline AT4G27520.1 & $\begin{array}{c}\text { ENODL2 AtENODL2 early } \\
\text { nodulin-like protein } 2\end{array}$ & 0,432 & 0,274 & 0,583 & 0,631 & 35 & 0,489 & 0,271 & 0,509 & 0,648 \\
\hline AT1G72610.1 & $\begin{array}{l}\text { GLP1 ATGER1 GER1 } \\
\text { germin-like protein } 1\end{array}$ & 0,448 & 0,276 & 0,493 & 0,693 & 35 & 0,489 & 0,271 & 0,509 & 0,648 \\
\hline AT5G38410.3 & $\begin{array}{c}\text { Ribulose bisphosphate } \\
\text { carboxylase (small chain) } \\
\text { family protein } \\
\end{array}$ & 0,476 & 0,259 & 0,456 & 0,706 & 35 & 0,489 & 0,271 & 0,509 & 0,648 \\
\hline $\begin{array}{c}\text { ATCG00030. } \\
1\end{array}$ & $\begin{array}{c}\text { TRNK TRNK-UUU TRNA } \\
\text { LYS Lysine tRNA }\end{array}$ & 0,455 & 0,226 & 0,560 & 0,655 & 35 & 0,489 & 0,271 & 0,509 & 0,648 \\
\hline AT5G60940.1 & $\begin{array}{l}\text { Transducin/WD40 repeat- } \\
\text { like superfamily protein }\end{array}$ & 0,511 & 0,229 & 0,474 & 0,680 & 35 & 0,489 & 0,271 & 0,509 & 0,648 \\
\hline $\begin{array}{c}\text { ATCG01150. } \\
1 \\
\end{array}$ & TRNR.3 tRNA-Arg & 0,469 & 0,203 & 0,537 & 0,672 & 35 & 0,489 & 0,271 & 0,509 & 0,648 \\
\hline AT3G23050.2 & $\begin{array}{c}\text { IAA7 AXR2 indole-3-acetic } \\
\text { acid } 7 \\
\end{array}$ & 0,399 & 0,320 & 0,561 & 0,651 & 36 & 0,395 & 0,311 & 0,520 & 0,689 \\
\hline $\begin{array}{c}\text { ATCG00070. } \\
1\end{array}$ & $\begin{array}{l}\text { PSBK photosystem II } \\
\text { reaction center protein } \mathrm{K} \\
\text { precursor }\end{array}$ & 0,393 & 0,328 & 0,549 & 0,661 & 36 & 0,395 & 0,311 & 0,520 & 0,689 \\
\hline AT1G73020.1 & unknown protein & 0,411 & 0,315 & 0,547 & 0,658 & 36 & 0,395 & 0,311 & 0,520 & 0,689 \\
\hline AT2G33050.1 & $\begin{array}{c}\text { AtRLP26 RLP26 receptor } \\
\text { like protein } 26 \\
\end{array}$ & 0,367 & 0,338 & 0,532 & 0,684 & 36 & 0,395 & 0,311 & 0,520 & 0,689 \\
\hline AT1G62560.1 & $\begin{array}{c}\text { FMO GS-OX3 flavin- } \\
\text { monooxygenase } \\
\text { glucosinolate S-oxygenase } \\
3 \\
\end{array}$ & 0,417 & 0,322 & 0,517 & 0,675 & 36 & 0,395 & 0,311 & 0,520 & 0,689 \\
\hline AT5G22500.1 & $\begin{array}{c}\text { FAR1 fatty acid reductase } \\
1\end{array}$ & 0,419 & 0,315 & 0,546 & 0,654 & 36 & 0,395 & 0,311 & 0,520 & 0,689 \\
\hline AT2G03980.1 & $\begin{array}{c}\text { GDSL-like } \\
\text { Lipase/Acylhydrolase } \\
\text { superfamily protein }\end{array}$ & 0,404 & 0,331 & 0,514 & 0,681 & 36 & 0,395 & 0,311 & 0,520 & 0,689 \\
\hline AT2G05310.1 & unknown protein & 0,398 & 0,323 & 0,532 & 0,674 & 36 & 0,395 & 0,311 & 0,520 & 0,689 \\
\hline AT1G03600.1 & $\begin{array}{l}\text { PSB27 photosystem II } \\
\text { family protein }\end{array}$ & 0,399 & 0,332 & 0,500 & 0,693 & 36 & 0,395 & 0,311 & 0,520 & 0,689 \\
\hline AT1G58602.2 & $\begin{array}{l}\text { LRR and NB-ARC domains- } \\
\text { containing disease } \\
\text { resistance protein } \\
\end{array}$ & 0,368 & 0,346 & 0,495 & 0,707 & 36 & 0,395 & 0,311 & 0,520 & 0,689 \\
\hline AT2G20260.1 & $\begin{array}{c}\text { PSAE-2 photosystem I } \\
\text { subunit E-2 }\end{array}$ & 0,371 & 0,330 & 0,539 & 0,680 & 36 & 0,395 & 0,311 & 0,520 & 0,689 \\
\hline AT3G62750.1 & BGLU8 beta glucosidase 8 & 0,368 & 0,344 & 0,472 & 0,724 & 36 & 0,395 & 0,311 & 0,520 & 0,689 \\
\hline AT3G26060.2 & $\begin{array}{l}\text { ATPRX Q Thioredoxin } \\
\text { superfamily protein }\end{array}$ & 0,388 & 0,337 & 0,472 & 0,716 & 36 & 0,395 & 0,311 & 0,520 & 0,689 \\
\hline AT4G09650.1 & $\begin{array}{c}\text { ATPD ATP synthase delta- } \\
\text { subunit gene }\end{array}$ & 0,393 & 0,324 & 0,523 & 0,683 & 36 & 0,395 & 0,311 & 0,520 & 0,689 \\
\hline AT5G62470.2 & $\begin{array}{l}\text { MYB96 myb domain } \\
\text { protein } 96\end{array}$ & 0,410 & 0,317 & 0,551 & 0,654 & 36 & 0,395 & 0,311 & 0,520 & 0,689 \\
\hline AT1G01140.3 & $\begin{array}{c}\text { CIPK9 PKS6 CBL- } \\
\text { interacting protein kinase } 9 \\
\end{array}$ & 0,380 & 0,327 & 0,516 & 0,694 & 36 & 0,395 & 0,311 & 0,520 & 0,689 \\
\hline AT1G78970.1 & $\begin{array}{l}\text { LUP1 ATLUP1 lupeol } \\
\text { synthase } 1\end{array}$ & 0,400 & 0,325 & 0,493 & 0,701 & 36 & 0,395 & 0,311 & 0,520 & 0,689 \\
\hline AT5G52970.1 & $\begin{array}{l}\text { thylakoid lumen } 15.0 \mathrm{kDa} \\
\text { protein }\end{array}$ & 0,401 & 0,293 & 0,553 & 0,669 & 36 & 0,395 & 0,311 & 0,520 & 0,689 \\
\hline AT1G10640.1 & $\begin{array}{l}\text { Pectin lyase-like } \\
\text { superfamily protein }\end{array}$ & 0,389 & 0,299 & 0,551 & 0,675 & 36 & 0,395 & 0,311 & 0,520 & 0,689 \\
\hline AT2G23670.1 & $\begin{array}{l}\text { YCF37 homolog of } \\
\text { Synechocystis YCF37 }\end{array}$ & 0,377 & 0,321 & 0,482 & 0,723 & 36 & 0,395 & 0,311 & 0,520 & 0,689 \\
\hline $\begin{array}{c}\text { ATCG00710. } \\
1 \\
\end{array}$ & $\begin{array}{l}\text { PSBH photosystem II } \\
\text { reaction center protein } \mathrm{H}\end{array}$ & 0,419 & 0,292 & 0,561 & 0,651 & 36 & 0,395 & 0,311 & 0,520 & 0,689 \\
\hline AT3G16520.3 & $\begin{array}{l}\text { UGT88A1 UDP-glucosyl } \\
\text { transferase } 88 \mathrm{~A} 1\end{array}$ & 0,370 & 0,308 & 0,525 & 0,702 & 36 & 0,395 & 0,311 & 0,520 & 0,689 \\
\hline AT1G19670.1 & $\begin{array}{l}\text { ATCLH1 CORI1 ATHCOR1 } \\
\text { CLH1 chlorophyllase } 1\end{array}$ & 0,383 & 0,304 & 0,526 & 0,696 & 36 & 0,395 & 0,311 & 0,520 & 0,689 \\
\hline AT4G27440.2 & PORB protochlorophyllide & 0,404 & 0,302 & 0,500 & 0,704 & 36 & 0,395 & 0,311 & 0,520 & 0,689 \\
\hline
\end{tabular}


Anhang

\begin{tabular}{|c|c|c|c|c|c|c|c|c|c|c|}
\hline & oxidoreductase B & & & & & & & & & \\
\hline AT2G27402.1 & unknown protein & 0,395 & 0,316 & 0,471 & 0,723 & 36 & 0,395 & 0,311 & 0,520 & 0,689 \\
\hline AT4G21840.1 & $\begin{array}{l}\text { ATMSRB8 MSRB8 } \\
\text { methionine sulfoxide } \\
\text { reductase B8 }\end{array}$ & 0,435 & 0,304 & 0,478 & 0,700 & 36 & 0,395 & 0,311 & 0,520 & 0,689 \\
\hline AT4G29030.1 & $\begin{array}{l}\text { Putative membrane } \\
\text { lipoprotein }\end{array}$ & 0,367 & 0,294 & 0,507 & 0,722 & 36 & 0,395 & 0,311 & 0,520 & 0,689 \\
\hline AT2G19650.1 & $\begin{array}{l}\text { Cysteine/Histidine-rich } \mathrm{C1} \\
\text { domain family protein }\end{array}$ & 0,415 & 0,279 & 0,498 & 0,709 & 36 & 0,395 & 0,311 & 0,520 & 0,689 \\
\hline AT1G04800.1 & glycine-rich protein & 0,415 & 0,278 & 0,506 & 0,703 & 36 & 0,395 & 0,311 & 0,520 & 0,689 \\
\hline $\begin{array}{c}\text { ATCG01010. } \\
1\end{array}$ & \begin{tabular}{|c|} 
NDHF NADH-Ubiquinone \\
oxidoreductase (complex I) \\
chain 5 protein
\end{tabular} & 0,419 & 0,262 & 0,537 & 0,684 & 36 & 0,395 & 0,311 & 0,520 & 0,689 \\
\hline AT5G52780.1 & \begin{tabular}{|c|} 
Protein of unknown function \\
(DUF3464)
\end{tabular} & 0,385 & 0,258 & 0,527 & 0,712 & 36 & 0,395 & 0,311 & 0,520 & 0,689 \\
\hline AT3G57130.1 & $\begin{array}{c}\begin{array}{c}\text { BOP1 Ankyrin repeat family } \\
\text { protein / BTB/POZ domain- } \\
\text { containing protein }\end{array} \\
\end{array}$ & 0,384 & 0,271 & 0,542 & 0,697 & 36 & 0,395 & 0,311 & 0,520 & 0,689 \\
\hline AT1G10360.1 & $\begin{array}{c}\text { ATGSTU18 GST29 } \\
\text { GSTU18 glutathione S- } \\
\text { transferase TAU } 18\end{array}$ & 0,350 & 0,340 & 0,536 & 0,689 & 37 & 0,345 & 0,294 & 0,560 & 0,692 \\
\hline AT2G38230.1 & \begin{tabular}{|c|} 
ATPDX1.1 PDX1.1 \\
pyridoxine biosynthesis 1.1
\end{tabular} & 0,338 & 0,336 & 0,542 & 0,692 & 37 & 0,345 & 0,294 & 0,560 & 0,692 \\
\hline AT2G45180.1 & $\begin{array}{l}\text { Bifunctional inhibitor/lipid- } \\
\text { transfer protein/seed } \\
\text { storage } 2 \mathrm{~S} \text { albumin } \\
\text { superfamily protein } \\
\end{array}$ & 0,315 & 0,344 & 0,538 & 0,702 & 37 & 0,345 & 0,294 & 0,560 & 0,692 \\
\hline AT5G66190.2 & $\begin{array}{c}\text { ATLFNR1 ferredoxin- } \\
\text { NADP }(+) \text {-oxidoreductase } 1\end{array}$ & 0,324 & 0,332 & 0,536 & 0,705 & 37 & 0,345 & 0,294 & 0,560 & 0,692 \\
\hline AT3G55240.1 & $\begin{array}{l}\text { Plant protein } 1589 \text { of } \\
\text { unknown function }\end{array}$ & 0,329 & 0,335 & 0,529 & 0,707 & 37 & 0,345 & 0,294 & 0,560 & 0,692 \\
\hline AT4G03270.1 & CYCD6;1 Cyclin D6;1 & 0,352 & 0,317 & 0,575 & 0,668 & 37 & 0,345 & 0,294 & 0,560 & 0,692 \\
\hline AT4G19380.1 & $\begin{array}{l}\text { Long-chain fatty alcohol } \\
\text { dehydrogenase family } \\
\text { protein }\end{array}$ & 0,332 & 0,331 & 0,546 & 0,695 & 37 & 0,345 & 0,294 & 0,560 & 0,692 \\
\hline AT5G38520.2 & $\begin{array}{l}\text { alpha/beta-Hydrolases } \\
\text { superfamily protein }\end{array}$ & 0,354 & 0,319 & 0,557 & 0,680 & 37 & 0,345 & 0,294 & 0,560 & 0,692 \\
\hline AT5G67280.1 & RLK receptor-like kinase & 0,376 & 0,303 & 0,581 & 0,655 & 37 & 0,345 & 0,294 & 0,560 & 0,692 \\
\hline AT1G49430.1 & $\begin{array}{l}\text { LACS2 LRD2 long-chain } \\
\text { acyl-CoA synthetase } 2\end{array}$ & 0,326 & 0,305 & 0,589 & 0,673 & 37 & 0,345 & 0,294 & 0,560 & 0,692 \\
\hline AT4G34760.1 & $\begin{array}{c}\text { SAUR-like auxin-responsive } \\
\text { protein family }\end{array}$ & 0,323 & 0,321 & 0,553 & 0,698 & 37 & 0,345 & 0,294 & 0,560 & 0,692 \\
\hline AT3G53280.1 & $\begin{array}{c}\text { CYP71B5 cytochrome } \\
\text { p450 71b5 }\end{array}$ & 0,327 & 0,314 & 0,564 & 0,691 & 37 & 0,345 & 0,294 & 0,560 & 0,692 \\
\hline $\begin{array}{c}\text { ATCG00090. } \\
1\end{array}$ & TRNS. 1 tRNA-Ser & 0,365 & 0,314 & 0,540 & 0,691 & 37 & 0,345 & 0,294 & 0,560 & 0,692 \\
\hline AT1G14700.2 & $\begin{array}{c}\text { PAP3 ATPAP3 purple acid } \\
\text { phosphatase } 3 \\
\end{array}$ & 0,337 & 0,320 & 0,538 & 0,703 & 37 & 0,345 & 0,294 & 0,560 & 0,692 \\
\hline AT4G01050.1 & $\begin{array}{c}\text { TROL thylakoid rhodanese- } \\
\text { like }\end{array}$ & 0,345 & 0,313 & 0,535 & 0,705 & 37 & 0,345 & 0,294 & 0,560 & 0,692 \\
\hline AT3G18080.1 & $\begin{array}{l}\text { BGLU44 B-S glucosidase } \\
44\end{array}$ & 0,363 & 0,301 & 0,545 & 0,693 & 37 & 0,345 & 0,294 & 0,560 & 0,692 \\
\hline AT5G19600.1 & $\begin{array}{l}\text { SULTR3;5 sulfate } \\
\text { transporter } 3 ; 5\end{array}$ & 0,343 & 0,309 & 0,556 & 0,691 & 37 & 0,345 & 0,294 & 0,560 & 0,692 \\
\hline AT3G30730.1 & unknown protein & 0,376 & 0,276 & 0,599 & 0,652 & 37 & 0,345 & 0,294 & 0,560 & 0,692 \\
\hline AT5G57800.1 & $\begin{array}{c}\text { FLP1 YRE CER3 WAX2 } \\
\text { Fatty acid hydroxylase } \\
\text { superfamily } \\
\end{array}$ & 0,315 & 0,298 & 0,594 & 0,677 & 37 & 0,345 & 0,294 & 0,560 & 0,692 \\
\hline AT4G00400.1 & \begin{tabular}{|c|} 
GPAT8 AtGPAT8 glycerol- \\
3-phosphate \\
acyltransferase 8 \\
\end{tabular} & 0,342 & 0,301 & 0,579 & 0,676 & 37 & 0,345 & 0,294 & 0,560 & 0,692 \\
\hline AT4G28680.4 & $\begin{array}{l}\text { TYRDC L-tyrosine } \\
\text { decarboxylase }\end{array}$ & 0,321 & 0,298 & 0,560 & 0,703 & 37 & 0,345 & 0,294 & 0,560 & 0,692 \\
\hline AT1G68480.1 & $\begin{array}{l}\mathrm{JAG} \mathrm{C} 2 \mathrm{H} 2 \text { and } \mathrm{C} 2 \mathrm{HC} \text { zinc } \\
\text { fingers superfamily protein } \\
\end{array}$ & 0,313 & 0,293 & 0,592 & 0,683 & 37 & 0,345 & 0,294 & 0,560 & 0,692 \\
\hline AT2G43010.2 & $\begin{array}{c}\text { PIF4 SRL2 AtPIF4 } \\
\text { phytochrome interacting } \\
\text { factor } 4 \\
\end{array}$ & 0,325 & 0,312 & 0,558 & 0,697 & 37 & 0,345 & 0,294 & 0,560 & 0,692 \\
\hline AT1G78478.1 & MIR833A MIR833a; miRNA & 0,360 & 0,285 & 0,594 & 0,661 & 37 & 0,345 & 0,294 & 0,560 & 0,692 \\
\hline
\end{tabular}


Anhang

\begin{tabular}{|c|c|c|c|c|c|c|c|c|c|c|}
\hline AT1G65860.1 & $\begin{array}{c}\text { FMO GS-OX1 flavin- } \\
\text { monooxygenase } \\
\text { glucosinolate S-oxygenase } \\
1\end{array}$ & 0,345 & 0,305 & 0,542 & 0,703 & 37 & 0,345 & 0,294 & 0,560 & 0,692 \\
\hline AT3G03770.1 & $\begin{array}{l}\text { Leucine-rich repeat protein } \\
\text { kinase family protein }\end{array}$ & 0,311 & 0,296 & 0,571 & 0,700 & 37 & 0,345 & 0,294 & 0,560 & 0,692 \\
\hline AT2G39310.3 & jacalin-related lectin 22 & 0,316 & 0,301 & 0,560 & 0,704 & 37 & 0,345 & 0,294 & 0,560 & 0,692 \\
\hline AT3G62030.3 & ROC4 rotamase CYP 4 & 0,325 & 0,283 & 0,574 & 0,696 & 37 & 0,345 & 0,294 & 0,560 & 0,692 \\
\hline AT3G01600.1 & $\begin{array}{c}\text { anac044 NAC044 NAC } \\
\text { domain containing protein } \\
44\end{array}$ & 0,331 & 0,290 & 0,580 & 0,686 & 37 & 0,345 & 0,294 & 0,560 & 0,692 \\
\hline AT3G51600.1 & LTP5 lipid transfer protein 5 & 0,387 & 0,279 & 0,559 & 0,678 & 37 & 0,345 & 0,294 & 0,560 & 0,692 \\
\hline AT5G01530.1 & $\begin{array}{l}\text { LHCB4.1 light harvesting } \\
\text { complex photosystem II }\end{array}$ & 0,356 & 0,297 & 0,527 & 0,712 & 37 & 0,345 & 0,294 & 0,560 & 0,692 \\
\hline AT1G78490.1 & $\begin{array}{c}\text { CYP708A3 cytochrome } \\
\text { P450 family } 708 \text { subfamily } \\
\text { A polypeptide } 3\end{array}$ & 0,323 & 0,289 & 0,558 & 0,707 & 37 & 0,345 & 0,294 & 0,560 & 0,692 \\
\hline AT1G21500.1 & unknown protein & 0,360 & 0,279 & 0,542 & 0,706 & 37 & 0,345 & 0,294 & 0,560 & 0,692 \\
\hline $\begin{array}{c}\text { ATCG01160. } \\
1\end{array}$ & RRN5S & 0,382 & 0,271 & 0,592 & 0,656 & 37 & 0,345 & 0,294 & 0,560 & 0,692 \\
\hline AT4G21280.2 & $\begin{array}{c}\text { PSBQ PSBQA PSBQ-1 } \\
\text { photosystem II subunit QA }\end{array}$ & 0,356 & 0,280 & 0,539 & 0,710 & 37 & 0,345 & 0,294 & 0,560 & 0,692 \\
\hline AT5G63530.2 & $\begin{array}{l}\text { ATFP3 FP3 farnesylated } \\
\text { protein } 3 \\
\end{array}$ & 0,336 & 0,275 & 0,566 & 0,701 & 37 & 0,345 & 0,294 & 0,560 & 0,692 \\
\hline AT2G35260.1 & unknown protein & 0,364 & 0,261 & 0,577 & 0,683 & 37 & 0,345 & 0,294 & 0,560 & 0,692 \\
\hline AT1G64670.1 & $\begin{array}{c}\text { BDG1 alpha/beta- } \\
\text { Hydrolases superfamily } \\
\text { protein } \\
\end{array}$ & 0,362 & 0,277 & 0,531 & 0,714 & 37 & 0,345 & 0,294 & 0,560 & 0,692 \\
\hline AT2G06520.1 & $\begin{array}{c}\text { PSBX photosystem II } \\
\text { subunit X }\end{array}$ & 0,366 & 0,272 & 0,542 & 0,706 & 37 & 0,345 & 0,294 & 0,560 & 0,692 \\
\hline AT4G17245.1 & $\begin{array}{l}\text { RING/U-box superfamily } \\
\text { protein }\end{array}$ & 0,368 & 0,258 & 0,575 & 0,684 & 37 & 0,345 & 0,294 & 0,560 & 0,692 \\
\hline AT2G06850.1 & \begin{tabular}{|c|} 
EXGT-A1 EXT XTH4 \\
xyloglucan \\
endotransglucosylase/hydro \\
lase 4 \\
\end{tabular} & 0,339 & 0,256 & 0,593 & 0,684 & 37 & 0,345 & 0,294 & 0,560 & 0,692 \\
\hline AT4G36570.1 & ATRL3 RL3 RAD-like 3 & 0,327 & 0,277 & 0,550 & 0,717 & 37 & 0,345 & 0,294 & 0,560 & 0,692 \\
\hline AT1G69160.1 & unknown protein & 0,347 & 0,262 & 0,574 & 0,694 & 37 & 0,345 & 0,294 & 0,560 & 0,692 \\
\hline AT1G28670.1 & $\begin{array}{l}\text { ARAB-1 GDSL-like } \\
\text { Lipase/Acylhydrolase } \\
\text { superfamily protein } \\
\end{array}$ & 0,352 & 0,249 & 0,567 & 0,702 & 37 & 0,345 & 0,294 & 0,560 & 0,692 \\
\hline AT4G17240.1 & unknown protein & 0,385 & 0,254 & 0,542 & 0,702 & 37 & 0,345 & 0,294 & 0,560 & 0,692 \\
\hline AT4G15630.1 & $\begin{array}{l}\text { Uncharacterised protein } \\
\text { family (UPF0497) }\end{array}$ & 0,380 & 0,236 & 0,552 & 0,704 & 37 & 0,345 & 0,294 & 0,560 & 0,692 \\
\hline AT3G47470.1 & $\begin{array}{c}\text { LHCA4 CAB4 light- } \\
\text { harvesting chlorophyll- } \\
\text { protein complex I subunit } \\
\text { A4 }\end{array}$ & 0,360 & 0,248 & 0,565 & 0,700 & 37 & 0,345 & 0,294 & 0,560 & 0,692 \\
\hline AT4G16370.1 & $\begin{array}{c}\text { ATOPT3 OPT3 } \\
\text { oligopeptide transporter }\end{array}$ & 0,292 & 0,280 & 0,572 & 0,714 & 38 & 0,300 & 0,239 & 0,575 & 0,721 \\
\hline AT3G21670.1 & $\begin{array}{c}\begin{array}{c}\text { Major facilitator superfamily } \\
\text { protein }\end{array} \\
\end{array}$ & 0,268 & 0,283 & 0,568 & 0,725 & 38 & 0,300 & 0,239 & 0,575 & 0,721 \\
\hline AT5G57780.1 & unknown protein & 0,307 & 0,276 & 0,561 & 0,717 & 38 & 0,300 & 0,239 & 0,575 & 0,721 \\
\hline AT4G21620.2 & glycine-rich protein & 0,312 & 0,273 & 0,570 & 0,709 & 38 & 0,300 & 0,239 & 0,575 & 0,721 \\
\hline AT2G26250.1 & $\begin{array}{c}\text { FDH KCS10 3-ketoacyl- } \\
\text { CoA synthase } 10\end{array}$ & 0,328 & 0,260 & 0,580 & 0,699 & 38 & 0,300 & 0,239 & 0,575 & 0,721 \\
\hline AT1G14630.1 & unknown protein & 0,304 & 0,265 & 0,576 & 0,711 & 38 & 0,300 & 0,239 & 0,575 & 0,721 \\
\hline AT5G45950.1 & $\begin{array}{c}\text { GDSL-like } \\
\text { Lipase/Acylhydrolase } \\
\text { superfamily protein }\end{array}$ & 0,273 & 0,244 & 0,593 & 0,717 & 38 & 0,300 & 0,239 & 0,575 & 0,721 \\
\hline AT3G23450.1 & unknown protein & 0,301 & 0,254 & 0,579 & 0,714 & 38 & 0,300 & 0,239 & 0,575 & 0,721 \\
\hline AT5G14090.1 & unknown protein & 0,287 & 0,260 & 0,559 & 0,733 & 38 & 0,300 & 0,239 & 0,575 & 0,721 \\
\hline AT2G33850.1 & unknown protein & 0,270 & 0,255 & 0,591 & 0,716 & 38 & 0,300 & 0,239 & 0,575 & 0,721 \\
\hline AT1G72970.2 & $\begin{array}{l}\text { HTH EDA17 Glucose- } \\
\text { methanol-choline (GMC) } \\
\text { oxidoreductase family } \\
\text { protein }\end{array}$ & 0,316 & 0,236 & 0,597 & 0,699 & 38 & 0,300 & 0,239 & 0,575 & 0,721 \\
\hline
\end{tabular}




\begin{tabular}{|c|c|c|c|c|c|c|c|c|c|c|}
\hline AT5G11420.1 & \begin{tabular}{|c|}
$\begin{array}{c}\text { Protein of unknown function } \\
\text { DUF642 }\end{array}$ \\
\end{tabular} & 0,293 & 0,242 & 0,581 & 0,720 & 38 & 0,300 & 0,239 & 0,575 & 0,721 \\
\hline AT3G48200.1 & unknown protein & 0,286 & 0,251 & 0,562 & 0,735 & 38 & 0,300 & 0,239 & 0,575 & 0,721 \\
\hline AT5G07690.1 & $\begin{array}{l}\text { MYB29 ATMYB29 PMG2 } \\
\text { myb domain protein } 29\end{array}$ & 0,283 & 0,242 & 0,573 & 0,730 & 38 & 0,300 & 0,239 & 0,575 & 0,721 \\
\hline AT5G13140.1 & $\begin{array}{l}\text { Pollen Ole e } 1 \text { allergen and } \\
\text { extensin family protein }\end{array}$ & 0,314 & 0,238 & 0,556 & 0,732 & 38 & 0,300 & 0,239 & 0,575 & 0,721 \\
\hline AT5G25610.1 & $\begin{array}{c}\text { RD22 ATRD22 BURP } \\
\text { domain-containing protein }\end{array}$ & 0,272 & 0,237 & 0,582 & 0,729 & 38 & 0,300 & 0,239 & 0,575 & 0,721 \\
\hline AT1G55260.2 & $\begin{array}{l}\text { Bifunctional inhibitor/lipid- } \\
\text { transfer protein/seed } \\
\text { storage } 2 \mathrm{~S} \text { albumin } \\
\text { superfamily protein }\end{array}$ & 0,302 & 0,228 & 0,579 & 0,722 & 38 & 0,300 & 0,239 & 0,575 & 0,721 \\
\hline \begin{tabular}{|c|} 
ATCG00420. \\
1
\end{tabular} & $\begin{array}{c}\mathrm{NDHJ} \text { NADH } \\
\text { dehydrogenase subunit } \mathrm{J}\end{array}$ & 0,356 & 0,226 & 0,549 & 0,722 & 38 & 0,300 & 0,239 & 0,575 & 0,721 \\
\hline AT2G26690.1 & $\begin{array}{c}\text { Major facilitator superfamily } \\
\text { protein }\end{array}$ & 0,303 & 0,224 & 0,587 & 0,716 & 38 & 0,300 & 0,239 & 0,575 & 0,721 \\
\hline AT1G69530.5 & EXPA1 expansin A1 & 0,329 & 0,213 & 0,586 & 0,709 & 38 & 0,300 & 0,239 & 0,575 & 0,721 \\
\hline AT1G80100.1 & $\begin{array}{c}\text { AHP6 HP6 histidine } \\
\text { phosphotransfer protein } 6\end{array}$ & 0,251 & 0,237 & 0,579 & 0,738 & 38 & 0,300 & 0,239 & 0,575 & 0,721 \\
\hline $\begin{array}{c}\text { ATCG01200. } \\
1\end{array}$ & TRNI.3 tRNA-Ile & 0,319 & 0,217 & 0,568 & 0,727 & 38 & 0,300 & 0,239 & 0,575 & 0,721 \\
\hline AT4G36250.1 & $\begin{array}{l}\text { ALDH3F1 aldehyde } \\
\text { dehydrogenase 3F1 }\end{array}$ & 0,284 & 0,215 & 0,576 & 0,736 & 38 & 0,300 & 0,239 & 0,575 & 0,721 \\
\hline AT1G72645.1 & unknown protein & 0,265 & 0,213 & 0,573 & 0,745 & 38 & 0,300 & 0,239 & 0,575 & 0,721 \\
\hline$\underset{1}{\text { ATCG00210. }}$ & $\begin{array}{c}\text { YCF6 electron transporter } \\
\text { transferring electrons within } \\
\text { cytochrome b6/f complex of } \\
\text { photosystem Ils }\end{array}$ & 0,346 & 0,204 & 0,570 & 0,717 & 38 & 0,300 & 0,239 & 0,575 & 0,721 \\
\hline AT3G20820.1 & $\begin{array}{c}\text { Leucine-rich repeat (LRR) } \\
\text { family protein }\end{array}$ & 0,287 & 0,202 & 0,606 & 0,714 & 38 & 0,300 & 0,239 & 0,575 & 0,721 \\
\hline $\begin{array}{c}\text { ATCG00430. } \\
1\end{array}$ & $\begin{array}{l}\text { PSBG photosystem II } \\
\text { reaction center protein G }\end{array}$ & 0,357 & 0,181 & 0,564 & 0,723 & 38 & 0,300 & 0,239 & 0,575 & 0,721 \\
\hline AT4G24510.1 & $\begin{array}{c}\text { CER2 VC2 VC-2 HXXXD- } \\
\text { type acyl-transferase family } \\
\text { protein }\end{array}$ & 0,280 & 0,349 & 0,516 & 0,730 & 39 & 0,314 & 0,289 & 0,525 & 0,735 \\
\hline AT4G03210.2 & $\begin{array}{c}\text { XTH9 xyloglucan } \\
\text { endotransglucosylase/hydro } \\
\text { lase } 9\end{array}$ & 0,305 & 0,338 & 0,532 & 0,714 & 39 & 0,314 & 0,289 & 0,525 & 0,735 \\
\hline AT1G08380.1 & $\begin{array}{c}\text { PSAO photosystem I } \\
\text { subunit } O\end{array}$ & 0,321 & 0,335 & 0,528 & 0,711 & 39 & 0,314 & 0,289 & 0,525 & 0,735 \\
\hline AT1G60260.1 & BGLU5 beta glucosidase 5 & 0,335 & 0,345 & 0,504 & 0,717 & 39 & 0,314 & 0,289 & 0,525 & 0,735 \\
\hline AT5G13630.2 & GUN5 & 0,326 & 0,320 & 0,515 & 0,726 & 39 & 0,314 & 0,289 & 0,525 & 0,735 \\
\hline AT5G24155.1 & $\begin{array}{l}\text { FAD/NAD(P)-binding } \\
\text { oxidoreductase family } \\
\text { protein } \\
\end{array}$ & 0,286 & 0,323 & 0,538 & 0,724 & 39 & 0,314 & 0,289 & 0,525 & 0,735 \\
\hline AT5G24160.1 & $\begin{array}{l}\text { SQE6 squalene } \\
\text { monoxygenase } 6\end{array}$ & 0,286 & 0,317 & 0,557 & 0,713 & 39 & 0,314 & 0,289 & 0,525 & 0,735 \\
\hline AT3G08940.2 & $\begin{array}{l}\text { LHCB4.2 light harvesting } \\
\text { complex photosystem II }\end{array}$ & 0,320 & 0,338 & 0,476 & 0,746 & 39 & 0,314 & 0,289 & 0,525 & 0,735 \\
\hline AT2G32860.2 & $\begin{array}{c}\text { BGLU33 beta glucosidase } \\
33\end{array}$ & 0,324 & 0,325 & 0,507 & 0,729 & 39 & 0,314 & 0,289 & 0,525 & 0,735 \\
\hline AT3G05600.1 & $\begin{array}{l}\text { alpha/beta-Hydrolases } \\
\text { superfamily protein }\end{array}$ & 0,289 & 0,319 & 0,535 & 0,727 & 39 & 0,314 & 0,289 & 0,525 & 0,735 \\
\hline AT4G21750.2 & $\begin{array}{c}\text { ATML1 Homeobox-leucine } \\
\text { zipper family protein / lipid- } \\
\text { binding START domain- } \\
\text { containing protein }\end{array}$ & 0,316 & 0,315 & 0,516 & 0,731 & 39 & 0,314 & 0,289 & 0,525 & 0,735 \\
\hline AT2G47240.2 & $\begin{array}{c}\text { LACS1 AMP-dependent } \\
\text { synthetase and ligase family } \\
\text { protein } \\
\end{array}$ & 0,276 & 0,309 & 0,523 & 0,745 & 39 & 0,314 & 0,289 & 0,525 & 0,735 \\
\hline AT5G66570.1 & $\begin{array}{c}\text { PSBO-1 OEE1 OEE33 } \\
\text { OE33 PSBO1 MSP-1 PS II } \\
\text { oxygen-evolving complex } 1\end{array}$ & 0,305 & 0,313 & 0,524 & 0,731 & 39 & 0,314 & 0,289 & 0,525 & 0,735 \\
\hline AT3G26932.2 & $\begin{array}{l}\text { DRB3 dsRNA-binding } \\
\text { protein } 3 \\
\end{array}$ & 0,288 & 0,310 & 0,516 & 0,745 & 39 & 0,314 & 0,289 & 0,525 & 0,735 \\
\hline AT4G37930.1 & $\begin{array}{c}\text { SHM1 STM SHMT1 serine } \\
\text { transhydroxymethyltransfer } \\
\text { ase } 1\end{array}$ & 0,315 & 0,303 & 0,533 & 0,724 & 39 & 0,314 & 0,289 & 0,525 & 0,735 \\
\hline AT2G20570.2 & $\begin{array}{l}\text { GPRI1 GBF's pro-rich } \\
\text { region-interacting factor } 1\end{array}$ & 0,339 & 0,308 & 0,500 & 0,735 & 39 & 0,314 & 0,289 & 0,525 & 0,735 \\
\hline
\end{tabular}




\begin{tabular}{|c|c|c|c|c|c|c|c|c|c|c|}
\hline AT1G51805.2 & $\begin{array}{l}\text { Leucine-rich repeat protein } \\
\text { kinase family protein }\end{array}$ & 0,281 & 0,297 & 0,558 & 0,723 & 39 & 0,314 & 0,289 & 0,525 & 0,735 \\
\hline $\begin{array}{c}\text { ATCG00330. } \\
1\end{array}$ & $\begin{array}{l}\text { RPS14 chloroplast } \\
\text { ribosomal protein S14 }\end{array}$ & 0,323 & 0,299 & 0,519 & 0,733 & 39 & 0,314 & 0,289 & 0,525 & 0,735 \\
\hline AT4G09010.1 & $\begin{array}{c}\text { APX4 TL29 ascorbate } \\
\text { peroxidase } 4\end{array}$ & 0,351 & 0,292 & 0,524 & 0,719 & 39 & 0,314 & 0,289 & 0,525 & 0,735 \\
\hline AT5G58330.3 & $\begin{array}{c}\text { lactate } / \text { malate } \\
\text { dehydrogenase family } \\
\text { protein }\end{array}$ & 0,329 & 0,289 & 0,531 & 0,726 & 39 & 0,314 & 0,289 & 0,525 & 0,735 \\
\hline AT2G46820.2 & $\begin{array}{l}\text { PTAC8 TMP14 PSAP PSI-P } \\
\text { photosystem I P subunit }\end{array}$ & 0,299 & 0,305 & 0,504 & 0,751 & 39 & 0,314 & 0,289 & 0,525 & 0,735 \\
\hline AT4G08150.1 & $\begin{array}{l}\text { KNAT1 BP BP1 } \\
\text { KNOTTED-like from } \\
\text { Arabidopsis thaliana }\end{array}$ & 0,271 & 0,298 & 0,547 & 0,734 & 39 & 0,314 & 0,289 & 0,525 & 0,735 \\
\hline AT1G76100.1 & PETE1 plastocyanin 1 & 0,302 & 0,297 & 0,524 & 0,739 & 39 & 0,314 & 0,289 & 0,525 & 0,735 \\
\hline AT3G48420.1 & $\begin{array}{c}\text { Haloacid dehalogenase-like } \\
\text { hydrolase (HAD) } \\
\text { superfamily protein }\end{array}$ & 0,323 & 0,279 & 0,544 & 0,722 & 39 & 0,314 & 0,289 & 0,525 & 0,735 \\
\hline AT4G33000.3 & $\begin{array}{c}\text { CBL10 ATCBL10 } \\
\text { calcineurin B-like protein } 10 \\
\end{array}$ & 0,327 & 0,282 & 0,524 & 0,734 & 39 & 0,314 & 0,289 & 0,525 & 0,735 \\
\hline AT1G52410.2 & $\begin{array}{c}\text { TSA1 } \\
\text { TSK-associating } \\
\text { protein } 1\end{array}$ & 0,321 & 0,279 & 0,549 & 0,720 & 39 & 0,314 & 0,289 & 0,525 & 0,735 \\
\hline AT4G13840.1 & $\begin{array}{c}\text { HXXXD-type acyl- } \\
\text { transferase family protein }\end{array}$ & 0,314 & 0,278 & 0,523 & 0,742 & 39 & 0,314 & 0,289 & 0,525 & 0,735 \\
\hline AT1G09340.1 & $\begin{array}{l}\text { CRB CSP41B HIP1.3 } \\
\text { chloroplast RNA binding }\end{array}$ & 0,313 & 0,276 & 0,539 & 0,732 & 39 & 0,314 & 0,289 & 0,525 & 0,735 \\
\hline AT3G43720.2 & $\begin{array}{l}\text { Bifunctional inhibitor/lipid- } \\
\text { transfer protein/seed } \\
\text { storage } 2 \mathrm{~S} \text { albumin } \\
\text { superfamily protein }\end{array}$ & 0,288 & 0,271 & 0,528 & 0,751 & 39 & 0,314 & 0,289 & 0,525 & 0,735 \\
\hline AT1G52220.3 & $\begin{array}{c}\text { BEST Arabidopsis thaliana } \\
\text { protein match: photosystem } \\
\text { I P subunit } \\
\text { (TAIR:AT2G46820.2) }\end{array}$ & 0,325 & 0,266 & 0,521 & 0,743 & 39 & 0,314 & 0,289 & 0,525 & 0,735 \\
\hline AT3G47295.1 & unknown protein & 0,336 & 0,254 & 0,520 & 0,743 & 39 & 0,314 & 0,289 & 0,525 & 0,735 \\
\hline AT5G47610.1 & $\begin{array}{l}\text { RING/U-box superfamily } \\
\text { protein }\end{array}$ & 0,294 & 0,248 & 0,534 & 0,753 & 39 & 0,314 & 0,289 & 0,525 & 0,735 \\
\hline AT1G68590.2 & $\begin{array}{c}\text { Ribosomal protein PSRP- } \\
3 / Y c f 65\end{array}$ & 0,342 & 0,259 & 0,508 & 0,747 & 39 & 0,314 & 0,289 & 0,525 & 0,735 \\
\hline AT1G01320.2 & $\begin{array}{c}\text { Tetratricopeptide repeat } \\
\text { (TPR)-like superfamily } \\
\text { protein } \\
\end{array}$ & 0,334 & 0,249 & 0,532 & 0,737 & 39 & 0,314 & 0,289 & 0,525 & 0,735 \\
\hline AT1G54780.1 & $\begin{array}{l}\text { TLP18.3 thylakoid lumen } \\
18.3 \mathrm{kDa} \text { protein }\end{array}$ & 0,299 & 0,262 & 0,515 & 0,760 & 39 & 0,314 & 0,289 & 0,525 & 0,735 \\
\hline AT5G22800.1 & $\begin{array}{c}\text { EMB86 EMB1030 EMB263 } \\
\text { Alanyl-tRNA synthetase } \\
\text { class Ilc }\end{array}$ & 0,290 & 0,253 & 0,540 & 0,749 & 39 & 0,314 & 0,289 & 0,525 & 0,735 \\
\hline $\begin{array}{c}\text { ATCG00690. } \\
1 \\
\end{array}$ & $\begin{array}{l}\text { PSBT PSBTC photosystem } \\
\text { II reaction center protein T }\end{array}$ & 0,338 & 0,249 & 0,512 & 0,750 & 39 & 0,314 & 0,289 & 0,525 & 0,735 \\
\hline AT1G31330.1 & $\begin{array}{l}\text { PSAF photosystem I } \\
\text { subunit } F\end{array}$ & 0,345 & 0,247 & 0,529 & 0,735 & 39 & 0,314 & 0,289 & 0,525 & 0,735 \\
\hline AT2G26500.2 & $\begin{array}{l}\text { cytochrome b6f complex } \\
\text { subunit (petM) putative }\end{array}$ & 0,272 & 0,255 & 0,535 & 0,758 & 39 & 0,314 & 0,289 & 0,525 & 0,735 \\
\hline $\begin{array}{c}\text { ATCG01190. } \\
1\end{array}$ & TRNA.2 tRNA-Ala & 0,365 & 0,234 & 0,520 & 0,736 & 39 & 0,314 & 0,289 & 0,525 & 0,735 \\
\hline AT4G29020.1 & glycine-rich protein & 0,314 & 0,243 & 0,532 & 0,748 & 39 & 0,314 & 0,289 & 0,525 & 0,735 \\
\hline AT1G03630.2 & $\begin{array}{l}\text { POR C PORC } \\
\text { protochlorophyllide } \\
\text { oxidoreductase C }\end{array}$ & 0,360 & 0,223 & 0,502 & 0,754 & 39 & 0,314 & 0,289 & 0,525 & 0,735 \\
\hline AT4G10500.1 & $\begin{array}{l}\text { 2-oxoglutarate (2OG) and } \\
\mathrm{Fe}(\mathrm{II}) \text {-dependent oxygenase } \\
\text { superfamily protein }\end{array}$ & 0,239 & 0,381 & 0,475 & 0,756 & 40 & 0,254 & 0,288 & 0,481 & 0,786 \\
\hline AT5G58140.4 & PHOT2 NPL1 phototropin 2 & 0,248 & 0,344 & 0,507 & 0,751 & 40 & 0,254 & 0,288 & 0,481 & 0,786 \\
\hline AT1G61190.1 & $\begin{array}{l}\text { LRR and NB-ARC domains- } \\
\text { containing disease } \\
\text { resistance protein }\end{array}$ & 0,270 & 0,348 & 0,429 & 0,789 & 40 & 0,254 & 0,288 & 0,481 & 0,786 \\
\hline AT1G77490.1 & $\begin{array}{c}\text { TAPX thylakoidal ascorbate } \\
\text { peroxidase }\end{array}$ & 0,245 & 0,335 & 0,483 & 0,771 & 40 & 0,254 & 0,288 & 0,481 & 0,786 \\
\hline AT3G63140.1 & $\begin{array}{l}\text { CSP41A chloroplast stem- } \\
\text { loop binding protein of } 41 \\
\text { kDa }\end{array}$ & 0,254 & 0,322 & 0,469 & 0,782 & 40 & 0,254 & 0,288 & 0,481 & 0,786 \\
\hline AT3G18890.1 & NAD(P)-binding Rossmann- & 0,253 & 0,280 & 0,511 & 0,772 & 40 & 0,254 & 0,288 & 0,481 & 0,786 \\
\hline
\end{tabular}


Anhang

\begin{tabular}{|c|c|c|c|c|c|c|c|c|c|c|}
\hline & fold superfamily protein & & & & & & & & & \\
\hline AT5G09660.4 & $\begin{array}{l}\text { PMDH2 peroxisomal NAD- } \\
\text { malate dehydrogenase } 2\end{array}$ & 0,231 & 0,282 & 0,474 & 0,801 & 40 & 0,254 & 0,288 & 0,481 & 0,786 \\
\hline AT2G10940.2 & $\begin{array}{l}\text { Bifunctional inhibitor/lipid- } \\
\text { transfer protein/seed } \\
\text { storage } 2 \mathrm{~S} \text { albumin } \\
\text { superfamily protein }\end{array}$ & 0,259 & 0,291 & 0,410 & 0,825 & 40 & 0,254 & 0,288 & 0,481 & 0,786 \\
\hline AT4G03280.2 & $\begin{array}{c}\text { PETC PGR1 } \\
\text { photosynthetic electron } \\
\text { transfer C }\end{array}$ & 0,264 & 0,270 & 0,518 & 0,767 & 40 & 0,254 & 0,288 & 0,481 & 0,786 \\
\hline AT3G61310.1 & $\begin{array}{c}\text { AT hook motif DNA-binding } \\
\text { family protein }\end{array}$ & 0,309 & 0,259 & 0,481 & 0,779 & 40 & 0,254 & 0,288 & 0,481 & 0,786 \\
\hline AT5G44572.1 & unknown protein & 0,246 & 0,282 & 0,468 & 0,801 & 40 & 0,254 & 0,288 & 0,481 & 0,786 \\
\hline AT1G12900.4 & $\begin{array}{c}\text { GAPA-2 glyceraldehyde 3- } \\
\text { phosphate dehydrogenase } \\
\text { A subunit } 2\end{array}$ & 0,259 & 0,266 & 0,508 & 0,777 & 40 & 0,254 & 0,288 & 0,481 & 0,786 \\
\hline AT3G07185.1 & pre-tRNA & 0,266 & 0,261 & 0,517 & 0,770 & 40 & 0,254 & 0,288 & 0,481 & 0,786 \\
\hline AT4G16980.1 & $\begin{array}{l}\text { arabinogalactan-protein } \\
\text { family }\end{array}$ & 0,286 & 0,255 & 0,485 & 0,787 & 40 & 0,254 & 0,288 & 0,481 & 0,786 \\
\hline AT4G10060.1 & $\begin{array}{l}\text { Beta-glucosidase GBA2 } \\
\text { type family protein }\end{array}$ & 0,247 & 0,256 & 0,503 & 0,788 & 40 & 0,254 & 0,288 & 0,481 & 0,786 \\
\hline AT3G26450.1 & $\begin{array}{c}\text { Polyketide } \\
\text { cyclase/dehydrase and lipid } \\
\text { transport superfamily } \\
\text { protein }\end{array}$ & 0,223 & 0,262 & 0,494 & 0,799 & 40 & 0,254 & 0,288 & 0,481 & 0,786 \\
\hline AT2G05380.2 & $\begin{array}{c}\text { GRP3S glycine-rich protein } \\
3 \text { short isoform }\end{array}$ & 0,251 & 0,246 & 0,437 & 0,828 & 40 & 0,254 & 0,288 & 0,481 & 0,786 \\
\hline AT1G06680.2 & $\begin{array}{c}\text { PSBP-1 OEE2 PSII-P } \\
\text { photosystem II subunit P-1 }\end{array}$ & 0,223 & 0,239 & 0,486 & 0,810 & 40 & 0,254 & 0,288 & 0,481 & 0,786 \\
\hline AT3G47650.1 & $\begin{array}{l}\text { DnaJ/Hsp40 cysteine-rich } \\
\text { domain superfamily protein }\end{array}$ & 0,350 & 0,340 & 0,463 & 0,740 & 41 & 0,357 & 0,303 & 0,417 & 0,777 \\
\hline AT3G25880.1 & $\begin{array}{l}\text { NAD }(P) \text {-binding Rossmann- } \\
\text { fold superfamily protein }\end{array}$ & 0,384 & 0,345 & 0,357 & 0,778 & 41 & 0,357 & 0,303 & 0,417 & 0,777 \\
\hline AT2G39470.3 & PPL2 PsbP-like protein 2 & 0,360 & 0,341 & 0,451 & 0,742 & 41 & 0,357 & 0,303 & 0,417 & 0,777 \\
\hline AT5G64770.1 & $\begin{array}{l}\text { RGF9 Encodes a root } \\
\text { meristem growth factor } \\
\text { (RGF) }\end{array}$ & 0,363 & 0,341 & 0,382 & 0,779 & 41 & 0,357 & 0,303 & 0,417 & 0,777 \\
\hline AT4G38840.1 & $\begin{array}{l}\text { SAUR-like auxin-responsive } \\
\text { protein family }\end{array}$ & 0,344 & 0,338 & 0,428 & 0,764 & 41 & 0,357 & 0,303 & 0,417 & 0,777 \\
\hline AT4G12830.1 & $\begin{array}{l}\text { alpha/beta-Hydrolases } \\
\text { superfamily protein }\end{array}$ & 0,344 & 0,328 & 0,450 & 0,756 & 41 & 0,357 & 0,303 & 0,417 & 0,777 \\
\hline AT1G21250.1 & $\begin{array}{l}\text { WAK1 PRO25 cell wall- } \\
\text { associated kinase }\end{array}$ & 0,376 & 0,317 & 0,415 & 0,765 & 41 & 0,357 & 0,303 & 0,417 & 0,777 \\
\hline AT5G56850.1 & unknown protein & 0,344 & 0,309 & 0,438 & 0,771 & 41 & 0,357 & 0,303 & 0,417 & 0,777 \\
\hline AT2G43620.1 & Chitinase family protein & 0,348 & 0,314 & 0,407 & 0,784 & 41 & 0,357 & 0,303 & 0,417 & 0,777 \\
\hline AT1G33600.1 & $\begin{array}{l}\text { Leucine-rich repeat (LRR) } \\
\text { family protein }\end{array}$ & 0,317 & 0,318 & 0,387 & 0,805 & 41 & 0,357 & 0,303 & 0,417 & 0,777 \\
\hline AT3G05730.1 & $\begin{array}{l}\text { Encodes a defensin-like } \\
\text { (DEFL) family protein. }\end{array}$ & 0,396 & 0,307 & 0,364 & 0,785 & 41 & 0,357 & 0,303 & 0,417 & 0,777 \\
\hline AT1G51110.1 & $\begin{array}{c}\text { Plastid-lipid associated } \\
\text { protein PAP / fibrillin family } \\
\text { protein }\end{array}$ & 0,329 & 0,272 & 0,460 & 0,779 & 41 & 0,357 & 0,303 & 0,417 & 0,777 \\
\hline AT2G34430.1 & $\begin{array}{c}\text { LHB1B1 LHCB1.4 light- } \\
\text { harvesting chlorophyll- } \\
\text { protein complex II subunit } \\
\text { B1 }\end{array}$ & 0,361 & 0,267 & 0,442 & 0,777 & 41 & 0,357 & 0,303 & 0,417 & 0,777 \\
\hline AT5G57300.2 & $\begin{array}{c}\text { S-adenosyl-L-methionine- } \\
\text { dependent } \\
\text { methyltransferases } \\
\text { superfamily protein }\end{array}$ & 0,342 & 0,271 & 0,398 & 0,807 & 41 & 0,357 & 0,303 & 0,417 & 0,777 \\
\hline AT5G61270.1 & $\begin{array}{l}\text { PIF7 phytochrome- } \\
\text { interacting factor7 }\end{array}$ & 0,378 & 0,235 & 0,408 & 0,797 & 41 & 0,357 & 0,303 & 0,417 & 0,777 \\
\hline AT3G14210.1 & $\begin{array}{l}\text { ESM1 epithiospecifier } \\
\text { modifier } 1\end{array}$ & 0,378 & 0,200 & 0,416 & 0,802 & 41 & 0,357 & 0,303 & 0,417 & 0,777 \\
\hline AT1G21270.1 & $\begin{array}{c}\text { WAK2 wall-associated } \\
\text { kinase } 2\end{array}$ & 0,247 & 0,361 & 0,378 & 0,816 & 42 & 0,292 & 0,278 & 0,333 & 0,848 \\
\hline AT1G80660.1 & AHA9 HA9 $\mathrm{H}(+)$-ATPase 9 & 0,253 & 0,336 & 0,338 & 0,842 & 42 & 0,292 & 0,278 & 0,333 & 0,848 \\
\hline AT1G29510.1 & $\begin{array}{l}\text { SAUR68 SAUR-like auxin- } \\
\text { responsive protein family }\end{array}$ & 0,295 & 0,333 & 0,338 & 0,830 & 42 & 0,292 & 0,278 & 0,333 & 0,848 \\
\hline AT5G07100.1 & $\begin{array}{l}\text { WRKY26 WRKY DNA- } \\
\text { binding protein } 26\end{array}$ & 0,278 & 0,309 & 0,366 & 0,832 & 42 & 0,292 & 0,278 & 0,333 & 0,848 \\
\hline
\end{tabular}




\begin{tabular}{|c|c|c|c|c|c|c|c|c|c|c|}
\hline AT3G16660.1 & $\begin{array}{c}\text { Pollen Ole e } 1 \text { allergen and } \\
\text { extensin family protein }\end{array}$ & 0,303 & 0,277 & 0,313 & 0,857 & 42 & 0,292 & 0,278 & 0,333 & 0,848 \\
\hline AT5G44568.1 & unknown protein & 0,245 & 0,289 & 0,300 & 0,875 & 42 & 0,292 & 0,278 & 0,333 & 0,848 \\
\hline AT2G41090.1 & $\begin{array}{l}\text { Calcium-binding EF-hand } \\
\text { family protein }\end{array}$ & 0,248 & 0,230 & 0,301 & 0,891 & 42 & 0,292 & 0,278 & 0,333 & 0,848 \\
\hline AT2G33620.3 & $\begin{array}{l}\text { AT hook motif DNA-binding } \\
\text { family protein }\end{array}$ & 0,371 & 0,217 & 0,328 & 0,841 & 42 & 0,292 & 0,278 & 0,333 & 0,848 \\
\hline AT5G25980.3 & $\begin{array}{l}\text { TGG2 BGLU37 glucoside } \\
\text { glucohydrolase } 2\end{array}$ & 0,391 & 0,154 & 0,334 & 0,844 & 42 & 0,292 & 0,278 & 0,333 & 0,848 \\
\hline AT5G01900.1 & $\begin{array}{c}\text { WRKY62 ATWRKY62 } \\
\text { WRKY DNA-binding protein } \\
62\end{array}$ & 0,107 & 0,412 & 0,243 & 0,871 & 43 & 0,121 & 0,289 & 0,188 & 0,923 \\
\hline AT2G26400.1 & $\begin{array}{c}\text { ARD ATARD3 ARD3 } \\
\text { acireductone dioxygenase } 3\end{array}$ & 0,163 & 0,307 & 0,294 & 0,890 & 43 & 0,121 & 0,289 & 0,188 & 0,923 \\
\hline AT5G22570.1 & $\begin{array}{c}\text { WRKY38 ATWRKY38 } \\
\text { WRKY DNA-binding protein } \\
38\end{array}$ & 0,074 & 0,337 & 0,164 & 0,924 & 43 & 0,121 & 0,289 & 0,188 & 0,923 \\
\hline AT3G22231.1 & $\begin{array}{l}\text { PCC1 pathogen and } \\
\text { circadian controlled } 1\end{array}$ & 0,132 & 0,242 & 0,119 & 0,954 & 43 & 0,121 & 0,289 & 0,188 & 0,923 \\
\hline AT5G03350.1 & Legume lectin family protein & 0,131 & 0,146 & 0,118 & 0,974 & 43 & 0,121 & 0,289 & 0,188 & 0,923 \\
\hline AT3G01500.2 & CA1 carbonic anhydrase 1 & 0,215 & 0,176 & 0,245 & 0,929 & 44 & 0,230 & 0,127 & 0,295 & 0,914 \\
\hline AT3G01500.3 & CA1 carbonic anhydrase 1 & 0,226 & 0,163 & 0,318 & 0,906 & 44 & 0,230 & 0,127 & 0,295 & 0,914 \\
\hline AT1G49750.1 & $\begin{array}{l}\text { Leucine-rich repeat (LRR) } \\
\text { family protein }\end{array}$ & 0,141 & 0,130 & 0,336 & 0,922 & 44 & 0,230 & 0,127 & 0,295 & 0,914 \\
\hline AT3G16670.1 & $\begin{array}{c}\text { Pollen Ole e } 1 \text { allergen and } \\
\text { extensin family protein }\end{array}$ & 0,276 & 0,087 & 0,221 & 0,931 & 44 & 0,230 & 0,127 & 0,295 & 0,914 \\
\hline AT2G24270.3 & $\begin{array}{l}\text { ALDH11A3 aldehyde } \\
\text { dehydrogenase } 11 \mathrm{~A} 3\end{array}$ & 0,294 & 0,077 & 0,357 & 0,883 & 44 & 0,230 & 0,127 & 0,295 & 0,914 \\
\hline AT1G32060.1 & PRK phosphoribulokinase & 0,157 & 0,259 & 0,400 & 0,865 & 45 & 0,213 & 0,162 & 0,422 & 0,863 \\
\hline AT1G66970.2 & SVL2 SHV3-like 2 & 0,197 & 0,207 & 0,413 & 0,865 & 45 & 0,213 & 0,162 & 0,422 & 0,863 \\
\hline AT4G16990.5 & $\begin{array}{c}\text { RLM3 disease resistance } \\
\text { protein (TIR-NBS class) } \\
\text { putative }\end{array}$ & 0,226 & 0,204 & 0,419 & 0,856 & 45 & 0,213 & 0,162 & 0,422 & 0,863 \\
\hline AT5G18030.1 & $\begin{array}{c}\text { SAUR-like auxin-responsive } \\
\text { protein family }\end{array}$ & 0,165 & 0,207 & 0,417 & 0,870 & 45 & 0,213 & 0,162 & 0,422 & 0,863 \\
\hline AT5G44580.1 & unknown protein & 0,264 & 0,196 & 0,429 & 0,841 & 45 & 0,213 & 0,162 & 0,422 & 0,863 \\
\hline AT2G35830.2 & unknown protein & 0,250 & 0,175 & 0,402 & 0,863 & 45 & 0,213 & 0,162 & 0,422 & 0,863 \\
\hline AT1G31580.1 & ECS1 CXC750 ECS1 & 0,133 & 0,143 & 0,415 & 0,889 & 45 & 0,213 & 0,162 & 0,422 & 0,863 \\
\hline AT5G14740.5 & $\begin{array}{l}\text { CA2 CA18 BETA CA2 } \\
\text { carbonic anhydrase } 2\end{array}$ & 0,299 & 0,116 & 0,396 & 0,860 & 45 & 0,213 & 0,162 & 0,422 & 0,863 \\
\hline AT5G38420.1 & $\begin{array}{c}\text { Ribulose bisphosphate } \\
\text { carboxylase (small chain) } \\
\text { family protein }\end{array}$ & 0,238 & 0,108 & 0,438 & 0,860 & 45 & 0,213 & 0,162 & 0,422 & 0,863 \\
\hline AT3G22120.1 & $\begin{array}{l}\text { CWLP cell wall-plasma } \\
\text { membrane linker protein }\end{array}$ & 0,216 & 0,087 & 0,468 & 0,852 & 45 & 0,213 & 0,162 & 0,422 & 0,863 \\
\hline AT5G26000.2 & $\begin{array}{l}\text { TGG1 BGLU38 } \\
\text { thioglucoside } \\
\text { glucohydrolase } 1 \\
\end{array}$ & 0,202 & 0,081 & 0,446 & 0,868 & 45 & 0,213 & 0,162 & 0,422 & 0,863 \\
\hline AT1G42970.1 & $\begin{array}{c}\text { GAPB glyceraldehyde-3- } \\
\text { phosphate dehydrogenase } \\
\text { B subunit }\end{array}$ & 0,200 & 0,193 & 0,494 & 0,824 & 46 & 0,167 & 0,144 & 0,514 & 0,827 \\
\hline AT5G38980.1 & unknown protein & 0,194 & 0,189 & 0,504 & 0,820 & 46 & 0,167 & 0,144 & 0,514 & 0,827 \\
\hline AT3G55800.1 & $\begin{array}{l}\text { SBPASE sedoheptulose- } \\
\text { bisphosphatase }\end{array}$ & 0,207 & 0,178 & 0,488 & 0,829 & 46 & 0,167 & 0,144 & 0,514 & 0,827 \\
\hline AT3G54050.1 & $\begin{array}{c}\text { HCEF1 high cyclic electron } \\
\text { flow } 1\end{array}$ & 0,159 & 0,173 & 0,469 & 0,851 & 46 & 0,167 & 0,144 & 0,514 & 0,827 \\
\hline AT1G78170.1 & unknown protein & 0,158 & 0,151 & 0,548 & 0,807 & 46 & 0,167 & 0,144 & 0,514 & 0,827 \\
\hline AT2G30570.1 & $\begin{array}{l}\text { PSBW photosystem II } \\
\text { reaction center W }\end{array}$ & 0,204 & 0,167 & 0,530 & 0,806 & 46 & 0,167 & 0,144 & 0,514 & 0,827 \\
\hline AT1G09310.1 & $\begin{array}{c}\text { Protein of unknown function } \\
\text { DUF538 }\end{array}$ & 0,123 & 0,185 & 0,509 & 0,832 & 46 & 0,167 & 0,144 & 0,514 & 0,827 \\
\hline AT1G68530.2 & $\begin{array}{c}\text { CUT1 POP1 CER6 G2 } \\
\text { KCS6 3-ketoacyl-CoA } \\
\text { synthase } 6\end{array}$ & 0,192 & 0,163 & 0,502 & 0,827 & 46 & 0,167 & 0,144 & 0,514 & 0,827 \\
\hline AT2G42220.1 & $\begin{array}{l}\text { Rhodanese/Cell cycle } \\
\text { control phosphatase } \\
\text { superfamily protein }\end{array}$ & 0,215 & 0,160 & 0,521 & 0,810 & 46 & 0,167 & 0,144 & 0,514 & 0,827 \\
\hline
\end{tabular}


Anhang

\begin{tabular}{|c|c|c|c|c|c|c|c|c|c|c|}
\hline AT2G45190.1 & $\begin{array}{l}\text { AFO FIL YAB1 Plant- } \\
\text { specific transcription factor } \\
\text { YABBY family protein }\end{array}$ & 0,194 & 0,145 & 0,541 & 0,806 & 46 & 0,167 & 0,144 & 0,514 & 0,827 \\
\hline AT1G44575.2 & $\begin{array}{c}\text { NPQ4 PSBS Chlorophyll A- } \\
\text { B binding family protein }\end{array}$ & 0,194 & 0,153 & 0,544 & 0,802 & 46 & 0,167 & 0,144 & 0,514 & 0,827 \\
\hline AT1G55670.1 & $\begin{array}{c}\text { PSAG photosystem I } \\
\text { subunit G }\end{array}$ & 0,183 & 0,153 & 0,515 & 0,823 & 46 & 0,167 & 0,144 & 0,514 & 0,827 \\
\hline AT1G20340.1 & $\begin{array}{c}\text { DRT112 PETE2 } \\
\text { Cupredoxin superfamily } \\
\text { protein }\end{array}$ & 0,200 & 0,147 & 0,522 & 0,816 & 46 & 0,167 & 0,144 & 0,514 & 0,827 \\
\hline AT1G14440.2 & $\begin{array}{l}\text { AtHB31 HB31 ZHD4 } \\
\text { homeobox protein } 31\end{array}$ & 0,173 & 0,136 & 0,500 & 0,838 & 46 & 0,167 & 0,144 & 0,514 & 0,827 \\
\hline AT2G21330.3 & $\begin{array}{c}\text { FBA1 fructose- } \\
\text { bisphosphate aldolase } 1\end{array}$ & 0,174 & 0,124 & 0,494 & 0,843 & 46 & 0,167 & 0,144 & 0,514 & 0,827 \\
\hline AT4G10340.1 & $\begin{array}{c}\text { LHCB5 light harvesting } \\
\text { complex of photosystem II } 5\end{array}$ & 0,194 & 0,120 & 0,532 & 0,816 & 46 & 0,167 & 0,144 & 0,514 & 0,827 \\
\hline AT3G14420.6 & $\begin{array}{l}\text { Aldolase-type TIM barrel } \\
\text { family protein }\end{array}$ & 0,132 & 0,119 & 0,488 & 0,855 & 46 & 0,167 & 0,144 & 0,514 & 0,827 \\
\hline AT4G28750.1 & $\begin{array}{c}\text { PSAE-1 Photosystem I } \\
\text { reaction centre subunit IV / } \\
\text { PsaE protein }\end{array}$ & 0,179 & 0,113 & 0,534 & 0,819 & 46 & 0,167 & 0,144 & 0,514 & 0,827 \\
\hline AT5G42530.1 & unknown protein & 0,086 & 0,104 & 0,498 & 0,857 & 46 & 0,167 & 0,144 & 0,514 & 0,827 \\
\hline AT5G38430.1 & $\begin{array}{c}\text { Ribulose bisphosphate } \\
\text { carboxylase (small chain) } \\
\text { family protein } \\
\end{array}$ & 0,077 & 0,087 & 0,485 & 0,867 & 46 & 0,167 & 0,144 & 0,514 & 0,827 \\
\hline AT2G15050.1 & $\begin{array}{l}\text { LTP LTP7 lipid transfer } \\
\text { protein }\end{array}$ & 0,069 & 0,054 & 0,574 & 0,814 & 46 & 0,167 & 0,144 & 0,514 & 0,827 \\
\hline AT3G59400.1 & $\begin{array}{c}\text { GUN4 enzyme } \\
\text { binding;tetrapyrrole binding }\end{array}$ & 0,235 & 0,230 & 0,560 & 0,760 & 47 & 0,245 & 0,202 & 0,534 & 0,782 \\
\hline AT4G04890.1 & PDF2 protodermal factor 2 & 0,253 & 0,243 & 0,527 & 0,774 & 47 & 0,245 & 0,202 & 0,534 & 0,782 \\
\hline AT5G54770.1 & $\begin{array}{c}\text { THI1 TZ THI4 thiazole } \\
\text { biosynthetic enzyme } \\
\text { chloroplast (ARA6) (THI1) } \\
\text { (THI4) }\end{array}$ & 0,210 & 0,242 & 0,573 & 0,754 & 47 & 0,245 & 0,202 & 0,534 & 0,782 \\
\hline AT1G32470.1 & $\begin{array}{l}\text { Single hybrid motif } \\
\text { superfamily protein }\end{array}$ & 0,237 & 0,237 & 0,546 & 0,767 & 47 & 0,245 & 0,202 & 0,534 & 0,782 \\
\hline AT5G07180.1 & ERL2 ERECTA-like 2 & 0,235 & 0,239 & 0,530 & 0,779 & 47 & 0,245 & 0,202 & 0,534 & 0,782 \\
\hline AT2G05540.1 & Glycine-rich protein family & 0,205 & 0,244 & 0,517 & 0,794 & 47 & 0,245 & 0,202 & 0,534 & 0,782 \\
\hline AT3G55330.1 & PPL1 PsbP-like protein 1 & 0,275 & 0,228 & 0,500 & 0,789 & 47 & 0,245 & 0,202 & 0,534 & 0,782 \\
\hline AT2G23000.1 & $\begin{array}{c}\text { scpl10 serine } \\
\text { carboxypeptidase-like } 10\end{array}$ & 0,186 & 0,226 & 0,559 & 0,776 & 47 & 0,245 & 0,202 & 0,534 & 0,782 \\
\hline AT3G46780.1 & $\begin{array}{c}\text { PTAC16 plastid } \\
\text { transcriptionally active } 16\end{array}$ & 0,291 & 0,223 & 0,530 & 0,765 & 47 & 0,245 & 0,202 & 0,534 & 0,782 \\
\hline AT4G27300.1 & $\begin{array}{c}\text { S-locus lectin protein kinase } \\
\text { family protein }\end{array}$ & 0,201 & 0,230 & 0,579 & 0,756 & 47 & 0,245 & 0,202 & 0,534 & 0,782 \\
\hline AT5G23060.1 & $\begin{array}{l}\text { CaS calcium sensing } \\
\text { receptor }\end{array}$ & 0,264 & 0,225 & 0,532 & 0,773 & 47 & 0,245 & 0,202 & 0,534 & 0,782 \\
\hline AT4G12800.1 & $\begin{array}{c}\text { PSAL photosystem I } \\
\text { subunit I }\end{array}$ & 0,253 & 0,217 & 0,542 & 0,771 & 47 & 0,245 & 0,202 & 0,534 & 0,782 \\
\hline AT3G26650.1 & $\begin{array}{c}\text { GAPA GAPA-1 } \\
\text { glyceraldehyde 3-phosphate } \\
\text { dehydrogenase A subunit }\end{array}$ & 0,272 & 0,206 & 0,507 & 0,791 & 47 & 0,245 & 0,202 & 0,534 & 0,782 \\
\hline AT4G21650.1 & Subtilase family protein & 0,297 & 0,195 & 0,546 & 0,759 & 47 & 0,245 & 0,202 & 0,534 & 0,782 \\
\hline AT1G70760.1 & $\begin{array}{l}\text { CRR23 inorganic carbon } \\
\text { transport protein-related }\end{array}$ & 0,247 & 0,219 & 0,511 & 0,794 & 47 & 0,245 & 0,202 & 0,534 & 0,782 \\
\hline AT1G32900.1 & $\begin{array}{l}\text { UDP-Glycosyltransferase } \\
\text { superfamily protein }\end{array}$ & 0,210 & 0,208 & 0,546 & 0,784 & 47 & 0,245 & 0,202 & 0,534 & 0,782 \\
\hline AT1G29660.1 & $\begin{array}{c}\text { GDSL-like } \\
\text { Lipase/Acylhydrolase } \\
\text { superfamily protein }\end{array}$ & 0,235 & 0,204 & 0,522 & 0,794 & 47 & 0,245 & 0,202 & 0,534 & 0,782 \\
\hline AT4G38970.2 & $\begin{array}{c}\text { FBA2 fructose- } \\
\text { bisphosphate aldolase } 2\end{array}$ & 0,214 & 0,200 & 0,581 & 0,759 & 47 & 0,245 & 0,202 & 0,534 & 0,782 \\
\hline AT1G15820.1 & $\begin{array}{c}\text { LHCB6 CP24 light } \\
\text { harvesting complex } \\
\text { photosystem II subunit } 6\end{array}$ & 0,245 & 0,205 & 0,506 & 0,801 & 47 & 0,245 & 0,202 & 0,534 & 0,782 \\
\hline AT3G16140.1 & $\begin{array}{l}\text { PSAH-1 photosystem I } \\
\text { subunit } \mathrm{H}-1\end{array}$ & 0,244 & 0,207 & 0,524 & 0,789 & 47 & 0,245 & 0,202 & 0,534 & 0,782 \\
\hline AT2G39730.3 & RCA rubisco activase & 0,257 & 0,193 & 0,578 & 0,750 & 47 & 0,245 & 0,202 & 0,534 & 0,782 \\
\hline AT3G61470.1 & $\begin{array}{l}\text { LHCA2 photosystem I light } \\
\text { harvesting complex gene } 2\end{array}$ & 0,228 & 0,197 & 0,517 & 0,801 & 47 & 0,245 & 0,202 & 0,534 & 0,782 \\
\hline
\end{tabular}




\begin{tabular}{|c|c|c|c|c|c|c|c|c|c|c|}
\hline AT1G30380.1 & $\begin{array}{c}\text { PSAK photosystem I } \\
\text { subunit K }\end{array}$ & 0,283 & 0,199 & 0,516 & 0,784 & 47 & 0,245 & 0,202 & 0,534 & 0,782 \\
\hline AT2G26910.1 & $\begin{array}{c}\text { PDR4 ATPDR4 pleiotropic } \\
\text { drug resistance } 4\end{array}$ & 0,231 & 0,183 & 0,574 & 0,764 & 47 & 0,245 & 0,202 & 0,534 & 0,782 \\
\hline AT1G61520.3 & $\begin{array}{l}\text { LHCA3 photosystem I light } \\
\text { harvesting complex gene } 3\end{array}$ & 0,263 & 0,195 & 0,578 & 0,748 & 47 & 0,245 & 0,202 & 0,534 & 0,782 \\
\hline AT1G52220.2 & unknown protein & 0,290 & 0,195 & 0,528 & 0,774 & 47 & 0,245 & 0,202 & 0,534 & 0,782 \\
\hline AT4G05180.1 & $\begin{array}{c}\text { PSBQ PSBQ-2 PSII-Q } \\
\text { photosystem II subunit Q-2 }\end{array}$ & 0,258 & 0,191 & 0,544 & 0,775 & 47 & 0,245 & 0,202 & 0,534 & 0,782 \\
\hline AT5G04140.2 & $\begin{array}{c}\text { GLU1 GLS1 GLUS FD- } \\
\text { GOGAT glutamate } \\
\text { synthase } 1 \\
\end{array}$ & 0,235 & 0,186 & 0,537 & 0,788 & 47 & 0,245 & 0,202 & 0,534 & 0,782 \\
\hline AT5G53210.1 & $\begin{array}{l}\text { SPCH basic helix-loop- } \\
\text { helix (bHLH) DNA-binding } \\
\text { superfamily protein }\end{array}$ & 0,259 & 0,169 & 0,524 & 0,793 & 47 & 0,245 & 0,202 & 0,534 & 0,782 \\
\hline AT1G20020.3 & $\begin{array}{c}\text { ATLFNR2 ferredoxin- } \\
\text { NADP }(+) \text {-oxidoreductase } 2\end{array}$ & 0,253 & 0,189 & 0,478 & 0,820 & 47 & 0,245 & 0,202 & 0,534 & 0,782 \\
\hline AT2G34420.1 & $\begin{array}{c}\text { LHB1B2 LHCB1.5 } \\
\text { photosystem II light } \\
\text { harvesting complex gene } \\
\text { B1B2 } \\
\end{array}$ & 0,306 & 0,192 & 0,511 & 0,780 & 47 & 0,245 & 0,202 & 0,534 & 0,782 \\
\hline AT3G54050.2 & $\begin{array}{c}\text { HCEF1 high cyclic electron } \\
\text { flow } 1\end{array}$ & 0,222 & 0,186 & 0,531 & 0,796 & 47 & 0,245 & 0,202 & 0,534 & 0,782 \\
\hline AT1G68010.2 & $\begin{array}{l}\text { HPR hydroxypyruvate } \\
\text { reductase }\end{array}$ & 0,198 & 0,184 & 0,539 & 0,798 & 47 & 0,245 & 0,202 & 0,534 & 0,782 \\
\hline AT4G28080.1 & $\begin{array}{l}\text { Tetratricopeptide repeat } \\
\text { (TPR)-like superfamily } \\
\text { protein }\end{array}$ & 0,265 & 0,180 & 0,519 & 0,792 & 47 & 0,245 & 0,202 & 0,534 & 0,782 \\
\hline AT2G26330.1 & $\begin{array}{c}\text { ER QRP1 Leucine-rich } \\
\text { receptor-like protein kinase } \\
\text { family protein }\end{array}$ & 0,245 & 0,173 & 0,494 & 0,816 & 47 & 0,245 & 0,202 & 0,534 & 0,782 \\
\hline AT1G64710.2 & $\begin{array}{c}\text { GroES-like zinc-binding } \\
\text { dehydrogenase family } \\
\text { protein }\end{array}$ & 0,232 & 0,179 & 0,553 & 0,780 & 47 & 0,245 & 0,202 & 0,534 & 0,782 \\
\hline AT1G51805.1 & $\begin{array}{l}\text { Leucine-rich repeat protein } \\
\text { kinase family protein }\end{array}$ & 0,231 & 0,196 & 0,491 & 0,817 & 47 & 0,245 & 0,202 & 0,534 & 0,782 \\
\hline AT2G38540.1 & $\begin{array}{l}\text { LP1 LTP1 ATLTP1 lipid } \\
\text { transfer protein } 1\end{array}$ & 0,279 & 0,162 & 0,529 & 0,785 & 47 & 0,245 & 0,202 & 0,534 & 0,782 \\
\hline AT3G56940.1 & $\begin{array}{c}\text { CRD1 CHL27 ACSF } \\
\text { dicarboxylate diiron protein } \\
\text { putative (Crd1) }\end{array}$ & 0,261 & 0,174 & 0,555 & 0,771 & 47 & 0,245 & 0,202 & 0,534 & 0,782 \\
\hline AT1G78970.2 & $\begin{array}{c}\text { LUP1 ATLUP1 lupeol } \\
\text { synthase } 1\end{array}$ & 0,218 & 0,169 & 0,551 & 0,787 & 47 & 0,245 & 0,202 & 0,534 & 0,782 \\
\hline AT3G56940.2 & $\begin{array}{l}\text { CRD1 dicarboxylate diiron } \\
\text { protein putative (Crd1) }\end{array}$ & 0,225 & 0,154 & 0,526 & 0,806 & 47 & 0,245 & 0,202 & 0,534 & 0,782 \\
\hline AT2G15050.3 & $\begin{array}{l}\text { LTP LTP7 lipid transfer } \\
\text { protein }\end{array}$ & 0,179 & 0,205 & 0,584 & 0,765 & 48 & 0,187 & 0,144 & 0,590 & 0,770 \\
\hline AT1G27950.1 & $\begin{array}{c}\text { LTPG1 } \\
\text { glycosylphosphatidylinositol } \\
\text {-anchored lipid protein } \\
\text { transfer } 1 \\
\end{array}$ & 0,223 & 0,191 & 0,592 & 0,751 & 48 & 0,187 & 0,144 & 0,590 & 0,770 \\
\hline AT1G51500.1 & $\begin{array}{l}\text { CER5 D3 ABCG12 WBC12 } \\
\text { ATWBC12 ABC-2 type } \\
\text { transporter family protein }\end{array}$ & 0,196 & 0,198 & 0,578 & 0,767 & 48 & 0,187 & 0,144 & 0,590 & 0,770 \\
\hline AT4G39330.2 & $\begin{array}{l}\text { ATCAD9 CAD9 cinnamyl } \\
\text { alcohol dehydrogenase } 9\end{array}$ & 0,191 & 0,186 & 0,593 & 0,759 & 48 & 0,187 & 0,144 & 0,590 & 0,770 \\
\hline AT3G23290.2 & $\begin{array}{l}\text { LSH4 Protein of unknown } \\
\text { function (DUF640) }\end{array}$ & 0,166 & 0,175 & 0,564 & 0,790 & 48 & 0,187 & 0,144 & 0,590 & 0,770 \\
\hline AT1G45201.2 & $\begin{array}{c}\text { ATTLL1 TLL1 } \\
\text { triacylglycerol lipase-like } 1\end{array}$ & 0,196 & 0,171 & 0,620 & 0,740 & 48 & 0,187 & 0,144 & 0,590 & 0,770 \\
\hline AT3G16530.1 & Legume lectin family protein & 0,167 & 0,178 & 0,584 & 0,774 & 48 & 0,187 & 0,144 & 0,590 & 0,770 \\
\hline AT4G13495.2 & other RNA & 0,166 & 0,174 & 0,583 & 0,776 & 48 & 0,187 & 0,144 & 0,590 & 0,770 \\
\hline AT2G24270.4 & $\begin{array}{l}\text { ALDH11A3 aldehyde } \\
\text { dehydrogenase } 11 \mathrm{~A} 3\end{array}$ & 0,222 & 0,173 & 0,574 & 0,769 & 48 & 0,187 & 0,144 & 0,590 & 0,770 \\
\hline AT2G32690.4 & $\begin{array}{c}\text { ATGRP23 GRP23 glycine- } \\
\text { rich protein } 23\end{array}$ & 0,232 & 0,167 & 0,583 & 0,760 & 48 & 0,187 & 0,144 & 0,590 & 0,770 \\
\hline AT1G29670.1 & $\begin{array}{c}\text { GDSL-like } \\
\text { Lipase/Acylhydrolase } \\
\text { superfamily protein }\end{array}$ & 0,181 & 0,161 & 0,601 & 0,762 & 48 & 0,187 & 0,144 & 0,590 & 0,770 \\
\hline AT1G06360.1 & \begin{tabular}{|c} 
Fatty acid desaturase family \\
protein
\end{tabular} & 0,212 & 0,136 & 0,600 & 0,759 & 48 & 0,187 & 0,144 & 0,590 & 0,770 \\
\hline AT4G33220.1 & PME44 ATPME44 pectin & 0,204 & 0,160 & 0,574 & 0,777 & 48 & 0,187 & 0,144 & 0,590 & 0,770 \\
\hline
\end{tabular}




\begin{tabular}{|c|c|c|c|c|c|c|c|c|c|c|}
\hline & methylesterase 44 & & & & & & & & & \\
\hline AT2G05070.1 & $\begin{array}{c}\text { LHCB2.2 LHCB2 } \\
\text { photosystem II light } \\
\text { harvesting complex gene } \\
2.2\end{array}$ & 0,198 & 0,156 & 0,583 & 0,772 & 48 & 0,187 & 0,144 & 0,590 & 0,770 \\
\hline AT5G46110.4 & $\begin{array}{l}\text { APE2 TPT Glucose-6- } \\
\text { phosphate/phosphate } \\
\text { translocator-related }\end{array}$ & 0,205 & 0,154 & 0,558 & 0,789 & 48 & 0,187 & 0,144 & 0,590 & 0,770 \\
\hline AT4G02770.1 & $\begin{array}{c}\text { PSAD-1 photosystem I } \\
\text { subunit D-1 }\end{array}$ & 0,218 & 0,149 & 0,595 & 0,760 & 48 & 0,187 & 0,144 & 0,590 & 0,770 \\
\hline AT2G36870.1 & $\begin{array}{c}\text { XTH32 xyloglucan } \\
\text { endotransglucosylase/hydro } \\
\text { lase } 32\end{array}$ & 0,233 & 0,150 & 0,559 & 0,781 & 48 & 0,187 & 0,144 & 0,590 & 0,770 \\
\hline AT1G45201.1 & $\begin{array}{c}\text { ATTLL1 TLL1 } \\
\text { triacylglycerol lipase-like } 1\end{array}$ & 0,197 & 0,143 & 0,607 & 0,757 & 48 & 0,187 & 0,144 & 0,590 & 0,770 \\
\hline AT5G15780.1 & $\begin{array}{c}\text { Pollen Ole e } 1 \text { allergen and } \\
\text { extensin family protein }\end{array}$ & 0,240 & 0,137 & 0,567 & 0,776 & 48 & 0,187 & 0,144 & 0,590 & 0,770 \\
\hline AT3G04290.1 & $\begin{array}{l}\text { ATLTL1 LTL1 Li-tolerant } \\
\text { lipase } 1\end{array}$ & 0,234 & 0,131 & 0,584 & 0,766 & 48 & 0,187 & 0,144 & 0,590 & 0,770 \\
\hline AT2G38530.1 & $\begin{array}{l}\text { LTP2 LP2 cdf3 lipid } \\
\text { transfer protein } 2\end{array}$ & 0,165 & 0,136 & 0,597 & 0,773 & 48 & 0,187 & 0,144 & 0,590 & 0,770 \\
\hline AT1G17840.1 & $\begin{array}{l}\text { WBC11 ABCG11 DSO } \\
\text { COF1 ATWBC11 white- } \\
\text { brown complex homolog } \\
\text { protein } 11\end{array}$ & 0,196 & 0,138 & 0,572 & 0,785 & 48 & 0,187 & 0,144 & 0,590 & 0,770 \\
\hline AT2G24270.1 & $\begin{array}{l}\text { ALDH11A3 aldehyde } \\
\text { dehydrogenase } 11 \mathrm{~A} 3\end{array}$ & 0,194 & 0,128 & 0,614 & 0,755 & 48 & 0,187 & 0,144 & 0,590 & 0,770 \\
\hline AT1G52230.1 & $\begin{array}{l}\text { PSAH2 PSAH-2 PSI-H } \\
\text { photosystem I subunit H2 }\end{array}$ & 0,216 & 0,137 & 0,597 & 0,760 & 48 & 0,187 & 0,144 & 0,590 & 0,770 \\
\hline AT1G70830.5 & MLP28 MLP-like protein 28 & 0,161 & 0,143 & 0,630 & 0,746 & 48 & 0,187 & 0,144 & 0,590 & 0,770 \\
\hline AT2G36870.2 & $\begin{array}{c}\text { XTH32 xyloglucan } \\
\text { endotransglucosylase/hydro } \\
\text { lase } 32 \\
\end{array}$ & 0,126 & 0,131 & 0,577 & 0,796 & 48 & 0,187 & 0,144 & 0,590 & 0,770 \\
\hline AT2G42840.1 & PDF1 protodermal factor 1 & 0,185 & 0,119 & 0,619 & 0,754 & 48 & 0,187 & 0,144 & 0,590 & 0,770 \\
\hline AT5G67385.1 & $\begin{array}{l}\text { Phototropic-responsive } \\
\text { NPH3 family protein }\end{array}$ & 0,166 & 0,127 & 0,586 & 0,783 & 48 & 0,187 & 0,144 & 0,590 & 0,770 \\
\hline AT2G15050.2 & $\begin{array}{l}\text { LTP LTP7 lipid transfer } \\
\text { protein } \\
\end{array}$ & 0,165 & 0,133 & 0,576 & 0,789 & 48 & 0,187 & 0,144 & 0,590 & 0,770 \\
\hline AT3G16370.1 & $\begin{array}{c}\text { GDSL-like } \\
\text { Lipase/Acylhydrolase } \\
\text { superfamily protein }\end{array}$ & 0,169 & 0,120 & 0,617 & 0,759 & 48 & 0,187 & 0,144 & 0,590 & 0,770 \\
\hline AT3G21055.1 & $\begin{array}{c}\text { PSBTN photosystem II } \\
\text { subunit T }\end{array}$ & 0,189 & 0,129 & 0,557 & 0,798 & 48 & 0,187 & 0,144 & 0,590 & 0,770 \\
\hline AT4G37800.1 & $\begin{array}{c}\text { XTH7 xyloglucan } \\
\text { endotransglucosylase/hydro } \\
\text { lase } 7 \\
\end{array}$ & 0,194 & 0,117 & 0,642 & 0,733 & 48 & 0,187 & 0,144 & 0,590 & 0,770 \\
\hline AT5G08000.1 & $\begin{array}{c}\text { E13L3 PDCB2 glucan } \\
\text { endo-13-beta-glucosidase- } \\
\text { like protein } 3 \\
\end{array}$ & 0,184 & 0,115 & 0,594 & 0,775 & 48 & 0,187 & 0,144 & 0,590 & 0,770 \\
\hline AT5G54270.1 & $\begin{array}{l}\text { LHCB3 LHCB3*1 light- } \\
\text { harvesting chlorophyll B- } \\
\text { binding protein } 3\end{array}$ & 0,200 & 0,131 & 0,555 & 0,797 & 48 & 0,187 & 0,144 & 0,590 & 0,770 \\
\hline AT2G39010.1 & $\begin{array}{c}\text { PIP2E PIP2;6 plasma } \\
\text { membrane intrinsic protein } \\
2 \mathrm{E} \\
\end{array}$ & 0,156 & 0,116 & 0,569 & 0,799 & 48 & 0,187 & 0,144 & 0,590 & 0,770 \\
\hline AT4G13495.1 & other RNA & 0,168 & 0,107 & 0,591 & 0,781 & 48 & 0,187 & 0,144 & 0,590 & 0,770 \\
\hline AT3G44970.1 & $\begin{array}{l}\text { Cytochrome P450 } \\
\text { superfamily protein }\end{array}$ & 0,086 & 0,105 & 0,606 & 0,784 & 48 & 0,187 & 0,144 & 0,590 & 0,770 \\
\hline AT4G38770.1 & $\begin{array}{c}\text { PRP4 ATPRP4 proline-rich } \\
\text { protein } 4 \\
\end{array}$ & 0,166 & 0,092 & 0,636 & 0,748 & 48 & 0,187 & 0,144 & 0,590 & 0,770 \\
\hline AT1G29930.1 & $\begin{array}{l}\text { CAB1 AB140 CAB140 } \\
\text { LHCB1.3 chlorophyll A/B } \\
\text { binding protein } 1\end{array}$ & 0,143 & 0,078 & 0,608 & 0,777 & 48 & 0,187 & 0,144 & 0,590 & 0,770 \\
\hline AT5G01870.1 & $\begin{array}{l}\text { Bifunctional inhibitor/lipid- } \\
\text { transfer protein/seed } \\
\text { storage } 2 \mathrm{~S} \text { albumin } \\
\text { superfamily protein } \\
\end{array}$ & 0,226 & 0,272 & 0,658 & 0,665 & 49 & 0,240 & 0,225 & 0,622 & 0,709 \\
\hline AT3G20470.1 & $\begin{array}{l}\text { GRP-5 ATGRP-5 GRP5 } \\
\text { ATGRP5 glycine-rich } \\
\text { protein } 5\end{array}$ & 0,243 & 0,283 & 0,602 & 0,706 & 49 & 0,240 & 0,225 & 0,622 & 0,709 \\
\hline AT3G19710.1 & $\begin{array}{l}\text { BCAT4 branched-chain } \\
\text { aminotransferase } 4\end{array}$ & 0,215 & 0,269 & 0,638 & 0,688 & 49 & 0,240 & 0,225 & 0,622 & 0,709 \\
\hline
\end{tabular}




\begin{tabular}{|c|c|c|c|c|c|c|c|c|c|c|}
\hline AT1G20620.5 & $\begin{array}{c}\text { CAT3 SEN2 ATCAT3 } \\
\text { catalase } 3\end{array}$ & 0,231 & 0,267 & 0,618 & 0,702 & 49 & 0,240 & 0,225 & 0,622 & 0,709 \\
\hline AT4G12545.1 & $\begin{array}{l}\text { Bifunctional inhibitor/lipid- } \\
\text { transfer protein/seed } \\
\text { storage } 2 \mathrm{~S} \text { albumin } \\
\text { superfamily protein }\end{array}$ & 0,206 & 0,252 & 0,646 & 0,691 & 49 & 0,240 & 0,225 & 0,622 & 0,709 \\
\hline AT5G65010.2 & $\begin{array}{l}\text { ASN2 asparagine } \\
\text { synthetase } 2\end{array}$ & 0,279 & 0,252 & 0,619 & 0,689 & 49 & 0,240 & 0,225 & 0,622 & 0,709 \\
\hline AT5G58390.1 & $\begin{array}{c}\text { Peroxidase superfamily } \\
\text { protein }\end{array}$ & 0,262 & 0,242 & 0,628 & 0,691 & 49 & 0,240 & 0,225 & 0,622 & 0,709 \\
\hline AT1G61520.2 & $\begin{array}{l}\text { LHCA3 photosystem I light } \\
\text { harvesting complex gene } 3\end{array}$ & 0,260 & 0,242 & 0,619 & 0,701 & 49 & 0,240 & 0,225 & 0,622 & 0,709 \\
\hline AT1G37130.1 & \begin{tabular}{|c|} 
NIA2 B29 NIA2-1 CHL3 NR \\
NR2 ATNR2 nitrate \\
reductase 2
\end{tabular} & 0,224 & 0,290 & 0,589 & 0,720 & 49 & 0,240 & 0,225 & 0,622 & 0,709 \\
\hline AT4G28250.2 & $\begin{array}{c}\text { ATEXPB3 EXPB3 ATHEXP } \\
\text { BETA } 1.6 \text { expansin B3 }\end{array}$ & 0,248 & 0,235 & 0,665 & 0,664 & 49 & 0,240 & 0,225 & 0,622 & 0,709 \\
\hline AT3G49110.1 & $\begin{array}{l}\text { PRX33 PRXCA ATPRX33 } \\
\text { ATPCA peroxidase CA }\end{array}$ & 0,232 & 0,232 & 0,617 & 0,715 & 49 & 0,240 & 0,225 & 0,622 & 0,709 \\
\hline AT2G16630.1 & $\begin{array}{c}\text { Pollen Ole e } 1 \text { allergen and } \\
\text { extensin family protein }\end{array}$ & 0,269 & 0,243 & 0,624 & 0,693 & 49 & 0,240 & 0,225 & 0,622 & 0,709 \\
\hline AT4G04223.1 & other RNA & 0,158 & 0,245 & 0,642 & 0,709 & 49 & 0,240 & 0,225 & 0,622 & 0,709 \\
\hline AT1G73602.1 & $\begin{array}{l}\text { CPuORF32 conserved } \\
\text { peptide upstream open } \\
\text { reading frame } 32\end{array}$ & 0,252 & 0,248 & 0,605 & 0,714 & 49 & 0,240 & 0,225 & 0,622 & 0,709 \\
\hline AT4G23680.1 & $\begin{array}{c}\text { Polyketide } \\
\text { cyclase/dehydrase and lipid } \\
\text { transport superfamily } \\
\text { protein }\end{array}$ & 0,232 & 0,247 & 0,583 & 0,738 & 49 & 0,240 & 0,225 & 0,622 & 0,709 \\
\hline AT4G13493.1 & MIR850A MIR850a; miRNA & 0,215 & 0,209 & 0,679 & 0,670 & 49 & 0,240 & 0,225 & 0,622 & 0,709 \\
\hline AT1G56430.1 & $\begin{array}{c}\text { ATNAS4 NAS4 } \\
\text { nicotianamine synthase } 4\end{array}$ & 0,191 & 0,221 & 0,627 & 0,722 & 49 & 0,240 & 0,225 & 0,622 & 0,709 \\
\hline AT1G67740.1 & $\begin{array}{c}\text { PSBY YCF32 photosystem } \\
\text { II BY }\end{array}$ & 0,262 & 0,228 & 0,597 & 0,724 & 49 & 0,240 & 0,225 & 0,622 & 0,709 \\
\hline AT1G78370.1 & $\begin{array}{c}\text { ATGSTU20 GSTU20 } \\
\text { glutathione S-transferase } \\
\text { TAU } 20 \\
\end{array}$ & 0,232 & 0,220 & 0,622 & 0,715 & 49 & 0,240 & 0,225 & 0,622 & 0,709 \\
\hline AT2G42610.2 & $\begin{array}{c}\text { LSH10 Protein of unknown } \\
\text { function (DUF640) }\end{array}$ & 0,225 & 0,203 & 0,654 & 0,694 & 49 & 0,240 & 0,225 & 0,622 & 0,709 \\
\hline AT4G25960.1 & PGP2 P-glycoprotein 2 & 0,235 & 0,215 & 0,590 & 0,742 & 49 & 0,240 & 0,225 & 0,622 & 0,709 \\
\hline AT5G24140.1 & $\begin{array}{l}\text { SQP2 squalene } \\
\text { monooxygenase } 2\end{array}$ & 0,222 & 0,202 & 0,657 & 0,692 & 49 & 0,240 & 0,225 & 0,622 & 0,709 \\
\hline AT2G21140.1 & $\begin{array}{c}\text { ATPRP2 PRP2 proline-rich } \\
\text { protein } 2\end{array}$ & 0,267 & 0,199 & 0,605 & 0,723 & 49 & 0,240 & 0,225 & 0,622 & 0,709 \\
\hline AT2G37640.1 & $\begin{array}{c}\text { ATEXPA3 ATEXP3 } \\
\text { ATHEXP ALPHA 1.9 EXP3 } \\
\text { Barwin-like endoglucanases } \\
\text { superfamily protein } \\
\end{array}$ & 0,266 & 0,207 & 0,593 & 0,731 & 49 & 0,240 & 0,225 & 0,622 & 0,709 \\
\hline AT2G05520.6 & $\begin{array}{l}\text { GRP-3 ATGRP-3 glycine- } \\
\text { rich protein } 3\end{array}$ & 0,228 & 0,208 & 0,587 & 0,749 & 49 & 0,240 & 0,225 & 0,622 & 0,709 \\
\hline AT5G63180.1 & $\begin{array}{c}\text { Pectin lyase-like } \\
\text { superfamily protein }\end{array}$ & 0,265 & 0,196 & 0,616 & 0,715 & 49 & 0,240 & 0,225 & 0,622 & 0,709 \\
\hline AT2G30670.1 & $\begin{array}{l}\text { NAD(P)-binding Rossmann- } \\
\text { fold superfamily protein }\end{array}$ & 0,212 & 0,227 & 0,659 & 0,685 & 49 & 0,240 & 0,225 & 0,622 & 0,709 \\
\hline AT5G10180.1 & $\begin{array}{l}\text { AST68 SULTR2; } 1 \text { slufate } \\
\text { transporter } 2 ; 1\end{array}$ & 0,226 & 0,199 & 0,611 & 0,732 & 49 & 0,240 & 0,225 & 0,622 & 0,709 \\
\hline AT1G67090.2 & $\begin{array}{c}\text { RBCS1A ribulose } \\
\text { bisphosphate carboxylase } \\
\text { small chain } 1 \mathrm{~A}\end{array}$ & 0,278 & 0,197 & 0,616 & 0,711 & 49 & 0,240 & 0,225 & 0,622 & 0,709 \\
\hline AT5G45670.1 & $\begin{array}{c}\text { GDSL-like } \\
\text { Lipase/Acylhydrolase } \\
\text { superfamily protein }\end{array}$ & 0,253 & 0,172 & 0,642 & 0,703 & 49 & 0,240 & 0,225 & 0,622 & 0,709 \\
\hline AT5G14920.2 & $\begin{array}{c}\text { Gibberellin-regulated family } \\
\text { protein }\end{array}$ & 0,256 & 0,167 & 0,601 & 0,738 & 49 & 0,240 & 0,225 & 0,622 & 0,709 \\
\hline AT1G69530.4 & $\begin{array}{c}\text { ATEXPA1 EXP1 AT-EXP1 } \\
\text { ATEXP1 ATHEXP ALPHA } \\
1.2 \text { EXPA1 expansin A1 } \\
\end{array}$ & 0,264 & 0,167 & 0,600 & 0,736 & 49 & 0,240 & 0,225 & 0,622 & 0,709 \\
\hline AT1G21060.1 & $\begin{array}{c}\text { Protein of unknown function } \\
\text { DUF547 }\end{array}$ & 0,284 & 0,153 & 0,615 & 0,720 & 49 & 0,240 & 0,225 & 0,622 & 0,709 \\
\hline AT4G22610.1 & $\begin{array}{c}\text { Bifunctional inhibitor/lipid- } \\
\text { transfer protein/seed } \\
\text { storage } 2 \mathrm{~S} \text { albumin } \\
\text { superfamily protein } \\
\end{array}$ & 0,181 & 0,241 & 0,723 & 0,622 & 50 & 0,171 & 0,147 & 0,718 & 0,653 \\
\hline
\end{tabular}


Anhang

\begin{tabular}{|c|c|c|c|c|c|c|c|c|c|c|}
\hline AT5G42580.1 & $\begin{array}{l}\text { CYP705A12 cytochrome } \\
\text { P450 family } 705 \text { subfamily } \\
\text { A polypeptide } 12\end{array}$ & 0,188 & 0,225 & 0,734 & 0,612 & 50 & 0,171 & 0,147 & 0,718 & 0,653 \\
\hline AT2G24850.1 & $\begin{array}{l}\text { TAT3 TAT tyrosine } \\
\text { aminotransferase } 3\end{array}$ & 0,178 & 0,196 & 0,690 & 0,674 & 50 & 0,171 & 0,147 & 0,718 & 0,653 \\
\hline AT3G02620.1 & $\begin{array}{c}\text { Plant stearoyl-acyl-carrier- } \\
\text { protein desaturase family } \\
\text { protein }\end{array}$ & 0,146 & 0,188 & 0,703 & 0,671 & 50 & 0,171 & 0,147 & 0,718 & 0,653 \\
\hline AT1G19350.5 & $\begin{array}{c}\text { BES1 BZR2 } \\
\text { Brassinosteroid signalling } \\
\text { positive regulator (BZR1) } \\
\text { family protein }\end{array}$ & 0,232 & 0,170 & 0,692 & 0,661 & 50 & 0,171 & 0,147 & 0,718 & 0,653 \\
\hline AT1G53480.2 & $\begin{array}{c}\text { MRD1 mto } 1 \text { responding } \\
\text { down } 1\end{array}$ & 0,126 & 0,164 & 0,729 & 0,652 & 50 & 0,171 & 0,147 & 0,718 & 0,653 \\
\hline AT3G44990.1 & $\begin{array}{c}\text { XTR8 ATXTR8 XTH31 } \\
\text { xyloglucan endo- } \\
\text { transglycosylase-related } 8\end{array}$ & 0,264 & 0,148 & 0,707 & 0,640 & 50 & 0,171 & 0,147 & 0,718 & 0,653 \\
\hline AT1G73600.2 & $\begin{array}{l}\text { S-adenosyl-L-methionine- } \\
\text { dependent } \\
\text { methyltransferases } \\
\text { superfamily protein } \\
\end{array}$ & 0,150 & 0,130 & 0,739 & 0,644 & 50 & 0,171 & 0,147 & 0,718 & 0,653 \\
\hline AT3G59060.4 & $\begin{array}{l}\text { PIL6 PIF5 phytochrome } \\
\text { interacting factor } 3 \text {-like } 6\end{array}$ & 0,261 & 0,131 & 0,674 & 0,679 & 50 & 0,171 & 0,147 & 0,718 & 0,653 \\
\hline AT4G04223.2 & other RNA & 0,103 & 0,124 & 0,680 & 0,715 & 50 & 0,171 & 0,147 & 0,718 & 0,653 \\
\hline AT1G69530.2 & $\begin{array}{c}\text { ATEXPA1 EXP1 AT-EXP1 } \\
\text { ATEXP1 ATHEXP ALPHA } \\
1.2 \text { EXPA1 expansin A1 }\end{array}$ & 0,219 & 0,115 & 0,726 & 0,642 & 50 & 0,171 & 0,147 & 0,718 & 0,653 \\
\hline AT5G42600.1 & MRN1 marneral synthase & 0,091 & 0,114 & 0,728 & 0,670 & 50 & 0,171 & 0,147 & 0,718 & 0,653 \\
\hline AT3G22142.1 & $\begin{array}{l}\text { Bifunctional inhibitor/lipid- } \\
\text { transfer protein/seed } \\
\text { storage } 2 \mathrm{~S} \text { albumin } \\
\text { superfamily protein }\end{array}$ & 0,182 & 0,100 & 0,666 & 0,716 & 50 & 0,171 & 0,147 & 0,718 & 0,653 \\
\hline AT4G22210.1 & $\begin{array}{l}\text { LCR85 low-molecular- } \\
\text { weight cysteine-rich } 85\end{array}$ & 0,073 & 0,088 & 0,786 & 0,608 & 50 & 0,171 & 0,147 & 0,718 & 0,653 \\
\hline AT3G59060.3 & $\begin{array}{l}\text { PIL6 PIF5 phytochrome } \\
\text { interacting factor } 3 \text {-like } 6\end{array}$ & 0,176 & 0,068 & 0,788 & 0,586 & 50 & 0,171 & 0,147 & 0,718 & 0,653 \\
\hline
\end{tabular}




\section{Literaturverzeichnis}

Aida, M. et al., 1997. Genes involved in organ separation in Arabidopsis: an analysis of the cup-shaped cotyledon mutant. The Plant cell, 9(6), pp.841-57.

Alanen, H.I. et al., 2003. Defining the domain boundaries of the human protein disulfide isomerases. Antioxidants \& Redox Signaling, 5(4), pp.367-74.

Anderson, M., Chen, Z. \& Klessig, D., 1998. Possible involvement of lipid peroxidation in salicylic acid-mediated induction of PR-1 gene expression. Phytochemistry, 47(4), pp.555-566.

Armstrong, R.N., 1991. Glutathione S-transferases: reaction mechanism, structure, and function. Chemical Research in Toxicology, 4(2), pp.131-40.

Attallah, C. V et al., 2007. Characterization of Arabidopsis thaliana genes encoding functional homologues of the yeast metal chaperone Cox19p, involved in cytochrome c oxidase biogenesis. Plant Molecular Biology, 65(3), pp.343-55.

Babbs, C., Pham, J. \& Coolbaugh, R., 1989. Lethal hydroxyl radical production in paraquat-treated plants. Plant Physiology, 90, pp.1267-1270.

Baerson, S.R. et al., 2005. Detoxification and transcriptome response in Arabidopsis seedlings exposed to the allelochemical benzoxazolin-2(3H)-one. The Journal of Biological Chemistry, 280(23), pp.21867-81.

Ball, L. et al., 2004. Evidence for a direct link between glutathione biosynthesis and stress defense gene expression in Arabidopsis. The Plant Cell, 16(9), pp.244862.

Benfey, P.N., Ren, L. \& Chua, N.H., 1989. The CaMV 35S enhancer contains at least two domains which can confer different developmental and tissue-specific expression patterns. The EMBO Journal, 8(8), pp.2195-202.

Berendzen, K.W. et al., 2012. Bioinformatic cis-element analyses performed in Arabidopsis and rice disclose bZIP- and MYB-related binding sites as potential AuxRE-coupling elements in auxin-mediated transcription. BMC Plant Biology, 12(1), p.125.

Berger, S. et al., 2007. Visualization of dynamics of plant-pathogen interaction by novel combination of chlorophyll fluorescence imaging and statistical analysis: differential effects of virulent and avirulent strains of $P$. syringae and of oxylipins on A. thaliana. Journal of Experimental Botany, 58(4), pp.797-806.

Beynon, E.R. et al., 2009. The role of oxophytodienoate reductases in the detoxification of the explosive 2,4,6-trinitrotoluene by Arabidopsis. Plant Physiology, 151(1), pp.253-61. 
Biteau, B., Labarre, J. \& Toledano, M.B., 2003. ATP-dependent reduction of cysteine - sulphinic acid by $S$. cerevisiae sulphiredoxin. Nature, 425(October), pp.980984.

Bolle, C., 2004. The role of GRAS proteins in plant signal transduction and development. Planta, 218(5), pp.683-92.

Bolle, C., Koncz, C. \& Chua, N., 2000. PAT1, a new member of the GRAS family, is involved in phytochrome A signal transduction. Genes \& Development, 14, pp.1269-1278.

Bolwell, G.P., Bozak, K. \& Zimmerlin, A., 1994. Plant cytochrome P450. Phytochemistry, 37(6), pp.1491-506.

Borsani, O., Valpuesta, V. \& Botella, M. a, 2001. Evidence for a role of salicylic acid in the oxidative damage generated by $\mathrm{NaCl}$ and osmotic stress in Arabidopsis seedlings. Plant Physiology, 126(3), pp.1024-30.

Bosworth, C. a et al., 2009. Dinitrosyliron complexes and the mechanism(s) of cellular protein nitrosothiol formation from nitric oxide. Proceedings of the National Academy of Sciences of the United States of America, 106(12), pp.4671-6.

Breitenbach, H.H. et al., 2014. Contrasting Roles of the Apoplastic Aspartyl Protease APOPLASTIC, ENHANCED DISEASE SUSCEPTIBILITY1-DEPENDENT1 and LEGUME LECTIN-LIKE PROTEIN1 in Arabidopsis Systemic Acquired Resistance. Plant Physiology, 165(2), pp.791-809.

$\mathrm{Bu}, \mathrm{Q}$. et al., 2008. Role of the Arabidopsis thaliana NAC transcription factors ANAC019 and ANAC055 in regulating jasmonic acid-signaled defense responses. Cell Research, 18(7), pp.756-67.

Casagrande, S. et al., 2002. Glutathionylation of human thioredoxin: a possible crosstalk between the glutathione and thioredoxin systems. Proceedings of the National Academy of Sciences of the United States of America, 99(15), pp.9745-9.

Chen, I.-P. et al., 2003. The transcriptional response of Arabidopsis to genotoxic stress - a high-density colony array study (HDCA). The Plant Journal, 35(6), pp.771-786.

Chomczynski, P., 1993. A reagent for the single-step simultaneous isolation of RNA, DNA and proteins from cell and tissue samples. BioTechniques, 15(3), pp.5324, 536-7.

Clough, S.J., 2005. Floral dip: agrobacterium-mediated germ line transformation. Methods in Molecular Biology (Clifton, N.J.), 286, pp.91-102.

Coleman, J., Blake-Kalff, M. \& Davies, E., 1997. Detoxification of xenobiotics by plants: chemical modification and vacuolar compartmentation. Trends in Plant Science, 1385(97). 
Denu, J.M. \& Tanner, K.G., 1998. Specific and reversible inactivation of protein tyrosine phosphatases by hydrogen peroxide: evidence for a sulfenic acid intermediate and implications for redox regulation. Biochemistry, 37(16), pp.5633-42.

Després, C., Chubak, C. \& Rochon, A., 2003. Arabidopsis NPR1 disease resistance protein is a novel cofactor that confers redox regulation of DNA binding activity to the basic domain/leucine zipper transcription. The Plant Cell, 15(September), pp.2181-2191.

Dill, A., Jung, H.S. \& Sun, T.P., 2001. The DELLA motif is essential for gibberellininduced degradation of RGA. Proceedings of the National Academy of Sciences of the United States of America, 98(24), pp.14162-7.

Dinkova-Kostova, A.T., Holtzclaw, W.D. \& Kensler, T.W., 2005. The role of Keap1 in cellular protective responses. Chemical Research in Toxicology, 18(12), pp.1779-91.

Dixon, D. et al., 1998. Glutathione-mediated detoxification systems in plants. Current Opinion in Plant Biology, pp.258-266.

Du, Z. et al., 2010. agriGO: a GO analysis toolkit for the agricultural community. Nucleic Acids Research, 38(Web Server issue), pp.W64-70.

Ekman, D., Lorenz, W. \& Przybyla, A., 2003. SAGE analysis of transcriptome responses in Arabidopsis roots exposed to 2, 4, 6-trinitrotoluene. Plant Physiology, 133, pp.1397-1406.

Fan, W. \& Dong, X., 2002. In vivo interaction between NPR1 and transcription factor TGA2 leads to salicylic acid-mediated gene activation in Arabidopsis. The Plant Cell Online, 14(June), pp.1377-1389.

Farmer, E.E. \& Davoine, C., 2007. Reactive electrophile species. Current Opinion in Plant Biology, 10(4), pp.380-6.

Feechan, A. et al., 2005. A central role for S-nitrosothiols in plant disease resistance. Proceedings of the National Academy of Sciences of the United States of America, 102(22), pp.8054-9.

Fields, S. \& Song, O., 1989. A novel genetic system to detect protein-protein interactions. Nature, 340(6230), pp.245-6.

Fode, B. et al., 2008. The Arabidopsis GRAS protein SCL14 interacts with class II TGA transcription factors and is essential for the activation of stress-inducible promoters. The Plant Cell, 20(11), pp.3122-35.

Freedman, R.B. et al., 1998. Experimental and theoretical analyses of the domain architecture of mammalian protein disulphide-isomerase. Biological Chemistry, 379(3), pp.321-8. 
Freedman, R.B., Klappa, P. \& Ruddock, L.W., 2002. Protein disulfide isomerases exploit synergy between catalytic and specific binding domains. EMBO Reports, 3(2), pp.136-40.

Fukaki, H. et al., 1998. Genetic evidence that the endodermis is essential for shoot gravitropism in Arabidopsis thaliana. The Plant Journal, 14(4), pp.425-30.

Garretón, V. et al., 2002. The as-1 promoter element is an oxidative stressresponsive element and salicylic acid activates it via oxidative species. Plant Physiology, 130, pp.1516-1526.

Gietz, R.D. \& Woods, R.A., 2002. Transformation of yeast by lithium acetate/singlestranded carrier DNA/polyethylene glycol method. Methods in Enzymology, 350, pp.87-96.

Greb, T. et al., 2003. Molecular analysis of the LATERAL SUPPRESSOR gene in Arabidopsis reveals a conserved control mechanism for axillary meristem formation. Genes \& Development, 17(9), pp.1175-87.

Grzam, A. et al., 2007. Gamma-Glutamyl transpeptidase GGT4 initiates vacuolar degradation of glutathione S-conjugates in Arabidopsis. FEBS Letters, 581(17), pp.3131-8.

Gupta, R. \& Luan, S., 2003. Redox Control of Protein Tyrosine Phosphatases and Mitogen-Activated Protein Kinases in Plants. Plant Physiology, 132, pp.11491152.

Hanahan, D., 1983. Studies on transformation of Escherichia coli with plasmids. Journal of Molecular Biology, 166(4), pp.557-80.

Hartley, J.L., Temple, G.F. \& Brasch, M.A., 2000. DNA Cloning Using In Vitro SiteSpecific Recombination. Genome Research, 10(11), pp.1788-1795.

Hausladen, a et al., 1996. Nitrosative stress: activation of the transcription factor OxyR. Cell, 86(5), pp.719-29.

Heery, D.M. et al., 1997. A signature motif in transcriptional co-activators mediates binding to nuclear receptors. Nature, 387(6634), pp.733-6.

Helariutta, Y. et al., 2000. The SHORT-ROOT gene controls radial patterning of the Arabidopsis root through radial signaling. Cell, 101(5), pp.555-67.

Hess, D.T. et al., 2001. S-nitrosylation: spectrum and specificity. Nature Cell Biology, 3(2), pp.E46-9.

$\mathrm{Hu}, \mathrm{H}$. et al., 2006. Overexpressing a NAM, ATAF, and CUC (NAC) transcription factor enhances drought resistance and salt tolerance in rice. Proceedings of the National Academy of Sciences of the United States of America, 103(35), pp.12987-12992. 
Ishii, T. et al., 2006. Mass spectroscopic characterization of protein modification by malondialdehyde. Chemical Research in Toxicology, 19(1), pp.122-9.

James, P., Halladay, J. \& Craig, E.A., 1996. Genomic libraries and a host strain designed for highly efficient two-hybrid selection in yeast. Genetics, 144(4), pp.1425-36.

Jensen, M.K. et al., 2007. The HvNAC6 transcription factor: a positive regulator of penetration resistance in barley and Arabidopsis. Plant Molecular Biology, 65(12), pp.137-50.

Jensen, M.K. et al., 2008. Transcriptional regulation by an NAC (NAM-ATAF1,2CUC2) transcription factor attenuates ABA signalling for efficient basal defence towards Blumeria graminis f. sp. hordei in Arabidopsis. The Plant Journal, 56(6), pp.867-80.

Jeong, J.S. et al., 2010. Root-specific expression of OsNAC10 improves drought tolerance and grain yield in rice under field drought conditions. Plant Physiology, 153(1), pp.185-97.

Kaever, A. et al., 2009. MarVis: a tool for clustering and visualization of metabolic biomarkers. BMC Bioinformatics, 10, p.92.

Katagiri, F., Seipel, K. \& Chua, N., 1992. Identification of a novel dimer stabilization region in a plant bZIP transcription activator. Molecular and Cellular Biology, 12(11).

Kim, S.F., Huri, D. a \& Snyder, S.H., 2005. Inducible nitric oxide synthase binds, Snitrosylates, and activates cyclooxygenase-2. Science, 310(5756), pp.1966-70.

Kim, S.O. et al., 2002. OxyR: a molecular code for redox-related signaling. Cell, 109(3), pp.383-96.

Koornneef, A. et al., 2008. Kinetics of salicylate-mediated suppression of jasmonate signaling reveal a role for redox modulation. Plant Physiology, 147(3), pp.135868.

Köster, J. et al., 2012. Xenobiotic- and jasmonic acid-inducible signal transduction pathways have become interdependent at the Arabidopsis CYP81D11 promoter. Plant Physiology, 159(1), pp.391-402.

Krawczyk, S. et al., 2002. Analysis of the spacing between the two palindromes of activation sequence-1 with respect to binding to different TGA factors and transcriptional activation potential. Nucleic Acids Research, 30(3), pp.775-81.

Kuge, S., Jones, N. \& Nomoto, a, 1997. Regulation of yAP-1 nuclear localization in response to oxidative stress. The EMBO Journal, 16(7), pp.1710-20.

Laemmli, U.K., 1970. Cleavage of structural proteins during the assembly of the head of bacteriophage T4. Nature, 227(5259), pp.680-5. 
Landy, A., 1989. Dynamic, structural, and regulatory aspects of lambda site-specific recombination. Annual Review of Biochemistry, 58(58), pp.913-949.

Di Laurenzio, L. et al., 1996. The SCARECROW gene regulates an asymmetric cell division that is essential for generating the radial organization of the Arabidopsis root. Cell, 86(3), pp.423-33.

Lee, S. et al., 2002. Gibberellin regulates Arabidopsis seed germination via RGL2, a GAl/RGA-like gene whose expression is up-regulated following imbibition. Genes \& Development, 16(5), pp.646-58.

Lee, S.-O. et al., 2010. Protein disulphide isomerase is required for signal peptide peptidase-mediated protein degradation. The EMBO Journal, 29(2), pp.363-75.

Li, L. et al., 2002. Functional cloning and characterization of a plant efflux carrier for multidrug and heavy metal detoxification. The Journal of Biological Chemistry, 277(7), pp.5360-8.

Li, S., Gutsche, N. \& Zachgo, S., 2011. The ROXY1 C-terminal L**LL motif is essential for the interaction with TGA transcription factors. Plant Physiology, 157(4), pp.2056-68.

Li, X. et al., 2003. Control of tillering in rice. Nature, 422(6932), pp.618-21.

Lillig, C.H. et al., 2003. Redox regulation of 3'-phosphoadenylylsulfate reductase from Escherichia coli by glutathione and glutaredoxins. The Journal of Biological Chemistry, 278(25), pp.22325-30.

Liu, X. \& Lam, E., 1994. Two binding sites for the plant transcription factor ASF-1 can respond to auxin treatments in transgenic tobacco. The Journal of Biological Chemistry, 269(1), pp.668-75.

Ma, Z. et al., 2014. Arabidopsis miR171-Targeted Scarecrow-Like Proteins Bind to GT cis-Elements and Mediate Gibberellin-Regulated Chlorophyll Biosynthesis under Light Conditions. PLoS Genetics, 10(8), p.e1004519.

Martinoia, E. et al., 2001. Multifunctionality of plant ABC transporters - more than just detoxifiers. Planta, 214(3), pp.345-355.

Marty, L. et al., 2009. The NADPH-dependent thioredoxin system constitutes a functional backup for cytosolic glutathione reductase in Arabidopsis. Proceedings of the National Academy of Sciences of the United States of America, 106(22), pp.9109-14.

Mateo, A. et al., 2006. Controlled levels of salicylic acid are required for optimal photosynthesis and redox homeostasis. Journal of Experimental Botany, 57(8), pp.1795-807.

Matsui, K., 2006. Green leaf volatiles: hydroperoxide lyase pathway of oxylipin metabolism. Current opinion in plant biology, 9(3), pp.274-80. 
McMillan, B. \& Bradfield, C., 2007. The aryl hydrocarbon receptor sans xenobiotics: endogenous function in genetic model systems. Molecular Pharmacology, 72(3), pp.487-498.

Menezes, R. a et al., 2004. Yap8p activation in Saccharomyces cerevisiae under arsenic conditions. FEBS Letters, 566(1-3), pp.141-6.

Meng, T.-C., Fukada, T. \& Tonks, N.K., 2002. Reversible oxidation and inactivation of protein tyrosine phosphatases in vivo. Molecular Cell, 9(2), pp.387-99.

Meyer, Y. et al., 2008. Glutaredoxins and thioredoxins in plants. Biochimica et Biophysica Acta, 1783(4), pp.589-600.

Miao, Y. et al., 2006. An Arabidopsis glutathione peroxidase functions as both a redox transducer and a scavenger in abscisic acid and drought stress responses. The Plant Cell, 18(10), pp.2749-66.

Michel, K. et al., 2006. Transcriptional changes in powdery mildew infected wheat and Arabidopsis leaves undergoing syringolin-triggered hypersensitive cell death at infection sites. Plant Molecular Biology, 62(4-5), pp.561-78.

Michelet, L. et al., 2005. Glutathionylation of chloroplast thioredoxin $\mathrm{f}$ is a redox signaling mechanism in plants. Proceedings of the National Academy of Sciences of the United States of America, 102(45), pp.16478-83.

Modolo, L. V et al., 2005. Nitrite as the major source of nitric oxide production by Arabidopsis thaliana in response to Pseudomonas syringae. FEBS Letters, 579(17), pp.3814-20.

Molinari, M. et al., 2002. Sequential assistance of molecular chaperones and transient formation of covalent complexes during protein degradation from the ER. The Journal of Cell Biology, 158(2), pp.247-57.

Mou, Z., Fan, W. \& Dong, X., 2003. Inducers of plant systemic acquired resistance regulate NPR1 function through redox changes. Cell, 113(7), pp.935-44.

Mueller, M.J., 2004. Archetype signals in plants: the phytoprostanes. Current Opinion in Plant Biology, 7(4), pp.441-8.

Mueller, M.J. \& Berger, S., 2009. Reactive electrophilic oxylipins: pattern recognition and signalling. Phytochemistry, 70(13-14), pp.1511-21.

Mueller, S. et al., 2008. General detoxification and stress responses are mediated by oxidized lipids through TGA transcription factors in Arabidopsis. The Plant Cell, 20(3), pp.768-85.

Muthuramalingam, M., Dietz, K.-J. \& Ströher, E., 2010. Thiol-Disulfide Redox Proteomics in Plant Research. In R. Sunkar, ed. Plant Stress Tolerance. Methods in Molecular Biology. Totowa, NJ: Humana Press. 
Nakajima, K. et al., 2001. Intercellular movement of the putative transcription factor SHR in root patterning. Nature, 413(6853), pp.307-11.

Nemeth, K. et al., 1998. Pleiotropic control of glucose and hormone responses by PRL1, a nuclear WD protein, in Arabidopsis. Genes \& Development, 12(19), pp.3059-3073.

Nishiyama, T. et al., 2003. Comparative genomics of Physcomitrella patens gametophytic transcriptome and Arabidopsis thaliana: implication for land plant evolution. Proceedings of the National Academy of Sciences of the United States of America, 100(13), pp.8007-12.

Noctor, G., 2006. Metabolic signalling in defence and stress: the central roles of soluble redox couples. Plant, Cell and Environment, 29(3), pp.409-425.

Olsen, A.N. et al., 2005. NAC transcription factors: structurally distinct, functionally diverse. Trends in Plant Science, 10(2), pp.79-87.

Pandey, S.P. \& Somssich, I.E., 2009. The role of WRKY transcription factors in plant immunity. Plant Physiology, 150(4), pp.1648-55.

Parisy, V. et al., 2007. Identification of PAD2 as a gamma-glutamylcysteine synthetase highlights the importance of glutathione in disease resistance of Arabidopsis. The Plant Journal, 49(1), pp.159-72.

Pawloski, J.R., Hess, D.T. \& Stamler, J.S., 2001. Export by red blood cells of nitric oxide bioactivity. Nature, 409(6820), pp.622-6.

Peng, J. et al., 1997. The Arabidopsis GAI gene defines a signaling pathway that negatively regulates gibberellin responses. Genes \& Development, 11(23), pp.3194-3205.

Pirneskoski, A. et al., 2004. Molecular characterization of the principal substrate binding site of the ubiquitous folding catalyst protein disulfide isomerase. The Journal of Biological Chemistry, 279(11), pp.10374-81.

Puranik, S. et al., 2012. NAC proteins: regulation and role in stress tolerance. Trends in Plant Science, 17(6), pp.369-81.

Pysh, L.D. et al., 1999. The GRAS gene family in Arabidopsis: sequence characterization and basic expression analysis of the SCARECROW-LIKE genes. The Plant Journal, 18(1), pp.111-9.

Qin, X.F. et al., 1994. Immediate early transcription activation by salicylic acid via the cauliflower mosaic virus as-1 element. The Plant Cell, 6(6), pp.863-74.

Ramel, F. et al., 2012. Xenobiotic sensing and signalling in higher plants. Journal of Experimental Botany, 63(11), pp.3999-4014.

Ratnakaran, N., 2014. "Identification of the role of Arabidopsis ATAF-type NAC transcription factors in plant stress and development ." 
Remans, T. et al., 2010. Metal-specific and NADPH oxidase dependent changes in lipoxygenase and NADPH oxidase gene expression in Arabidopsis thaliana exposed to cadmium or excess copper. Functional Plant Biology, 37(6), p.532.

Rey, P. et al., 2007. The Arabidopsis thaliana sulfiredoxin is a plastidic cysteinesulfinic acid reductase involved in the photooxidative stress response. The Plant Journal

Richards, D.E., Peng, J. \& Harberd, N.P., 2000. Plant GRAS and metazoan STATs: one family? BioEssays: News and Reviews in Molecular, Cellular and Developmental Biology, 22(6), pp.573-7.

Sabatini, S. et al., 2003. SCARECROW is involved in positioning the stem cell niche in the Arabidopsis root meristem. Genes \& Development, 17(3), pp.354-8.

Sandermann, H., 1992. Plant metabolism of xenobiotics. Trends in Biochemical Sciences, 17(2), pp.82-4.

Sandermann, H., Scheel, D. \& vdTrenck, T., 1984. Use of plant cell cultures to study the metabolism of environmental chemicals. Ecotoxicology and Environmental Safety, 8(2), pp.167-82.

Sassa, N. et al., 2001. The molecular characterization and in situ expression pattern of pea SCARECROW gene. Plant \& Cell Physiology, 42(4), pp.385-94.

Satoh, T. et al., 2006. Activation of the Keap1/Nrf2 pathway for neuroprotection by electrophillic phase II inducers. Proceedings of the National Academy of Sciences of the United States of America, 103, pp.768-773.

Schlaeppi, K. et al., 2008. The glutathione-deficient mutant pad2-1 accumulates lower amounts of glucosinolates and is more susceptible to the insect herbivore Spodoptera littoralis. The Plant Journal, 55(5), pp.774-86.

Schmittgen, T.D. \& Livak, K.J., 2008. Analyzing real-time PCR data by the comparative C(T) method. Nature Protocols, 3(6), pp.1101-8.

Schumacher, K. et al., 1999. The Lateral suppressor (Ls) gene of tomato encodes a new member of the VHIID protein family. Proceedings of the National Academy of Sciences of the United States of America, 96(1), pp.290-5.

Schützendübel, A. \& Polle, A., 2002. Plant responses to abiotic stresses: heavy metal-induced oxidative stress and protection by mycorrhization. Journal of Experimental Botany, 53(372), pp.1351-65.

Seo, P.J. et al., 2010. Cold activation of a plasma membrane-tethered NAC transcription factor induces a pathogen resistance response in Arabidopsis. The Plant Journal, 61(4), pp.661-71.

Sheen, J., 2001. Signal transduction in maize and Arabidopsis mesophyll protoplasts. Plant Physiology, 127(4), pp.1466-75. 
Siemsen, T., 2005. Die Bedeutung des Proteins Scarecrow-like 14 bei der Regulation der Transkription von Stressgenen

Silverstone, a L., Ciampaglio, C.N. \& Sun, T., 1998. The Arabidopsis RGA gene encodes a transcriptional regulator repressing the gibberellin signal transduction pathway. The Plant Cell, 10(2), pp.155-69.

Silverstone, A.L. et al., 2001. Repressing a repressor: gibberellin-induced rapid reduction of the RGA protein in Arabidopsis. The Plant Cell, 13(7), pp.1555-66.

Simon, C. et al., 2014. The secondary metabolism glycosyltransferases UGT73B3 and UGT73B5 are components of redox status in resistance of Arabidopsis to Pseudomonas syringae pv. tomato. Plant, Cell \& Environment, 37(5), pp.111429.

Souer, E. et al., 1996. The no apical meristem gene of Petunia is required for pattern formation in embryos and flowers and is expressed at meristem and primordia boundaries. Cell, 85(2), pp.159-70.

Spadaro, D. et al., 2010. The redox switch: dynamic regulation of protein function by cysteine modifications. Physiologia Plantarum, 138(4), pp.360-71.

Spoel, S.H. \& Loake, G.J., 2011. Redox-based protein modifications: the missing link in plant immune signalling. Current Opinion in Plant Biology, 14(4), pp.358-64.

Stamler, J.S. et al., 1997. (S)NO signals: translocation, regulation, and a consensus motif. Neuron, 18(5), pp.691-6.

Sun, X., Jones, W.T. \& Rikkerink, E.H. a, 2012. GRAS proteins: the versatile roles of intrinsically disordered proteins in plant signalling. The Biochemical Journal, 442(1), pp.1-12.

Sung, D.Y., Vierling, E. \& Guy, C.L., 2001. Comprehensive expression profile analysis of the Arabidopsis Hsp70 gene family. Plant Physiology, 126(2), pp.789-800.

Tada, Y. et al., 2008. Plant immunity requires conformational changes of NPR1 via Snitrosylation and thioredoxins. Science, 321(5891), pp.952-6.

Tian, C. et al., 2004. Genome-wide analysis of the GRAS gene family in rice and Arabidopsis. Plant Molecular Biology, 54(4), pp.519-32.

Torres, M.A. \& Dangl, J.L., 2005. Functions of the respiratory burst oxidase in biotic interactions, abiotic stress and development. Current Opinion in Plant Biology, 8(4), pp.397-403.

Uquillas, C. et al., 2004. NPR1-independent activation of immediate early salicylic acid-responsive genes in Arabidopsis. Molecular Plant-Microbe Interactions, 17(1), pp.34-42. 
Vanacker, H., Carver, T.L. \& Foyer, C.H., 2000. Early $\mathrm{H}(2) \mathrm{O}(2)$ accumulation in mesophyll cells leads to induction of glutathione during the hyper-sensitive response in the barley-powdery mildew interaction. Plant Physiology, 123(4), pp.1289-300.

Vollenweider, S. et al., 2000. Fatty acid ketodienes and fatty acid ketotrienes: Michael addition acceptors that accumulate in wounded and diseased Arabidopsis leaves. The Plant Journal, 24(4), pp.467-76.

Wang, C. et al., 2012. Human protein-disulfide isomerase is a redox-regulated chaperone activated by oxidation of domain a'. The Journal of Biological Chemistry, 287(2), pp.1139-49.

Wang, X. et al., 2009. The Arabidopsis ATAF1, a NAC transcription factor, is a negative regulator of defense responses against necrotrophic fungal and bacterial pathogens. Molecular Plant-Microbe Interactions, 22(10), pp.1227-38.

Wang, Y.-Q. et al., 2009. S-nitrosylation of AtSABP3 antagonizes the expression of plant immunity. The Journal of Biological Chemistry, 284(4), pp.2131-7.

Weber, H. et al., 2004. Selective and powerful stress gene expression in Arabidopsis in response to malondialdehyde. The Plant Journal, 37(6), pp.877-888.

Weerapana, E. et al., 2010. Quantitative reactivity profiling predicts functional cysteines in proteomes. Nature, 468(7325), pp.790-795.

Weigel, R., Pfitzner, U. \& Gatz, C., 2005. Interaction of NIMIN1 with NPR1 modulates PR gene expression in Arabidopsis. The Plant Cell Online, 17(April), pp.12791291.

Welner, D.H. et al., 2012. DNA binding by the plant-specific NAC transcription factors in crystal and solution: a firm link to WRKY and GCM transcription factors. The Biochemical Journal, 444(3), pp.395-404.

Wen, C.-K. \& Chang, C., 2002. Arabidopsis RGL1 encodes a negative regulator of gibberellin responses. The Plant Cell, 14(1), pp.87-100.

Winger, A.M., Millar, A.H. \& Day, D.A., 2005. Sensitivity of plant mitochondrial terminal oxidases to the lipid peroxidation product 4-hydroxy-2-nonenal (HNE). The Biochemical Journal, 387(Pt 3), pp.865-70.

Wood, M.J., Andrade, E.C. \& Storz, G., 2003. The redox domain of the Yap1p transcription factor contains two disulfide bonds. Biochemistry, 42(41), pp.11982-91.

Wysocka-Diller, J.W. et al., 2000. Molecular analysis of SCARECROW function reveals a radial patterning mechanism common to root and shoot. Development, 127(3), pp.595-603. 
Xie, Q. et al., 2000. Arabidopsis NAC1 transduces auxin signal downstream of TIR1 to promote lateral root development. Genes \& Development, 14(23), pp.30243036.

Xiong, Y. et al., 2009. Characterization of Arabidopsis 6-phosphogluconolactonase TDNA insertion mutants reveals an essential role for the oxidative section of the plastidic pentose phosphate pathway in plant growth and development. Plant \& Cell Physiology, 50(7), pp.1277-91.

Zhang, B. \& Singh, K.B., 1994. ocs element promoter sequences are activated by auxin and salicylic acid in Arabidopsis. Proceedings of the National Academy of Sciences of the United States of America, 91(7), pp.2507-11.

Zhang, D., lyer, L.M. \& Aravind, L., 2012. Bacterial GRAS domain proteins throw new light on gibberellic acid response mechanisms. Bioinformatics, 28(19), pp.240711.

Zhang, Y. et al., 2003. Knockout analysis of Arabidopsis transcription factors TGA2, TGA5, and TGA6 reveals their redundant and essential roles in systemic acquired resistance. The Plant Cell, 15(11), pp.2647-53.

Zhou, J.M. et al., 2000. NPR1 differentially interacts with members of the TGA/OBF family of transcription factors that bind an element of the PR-1 gene required for induction by salicylic acid. Molecular Plant-Microbe Interactions, 13(2), pp.191202. 


\section{Abkürzungsverzeichnis}

A

2,4-D

A. thaliana

A.

thumefaciens

amp

APS

as-1

$\mathrm{BHA}$

$b p$

BSA

bZIP

C

ca.

CaMV

cDNA

ChIP

CIAP

$\mathrm{Da}$

ddNTPs

DMSO

DMTU

DNA

DNase

dNTP

DTT

E. coli

ECL

EDTA

et al.

$\mathrm{EtBr}$

g

G

GAL4-AD

GFP

$\mathrm{h}$

$\mathrm{H}$

HEPES

HSP

JA

$\mathrm{kb}$

lacZ

Leu

LiAc

Met

$\min$

MOPS

mPEG-Mal-
Ampere

2,4-Dichlorphenoxyessigsäure

Arabidopsis thaliana

Agrobacterium thumefaciens

Ampicillin

Ammoniumpersulfat

activating sequence 1

3-t-butyl-4-Hydroxyanisol

Basenpaar

bovines Serumalbumin

basischer Leucin-Zipper

Cytosin

circa

Blumenkohlmosaikvirus

komplementäre DNA

Chromatin-Immunopräzipitation

Calf Intestine Alcaline Phosphatase

Dalton

Didesoxyribonukleotide

Dimethylsulfoxid

Dimethylthiourea

Desoxyribonukleinsäure

Desoxyribonuklease

Desoxynukleotidtriphosphat

Dithiothreitol

Escherichia coli

Enhanced Chemiluminescence

Ethylendiamidtetraessigsäure

und Andere (et alii)

Ethidiumbromid

Erdbeschleunigung

Guanin

GAL4-Aktivierungsdomäne

grün fluoreszierendes Protein

Stunde

Histidin

$\mathrm{N}$-[2-Hydroxyethyl]-piperazin-N'-[Ethansulfonsäure]

Heringssperma-DNA

Jasmonsäure

Kilobasen

ß-Galactosidase-Gen

Leucin

Lithiumacetat

Methionin

Minute

3-(N-Morpholino)propansulfonsäure

Methoxypolyethylen Glycol Maleimid-5000 


\begin{tabular}{|c|c|}
\hline \multicolumn{2}{|l|}{5000} \\
\hline mRNA & Boten-Ribonukleinsäure \\
\hline MS & Murashige und Skoog Medium \\
\hline NLS & Kernlokalisationssignal \\
\hline NPR1 & NONEXPRESSOR OF PR GENES 1 \\
\hline OD & optische Dichte \\
\hline oNPG & o-Nitrophenyl-B-D-Galactopyranosid \\
\hline OPDA & 12-oxo-Phytodiensäure \\
\hline PAA & Polyacrylamid \\
\hline PAGE & Polyacrylamidgelelektrophorese \\
\hline PCR & Polymerasekettenreaktion \\
\hline PEG & Polyethylenglykol \\
\hline $\mathrm{pH}$ & negativer dekadischer Logarhytmus der Protonenkonzentration \\
\hline PMSF & Phenyl-Methyl-Sulfonyl-Fluorid \\
\hline $\operatorname{Poly}(A)-$ & Polyadenyl- \\
\hline PR & pathogenesis-related \\
\hline PVDF & Polyvinylidenefluorid \\
\hline $\mathrm{R}$ & Wiederstand \\
\hline RES & reaktive elektrophile Spezies \\
\hline RNA & Ribonukleinsäure \\
\hline RNase & Ribonuklease \\
\hline RNS & reaktive Stickstoffspezies \\
\hline ROS & reaktive Sauerstoffspezies \\
\hline rpm & Umdrehungen pro Minute \\
\hline RT & Raumtemperatur \\
\hline SA & Salicylsäure \\
\hline SCL14 & SCARECROW-like 14 \\
\hline SD & Hefe Minimalmedium \\
\hline SDS & Natriumdodecylsulfat \\
\hline sek & Sekunde \\
\hline ss & einzelsträngig \\
\hline B-Gal & B-Galaktosidase \\
\hline $\mathrm{T}$ & Thymin \\
\hline TE & Tris-EDTA-Puffer \\
\hline TEMED & N,N,N',N'-Tetraethylendiamin \\
\hline TIBA & 2,3,5-Triiodobenzoesäure \\
\hline Tris & Tris(hydroxymethyl)aminomethan \\
\hline Trp & Tryptophan \\
\hline$U$ & definierte Enzymeinheit \\
\hline ü.N. & über Nacht \\
\hline $\mathrm{v} / \mathrm{v}$ & Volumenprozent \\
\hline$w / v$ & Gewichtsprozent \\
\hline
\end{tabular}




\section{Danksagung}

An dieser Stelle möchte ich mich bei all Jenen bedanken, die durch ihre Unterstützung zum Gelingen dieser Arbeit beigetragen, bzw. diese überhaupt erst ermöglicht haben.

An erster Stelle geht mein Dank an Frau Prof. Dr. Christiane Gatz, die mich in Ihre Abteilung aufgenommen und mir damit die Möglichkeit, diese Arbeit anzufertigen überhaupt erst gegeben hat. Vielen Dank auch für die vielen Anregungen und konstruktiven Diskussionen im Verlauf dieser Arbeit.

Vielen Dank an Herrn Prof. Dr. Volker Lipka für viel konstruktive Kritik im Rahmen des Thesis Commitees und für die Übernahme der Zweitkorrektur dieser Arbeit.

Vielen Dank an Frau Prof. Dr. Andrea Polle, Frau Jun. Prof. Cynthia Gleason, Herrn Prof. Dr. Ivo Feussner und Herrn PD Dr. Thomas Teichmann für die Teilnahme an meiner Prüfungskommission.

Vielen Dank an Dr. Corinna Thurow für die Einführung in die Mysterien der pflanzlichen Molekularbiologie und für die unermüdliche Hilfe und die zahlreichen Anregungen bei methodischen Problemen.

Vielen Dank an Dr. Guido Kriete für die blitzschnelle Hilfe bei jeglichen Problemen technischer Art und für das Organisieren aller großen und kleinen Spielzeuge, die man im Laboralltag so braucht.

Vielen Dank an unsere TAs Anna, Larissa und Ronny führ ihre ausgezeichnete handwerkliche Unterstützung und an Anna zusätzlich für die angenehme Atmosphäre in unseren gemeinsamen Laboren in den letzten viereinhalb Jahren.

Vielen Dank an alle Weiteren aktuellen und ehemaligen Mitglieder der Abteilung für eine Angenehme Atmosphäre im Labor und während der Pausen. Besonderer Dank geht hierbei an Johanna, Martin und Frederik für viele nette Gespräche, gemeinsame Unternehmungen und erlebnisreiche Rollenspielabende. 
Ein ganz besonderer Dank geht an meine Eltern, die mich auf meinem Weg immer unterstützt und mich in meinen Vorhaben bekräftigt haben. Vielen Dank für so manchen guten Rat, so manchen schönen Augenblick und dafür, dass ich immer weiß dass Ihr für mich da seid, egal ob die Sonne scheint oder die Unwetter mit Macht über mich hereinbrechen.

Ein ebenso besonderer Dank geht an Julia. Danke für die wundervollen letzten drei Jahre und für alle, die ich noch gemeinsam mit Dir erleben darf. Alles ist gut! 


\section{Lebenslauf}

\section{Beruflicher Werdegang}

seit 01.2010

Dissertationsthema

08. $2009-12.2009$

$10.2004-07.2009$

Institut der Diplomarbeit

Titel der Diplomarbeit

$01.2004-09.2004$

$07.2003-12.2003$

\section{Zivildienst}

$09.2002-06.2003$

\section{Schulische Laufbahn}

$08.1995-06.2002$

$08.1993-06.1995$

$08.1989-06.1993$
Promotion an der Georg August Universität Göttingen,

Abteilung Molekularbiologie und Physiologie der Pflanze

Transkriptionelle Regulation des pflanzlichen Detoxifikationsprogramms durch das GRAS-Protein SCL14

Wissenschaftliche Hilfskraft Universität Kassel, Abteilung Biochemie

Studium der Biologie an der Universität Kassel mit Abschluss Diplom

Institut für Biologie Abteilung Biochemie

Quantifizierung von cyclischen Nukleotiden in vivo und in vitro

Anstellung als Rettungssanitäter DRK Kreisverband Hameln - Pyrmont

Aushilfe im Rettungsdienst DRK Kreisverband Hameln - Pyrmont

Zivildienst mit Ausbildung zum

Rettungssanitäter

DRK Kreisverband Hameln - Pyrmont

Besuch des

Schiller - Gymnasiums Hameln

Abschluss Abitur

Besuch der

Orientierungsstufe Hessisch - Oldendorf

Besuch der

Grundschule Großenwieden 